\title{
Meliponini neotropicais: o gênero Partamona Schwarz, 1939 (Hymenoptera, Apidae) ${ }^{1}$
}

\author{
Silvia R. M. Pedro ${ }^{2}$ \\ João M. F. Camargo 2,3
}

\begin{abstract}
Neotropical Meliponini: the genus Partamona Schwarz, 1939 (Hymenoptera, Apidae). The systematics and biogeography of Partamona Schwarz, a Neotropical genus of stingless bees (Meliponini, Apinae, Apidae), are revised. Seventeen new species are described: P. epiphytophila sp. nov., $P$. subtilis sp. nov., P. nhambiquara sp. nov., $P$. batesi $\mathbf{s p .}$ nov., $P$. yungarum sp. nov., $P$. vitae sp. nov., $P$. ferreirai $\mathbf{s p .}$ nov., . gregaria $\mathbf{s p .}$ nov., $P$. auripennis sp. nov., $P$. nigrilabris sp. nov., $P$. combinata sp. nov., $P$. chapadicola sp. nov., $P$. seridoensis $\mathbf{s p . ~ n o v . , ~} P$. littoralis $\mathbf{s p . ~ n o v . , ~} P$. criptica sp. nov., $P$. rustica sp. nov. and $P$. sooretamae sp. nov. Partamona pseudomusarum Camargo, 1980, is considered as junior synonym of P. vicina Camargo, 1980. Types of P. grandipennis (Schwarz, 1951), P. xanthogastra Pedro \& Camargo, 1996-1997, P. pearsoni (Schwarz, 1938), P. ailyae Camargo, 1980, P. pseudomusarum, P. vicina, P. mulata Moure in Camargo, 1980, P. aequatoriana Camargo, 1980, P. mourei Camargo, 1980, P. peckolti, (Friese, 1901), P. testacea (Klug, 1807), P. helleri (Friese, 1900) and P. musarum (Cockerell, 1917) were examined. Lectotypes of P. orizabaensis (Strand, 1919), and P. cupira (Smith, 1863) are designated. An identification key for the species and drawings of morphological characters are presented. A phylogenetic hypothesis, based mainly on morphological characters is proposed. Four groups are defined, considering the shape of mandible of workers and sternum VII of males: bilineata / epiphytophila group (western Amazon to México), including P. bilineata (Say), P. grandipennis, P. xanthogastra P. orizabaensis P. peckolti $P$. epiphytophila sp. nov., $P$. subtilis sp. nov., . nhambiquara sp. nov., $P$. batesi sp. nov., $P$. yungarum sp. nov. and $P$. vitae sp. nov.; musarum group (Central Brazil, north of South America to Central America), including P. musarum, $P$. aequatoriana, $P$. vicina, $P$. mourei, $P$. pearsoni, $P$. ferreirai sp. nov., $P$. gregaria sp. nov. and $P$. testacea; nigrior group (Central Brazil to northeast of South America) including P. nigrior (Cockerell, 1925), P. auripennis sp. nov., P. nigrilabris sp. nov., $P$. combinata $\mathbf{s p . ~ n o v . , ~} P$. chapadicola sp. nov., $P$. seridoensis $\mathbf{s p . ~ n o v . ~ a n d ~} P$. littoralis sp. nov., and cupira group (southeastern and Central Brazil), including $P$. cupira, $P$. mulata, . ailyae, $P$. sooretamae sp. nov., $P$. criptica sp. nov., $P$. rustica sp. nov. and $P$. helleri. Some geographic distribution patterns, congruent with that of other Meliponini bees, are commented.
\end{abstract}

KEYwORDs. Biogeography; Partamona; phylogeny; stingless bees; systematics.

\section{INTRODUÇÃO}

Partamona Schwarz, 1939, é um gênero de abelhas sociais, sem ferrão, produtoras de mel, exclusivamente neotropical, com ampla distribuição (do sul do Brasil ao México). Ocorre em matas, cerrado, caatinga, regiões montanhosas (cordilheiras andinas e centro-americanas), chegando até mais de $2.000 \mathrm{~m}$ de altitude; algumas espécies toleram bem o ambiente antrópico. São abelhas agressivas que nidificam em uma ampla variedade de substratos, sendo que muitas espécies são termitófilas obrigatórias. Até o presente estudo, eram reconhecidas 17 espécies e subespécies de Partamona: P. aequatoriana Camargo, 1980, P. ailyae Camargo, 1980, P. bilineata (Say, 1837),
P. cupira (Smith, 1863), P. grandipennis (Schwarz, 1951), P. helleri (Friese, 1900), P. mourei Camargo, 1980, P. mulata Moure in Camargo, 1980, P. nigrior (Cockerell, 1925), P. nigrita (Friese, 1901), P. pearsoni (Schwarz, 1938), P. peckolti peckolti (Friese, 1900), P. peckolti musarum (Cockerell, 1917), P. pseudomusarum Camargo, 1980, P. testacea (Klug, 1807), P. vicina Camargo, 1980, e P. xanthogastra Pedro \& Camargo, 1996-1997. Uma revisão sistemática do "grupo testacea" foi apresentada por CAmargo (1980), abordando questões sobre a variação geográfica infra-específica e sobre o comportamento de nidificação. No presente trabalho são apresentadas descrições de novas espécies, chave de identificação, hipótese de filogenia e comentários sobre a biogeografia de Partamona, em

1. Dedicado ao Prof. Pe. Jesus Santiago Moure, pelo seu $90^{\circ}$ aniversário (02.IX.2002).

2. Departamento de Biologia, Faculdade de Filosofia, Ciências e Letras de Ribeirão Preto, Universidade de São Paulo. Av. Bandeirantes 3900 , 14040-901 Ribeirão Preto-SP, BRASIL.

3. Pesquisador do CNPq, proc. 300014/84-8 RN. Endereço eletrônico: jmfdcama@usp.br / jmafcama@ffclrp.usp.br 
continuidade à série de revisões dos gêneros de Meliponini Neotropicais, iniciada por Camargo e Moure, na qual já foram tratados Paratrigona Schwarz, 1938, e Aparatrigona Moure, 1951 (Camargo \& Moure, 1994), Camargoia Moure, 1989 (CAmargo, 1996b) e Geotrigona Moure, 1943 (CAmargo \& MOURe, 1996).

\section{MATERIALE MÉTODOS}

Para este estudo, foram examinados mais de 26.000 exemplares montados em alfinetes, além de milhares em álcool, a maior parte dos quais depositada na Coleção do Departamento de Biologia da Faculdade de Filosofia, Ciências e Letras de Ribeirão Preto, Universidade de São Paulo (RPSP). Outras instituições e pesquisadores que forneceram material estão listados abaixo. As abreviações citadas no item "Material examinado" são as recomendadas por ARNETT et al. (1993). Coleções particulares são abreviadas pelo nome do seu proprietário.

AMNH- American Museum of Natural History, Dr. Jerome G. Rozen Jr.

BHMH- Museu de História Natural, Universidade Federal de Minas Gerais, Dr. Fernando Silveira

BMNH- Natural History Museum (British Museum), Dr. David G. Notton

CMNH- Carnegie Museum of Natural History, Dr. John E. Rawlins

CUIC-Cornell University Insect Collection, Dr. George Eickwort (in memorian)

DEIC- Deutsches Entomologisches Institut, Eberswalde, Dr. Andreas Taeger

DZUP- Depto. de Zoologia, Universidade Federal do Paraná, Dr. Jesus Santiago Moure.

INPA- Instituto Nacional de Pesquisas da Amazonia, Francisco Peralta.

MELO-Dr. Gabriel A. R. Melo, coleção particular

MSUC- Michigan State University Collection, Dr. Frederick Stehr

MUCR- Museo de Insectos, Universidad de Costa Rica, Dr. Jorge Arturo Lobo Segura

MZSP- Museu de Zoologia de São Paulo, Dr. Carlos Roberto F. Brandão

NZCS- National Zoological Collection of Suriname, Bart De Dijn

OLIV-Márcio L. de Oliveira, coleção particular

SEMC- Snow Entomological Museum, University of Kansas, Dr. Robert Brooks

STRI- Smithsonian Tropical Research Institute, Dr. David W. Roubik

UFVB- Museu de Entomologia, Universidade Federal de Viçosa, Dr. Lúcio A.O. Campos

USNM- U.S. National Museum of Natural History, Smithsonian Institution, Dr. Ronald McGinley

ZMHB- Zoologisches Museum der Humboldt Universität, Berlim, Dr. F. Koch
Para interpretação das espécies descritas foram examinados os tipos de $P$. grandipennis, $P$. pearsoni, $P$. xanthogastra, $P$. ailyae, $P$. pseudomusarum, $P$. vicina, $P$. mulata. $P$. aequatoriana, P. mourei, P. cupira, P. orizabaensis, P. peckolti, $P$. testacea e P. musarum. Foram designados lectótipos e paralectótipos para $P$. cupira e $P$. orizabaensis. O exemplar único, no qual foi baseada a redescrição de $P$. testacea, é reconhecido como holótipo. De $P$. helleri, foram examinados exemplares com etiqueta de "TyPus", em papel de cor salmão, e etiqueta de determinação manuscrita, possivelmente do punho de Friese (mas com a data de determinação posterior à descrição), que provavelmente pertencem à série tipo. Além do material tipo das espécies descritas, também foram examinados exemplares selecionados como tipos por Schwarz, de "Trigona (Paratrigona) (sic) testacea var. centralis" e de "Trigona (Partamona) testacea var. atahualpa", porém não publicados. A interpretação de P. bilineata foi feita com base na descrição original de SAY (1837) e em Ayala (1992). Partamona nigrior foi interpretada segundo a descrição original de CoCKERELL (1925).

A terminologia e forma de apresentação (diagnose, dimensões, forma e proporções, etc.) seguem CAMARGO \& Moure (1996). Tergos e esternos abdominais são indicados, ao longo do texto, como TII-TVIII e EII-EVIII, respectivamente. O termo propódeo refere-se ao $1^{\circ}$ tergo abdominal, incorporado ao tórax. As pernas são indicadas com numerais romanos - I, II, III (pró, meso e metatorácicas, respectivamente). As abreviações "l.m.c." e "c.a.a.", no item "Diagnose", referem-se a largura máxima da cabeça e comprimento da asa anterior. Medidas de comprimento da asa anterior foram tomadas entre o ápice do esclerito costal e a ponta da asa, exceto quando indicado de outra forma (medidas incluindo a tégula). Os caracteres mencionados na chave de identificação para as espécies de Partamona e no item "Diagnose", referem-se às operárias, exceto quando indicado. $\mathrm{O}$ diâmetro do escapo foi medido na sua porção mais larga. A largura do mesoscuto foi medida entre as tégulas. Nas descrições das espécies novas e redescrições, os cálculos de proporções foram feitos com base nas medidas dos espécimens tipo indicadas nas tabelas X-XIV. Os números seguidos pela letra c (e.g. 21c, 665c), referem-se aos números de série dos ninhos, cujo material está depositado da coleção do Departamento de Biologia da Faculdade de Filosofia, Ciências e Letras de Ribeirão Preto (RPSP).

No item "Material examinado" foram transcritas as informações originais constantes das etiquetas de procedência, apenas os meses foram indicados em algarismos romanos e os anos com 4 algarismos. Algumas localidades indicadas de forma imprecisa, não foram localizadas nos mapas. Países e suas subdivisões (estados, províncias, etc.) foram listados de oeste para leste e de norte para sul, conforme Zanella et al. (2000).

No item "Diagnose" é apresentado um conjunto de caracteres que permite reconhecer a espécie, embora estes não sejam necessariamente autapomórficos. Muitas espécies de Partamona são praticamente idênticas na aparência e apresentam o mesmo conjunto diagnóstico; nestes casos, foram acrescentados, no item "Comentários", outras características, 
como tamanho, distribuição geográfica, substrato de nidificação, que podem auxiliar o reconhecimento da espécie em questão. É importante ressaltar que existem pouquíssimos caracteres estruturais de importância taxonômica dentro de Partamona.

As mensurações foram feitas em microscópio estereoscópico Wild M5A equipada com ocular micrométrica; os desenhos foram feitos com auxílio de câmara clara.

Para a construção das hipóteses de filogenia, utilizou-se os programas PAUP - Phylogenetic Analysis Using Parsimony, versão 3.1.1. (SwOFFORD, 1993), e MacClade, versão 3.05 (Maddison \& MAdDison, 1995).

O levantamento de literatura para composição das listas sinonímicas foi encerrado em 1998, com exceção do trabalho de Ayala (1999), e pode não estar completo. (Este trabalho, foi inicialmente submetido para publicação nos Arquivos de Zoologia, São Paulo, em 09/VI/1999, aí permanecendo até 10/V/2002, portanto, a literatura não foi atualizada nesse período).

\section{Gênero Partamona Schwarz}

Trigona (Patera) Schwarz, 1938: 475 (praeoc.).

Espécie Tipo: Melipona testacea Klug, 1807 (por designação original).

Trigona (Partamona) Schwarz, 1939a: 23 (nom. nov. para Patera Schwarz, 1938, non Patera Lesson, 1837); Wille, 1979: 268.

Partamona; Moure, 1951: 56-58; 1992: 121-122; Camargo \& Moure, 1988: 293-294 (por inferência); Camargo, 1989: 47, 59; Camargo \& Pedro, 1992a: 45, 48, 49; 1992b: 513, 515; Roubik et al., 1997: 67, 68, 76, 78, 79; Michener, 1990: 115.

Partamona (Partamona); Moure, 1953: 247-249; 1961: 183, 184, 186; Camargo, 1980: 7-13.

Schwarz (1938) criou Patera como um subgênero de Trigona Jurine, 1807, elegendo como espécie-tipo Melipona testacea Klug, 1807. Descobriu-se, em seguida, que o nome Patera já havia sido utilizado por Lesson (1837, apud SCHWARZ 1939a: 23); diante disso, Schwarz (1939a) deu o nome de Partamona em substituição ao nome pré-ocupado. (O nome Partamona refere-se a uma tribo indígena da linhagem Arawak, habitante do interior da Guiana (SCHWARZ, 1939a), e "Patera", um nome sugerido por F. E. Lutz, refere-se à forma da tíbia III da operária ("pires" ou "prato raso"; SCHWARZ, 1938).

Posteriormente, Moure (1951) erigiu-o ao nível de gênero e, em 1953, esse mesmo autor, propõe a inclusão de Nogueirapis Moure, 1953 e Parapartamona Schwarz, 1948 como subgêneros de Partamona. Essa classificação também foi admitida por Camargo (1980). Wille (1979), por sua vez, considerou Parapartamona como um sinônimo de Partamona e manteve Nogueirapis como um gênero independente. Mais recentemente, Michener (1990) seguiu, de certa forma, a proposta de Wille, considerando Parapartamona como sinônimo de Partamona mas passando a considerar Nogueirapis como um subgênero de Plebeia. No presente texto, considera-se Partamona, Parapartamona e Nogueirapis como gêneros independentes, como vem sendo adotado nos trabalhos mais recentes (CAmargo \& Moure 1988, CAMARgo 1989; Camargo \& Pedro 1992 a,b, Moure 1992, RoubiK et al. 1997).
A diagnose para o gênero Partamona, apresentada a seguir, é baseada no sistema de Moure $(1951,1961)$ :

a) Integumento liso e polido, exceto pelos pontos pilígeros, com máculas amarelas na cabeça e tórax; clípeo com desenho amarelo aproximadamente em forma de dois $\mathbf{L}$ contrapostos; pubescência normal, com cerdas eretas no clípeo, sem pêlos plumosos na face; cerdas eretas nos esternos da operária, delgadas e fortemente encurvadas no ápice; olhos compostos sem pilosidade aparente.

b) Cabeça mais larga que o tórax. Face normal, olhos subparalelos, a interorbital máxima usualmente maior que o comprimento do olho; órbita interna fracamente sinuosa; tangente alveolar superior um pouco abaixo do meio da face; distância interalveolar ca. 4/5 da alveolorbital. Porção superior da fronte convexa, em continuidade com a convexidade geral da face, sem carena frontal definida, mas com uma elevação até pouco acima da tangente alveolar superior; sulco frontal evidente.

c) Clípeo com bordo distal reto, superfície suavemente deprimida médio-apicalmente, seu comprimento variando entre ca. $1 / 3$ e $2 / 5$ da distância clipeocelar; sutura epistomal convergindo superiormente, com os lados levemente encurvados; canto inferior afastado da órbita por pouco mais que um diâmetro do $2^{\circ}$ flagelômero.

d) Mandíbula com dois dentes no terço interno, separados por arco profundo ou reentrância. Labro fortemente convexo. Área malar longa, variando de 0,7 a 1,8 vezes o diâmetro do $2^{\circ}$ flagelômero. Gena, de perfil, igual ou mais larga que o olho.

e) Vértice arredondado, acima da tangente orbital superior, um pouco elevado entre os ocelos; sem carena pré-occipital e sem carena pós-ocelar; bordo posterior fortemente procurvo e afastado dos ocelos laterais um pouco menos que um diâmetro destes; distância entre os ocelos laterais variando de 0,8 a 1,5 vezes a ocelorbital, e aproximadamente 1,6 a 2,0 vezes o diâmetro do ocelo médio.

f) Escapo mais curto ou, no máximo, igual à distância alvéoloocelo lateral; $2^{\circ}$ flagelômero aproximadamente tão longo quanto o seu próprio diâmetro, ligeiramente mais curto que os demais.

g) Sulco médio mesoscutal, linhas prescutais e parapsidais fracamente impressos. Escutelo arredondado, pouco projetado sobre o metanoto.

h) Asa anterior longa, ultrapassando o ápice do abdômen; pterostigma grande, mais largo que o diâmetro do $2^{\circ}$ flagelômero, e cerca de 4,5 vezes mais longo que o diâmetro deste; prestigma mais curto que a largura do pterostigma; célula marginal aproximadamente 4,5 vezes mais longa que a sua largura, lanceolada, e quase fechada no ápice. Bifurcação entre $\mathrm{M} \mathrm{e} \mathrm{Cu}$ anterior ou geralmente coincidente com a cu-v. Ângulo submarginal, entre Rs e Rs+M entre $100^{\circ} \mathrm{e} 120^{\circ}$ (Fig. 11). Rs $+\mathrm{M}$ forte, curvada no ponto em que recebe a primeira $\mathrm{m}$-cu e continuando finamente até o bordo alar. $\mathrm{Cu}$ forte, adelgaçada até o bordo alar. Células submarginais fracamente delimitadas. Asa posterior com 
venação normal. Hâmulos, 5 a 6 . Lóbulo jugal cerca de 4/9 do vanal.

i) Tíbia posterior (Figs. 2, 3, 12) quase tão larga quanto a metade do seu comprimento; o canto póstero-distal anguloso e a margem distal um pouco sinuada; corbícula muito desenvolvida, ocupando quase toda a superfície externa da tíbia, fortemente côncava, com 1-3 cerdas, muito longas, apicalmente sinuosas, inseridas na metade superior da superfície corbicular e estendendo-se quase até o bordo apical (Fig. 2); cerdas corbiculares marginais simples (Fig. 2). Elevação interna curto-denso-pilosa (= área quirotriquiada, $c f$. MicheNER, 1990) muito larga, estendendose até o bordo posterior, deixando apenas uma estreita margem glabra, não rebaixada (Fig. 3). Penicilo e rastelo bem desenvolvidos (Figs. 2, 12).

j) Basitarso posterior achatado, ca. de 1,8 vezes mais longo que largo, bordo anterior convexo, o posterior levemente côncavo no terço basal e fortemente convexo nos $2 / 3$ apicais, mais convergente para cima, a largura máxima no quarto distal, o bordo distal sinuado ou não (Figs. 2, 3, 12), o canto posterior arredondado; sem área basal sedosa (área com pêlos curtos e densos, com aspecto sedoso $=$ "sericeous area", de Michener, 1990) na face interna (Fig. 3).

k) Propódeo medianamente desenvolvido, com aproximadamente a metade anterior em declive suave, ca. de $45^{\circ} \mathrm{em}$ relação a superfície vertical posterior; com a pontuação pilígera uniformemente distribuída, exceto uma faixa mediana glabra, lisa, polida; o espaço entre os pontos, liso-polido. Abdômen quase tão largo quanto o tórax, porém bastante curto e mais ou menos achatado superiormente, aquilhado inferiormente. Tergo II praticamente liso, apenas com tesselado suave junto a margem distal, TIII com pontos pilígeros esparsos, e os seguintes com uma faixa pré-apical larga, mais densa e fortemente pontuada.

l) Esternos V-IX e genitália do macho como nas figuras 20-28; espata muito desenvolvida, recobrindo os gonocoxitos por inteiro (Fig. 28).
O integumento liso, polido, clípeo com desenhos amarelos aproximadamente em forma de dois $\mathbf{L}$ contrapostos, ausência de pêlos plumosos na face e cerdas dos esternos encurvadas apicalmente (a), combinados com a forma dos dentes da mandíbula, do basitarso e tíbia III da operária (i) (Figs. 2, 12), permitem distinguir facilmente Partamona dos demais Meliponini. A forma da tíbia III, o ângulo submarginal aberto (h; Fig. 11), além do tamanho maior, separam facilmente as espécies desse gênero daquelas de Nogueirapis; de Parapartamona, facilmente se distingue pelo integumento liso e polido, entre a pontuação pilígera relativamente esparsa, e pela posição mais vertical do propódeo, que confere uma forma mais globosa ao tórax (em Parapartamona tórax e propódeo são mais alongados, a área basal do propódeo ficando em posição quase horizontal). Outros caracteres distintivos para esses gêneros podem ser vistos em Moure (1992). De Meliwillea Roubik et al., 1997 e Scaptotrigona Moure, 1942, distingue-se, principalmente, pela forma da tíbia III (Figs. 12, 14, 15).

As principais autapomorfias do gênero são: tíbia III da operária muito larga, a largura aproximadamente igual a metade do comprimento da tíbia (Figs. 2,12), a corbícula em forma de colher, ocupando, no mínimo, $2 / 3$ da tíbia, o padrão das máculas da face, e, nos machos, a forma dos esternos pré-genitais e genitália (Figs. 20-28), principalmente da espata, muito grande, recobrindo os gonocoxitos. A forma do basitarso III (Figs. 2, 12) e as cerdas encurvadas apicalmente nos esternos das operárias também ocorrem no gênero australiano Austroplebeia Moure, 1961, mas em nenhum gênero neotropical; em Meliwillea e Scaptotrigona as cerdas são multisinuosas no ápice (Fig. 39, em RouBiK et al., 1997) e representam um estado distinto daquele de Partamona.

\section{Relações filogenéticas}

Propostas de relações filogenéticas para gêneros de Meliponini, incluindo Partamona, foram apresentadas por Michener (1990), Camargo \& Pedro (1992 a) e Roubik et al.

Tabela I. Matriz de estados de caracteres para Partamona e gêneros relacionados.

\begin{tabular}{lccccccccccccccccccccccc}
\hline & 1 & 2 & 3 & 4 & 5 & 6 & 7 & 8 & 9 & 10 & 11 & 12 & 13 & 14 & 15 & 16 & 17 & 18 & 19 & 20 & 21 & 22 \\
\hline Plebeia & 0 & 0 & 0 & 0 & $0-1$ & 0 & 0 & 0 & 0 & 0 & 0 & 0 & 0 & 0 & 0 & 0 & 1 & 0 & 0 & 0 & 0 & 0 \\
Melipona & 1 & 3 & 0 & 0 & 3 & 0 & 0 & 0 & 0 & 0 & 2 & 2 & 0 & 0 & 0 & 0 & 0 & 0 & 0 & 0 & 0 & 0 \\
Nogueirapis & 1 & 1 & 0 & 1 & 1 & 1 & 1 & 1 & 0 & 0 & 0 & 0 & 0 & 0 & 0 & 0 & 0 & 0 & 0 & 0 & 0 & 0 \\
Parapartamona & 1 & 2 & 1 & 1 & 1 & 1 & 1 & 1 & 0 & 0 & 0 & 0 & 0 & 1 & 2 & 0 & 0 & 0 & 0 & 0 & 0 & 0 \\
Partamona & 1 & 2 & 1 & 1 & 1 & 1 & 1 & 2 & 0 & 2 & 0 & 0 & 0 & 1 & 2 & 0 & 0 & 1 & 0 & 0 & 0 & 0 \\
Meliwillea & 1 & 2 & 1 & 1 & 0 & 0 & 0 & 0 & 1 & 1 & 0 & 1 & 0 & 0 & 0 & 0 & 0 & 2 & 1 & 1 & 1 & 1 \\
Scaptotrigona & 1 & 2 & 1 & 0 & 0 & 0 & 0 & 0 & 1 & 1 & 1 & 1 & 0 & 0 & 1 & 1 & 2 & 2 & 1 & 1 & 1 & 1 \\
Nannotrigona & 1 & 0 & 0 & 0 & 0 & 0 & 0 & 0 & 1 & 1 & 1 & 1 & 0 & 0 & 1 & 1 & 1 & 0 & 0 & 0 & 0 & 0 \\
Aparatrigona & 1 & 0 & 0 & 0 & 2 & 0 & 0 & 0 & 1 & 1 & 1 & 0 & 1 & 0 & 0 & 0 & 0 & 0 & 0 & 0 & 0 & 0 \\
Paratrigona & 1 & 0 & 0 & 0 & 2 & 0 & 0 & 0 & 1 & 1 & 1 & 0 & 1 & 0 & 0 & 0 & 0 & 0 & 0 & 0 & 0 & 0 \\
\hline
\end{tabular}


(1997). A área quirotriquiada na superfície interna da tíbia III, alargada, estendida quase até o bordo posterior, e ausência de rebaixo (como na figura 3), constitui um estado derivado, como discutido por CAMARgo \& Pedro (1992 a) e RoubiK et al. (1997), reunindo Partamona, Parapartamona, Paratrigona, Aparatrigona, Scaptotrigona, Nannotrigona Cockerell, 1922, Nogueirapis, Meliwillea e Melipona, em um clado monofilético, neotropical (CAMARgo \& Pedro, 1992 a; RoubiK et al., 1997).

Na hipótese apresentada por RouвiK et al. (1997), utilizando 11 caracteres, Partamona e Parapartamona são considerados como grupos irmãos, por compartilharem a apomorfia corbícula largamente escavada. Esses dois táxons aparecem como irmãos de Scaptotrigona e Meliwillea, pelo espaço malar longo e pelo ângulo submarginal da asa anterior aberto. No presente estudo, com o objetivo de explorar mais detalhadamente as relações entre Partamona e os gêneros acima mencionados, uma nova matriz foi construída (Tab. I), incluindo 9 dos caracteres usados por RouBiK et al. (1997), alguns deles recodificados, além de 13 novos caracteres, listados a seguir.

1) Margem posterior glabra da superfície interna da tíbia III, operária:

0. rebaixada em degrau, ao longo de todo o bordo posterior da área quirotriquiada;

1. plana (Fig. 3), ou apenas com leve rebaixo na porção basal da área quirotriquiada.

Em algumas espécies de Melipona Illiger, 1806, (grupo marginata), alguns indivíduos de Nogueirapis mirandula (Cockerell, 1917) e uma espécie nova, não descrita, de Nogueirapis do Equador, a margem posterior é suavemente rebaixada na porção basal, entretanto não é comparável àquela de Plebeia Schwarz, 1938, que apresenta rebaixo forte acompanhando todo o bordo posterior da área quirotriquiada. Portanto, para a construção da matriz, Melipona e Nogueirapis foram codificados com o estado 1.

2)Asa, forma da célula média, operária:

0. padrão Plebeia (M ca. 0,8x o comprimento da $\mathrm{Cu}$ e 1,2-1,3x mais longa que Rs $+\mathrm{M}$, o ângulo entre $\mathrm{Me}$ $\mathrm{Rs}+\mathrm{M}$ aberto, ca. $114^{\circ}$; o vértice da célula aproximadamente na direção do meio da $\mathrm{Cu}$; Figs. 4, $8,10)$;

1. padrão Nogueirapis (M ca. de $0,8-0,9 \mathrm{x}$ o comprimento da $\mathrm{Cu}$ e 1,6x mais longa que Rs+M, o ângulo entre a $\mathrm{M}$ e Rs+M aberto, ca. $114^{\circ}$; o vértice da célula aproximadamente na direção do terço distal da $\mathrm{Cu}$; Fig. 6);

2. padrão Partamona-Scaptotrigona (M ca. de 1,0x o comprimento da $\mathrm{Cu}$ e 1,8-2,6x mais longa que Rs $+\mathrm{M}$, o ângulo entre $\mathrm{M} \mathrm{e} \mathrm{Rs}+\mathrm{M}$ ca. $90^{\circ}-105^{\circ}$; o vértice da célula na direção do quinto distal da $\mathrm{Cu}$; Figs. 5, 7, 9 , $11)$;

3. padrão Melipona (M ca. 0,8-1,0x o comprimento da $\mathrm{Cu}$ e 1,3-1,6x mais longa que Rs+M, o ângulo entre $M$ e Rs+M muito aberto, $120^{\circ}-130^{\circ}$; o vértice da célula aproximadamente na direção do $1 / 4-1 / 5 \mathrm{da} \mathrm{Cu}$ ).

3) Ângulo submarginal, entre Rs e Rs $+M$, operária:

0 . agudo até levemente aberto (ca. 100 ; Figs. 4, 5, 8, 10);

1. obtuso $\left(105^{\circ}-140^{\circ}\right.$; Figs. $\left.6,7,9,11\right)$.

4) Pilosidade na face, operária:

0. com pêlos plumosos;

1. apenas pêlos simples.

5) Espaço entre os 2 dentes do canto interno da mandíbula, operária:

0 . em arco raso, dentes muito espaçados, padrão Scaptotrigona (Fig. 3, em RouBiK et al., 1997);

1. em arco profundo (Figs. 31-66);

2. em V, tipo Paratrigona - Aparatrigona;

3. em lâmina quase reta, dentes muito pequenos e espaçados, tipo Melipona.

6) Cerdas especializadas na cavidade corbicular, operária:

0 . ausentes;

1. presentes.

Considerou-se como cerdas especializadas, aquelas muito longas e fortes, inseridas na superfície côncava da corbícula. $\mathrm{Na}$ maioria das espécies de Partamona estão presentes 2-3 cerdas muito longas com o ápice sinuoso, inseridas na porção posterior do terço superior da área corbicular, conforme apresentado na figura 2. Em P. grandipennis e P. xanthogastra está presente uma única cerda inserida aproximadamente na metade da corbícula. Em algumas espécies de Parapartamona aparecem 1-2 cerdas, largamente sinuosas, aproximadamente em forma de $\mathrm{S}$, inseridas no meio da corbícula. Nogueirapis apresenta 1-2 cerdas muito longas e retas, na metade ou no terço superior da área corbicular e chegando até o ápice da tíbia. É possível que o desenvolvimento dessas cerdas esteja associado a expansão da área corbicular (veja caráter 14), auxiliando na sustentação do material carregado na corbícula (pólen, resina e, no caso de Partamona e Melipona, também terra), e podem ter evoluído independentemente nesses três gêneros. Nos gêneros codificados com o estado 0 podem aparecer algumas cerdas curtas, simples e retas, implantadas na área corbicular.

7) Cerdas no EVI, macho:

0 . simples, delgadas, geralmente curtas;

1. longas, fortes, eretas, encurvadas no ápice (Figs. 21, 29).

Cerdas modificadas, longas e fortes, também aparecem no EVI dos machos de algumas espécies de Paratrigona (e.g. $P$. opaca (Cockerell, 1917), P. lophocoryphe Moure, 1963, P. haeckeli,(Friese, 1900), P. prosopiformis (Gribodo, 1893); cf. Camargo \& Moure, 1994), porém são bastante distintas daquelas de Partamona, Parapartamona e Nogueirapis, e devem constituir derivações dentro de Paratrigona. Algumas espécies de Melipona também apresentam cerdas longas e 
encurvadas no ápice, porém são cerdas mais finas e mais abundantes que aquelas encontradas em Partamona, Parapartamona e Nogueirapis.

8) Comprimento da área quirotriquiada em relação ao bordo apical da tíbia III, operária:

0 . chegando até a margem;

1. deixando margem estreita glabra;

2. deixando larga margem glabra (1/8 do comprimento da área quirotriquiada; Fig. 3 ).

9) Cerdas marginais da corbícula, operária:

0 . não diferenciadas;

1. muito longas, encurvadas para dentro, recobrindo a área corbicular (Figs. 19-20 em RouBIK et al., 1997).

10) Basitarso III, operária:

0. com lados subparalelos ou a margem posterior suavemente encurvada, um pouco alargado para o ápice (Figs. 13, 16, 18);

1. com a margem posterior convexa medianamente, tipo Scaptotrigona (Figs. 14, 15, 19);

2. com a margem posterior fortemente sinuada, a maior largura próxima do ápice. (Figs. 2, 12).

Aparatrigona e algumas espécies de Paratrigona apresentam o basitarso nitidamente no estado 1 .

11) Escutelo, operária:

0 . curto, superfície dorsal convexa;

1. longo, estendendo-se bem além da base do propódeo, superfície dorsal achatada;

2. longo, estendendo-se um pouco além da base do propódeo, superfície dorsal fortemente convexa.

O estado 2 está presente em algumas espécies de Melipona, e pode constituir uma derivação interna no gênero.

12) Célula marginal da asa anterior, operária:

0 . ca. $4 \mathrm{x}$ mais longa que larga (Figs. 4, 6, 8, 9, 11), maior largura na altura da tangente apical do pterostigma, afilada e sinuada para o ápice;

1. ca. $4 \mathrm{x}$ mais longa que larga (Figs. 5, 7, 10), maior largura além da tangente apical do pterostigma, em curva suave para o ápice, não sinuada;

2. ca. de $6 x$ mais longa que larga, maior largura medianamente, em curva suave, não sinuada (Melipona).

13) Mandíbula, operária:

0 . bidentada;

1. quadridentada.

14) Corbícula, operária:

0 . suavemente côncava;

1. fortemente côncava.
15) Forma da tíbia III, operária:

0 . suavemente alargada em direção ao ápice, a margem posterior suavemente convexa, o ângulo pósterodistal agudo, margem distal nitidamente côncava (padrão Plebeia; Figs. 14, 16, 17, 18);

1. bastante alargada em direção ao ápice, com a margem posterior apenas levemente convexa, praticamente triangular, o canto póstero-distal em ângulo agudo mas não projetado e a margem distal apenas levemente côncava (Figs. 15, 19);

2. muito alargada, com a margem posterior sinuada e convexa para o ápice a partir do $1 / 4-1 / 3$ basal, o bordo distal côncavo (Figs. 12, 13).

16) Fóvea escutelar, operária:

0 . ausente;

1. presente.

17) Elevação pré-occipital, operária:

0 . arredondada;

1. angulada;

2. com carena em forma de lâmina.

18) Pêlos ventrais do tórax e esternos, operária:

0 . simples;

1. sinuosos no ápice;

2. multisinuosos (Fig. 39, RouBIK et al., 1997: 77).

19) Área malar, operária:

0 . linear até, no máximo, $1,5 x$ o diâmetro do $2^{\circ}$ flagelômero; 1. longa, ca. de $2 \mathrm{x}$ o diâmetro do $2^{\circ}$ flagelômero.

20) Tomento nos tergos abdominais, operária:

0 . ausente;

1. presente.

21) Manchas amarelas na cabeça e tórax, operária:

0 . presentes;

1. ausentes.

22) Comprimento do olho em relação à distância interorbital superior, operária:

0 . tão ou mais longo que a distância interorbital superior $(1,00-1,41)$;

1. nitidamente mais curto que a distância interorbital superior $(0,8-0,9)$.

Para a obtenção dos cladogramas mais parcimoniosos, a matriz (Tab. I) foi analisada pelo programa Phylogenetic Analysis Using Parsimony - PAUP (versão 3.1.1), através de "busca exaustiva", com todos os caracteres não ordenados e com pesos iguais, otimizados por ACCTRAN ("accelerated transformation"). Como resultado, foram obtidos 3 cladogramas de comprimento mínimo (comprimento 40, índice de consistência 0,82 , índice de retenção 0,82 , e índice de consistência reescalonado 0,68). Em todas as opções os clados (Nogueirapis 
(Partamona, Parapartamona)) e ((Nannotrigona (Meliwillea, Scaptotrigona)) (Aparatrigona, Paratrigona)) permanecem inalterados e, portanto, também nas árvores de consenso ("strict, semistrict, majory rule, adams"). Uma das opções de comprimento mínimo é apresentada na figura 174. Nos outros dois cladogramas de comprimento mínimo, Melipona ora sai como irmão do clado (Nogueirapis (Partamona, Parapartamona)), ora de ((Nannotrigona (Meliwillea, Scaptotrigona)) (Aparatrigona, Paratrigona)).

Considerando as hipóteses mais parcimoniosas, Parapartamona constitui o mais provável grupo irmão de Partamona pela corbícula fortemente escavada e a tíbia III muito alargada (15.2, Figs. 2, 12, 13). O clado (Nogueirapis (Partamona, Parapartamona)) apresenta como sinapomorfias a forma dos dentes da mandíbula (caráter 5.1; Figs.31-66), a presença de cerdas especializadas na área corbicular (6.1), e EVI dos machos (7.1; Figs. 21, 29). A presença apenas de pêlos simples na face (4.1) é compartilhada por esses três gêneros e também por Meliwillea. O espaço glabro entre a área quirotriquiada e o bordo distal da tíbia III é mais nítido em Partamona (8.2), mas também aparece em Nogueirapis e Parapartamona (8.1). Nestas hipóteses, porém, o padrão da venação alar, principalmente forma da célula média e ângulo submarginal (caracteres 2 e 3 respectivamente), que é absolutamente idêntico em (Partamona, Parapartamona) e (Scaptotrigona, Meliwillea) aparece como homoplástico [em uma das opções de comprimento um pouco mais longo, 42, o clado (Nogueirapis (Partamona, Parapartamona)) aparece como irmão de (Meliwillea, Scaptotrigona)]. Por outro lado, o agrupamento ((Nannotrigona (Meliwillea, Scaptotrigona)), (Paratrigona, Aparatrigona)) aparece bem justificado pela forma e disposição das cerdas marginais da corbícula (9.1), forma do basitarso III das operárias (10.1), e também pelo escutelo achatado e projetado sobre o metanoto (que sofre reversão em Meliwillea). Além disso, Nannotrigona, Scaptotrigona e Meliwillea compartilham padrão muito similar de genitália e esternos pré-genitais (RouBIK et al., 1997), que não foram considerados na análise devido a dificuldade de separação em estados.

Melipona é um gênero que apresenta muitas autapomorfias, como o padrão de venação da asa (principalmente a forma da

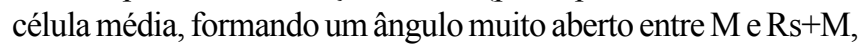
caráter 2.3, o ângulo submarginal entre Rs e Rs+M muito fechado, e a célula marginal muito longa e estreita, 12.2), a forma dos dentes da mandíbula (5.3), o escutelo arredondado e projetado sobre o metanoto (11.2), além de caracteres da biologia que não foram codificados aqui. É possível que Melipona constitua um gênero externo ao clado analisado aqui, mas sua posição só poderá ser melhor esclarecida em uma análise que inclua todos os gêneros de Meliponini.

Sob a óptica da biogeografia de vicariância, os padrões de distribuição dos gêneros estudados são pouco esclarecedores sobre a história evolutiva do grupo. Partamona (Fig. 158), Scaptotrigona, Nannotrigona e Paratrigona são gêneros amplamente distribuídos na região neotropical, desde o sul do Brasil ou noroeste da Argentina, até o México, constituindo réplicas biogeográficas, e apresentam grande diversidade de espécies. Os demais gêneros apresentam distribuições bem mais restritas, com poucas espécies: Aparatrigona ocorre apenas na Bacia Amazônica - A impunctata (Ducke, 1916), e no Panamá/NW da Colômbia - A. isopterophila (Schwarz, 1934); dados de Camargo \& Moure, 1994, e Camargo, 1996a; Meliwillea, monotípico, é endêmico das regiões montanhosas da Costa Rica e oeste do Panamá (Roubik et al., 1997); Nogueirapis (Fig. 159) ocorre do oeste da Bacia Amazônica até a Guiana Francesa [N. butteli (Friese, 1900) e N. minor Moure \& Camargo, 1982], e na Costa Rica e Panamá, além de ter sido registrada na ilha de Gorgona, no litoral pacífico da Colômbia (N. mirandula; Wille, 1964); Parapartamona, com 7 espécies descritas ( $c f$. Moure, 1992), é restrito aos bosques montanos das encostas andinas oriental e ocidental (Fig. 159) entre 1500-2750 m de altitude (dados de Camargo, observação pessoal, Coloma, 1986 e Bravo, 1992; Roubik, 1989, menciona $3400 \mathrm{~m}$, entretanto não existe nenhum dado consistente que indique Parapartamona nessas altitudes).

A hipótese de Parapartamona como grupo-irmão de Partamona não é esclarecedora de eventos de vicariância ou quebras biogeográficas. O padrão distribucional de Parapartamona, restrito a grandes altitudes (Fig. 159), tem, possivelmente, um caráter relictual. Atualmente, há uma certa exclusão altitudinal entre esses dois gêneros na região andina, Partamona é comum até a faixa dos $1.500 \mathrm{~m}$ de altitude (exceto $P$. peckolti, que, segundo dados de etiqueta, pode chegar até $2.000 \mathrm{~m}$ na Colômbia), acima dessa altitude são encontrados apenas exemplares de Parapartamona. Na Costa Rica e noroeste do Panamá Partamona grandipennis é endêmica das regiões montanhosas (Fig. 160) e dados de etiquetas indicam que $P$. orizabaensis pode chegar até 11.000 pés - ca. $3.350 \mathrm{~m}$.

\section{Filogenia das espécies de Partamona}

\section{Caracteres estudados}

Abaixo, são apresentados e discutidos os caracteres usados na análise fillogenética para as espécies de Partamona (Tab. II); a polarização dos estados foi feita segundo o critério de grupo externo; na matriz foram incluídos Plebeia droryana (Friese, 1900), Nogueirapis butteli e Parapartamona vittigera Moure, 1992, como representantes de fora. Em muitos caracteres, especialmente os estruturais, os estados plesiomórficos considerados para as espécies de Partamona não são exatamente iguais aos dos grupos externos; a polarização foi feita tentativamente, considerando o grau maior ou menor de semelhança das estruturas. Além dos caracteres relacionados a seguir, muitos outros foram estudados (e.g. cor do integumento, forma da mancha subocelar, forma da estria escutelar, ângulo submarginal da asa anterior, comprimento do clípeo em relação à distância clipeocelar, forma do basitarso III da operária, forma do vértice da cabeça, largura da faixa glabra e pontuação pilígera na base do propódeo, forma do escutelo, pilosidade do EVI dos machos, etc.), entretanto, não foram incluídos na análise por não apresentarem descontinuidades 
Tabela II. Matriz para as espécies de Partamona; grupo externo: Plebeia droryana, Nogueirapis butteli, Parapartamona vittigera. Os caracteres usados para a construção da hipótese de filogenia (Fig. 175), estão indicados por asterisco (*).

\begin{tabular}{|c|c|c|c|c|c|c|c|c|c|c|c|c|c|c|c|c|c|c|c|c|c|c|c|c|c|c|c|}
\hline & $1 *$ & $2^{*}$ & $3 *$ & $4^{*}$ & $5 *$ & $6^{*}$ & 7 & 8 & 9 & 10 & 11 & 12 & 13 & 14 & $15^{*}$ & $16^{*}$ & $17^{*}$ & $18^{*}$ & $19 *$ & $20 *$ & $21^{*}$ & $22 *$ & $23 *$ & $24 *$ & $25^{*}$ & $26^{*}$ & $27 *$ \\
\hline P. droryana & 0 & 0 & 0 & 0 & 0 & 0 & 0 & 0 & 0 & 0 & 2 & 0 & 0 & 0 & 0 & 0 & 0 & 0 & 2 & 0 & 0 & 0 & 0 & 0 & 0 & 0 & 0 \\
\hline Privica & 0 & 0 & 0 & 0 & 0 & 0 & 1 & & 0 & 0 & 1 & & 1 & & & & & & & & & & 0 & & & & \\
\hline$P$. vittigera & 0 & 0 & 2 & 1 & 1 & 2 & 2 & 1 & 0 & 0 & 0,1 & 0 & 0,1 & 0 & 0 & & & & & & & 0 & 1 & 0 & 0 & 0 & \\
\hline$P$. grandipen & 0 & 1 & 2 & 1 & 1 & 2 & 2 & 1 & 0,1 & 0 & 1 & 0 & 0 & 0 & 0 & 0 & 1 & 2 & 0 & 0 & 1 & 1 & 2 & 1 & 1 & $?$ & 1 \\
\hline & 0 & 1 & 1 & 0 & 1 & 2 & 2 & 1 & 0,1 & 0 & 1 & 0 & 1 & 0 & 0 & 0 & 1 & ? & ? & $?$ & $?$ & 1 & 2 & 1 & 1 & $?$ & 1 \\
\hline$P . b$ & 0 & 1 & 1 & 0 & 0 & 0 & 1 & 0 & 0 & 0 & 0,1 & 0 & 0,1 & 0 & 0 & 0 & 1 & 2 & 0 & 0 & 1 & 1 & 2 & 1 & 1 & 1 & 1 \\
\hline P. orizal & 0 & 1 & 1 & 0 & 0 & 0 & 1 & & 1 & 0 & 1 & 0 & 0 & 0 & 0 & 0 & 1 & 1 & 1 & 0 & 0 & 1 & 2 & 1 & 1 & 1 & 1 \\
\hline$P . p e$ & 0 & 0,1 & 1 & 0 & 0 & 0 & 1 & 1 & 1 & 0 & 1 & 0 & 0 & 0 & 0 & 0 & 1 & 1 & 1 & & 0 & 1 & 2 & 1 & 1 & 1 & \\
\hline ilis & 0 & 1 & 1 & 0 & 0 & 0 & 1 & 0 & 0 & 0 & 1 & 0,1 & 0,1 & 0 & 0 & 0 & 1 & $?$ & $?$ & $?$ & $?$ & 1 & 2 & 1 & 1 & $?$ & 1 \\
\hline P. e & 0 & 1 & 1 & 0 & 0 & 0 & 0,1 & 1 & 1 & 0 & 1 & 0 & 0 & 1 & 0 & 0 & 1 & 0 & 0 & 0 & 0 & 1 & 2 & 1 & 1 & 1 & 1 \\
\hline P. $n$ & 0 & 1 & 1 & 0 & 0 & 0 & 1 & 1 & 1 & 0 & 1 & 0 & 0 & 1 & 0 & 0 & 1 & 0 & 0 & 0 & 0 & 1 & 2 & 1 & 1 & 1 & 1 \\
\hline P. bat & 0 & 1 & 1 & 0 & 0 & 0 & 1 & 0 & 1 & 0 & 1 & 0 & 0 & 0,1 & 0 & 0 & 1 & 0 & 0 & 0 & 0 & 1 & 2 & 1 & 1 & 1 & 1 \\
\hline & 0 & 1 & 1 & 0 & 0 & 0 & 2 & 1 & 1 & 0 & 1 & 0 & 0 & 1 & 0 & C & 1 & & & & & 1 & 2 & 1 & 1 & $?$ & 1 \\
\hline & 0 & 1 & 1 & 0 & 0 & 0 & 1 & 0 & 0 & 0 & 1 & 1 & 1 & 0 & 0 & 0 & 1 & $?$ & & & & 1 & 2 & 1 & 1 & $?$ & 1 \\
\hline$P . c$ & 2 & 0 & 2 & 0 & 0 & 0 & 1 & 0 & 0 & 0 & 1 & 1 & 1 & 0 & 0 & 0 & 1 & $?$ & $?$ & $?$ & $?$ & 1 & 2 & 1 & 1 & $?$ & 1 \\
\hline$P . r$ & 2 & 0 & 1 & 0 & 0 & 0 & 1 & 0 & 0 & 0 & 1 & 1 & 1 & 0 & 0 & 0 & 1 & 0 & 0 & 0 & 0 & 1 & 2 & 1 & 1 & 1 & 1 \\
\hline & 2 & 0 & 0 & 0 & 0 & 0 & 0 & & 0 & 0 & 1 & 1 & 1 & 0 & 0 & 0 & 1 & 0 & 0 & 0 & 0 & 1 & 2 & 1 & 1 & 1 & 1 \\
\hline & 2 & 0 & 1 & c & c & 0 & 0 & & 0 & 0 & 1 & 1 & 1 & 0 & 0 & & 1 & & & & & 1 & 2 & 1 & 1 & 1 & 1 \\
\hline P. $p$ & 2 & 0 & 1 & 0 & 0 & 0 & 0 & 1 & 0 & 0 & 1,2 & 0 & 0 & 0 & 0 & & 1 & & & & 0 & 1 & 2 & 1 & 1 & 1 & \\
\hline P. $g$ & 2 & 0 & 1 & 0 & 0 & 1 & 0 & 0 & 1 & 1 & 0 & 0 & 0 & 1 & 0 & 0 & 1 & 0 & 0 & 0 & 0 & 1 & 2 & 1 & 1 & 1 & 1 \\
\hline & 2 & 0 & 1 & 0 & 0 & 0 & 1 & & 0 & 0 & 1 & 0,1 & 0,1 & 0 & 0 & 0 & 1 & 0 & 0 & 0 & 1 & 1 & 2 & 1 & 1 & 1 & 1 \\
\hline & 2 & 0 & 1 & 0 & 0 & 0,1 & 0 & & 1 & 0,1 & 2 & 0 & 0 & 1 & 0 & 0 & 1 & 0 & 0 & 0 & 1 & 1 & 2 & 1 & 1 & 1 & 1 \\
\hline & 2 & 0 & 1 & 0 & 0 & 0 & 0 & & 1 & 0 & 2 & 0 & 0 & 2 & 0,1 & 0 & 1 & 0 & 1 & 1 & 1 & 1 & 2 & 1 & 1 & 1 & 1 \\
\hline$P$. & 2 & 0 & 1 & 0 & 0 & 1 & 0 & & 1 & 1 & 2 & c & 0 & 2 & 1 & & 1 & & & & & 1 & & 1 & 1 & 1 & 1 \\
\hline P. & 2 & 0 & 1 & 0 & 0 & 0 & 0 & ( & 1 & 0 & 2 & 0 & 0 & 0,2 & 0,1 & 0 & 1 & & & & $?$ & 1 & 2 & 1 & 1 & $?$ & 1 \\
\hline$P$. & 2 & 0 & 1 & 0 & 0 & 0 & 0,1 & ( & 1 & 0 & 0,2 & 0 & 0 & 0,2 & 0,1 & 0 & 1 & 0 & 1 & 0 & 1 & 1 & 2 & 1 & 1 & 1 & 1 \\
\hline & 2 & 0 & 1 & 0 & 0 & 0 & 0 & & 1 & 0 & 0 & 0 & 0 & 1 & 0 & 0 & 1 & 0 & 1 & 0 & 1 & 1 & 2 & 1 & 1 & 1 & 1 \\
\hline$P$. & 2 & 0 & 1 & 0 & 0 & 0 & 0 & & 1 & 0 & 0 & 0 & 0 & 1 & 0 & 0 & 1 & 0 & 1 & o & 1 & 1 & 2 & 1 & 1 & 1 & 1 \\
\hline P. littoralis & 2 & 0 & 0 & 0 & 0 & 0 & 2 & & 1 & 0 & 1 & 0 & 0 & 0,1 & 0 & 0 & 1 & $?$ & & $?$ & $?$ & 1 & 2 & 1 & 1 & $?$ & 1 \\
\hline P. ailyae & 1 & 0 & 1 & 0 & 0 & 0 & 1 & & 1 & 0 & 0 & 0 & 0 & 1 & 0 & 1 & 2 & 0 & 1 & 0 & 1 & 1 & 2 & 1 & 1 & 1 & 1 \\
\hline P. sc & 1 & 0 & 1 & 0 & 0 & 0 & 2 & & 1 & 0 & 0 & 0 & 0 & 1 & 0 & 1 & 2 & 2 & 8 & 2 & $?$ & 1 & 2 & 1 & 1 & $?$ & 1 \\
\hline & 1 & 0 & 1 & 0 & 0 & 0 & 1 & ( & 1 & 0 & 0 & 0 & 0 & 1 & 0 & 0 & 1 & 0 & 1 & 0 & 1 & 1 & 2 & 1 & 1 & 1 & 1 \\
\hline & 1 & 0 & 1 & 0 & 0 & 0 & 1 & & 1 & 0 & 0 & 0 & 0 & 0,1 & 0 & 0 & 1 & 0 & 1 & 0 & 1 & 1 & 2 & 1 & 1 & 1 & 1 \\
\hline & 1 & 0 & 1 & 0 & 0 & c & 2 & & 1 & ( & ( & & & 0 & & & 1 & & 1 & & 1 & 1 & 2 & 1 & 1 & 1 & 1 \\
\hline & 1 & 0 & 1 & 0 & 0 & 0 & 2 & & 1 & & 0 & & 0 & 1 & & & 1 & & 1 & & 1 & 1 & 2 & 1 & 1 & 1 & 1 \\
\hline P. helleri & 1 & 0 & 1 & 0 & 0 & 0 & 1,2 & & 1 & 0 & 0 & 0 & 0 & 1 & 0 & 0 & 1 & 0 & 1 & 0 & 1 & 1 & 2 & 1 & 1 & 1 & 1 \\
\hline
\end{tabular}

que permitissem a separação em classes discretas, ou por apresentarem grande variação intraespecífica. Os caracteres 22-26, não são informativos para a filogenia das espécies, foram incluídos apenas para indicar a monofilia do gênero, e estão discutidos no item 3 .

1) Mandíbula, comprimento dos dentes em relação ao bordo laminar distal da mandíbula, operária:

0 . o ápice dos dentes aproximadamente no nível do bordo (Figs. 31-42);

1. dentes um pouco recuados em relação ao bordo (Figs. 43-50);

2. dentes muito recuados em relação ao bordo (Figs. 5166).

Parapartamona, bem como Nogueirapis e Plebeia apresentam o estado 0 (Fig. 31), entretanto a forma dos dentes da mandíbula não tem correspondência com aquela das espécies de Partamona codificadas com o mesmo estado. Dentes recuados estão presentes apenas em algumas espécies de Partamona, não ocorrendo em outros Meliponini.

Esse caráter é avaliado com maior segurança somente em exemplares jovens; operárias velhas, geralmente apresentam forte desgaste no ápice da mandíbula (em alguns casos os dentes ficam completamente desgastados).

2) Mandíbula, espaçamento dos dentes, operária:

0 . o espaço entre os dentes aproximadamente igual ao espaço entre o dente médio e o ápice interno do bordo distal da mandíbula (Figs. 31, 32, 43-66);

1. o espaço entre os dentes, muito grande, em arco largo e profundo, nitidamente maior que o espaço entre o ápice do dente médio e o ápice interno do bordo distal da mandíbula (Figs. 33-42).

Em Plebeia, Nogueirapis e Parapartamona os dentes da 
mandíbula apresentam formas diferentes daqueles de Partamona e foram codificados no estado 0; mesmo em Nogueirapis, que apresenta os dentes mais espaçados, o espaço entre eles não forma um semicírculo (Fig. 32) como nas espécies de Partamona.

3) Área malar, comprimento, operária:

0 . área malar curta (ca. 0,8 vezes mais curta que o diâmetro do $2^{\circ}$ flagelômero);

1. área malar aproximadamente tão longa quanto o diâmetro do $2^{\circ}$ flagelômero $(0,9-1,2 \mathrm{x})$;

2. área malar longa (ca. de $1,5 \mathrm{x}$ o diâmetro do $2^{\circ}$ flagelômero, ou mais longa).

Área malar longa está presente apenas em P. grandipennis, P. aequatoriana (Tab. V) e nas espécies de Parapartamona; área malar curta (ca. de $0,8 \mathrm{x}$ o diâmetro do $2^{\circ}$ flagelômero), ocorre em P. mourei e P. littoralis. Nas espécies de Plebeia e Nogueirapis a área malar é praticamente linear e foram codificadas junto com $P$. mourei e $P$. littoralis. Nas demais espécies de Partamona ocorre um gradiente nas medidas, dificultando a separação em classes (Tab. V).

4) Comprimento da asa anterior em relação à largura máxima da cabeça, operária:

0. normal (ca. 2,0 - 2,6x mais longa que a largura máxima da cabeça);

1. longa (ca. 3,0x ou mais longa que a largura máxima da cabeça).

Asa muito longa em relação ao tamanho do corpo é um estado exclusivo de $P$. grandipennis e das espécies de Parapartamona; nas outras espécies de Partamona, embora exista variação no comprimento, não ocorrem descontinuidades que permitam a separação em mais classes (Tab. IX).

5) Distância interocelar em relação à distância ocelorbital, operária (Fig. 1):

0 . maior que a ocelorbital;

1. menor ou igual à ocelorbital.

O estado 1 está presente apenas em P. grandipennis (interocelar menor que ocelorbital), P. xanthogastra (distâncias aproximadamente iguais; Tab. VI) e nas espécies de Parapartamona, o grupo irmão.

6) Veias alares, operária:

0 . méleas ou ferrugíneas, uniformemente escurecidas, ou somente $\mathrm{C}$ e $\mathrm{R}$ mais escuras em direção à base da asa;

1. méleo-claras ou amarelas;

2. ferrugíneo-escuras, exceto o pterostigma, amarelado.

O estado 2 é exclusivo de $P$. grandipennis, $P$. xanthogastra e espécies de Parapartamona.
7) Cor da membrana das asas:

0. hialinas;

1. levemente ferrugíneas;

2. ferrugíneo-escuras.

8) Cerdas da base do escapo, operária:

0 . curtas (0,5-1,2x o diâmetro do escapo), pouco diferenciadas em relação às demais cerdas do escapo;

1. longas (mais de 1,3x o diâmetro do escapo), diferenciadas em relação às demais cerdas do escapo.

Este caráter é de difícil avaliação e subdivisão em classes; algumas espécies como $P$. helleri, $P$. peckolti, $P$. yungarum apresentam uma ou duas cerdas bem longas e diferenciadas na base do escapo; outras espécies, como $P$. mourei, $P$. vicina, além das espécies de Plebeia e Nogueirapis, apresentam apenas cerdas curtas em todo o escapo (Tab. VII). Para a maior parte das espécies de Partamona não ocorrem descontinuidades que permitam a separação em classes. Algumas espécies de Parapartamona apresentam uma cerda muito longa na base do escapo, chegando até mais de três vezes o diâmetro deste; e pode não ser um estado homólogo àquele encontrado nas espécies de Partamona.

9) Cor das cerdas dos esternos, operária:

0 . amarelo-palha ou esbranquiçada;

1. fuscas ou enegrecidas.

Cerdas claras, amareladas ou esbranquiçadas, aparecem em todas as espécies de Partamona com integumento amarelo (inclusive nos exemplares escurecidos de $P$. testacea e $P$. subtilis), mas também aparecem em algumas poucas espécies com integumento enegrecido ( $P$. pearsoni, $P$. bilineata), onde as cerdas são bem esbranquiçadas. Em populações de $P$. xanthogastra e P. grandipennis aparecem os dois estados aproximadamente com a mesma freqüência. Em Parapartamona, Nogueirapis e Plebeia apenas o estado 0 está presente. É possível que nas espécies de Partamona com integumento amarelo, a cor clara das cerdas dos esternos esteja relacionada a despigmentação geral do corpo, e não constitua estado correspondente ao encontrado nas espécies com integumento preto.

10) Cor das microtríquias das asas, operária:

0 . enegrecidas ou fuscas em toda ou quase toda a asa; amarelas apenas na região do pterostigma;

1. amarelas em toda a asa ou na maior parte; fuscas apenas no ápice e/ou base.

Em algumas espécies de Partamona, como $P$. combinata e $P$. batesi, a proporção de microtríquias amarelas e pretas na asa é bastante variável, inclusive em exemplares do mesmo ninho. Em Parapartamona, Nogueirapis e Plebeia aparecem apenas microtríquias pretas em toda a asa.

O exame das asas para análise da cor das microtríquias foi feito sob luz branca fria, sobre fundo âmbar, com as asas na 
posição vertical.

11) Forma das estrias paroculares, operária:

0 . terminando suavemente, um pouco abaixo da tangente interorbital superior (Figs. 128, 137-142, 145, 151, 152);

1. terminando abruptamente no nível da tangente interorbital superior, ou chegando no topo do olho (Figs. 129-136, 143, 146-150);

2. terminando no nível da maior distância interorbital, aproximadamente no meio da fronte (Figs. 144, 154157).

A subdivisão em classes é apresentada tentativamente, considerando as características menos variáveis das manchas. A forma das manchas paroculares nas espécies de Parapartamona, Nogueirapis e Plebeia não correspondem exatamente àquelas de Partamona; foram colocadas tentativamente nos mesmo estados de Partamona apenas para efeito de codificação.

12) Cor do integumento da cabeça e tórax, operária:

0 . preto, castanho-escuro, ou mesclado (predominantemente escurecido);

1. inteiramente ou predominantemente amarelo.

A pigmentação do integumento é bastante variável em algumas espécies, como $P$. peckolti e $P$. subtilis (com exemplares pretos, mesclados ou, raramente, amarelados) e $P$. aequatoriana (com indivíduos amarelos e mesclados). Operárias de $P$. mourei são amareladas, mas machos da região do rio Trombetas são pretos. Exemplares de $P$. testacea são amarelados na maior parte da sua área de distribuição, entretanto, acima de $750 \mathrm{~m}$, nas encostas orientais andinas, aparecem populações de ninhos com formas amarelas, pretas e intermediárias, e ninhos apenas com exemplares pretos, indicando que pode haver influência de fatores ambientais na pigmentação do integumento. Exemplares de Parapartamona são enegrecidos na cabeça e tórax. Espécies de Plebeia variam de amarelas até pretas e de Nogueirapis são inteiras ou predominantemente amarelas.

13) Cor do integumento do abdômen, operária:

0 . preto ou castanho-escuro;

1. inteiro ou predominantemente amarelo.

Embora o integumento da cabeça, tórax e abdômen apresentem uma só coloração na maioria das espécies de Partamona, a cor do abdômen foi tratada como um caráter independente pelo fato de $P$. xanthogastra e alguns exemplares de P. bilineata da Guatemala e El Salvador, apresentarem cabeça e tórax enegrecidos e abdômen amarelado. Algumas espécies de Parapartamona também apresentam o abdômen mais claro.

14) Cor da mandíbula, exceto o bordo laminar distal e côndilos, operária:

0 . inteira amarela, ou pelo menos a $1 \frac{1}{2}$ basal amarela, no restante, ferrugínea;

1. inteira ou predominantemente ferrugínea, amarelada apenas na base;

2. preta por inteiro ou parcialmente.

Caráter de difícil codificação e separação em classes. A proporção entre a área amarelada e ferrugínea é bastante variável, mesmo entre indivíduos da mesma espécie. Nos grupos externos ocorre apenas o estado 0.

15) Cor do labro, operária:

0 . amarelado;

1. enegrecido.

Labro enegrecido é uma condição derivada, compartilhada por $P$. nigrior, $P$. auripennis, $P$. nigrilabris e $P$. combinata. Alguns exemplares de $P$. nigrior da ilha de Trinidad apresentam labro amarelado. P. combinata apresenta uma proporção maior de indivíduos com labro amarelado, entretanto, em amostras de ninhos é possível encontrar pelo menos alguns exemplares com labro escurecido. Em Parapartamona, Plebeia e Nogueirapis apenas o estado 0 está presente.

16) Reflexo violeta no clípeo e áreas paroculares inferiores, operária:

0 . ausente;

1. presente.

A condição derivada é exclusiva de $P$. ailyae e $P$. sooretamae. Para a visualização de reflexos violetas foi utilizada luz branca fria.

17) Manchas clipeais, operária:

0 . uma única mancha, mais ou menos difusa, no meio ou em todo o clípeo;

1. duas manchas contrapostas, triangulares ou em forma de L, próximas uma da outra; a distância entre elas, aproximadamente igual ao diâmetro do $2^{\circ}$ flagelômero;

2. duas manchas contrapostas, triangulares, mais ou menos difusas e afastadas uma da outra por uma distância maior que o diâmetro do $2^{\circ}$ flagelômero.

O estado 2 é exclusivo de $P$. ailyae e $P$. sooretamae, nas demais espécies de Partamona ocorre o estado 1. Exemplares jovens, ainda não completamente pigmentados, podem apresentar as manchas clipeais um pouco mais afastadas que o normal. Em Plebeia, Nogueirapis e Parapartamona as manchas clipeais não são correspondentes àquelas de Partamona; foram colocada no estado 0 apenas para efeito de codificação.

18) Forma da superfície externa do basitarso III, macho (Figs. 67-97):

0. achatado ou convexo-côncavo;

1. um pouco intumescido;

2. fortemente intumescido. 
Basitarso fortemente intumescido é encontrado apenas nos machos de $P$. bilineata e $P$. grandipennis; a condição intermediária aparece em $P$. orizabaensis e $P$. peckolti.

19) Projeção mediana do EVII, macho (Figs. 98-127):

0 . de lados convergentes para o ápice, aproximadamente triangular (Figs. 99-101, 104-114);

1. de lados subparalelos (Figs. 102, 103, 115-127);

2. projeção mediana reduzida ou ausente.

Embora a forma do EVII seja um caráter estrutural importante na definição das afinidades filogenéticas das espécies de Partamona, a codificação é bastante difícil, além do fato de que não são conhecidos machos de todas as espécies. Tentativamente, a forma da projeção mediana do esterno foi dividida em dois caracteres $(19,20)$, considerando os padrões menos variáveis entre os machos da mesma espécie. O estado 2, projeção mediana reduzida ou ausente, ocorre apenas nas espécies de Plebeia, e constitui uma derivação dentro de Meliponini.

20) Ápice da projeção mediana do EVII, macho (Figs. 98-127): 0 . em ponta ou aproximadamente em forma de ogiva (Figs. 98-114, 116, 118-127);

1. arredondado (Figs. 115, 117).

Em Plebeia droryana e nas espécies deste gênero que apresentam projeção no EVII, o ápice é em ponta, mas na maioria das espécies de Plebeia, a projeção mediana é ausente (veja caráter anterior).

21) Forma do basitarso III, macho:

0. alongado, mais de 2,1x mais longo que largo (Figs. 67, 72-81);

1. curto e largo, menos que $2 \mathrm{x}$ mais longo que largo (Figs. 70,71, 82-97).

Caráter de difícil avaliação e separação em estados.

22) Forma do basitarso III, operária:

0 . de lados subparalelos (Figs. 13, 18);

1. com a margem posterior fortemente sinuada, a maior largura próxima do ápice (Figs. 2, 12).

23) Forma da tíbia III, operária:

0 . suavemente alargada em direção ao ápice, a margem posterior suavemente convexa;

1. alargada a partir do $1 / 3$ basal (Fig. 13);

2. alargada a partir do $1 / 4$ basal (Figs. 2, 12).

24) Comprimento da área quirotriquiada em relação ao bordo apical da tíbia III, operária:

0 . chegando até a margem ou deixando estreita margem glabra, menor que $1 / 8$ do comprimento da área quirotriquiada;

1. deixando uma larga margem glabra, ca. de 1/8 do comprimento da área quirotriquiada (Fig. 3).

25) Pêlos ventrais no tórax e esternos, operária:

0 . simples;

1. sinuosos no ápice.

26) Tamanho da espata, macho:

0. pequena, não recobrindo, ou apenas parcialmente, os gonocoxitos;

1. grande, recobrindo os gonocoxitos por inteiro.

27) Margem posterior glabra da superfície interna da tíbia III, operária:

0. rebaixada em degrau, ao longo de todo o bordo posterior da área quirotriquiada;

1. plana (Fig. 3), ou apenas com leve rebaixo, na porção basal da área quirotriquiada.

\section{Análise filogenética e biogeográfica}

A dificuldade na proposição de hipóteses de filogenia para as espécies de Partamona, encontra-se, fundamentalmente, na escassez de caracteres morfológicos (estruturais), pelo menos ao nível em que este estudo foi conduzido, passíveis de codificação e polarização, e indicativos das relações interespecíficas. Partamona é um grupo bastante uniforme com relação aos caracteres morfológicos. A genitália dos machos estudados não varia quanto a forma, apenas quanto ao tamanho, proporcionalmente ao tamanho dos indivíduos. Os esternos V e VI apresentam alguma variação quanto a forma e também com relação ao número, tamanho e forma das cerdas, mas não há descontinuidades que permitam a codificação em classes discretas. Com relação aos caracteres estruturais, apenas a forma dos dentes da mandíbula e esterno VII dos machos apresentam descontinuidades que permitem a separação em estados, pelo menos tentativamente. As espécies são reconhecidas principalmente pela combinação das variações na coloração do integumento, cor da pilosidade e asas, comprimento de cerdas do escapo, e a forma dos dentes da mandíbula. Caracteres comportamentais relacionados a arquitetura dos ninhos, por outro lado, parecem ser mais consistentes para uma análise filogenética do grupo.

Em uma primeira análise da matriz de caracteres para as espécies de Partamona (Tab. II), nota-se o grande número de polimorfismos e a incongruência entre a maioria dos caracteres estudados, inclusive daqueles estruturais, como a forma dos dentes da mandíbula $(1,2)$, basitarso III e EVII dos machos (1821). O fato de que não se conhecem os machos de algumas espécies, também aumenta a dificuldade na construção de uma hipótese de filogenia para o grupo. Considerando esses fatores, além do pequeno número de caracteres informativos sobre as relações entre as espécies, optou-se pela construção manual de uma hipótese de filogenia, baseada principalmente nos caracteres estruturais da mandíbula, EVII e basitarso III do macho e naqueles menos polimórficos e congruentes com os caracteres estruturais (19 caracteres, 1-6 e 15-27, Tab. II). Para a 
composição da hipótese, utilizou-se o programa MacClade, versão 3.05 (MADDISON \& MADDISON, 1995). No cladograma resultante (Fig. 175; comprimento 45, índices de consistência 0,68 , retenção 0,85 e consistência reescalonado 0,58 ), a primeira dicotomia separa as espécies que apresentam os dentes muito espaçados e no nível do bordo distal da mandíbula - grupo bilineata / epiphytophila ( $P$. bilineata, $P$. xanthogastra, $P$. grandipennis, $P$. orizabaensis, $P$. peckolti, $P$. subtilis, $P$. epiphytophila, P. nhambiquara, P. batesi, P. yungarum, P. vitae), das demais espécies, que apresentam os dentes recuados; neste último grupo, uma divisão subseqüente separa as espécies cujos machos apresentam o EVII com projeção mediana de lados subparalelos e basitarso III curto e largo (grupos nigrior e cupira), das espécies do grupo musarum ( $P$. musarum, $P$. aequatoriana, $P$. mourei, $P$. vicina, $P$. pearsoni, $P$. gregaria, $P$. ferreirai, $P$. testacea), que conservam o EVII com a projeção mediana triangular e basitarso III longo e estreito (embora os grupos nigrior e musarum não estejam definidos na hipótese apresentada, isto é, sem apomorfias compartilhadas, optou-se por usar essa terminologia, já que tais conjuntos de espécies apresentam combinações exclusivas de estados com relação aos dentes da mandíbula da operária, forma do EVII e basitarso III do macho). A projeção mediana do EVII com lados subparalelos aparece homoplasticamente em $P$. peckolti e $P$. orizabaensis (grupo bilineata / epiphytophila). Em níveis mais finos, o intumescimento do basitarso III dos machos reúne $P$. bilineata, P. grandipennis, . orizabaensis e $P$. peckolti em um clado presumivelmente monofilético (subgrupo bilineata); embora não se conheça o macho de $P$. xanthogastra, esta espécie também foi incluída aqui por compartilhar com $P$. grandipennis, a coloração das veias alares e a distância interocelar menor ou igual a ocelorbital. $P$. peckolti e $P$. orizabaensis compartilham a forma do EVII e o basitarso III pouco intumescido. No grupo nigrior, que inclui P. seridoensis, $P$. chapadicola, P. nigrilabris, $P$. combinata, $P$. auripennis e $P$. nigrior, as quatro últimas espécies apresentam escurecimento do labro e mandíbulas e manchas paroculares curtas e alargadas embaixo (Figs. 154-157), e P. nigrior e P. auripennis são as únicas espécies com a projeção mediana do EVII dos machos de ápice arredondado (Figs. 115, 117). Dentro do grupo cupira (P. cupira, P. mulata, P. criptica, P. rustica, P. helleri, P. ailyae, P. sooretamae), P. ailyae e P. sooretamae compartilham o brilho violeta do clípeo e a forma das manchas clipeais.

Tentativas de análise através de métodos computacionais, mostraram-se pouco esclarecedoras, visto que os caracteres estudados são, na maior parte dos casos, incongruentes entre si, além de apresentarem muitos polimorfismos. Utilizando-se o programa PAUP (SWOFFORD, 1993), com a matriz completa (27 caracteres, não ordenados), foram obtidas mais de 10.000 árvores de comprimento mínimo (98). Nas árvores de consenso, obtidas à partir dessas 10.000 árvores de comprimento mínimo, os grupos bilineata / epiphytophila e cupira também aparecem como grupos monofiléticos, da mesma forma que na hipótese apresentada na figura 175; as demais espécies ocupam posições variadas no cladograma, dependendo do método de consenso aplicado.
Com relação a biogeografia, só recentemente, após o acúmulo extensivo de dados sobre a distribuição de alguns grupos de Meliponini neotropicais, compilados por CAMARGO (1989, 1994, 1996a), e proposições de hipóteses de filogenia (Camargo \& Moure, 1994, 1996, Camargo, 1996b), tem sido possível uma análise mais profunda dos padrões históricos desse grupo. Um modelo de seqüência de eventos de disjunções (vicariância), que produziram a diversidade atual de Meliponini na região neotropical, foi proposto por CAMARGO (1996a), baseado nos padrões de distribuição e nas hipóteses de filogenia de Paratrigona, Aparatrigona (CAmargo \& Moure, 1994), e Geotrigona (CAmargo \& Moure, 1996).

Para Partamona, entretanto, a hipótese apresentada na figura 175, ainda está longe de ser resolvida, principalmente devido à escassez de caracteres informativos sobre as relações interespecíficas. Apenas ao nível de alguns grupos de espécies melhor definidos no cladograma, é possível inferir padrões biogeográficos que são concordantes com aqueles apresentados por outros Meliponini, revelando uma história biogeográfica comum.

A área atualmente ocupada pelo grupo bilineata / epiphytophila (Figs. 160-163, 175), que abrange o oeste da Amazônia até as encostas andinas orientais (P. epiphytophila, P. nhambiquara, P. subtilis, P. batesi, P. yungarum, P. vitae) e a porção desde o noroeste da América do Sul, a oeste dos Andes equatorianos, até o México (clado $P$. bilineata, $P$. grandipennis, P. xanthogastra, P. orizabaensis, P. peckolti), corresponde àquela ocupada pelo grupo leucogastra / fulvohirta, de Geotrigona (traçado AmW+Pac - CAMARGo 1996a; CAmargo \& Moure, 1996). A hipótese apresentada na figura 175 sugere, entretanto, uma quebra inicial separando essa região do restante da América do Sul, enquanto que, na hipótese apresentada por CAMARGO (1996a) e CAMARGO \& Moure (1996), a separação do traçado $\mathrm{AmW}+$ Pac só vem acontecer mais tarde na história de Geotrigona. Um evento posterior, separando o componente do Pacífico (Pac. - subgrupo bilineata) da região oeste da Amazônia (AmW - subgrupo epiphytophila), também encontra respaldo na história dos gêneros Geotrigona e Paratrigona (CAMARGO, 1996a).

Dentro do subgrupo bilineata, que ocupa o traçado Pacífico (Pac. - oeste dos Andes equatorianos até o México; CAmargo, 1996a), as espécies do clado $P$. grandipennis $+P$. xanthogastra apresentam distribuições bastante restritas (Fig. 160) e mutuamente exclusivas. P. grandipennis ocorre nas terras altas da Costa Rica até o oeste do Panamá (Ûøòróß́́ Gámar Go, 19961997), padrão bastante semelhante àquele do gênero Meliwillea, considerado uma relíquia biogeográfica (RouBIK et al., 1997), e P. xanthogastra é restrita às baixas altitudes, a leste do Canal do Panamá (Fig. 160). Outros exemplos de endemismos no Panamá e Costa Rica são encontrados em Paratrigona (CAMARgo \& Moure, 1994), Geotrigona (CAMARGO $\&$ Moure, 1996), e outros Meliponini ainda não revisados (RouBIK, 1992), o que indica uma seqüência complexa de eventos de vicariância nessa região. Partamona bilineata, a espécie irmã do clado $P$. grandipennis $+P$. xanthogastra (Fig. 175), é amplamente distribuída no México (Fig. 160) e chega até El 
Salvador e Honduras (embora exista variação em vários caracteres, principalmente coloração do integumento e pilosidade, aparentemente não existe identidade geográfica, exceto uma população diferenciada em El Salvador e Guatemala - veja discussão em P. bilineata). AyAla (1992) reporta diversos padrões de endemismos para o México que não foram detectados em P. bilineata. Partamona orizabaensis e $P$. peckolti, provavelmente espécies irmãs, também excluem-se geograficamente. P. orizabaensis (Fig. 161) ocorre apenas na porção sul do México (mas não na península de Yucatan) até o extremo oeste do Panamá, e pode constituir uma população alóctone nas terras mexicanas. P. peckolti ocorre mais ao sul, acompanhando a faixa pré-andina a oeste dos Andes equatorianos e chega a contornar o extremo norte da cordilheira (Fig. 162). As demais espécies, do subgrupo epiphytophila, são endêmicas do oeste da Amazônia. P. subtilis sp. nov. (uma espécie rara, coletada apenas no estado do Acre e região do Beni, Bolívia, Fig. 163), P. batesi sp. nov. (restrita a região de Tefé, Fig. 163), P. yungarum sp. nov. (Yungas Bolivianas, Fig. 163) e P. nhambiquara sp. nov. (Rondônia e Mato grosso, Fig. 163). P. epiphytophila sp. nov., tem uma distribuição um pouco maior, em sobreposição com outras espécies do grupo (Fig. 162). Esse padrão de endemismo constitui uma réplica daquele apresentado para Geotrigona fulvohirta (Friese, 1900) e Paratrigona pacifica (Schwarz, 1943) e P. prosopiformis (CAmargo \& Moure, 1996).

A área de distribuição do grupo cupira (Figs. 171-173) corresponde ao traçado Centro Sudeste da América do Sul e região Atlântica (CSE+Atl) apresentado por CAMARGo (1996a), para os gêneros Paratrigona (lineata+subnuda) e Geotrigona (mombuca + subterranea), entretanto, estende-se mais ao norte do rio Amazonas (P. ailyae, Fig. 171). Na região sudeste, endemismos restritos, mutuamente exclusivos, ou apenas parcialmente sobrepostos, também podem ser vistos no Fig. 172, para $P$. mulata, . cupira, $P$. criptica $\mathbf{s p . ~ n o v . ~ e ~} P$. rustica $\mathbf{s p .}$ nov. Já $P$. helleri, se sobrepõe com $P$. cupira, $P$. criptica sp. nov., $P$. sooretamae sp. nov. e em menor extensão com $P$. rustica $\mathbf{s p .}$ nov. Outro endemismo nítido da região atlântica é aquele apresentado por $P$. sooretamae sp. nov., da região do Espírito Santo (Fig. 171), um relacionado direto de P. ailyae (talvez apenas uma população divergente isolada geograficamente, veja discussão em $P$. ailyae e $P$. sooretamae sp. nov.). Em $P$. helleri também aparece uma população um pouco diferenciada na região do ES (veja discussão em $P$. helleri), indicando que eventos de vicariância mais recentes produziram endemismos menores, dentro do traçado Atlântico. Em Meliponini, outro caso de endemismo na região do Espírito Santo foi registrado para Melipona (Michmelia) capixaba Moure \& Camargo, 1994; esta espécie, entretanto, está relacionada com grupos da região noroeste da América do Sul (Moure \& CAMARGO, 1994).

No norte da Amazônia, área ocupada pelas espécies dos grupos musarum e nigrior, a situação é bastante complexa, havendo várias réplicas nos padrões de endemismos, como é o caso, por exemplo, de $P$. mourei, $P$. ferreirai sp. nov. e $P$. auripennis sp. nov. (Figs. 167,168,169), e espécies de larga distribuição, como é o caso de P. testacea e P. vicina (Figs. 164,
165), indicando uma história biogeográfica muito mais intrincada do que aquela sugerida por CAMARGO (1996a) para esse traçado. Entretanto, o cladograma biológico para as espécies de Partamona, aqui apresentado, resolvido apenas parcialmente, não permite qualquer esclarecimento sobre a história evolutiva nesse espaço geográfico.

\section{Chave para as espécies de Partamona.}

A chave apresentada a seguir, foi preparada com a intenção de se preservar os "agrupamentos naturais" obtidos através da hipótese de filogenia. Para o reconhecimento dos grandes grupos, o principal caráter relaciona-se aos dentes da mandíbula (difícil de ser avaliado em exemplares coletados em vôo, que geralmente apresentam as mandíbulas desgastadas) e a forma do EVII dos machos. São poucos os caracteres que podem auxiliar no reconhecimento das espécies, a maioria dos quais relacionados ao padrão de coloração do tegumento e asas. Para muitas espécies é necessário que se considere uma combinação de vários caracteres e, em muitos casos, informações sobre a procedência do exemplar e dados sobre o substrato de nidificação, são bastante úteis.

1. Dentes da mandíbula muito espaçados, o ápice dos dentes no nível do bordo laminar distal (Figs. 3342); EVII dos machos como nas figuras 100 a 107; integumento preto, bicolorido (cabeça e tórax enegrecidos, abdômen amarelado), amarelado ou mesclado; oeste da região Amazônica, costas do Pacífico no Equador e Colômbia, e do Panamá até o México (grupo bilineata/ epiphytophila) ................ 2

Dentes da mandíbula um pouco ou muito recuados em relação ao bordo distal laminar (Figs. 43-66), espaço entre os dentes aproximadamente igual ao espaço entre o dente médio e o bordo distal; EVII dos machos como nas figuras 108 a 127; abelhas pretas ou amarelas; do norte da América do Sul até o nordeste de SC, Brasil e norte do Paraguai; oeste dos Andes, nas costas do Equador e Colômbia; na América Central, do Panamá até Honduras ......... 12

2. (1). Abelhas grandes (largura máxima da cabeça entre 2,75 a $2,95 \mathrm{~mm}$; comprimento das asas anteriores entre 6,85 e $8,30 \mathrm{~mm}$ ); membrana das asas ferrugíneoescura, com microtríquias enegrecidas e veias ferrugíneo-escuras exceto o pterostigma, que é alaranjado; distância interocelar menor ou igual à ocelorbital; área basal do propódeo uniformemente pilosa, sem faixa glabra mediana; escapo com cerdas mais longas que o seu diâmetro, as da base um pouco mais longas (entre 1,3 a 1,7x o diâmetro do escapo); integumento enegrecido ao menos na cabeça e tórax; Costa Rica e Panamá ....................... 3

Abelhas menores (largura máxima da cabeça menor que $2,75 \mathrm{~mm}$; comprimento da asa anterior, menor que $6,85 \mathrm{~mm}$ ); membrana das asas levemente ferrugínea 
ou hialina; microtríquias enegrecidas ou amareladas e veias e pterostigma ferrugíneos ou amarelados; distância interocelar maior que a ocelorbital; área basal do propódeo com ou sem faixa mediana glabra; escapo com cerdas mais curtas ou iguais ao seu diâmetro ou, se mais longas, apenas na base; integumento preto, amarelado ou mesclado .......... 4

3.(2). Integumento preto em todo o corpo, exceto pelas máculas amarelas na cabeça e tórax; estrias paroculares alargadas embaixo (ca. 1,5x o diâmetro do $2^{\circ}$ flagelômero; Fig. 132); integumento da fronte e ao redor dos ocelos levemente tesselado e opaco; asas muito longas, cerca de 2,8 a 3,0 x mais longas que a largura máxima da cabeça; área malar longa, ca. 1,4 a 1,8 x o diâmetro do $2^{\circ}$ flagelômero; tíbia III alongada, 2,2-2,4x mais longa que larga; distância interocelar menor que a ocelorbital; mandíbula como na figura 35; EVII do macho com projeção mediana triangular (Fig. 100); basitarso III do macho fortemente intumescido, tíbia III alargada em direção ao ápice (Fig. 71); ninhos desconhecidos; regiões montanhosas da cordilheira central da Costa Rica e noroeste do Panamá (Fig. 160) ...

P. grandipennis (Schwarz)

Cabeça e tórax pretos, abdômen amarelado; estrias paroculares aproximadamente com a mesma largura em toda a extensão, ou um pouco mais largas embaixo (0,8-1,0x o diâmetro do $2^{\circ}$ flagelômero), chegando até o topo do olho, o contorno interno irregularmente sinuoso (Fig. 131); integumento da fronte e ao redor dos ocelos, liso, polido, como no restante do corpo; asas ca. de 2,4-2,5x a largura máxima da cabeça; área malar aproximadamente tão longa quanto o diâmetro do $2^{\circ}$ flagelômero $(0,9$ 1,2x); tíbia III 2,0-2,2x mais longa que larga; distância interocelar aproximadamente igual à ocelorbital; mandíbula como na figura 36; macho desconhecido; ninho sob raízes de epífitas; florestas tropicais do Panamá Central (Fig. 160)... P. xanthogastra Pedro \& Camargo

4.(2'). Dentes da mandíbula muito espaçados, a distância entre eles $3 \mathrm{x}$ maior que entre o ápice do dente médio e o bordo apical (Figs. 33, 34)

Espaço entre os dentes da mandíbula $2 \mathrm{x}$ maior que a distância entre o dente médio e o bordo laminar (Figs. 37-42) . .6

5.(4). Abelhas grandes, robustas (largura máxima da cabeça entre 2,59 e 2,72 mm); integumento preto; estrias paroculares como na figura 133; mandíbula como na figura 33; cerdas dos esternos enegrecidas; cerdas da base do escapo nitidamente mais longas que o diâmetro deste (1,25 a 1,73x); bifurcação de $\mathrm{M}+\mathrm{Cu}$ geralmente coincidente com a cu-v; EVII do macho com projeção mediana triangular (Fig. 104); tíbia e basitarso III do macho como na figura 75; ninhos em epífitas e outros substratos parcialmente protegidos; oeste da bacia amazônica, Brasil, até os andes orientais na Bolívia, Peru, Equador e Colômbia (Fig. 162)

P. epiphytophila $\mathbf{s p . ~ n o v}$

Abelhas pequenas, longilíneas (largura máxima da cabeça ca. 2,28-2,42 mm); integumento variável, preto, amarelado ou mesclado; estrias paroculares como na figura 134; mandíbula como na figura 34 ; cerdas da porção ventral do tórax e dos esternos esbranquiçadas; cerdas da base do escapo tão curtas quanto as demais $(0,7-0,9 \mathrm{x}$ o diâmetro do escapo); bifurcação da $\mathrm{M}+\mathrm{Cu}$ anterior à cu-v; machos e ninhos desconhecidos; Acre, Brasil, norte da Bolívia (região do Beni) e sudeste do Peru(Fig. 163) P. subtilis sp. nov.

6. (4'). Cerdas dos esternos inteiramente esbranquiçadas; integumento preto em todo o corpo ou com o abdômen amarelado ou castanho claro (populações de El Salvador e Guatemala); estrias paroculares afiladas e apagadas em cima, como na figura 128; membrana das asas anteriores levemente ferrugínea ou hialina; microtríquias enegrecidas por toda a asa ou amarelas na metade basal (populações de El Salvador e Guatemala); mandíbula como na figura 38; basitarso III do macho fortemente intumescido; basitarso III e tíbia III do macho como nas figuras 69, 70; EVII do macho com projeção mediana triangular (como na figura 101); ninhos em cavidades diversas, não associados com térmitas; terras baixas do México, até El Salvador e Honduras (Fig. 160)

P. bilineata (Say)

Cerdas dos esternos por inteiro enegrecidas ou, pelo menos na base; integumento preto, amarelado ou mesclado; estrias paroculares não estreitadas e não apagadas em cima, como nas figuras 129, 130, 135 e 136; membrana das asas ferrugíneo-escura até hialina; microtríquias enegrecidas por toda a asa ou amareladas na região do pterostigma; mandíbula como nas figuras $37,39,40,41$ e 42 ; basitarso III do macho com forma variável; esterno VII do macho com projeção mediana triangular (Figs. 106 e 107) ou de lados subparalelos (Figs. 102 e 103); ninhos em substratos variados; oeste da Amazônia e Brasil Central; costas do Equador e Colômbia até sudeste do México 7

7.(6'). Membrana das asas anteriores ferrugíneo-escura; microtríquias enegrecidas por toda a asa; veias ferrugíneo-escuras; integumento preto; na cabeça, castanho muito escuro; máculas da cabeça e tórax apagadas; estrias paroculares como na figura 136; 
bifurcação da veia $\mathrm{M}+\mathrm{Cu}$ anterior em relação à cu$\mathrm{v}$; cerdas da base do escapo nitidamente mais longas que o diâmetro deste (1,50-1,88x); mandíbula como na figura 40; macho e ninhos desconhecidos; Yungas bolivianas até Paraguai (Fig. 163) ................................... P. yungarum sp. nov.

Asas hialinas ou levemente ferrugíneas; microtríquias enegrecidas por toda a asa, ou amareladas na região do pterostigma; cor das veias variável; integumento preto, amarelado ou mesclado; máculas da cabeça e tórax nítidas; bifurcação da veia $\mathrm{M}+\mathrm{Cu}$ coincidente ou levemente anterior à cu-v; cerdas da base do escapo variáveis; mandíbulas como nas figuras $37,39,41$ e 42 ...... 8

8.(7’). Abelhas da região oeste da Amazônia, Brasil Central, até encostas orientais dos Andes; EVII do macho com projeção mediana triangular (Figs. 106, 107); basitarso III do macho achatado (espécies com machos conhecidos); ninhos em termiteiros arborícolas (espécies com ninhos conhecidos) .. 9

Abelhas das terras ocidentais aos Andes equatorianos até o sudeste do México; EVII do macho com projeção mediana de lados aproximadamente subparalelos (Figs. 102, 103); basitarso III do macho um pouco intumescido; ninhos em diversos substratos, não associados à térmitas .... 11

9.(8). Integumento amarelado, sutura epistomal, basitarso III e 1/4 apical da tíbia III escurecidos; estrias paroculares como na figura 147; cerdas do escapo mais curtas que o diâmetro deste; mandíbula como na figura 40 ( $P$. yungarum) bifurcação de $\mathrm{M}+\mathrm{Cu}$ geralmente anterior à cu-v; ninho desconhecido; sul da Venezuela: Amazonas e Bolivar (Fig. 163) .. P. vitae sp. nov.

Integumento inteiro preto; estrias paroculares como nas figuras 133 e 135; cerdas da base do escapo iguais ou mais longas que seu diâmetro; mandíbula como nas figuras 41 e 42; bifurcação da veia $\mathrm{M}+\mathrm{Cu}$ coincidente ou levemente anterior à cu-v; Brasil Central e centroeste da Amazônia 10

10(9'). Estrias paroculares como na figura 133; cerdas da base do escapo iguais ou um pouco mais longas que o diâmetro deste $(0,93-1,47 x)$; mandíbula como na figura 42; EVII do macho como na figura 106; tíbia e basitarso III do macho como na figura 76; ninho em termiteiro arborícola, freqüentemente em grandes agregações; abelhas da região de Tefé, AM, Brasil (Fig. 163) P. batesi sp. nov.

Estrias paroculares como na figura 135; cerdas da base do escapo conspicuamente mais longas que o diâmetro deste $(1,27$ - 1,75x); mandíbula como na figura 41; EVII do macho como na figura 107; tíbia e basitarso III do macho como na figura $75(P$. epiphytophila sp. nov.); ninho em oco de árvore viva (em termiteiro ?); endêmica da região de RO até MT e GO, Brasil (Fig. 163)

P. nhambiquara sp. nov.

11(8'). Asas anteriores com microtríquias enegrecidas, veias escurecidas, principalmente na metade basal; integumento preto; estrias paroculares como na figura 129; cerdas da base do escapo um pouco mais longas que o diâmetro deste $(1,27-1,75 x)$; mandíbula como na figura 37; EVII do macho como na figura 102; tíbia e basitarso III do macho como na figura 72; ninhos em diversas cavidades, em ninhos abandonados de aves, na base de folhas de palmeiras, não associados à térmitas; sudeste do México até o noroeste do Panamá (Fig. 161) P. orizabaensis (Strand)

Asas com microtríquias fuscas, ou amarelas apenas na região do pterostigma; veias ferrugíneas; integumento mesclado ou enegrecido, raramente amarelado; estrias paroculares como na figura 130; cerdas da base do escapo nitidamente mais longas que o diâmetro deste (1,71-2,20x); mandíbula como na figura 39; EVII do macho como na figura 103; tíbia e basitarso III do macho como nas figuras 73 e 74; ninhos sob raízes de epífitas e diversos outros tipos de substratos, como cavidades e outros lugares protegidos, não associados à térmitas; costa do Pacífico no Equador até o Panamá Central, a leste, até a Venezuela (Fig. 162)

P.peckolti (Friese)

12.(1').Dentes da mandíbula aproximadamente eqüidistantes e um pouco recuados em relação ao bordo apical (Figs. 43-50); EVII do macho com a projeção mediana de lados aproximadamente subparalelos (Figs. 122-127); sudeste do Brasil até bacia amazônica e sul da Venezuela (grupo cupira) ......13

Dentes da mandíbula curtos e fortemente recuados em relação ao bordo apical (Figs. 51-66); EVII do macho variável; do Brasil Central até a Venezuela e do oeste do Equador até Panamá (grupos musarum e nigrior)

13.(12).Clípeo, fronte e áreas paroculares com leve brilho violeta; mandíbula como na figura 47 e estrias paroculares como na figura 142; manchas clipeais afastadas por uma distância maior que um diâmetro do escapo; escutelo com duas ou mais cerdas muito longas no ápice, 1,2-1,5x o comprimento do escutelo; bifurcação da veia $\mathrm{M}+\mathrm{Cu}$ anterior à cu$\mathrm{v}$; cerdas das áreas paroculares, ao lado dos alvéolos, curtas, menores que o diâmetro do escapo, pouco diferenciadas em relação às cerdas curtas decumbentes; ES e Brasil Central até sul da Venezuela 14 
Sem brilho violeta no clípeo e fronte; mandíbulas e estrias paroculares como nas figuras $43-46$, 4850 e 137-141, respectivamente; manchas clipeais mais próximas entre si; escutelo com as cerdas mais curtas ou tão longas quanto o comprimento deste, todas com comprimento mais ou menos uniforme; bifurcação de $\mathrm{M}+\mathrm{Cu}$ coincidente com a cu-v; cerdas das áreas paroculares variáveis; sudeste do Brasil e Bolívia 15

14.(13). Asas levemente ferrugíneas, veias méleas, escurecidas pelas microtríquias, pterostigma mais claro; tíbia e basitarso III do macho alargados, tíbia formando uma pequena corbícula, com o canto pósterodistal anguloso (Fig. 97); EVII do macho como na figura 126; ninhos em termiteiros em troncos podres, na base de árvores vivas ou em termiteiros de "murundu"; Brasil Central até sul da Venezuela (Fig. 171) ............. P. ailyae Camargo

Asas ferrugíneo-escuras, veias enegrecidas; machos e ninhos desconhecidos; endêmica do ES, Brasil (Fig. 171) ............................ P. sooretamae sp. nov.

15.(13'). Cerdas da base do escapo nitidamente mais longas que o diâmetro deste (se tão longas quanto o diâmetro do escapo, então a largura máxima da cabeça entre 2,66 e 2,76 mm); estrias paroculares não muito alargadas embaixo (Figs. 139, 141); asas geralmente ferrugíneo-escuras (se mais claras, as cerdas do escapo longas) .. 16

Cerdas do escapo curtas ou no máximo um pouco mais longas que o diâmetro deste (1,07-1,25x); estrias paroculares variáveis (Figs. 137, 138, 140); asas levemente ferrugíneas (se ferrugíneo-escuras, as cerdas do escapo curtas) 17

16.(15). Flagelo castanho-escuro; cerdas do escapo geralmente muito longas (1,67-2,14x o diâmetro do escapo), se mais curtas $(1,00-1,50 x)$ a largura máxima da cabeça entre 2,66 e 2,76 mm (RJ e ES, Brasil); estrias paroculares pouco alargadas embaixo (Fig. 141); mandíbula como nas figuras 48-50; tíbia e basitarso III do macho como na figura 92 ; EVII do macho como na figura 127; ninhos geralmente não associados a térmitas, ocupando diversos tipos de cavidades, ninhos abandonados de aves, raízes de epífitas, até livres (na região de Paraopeba-MG, ninhos em termiteiros arborícolas); floresta atlântica, de SC até BA; a oeste até as cabeceiras do rio São Francisco, MG, Brasil, região de cerrado (Fig. 173) P. helleri (Friese)

Flagelo castanho-claro ou alaranjado; cerdas da base do escapo um pouco mais curtas (entre 1,27-1,64x o diâmetro do escapo); estrias paroculares como na figura 139; mandíbula como na figura 46; tíbia e basitarso III do macho como na figura 93; EVII do macho como na figura 122; ninhos em termiteiros arborícolas externos e em cumeeira de habitações humanas, Vale do São Francisco, nordeste de MG até sudoeste, da BA, Brasil (Fig. 172) …………………………....... P. rustica sp. nov.

17.(15'). Asas ferrugíneo-escuras; estrias paroculares alargadas embaixo (ca. 1,5x o diâmetro do $2^{\circ}$ flagelômero, afilando abruptamente pouco acima das fóveas tentoriais, chegando até a altura da interorbital máxima (Fig. 140); cerdas da base do escapo ca. 0,93-1,25x o diâmetro deste; mandíbula como na figura 45, tíbia e basitarso do macho como na figura 95; EVII do macho como na figura 125; ninhos em termiteiros em ocos de árvores; mata atlântica, do norte de SP até ES, Brasil (Fig. 172) P. criptica sp. nov.

Asas levemente ferrugíneas; estrias paroculares apenas levemente alargadas embaixo, como nas figuras $(137,138)$; cerdas da base do escapo entre 0,65 e 1,00x o diâmetro deste; ninhos em termiteiros epígeos do tipo "murundu" .......... 18

18.(17'). Integumento preto; estrias paroculares como na figura 137; flagelo castanho-claro ou alaranjado; pilosidade de comprimento normal; cerdas eretas no disco do mesoscuto com comprimento igual ou pouco maior que o diâmetro do escapo; cerdas eretas das áreas paroculares, ao lado dos alvéolos, robustas, mais longas que o diâmetro do escapo; mandíbula como na figura 43; tíbia e basitarso III do macho como na figura 94; EVII do macho como na figura 123; MG, GO, DF, MS, Brasil (Fig. 172) ............................ P. cupira (Smith)

Integumento variando de castanho-ferrugíneo até enegrecido; estrias paroculares como na figura 138; flagelo da antena castanho escuro até alaranjado; pilosidade curta; cerdas do disco do mesoscuto geralmente mais curtas que o diâmetro do escapo; cerdas eretas das áreas paroculares curtas, menores que o diâmetro do escapo e indiferenciadas em relação às cerdas curtas decumbentes; mandíbula como na figura 44, tíbia e basitarso III do macho como na figura 96; EVII do macho como na figura 124; Sul de MT, MS, Brasil, até savanas da Bolívia (Fig. 172) P. mulata Moure in Camargo

19.(12'). Labro e mandíbulas enegrecidos; integumento preto; cerdas da base do escapo entre 0,77 e 1,27x o diâmetro deste; EVII do macho com a projeção mediana de lados aproximadamente subparalelos (Figs. 115-119, espécies com machos conhecidos); grupo nigrior (parte) ................. 20

Labro e mandíbulas amarelados; integumento preto 
ou amarelo; cerdas da base do escapo variáveis; EVII variável 23

20.(19). Estrias paroculares alargadas embaixo (um pouco mais que o diâmetro do $2^{\circ}$ flagelômero), afilando suavemente para cima, até desaparecer na altura da interorbital máxima, geralmente pouco conspícuas (Figs. 154, 155, 157) asas hialinas com microtríquias amareladas ou enegrecidas; cerdas do escapo variáveis 21

Estrias paroculares mais estreitas, geralmente terminando um pouco abaixo da interorbital superior (Fig. 156), nítidas, ou como na figura 154; asas levemente ferrugíneas com microtríquias enegrecidas por toda a asa, ou amarelas no pterostigma e regiões adjacentes; mandíbula como na figura 56 de $P$. auripennis sp. nov.; tíbia e basitarso III do macho como na figura 89; EVII do macho como nas figuras 118, 119; ninho em termiteiro arborícola externo, betuminoso; Brasil Central até Belém, PA (Fig. 169, também exemplares com labro amarelo, veja item 35') P. combinata sp. nov. (parte)

21.(20). Microtríquias amarelas em toda a extensão da asa, as veias méleo-claras; estrias paroculares como na figura 155; mandíbula como nas figuras 55, 56; tíbia e basitarso III do macho como na figura 88; EVII do macho como na figura 117; ninho em termiteiro arborícola; norte do Amazonas, Brasil, até Guianas (Fig. 169) ........ P. auripennis sp. nov.

Microtríquias enegrecidas em toda a extensão da asa, ou amarelas apenas na região do pterostigma; veias ferrugíneas . 21

22.(21'). Estrias paroculares como na figura 154; mandíbula como nas figuras 51,52; tíbia e basitarso III do macho como nas figuras 85-87; EVII do macho como nas figuras 115,116 . Trinidad, Venezuela, Guiana, até RR, Brasil (Fig. 169)

P. nigrior (Cockerell)

Estrias paroculares como na figura 157; mandíbula como na figura 56 ( $P$. auripennis sp. nov.) (exemplares também com labro e mandíbulas amarelos, veja item 35); macho desconhecido; só conhecida de Salvador, BA, Brasil (Fig. 169) P. nigrilabris sp. nov. (parte)

23.(19'). Integumento predominantemente amarelo ou castanhoclaro, se preto, então a bifurcação de $\mathrm{M}+\mathrm{Cu}$ nitidamente anterior à cu-v (exemplares das encostas andinas orientais) 24

Integumento preto, bifurcação de $\mathrm{M}+\mathrm{Cu}$ coincidente ou levemente anterior ou posterior à cu-v ....... 28

24.(23). Dentes da mandíbula muito curtos, fortemente recuados em relação ao bordo apical, como nas figuras 60,61 ; bifurcação da veia $\mathrm{M}+\mathrm{Cu}$ nitidamente anterior à cu-v; membrana das asas levemente ferrugíneo-amarelada na metade basal, microtríquias fuscas em toda a asa; integumento geralmente amarelo, com a sutura epistomal e mesepisternos, na porção ventral, escurecidos; tíbia III com 1/3 a 1/2 da porção apical enegrecida, em contraste com o integumento amarelado (em populações das encostas orientais andinas, acima de $750 \mathrm{~m}$ de altitude aparecem indivíduos com integumento enegrecido em todo o corpo); estrias paroculares como na figura 150; tíbia III do macho fortemente alargada para o ápice (Fig. 82 ), basitarso III do macho como na figura 82 ; EVII do macho com projeção mediana triangular estreita (Figs. 113, 114); ninhos sempre subterrâneos, em termiteiros, ninhos de Atta spp., e outras cavidades subterrâneas; Guianas, bacia amazônica, da região pré-andina até o Maranhão; há registros isolados para o Ceará e Piauí, Brasil (Fig. 164) ................. P. testacea (Klug)

Dentes da mandíbula não tão fortemente recuados (Figs. 62-66); bifurcação de $\mathrm{M}+\mathrm{Cu}$ geralmente coincidente, levemente anterior, ou posterior à cu-v; asas e microtríquias variáveis, integumento amarelo ou castanho claro, com ou sem áreas enegrecidas; estrias paroculares como na figura 146; tíbia III do macho não alargada para o ápice; basitarso III do macho como nas figuras 80 e 81 ; EVII do macho com projeção mediana triangular larga (Figs. 110, 111, espécies com machos conhecidos); ninhos em vários substratos, mas não subterrâneos; grupo musarum (parte) .... 25

25.(24'). Bifurcação de $\mathrm{M}+\mathrm{Cu}$ geralmente posterior à cu-v; área malar geralmente maior que o diâmetro do $2^{\circ}$ flagelômero (1,00-1,70x); cerdas eretas das áreas paroculares, ao lado dos alvéolos, curtas, pouco diferenciadas em relação às cerdas curtas decumbentes; ninhos não associados à térmitas; costa do Pacífico, no Equador, norte da Colômbia até Am. Central 26

Bifurcação de $\mathrm{M}+\mathrm{Cu}$ geralmente coincidente com a cu-v; área malar mais curta $(0,75-1,10 x$ o diâmetro do escapo); cerdas eretas das áreas paroculares, ao lado dos alvéolos, mais longas que as decumbentes; ninhos em termiteiros arborícolas externos; Brasil Central, Amazônia até Guianas 27

26.(25). Área malar muito longa (1,30-1,79x o diâmetro do $2^{\circ}$ flagelômero); estrias paroculares muito alargadas embaixo, atingindo a sutura epistomal ou quase, afilando repentinamente na altura das fóveas tentoriais (ca. 1,5x o diâmetro do $2^{\circ}$ flagelômero; 
Fig. 149) e alcançando o vértice; contorno da margem posterior da tíbia III, onde se inicia a corbícula, suavemente sinuoso; mandíbula como nas figuras 64, 65; macho desconhecido; ninho entre raízes de epífitas; costa do Pacífico no Equador e Colômbia até Panamá Central (Fig. 167) .............................. P. aequatoriana Camargo Área malar tão longa quanto o diâmetro do $2^{\circ}$ flagelômero $(0,9-1,2 \mathrm{x})$; estrias paroculares aproximadamente com a mesma largura em toda a sua extensão ou muito alargadas embaixo (Fig. 148); contorno da margem posterior da tíbia III, onde se inicia a corbícula, com recorte nitidamente sinuado; mandíbula como na figura 66; basitarso e tíbia III do macho como na figura 81 (de P. vicina); EVII do macho com projeção mediana curta e triangular (como na figura 110 , de $P$. vicina); ninho em ninhos abandonados de aves; norte da Colômbia até Honduras (Fig. 167) P. musarum (Cockerell)

27.(25'). Integumento completamente amarelo, inclusive a sutura epistomal, área ao redor dos ocelos e porção ventral dos mesepisternos; tíbia III geralmente amarela por inteiro ou enegrecida parcialmente em populações do Brasil Central (em outras regiões podem aparecer indivíduos com uma pequena mancha escurecida no quarto apical da tíbia); área malar ca. de $0,82-1,14 \mathrm{x}$ o diâmetro do $2^{\circ}$ flagelômero; mandíbula como na figura 62; tíbia e basitarso III do macho como na figura 81; EVII do macho como na figura 110; ninhos em termiteiros arborícolas; bacia amazônica até Brasil Central (Fig. 165) ..

P. vicina Camargo

Integumento castanho ferrugíneo ou amarelado (machos enegrecidos, na região do rio Trombetas, PA, Brasil); sutura epistomal, área ao redor dos ocelos e porção ventral dos mesepisternos escurecidas em contraste com o integumento claro; tíbia III parcialmente enegrecida; área malar muito curta, ca. 0,75-0,93x o diâmetro do $2^{\circ}$ flagelômero; mandíbula como na figura 63; tíbia e basitarso III do macho como na figura 80; EVII do macho como na figura 111; ninhos em termiteiros arborícolas; norte dos rios Negro e Amazonas, Brasil, até Guianas (Fig. 167) P. mourei Camargo

28.(23’). Asas ferrugíneo-escuras com microtríquias escurecidas em toda a sua extensão; estrias paroculares mais estreitas que o diâmetro do $2^{\circ}$ flagelômero, aproximadamente com a mesma largura em toda a extensão (Fig. 153); mancha subocelar muito alongada, ca. de $1,5 \mathrm{x}$ o diâmetro do ocelo médio; área malar curta $(0,82-0,89 x$ o diâmetro do $2^{\circ}$ flagelômero); só conhecida de Natal, RN, Brasil (Fig. 169)

P. littoralis sp. nov.

Asas hialinas ou levemente ferrugíneas, com microtríquias fuscas ou amarelas; estrias paroculares um pouco alargadas embaixo; mancha subocelar aproximadamente tão longa quanto o diâmetro do ocelo médio ou mais curta; área malar aproximadamente igual ao diâmetro do $2^{\circ}$ flagelômero 29

29.(28'). Asas hialinas com microtríquias amarelas em toda a sua extensão, ou apenas a base e o ápice com microtríquias escuras; veias méleo-claras; EVII do macho com projeção mediana triangular (Figs. 105 e 108); grupo musarum (parte) ....... 30

Asas hialinas ou levemente ferrugíneas, com microtríquias enegrecidas em toda a sua extensão, ou amarelas apenas na região do pterostigma; veias variáveis; EVII do macho variável. 31

30.(29). Microtríquias amarelas em toda a asa; máculas da face e tórax geralmente pouco conspícuas; estrias paroculares como na figura 144; mandíbula como na figura 53; tíbia e basitarso III do macho como na figura 83; EVII do macho como na figura 108; ninho em termiteiro em ocos de árvores mortas ou galhos secos; populações da região do Trombetas, PA, Brasil (Fig. 168) P. ferreirai sp. nov. (parte)

Microtríquias amarelas em quase toda a asa, enegrecidas no ápice e/ou na base; máculas da face e tórax geralmente nítidas; estrias paroculares como na figura 145; mandíbula como na figura 59; tíbia e basitarso III do macho como na figura 77; EVII do macho como na figura 105; ninho em termiteiros arborícolas externos; região do baixo rio Tapajós, PA, Brasil (Fig. 166) P. gregaria $\mathbf{s p . ~ n o v . ~}$

31.(29'). Cerdas do escapo nitidamente mais longas que o diâmetro deste (2,69-2,46x), bem diferenciadas em relação às demais cerdas do escapo; cerdas da região ventral do tórax e abdômen esbranquiçadas; TIII com a franja pré-marginal contínua na região mediana (as cerdas tão longas quanto $0,7-1,2 \mathrm{x}$ o diâmetro do escapo); abelhas pequenas (largura máxima da cabeça entre 2,24-2,40 mm); estrias paroculares como na figura 143 ; mandíbula como na figura 54 ; tíbia e basitarso III do macho como nas figuras 78,79; EVII do macho com projeção mediana triangular (Fig. 112); ninhos em termiteiros arborícolas externos; norte-nordeste da Amazônia até MA, Brasil, Suriname e Guiana Francesa (Fig. 166) 
P. pearsoni (Schwarz)

Cerdas da base do escapo mais curtas, no máximo 1,50x o diâmetro do escapo; cerdas dos esternos enegrecidas; TIII com a franja pré-marginal interrompida medianamente ou com as cerdas muito mais curtas que o diâmetro do escapo; geralmente abelhas maiores (largura máxima da cabeça entre 2,34 e 2,64 mm); estrias paroculares como nas figuras 144,151, 152, 156 e 157; tíbia e basitarso III do macho como nas figuras 83,84 , 89, 90 e 91 ; EVII dos machos variáveis .......... 32

32.(31'). Mandíbula como no figura 53; tíbia e basitarso III do macho como na figura 84; EVII do macho com projeção mediana em triângulo aberto (Fig. 109); ninho em termiteiro dentro de oco de árvores mortas ou galhos secos; populações do norte do Amazonas, rio Negro, Brasil, até Guianas (Fig. 168) P. ferreirai sp. nov. (parte) Mandíbulas como nas figuras 57 e 58; tíbia e basitarso III do macho como nas figuras 89 a 91 ; EVII do macho com projeção mediana de lados aproximadamente subparalelos (Figs. 120, 121); Brasil Central - sudeste, até nordeste (Figs. 169, 170); grupo nigrior (parte) 33

33.(32'). Asas hialinas; nordeste do Brasil 34 Asas levemente ferrugíneas; Brasil Central-sudeste

34.(33). Máculas na face e tórax nítidas; asas hialinas com microtríquias enegrecidas em toda a sua extensão ou amarelas na região do pterostigma, veias méleas escurecidas pelas microtríquias fuscas; estrias paroculares como na figura 151; mandíbula como na figura 57 , tíbia e basitarso III do macho como na figura 90; EVII do macho como na figura 120; ninho em termiteiros em ocos de árvores, geralmente vivas; MA, TO, PE, PA, Brasil (Fig. 170)

P. chapadicola $\mathbf{\text { sp. nov. }}$

Máculas menos conspícuas, no tórax geralmente apagadas; asas hialinas com microtríquias enegrecidas em toda a sua extensão; veias escurecidas; estrias paroculares como na figura 152; mandíbula como na figura 58; tíbia e basitarso III do macho como na figura 91; EVII do macho como na figura 121; ninho em termiteiros arborícolas externos, de terra; MA até PB, PE e RN, Brasil (Fig. 170) .

P. seridoensis sp. nov.

35.(33'). Abelhas de porte pequeno (largura máxima da cabeça entre 2,24 e 2,38 mm); estrias paroculares alargadas embaixo, um pouco apagadas, chegando até a altura da linha da maior distância interorbital (Fig. 157); nidificação desconhecida; só conhecida de Salvador, BA, Brasil (Fig. 169) P. nigrilabris sp. nov. (parte)

Abelhas de porte maior (largura máxima da cabeça entre 2,30 e 2,60 mm); estrias paroculares mais estreitas, geralmente chegando até a altura da interorbital superior, nítidas (Fig. 156); cerdas da base do escapo um pouco mais longas que o diâmetro deste $(0,86-1,27 \mathrm{x})$; ninho em termiteiros arborícolas externos, betuminosos; Brasil Central (Fig. 169) P. combinata $\mathbf{s p . ~ n o v . ~ ( p a r t e ) ~}$

\section{As espécies de Partamona.}

\section{Grupo bilineata / epiphytophila}

Partamona bilineata (Say, 1837)

(Figs. 38, 128, operária; 69, 70, 101, macho; 160, distribuição; Tabs. II-IX)

Trigona bilineata Say, 1837:414, 415.1; Smith, 1854:413.38; ?Le Conte, 1859:788.1; ?Cockerell, 1905:323; 1913:11.

Trigona cupira; Silvestri, 1910:65-71; Cockerell, 1912:314;1913:10, 14 (partim, Guatemala);1928:171; Wheeler, 1913:3, 4; Strand, 1919 (1917):70; Roubik \& Wheeler, 1982:127.

Trigona orizabaensis; Bullock et al., 1989:392.

?Trigona pallida var. nigrita Friese, 1901:269.

Trigona testacea orizabaensis; Wille \& Michener, 1973:12

Trigona testacea orizabensis; (sic) Wille \& Michener, 1973:45, 56.

Trigona (Partamona) cupira; Cockerell, 1949:490.

Trigona (Partamona) testacea orizabaensis; Schwarz, 1949:363, 368; Ayala, 1992:1, 31, 56.

Trigona (Partamona) testacea variety orizabaënsis; Schwarz, 1948:363, 376; Cockerell, 1949:490; Rau, 1943:641-643.

Melipona bilineata; DallaTorre, 1896:576.

?Melipona pallida pallida aberr. nigritula; Ducke, 1916:120.41a.; 1925:412.

Partamona bilineata; Camargo, 1988b:358; Michener, 1990:115; Ayala, 1992:1, 5, 14, 28-31, 44, 46, 56, 57, 59, Figs. 80-85, 127; 1999:7, 15, 19, 53-58, 61 (designação do neótipo); Godinez, 1997:21, 4043,52 .

Partamona cupira; Gonzales, 1983-1984:191,192.

Partamona orizabaensis; Ayala, 1988:406, 448.

Partamona aff. orizabaensis; Camargo, 1988b:358.

Partamona (Partamona) orizabaensis; Camargo, 1980:9.

?Partamona (Partamona) nigrita; Camargo, 1980:9 (nigritula), 58, 64.

Diagnose. Abelhas de porte médio (1.m.c. 2,3-2,5 mm; c.a.a. 5,3-6,1 mm; Tabs. III, IV). Integumento preto. Mandíbula com ca. de $1 / 2$ da porção basal amarela ou descolorida e a porção distal castanho-ferrugínea ou predominantemente amarelada; ápice ferrugíneo-escuro, côndilos pretos. Flagelo castanho escuro ou amarelado. Estrias paroculares estreitas (ca. 0,6x o diâmetro do $2^{\circ}$ flagelômero), levemente alargadas embaixo (ca. 1,0-1,2x o diâmetro do $2^{\circ}$ flagelômero), em cima chegando nítidas até a altura da interorbital superior ou desaparecendo na interorbital máxima (Fig. 128). Máculas do tórax pouco conspícuas. Pilosidade predominantemente preta; nos esternos e região ventral dos mesepisternos, coxas e trocanteres, brancas. Membrana das asas levemente ferrugínea; microtríquias pretas; veias méleas, escurecidas pelas 
microtríquias. Cerdas do escapo mais curtas que o diâmetro deste, ou apenas 1 ou 2 cerdas na base um pouco mais longas que as demais $(0,8-1,1 \mathrm{x}$ o diâmetro do escapo; Tab. VII). Cerdas eretas das áreas paroculares, ao lado dos alvéolos, delgadas, mais curtas ou tão longas quanto o diâmetro do escapo. Cerdas do escutelo 0,9-1,0x o comprimento deste. Área basal do propódeo uniformemente pilosa. Dentes da mandíbula como na figura 38. Área malar, distância interocelar, distância ocelorbital, tíbia III e comprimento da asa anterior, normais (Tabs. V, VI, VIII, IX). Bifurcação da $\mathrm{M}+\mathrm{Cu}$ geralmente coincidente com a cu-v (raramente levemente anterior). Macho, basitarso III curto e largo, fortemente intumescido; tíbia III estreita (Figs. 69, 70); EVII com a projeção mediana curta e triangular, chanfros laterais curtos e largos (Fig. 101).

Variação. Exemplares procedentes da península de Yucatan são consideravelmente menores que os de outras regiões do México (l.m.c. 2,1-2,4 mm), com asas proporcionalmente mais curtas (c.a.a. / 1.m.c. 2,2-2,3). Entre eles predominam indivíduos com flagelos claros e venação alar também um pouco mais clara. Em El Salvador e Guatemala ocorrem indivíduos com o abdômen amarelado ou ferrugíneo, asas hialinas com microtríquias amarelas na metade basal ou na maior parte das asas, e com estrias paroculares um pouco mais largas, que chegam nítidas até o topo do olho. Entretanto, esses caracteres não são estáveis, variando bastante em diferentes combinações, em indivíduos da mesma localidade. No material procedente de Santa Tecla, El Salvador, nos. 593 (4 ops., USNM), 586 ( 7 ops., USNM) e 531 (4 machos, USNM), há indivíduos com abdômen amarelo ou preto na mesma série, e os machos são idênticos àqueles do México (abdômen escuro, asas com microtríquias escuras). Nesse caso, um número maior de exemplares proveniente da região, material seguramente de ninhos e dados da biologia, poderão esclarecer melhor a situação dessas populações. Outros caracteres que se mostram bastante variáveis mas, aparentemente, sem regularidade geográfica, pelo menos em relação ao material examinado, são: intensidade das máculas da face (apagadas em muitos exemplares, mas não em todos, de Jalisco, Guerrero, Oaxaca, Michoacan e, por outro lado, muito vivas em exemplares de Tapachula, Chiapas), cor do integumento da cabeça, enegrecido ou castanho escuro, cor do flagelo (de castanho-escuro até amarelado, variando muito em toda a distribuição de $P$. bilineata, exceto em Yucatan onde predominam exemplares com flagelo claro) e cor da membrana das asas (uma leve variação na intensidade de ferrugíneo, mas nunca chega a ser muito escura; asas hialinas foram encontradas apenas nos exemplares de Durango: Rio Chico e Paraíso).

\section{Macho. Figuras 69, 70, 101.}

Material-tipo. SAY (1837) não menciona número de exemplares considerados como tipos, e como procedência indica apenas "México". Ayala (1999), de acordo com o artigo 75 do Código de Nomenclatura Zoológica fez a designação do neótipo, de MÉXICO, Veracruz: Xico, Cascada de Texolo, depositado na UNAM. O material tipo não foi examinado.
Material examinado. MÉXICO. Mex. (localidade?), sem data, anônimo, Collection C. F. Baker, 2154 (1 op., AMNH); Mex. (localidade?), sem data, anônimo, 54142 (1 op., AMNH). Sinaloa: Atkil, 15.VIII.1962, A.E. \& M.M. Michelbacher domestic squash, 751.1 (1 op., USNM); Palmito, 5 mi. W, 6100 ft., 1.VII.1961, R. A. Scheibner, (1 op., MSUC). Durango: Paraiso, 6 Mi. W., 6600 ft., 23.IX.1950, Ray F. Smith (3 ops., AMNH); Rio Chico, 6400 ft., 3.VII.1961, R.A. Scheibner (2 ops., MSUC). Tamaulipas: Brownsville (Matamoros ?, procedência duvidosa), 9.IX.1944, cabin of plane, No. 57842, Lot No. 44-22968 (1 op., USNM); ibidem, 17.X.1945, in plane, No. 59589, Lot no. 41-19003 (2 ops., USNM). San Luis Potosi: El Salto Falls, 400 m, 4.VII.1990, I. Yarom (12 ops., SEMC; 2 ops., RPSP); ibidem, 12 km NW El Naranjo, 400 m, 4.VII.1990, R.L. Minckley (8 ops., SEMC; 1 op., RPSP); ibidem, idem, 26.VII.1990, D. Conlon (1 op., SEMC); El Salto, 1500', 24.VIII.1954, R.R. Dreisbach (1 op., MSUC); ibidem, idem, 1700', 25.VIII.54 (1 op., MSUC); ibidem, 1800(alt.?), 8.VI.1961, U. Kans. Mex. Exped. (1 op., RPSP); ibidem, idem, 20.VII.1962 (1 op., RPSP); ibidem, El Naranjo, 29.VI.1965, Paul J. Spangler (11 ops., USNM; 1 op., RPSP); Tamazunchale, sem data, Phil Rau, 1359, 1376 (3 ops., AMNH); ibidem, idem, T, 1375 (1 macho, RPSP); ibidem, $11 \mathrm{~km} \mathrm{~S}$ on hwy 185, $210 \mathrm{~m}$, 10.VII.1990, D. Conlon (1 op., SEMC); ibidem, $16 \mathrm{~km} \mathrm{SW,} \mathrm{20.VIII.1988,}$ D. Yanega, on Hyptis (1 op. SEMC); ibidem, $18.1 \mathrm{~km} \mathrm{~S}, 820 \mathrm{~m}$, 10.VII.1990, R.L. Minckley (2 ops., SEMC); ibidem, $10 \mathrm{mi}$. SW, 12.VIII.1972, G.F. \& S. Hevel (1 op., USNM); Xilitla, 23.VII.1954, R.R. Dreisbach (1 op., MSUC); ibidem, idem, 3500', 21.VII.1954 (3 ops., MSUC); ibidem, 1450 ft., 23.VII.1954, Univ. Kans. Mex. Exped. (1 op., RPSP). Nayarit: San Blas, 1 mi. E, 8.IV.1963, G.W. Frankie (1 op., USNM). Jalisco: Autlan, 6 mi. S.W., 25.VII.1963, R.L. Westcott (1 op., DZUP); Catalitlan, 10.VII.56, R. \& K. Dreisbach (6 ops., MSUC; 1 op., RPSP); Chamela, 27.IX.1985, R.J. McGinley (1 op., USNM); ibidem, idem, Chamela Station, 10-11.VII.1989 (11 ops., USNM; 1 op., RPSP); ibidem, Estación de Biologia, 2.X.1985, J.G. Rozen (2 ops., AMNH); ibidem, idem, 12.VII.1989 (1 op., AMNH), 14.VII.1989 (1 op., AMNH); Plan de Barrancas, 1 mi. W., 31.VII.1964, W.J. Gertsch, J.A. Woods (2 ops., AMNH); Playa Teopa, 8 km S. Careyes, 4.X.1985, J.G. Rozen (1 op., AMNH). Querétaro: Jalpan de Serra, 770 m, 24.V.1989, D. Yanega, on Antigonon lepolopus (1 op., SEMC); ibidem, idem, 9.VII.1990 (1 op., SEMC). Hidalgo: Cardonal, $24 \mathrm{~km} \mathrm{NW}$ (Barranco del Tulantango), 1590 m, 13.VII.1990, R.L. Minckley,ex: Cassia (1 op., SEMC); Chapulhuacan, 3100 ft., 2.VIII.1963, J.P. Donahue (1 op., MSUC); El Chico, 11.III.1992, L. Godínez, 817 (2 ops., SEMC); Molango, 15.II.1992, L. Godínez, 706 (7 ops., SEMC; 1 op., RPSP); ibidem, idem, 819, ex: Bidens odorata (4 ops., SEMC); San Luis Potosi-Hidalgo border, $19.5 \mathrm{~km} \mathrm{~S}$., on Hwy 85, $1200 \mathrm{~m}, 11$. VII.1990, D. Conlon and R.L. Minckley (9 ops., SEMC; 2 ops., RPSP); ibidem, Hwy. 85 (km 232), 1200 m, 11.VII.1990, I. Yarom (2 ops., SEMC); Tulancingo, 11.III.1992, L. Godínez, 816 (1 op., SEMC). Colima: Colima, W.M. Mann (1 op., USNM); ibidem, L. Conradt, 131 (1 op., USNM); ibidem, II.1921 (51), anônimo (2 ops., Ac. 39959, AMNH); ibidem, sem data, L. Conradt (6 ops., USNM); State of Colima (localidade ?) L. Conradt (3 ops., USNM). Michoacán: Buena Vista, N of Playa Azul, 700 m, 2.XI.1987, L. Godinez, LG-286, (1 op., SEMC); Dr. Miguel Silva, 1450 m, 9 km S Ario de Rosales, 29.X.1987, L. Godinez, LG-242, (2 ops., SEMC); El Cangrejo, $20 \mathrm{~km}$ N La Huacana, 1090 m, 30.X.1987, L. Godinez, LG-252 (1 op., SEMC); Playa Azul, 54 km N, 800 m, 2.XI.1987, L. Godinez, 290 (1 op., SEMC); Tancitaro, 6000 ft., 28.VII.1941, H. Hoogstraal, h506 (2 ops., AMNH); ibidem, idem, 25.VI.1941, h217 (1 op., AMNH; 1 op., RPSP), 26.VI1941, h244 (1 op., AMNH), 12.VIII.1940, Hy-73 (2 ops., AMNH), 6000ft., 12.VIII.1940 (1 op., RPSP), 15.VIII.1940, Hy-76 (1 op., AMNH); ibidem, Cerro Tancitaro, 7800 ft., 7.VII.1941, H. Hoogstraal h307 (1 op., AMNH); Tuxpan, 5.IV.1941 (49), anônimo (2 ops., AMNH); Tzitzio, 3 mi. N, 5500', 29.VII.1962, U. Kans. Mex. Exped. (5 ops., RPSP); ibidem, idem, 2 mi. S., 4450', 29.VII.1962 (1 op., RPSP). México: Chalma, 1700 m, 20.X.1990, 1. Godínez, 620, ex: Bidens anthemoides (4 ops., SEMC); ibidem, idem, 26.XI.1990, 630 (2 ops., SEMC); Tonatico, XII.1946, anônimo (3 ops., AMNH). Distrito Federal: Dist. Fedrl. (localidade ?), sem data, J.R. Inda (1 op., USNM). Morelos: Cuantlixeo, sem data, anônimo, "En un agujero abajo de la iglesia. Bravas" (2 ops., AMNH); Cuautla, 28.X.1922, EG Smyth (1 op. USNM); Cuernavaca, 21.IX.1944, NLH Krauss (2 ops., USNM); ibidem, 
idem, X.1944 (1 op., USNM), III.1945 (4 op., USNM), VIII.1959 (1 op., USNM), VII.1965 (3 op., USNM), VII.1965 (1 op., USNM); ibidem, sem data, Crawford (9 ops., USNM; 1 op., RPSP); ibidem, IV(ano?) W. M. Mann (1 op., USNM); ibidem, II.1936, L.H. Weld (4 ops., USNM); ibidem, 29.VIII.1970, S.W.T. Batra (7 ops., USNM); ibidem, 6000', 26.VIII.1956, R. \& K. Dreisbach (2 ops., MSUC); ibidem, 13.X.1908, anônimo (8 ops., RPSP); ibidem, 12 mi. E., 4200', 12.VIII.1954, R.R. Dreisbach (2 ops., MSUC); Huajitlan, 27.IX.1957, R. \& K. Dreisbach (1 op., MSUC); Matamoros, 10.VIII.1903, W.L. Tower Collection, F 1312 (1 op., AMNH); Oaxtepec, 19.II.1939 (38), A. Dampf (1 op., AMNH); Tepoztlan, 20.VIII.1956, R. \& K. Dreisbach (2 ops., MSUC); ibidem, 6.VI.1943, L. Vazquez, fruit juice bottles (2 ops., AMNH). Puebla: Atlixco, 23.VII.1956, R. \& K. Dreisbach (4 ops., MSUC; 1 op., RPSP); Matamoros Izucar, 7 mi. N, 4,450', 19.VIII.1962, U. Kans. Mex. Exped. (1 op., SEMC). Veracruz: V.C. (localidade ?), sem data, anônimo No. 53.14 e No. 5 McL8 (2 ops., USNM); Brecha Teocelo Santa Rosa 1 km, 372 m, 16.VI.1990, Gregorio Rodriguez (1 op., SEMC); Catemaco, 2.VIII.1962, A.E. \& M.M. Michelbacher, domestic squash, 851.1 ( 8 ops., USNM); ibidem, $\sim 30 \mathrm{~km}$ east, on cliff side, 11.I.1982, B.H. Smith (23 ops., SEMC; 4 ops., RPSP); ibidem, $32 \mathrm{~km} \mathrm{~N}$. UNAM Preserve, 6.I.1982, E.M. May (1 op., SEMC); ibidem, idem, malaise trap (1 op., SEMC); ibidem, $34 \mathrm{~km} \mathrm{~N}, 2-3 \mathrm{~km}$ on rd to Sontecomapan, 5.I.1982, B.H. Smith ( 2 ops., SEMC); ibidem, 19.VI.1964, J.C. \& D. Pallister (2 ops., AMNH); ibidem, Lake Catemaco, 1000', 23.VII.1955, P. \& C. Vauric (2 ops., AMNH); ibidem, idem, 24.XI.1962 (2 ops., AMNH); Coatepec, 16.VI.1990, Gregorio Rodriguez (5 ops., SEMC; 1 op., RPSP); Cordoba, VII.1965, NLH Krauss (3 ops., USNM); ibidem, 4.VIII.1962, A.E. \& M.M. Michelbacher, squash, 852.1 (1 op., USNM); ibidem, sem data, Crawford (3 ops., USNM); ibidem, 12.V.1946, J. \& D. Pallister (1 op., AMNH); ibidem, sem data, Phil Raw, 1382 (1 op., AMNH); ibidem, 156 (data?), Fredk Knab (1 op., AMNH); Coscomatepec, 7.XI.57, R. \& K. Dreisbach (1 op., MSUC); Coyame, Lago de Catemaco, 16.VII.1963, D.R. Whitehead, blacklights (1 op., USNM); ibidem, idem, 1018.VII.1963 (1 op, USNM); Est. "Jostoxtlas", 1.I.1982, J.U. Labougle (1 op., SEMC); El Tajin, 29.XII.1971, N. Weaver, 63.1, (13 ops., RPSP); Fortín, 22.VIII.1946, H.F. Schwarz (1 op., AMNH); Fortin de las Flores, 5.VIII.1962, A.E. \& M.M. Michelbacher, domestic squash, 853.1, 061007-10 (3 ops., USNM); Huatusco, 16 km SE., 1400 m, 18.VII.1990, W. Bell, D. Conlon, R.L. Minckley (1 op., SEMC); ibidem, idem, 24 km S., 1100 m, 17.VII.1990 (2 ops., SEMC), 32.2 km S., (4 ops., SEMC); ibidem, Huatusco to Fortin de las Flores, Hwy 125, 2.I.1989, B N Danforth \& R L Minckley (1 op., SEMC); ibidem, S Huatusco, hwy 125, Jct. Ixhuatlan, 1430 m, 17.VII.1990, I. Yarom (1 op., SEMC); Ixhuatlan S [SE Huatusco], coffee plantation along gravel road, $1130 \mathrm{~m}, 17-$ 18.VII.1990, I. Yarom (10 ops., SEMC; 2 ops., RPSP); Jalapa, 15.XI.1963, NLH Krauss (3 ops., USNM); ibidem, idem, III.1965 (2 machos, 2 ops., AMNH), III, VI.1965 (21 machos, 3 ops., USNM; 2 machos RPSP); ibidem, sem data, Crawford (1 op., USNM); ibidem, 1-6.VIII.1961, R \& K Dreisbach (5 ops., MSUC; 1 op., RPSP); ibidem, 19.V.1946, J. \& D. Pallister (1 op., AMNH); ibidem, idem, 22.V.1946 (1 op., AMNH); ibidem, 10.VI.1908, anônimo (8 ops., RPSP); ibidem, 10 miles south, sem data, Phil Raw, 2427 (2 ops., AMNH); Minatitlan, 8-26.IX.1961, R. \& K. Dreisbach (1 op., MSUC); Orizaba, 13.VIII.1949, E.G. Smyth (1 op., DZUP); ibidem, 5.II.1962, P. Reyes, F. Aguilar (7 ops., MZSP); ibidem, 5.VIII.1962, A.E. \& M.M. Michelbacher, domestic squash, 854.1 (4 ops., USNM); ibidem, 4.XI.1957, R \& K Dreisbach (1 op., MSUC); ibidem, idem, 12-22.VIII.1961 (3 ops., MSUC); ibidem, XII.1857, H.H.S. \& F.D.G. (1 op., AMNH); ibidem, sem data, Mann (2 ops., AMNH; 1 op., RPSP); ibidem, I.1945, NLH Krauss (5 ops., USNM); Papantla along Rio Tecolutla, 1.I.1989, B N Danforth \& R L Minckley (1 op., SEMC); Presidio, 1000', 14.VII.1965, R.R. Snelling, on rotting bananas (8 ops., USNM); Puente Nationale, 10.VIII.1961, R \& K Dreisbach (2 ops., MSUC); Rio Blanco, 13.XI.1957, R. \& K. Dreisbach (4 ops., MSUC); Rio Nautla, 3.18(data?), No. 7, "N. America, Cockerell. 1905-111" (1 op., AMNH); ibidem, 3.18(data?), No. 15, No. 16, anônimo (prov. Cockerell) (2 ops., USNM); Santiago Tuxtla, 11.VIII.1956, R \& K. Dreisbach (6 ops., MSUC; 1 op., RPSP); S. Lucrecia, sem data, Crawford (7 ops., USNM); ibidem, St. Lucrecia Tehuantepec, IV(ano?), WM Mann (1 op., USNM); Teocelo, 1.VIII.1987, L. Mondragon, 59 (1 op., SEMC); ibidem, idem, 30.VIII.1987, 46 (1 op., SEMC); Veracruz, VII.1959,
NLH Krauss (1 op., USNM); ibidem, 28.VII-11.VIII.1956, R. \& K. Dreisbach (2 ops., MSUC). Guerrero: Ayotzinapa Tixtla Valley, 12.I.1941 (46), A. Dampf (1 op., AMNH); Chilpancingo, 26.VIII.1970, S.W.T. Batra (1 op., USNM); ibidem, 24.VII.1961, R. \& K. Dreisbach (4 ops., MSUC; 1 op., RPSP); Iguala, sem data, Phil Rau, 1343 (2 ops., AMNH); Olmitemi, IX.1962, G. Halffter (2 ops., DZUP); Omiltemo, 8.000 ft. VIII (ano?), H.H. Smith (1 op., AMNH); Taxco, 27.VII.1951, M. Quigley (1 op., USNM); ibidem, 7.IX.1944, NLH Krauss (1 op., USNM); ibidem, VII.1959 (2 ops., USNM); Rincon, 2800 ft. VII (ano?) H.H. Smith (1 op., AMNH). Oaxaca: Cuicatlan, 19.IX.1948, L. Vasquez Yolomdo (?) (1 op., AMNH); Huajuapan, 13 mi. S.E., 6000ft, 4.VII.1953, Univ. Kans. Mex. Expedition, on Salix (1 op., RPSP); La Concordia, Pochutla, 4.IV.1933, C.V. Morton, E. Makrinius, 64 (9 ops., USNM); Oaxaca (localidade?), sem data, Crawford (5 ops., USNM); Guelatao, 20.II.1991, L. Godínez, 663, ex: Bidens pilosa (2 ops., SEMC); Palomares, 521.IX.1961, R \& K Dreisbach (1 op., MSUC); Tamazulápan, 2 mi. NW, 6000ft. 28.VI.1961, U. Kans. Exped. (2 ops., RPSP); ibidem, $3.2 \mathrm{~km}$ NW, $5524 \mathrm{~m}$ ( $s i c=$ pés?), 23.VI.1955, J.R. Acorn (3 ops., SEMC); Teatitlan, 1050 m III.1949, anônimo (2 ops., AMNH); Temescaltepec, 2.VI.1933, H.E. Hinton, R.L. Usinger (2 ops., AMNH); ibidem, idem, Real de Arriba, 27.V.1933 (1 op., AMNH); Totolapan, 37 Mi. NW, 24.VIII.1965, Paul J. Spangler (1 op., USNM). Tabasco: Teapa, II.1913(?), H.H.S., "Godman-Salvin Collection 1913-214" (2 ops., AMNH). Yucatan: Chichen Itza, VI.1929, J. Bequaert (2 ops., Ac. 29975, AMNH); Colonia Yucatan, 16.VIII.1964, J.C. \& D. Pallister (1 op., AMNH); ibidem, idem, 15.VIII.1964 (1 op., AMNH), 21.VIII.1952, C.R. Vose Fund. Explorers Club, AMNH Exped. (1 op., AMNH); Mérida, XI.1961, NLH Krauss (2 ops., USNM); ibidem, XII.1981, Camargo (53 ops., 1 macho, RPSP); ibidem, 8.V.1974, J.G. Acereto, "Xhuc-cab" (13 ops., RPSP); N. Yucatan (localidade?), 1913(data?), Gaumer, "Godman \& Salvin Coll. Brit. Mus. 1913-214" (2 machos, 1 op., AMNH; 1 op., RPSP); Valladolid, 14.IX.1952, J. \& D. Pallister, C.R. Vose Fund. Explorers Club, AMNH Exped. (1 op., AMNH); Yaxcaba, 20.I.1972, N. Weaver, 91.1 (14 ops., RPSP), ibidem, idem, 20.I.1972, 91.4 (9 ops., RPSP), 27.I.1978, 17.4, (5 ops., RPSP), 2-13.II.1978, 17.13 (7 ops., RPSP), 215.II.1978, 24.4, (6 ops., RPSP), 3.III.1978, 23.1, (9 ops., RPSP; 2 ops., SEMC); Yucatan (localidade ?), IX.1939 (42), A. Dampf (1 op., AMNH). Quintana Roo: Felipe Carrillo Puerto, 11-13.X.1986, R.J. McGinley (17 ops., USNM; 2 ops., RPSP); ibidem, 20 km N 7.X.1986, D. Roubik, Labiatae (2 ops., STRI); ibidem, $23 \mathrm{~km} \mathrm{W,} \mathrm{12.X.1986,} \mathrm{J.G.}$ Rozen (1 op., AMNH); ibidem, idem, 13.X.1986 (1 op., AMNH); Palmas, 4.V.1989, E. Cabrera \& W. Coli, Borreria verticillata (3 ops., STRI); Puerto Morelas, 10.X.1986, R.J. McGinley (9 ops., USNM); Tancah, 20.IV.1960, JFG Clarker (2 machos, USNM). Chiapas: Cintalapa, 12 mi. west, 14.VI.1972, anônimo (12 ops., MSUC); Escuintla, sem data, Crawford (1 op., USNM); Mapastepec, 6.VII.1965, P.J. Spangler (1 op., USNM); ibidem, on way from Mapastepec to Finca Prusia, Sierra Madre de Chiapas, 1920 m, virgin forest, 3.XII.1932, Alf. Dampf (1 op., Ac. 35268, AMNH); Palenque, 10.I.1969, J.K. Doutt (1 op., CMNH); Tapachula, V(ano?), Wm Mann (10 ops., USNM; 1 op. RPSP); Tuxtla Gutierrez, 15.XI.1963, A.E. \& M.M. Michelbacher, 152.3, 08.45-0930 (1 op., USNM); ibidem, idem, squash, 152.1, 0710-07.30 (1 op., USNM). BELIZE. Belize: Belize (cidade?), sem data, Johnson (15 ops., USNM; 2 ops., RPSP); ibidem, sem data, anônimo (6 ops., USNM). Corozal: Santa Elena 15 mi. S, 1 VII.1966, U. Kans. Mex. Exped. (4 ops., SEMC; 1 macho, RPSP). Cayo: Belmopan, VII.1975, N.L.H. Krauss (1 op., SEMC). Toledo: Punta Gorda, III.1931, J.C. Lutz Collection 1961 (1 op., USNM). District ? Rio Grande, VIII.1935, H.S. Parish (1 macho, 1 op., CNMH). GUATEMALA. Guatemala (cidade?), on Crotalaria agathiflora, sem data, anônimo (1 op., AMNH). Huehuetenango: Concepcion, $1400 \mathrm{ft}$., CN Ainslie (1 op., USNM). Quiché: Chichicastenango, VIII.1959, NLH Krauss (1 op., USNM); ibidem, 27.VII.1947, D. Schwarz (2 ops., AMNH); ibidem, El Quiche, 20.X.1963, A.E. \& M.M. Michelbacher, Cucurbita ficifolia, 205.1 (4 ops., USNM). Alta Verapaz: Cacao, 3-9 3 (data?), Schwarz \& Barber, on cotton (1 op., USNM); Coban, VIII.1953, Krauss (1 op., RPSP); ibidem, 12.VIII.1947, D.M.\& F. Schwarz (2 ops., AMNH); ibidem, $2 \mathrm{~km} \mathrm{E,}$ 2.VII.1993, $1330 \mathrm{~m}$, R. Brooks \& J. Ashe (1 op., SEMC); ibidem, idem, $6.7 \mathrm{~km}$ NE, 2.VII.1993, $1450 \mathrm{~m}$ (1 op., SEMC); Cocas Trece Aguas, 3.V.1901, D. Mac Lachlan (2 ops., USNM); San Cristobal, I(ano?), 
anônimo (2 ops., Ac. 4875, AMNH). Izabal: Lago de Izabel (sic, Izabal), Castillo de San Filipe, 17.II.1989, C. Michener \& D.W. Brzoska (1 op., SEMC); Matias de Galvez, 14-15.VIII.1965, Paul J. Spangler (1 op., USNM); Quirigua, 20-II.1912, WP Cockerell, 16 (1 op., AMNH). Baja Verapaz: Chica, 5.IV.1961, F.A. Ruhoff (1 op., USNM); Purulhá, 13 km NW, 2.VII.1993, 1530 m, R. Brooks \& J. Ashe (5 ops., SEMC; 1 op., RPSP); Purula, (sic?) sem data, Champion (1 op., AMNH); Salamá, 17 km N, Hwy 5, 1700 m, 29.VI.1993 R. Brooks, J. Ashe (3 ops., SEMC); ibidem, idem, 17 km N, 1200 m, 30.VI.1993 (1 op., SEMC); S. Geronimo, 1913 (?), Champion, "Godman \& Salvin Coll. Brit. Mus. 1913-214” (1 op., AMNH; 1 op., BMNH). Sololá: Atitlan Lake, 6000 ft., 27.II.1932, C.N. Ainslie (2 ops., USNM); ibidem, III.1938, Paul Richard (2 ops., AMNH). Chimaltenango: Yepocapa, V.1948, HT Dalmat (10 ops., USNM); ibidem, idem, 17.IV.1948 (1 op., USNM), 21.IV.1948 (2 ops., USNM); ibidem, 12.VIII.1987, H Te. Salmat (4 ops., USNM); ibidem, Finca Conchita, 16.II.1948, A.F.M. (1 op., USNM). Sacatepéquez: Antigua, 14.V.1923, EG Smyth (5 ops., USNM); ibidem, X.1965, NLH Krauss (6 ops., USNM); ibidem, idem, XII.1965 (2 ops., USNM); ibidem, (data ilegível), A. Pelen (1 op., USNM); Duenas, 1913(data?) G.C. Champion, "Godman \& Salvin Coll. Brit. Mus., 1913-214" (2 ops., AMNH). Guatemala: Amatitlan, 6.VIII.1965, P. J. Spangler (1 op., USNM); Guatemala City, 5000 ft., III.1932, CN Ainslie (15 ops., USNM; 2 ops., RPSP); ibidem, sem data, Champion (2 ops., AMNH); ibidem, XII.1911, W. M. Wheeler (1 op., Ac. 5634, AMNH); ibidem, J. Rodriguez (1 op., CMNH); ibidem, sem data,WP Cockerell (1 op., AMNH): ibidem, via Mérida Mex., 15.VII.1944, Hughes - 413, Plane LG-ABA, Lot No. 44-19336 (1 op., USNM); ibidem, idem, 9.VII.1944, Hughes - 398A, Plane NC 19903, Lot No. 44-19336 (1 op., USNM); ibidem, 25.XI.1975, S.W. Batra (3 ops., USNM); ibidem, nr. Guatemala City, 1932, C.N. Ainslie (1 op., USNM). El Progreso: El Progreso, 49.9 miles NE of Guatemala City, Puente El Hato, 5.VIII.1966, U. Kans. Mex. Exped. (1 op., SEMC); San Augustin Ac., 11-21.VIII.1965, Flint \& Ortiz (1 macho, 3 ops., USNM). Zacapa: Gualan, 18.II.1912, WP Cockerell (1 op., USNM); ibidem, idem, sem data (1 op., USNM; 3 ops., AMNH); ibidem, 7 km S, 23.VI.1993, R. Brooks, J. Ashe, on mango fruit (5 ops., SEMC; 1 op., RPSP); La Union, 3.5 km SE, 1500 m, 25.VI.1993, F. Gérnier, human feces trap (2 ops., SEMC); Teculután, 340 m, 25.VI.1993, R Brooks \& J. Ashe, 107, ex: Tribulus cistoides (6 ops., SEMC; 1 op., RPSP); ibidem, idem, 4,6 km W, 340 m, 25.VI.1993, 106, ex: Valeriana palmeri (1 op., SEMC); Zacapa, 15.XII.1911, Wm M. Wheeler (1 op., USNM); ibidem, idem (1 op., Ac. 5634, AMNH); ibidem, 30.IX.1929, D.M. Bates, N. 311 (2 ops., Ac. 30428, AMNH). Retalhuléu: Helvetia, 1,000 m, San Sebastian Reu., 21-22.IV.1931, J. Bequaert (1 macho, AMNH); S. Sebastian Retalhuleu, 1925, L. Thiel (1 op., USNM). Depto. ?: Cayuga, IV.1915, Wm Schaus (1 op., USNM); Culpan, 28.I.1930 Marston Bates, on manure (2 ops., Ac. 30428, AMNH); El Rancho, 900 ft., 17.II.1937, CN Ainslie (1 op., USNM); Estancia Virgen, Finca La Cajita, 12.VII.1965, Paul J. Spangler (2 ops., USNM); Ingenio, 28.IV.1926, J.M. Aldrich (1 op., USNM); Puerto Parade, 22.XI.1975, S.W. Batra (1 op., USNM); Ratigua (sic = Antigua ?), 25.VII.1947, D. Schwarz (2 ops., AMNH). HONDURAS. Santa Bárbara: Mt. Santa Barbara, $11.5 \mathrm{~km} \mathrm{~S} \mathrm{\&}$ $5.6 \mathrm{~km}$ W Peña Blanca, $14^{\circ} 57^{\prime} \mathrm{N}, 88^{\circ} 05^{\prime} \mathrm{W}, 1800 \mathrm{~m}, 20 . \mathrm{VI} .1994, \mathrm{R}$. Brooks, J. Ashe (2 ops., SEMC). Cortés: San Pedro Sula, VIII.1975, N.L.H. Krauss (2 ops., USNM). Comayagua: Agua Azul, 27.XII.1946, Mrs. Williams (2 ops., USNM); Francisco Morazán: Uyaca Peak, 23.III.1947, Ruaw (4 ops., USNM). EL SALVADOR. Santa Ana: Santana, 5500 ft., 14.VIII.1959, PA Berry, volcano (1 op., USNM). Sonsonate: Sonsonate, 18.X.1987, Navarrata R., Musacea (1 op., 920984, RPSP); ibidem, 19.VIII.1905, Fredk Knab (1 op., AMNH). La Libertad: Opico, 12.II.1956, P.A.B., No. 714-154, (1 op., USNM); Quezaltepec, 11.VII.1961, M.E. Irwin (1 op., DZUP); Santa Tecla (= Nueva San Salvador) 900-950 m, VIII.1975, N.L.H. Krauss (3 ops., SEMC); ibidem, 10.VI.1954, anônimo (2 ops., USNM); ibidem, 18.III.1955, P.A.B., No. 593 (4 ops., USNM); ibidem, idem, 11.III.1954, No. 531 (4 machos, USNM), 11.III.1955, No. 586, (7 ops., USNM); ibidem, 16.XII.1953, M. Salazar (1 op., USNM). San Salvador: Apopa, 10.XI.1991, Lopez, R. (1 op., 920981, RPSP); San Salvador, 10.VI.1958, L. J. Bottimer (1 macho, 8 ops., USNM; 1 op., RPSP); ibidem, idem, 9.VI.1958 (1 op., USNM); ibidem, 2.V.1958, OL Cartwright (1 op., USNM); ibidem, idem, 10.VI.1958 (1 op., USNM); ibidem, 24.VII.1954, anônimo, Mimosa pudica (2 ops., AMNH). Cuscatlán: Cojutepeque, 15.II.1986, Rodriguez Urrutia (1 op., 920983, RPSP). Depto. ? Sn. Andrés, sem data, C. Morales (1 op., 921117, RPSP); S. Ramon, 27.XII.1985, Enid Teos (2 ops., 920982, 920985, RPSP); Universidad (cidade?), 4.II.1965, SS \& WD Duckworth (1 op., USNM)

Distribuição geográfica e hábitat. Terras baixas e quentes do México até o norte de Honduras e El Salvador (Fig. 160). Dentre as espécie de Partamona é a que chega às maiores latitudes ao norte. A localidade de "Brownsville" (EUA, divisa com Matamoros, México) foi marcada com dúvidas, pois na etiqueta constam os seguintes dizeres: "Mexico x-17-45. Brownsville No 59589 In plane" (2 ops.) e "Mexico ix-9-44, Brownsville No. 57842" "cabin of plane" (1 op.), provenientes do USNM. Dados de etiqueta indicam que pode chegar até mais de $2.400 \mathrm{~m}$ de altitude (México, Guerrero, Omiltemo, 8,000 $\mathrm{ft})$.

Nidificação. Ocupa diversos tipos de cavidades ou lugares protegidos, sob pontes, galerias sob estradas, buracos e fendas em paredes de ruínas (RAU, 1943).

Discussão. Com falta de informação sobre os tipos de "Trigona bilineata" Say, 1837 e de "Trigona orizabaënsis" Strand, 1917, SchwARz (1948: 363, 1949: 363), considerou-os como sinônimos, muito embora a descrição de SAY (1837) não aponte nenhum caráter mais seguro indicando que $T$. bilineata pertença ao gênero Partamona; este autor menciona apenas duas manchas no clípeo (".... and two lines on the nasus pale"), e ao comparar com "Trigona ruficrus" $[=T$. spinipes (Fabricius, 1793)], chama atenção para o fato de que a última espécie possui as tíbias posteriores densamente ciliadas. SAY não faz qualquer referência, entretanto, a forma da tíbia III, o que certamente deixa alguma dúvida sobre a colocação de bilineata em Partamona. Ayala (1999) designou neótipo para P. bilineata, mas na sua proposta de sinonímia, não faz referência a "Trigona pallida var. nigrita n. var.” Friese, 1901, procedente de Córdoba, México, que pode corresponder à $P$. bilineata ou $P$. orizabaensis. Sobre T. nigrita, DuCKE $(1902,1916)$ menciona que FRIESE (1901), nomeou uma forma de transição entre $M$. pallida e $M$. cupira, com o tórax claro e o abdômen escuro como "pallida, var. nigritula" ( sic $=$ nigrita), o que corresponderia a Trigona peckolti, sensu DuCKE $(1902,1916)$. Porém o exemplar examinado por Ducke (depositado no MZSP), é na realidade $P$. peckolti, como já observado por CAMARGO (1980:64), em cuja etiqueta de procedência consta apenas "Cordova t.c.", e possivelmente corresponde a Córdoba, Colômbia, ou pode ter havido erro de etiquetagem (na etiqueta adicional de Ducke, datando 1913, é que consta "Cordova Mex.”). A descrição apresentada por FrIESE (1901), é um tanto quanto abreviada, e não é certeza que o exemplar examinado por Ducke (e também neste trabalho), faça parte da série do tipo, pois a etiqueta de determinação do punho de Friese, data de 1904. Se os exemplares da série do tipo de "nigrita" realmente procedem do México, esta espécie poderá corresponder tanto à Partamona bilineata quanto à $P$. orizabaensis, mas isso só poderá ser esclarecido com o exame do material tipo de $T$. nigrita 
(3 ops. e 1 macho).

Partamona bilineata se distingue de $P$. orizabaensis, com a qual se sobrepõe do sul do México até Honduras, pela pilosidade esbranquiçada nos esternos, pelas cerdas mais curtas na base do escapo, máculas pouco conspícuas no tórax, veias das asas mais claras, e estrias paroculares mais estreitas e geralmente menos conspícuas. Outras espécies do grupo bilineata / epiphytophila não entram em simpatria com $P$. bilineata; dos demais grupos, apenas $P$. musarum chega até Honduras, mas esta apresenta o integumento amarelo. Ayala (1992) menciona que os exemplares de Yucatan examinados por ele possuem as cerdas dos esternos "gríseas", mas no presente estudo, os espécimens examinados apresentaram cerdas esbranquiçadas, da mesma forma que exemplares de outras regiões do México. Machos procedentes da Península de Yucatan (Tancah e N. Yucatan) não apresentaram descontinuidades em relação aos de outras localidades do México. A análise de maior número de exemplares proveniente de ninhos, e de dados sobre os hábitos de nidificação, poderá auxiliar na decisão de se considerar as populações da Península de Yucatan como unidade taxonômica distinta. As descontinuidades observadas em exemplares de El Salvador e Guatemala não são estáveis, variando bastante, em diferentes combinações, em indivíduos da mesma localidade. Entretanto, só com o exame de material adicional, bem como informações sobre a biologia das populações nessa região, será possível esclarecer a situação.

Partamona grandipennis (Schwarz, 1951)

(Figs. 35, 132, operária; 71, 100, macho; 160, distribuição; Tabs. II-IX)

Trigona (Partamona) grandipennis Schwarz, 1951:4-7; Ägren \& Schemske, 1991:235, 237-239.

Trigona grandipennis; Michener, 1954:170.

Partamona grandipennis; Michener, 1990:115.; Roubik, 1992:500, 515, 516, 523; Bravo, 1992:864; Moure, 1992:132-133 (por um lapso, os comentários sobre esta espécie teve no cabeçalho o título Parapartamona grandipennis); Michener \& Roubik, 1993:256; Griswold, et al., 1995:690; Pedro \& Camargo, 1996-1997:199, 201207; Roubik et al., 1997:78.

Parapartamona grandipennis; Camargo, 1980:8.

Diagnose. Abelhas muito grandes (1.m.c. 2,7-2,9 mm, c.a.a. 7,6-8,3 mm; Tabs. III, IV). Integumento preto. Mandíbula predominantemente amarelada ou descolorida, ápice ferrugíneo, côndilos pretos. Flagelo enegrecido por inteiro ou apenas com o ápice um pouco mais claro. Estrias paroculares um pouco alargadas embaixo (ca. 1,3-1,5x o diâmetro do $2^{\circ}$ flagelômero), afilando gradualmente para cima e chegando até à altura da interorbital superior (Fig. 132). Mancha clipeal lembrando mais a forma de uma âncora do que de dois $\mathrm{L}$ contrapostos. Pilosidade predominantemente preta; nos mesepisternos, coxas, trocanteres e esternos, amarelada. Membrana das asas ferrugíneo-escura; microtríquias pretas; veias ferrugíneoescuras, exceto o pterostigma, alaranjado. Pilosidade do corpo longa, cerdas da fronte e do disco do mesoscuto ca. 1,8-2,0x o diâmetro do $2^{\circ}$ flagelômero. Cerdas ao longo de todo o lado interno do escapo, um pouco mais longas que o diâmetro deste; as da base ainda mais longas (1,3-1,8x o diâmetro do escapo; Tab. VII). Cerdas eretas das áreas paroculares, ao lado dos alvéolos, longas e robustas, mais longas que o diâmetro do escapo, muito conspícuas em relação às cerdas curtas decumbentes. Cerdas do escutelo 1,1-1,2x o comprimento deste. Uma das cerdas corbiculares situada medianamente na área corbicular. Integumento da fronte e ao redor dos ocelos com leve tesselado, opaco. Área basal do propódeo uniformemente pilosa, sem faixa glabra mediana, com pontuação pilígera fortemente marcada. Dentes da mandíbula muito espaçados, como na figura 35. Área malar muito longa (ca. 1,4-1,8x o diâmetro do $2^{\circ}$ flagelômero; Tab. V). Distância interocelar menor (ca. $0,8 \mathrm{x}$ ) que a ocelorbital (Tab. VI). Tíbia III longa, ca. 2,2-2,4x mais longa que larga (Tab. VIII). Asa anterior longa, ca. 2,8-3,0x mais longa que a largura máxima da cabeça (Tab. IX). Bifurcação da $\mathrm{M}+\mathrm{Cu}$ em relação à cu-v, variando de coincidente até nitidamente anterior. Macho, basitarso III curto e largo, fortemente intumescido; tíbia III alargada em direção ao ápice (Fig. 71); EVII com a projeção mediana curta e triangular, chanfros laterais curtos e largos (Fig. 100).

Variação. Exemplares da Costa Rica apresentam máculas mais apagadas, principalmente no clípeo ( $c f$. Pedro \& CAMARGO, 1996-1997).

Macho. Figuras 71, 100 (o macho estudado, de Guanacaste, Costa Rica, estava sem a genitália).

Material-tipo. Holótipo, operária, e alguns parátipos da mesma casta, da Costa Rica, Rio Susio, coll. H. Rogers, e Irazu (6000 e 7000 ft), depositados no AMNH e BMNH, e dois parátipos do Panamá, Chiriqui, Boquete, "March.20.1923. coll. F.M. Gaige", depositados no AMNH. Os parátipos examinados, com as seguintes etiquetas: "R. Susio ( sic = Sucio). Costa Rica. H. Rogers" e "Irazu, 6-7000 ft. H. Rogers", impressas, e ambas com etiqueta manuscrita de "PARATYPE" (em vermelho), e "Trigona (Partamona) grandipennis H.F. Schwarz".

Material examinado. COSTA RICA. Guanacaste: Monteverde Nat. Park, 17.VII.1983, D. Roubik (1 macho, STRI). Alajuela: SE slope of Volcan Poas, 6450 ft., 15.VII.1963, Michener \& Kerrfoot (8 ops., SEMC). Heredia: Vara Blanca, 10 mi. N, 1400 m, 17.IV.1965, D.H. Janzen (16 ops., SEMC; 2 ops., RPSP). Puntarenas: Las Alturas, 82 $82^{\circ} 50^{\prime} \mathrm{W}, 8^{\circ} 56^{\prime} \mathrm{N}$, 1600 m, II.1992, J. Lobo (5 ops., RPSP); Monteverde Reserve (trails near lab), 25.V.1993, C. Michalski, ex: flight intercept trap (2 ops., SEMC); ibidem, idem, 1.VI.1993 (1 op., SEMC); Monte Verde Campbell's Woods, 1520 m, 29.V.1992, M. Jameson, B. Ratcliffe (1 op., SEMC); San Vito, Estac. Biol. Las Alturas, 2000 mt., sem data, Hanson \& Godoy (1 op., RPSP). San José: Braulio Carrillo Nat. Pk., 8.XII.1981, D. Roubik (2 ops., STRI); ibidem, idem, $20 \mathrm{~km} \mathrm{N,} \mathrm{8.XII.1981} \mathrm{(4} \mathrm{ops.,} \mathrm{RPSP).}$ Cartago: Irazu, 6-7000 ft., sem data, H. Rogers (1 op., parátipo, NHMU). Prov?: R. Susio $($ sic $=$ Sucio), sem data, H. Rogers (1 op., parátipo, BMNH). PANAMÁ. Chiriqui: Boquete $5.6 \mathrm{~km} \mathrm{~N}$, La Culebra Trail, 849'23”N, 82²5'18”'W, 1450 m, 15.VI.1996, J. Ashe, R. Brooks, PAN1AB96 154 ex: misc collecting (1 op., SM0027339 KUNHM-ENT, SEMC); ibidem, $6 \mathrm{~km} \mathrm{~N}$, Cerro Pate Macho, $1000 \mathrm{~m}$, 25.IV.1981, Robt. W. Brooks (2 ops. SEMC); Cerro Colorado, $1400 \mathrm{~m}$ by road, 20.I.1988, D. W. Roubik (3 ops., STRI); Cerro Pando, 8 ${ }^{\circ} 54^{\prime} 42^{\prime \prime} \mathrm{N}, 82^{\circ} 43^{\prime} 18^{\prime \prime} \mathrm{W}$, 1850 m, 17.VI.1996, J. Ashe, R. Brooks, PAN1AB96 184 A, ex: flight intercept trap (1 op., SM0016797 KUNHM-ENT, SEMC).

Distribuição geográfica e hábitat. Matas úmidas de altitude 
nas montanhas da cordilheira central da Costa Rica e noroeste do Panamá (Schwarz, 1951; Pedro \& Camargo, 1996-1997, Fig. 160).

\section{Nidificação. Desconhecida.}

Discussão. Embora $P$. grandipennis, à primeira vista, seja bastante semelhante às espécies de Parapartamona (principalmente devido à coloração e comprimento das asas), tem todos os atributos de Partamona, como a forma da tíbia III, o padrão de venação das asas, o integumento liso e polido (o leve tesselado na fronte e área ao redor dos ocelos, em nada se assemelha a pontuação micropontilhada, opaca, de Parapartamona; outros caracteres em Moure, 1992). Por outro lado, entretanto, é a espécie mais divergente em relação às demais Partamona, considerando caracteres morfológicos ( $c f$. Pedro \& Camargo, 1996-1997; Moure, 1992), podendo ser facilmente reconhecida pela área malar e asas excepcionalmente longas, porte grande, distância interocelar menor que a ocelorbital, integumento da fronte e ao redor dos ocelos levemente tesselado, opaco, asas ferrugíneo-escuras com microtríquias enegrecidas e veias ferrugíneo-escuras, exceto o pterostigma que é alaranjado, além da pilosidade longa e relativamente abundante, e a mácula do clípeo aproximadamente em forma de âncora. Com Partamona xanthogastra, possivelmente sua espécie irmã, compartilha o padrão de coloração da asa, além de cerdas esbranquiçadas ou amareladas nos esternos, porte grande, asas e área malar longas (em $P$. xanthogastra um pouco mais curtas; Tabs. IV, V), distância interocelar menor ( $P$. grandipennis) ou igual à ocelorbital $(P$. xanthogastra; Tab. VI), cerdas longas ao longo de todo o comprimento do escapo e uma das cerdas corbiculares inseridas mais medianamente na área corbicular. Embora PEDRo \& CAmargo (1996-1997) tenham discutido a possibilidade de que $P$. grandipennis e $P$. xanthogastra pudessem constituir um clado independente, com derivação mais antiga dentro de Partamona (irmão das demais espécies), o intumescimento forte do basitarso III do macho, uma apomorfia compartilhada com P. bilineata, sugere uma história diferente (Fig. 175). Além disso, os dentes da mandíbula grandemente espaçados e no nível do bordo distal, constituem uma condição derivada, que reune $P$. grandipennis ao grupo bilineata / epiphytophila.

\section{Partamona xanthogastra Pedro \& Camargo, 1996-1997}

(Figs. 36, 131, operária; 160, distribuição; Tabs. II-IX)

Partamona xanthogastra Pedro \& Camargo, 1996-1997:199-208. Partamona aff. grandipennis; Roubik, 1992:500, 515, 516, 523. Partamona n. sp. near "grandipennis"; Roubik, 1993b:549.

Diagnose. Abelhas de porte grande (1.m.c. 2,7-3,0 mm, c.a.a. 6,6-7,4 mm; Tabs. III, IV). Cabeça e tórax pretos, abdômen amarelo-ferrugíneo. Mandíbula predominantemente amarelada, ferrugínea em direção ao ápice, côndilos e ápice ferrugíneoescuro até preto. Flagelo castanho-escuro ou enegrecido, o primeiro artículo mais claro em muitos exemplares. Estrias paroculares aproximadamente tão largas quanto o diâmetro do $2^{\circ}$ flagelômero, ou um pouco mais, com a mesma largura em toda a extensão, ou um pouco mais larga embaixo, chegando até o topo do olho, a margem interna irregularmente sinuosa (Fig. 131). Pilosidade predominantemente enegrecida; cerdas na região ventral dos mesepisternos, coxas, trocanteres e esternos, amarelo-palha ou esbranquiçada. Membrana das asas ferrugíneo escura; microtríquias enegrecidas ou fuscas; veias ferrugíneo-escuras, exceto o pterostigma, alaranjado. Cerdas ao longo de todo o lado interno do escapo longas, um pouco mais que o diâmetro do escapo, as da base ainda mais longas (1,3-1,7x; Tab. VII). Cerdas das áreas paroculares, ao lado dos alvéolos, tão longas quanto o diâmetro do escapo. Cerdas do escutelo 0,9-1,1x o comprimento deste. Área basal do propódeo uniformemente pilosa; os pontos pilígeros fortemente marcados. Uma das cerdas corbiculares situada mais medianamente na área corbicular. Dentes da mandíbula muito espaçados (Fig. 36). Distância interocelar aproximadamente tão longa quanto a ocelorbital. Área malar, tíbia III e comprimento da asa anterior, normais (Tabs. V, VI, VIII, IX). Bifurcação da $\mathrm{M}+\mathrm{Cu}$ coincidente ou anterior à cu-v.

\section{Macho. Desconhecido.}

Material-tipo. Holótipo, operária, com as seguintes etiquetas: "Colon Prov. Panamá Portobelo 15 km SW "Santa Rita Ridge"”; "18-VIII-1985 Camargo leg 851748"; "4"; "HOLOTYPE Partamona xanthogastra Camargo \& Pedro, 1995", e 11 operárias, parátipos, da mesma localidade, nos. 851746, 851748-B, 851749, 851750, 851751, 851752, 851753, depositados na RPSP. Outros parátipos: 3 operárias de "PANAMÁ: Colon Prov., Santa Rita Ridge - 12 km SW Portobelo, 20 Aug 1985, D. Roubik coll" (STRI); 1 operária de "PANAMÁ: Colon Prov. $30 \mathrm{~km}$ SE. Colon (Santa Rita Ridge) 20- -1983, Doug Yanega', e etiqueta adicional manuscrita, "Santa Rita Pan., 20 Jan. 1983 D. Yanega G", Partamona n. sp. aff. grandipennis Det. D. Roubik, 1991 (SEMC);

Material examinado. PANAMÁ. Veraguas: Puerto Pilon, 15.IV.1983, D. Roubik, 87 (2 ops., STRI); ibidem, idem, 24 km NE S.R., 20.I.1983, 77 (3 ops., RPSP). Panamá: Chepo, 23 km E. Carti Rd. 10.VI.1982, D. Roubik, 50 (3 ops., STRI); ibidem, idem, E Carti, 1.X.1980, 34 (1 op., STRI; 5 ops., RPSP); E. Cerro Jefe, 27.III.1982, D. Roubik, 1 (1 op., STRI).

Distribuição geográfica e hábitat. Florestas tropicais do Panamá Central (Fig. 160; RouBIK, 1992, = P. aff. grandipennis; Pedro \& Camargo, 1996-1997).

Nidificação. Ninhos em emaranhado de raízes, sob epífitas (RouBIK, 1992)

Discussão. Uma característica notável em xanthogastra é o padrão bicolor do integumento, enegrecido na cabeça e tórax e amarelo-ferrugíneo no abdômen, só observado nesta espécie. É, possivelmente, uma espécie relacionada a grandipennis, também das regiões altas do Panamá e Costa Rica. Apresenta diversos caracteres distintivos, principalmente a cor das asas, distância interocelar aproximadamente igual a ocelorbital, e dentes da mandíbula muito espaçados (veja PEDRo \& CAMARGO, 1996-1997 e comentários sobre P. grandipennis). 
Partamona peckolti (Friese, 1901)

(Figs. 39, 130, operária; 73, 74, 103, macho; 162, distribuição; Tabs. II-IX)

Trigona peckolti Friese, 1901:265.2, 266.

?Trigona rhumbleri Friese, 1900:389.38 (partim, Colômbia).

Trigona cupira; Cockerell, 1920: 464 (partim, Panamá); 1928:171; Rau, 1933i:17-29; Michener, 1954:170; Roubik, 1982:358; Roubik \& Wheeler, 1982:127, 134; Nates-Parra, 1983:155.

Trigona mulata; Roubik, 1983:352.

Trigona cupira peckolti; Marianno, 1911:90.13-A (cit. partim).

Trigona aff. cupira; Roubik, 1990:663; 1992:500, 511, 512, 523; Sakagami, et al., 1993:262.

Trigona testacea cupira; Schwarz, 1932b:552; 1934:18; 1939b:89, 90; Michener, 1946:190.

Trigona (Partamona) cupira; Roubik \& Wheeler, 1982:131.

Trigona (Partamona) gr. cupira; Nates-Parra, 1983:155, 156; NatesParra \& Cepeda, 1983:69, 71, 72, 74

Trigona (Partamona) aff. cupira; Roubik, 1983:327, 329, 330, 331, 335, 339, 342, 345, 346, 348, 349, 350, 353.

Trigona (Partamona) peckolti; Nates-Parra, 1983:157.

Trigona (Partamona) testacea peckolti; Schwarz, 1948:437.

Trigona (Partamona) testacea cupira; Schwarz, 1948:19, 39, 102.

Trigona (Partamona) grupo cupira; Parra, 1988-1990:80-83, 88-90, 94, 97, 101, 108.

?Trigona (Partamona) sp.; Nates-Parra, 1983:155, 157.

Melipona pallida subsp. ? peckolti; Ducke, 1916:121.41.c; 1925:412.42b (partim).

Partamona peckolti; Michener, 1990:115; Camargo, 1992:81; Coloma, 1986:27, 31, 73, 107, 126, 132, 136, 137, 140.

Partamona peckolti peckolti; Roubik, 1992:500, 511, 512, 523.

Partamona near cupira; ?Michener, 1990:95, 100, 102, 105, 111, 115, 146; ?Michener \& Roubik, 1993:256, 257; Roubik, 1993a:665.

Partamona n. sp. near "cupira"; Roubik, 1993b:549.

Partamona sp. (grupo cupira); Coloma, 1986:107, 132, 136, 137.

Partamona gr. cupira; Cepeda, 1996:7.

Partamona aff. cupira; Roubik, et al., 1995:199, 206.

Partamona (Partamona) sp. gr. cupira; Villa \& Vergara, 1982:149, 153, 154, 156, 158.

Partamona (Partamona) peckolti peckolti; Camargo, 1980:9, 23, 5764, 74, 75, 77, 143, 162, 163, 164, 173-175.

Partamona (Partamona) sp.; Villa \& Vergara, 1982:149, 156, 158.

Diagnose. Abelhas de porte médio a pequeno (1.m.c. 2,3-2,5 $\mathrm{mm}$, c.a.a. 5,5-6,3 mm; Tabs. III, IV). Integumento preto, mesclado com castanho claro, ou todo amarelo; sutura epistomal, basitarso e tíbia III (por inteiro, ou a metade apical nos indivíduos amarelos), enegrecidos. Mandíbula com 1/3-1/2 basal amarelado e a porção distal castanho-ferrugínea, ápice ferrugíneo-escuro, côndilos ferrugíneos até pretos. Flagelo castanho escuro ou claro. Estrias paroculares estreitas $(0,6-$ $0,8 x$ o diâmetro do $2^{\circ}$ flagelômero), um pouco alargadas embaixo (ca. 1,0-1,2x o diâmetro do $2^{\circ}$ flagelômero), ou aproximadamente com a mesma largura em toda a extensão $(1,0-1,2 x)$, chegando até a interorbital superior (Fig. 130). Pilosidade preta; cerdas eretas dos mesepisternos, coxas e trocanteres, enegrecidas ou esbranquiçadas. Membrana das asas levemente ferrugínea; microtríquias pretas em toda asa ou amareladas apenas no pterostigma e áreas adjacentes; veias méleas, escurecidas pelas microtríquias fuscas. Cerdas da base do escapo muito mais longas que o diâmetro deste (1,7-2,2x, Tab. VII). Cerdas eretas das áreas paroculares, ao lado dos alvéolos, muito longas e robustas, mais longas que o diâmetro do escapo, bem destacadas em relação à pilosidade decumbente. Cerdas do escutelo $0,8-1,0 x$ o comprimento deste. Dentes da mandíbula espaçados como na figura 39. Área malar, distância interocelar, distância ocelorbital, tíbia III, comprimento da asa anterior, normais (Tabs. V, VI, VIII, IX). Bifurcação da M+Cu geralmente coincidente com a cu-v (raramente levemente anterior). Macho, basitarso III alongado, um pouco intumescido; tíbia III alargada em direção ao ápice (Figs. 73, 74); EVII com a projeção mediana curta, de lados aproximadamente subparalelos, chanfros laterais profundos e estreitos (Fig. 103).

Variação. Alguns indivíduos de Manabí, Cotopaxi e Esmeraldas (Equador), apresentam asas mais claras (membrana amarelada na metade basal da asa, veias uniformemente méleoclaras, inclusive $\mathrm{C}$ e $\mathrm{R}$, e as microtríquias na metade basal da asa amarelo-ferrugíneas), máculas da face amarelo-vivas; estrias paroculares um pouco alargadas (embaixo ca. $2 \mathrm{x} \mathrm{o}$ diâmetro do $2^{\circ}$ flagelômero, acima pouco mais que 1 diâmetro), flagelo castanho-amarelado, pêlos ventrais do tórax e abdômen amarelados. No material de Paratebueno, Cundinamarca (Colômbia), a cor das máculas também é amarelo-viva e o flagelo castanho-amarelado, porém as estrias paroculares são mais estreitas, as asas apenas com microtríquias fuscas, $\mathrm{C}$ e $\mathrm{R}$ escurecidas e pterostigma mais claro, como nas demais $P$. peckolti. Nestes exemplares, as cerdas da base do escapo são mais curtas (1,1-1,3x o diâmetro do escapo) que nas P. peckolti em geral, e podem constituir uma espécie distinta.

Quanto à cor geral do integumento, no Panamá e Venezuela predominam indivíduos pretos, mas foram examinados alguns exemplares de Coclé, San Blás, Colón (Panamá), e da parte oeste da Venezuela, acompanhando a Cordilheira de Mérida (Trujillo, Caracas, Mérida, Lara e Táchira), com integumento mesclado ou castanho escuro. Nas encostas ocidentais dos Andes, principalmente no Equador, predominam populações com integumento claro, embora também apareçam exemplares enegrecidos. Em um ninho estudado por um de nós (J.M.F. Camargo), em Sta. Rosa, Pichincha, $2450 \mathrm{~m}$., foram observados apenas exemplares pretos. Em amostras de ninhos coletados em Fredônia, Antióquia, Colômbia, aparecem desde indivíduos mesclados até pretos (ninhos no. 083 e 130), ou só pretos (no. 93, 95, 132). Em ninhos coletados em Bolívar, Antióquia (nos. 74-A e 74-B) a maioria dos indivíduos são pretos, mas alguns apresentam áreas mais claras na fronte e mesepisternos. Já na amostra do ninho 013, coletado em Venecia, Antióquia, predominam exemplares mesclados (apenas 1 enegrecido).

\section{Macho. Figuras 73, 74, 103.}

Material-tipo. Fazem parte da série tipo, seis operárias da Colômbia, Popayan, e uma do Equador, no ZMHB e AMNH. Duas operárias de Popayan (ZMHB e MZSP) e uma do Equador (AMNH), provavelmente síntipos, foram examinadas, conforme consta na lista abaixo.

Material examinado. PAÍS ?.Sn. Vicente, 5.XII.1972, O. Mero, cítricos (1 op., USNM); Colômbia ?, México ?: Cordova, t.c., 18.306, etqs. adicionais de Friese, "Tr. pallida v. nigrita 1904 Friese det. Fr.", e de Ducke "Trigona pallida Latr. subsp. nigrita Fr. Cordova (Mexico) Ducke rev. 13"(veja discussão); Colômbia ?, Equador ?. San Bartolo, Andes, 22.VI.1930, C.H. Ballow, 57 (9 ops. montadas em alfinetes, 18 ops. em 
cápsula de gelatina, USNM). PANAMÁ. Herrera: Las Minas, $15 \mathrm{~km} \mathrm{SW}$ Cerro Alto Higo, 20.V.1987, D. Roubik (2 ops., STRI). Colón: Colón, 9.IX.1979, D. Roubik, 16 (1 op., STRI); ibidem, Coco Solo, 19.II.1980, D. Roubik, 11 (1 op., 2 machos, STRI; 2 ops., 3 machos, RPSP); Curiche, Choco Colón, VIII-IX.1967, G.B. Fairchild, ex: malaise trap (5 ops., MSUC; 1 op., RPSP); Parque Nac. Soberania, Pipeline Rd. km 6.1, 0907'N, 7945'W, 40 m, 4-7.VI.1995, J. Ashe, R. Brooks, 138 ex: flight intercept trap (2 ops., SM0057343, SM0057344 KUNHM-ENT, SEMC); ibidem, idem, 7-21.VI.1995, ex: flight intercept trap, 265 (4 ops., SM0057338, SM0057339, SM0057341, SM0057348 KUNHMENT, SEMC); ibidem, Pipeline Road, km 6 N Gamboa, 26.VIII.1982, D. Roubik, 124 (1 op., STRI; 2 ops., RPSP); ibidem, idem, km 1 N Gamboa, IV.1982 (1 op., 3 machos, STRI), 21.V.1981, 106 (1 op., RPSP); ibidem, Pipeline Road, km 8, 10.III-15.IV.1991, T. Touré, on carrion (1 op., STRI); Portobelo, 15.IX.1979, D. Roubik, 23 (2 ops., STRI); ibidem, idem, 15.IX.1979, 18 (1 op., STRI; 2 ops., RPSP); ibidem, $15 \mathrm{~km} \mathrm{SW,}$ "Santa Rita Ridge", 18.VIII.1985, Camargo (216 ops., 1 macho, RPSP); Teresita, Choco Colón, VIII-IX.1967, G.B. Fairchild, ex: malaise trap (33 ops., MSUC; 2 ops., RPSP). Coclé: El Copé, 31.I.1981, David W. Inoue ( 2 ops., STRI); ibidem, $7.2 \mathrm{~km} \mathrm{NE}, 08^{\circ} 37^{\prime} \mathrm{N}, 80^{\circ} 35^{\prime} \mathrm{W}, 730 \mathrm{~m}$, 20.V-7.VI.1995, J. Ashe, R. Brooks, flt. intercept trap, 140 (1 op., SM 0057347 KUNHM-ENT, SEMC); El Vale de Anton, 2500 ft., 5.VI.1945, C.D. Michener (1 op., AMNH); ibidem, idem, 1.IV.1945, "white hair on abdomen" (1 op., AMNH; 1 op., RPSP). Panamá: Ancon, IV.1911, Kraft, "arc-light globe" (1 op., USNM); ibidem, 21.III.1929, James Zetek, Z-3166 (2 ops., USNM); ibidem, Ancon Hill, Canal Zone, 20.XII.1944, C.D. Michener (1 op., AMNH), ibidem, idem, 6.I.1945, (2 ops., AMNH); ibidem, X.1946, N.L.H. Kraus (1 op., RPSP); Balboa, CZ, 26.III.1923, Implaris (1 op., USNM); ibidem, via Mexico VII.1944, Hughes - 400, Plane - NC19910, Lot No. 44-19336, 400 (1 op., USNM); ibidem, 8.XI.1914, T. Hallinan (1 macho, AMNH); Barro Colorado Island, 21.XII.1928, CH Curran, "PARATYPE", "Trigona testacea var. centralis H.F. Schwarz" (1 op., STRI); ibidem, 28.I.1983, Doug Yanega (2 ops., SEMC); ibidem, 18.III.1969, R.E. Munroe (1 op., USNM); ibidem, 31.V.1939, W. Kemp (2 ops., USNM); ibidem, 18.X.1935, Zetek, in celotex ceiling, 3585 (19 ops., USNM); ibidem, idem, VI.1937, fruit fly trap, 3894 (1 op., USNM), 14.VI.1939, 4453, Lot No. 39-12571 (3 ops., 4 machos, USNM), VI.1939, 4497, Lot No. 39-15883 (2 ops., USNM), IV.1940, 4647, Lot No. 40-8104 (2 machos, USNM), V.1923, 24-40, No. 4656, Lot No. 40-14769 (1 macho, USNM), VI.1940, No. 4669, Lot No. 40-22219 (1 op., USNM), 2.VII.1941, at light, 16982, 4828 ( 1 macho, USNM); ibidem, W. Callee, 964 ( 1 op., USNM); ibidem, 25.II.1947, Snyder, "Z.M.A. house, nest on roof" (9 ops., USNM); ibidem, 15.VIII-26.IX.1928, Phil Rau, 7070 (1 op., USNM); ibidem, idem, 7238 (1 op., USNM), 7240 (1 op., 4 machos, USNM), 7327 (4 ops., USNM), 7358 (1 op., USNM), 7518 (2 ops., USNM), 7556 (1 op., USNM), 7586 (1 ор., USNM), 7656 ( 1 op., USNM), 7664 ( 1 op., USNM), 7667 (1 op., USNM), 7721 ( 2 ops., USNM), 7796 (1 op., USNM), 7825 (1 op., USNM), 7954 (2 ops., USNM); ibidem, 22.III.1930, anônimo, 3, F 330322 Li, (1 op., STRI); ibidem, 3.IV.1978, Silberglied, Aiello, at light (1 macho, USNM); ibidem, idem, 18.V.1978, "at fruit in monkey cage" (6 ops., USNM), 12.VI.1978, malaise trap (1 op., USNM), 17.VI. 1978 (2 ops., USNM), 22.VI.1978 (1 op., USNM), 28.VI.1978 (2 ops., USNM); ibidem, 23.VI.1948, J.E. Graf (2 ops., USNM); ibidem, 2528.III.1965, SS \& WD Duckworth (1 op., USNM); ibidem, idem, 1828.IV.1964, (1 op., USNM), 1-9.V.1964 (2 ops., 1 macho, USNM); ibidem, 17-21.II.1963, Blake \& Cochran (1 macho, USNM); ibidem, 22.III.1933, anônimo, F 330322Li, (1 op., AMNH); ibidem, $09^{\circ} 11^{\prime} \mathrm{N}$, 79 51'W, 8.VII.1994, D. Banks, ex: flight intercept trap (01 op. SEMC); ibidem, 23.VIII.1985, Camargo (24 ops., 851885-897; RPSP); ibidem, 12.VI.1956, Carl W. \& E. Rettenmeyer, 1957 (2 ops., RPSP); Canal Zone, VIII.1907, Aug. Busck, in raisins (1 op., USNM); ibidem, $3.2 \mathrm{~km}$ N of Cocoli, 31.X.1966, M.G. Naumann (4 ops., SEMC); Cano Saddle, Gatun Lake, 2.V.1923, R.C. Shannon, (68 ops., USNM; 2 ops., RPSP); Capira, Cerro Campana, 14.I.1983, D. Roubik, 38 (1 op., STRI; 1 op., RPSP); ibidem, idem, 11.VII.1982, 39 (3 ops., STRI), $12 \mathrm{~km} \mathrm{SW,}$ 19.VII.1981, 27 (2 ops., STRI), 5.XI.1980, 16 (1 op., RPSP), 12.VIII.1980, 4 (1 op., RPSP); Cerro Campana, 23.VIII.1975, G.W. Otis (4 ops., SEMC); ibidem, 8.I.1981, C.D. Michener (4 ops., SEMC); ibidem, 8 km NW Capira, 1000 m, 7.V.1981, R.W. Brooks, on Clethra lanata (7 ops., SEMC); Cerro Cobre, 14-26.III.1980, B. Smith (4 ops., SEMC); Chagres River, 14.VII.1918, H.F. Dietz \& J. Zetek, "limon plantation, RP G115, sweepings around cornfield", 14 (1 op., USNM); Chepo, 7.VII.1979, D. Roubik, 2 (1 op., STRI); Culebra - Arrijan Trail, 29.XI.1914, anônimo, 19433 (1 op., AMNH); Curundu, Canal Zone, 19.II.1983, D. Yanega (1 op., SEMC); ibidem, $20 \mathrm{~km} \mathrm{~N}$, 4.IV.1981, Robert W. Brooks (2 ops., SEMC); ibidem, idem, $5 \mathrm{~km} \mathrm{~N}$, 5.IV.1981, on Cassia (1 op., SEMC); Farfan, 28.II.1915, T. Hallinan, 19434 (2 machos, AMNH; 2 machos, RPSP); ibidem, idem, 25.II.1915, In.... (ilegível), "PARATYPE", "Trigona (Partamona) testacea var. centralis H.F. Schwarz" (1 op., RPSP), 24.X.1915, "PARATYPE", “Trigona (Partamona) testacea var. centralis H.F. Schwarz" (1 op., RPSP); ibidem, Farfan Rd. (C.Z.), 10 m, 5.I.1981, C.D. Michener (3 ops., SEMC); Fort San Lorenzo, Canal Zone, 8.III.1923, Zetek and Wheeler, 1878 (20 ops., USNM); Fort Sherman, 2 km E, 30.I.1980, Brian H. Smith (1 op., SEMC); Frijoles, 23.X.1918, Dietz and Zetek, G291 (1 op., USNM); ibidem, sem data, anônimo, Fs 011095, (1 op., AMNH); Gallegas Is., 20.V-11.VI.1981, B. Gill (8 ops., SEMC; 1 op., RPSP); Gamboa (C.Z.), 16.II.1983, Doug Yanega (1 op., SEMC); ibidem, idem, (km 10 Pipeline Road), 16.II.1983 (1 op., SEMC); ibidem,10.V.1972, R \& E Froeschner (6 ops., USNM); ibidem, Pipeline Rd., VII.1967, W.W. Wirth, malaise trap (1 op., USNM); ibidem, VII.1967, F.S. Blanton (2 ops., 1 macho, USNM); ibidem, $3 \mathrm{~km} \mathrm{~N}$, Pipeline Rd., I.1980, D. Roubik (2 machos, STRI); ibidem, $8 \mathrm{~km} \mathrm{NW,} \mathrm{Pipeline} \mathrm{Rd.,} \mathrm{12.I.1981,} \mathrm{C.D.} \mathrm{Michener} \mathrm{(4}$ ops., SEMC); ibidem, idem, 10 km NW Gamboa, 4.I.1981 (1 op., SEMC); ibidem, $6.9 \mathrm{~km} \mathrm{~S}$, Old Plantation Rd., 0905'N, 790 $40^{\prime} \mathrm{W}, 80 \mathrm{~m}, 7$ 22.VI.1995, J. Ashe, R. Brooks, flight intercept trap, 266 (1 op., SM005734 KUNHM-ENT, SEMC); ibidem, $12.8 \mathrm{~km} \mathrm{~N}, 18-29 . I I .1980$, Brian H Smith (2 machos, SEMC); ibidem, Pipeline Rd nr. Gamboa, C.Z., 16-18.V.1981, Robert W. Brooks (1 op., SEMC); Juan Mina,13.VII.1918, H.F. Dietz \& J. Zetek, "citrus plantation, on cowpeas", G90 (7 ops., USNM); ibidem, idem, 13.VII.1918, "swep from grass \& cowpeas", G 88 (1 op., USNM); ibidem, 24.VI.1945, C.D. Michener (1 op., AMNH); ibidem, idem, 9.VII.1945 (1 op., AMNH); ibidem, upper Chagres R., 30.I.1945 (2 ops., RPSP); La Campana, IX.1937, Jas Zetek, fruit fly trap, No. 3973, Lot No. 38-16492 (3 ops., USNM); Laguna, 25 mi NW Chame, 2600 ft., 29.IV.1945, C.D. Michener (2 ops., AMNH); Old Panamá, 14.III.1945, C.D. Michener (1 op., AMNH); ibidem, idem, 19.IV.1945 (1 op., AMNH), 30.XII.1945 (1 op., AMNH); Panamá City (Ancon Hill), 19.II.1983, Doug Yanega, 2-19 A (1 op., SEMC); ibidem, idem, 17.I.1983, 1.17 A (2 ops., SEMC); ibidem, II-III.1915, anônimo, "T. cupira Sm. Det. Schwarz", "HOMOTYPE" (2 ops., AMNH); ibidem, Davis (2 ops., 24507, AMNH); ibidem, 10.V.1945, C.D. Michener, "Trigona (Partamona) testacea var.", "Black hairs on abdomen" (1 op., AMNH); Porto Bello trail, sem data, A H Jennings (1 macho, USNM); Soberania Natl. Park, Pipeline Rd., km 8, 10.III-15.IV.1991, T. Touré, on carrion, (1 op., STRI); Summit, 1.V.1972, R \& E Froeschner (1 op., USNM); ibidem, Navy base, 10.IX.1974, D. Roubik, 13 (1 op., RPSP); Taboga Island, 19.VIII.1985, Camargo (13 ops., 851840-852, RPSP). San Blás: Kuna Yala, Carti - 8 km S, 15.VIII.1985, D. Roubik, honey H2O (3 ops., STRI); ibidem, Res. Indígena Kuna, 78³0’W, 9²0’N, 14 18.VIII.1985, Camargo (39 ops., 850960-984, RPSP); Pto. Obaldia beach, 11.X.1979, D. Roubik, 1 (2 ops., RPSP); ibidem, 5-10.X.1979, D. Roubik, 5 ( 2 ops., STRI). Darién: Cana Biological Station, $7^{\circ} 45^{\prime} 18^{\prime \prime} \mathrm{N}$, 77041'6”W, 530 m, 10.VI.1996, A. Gillogly PAN1AB96 (1 op.,

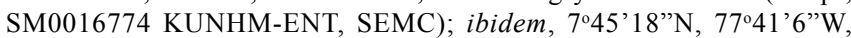
500-550 m, 4.VI.1996, J. Ashe, R. Brooks PAN1AB96 016 (1 op.,

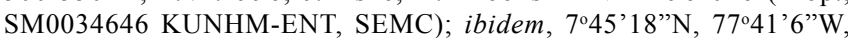
500-550 m, 03.VI.1996; J. Ashe, R. Brooks PAN1AB96 015, ex: Ludwigia (8 ops., SM0034610, SM004614, SM0034615, SM0034616, SM0034619, SM0034621, SM0034624 KUNHM-ENT; 1 ор.,

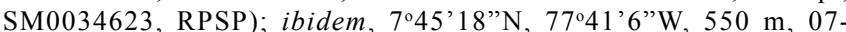
09.VI.1996, J. Ashe, R. Brooks, PAN1AB96 114 ex: flight intercept trap (1 op., SM0011438 KUNHM-ENT, SEMC); ibidem, 745'18”N, 77041'6”W, 600 m, 03-07.VI.1996; J. Ashe, R. Brooks PAN1AB96 067, ex: flight intercept trap (1 op., SM0011452 KUNHM-ENT, SEMC);

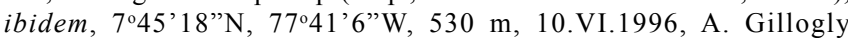
PAN1AB96 (1 op., SM0016773, SEMC); ibidem, Serranía de Pirre, 745'18”N, 7741'6”'W, 1380 m, 07-09.VI.1996, J. Ashe, R. Brooks, PAN1AB96 111 ex: flight intercept trap (5 ops., SM0011453, 
SM0011454, SM0011455, SM0011457, SM0011458 KUNHM-ENT,

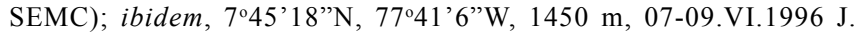
Ashe, R. Brooks, PAN1AB96 112, ex: flight intercept trap (1 op.,

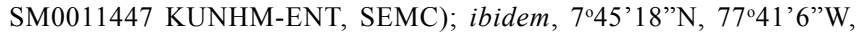
1200 m, 07-09.VI.1996; J. Ashe, R. Brooks, PAN1AB96 109, ex: flight intercept trap (1 op., SM0011434 KUNHM-ENT, SEMC); Canglón, 4.XI.1982, D. Roubik (3 ops., RPSP); ibidem, idem, $2 \mathrm{~km} \mathrm{~W}$, 15.V.198(?),12 (2 ops., RPSP); Prov.?: Cabima, 25.V.1911 August Busck (1 macho, USNM); Red Tank, 14.IV.1923, RC Shannon (1 op., USNM); Rio Corona, 3.V.1952, Carl W. Rettenmeyer, 502 (1 op., SEMC; 2 ops., AMNH); Sabanas, 20.IV.1923, RC Shannon (34 ops., USNM; 2 ops., RPSP). COLÔMBIA. Magdalena: Vista Nieve, Santa Marta, $5000 \mathrm{ft}$., 10.II.1927, G. Salt, on Eucalyptus (1 op., 1931-343, BMNH); ibidem, idem, at sap of Eucalyptus (1 op. AMNH). Antioquia: Bolivar, 24.VI.1986, J. Rincon, 74-A, 74-B (61 ops., nos. 910419-910442, RPSP); Fredonia, 18.III.1986, J. Rincon, 083 (30 ops., nos. 910223242, RPSP); ibidem, idem, 093, 095, 132130 (89 ops., nos., 910121146, 910243-910264, 910348-358, RPSP); Guarne, 2000 m, 3.X.1976, C.D. Michener (12 ops., SEMC; 2 ops., RPSP); La Estrela, II.1959, J. Förster (1 op., DZUP); Medellin, sem data, Gallego M. Noll, wild beehive in tree, 93 (2 ops., 148760, USNM); At Medellin, sem data, R.A. Toro, 75 (1 op., USNM); Mt. range bet. Bolivar \& Carmen, III.1929, W.A. Archer, Colombia SA'31, Lot no. 7896, I.6 (1 op., USNM); Queb. Potreros W La Fe, 26.II.1984, C.M \& O. S. Flint Jr. (3 ops., USNM); Redondo, XII.1956, J. Förster (20 ops., DZUP; 6 ops., RPSP); San Luís Medellin, 05.V.1990, J. Rincon (4 ops., 910100-910103, RPSP); Venecia, 18.III.1986, J. Rincon, 013 (16 ops., nos., 910185-194, RPSP); Rio Negro, 3.X.1976, C.D. Michener (6 ops., 2 machos, SEMC; 1 op., RPSP); Rio Porce, 1000 m, 2.X.1976, C.D. Michener (14 ops., SEMC; 2 ops., RPSP). Risaralda: Pereira, Parque Regional Natural Ucumarí, 18002000m, III.1991, L. Schneider (2 ops., 190122, SEMC); ibidem, idem, 1800m, X.1990 (1 op., L 90043, SEMC). Cundinamarca: Anolaima, 10.IX.1965, J.A. Ramos (1 op., USNM); ibidem, Anoloema (sic), San Isidro, 1950m, sem data, D. Roubik (3 ops., STRI); ibidem, idem, 1900 m, 28.VI.1985 (4 ops., RPSP); Arbelaéz, 21.VIII.1976, Guiomar (10 ops., RPSP); Bogotá, 31.XII.1972, G. Nates-Parra (5 ops., RPSP); Guayabetal, 10.V.1946, E.A. Chapin Sta. 46-7 (1 op., USNM); Paratebueno, $73^{\circ} 15^{\prime} 09 \mathrm{~W}$ ", 4²6'12"N, 20-24.IX.1977, G.N. Parra (4 ops., RPSP); Rio Negro below Pacho, sem data, Chapin, 664, (1 op., USNM); Sasaima, 800 m, 29.XII.1973, G. Parra (1 op., RPSP); Ubalá, 8.V.1977, G.N. Parra (2 ops., RPSP); ibidem, idem (F-2), 8.XI.1975 (2 ops., RPSP); Villeta, 28.VIII.1965, J.A. Ramos (2 ops., 3 machos, USNM). Valle: Anchicaya, 27.VII.1970, J. Campbell (1 op., SEMC); ibidem, 400m, 10.II.1977, M.D. Breed \& C.D. Michener (1 op., SEMC); Bajo Calima, 3 km NE, 24.VII.1980, D. Roubik, 5 (2 ops., STRI); Cali, 16.IX.1976, Bell, Breed \& C.D. Michener (2 ops., 2 machos, SEMC); ibidem, idem, 17.IX.1976 (2 ops., 1 macho, SEMC); ibidem, 1000m, 16.II.1977, M.D. Breed \& C.D. Michener (10 ops., SEMC; 2 ops., RPSP); ibidem, W of Cali, 1600m, 30.X.1976, Bell, Breed \& C.D. Michener (1 op., SEMC); ibidem, nr. Cali in mtas (?), 26.VIII.1969, D.H. Messersmith (1 op., USNM); ibidem, $10 \mathrm{~km} \mathrm{SW}$ of Cali, $1500 \mathrm{~m}, 16 . I I .1977, \mathrm{M}$. Breed, C.D. Michener (1 op., SEMC); ibidem, summit W of Cali, 2.II.1977, 2000m, M. Breed, C.D. Michener (42 ops., SEMC; 3 ops., RPSP); ibidem, idem, 17.IX.1976 (48 ops., SEMC; 3 ops., RPSP), 20.IX.1976 (6 ops., SEMC), 6.II.1977 (4 ops., SEMC); ibidem, 18.IX.1976, Bell, Breed \& Michener (1 op., SEMC); ibidem, idem, 2000m, 31.I1977 (1 op., SEMC); ibidem, 2000m, 30.III.1977, Lucy de Cuadros (2 ops., SEMC); ibidem, Cali District, Western Cordillera, 4,500 ft., 20.V.1935, Herbert F. Schwarz (2 ops., AMNH); ibidem, idem, 5,500 ft., 29.II.1935 (1 op., AMNH), 4900 ft., 27.I.1935 (1 op., RPSP); ibidem, 27.I.1935, Severo Quintero (1 op., AMNH); ibidem, Cauca Valley, 3260 ft., 11.II.1935, Herbert F. Schwarz (1 op., AMNH), ibidem, idem, 4.II.1935 (1 op., AMNH); Costa Rica, Valle del Cauca, 29.IV.1973, Jesus A. Reys ( 2 ops., nos. 23 e 26, USNM); El Carmen, 1370m, 22.IX.1976, Bell, Breed \& Michener (4 ops., SEMC); ibidem, El Carmen road W of Cali, 1900m, 5.II.1977, M.D. Breed \& C.D. Michener (1 op., SEMC); Hacienda Garcia, Cauca Valley, 30.I.1935, Herbert F. Schwarz (1 op., AMNH); ibidem, idem, 29.I.1935 (1 op., AMNH); Jamundi, 1000m, 14.II.1977, M.D. Breed \& C.D. Michener (1 op., SEMC); Lago Calima, $1500 \mathrm{~m}, 23 . I X .1976$, Bell, Breed \& Michener (2 ops., SEMC);
Loboguerrera, 740m, 25.IX.1976, Bell, Breed \& Michener (16 ops., 1 macho, SEMC; 2 ops., RPSP); ibidem, idem, 23.IX.1976 (1 op., SEMC); ibidem, near Loboguerrera, 6.X1976, Michael Breed (1 op., SEMC); ibidem, entre Loboguerrera y Dagua, 800m, 19.IX.1971, anônimo (1 op., SEMC); Old Buenaventura road, km 33, 1300m, 27.IX.1976, Bell, Breed \& Michener (23 ops., SEMC; 2 ops., RPSP); Pichinde, $1630 \mathrm{~m}$, 21.IX.1976, Bell, Breed, Michener (93 ops., SEMC; 4 ops., RPSP); ibidem, near Pichinde, 1900m, 3.II.1977, M.D. Breed \& C.D. Michener (10 ops., SEMC; 2 ops., RPSP); Queremal and Buenaventura bet. (between?), 3500-4000 ft., 3.II.1935, James Aranibar (2 ops., AMNH); ibidem, 3.II.1935, Herbert F. Schwarz (3 ops., AMNH; 1 op., RPSP); ibidem, idem, 12.II.1935 (2 ops., AMNH), 17.II.1935 (1 op., AMNH); ibidem, 17.II.1935, E.I. Huntington (2 ops., AMNH); Rio Anchicaya, 400m, 28.IX.1976, Bell, Breed \& Michener (4 ops., SEMC). Tolima: Melgar, 300m, 27.VII.1973, G. Parra (22 ops., RPSP). Meta: Guayahetal - E.1, 8.XI.1975, G. Nates (6 ops., RPSP); ibidem, idem, "ninho em parede", F.2 (2 ops., RPSP); Villavicencio, 1.XI.1965, J.A. Ramos (1 macho, USNM). Cauca: Popayan, 1900, Lehmann, "Trigona peckolti Fr. 1900 Friese det.", "Type" (1 op., ZMHB); ibidem, idem, "Trigona peckolti Fr. 1900 Friese det.", "Trigona pallida Latr. subsp. peckolti Fr., Columbia, Ducke rev. 13" (1 op., MZSP); ibidem, idem, 10-4 1900 ... (trecho ilegível), "TYPUS", "Trigona peckolti Friese det. Fr. 25" (1 op., AMNH); ibidem, alt. 7000-7800, 14.II.1935, Herbert F. Schwarz (2 ops., AMNH); ibidem, 7000-7800, 14.II.1835, E.I. Huntington (1 op., RPSP); ibidem, idem, alt. 6800, 15.II.1935 (2 ops., AMNH; 1 op., RPSP). Huila: San Augustin, 1760m, 10.VIII.1971, anônimo (1 op., SEMC); ibidem, 1.IX.1969, D.H. Messersmith (1 op., USNM). Depto. ?. Cincinnati, II.1924, H W Atkinson (1 op., USNM); S. Antonio, 17.IX.1900, anônimo, "Trigona alfkeni Friese det. 25" (1 op., AMNH). VENEZUELA. Lara: Sanaré, $16.1 \mathrm{~km}$ SE Yacambú N.P., 942'0”N, 69³5'6"W, 1450m, 2.VI.1998, J. Ashe, R. Brooks, R. Hanley, VEN1ABH98 178 (4 ops., SM0121847, 0121925, 0121927, 0122059, SEMC; 1 op., 0121928, RPSP). Aragua: Maracay, $24 \mathrm{~km} \mathrm{N,} 5000 \mathrm{ft}$., 23.I.1978, J.B. Heppner, cloud forest (3 ops., USNM); Ocumare DeLa Costa, 2 km N, 21-22.VI.1976, A.S. Menke \& D. Vincent (1 macho, USNM); Rancho Grande, 1100m, 27.XI.1967, G.I. Stage (12 ops., USNM; 2 ops., RPSP); ibidem, idem, nr. Rancho Grande, 900m, 26.XI.1967 (2 ops., USNM); ibidem, 11.I.1966, anônimo (1 op., USNM); ibidem, $1100 \mathrm{~m}, 22-23 . I .1978$, J.B. Heppner, blacklight cloud forest (1 macho, USNM); ibidem, nr. Maracay, 7.V.1946, gift of New York Zoo. Soc. Dept. Tropical Research William Beebe, Dir. (1 op., AMNH; 1 op., RPSP); ibidem, Rancho Grande Biol. Stn. Portachuelo Pass, $10^{\circ} 21^{\prime} \mathrm{N}$, 67041'W, 27.II.1995, 1150m, R. Brooks (3 ops., SEMC); ibidem, 1100m, 14.V.1998, J. Ashe, R. Brooks, R. Hanley, VEN1ABH98 033, ex: flight intercept trap (1 macho, SM0333499, SEMC); ibidem, idem, 1300m, 14.V-2.VI.1998, VEN1ABH98 184, ex: malaise trap (4 machos, SM0333558-561, 1 op., 0333557, SEMC; 1 macho, SM0333563, RPSP), 4.VI.1998, VEN1ABH98 186, ex: "insects moving thru pass against wind-migration" (41 ops., 1 macho, SM0333853, 03338555, 0333857$858,0333860-868,0333870-873,0333875-883,0333885-896$, 0333898-902, SEMC; 5 operárias, SM0333854, 0333856, 0333859, 0333884, 0333897, 1 macho, SM0333869, RPSP). Distrito Federal: Caracas Botanical Gardens, VII.1921, anônimo (1 op., SEMC); Puerto La Cruz, 1.VIII.1928, E. Holt (2 ops., Ac. 8497, CMNH); ibidem, idem, 10.XII.1928 (1 op., CMNH), 15.VIII.1928 (1 op., CMNH). Trujillo: San Pablo de Mendoza, 19.XI.1922, H. Pittier, "Partamona atrolutea n. sp. Det. J.S. Moure, 1957" (6 ops., 1 macho, USNM; 1 op., DZUP); San Pedro de Mendoza, 19.XI.1922, M. Pittier, "Partamona atrolutea n. sp. Det. J.S. Moure, 1957" (2 ops., USNM). Táchira: San Cristobol, $10 \mathrm{~km}$ SE P.N. Chorro El Indio, 744’3”N, 72¹3'1”W, 1320m, 29.V.1998, J. Ashe, R. Brooks, R. Hanley, VEN1ABH98 142 (2 ops., SM0122659, 0122662, SEMC; 1 op., SM0122618, RPSP); ibidem, idem, $8 \mathrm{~km} \mathrm{SE}$ P.N. Chorro El Indio, 744'15”N, 72¹1'37”W, 1425 m, 29.V.1998, VEN1ABH98 149 (1 op., SM0122604, SEMC). Mérida: Mérida, 35 km S El Vieia, 2.VI.1972, A.S. Menke \& D. Vincent (1 op., USNM). Bolivar: Rio Teuanen, 24 mi. N Kavanayen ca. 1600 m, 13.VIII.1970, R.E. Dietz (2 ops., USNM). Amazonas: Mt. Duida, 29.XI.1928, Tate, 403 (2 ops., Ac. 29500, AMNH). Estado?: Pico Peviquito, 16.VIII.1967, R.W. Poole (2 ops., 1 macho, USNM); San Esteban, XI.1939, Pablo Anduze (2 ops., USNM). EQUADOR. "Ecuador 1900" (localidade?), "TYPUS", "Trigona 
peckolti 1900 Friese det. Fr." (1 op., Ac. 22899, AMNH). Esmeraldas: Alto Tambo, 2.VIII.1991, D. Roubik "rainy" (4 ops., STRI); Esmeraldas, IX.1956, F.H. Walz ( 8 ops., RPSP); ibidem, idem ( 8 ops., DZUP); Quinindé, 1.VI.1985, L. Coloma (1 op., RPSP); ibidem, VI.1986, G. Onore, "on the human skin" (1 op., RPSP); San Mateo, 6.IX.1956, anônimo (2 ops., SEMC); ibidem, idem, 19.IX.1956 (2 ops., SEMC), 22.VII.1956 (3 ops., SEMC), 2.VIII.1956 (1 op., SEMC); ibidem, Parr. San Mateo, 19.IX.1956, F.H. Walz (1 op., MSUC). Carchi. Chical, 1250m, 0-56N, 78-11W, 18.VII.1983, J. Rawlins, M.Smyers (1 op., CMNH); ibidem, idem, 5.VIII.1983 (1 op., CMNH). Manabi: Junin, 28.XII.1985, M. Chieruzzi, "Chalaco negro" (1 op., RPSP); Tosagua, XII.1986, F. Bravo (3 ops., RPSP); Las Maravillas, VIII.1985, L. Coloma (1 op., RPSP). Pichincha: La Florida, III.1986, L. Coloma (1 op., RPSP); Infiernillo, IV.1986, O. Sanchez, ex: "chupando caña di azúcar" (1 op., RPSP); Las Palmas, 3000 ft., 5.II.1958, R.W. Hodges (1 op., MSUC); Quito, 50 km NW, Maquipucuna For. Res., 1300-1600m, 18.XII.1991, C. Carlton, R. Leschen (1 op., SEMC); ibidem, idem, $1350 \mathrm{~m}$, 20.XII.1991, 17, ex: at large (4 ops., SEMC), 1660m, 21.XII.1991, 22, ex: fit (1 op., SEMC), 1300-1400m, 22.XII.1991, 51 (7 ops., SEMC; 1 op., RPSP), 1660 m, 23.XII.1991, ex: light intercept, 61 (2 ops., SEMC), 1750m, 23.XII.1991 (1 op., SEMC); Quito - S. Domingo km 91, 9.II.1963, CH Dodson, 22 (1 op., USNM); Sta. Rosa, Andes Ocidentais, 7843'W, 0³'S, 2450m, 31.V.1987, Camargo, Onore (31 ops., ninho 404c, RPSP); Tandayapa, V.1986, L. Coloma (1 op., RPSP); Tinalandia, Santa (sic) Domingo, 14.VI.1976, S \& J Peck (2 ops., SEMC); ibidem, 800m, II.1983, M. Sharkey, L. Masner, mal. t., (3 ops., 1 macho, SEMC; 01 op., RPSP); Rio Ayampo (sic, Ayampe), Guayos - Monabi (sic) border, 26.VII.1976 S \& J Peck (1 op., SEMC); Rio Palanque Res. Sta., 200m, II.1983, M. Sharkey, L. Masner (4 ops., SEMC); Rio Toachi, $4 \mathrm{~km} \mathrm{E} \mathrm{of}$ Alluriquin, 17.IV.1977, Elaine R. Hodges (1 op., USNM). Cotopaxi. Las Pampas, III.1986, L. Coloma (2 ops, RPSP); ibidem, VII.1984, G. Onore (6 ops., RPSP); ibidem, 18.IX.1997, Mateus, ninho bromélia (6 ops., 973503-505, RPSP); Palo Quemado, VI.1986, Onore (4 ops., RPSP). Bolivar: Balzapamba, VII.1986, G. Onore (7 ops., RPSP); ibidem, sem data, L. Coloma, ex: "on the same nest on a wall of adobe" (2 ops., RPSP). Chimborazo. Naranjapata, Chilicay, 16.VI.1955, R. Levi Castillo (1 op., USNM).

Distribuição geográfica e hábitat: Matas tropicais, matas de altitude e áreas antrópicas na costa do Pacífico, no Equador e Colômbia, Panamá central, entrando pelos vales andinos da Colômbia e chegando até o noroeste da Venezuela. Conforme indicam as etiquetas de procedência chegam até altitudes de $2.000 \mathrm{~m}$ nos Andes (Fig. 162).

Nidificação. Buracos em parede (NATES-PARRA, in litt.), sob massas de raízes, em grandes agregações em buracos de paredes e ruínas (Villa \& Vergara, 1982; ColOMA, 1986; RouBIK, 1992 e CAMARGo, obs. pessoal; NATEs-PARRA \& CEPEDA, 1983, indicam associação com térmitas!). No material proveniente de “Arbelaez, Cundinamarca, 21-VIII-1976, Guiomar leg”, há uma etiqueta com as seguintes notas: "Z-"Perreras" o "Comejón", VIII-21/76 - Arbelaez (Cund.) Também las hemos encontrado em La Palma (Cundinamarca). Nido en pared (adobe o ladrillo). Se encuentras hasta 18 entradas juntas. Entrada en forma de trompeta: hecha con mezcla de cera, tierra y resina. Bastante agresivas: Se enredam en el pelo: cabello y muerdem Col. A. Villa - G. Nates".

Discussão. CAMARgo (1980), através da análise de caracteres morfométricos, considerou $P$. musarum como subespécie de $P$. peckolti. Entretanto, alguns caracteres importantes não foram considerados, como os dentes da mandíbula, que colocam $P$. musarum em um grupo distinto de $P$. peckolti. Também o comprimento das cerdas do escapo, que é um caráter importante na distinção dessas espécies, foi percebido somente mais tarde, já no final do seu trabalho (CAMARGo, 1980: 64). Além disso, essas duas espécies se sobrepõem amplamente (na sua revisão de 1980, CAmargo não havia incluído as espécies com integumento preto na análise). As cerdas muito longas na base do escapo e nas áreas paroculares, ao lado dos alvéolos (em alguns exemplares chegam a $2 x$ o diâmetro do escapo), além da forma dos dentes da mandíbula (Figs. 39 e 66), separam facilmente $P$. peckolti de $P$. musarum. $P$. peckolti é geralmente mais escura, com integumento castanho-claro, mesclado ou até completamente enegrecido; raramente são amareladas por inteiro como P. musarum, mas, nesses casos, o comprimento das cerdas do escapo e áreas paroculares são suficientes para distingüí-las. Das espécies do grupo bilineata / epiphytophila, distingue-se principalmente pela distribuição geográfica (lado ocidental dos Andes e Venezuela, Fig. 162), pelo espaço menor entre os dentes da mandíbula (Fig. 39) e pelas cerdas extremamente longas na base do escapo. Os machos apresentam o basitarso um pouco intumescido, como em $P$. orizabaensis, da qual difere (operárias) pelas asas mais claras, geralmente com microtríquias amarelas na região do pterostigma e veias mais claras. Um estudo infra-específico detalhado, incluindo dados sobre a biologia, material de ninhos e análise de gradientes altitudinais, pode auxiliar a entender os padrões de politipia em $P$. peckolti, ou até mesmo, revelar novas espécies.

Partamona orizabaensis (Strand, 1919)

(Figs. 37, 129, operária; 72, 102, macho; 161, distribuição; Tabs. II-IX, XIV)

Trigona orizabaënsis Strand, 1919(1917):71.

Trigona cupira; Cockerell, 1913:10 (partim, Costa Rica); 1920:464 (partim, Costa Rica); Roubik, 1981:178; Wille \& Orozco, 1975:253287.

Trigona (Partamona) cupira; Wille, 1961:121; 1983:52-55, 62; Wille \& Michener, 1973:12, 21, 31, 33, 40, 44, 56, 67, 87, 90, 91, 98, 112, 128-129, 130-137, 230, 264, 265.

Trigona (Partamona) aff. cupira; Waddington et al., 1986:97.

Trigona (Partamona) testacea variety; Cockerell, 1949:490; Schwarz, 1949:363, 368 .

Partamona amaura Ayala, 1992:5, 14, 28-29. Nom. nudum (ver item discussão).

Partamona cupira; Griswold, et al. 1995:659, 682, 684, 690.

Partamona orizabaensis; Ayala, 1999:7, 19, 57, 58.

Diagnose. Abelhas de porte médio (1.m.c. 2,3-2,6 mm, c.a.a. 5,5-6,3 mm; Tabs. III, IV). Integumento preto. Mandíbula predominantemente amarelada e a porção apical ferrugíneoescura, côndilos enegrecidos. Flagelo castanho escuro ou alaranjado. Estrias paroculares iguais ou um pouco mais estreitas que o diâmetro do $2^{\circ}$ flagelômero $(0,8-1,0)$, um pouco alargadas embaixo (ca. 1,1-1,3 x o diâmetro do $2^{\circ}$ flagelômero), afilando na altura das fóveas tentoriais, ou com a mesma largura em toda a extensão, chegando até a interorbital superior ou um pouco abaixo (Fig. 129). Pilosidade preta. Membrana das asas levemente ferrugíneas; microtríquias pretas; veias escurecidas, principalmente na $1 / 2$ basal da asa. Cerdas da base do escapo 
um pouco mais longas que o diâmetro deste (1,3 a 1,7x; Tab. VII). Cerdas eretas das áreas paroculares, ao lado dos alvéolos, um pouco mais longas que o diâmetro do escapo. Cerdas do escutelo $0,8-1,1 \mathrm{x}$ o comprimento deste. Área basal do propódeo uniformemente pilosa. Dentes da mandíbula como na figura 37. Área malar, distância interocelar, distância ocelorbital, tíbia III e comprimento da asa anterior normais (Tabs. V, VI, VIII, IX). Bifurcação da $\mathrm{M}+\mathrm{Cu}$ geralmente coincidente com a cu-v (raramente levemente anterior). Macho, basitarso III alongado, pouco intumescido; tíbia III alargada em direção ao ápice (Fig. 72); EVII com a projeção mediana curta, de lados aproximadamente subparalelos, os chanfros laterais profundos e estreitos (Fig. 102).

Variação. Alguns exemplares da Costa Rica, podem apresentar pilosidade mais clara na porção ventral do tórax e abdômen. Exemplares do México até Honduras com máculas mais nítidas no tórax (em exemplares da Costa Rica são bem apagadas).

\section{Operária.}

Dimensões. Comprimento total aproximado, 7,30 mm; da asa anterior, 6,14 $\mathrm{mm}$ (incluindo a tégula, 6,97 $\mathrm{mm}$ ); largura máxima da cabeça, 2,52 mm; do TIII, 2,24 mm (Tab. XIV).

Cor do integumento. Predominantemente preto, apenas os tarsômeros ferrugíneos. Tégulas castanho-escuras, translúcidas no meio. Labro amarelo, mandíbula amarela na base e ferrugínea em direção ao ápice, côndilos pretos. Escapo preto. Flagelo castanho escuro na face superior, mais claro por baixo, o $1^{\circ}$ artículo amarelado. Máculas nítidas, no clípeo e tórax menos conspícuas. Manchas do clípeo aproximadamente triangulares, castanho escuras, a distância entre elas um pouco menor que o diâmetro do $2^{\circ}$ flagelômero. Mancha supraclipeal um pouco mais nítida, aproximadamente em forma de acento circunflexo. Mancha nítida, amarela, em forma de gota invertida, abaixo do ocelo médio, tão longa quanto o diâmetro do ocelo e uma mancha irregular, alongada, acompanhando o sulco frontal. Estrias paroculares nítidas, amareladas, alargadas embaixo (ca. de 1,6x o diâmetro do escapo), difusas e mais estreitas na altura da interorbital máxima (ca. de $1 / 3$ do diâmetro do escapo), chegando até a altura da tangente do ocelo médio (interorbital superior), com cerca de 2/3 do diâmetro do escapo. Genas com uma pequena mancha amarela difusa no quarto inferior da margem do olho. Tórax com as estrias laterais do mesoscuto acastanhadas; acompanhando o bordo posterior do escutelo, uma estria a cada lado, castanho-escura; axilas pretas. Membrana da asa anterior uniformemente ferrugíneo-clara; microtríquias ferrugíneo-fuscas em toda a asa; veias méleas, escurecidas pelas microtríquias, C e R mais escuras em direção à base da asa.

Pilosidade. Predominantemente enegrecida, apenas as cerdas dos tarsômeros ferrugíneas. Cerdas ventrais do tórax e abdômen enegrecidas, apenas seus ápices mais claros. Área basal do propódeo sem faixa mediana glabra distinta. Franja pré-marginal do TIII, interrompida medianamente, onde há apenas microcerdas muito mais curtas que as laterais. Cerdas da base do escapo ca. de 1,75x o diâmetro deste. Área parocular inferior, ao lado dos alvéolos, com cerdas eretas tão longas quanto o diâmetro do escapo. Cerdas do clípeo tão longas quanto o diâmetro do escapo; na fronte, ca. $1,13 \mathrm{x}$, e no vértice 2,25x o diâmetro do escapo; no disco do mesoscuto, e nos lados do mesepisternos, tão longas quanto $1,88 \mathrm{x}$ e $1,75 \mathrm{x}$ o diâmetro do escapo. Cerdas mais longas no ápice do escutelo 0,95 x o comprimento deste.

Integumento. Liso e polido, apenas com a pontuação pilígera, típica do gênero.

Forma e proporções (Tab. XIV). Cabeça, 1,22x mais larga que longa, e 1,35x mais larga que a distância clipeocelar. Olhos, $2,45 \mathrm{x}$ mais longos que largos, subparalelos. Área malar ca. de $1,11 \mathrm{x}$ o diâmetro do $2^{\circ}$ flagelômero. Clípeo $0,52 \mathrm{x}$ mais curto que sua largura máxima, $0,93 \mathrm{x}$ a distância intertentorial e $0,36 \mathrm{x}$ a distância clipeocelar. Comprimento da mandíbula 0,56x a distância clipeocelar (apenas um dos paralectótipos com a mandíbula parcialmente aberta, o ápice do dente médio chegando no nível do bordo distal). Comprimento do escapo 0,94x a distância alvéolo-ocelo lateral, seu diâmetro um pouco menor que o do $2^{\circ}$ flagelômero. Distância interocelar 1,31x maior que a ocelorbital e ca. 1,75x o diâmetro do ocelo médio. Escutelo aproximadamente semicircular, ca. de $0,49 x$ mais curto que largo. Tíbias III carregadas com resina; em um dos paralectótipos com as seguintes proporções e forma: $0,94 \mathrm{x}$ mais curta que a cabeça, e 2,11x mais longa que larga; o canto póstero-distal subanguloso, um pouco projetado, a margem apical fracamente sinuada. Basitarso III 1,68x mais longo que largo; o canto póstero-distal arredondado e a margem apical um pouco projetada, em ângulo mais aberto que $90^{\circ} \mathrm{em}$ relação à margem anterior. Asa anterior 2,77x mais longa que larga, e 2,44x mais longa que a largura máxima da cabeça. Bifurcação de $\mathrm{M}+\mathrm{Cu}$ coincidente com a cu-v. Hâmulos, 5.

\section{Macho. Figuras 72, 102.}

Material-tipo. Lectótipo e paralectótipos (aqui designados), 6 operárias de "Orizaba", "Mexico", "Coll. Kraatz", "Syntypus", "Trigona orizabaensis m. Strand det.", depositados no DEIC. Todos examinados.

Material examinado: MÉXICO. Veracruz: Catemaco, $32 \mathrm{~km} \mathrm{~N}$, UNAM Preserve, 6.I.1982, E.M. May (1 op., SEMC); ibidem, 34 km N, $2-3 \mathrm{~km}$ on rd to Sontecomapan, 5.I.1982, B.H. Smith (1 op., SEMC); Chinameca, VI.1944, M. Guerra, Frank Johnson Donor (2 ops., AMNH); Coscomatepec, 4,8 mi NE, 4650 ft., 8.VIII.1969, George W. Byers, 17, cloud forest (1 op., SEMC); Huatusco, $7.1 \mathrm{~km} \mathrm{E,} \mathrm{1230m,} \mathrm{16.VII.1990,}$ R.L. Minckley, ex: Compositae (1 op., SEMC); ibidem, $7.1 \mathrm{~km} \mathrm{E}$, hwy 125, 1230m, 16.VII.1990, I. Yarom (2 ops., SEMC); ibidem, 32.2. km S, 1100 m, 17.VII.1990, W. Bell, D. Conlon, R.L. Minckley (2 ops., SEMC); Jalapa, sem data, Crawford (1 op, USNM); Orizaba, 5.VIII.1962, A.E. \& M.M. Michelbacher, domestic squash, 854.1 (1 op., USNM); ibidem, 12-22.VIII.1961 R.\&K. Dreisbach (2 ops., MSUC); Presidio 1000', 14.VII.1965, R.R. Snelling, "on rotting bananas" (2 ops., USNM). Oaxaca: Arroyo Choapan nr. Chiltepec, Rio Valle Nacional, 10.XII.1937, A. Dampf, 24, "Trigona (Partamona) testacea var. centralis H.F. Schwarz", "PARATYPE" (1 op., Ac. 39959, AMNH). Chiapas: Finca 
de La Victoria Motozintla, 6.V.1962, M.A. Vulcano (2 ops., MZSP); Finca Lubeca, 12.I.1945 (1 op., AMNH); Huixtla, 15.XII.1945, T. Schneirla (2 ops., AMNH); Prilucum (?) entre Puerto Cate y Bochil, 30.XI.1949, anônimo, 867 (1 op., AMNH). BELIZE. Toledo: Blue Creek Villlage, 9.VI.1981, Earthwatch Belize Expedition, D.H. Messersmith, W.E. Steiner, et al., "malaise trap set in clearing in rain forest valley" (1 op., USNM); ibidem, idem, 26.VI.1981 (1 op., USNM). District?: (localidade?), anônimo (1 op., USNM). GUATEMALA. Quetzaltenango: Zunil, $25.2 \mathrm{~km} \mathrm{SW}, 800 \mathrm{~m}, 20$. VI.1993, R. Brooks, J. Ashe, 054, ex: Bidens (3 ops., SEMC). Chimaltenango: Yepocapa, VI.1948, H.T. Dalmat (1 op., USNM): ibidem, idem, XII.1948 (1 op., USNM), I.1949 (1 op., USNM). Zacapa: La Union, 3.5 km SE, 1500m, 25.VI.1993, F. Génier, ex: human feces trap (1 op., SEMC). Escuintla: Escuintla, Grutas de São Pedro Martir, 10.VIII.1965, P.J. Spangler (2 ops., USNM). Depto.?: Esmeraldas, 5.I.1917, anônimo (4 ops., USNM; 1 op., RPSP); La Providencia, Obispo, sem data, J.M. Aldrich (1 op., USNM); ibidem, idem, 16.IV.1926 (1 op., USNM); Plancha de Piedra, 22.II.1909, Pelén, Collection F. Knab (1 op., USNM). HONDURAS. Atlántida: La Ceiba, 1.XII.1915, F.J. Dyer, 144 Bu-Bu (2 ops., USNM); ibidem, idem, 24.I.1916, 22350-22439,(1 op., AMNH), 9.XI.1917, 31050 (1 op., USNM), 20.II.1916, 4082 (1 op., USNM); ibidem, 25.IV.1963, H.L. Hansen (2 ops., MSUC); ibidem, 4.IV.1978, S.G. Wellso (1 op., MSUC); ibidem, 15.V.1949, E. Becker (3 ops., SEMC); ibidem, idem, 2.VI.1949, ex: light trap (1 op., SEMC), 10.VI.1949 (15 ops., SEMC; 3 ops., RPSP), 27.VI.1949 (4 ops., SEMC); ibidem, sem data, W.M. Mann (10 ops., USNM; 1 op., RPSP). Colón: Puerto Castilla, BF Hond., 6.V.1926, R.H. Painter (2 ops., MSUC). Santa Barbara: Mt. Santa Barbara, $11.5 \mathrm{~km} \mathrm{~S}$ \& 5.6 km W Peña Blanca, 145'N, 8806'W, 1800 m, 20.VI.1994, R. Brooks, J. Ashe (4 ops., SEMC; 1 op., RPSP). Cortés: San Pedro Sula, sem data, W.M. Mann (3 ops., USNM). Yoro: Olanchito, $12 \mathrm{~km} \mathrm{W,}$ 28.V.1949, E.C. Becker, ex: light trap (4 ops., SEMC); ibidem, idem, 16.VI.1949 (8 ops., SEMC; 2 ops. RPSP); Progreso, 20.III.1923, T.H. Hubbell, 126 (1 op., MSUC). Olancho: Catacamas, 20.II.1991, Curtis Gentry (1 op., SEMC); Dulce Nombre de Culmi, 7.II.1991, J. Bentley, 08 (2 ops., SEMC). Comayagua: Agua Azul, 27.XII.1946, Willians (1 op., USNM); Francisco Morazán: Agua Amarilla, 15.XII.1946, anônimo (prov. Cockerell) (2 ops., USNM); Tegucigalpa, 19.II.1946, T.D.A. Cockerell (2 ops., USNM); ibidem, .... W.P. (Cockerell?) ... 33 (parcialmente legível) (1 op., USNM); ibidem, 25.VI.1917, F.J. Dyer (8 ops., USNM); ibidem, idem, 26.VI.1917, 41167 (1 op., AMNH), 28.VIII.1917, 29662 (1 op., USNM), 19.X.1917, 30029, (1 op., Ac. 24309, AMNH), 23.X.1917, 30143 (1 op., AMNH), 9.XI.1917, 30591 (1 op., USNM), 11.XI.1917, 30592, 30659 (3 ops., USNM), 11.XI.1917, 30590 (1 op., AMNH), 15.XI.1917, $30905-30935$ (1 op., AMNH), 29.I.1918, 31919 (1 op., USNM), 7.II.1918, 33335 (1 op., USNM), 10.II.1918, "along mule trail s.y Comayagua from flowering about 2 to 7 high wood purple flowers" (3 ops., USNM), 10.II.1918, 34446 (1 op., AMNH), II-III.1918, 38268 to 38304 (1 op., USNM), 15.V.1918, 39962 (1 op., AMNH), 11.VI.1918, 40341-79, "orange .... in bloom 930-10 AM" (parcialmente legível) (2 machos, AMNH), 17.VI.1918, 40845 (1 op., USNM), 20.VI.1918 (1 op., USNM), 25.VI.1918 (3 ops., USNM), 26.VI.1918, 41167 "taken with cyanid ... orange ..." (ilegível) (4 ops., USNM), 30.VI.1918 (1 op., USNM), 10.VII.1918, 34189 (3 ops., USNM; 2 ops. AMNH), 20.VII.1918 (1 op., USNM), 22.VII.1918 (1 op., USNM), IX.1918 (1 op., USNM); Zamorano, I.1946, T.D.A. Cockerell (1 op., USNM); ibidem, idem, 6.II.1946 (1 op. em alfinete, 7 ops. em cápsula de gelatina, USNM), 12.II.1946 (11 ops., USNM), XI.1946 (9 ops., USNM), 1.XII.1946 (1 op. em alfinete, 7 ops., em cápsula de gelatina, USNM), 2-19.II.1947(?) (3 ops., USNM); ibidem, 6.II.1947(?), W.P (Cockerell?) (2 ops., USNM); ibidem, idem, 7.XII.1946(?) (1 op., USNM), XII.1946(?) (1 op., USNM); ibidem, 11.VI.1994, 14 N, 87º , $820 \mathrm{~m}$, Brooks, Ashe (7 ops., 1 macho, SEMC; 1 op., RPSP). El Paraiso: Guinope, Galeras, 10.III.1991, J. Bentley, 03 (2 ops., SEMC).Choluteca: Choluteca River Brix (?), D. Wilie (parcialmente legível) (1 op., USNM). Depto. ?: Cecilia, sem data, anônimo (2 ops., USNM). NICARÁGUA. Esteli: Esteli, 31 mi. N, 22.VIII.1972, G.F. \& S. Hevel (1 op., USNM). Chinandega: Chinandega (cidade?), sem data, Baker (1 macho, USNM). Matagalpa: La Trinidad, 29.X.1963, A.E. \& M.M. Michelbacher, squash, 310.1, 0700-0720 (1 op., USNM); Matagalpa (cidade?), 4.X.1952, Swain, 137, 52-11606, "in hole exposed root" (7 ops., USNM; 1 op., RPSP).
Manágua: Managua, 27.III.1985, D. Roubik (3 ops., STRI). Massaya: Jinotepe, 30.X.1963, A.E. \& M.M. Michelbacher, squash, 308.1, 0715 - 0720 (5 ops., USNM). Rivas: San Juan del Sur, 24.IX.1943, P.A. Woke, 1413, Lot No. 43-18231 (5 ops., USNM). Depto. ?: San Marcos, sem data, Baker, 2365 (2 ops., USNM). COSTA RICA. Costa Rica ?. Jesus de Barba, 1250m, 9.XI.1936, Nevermann 14. E... nest (ilegível) (4 machos, USNM); Costa Rica (localidade?), sem data, M. A. Carriker (23 ops., USNM); ibidem, sem data, Biolley (9 ops., CMNH). Guanacaste: Cañas, 4 km N, 15.VII.1965 D.H. Janzen (1 op., SEMC); "Congo", N. 189 20.IX.1937, A. Alfaro, "acc. 35598", "PARATYPE", "Trigona (Partamona) var. centralis H.F. Schwarz" (3 ops., RPSP); Santa Rosa Natl. Park, 16.II.1973, E.M. Barrows, "at water hole" (3 ops., SEMC); ibidem, 11.II-2.III.1979, C.K. Starr (1 op., SEMC); ibidem, Cerro El Hacha, 300m, 24.VIII-14.V.1985 (?), D. Janzen (1 op., AMNH). Alajuela: Palmares, 2 mi. W, 23.I.1965, D.H. Janzen (3 ops., SEMC); San Ramon Reserva Biologica, 800m, X.1992, J. Lobo (1 op., RPSP); Volcan Poas, S.E. slope of, $6450 \mathrm{ft} ., 15 . V I .1963$, Michener \& Kerfoot (1 op., RPSP); Zarcero, 1835m, 21.IX.1943, P. Knight, CR-35, Lot No. 43-17770 (1 op., USNM). Heredia: (localidade?), 10.VIII.1975, N.L.H. Krauss (3 ops., SEMC); Finca La Selva, near Pto. Viejo, 17-19.III.1973, D.C. Rentz, "daytime in cacao grove" (1 op., USNM); La Selva Biol. Station, 15.VI.1990, David Brzoska (1 op., SEMC); Puerto Viejo, 5 mi. E., 15.VII.1966, J.B. Karren, 4 (1 op., SEMC); ibidem, Sarapiqui, 30.VII.1965, D.H. Janzen (37 ops., USNM; 2 ops., RPSP); Vara Blanca, 10 mi. N., 1400m, 17.IV.1965, D.H. Janzen (6 ops., SEMC). Puntarenas: (localidade?) 0-10 m, VIII.1980, N.L.H. Krauss (4 ops., SEMC); Ballenas, 100m, X.1994, J. Lobo (1 op., RPSP); Esparta, 6 mi. W., 19.VI.1963, Wille, Michener, O'Conners, Kerfoot (4 ops., SEMC); ibidem, $6 \mathrm{mi}$. NE, 19.VI.1963, Michener, Wille, et al. (4 ops., RPSP); Golfito, 0m, IV.1993, J. Lobo (1 op., RPSP); ibidem, idem, Pl. Zancudo, 10m (1 op., RPSP); Gromaco, $34 \mathrm{~km} \mathrm{SE}$ of Potrero Grande, on Rio Coto Brus, 21.VII.1963, 1000 ft., C.D. Michener \& W. Kerfoot (14 ops., 8 machos, SEMC; 3 ops., 2 machos, RPSP); Las Cruces, 1.II.1965, R.L. Dressler (7 ops., DZUP; 1 op., RPSP); ibidem, Wilson Bot. Garden, Las Cruces Biol. Stn., 1200m, 27.III.1993, J \& A. Ashe, ex: flight intercept trap (1 op., SEMC); La Palma, Osa, 20m, III.1993, J. Lobo (1 op., RPSP); Las Alturas Biol. Sta., 1400-1600m, 23.V-1.VI.1992, C. Snyder (1 op., AMNH); Limoncitos, Coto Brus, 800m, III.1994, J. Lobo (1 op., RPSP); Macacona, 8 km N.E. of Esparta, 31.VI.1962, A. Wille \& C.D. Michener (1 op., RPSP); Mogos, Osa, 300m, VIII.1994, J. Lobo (1 op., RPSP); Monteverde, 1300-1400m, VIII.1980, N.L.H. Krauss (1 op., SEMC); ibidem, 1000-1500m, 16.V.1989, J. Ashe, R. Leschen, R. Brooks, 220 (1 op., SEMC); Parque Nacional Mañuel Antonio, 14.II.1986, W. T. Wcislo, 8621 (1 op., SEMC); Puntarenas, $11 \mathrm{~km}$ E. mouth Rio Barranca, 7.VIII.1964, G.C. Eickwort (1 op., RPSP); Quepos, 15 km N, 13.II.1986, W.T. Wcislo, 8613 (1 op., SEMC); Reserva Biologica Cararas, eastern boundary, 16.II.1986, W.T. Wcislo, 8626 (2 ops., SEMC); Rincon, 2.5 mi. SW, Osa Peninsula, $08^{\circ} 42^{\prime} \mathrm{N}, 8^{\circ} 29^{\prime} \mathrm{W}, 21-28 . I I .1968$, D.H. Janzen ( 3 ops., USNM); ibidem, $7 \mathrm{~km}$ W Osa Penn. Est. F. N. Aguas Buenas, 50m, 21-25.VI.1997, S \& J. Peck, CR1P97 024, ex: flight intercept trap (4 ops., SM0333564, 0333566, 0333570, SEMC); San Vito - Finca Las Cruces, 14.IV.1985, D. Roubik (7 ops., STRI); ibidem, $2 \mathrm{~km} \mathrm{S,} \mathrm{Finca} \mathrm{Las}$ Cruces, $08^{\circ} 42^{\prime} \mathrm{N}, 8^{\circ} 0^{\prime} \mathrm{W}, 4000^{\prime}$, 14.III.1969, D.C. Rentz (1 op., USNM); Upper Quebrada Máquina, 1400m, 24.V.1989, J. Ashe, R. Leschen, R. Brooks, 413, ex: light intercept (1 op., SEMC); Villa Neily, 512.VIII.1963, C.L. Hogue (1 op., DZUP). San José: Cerro de la Muerte, 11,000 ft., 27.III.1966, C.D. Michener (1 op., SEMC); El Llano, Alajuelita, 1800m, 10.X.1994, J. Lobo (3 ops., RPSP); Monterredondo, 19 Feb. 1960, A. Wille (4 ops., RPSP); Puredón San Isidro, 182, 7.VIII.1937, A. Alfaro, "PARATYPE", "Trigona (Partamona) testacea var. centralis H.F. Schwarz" (3 machos, RPSP); Sabanilla, $17 \mathrm{~km} \mathrm{NE}$, 21.III.1985, W.T. Wcislo, 36 (2 ops., SEMC); San Antonio de Escazú, 13-17.IV.1985, W. T. Wcislo, 46 (1 op., SEMC); ibidem, idem, 1350m, 23.XII.1987-16.I.1988, ex: malaise trap (2 ops., SEMC); San Isidro de El General, 700m, VIII.1980, N.L.H. Krauss (1 op., SEMC); ibidem, 1218 mi. N, 2.I.1989, A.S. Menke (1 op., USNM); San José, 1903, Burgdorf, "Tr. cupira v. luteicornis Fr. 1910 Friese det." (2 ops., 28084, AMNH); ibidem, idem, (1 op., Ac. 35178, AMNH); ibidem, IV.1928, J.F. Tristan (3 ops., USNM); ibidem, idem, 12.V.1930, on flowers Sechium edule (2 ops., USNM); ibidem, 2.III.1938, A. Alfaro (2 ops., Ac. 36567, AMNH); 
ibidem, idem, 20.IX.1937 (2 ops., Ac. 35874, AMNH), 24.VI.1937 (2 ops., AMNH), 18.VI.1938 (2 ops., Ac. 35874, AMNH); ibidem, sem data, M. Valerio, 13 (1 op., USNM); ibidem,10.IV.1965, D.H. Janzen (1 op., SEMC); ibidem, 1100-1200m, VIII.1980, N.L.H. Krauss (5 ops., SEMC); ibidem, 4.VI.1963, C.D. Michener (1 op., SEMC); ibidem, idem, 22.III.1966, taken on Gomphrena dispersa (10 ops., SEMC; 2 ops., RPSP); ibidem, Cd. Universitaria, 14.I.1985, W. T. Wcislo, 1 (1 op., SEMC); ibidem, 4.VI.1964, G. C. Eickwort (1 op., RPSP); ibidem, idem, 1.VIII.1964 (1 op., RPSP); San Mateo, IX.1921, anônimo (1 op., 2547, AMNH); San Pedro, 1200m, I.1992, J. Lobo (2 ops., RPSP); ibidem, idem, X.1994 (1 op., RPSP); San Pedro de Montes de Oca, 20.IV.1934, C.H. Ballou, Casuarina equisetifolia, (1 macho, 2367, USNM); ibidem, idem, 13.III.1934, on Callalily, 37 (4 ops., USNM), 5.X.1933, Asparagus officinalis, (2 ops., 1852, USNM); San Ramon de Tres Rios, 2 km West, 24.XII.1989, Wm. L. Downes (1 op., MSUC); Tres Rios, 2 km E at Rio Tiribí, 21.III.1985, W.T. Wcislo, 34 (3 ops., SEMC); Zurqui de Moravia, 1600m, VIII-IX.1989, Paul Hanson (1 op., RPSP); ibidem, idem, VIIIIX.1991 (1 op., 1 macho, RPSP), VI-VII.1991 (2 ops., 1 macho, RPSP), X-XII.1991 (2 ops., RPSP), IV.1992 (5 ops., RPSP). Cartago: La Cangreja, 2000m, 20.III.1993, J. Lobo (2 ops., RPSP); Navarro Farm, III.1924, H W Atkinson (3 ops., USNM); Orosi vic., 19.I.1988, Wm. L. Downes Jr. (1 op., MSUC); Pacayas, C. Werckele (1 op., 24504, AMNH); Tapanti, 1.IV.1966, C.D. Michener (4 ops., SEMC); ibidem, 1250m, 12.VI.1963, C.D. \& D.R. Michener (1 op., RPSP); Turrialba, 1.II.1965, R.L. Dressler (9 ops., DZUP); ibidem, 3.II -11.III.1944, T Grant (1 macho, USNM); ibidem, 600-700m, 12.VIII.1975, N.L.H. Krauss (1 op., SEMC); ibidem, 646m, 11.VII.1964, M.G. Naumann (1 macho, SEMC); ibidem, 1519.VII.1965, P. J. Spangler (7 ops., USNM); ibidem, 3 mi. W, 27.VIII.1972, G.F. \& S. Hevel (1 op., USNM); ibidem, 28.II.1980, H \& A Howden (1 op., SEMC); ibidem, 1,5 km E. Catie (nr. Rio Reventazón), 20.III.1985, W.T. Wcislo, 33 (3 ops., SEMC). Limón: Barra del Colorado, 1.I.1988, Wm. L. Downes Jr. (2 ops., MSUC); Beverly near Limon, 26.VIII.1963, C.D. Michener \& Wille (1 macho, SEMC); Pta. Uva, 0m, 27.X.1992, anônimo (1 op., RPSP); Q. Gonzales Viquez, 560m, III.1994, J. Lobo (1 op., RPSP); Zent, III.1924, WM Mann (1 op., USNM). Prov.?: Jocosal, 5000 ft., 3.III.1928, F.G. Wallace (1 op., AMNH); La Palma, sem data, anônimo, 133 (2 ops., USNM); Ocloro, V.1937, A. Alfaro (6 ops., USNM); S. A. Las Damas, 9.XII.1961, A. Wille (4 ops., DZUP); San Jeronimo (Puntarenas ?, Alajuela ?), 1400m, IV.1905, Biolley, "n. v. oreja de aragde mellifera" (?) (8 ops., 1 macho, CMNH); Santa Clara, Colombiana Farm, III-IV.1924, H.W. Atkinson (1 op., USNM). Taboga, 21.VI.1969, R.T. Schuh (1 op., AMNH). PANAMÁ. Bocas del Toro: Miramar, 29.VIII.1980, D. Roubik, 12 (1 op., STRI). Chiriqui: Boquete, 1000m, 17.I.1981, C.D. Michener (6 ops., 1 macho, SEMC; 1 op., RPSP); ibidem, idem, $5 \mathrm{~km} \mathrm{SE,} \mathrm{17.I.1981,} \mathrm{on} \mathrm{Cassia} \mathrm{(4}$ ops., SEMC; 1 op., RPSP); Cerro Punta, 6500 ft., 23.III.1969, R.L. Fisher, (1 op., MSUC); El Volcan, 26.II.1936, F. E. Lutz, L-2 (2 ops., AMNH); Fortuna, 26.V.1985, D.W. Roubik (3 ops., STRI); La Fortuna, “Cont. Divide Trail”, $08^{\circ} 46^{\prime} \mathrm{N}, 82^{\circ} 12^{\prime} \mathrm{W}, 1150 \mathrm{~m}, 9 . \mathrm{VI} .1995$, J. Ashe \& R. Brooks, 149 (1 op., SM0057349 KUNHM-ENT, SEMC); ibidem, 1100m, 23.V-9.VI.1995, J. Ashe, R. Brooks, 157, ex: flight intercept trap (2 ops., SM0057340, SM0057342 KUNHM-ENT, SEMC); San Felix $29.2 \mathrm{~km} \mathrm{~N}$, just $\mathrm{N}$ of Hoto Chami, $08^{\circ} 27^{\prime} \mathrm{N}, 81^{\circ} 46^{\prime} \mathrm{W}, 1030 \mathrm{~m}$, 8.VI.1995, J. Ashe \& R. Brooks, 142, ex: Spermacoce sp. (2 ops., SM0057350, SM0057351 KUNHM-ENT, SEMC); Volcan de Chiriqui, 19.VII.1981, N.L.H. Krauss (5 ops., SEMC; 1 op., RPSP); Volcan Hartmann's Finca, 3.VII.1981, B. Gill (1 op., SEMC); ibidem, 27.7 km W, $08^{\circ} 45^{\prime} \mathrm{N}, 82^{\circ} 48^{\prime} \mathrm{W}, 1450 \mathrm{~m}, 14-17$.VI.1995, J. Ashe \& R. Brooks, 231, ex: flight intercept trap (1 op., SM0057346 KUNHM-ENT, SEMC); ibidem, $15 \mathrm{~km} \mathrm{W,} \mathrm{1200m,} \mathrm{20-31.V.1977,} \mathrm{S.} \mathrm{Peck,} \mathrm{ex:} \mathrm{dung} \mathrm{(5} \mathrm{ops.,}$ SEMC; 1 op., RPSP).

Distribuição geográfica e hábitat. Ocorre em matas e áreas antrópicas do noroeste do Panamá até o sudeste do México (costa do Golfo do México, exceto Yucatan; Fig. 161). Segundo dados de etiqueta, pode chegar até mais de $3.300 \mathrm{~m}$ de altitude ("Costa Rica, San José Prov., Cerro de la Muerte, 11,000 ft., March 27, 1966, C.D. Michener”, 1 op., SEMC).
Nidificação. Cavidades no solo, entre a base de folhas de palmeiras, sob raízes de epífitas, em ninhos abandonados de aves, até quase totalmente expostos (WILLE \& MicheNER, 1973; Griswold et al., 1995). Nas etiquetas de uma série de 8 operárias consta a seguinte informação: "In hole exposed root Matagalpa Nicaragua X-4-52 Swain - 137 52-11606”.

Discussão. Esta espécie inclui parte dos exemplares considerados como "P. centralis" Schwarz, não publicada (Arroyo Choapan, Oaxaca, México, AMNH, Puredón San Isidro, e Congo, Guanacaste, Costa Rica, RPSP), e "Tr. cupira v. luteicornis" de Friese, 1910 (San José, Costa Rica), também não publicada. ScHWARz (1949: 363, 368), sem conhecer o material tipo, interpretou $P$. orizabaensis como sinônimo de $P$. bilineata, incluindo exemplares com pilosidade ventral esbranquiçada e considerou os exemplares de $P$. orizabaensis como "Trigona (Partamona) testacea variety", pela pilosidade ventral preta (chave, p. 368). P. orizabaensis distingue-se de P. bilineata, com a qual se sobrepõe no sudeste do México até Honduras, pelas cerdas escuras nos esternos, pelas asas com veias mais escuras, principalmente na metade basal, cerdas mais longas na base do escapo e pelas máculas em geral mais nítidas na cabeça e tórax. Ayala (1999) menciona também o tamanho maior de $P$. orizabaensis (= P. amaura Ayala, 1992) em relação a $P$. bilineata, e uma diferença na forma do basitarso III; entretanto esse autor teve pouco material de $P$. orizabaensis em mãos, proveniente de pequeno número de localidades, e na verdade existe considerável variação no tamanho dessas abelhas e na forma do basitarso III. No limite sul de sua distribuição (Chiriqui, Bocas de Toro, Panamá), onde faz limite com $P$. peckolti, pode ser reconhecida pelas veias mais escuras e pelas microtríquias enegrecidas em toda a asa (as cerdas da base do escapo de $P$. peckolti também são longas e as cerdas nos esternos 2-6 geralmente enegrecidas). Em populações da Costa Rica há uma certa variação no comprimento relativo da asa anterior, que pode estar relacionada com gradientes altitudinais, entretanto o número de exemplares examinados não foi suficiente para se chegar a uma conclusão. $P$. orizabensis compartilha com $P$. peckolti, também do grupo bilineata / epiphytophila, um certo grau de intumescimento no basitarso III dos machos, o que coloca essas duas espécies próximas a $P$. bilineata e $P$. grandipennis / P. xanthogastra (Fig. 175). Embora os dentes da mandíbula (Figs. 37, 39) indiquem claramente que $P$. orizabaensis e $P$. peckolti fazem parte do grupo bilineata / epiphytophila, pela hipótese apresentada, o EVII do macho, com projeção mediana de lados aproximadamente subparalelos, aparece como homoplástico em relação aos grupos nigrior e cupira.

\section{Partamona epiphytophila sp. nov.}

(Figs. 33, 133, operária; 75, 104, macho; 162, distribuição; Tabs. II-X)

Trigona (Partamona) cupira; Baumgartner \& Roubik, 1989:16. Trigona aff. cupira; Baumgartner \& Roubik, 1989:13, 14, 16. 
Diagnose. Abelhas grandes (1.m.c. 2,6-2,7 mm, c.a.a. 6,2-6,8 $\mathrm{mm}$, Tabs. III, IV). Integumento preto. Mandíbula predominantemente ferrugínea, apenas 1/4-1/3 basal amarelo, côndilos pretos, ápice ferrugíneo-escuro. Flagelo castanhoescuro ou enegrecido. Estrias paroculares estreitas (0,6-0,8x o diâmetro do $2^{\circ}$ flagelômero), aproximadamente com a mesma largura em toda a extensão ou um pouco alargadas embaixo (1,0-1,2x o diâmetro do $2^{\circ}$ flagelômero), chegando até a interorbital superior (Fig. 133). Pilosidade preta. Membrana das asas levemente ferrugínea; microtríquias pretas em toda a asa ou amarelas na região do pterostigma; veias méleas, mas escurecidas pelas microtríquias fuscas. Cerdas da base do escapo muito longas, 1,2-1,7x o diâmetro deste (Tab. VII). Cerdas eretas das áreas paroculares, ao lado dos alvéolos, aproximadamente tão longas quanto o diâmetro do escapo. Cerdas do escutelo 0,8 a 1,1x o comprimento deste. Área basal do propódeo com uma faixa glabra mediana, aproximadamente tão larga quanto o diâmetro do $2^{\circ}$ flagelômero. Dentes da mandíbula muito espaçados, como na figura 33. Área malar, distância interocelar, distância ocelorbital, tíbia III e comprimento da asa anterior, normais (Tabs. V, VI, VIII, IX). Bifurcação da $\mathrm{M}+\mathrm{Cu}$ geralmente coincidente com a cu-v (raramente levemente anterior). Macho, basitarso III alongado, achatado ou convexo-côncavo; tíbia III estreita (Fig. 75); EVII com a projeção mediana curta e triangular, os chanfros laterais curtos e largos (Fig. 104).

Variação. Asas um pouco mais escuras, ferrugíneas (mais escuras na metade basal) podem ser observadas em alguns exemplares do Peru, Bolívia e Colômbia. As máculas da face variam bastante de intensidade em exemplares de uma mesma série, desde amarelo-vivo, até castanho-apagado; todos os exemplares examinados de Napo, Ecuador apresentaram-se muito escuros, com as máculas quase imperceptíveis.

\section{Operária.}

Dimensões. Comprimento total aproximado, 5,98 mm; da asa anterior, $6,31 \mathrm{~mm}$ (incluindo a tégula, 7,22 $\mathrm{mm}$ ); largura máxima da cabeça, 2,64 mm; do TIII, 2,60 mm (Tab. X).

Cor do integumento. Predominantemente preto, apenas o metanoto e as tíbias III mais claros, na face mais para o castanhoescuro; os tarsômeros de todos os pares de pernas, ferrugíneos. Tégula ferrugíneo-escura, a porção discal mais clara, translúcida. Labro amarelado; mandíbula amarelada no terço basal e ferrugínea em direção ao ápice, côndilos enegrecidos. Escapo com a face inferior amarelada e a superior enegrecida. Flagelo castanho-enegrecido, um pouco mais claro na face inferior. Máculas nítidas. As manchas no clípeo aproximadamente em forma de L irregular, a distância entre elas, na porção mais apical do clípeo, aproximadamente igual ao diâmetro do $2^{\circ}$ flagelômero, apagadas. Mancha supraclipeal aproximadamente trapezoidal. Abaixo do ocelo, um triângulo invertido um pouco mais curto que o diâmetro do ocelo médio, nítido. Uma mancha margeando o sulco frontal. Estrias paroculares estreitas, de largura aproximadamente uniforme (ca. 0,75x o diâmetro do escapo), terminando um pouco antes da linha da menor distância interorbital superior. Genas com uma estria margeando a metade inferior do olho. Tórax com as estrias laterais do mesoscuto nítidas; as axilas com os $2 / 3$ anteriores amarelados; o bordo posterior do escutelo com uma faixa estreita interrompida medianamente. Membrana da asa anterior levemente ferrugínea; microtríquias enegrecidas em toda asa; veias méleas, escurecidas pelas microtríquias, $\mathrm{C} \mathrm{e} \mathrm{R}$ mais escuras na base.

Pilosidade. Enegrecida, inclusive na porção ventral do tórax (coxas, trocanteres, mesepisternos) e esternos. Área basal do propódeo com uma faixa glabra mediana. Franja pré-marginal do TIII com cerdas muito mais curtas na região mediana que nas laterais. Cerdas da base do escapo 1,50x mais longas que o diâmetro deste. Nas áreas paroculares inferiores, ao lado dos alvéolos, cerdas eretas ca. 0,88x o diâmetro do escapo. Cerdas do clípeo tão longas como o diâmetro do escapo; na fronte 1,06x o diâmetro do escapo; no vértice mais longas, ca. 2,13x o diâmetro do escapo; no disco do mesoscuto e na porção anterior da linha média respectivamente, 1,31 e 2,50x o diâmetro do escapo. As cerdas mais longas no ápice do escutelo com ca. de 1,03 x o comprimento deste.

Integumento. Liso e polido, apenas com a pontuação pilígera, típica do gênero.

Forma e proporções (Tab. X). Cabeça, 1,18x mais larga que longa, 1,32x mais larga que a distância clipeocelar. Olhos $2,41 \mathrm{x}$ mais longos que largos, levemente divergentes embaixo. Área malar ca. $1,13 \mathrm{x}$ o diâmetro do $2^{\circ}$ flagelômero. Clípeo $0,56 \mathrm{x}$ mais curto que sua largura máxima e $0,38 \mathrm{x}$ a distância clipeocelar. Comprimento da mandíbula $0,57 \mathrm{x}$ a distância clipeocelar; os dentes muito espaçados e no nível do bordo distal (Fig. 33). Comprimento do escapo $0,95 \mathrm{x}$ a distância alvéolo-ocelo lateral, seu diâmetro igual ao do $2^{\circ}$ flagelômero. Distância interocelar $1,42 \mathrm{x}$ maior que a ocelorbital e ca. $1,83 \mathrm{x}$ o diâmetro do ocelo médio. Escutelo aproximadamente semicircular, cerca de $0,49 \mathrm{x}$ mais curto que largo. Tíbia III $0,95 \mathrm{x}$ mais curta que a cabeça, $\mathrm{e}$ $2,07 \mathrm{x}$ mais longa que larga; canto póstero-distal arredondado, pouco projetado, a margem apical fracamente sinuada; contorno da margem posterior, suavemente sinuado. Basitarso III 1,48x mais longo que largo; canto póstero-distal levemente anguloso e margem apical em ângulo um pouco maior que $90^{\circ}$ em relação à margem anterior. Asa anterior 2,70x mais longa que larga e 2,39x a largura máxima da cabeça. Bifurcação de $\mathrm{M}+\mathrm{Cu}$ coincidente com a cu-v. Hâmulos, 5 .

\section{Macho. Figuras 75, 104.}

Material-tipo. Holótipo, operária, de "São Paulo de Olivença AM, Brasil. SA-19, 96-4b, 19,20-I-1977, Camargo, M. Mazucato leg.", ninho no. " $86 \mathrm{c}$ "; parátipos, do mesmo ninho, 35 operárias e 1 macho montados em alfinete, e vários machos e operárias em álcool, com a mesma etiqueta de procedência; ninho número " $85 \mathrm{c}$ ", com os mesmos dados de procedência, data e coletor, 32 operárias e 3 machos em alfinete, e vários exemplares em álcool, depositados na RPSP. 
Material examinado. COLÔMBIA. Cundinamarca: Cundinamarca (localidade?), XII.1958, J. Foester (4 ops., DZUP; 1 op., RPSP). Meta: Puerto López, 9 km NE, 26.VI.1985, D. Roubik (4 ops., STRI); Restrepo, 500m, 1436, J. Bequaert (1 op., Ac. 35658 AMNH). Amazonas: Letícia, 65 km W Amacayacu Nat. Park, 17-30.IX.1986, D. Roubik (2 ops., RPSP; 2 ops., STRI). VENEZUELA. Amazonas: Cerro de la Neblina base camp, 120m, 5.II.1984, Rozen \& Stupakoff (1 op., AMNH); Isla de las Hormigas, VIII.1951, Exp. Fco. Ven. Alto Orinoco (1 op., USNM); Orinoco, 14.II.1992, D. Wittmann (1 op., WITT); ibidem, idem, Huachamakari, $1780 \mathrm{~m}, 03 . I I .1992$ (1 op., WITT). EQUADOR. Sucumbios: Sacha Lodge, 0.5 $\mathrm{S}, 76.5^{\circ} \mathrm{W}, 270 \mathrm{~m}$, 22.II-4.III.1994, Hibbs, ex: malaise (1 op., SEMC); ibidem, idem, 4-14.III.1994 (2 ops., SEMC), 12-22.III.1994 (6 ops., SEMC; 1 op., RPSP), 13-23.III.1994 (4 ops., SEMC), 14-24.III.1994 (8 ops., SEMC; 1 op., RPSP), 24.III3.VI.1994 (3 ops., SEMC), 3.IV-4.V.1994 (2 ops., SEMC), 24.V3.VI.1994 (3 ops., SEMC), 13-23.VI.1994 (2 ops., SEMC), 23.VI3.VII.1994 (2 ops., SEMC), 3-13.VII.1994 (2 ops., SEMC), 1325.VII.1994 (1 op., SEMC), 25.VII-3.VIII.1994 (2 ops., SEMC), 27.VIII10.XI.1994 (3 ops., SEMC), 1-31.XII.1994 (1 op., SEMC); Yasuni National Park, Católica, 13-27.IV.1998, D. Roubik (7 ops., RPSP), 1426.IV.1998 (1 op., RPSP). Napo: Archidona, Andes Orientais, $77^{\circ} 49^{\prime}$ W, $0^{\circ} 55^{\prime}$ S, 750m, 6.VI.1986, Camargo, Bravo, Onore (118 ops., ninho 416c, RPSP); Coca, 20.I.1986, E. Martinez, 017 (1 op., RPSP); Campanarocha, 17.XI.1984, Mônica Chieruzzi, 074 (1 op., RPSP); Limoncocha, $00^{\circ} 24^{\prime} \mathrm{S}, 76^{\circ} 36^{\prime} \mathrm{W}, 25$.VI.1970, M.G. Naumann (1 op., SEMC); ibidem, $20 \mathrm{~km}$ from Limoncocha on Jivena River, Napo-Pastaza, 24.VI.1965, C.R. Patrick (5 ops., MSUC; 1 op., RPSP); Misahuali, 300m, III.1986, D. Sanchez, 061 (1 op., RPSP); Rio Hollin, Tena-Coca Rd., 1400m, 11.VII.1991, D. Roubik (2 ops., STRI); Sarayacu - Loreto Rd., $11.1 \mathrm{~km}, 1200 \mathrm{~m}, 14$. VII.1994, F. Génier, cloud forest, carrion tp. (1 op., SEMC); ibidem, idem, $7.3 \mathrm{~km}, 14$.VII.1994, cloud forest, ex: feces trap (1 op., SEMC); Tena (12 km SW), 7.VII.1976, Jeffrey Cohen, malaise trap (1 op., USNM); ibidem, 28.V.1977, Dave L. Vincent (1 macho, USNM); ibidem, idem, $12 \mathrm{~km} \mathrm{SW,} \mathrm{8.VIII.1976,} \mathrm{S} \mathrm{\&} \mathrm{J} \mathrm{Peck,} \mathrm{ex:}$ suspended carrion trap (3 ops., SEMC); ibidem, $10 \mathrm{~km} \mathrm{NE,} \mathrm{20.III.1983,}$ L. Masner (1 op., SEMC); ibidem, 16.III.1923, F.X. Williams, (2 ops., Ac. 35873AMNH; 1 op., RPSP). Pastaza: Llandia, 17 km N Puyo, 1000m, 19.VII.1994, F. Génier, "remnant rain for., feces tp." (1 op., SEMC); Puyo, 8-10.II.1976, Spangler et al., in malaise trap (1 op., USNM); ibidem, $12 \mathrm{~km} \mathrm{E,} \mathrm{2.II.1976,} \mathrm{Spangler} \mathrm{et} \mathrm{al.} \mathrm{(1} \mathrm{op.,} \mathrm{USNM);}$ ibidem, Puyo Oriente, 5.XII.1938, F. M. Brown (2 ops., AMNH; 1 op., RPSP); Tzapino, $1^{\circ} 11^{\prime} \mathrm{S}-77^{\circ} 14^{\prime} \mathrm{W}, 32 \mathrm{~km}$ NE Tigueno, $400 \mathrm{~m}$, 25.V.1976, Jeffrey Cohen, blacklight trap ( 3 ops., USNM). Morona Santiago: Macas, Rio Upano, 25.I.1939, F.M. Brown (2 ops., AMNH); Sucua, Rio Upano, 3.II.1939, F.M. Brown (2 ops., AMNH; 1 op., RPSP). Zamora Chinchipe; Zamora, 1-5.VI.1976, A Langley et al. (1 op., USNM); ibidem, idem, 6.VI.1976 (1 op., USNM); Zumbi, 10.VI.1976, A. Langley et al. (2 ops., USNM). Prov. ?: Limón, 900 m, E. Ecuador, II.1948, Z. Muller (2 ops., AMNH). PERU. Loreto: Amazon, nr Shishista River, 400m, 1.V.1992, James Danoff-Burg, ex: at light (1 op., SEMC); Apayacu River, mouth of the, nr. the Amazon by the Huitoto and Bora villages, 400m, 27.IV.1992, J. Danoff-Burg (3 ops., SEMC); Atacuari River near the Amazon, 400m, 28.IV.1992, J. Danoff-Burg, ex: nr. a bait of Eucalyptus oil (5 ops., SEMC); Pucallpa, 15.VII.1959, J.M. Schunke (3 ops., DZUP); ibidem, idem, 23.I.1963 (2 ops., DZUP); ibidem, 17.VII.1962, W.T. Van Velzen (1 op., MSUC); ibidem, idem, 25.VII.1962 (2 ops., MSUC), 1.VIII.1962, (1 op., MSUC),12.VIII.1962 (2 ops., MSUC), Rio Calleria, 19.VII.1962 (1 op., MSUC), Yarinacocha, 26.VII.1962 (4 ops., MSUC), 2.VIII.1962, (1op., MSUC); Teniente Lopez, $1.5 \mathrm{~km} \mathrm{~N}, 2^{\circ} 35,66^{\prime} \mathrm{S}, 76^{\circ} 06.92^{\prime} \mathrm{W}, 18$.VII.1993, Richard Leschen, 119, ex. flight intercept trap (1 op., RPSP); ibidem, idem, 20.VII.1993, 133 (1 op., RPSP); Iquitos, 21.VII.1964, L. H. Dodson (5 ops., SEMC); ibidem, 90m, 4.V.1992, A.C., J. Danoff-Burg, ex: netting (1 op., SEMC); ibidem, Vic. Iquitos, 18.XII.1963, R.M. Straw, "disturbed area, low shrubs" (1 op., USNM); Yurimaguas, $20 \mathrm{~km}$ below on rio Huallaga, 30.V.1964, R.M. Straw ( 2 ops., USNM). Huanuco: Tingo Maria, Rio Huallaga, $700 \mathrm{~m}$, 1.IV.1940, Weyrauch (1 op., AMNH); ibidem, idem, 670m, V.1947 (1 op., AMNH). Junín: Colonia Perené, Chanchamayo, 16.VII.1928, R.C. Shannon (2 machos, USNM); La Merced, Chanchamayo, XII.1954, J.D. Rivas S. (21 ops., DZUP; 5 ops. RPSP); ibidem, 800m, 1.III.1939,
Weyrauch (1 op., AMNH); ibidem, idem, 1.III.1939 (1 op., Ac. 37363, AMNH); ibidem, La Salud, 1300m, XII.1954, J.D. Rivas S. (30 ops., DZUP; 6 ops., RPSP); San Ramon, 8 km W, 1220m, 21.VI.1980, D. Baumgartner and B. Greenberg, "hemysynanthropic, fish \& liver bait" (1 op., STRI); ibidem,16 km W, 1433m, 22.VI.1980, D. Goodwin, "asynanthropic, liverbait" (1 op. STRI); ibidem, 21.VI.1980, M. Szyska, B. Greenberg, "fish \& liverbait 2.50 P.M." (1 op., STRI); ibidem, Valle Chanchamayo, 800m, 5.II.1940, W. Weyrauch (3 ops., Ac. 37363, AMNH); ibidem, idem, 10.II.1940, 13 (3 ops., AMNH), 10.II.1940,14 (3 ops., Ac. 37363, AMNH), 17.II.1940, 21 (3 ops., Ac. 37363, AMNH), 26.II.1940 (1 op., Ac. 37363, AMNH), sem data, 28 (2 ops., AMNH); Valle Chanchamayo, 1600m, sem data, Weyrauch, 180 (1 op., AMNH; 1 op., RPSP). Cuzco: Avispas, SE Cusco, IX.1962, L.E. Peña (1 op., MZSP); ibidem, idem, 20.IX.1962 (13 ops., DZUP; 3 ops., RPSP), 9.X.1962 (1 op., DZUP); Quincemil-Cuzco, 20.X.1961, Luis E. Peña (5 ops., DZUP); ibidem, idem, 20.VIII.1962 (2 ops., DZUP); Cuzco, Pilcopata, 600m, 8-10.XII.1979, J.B. Heppner, premontane moist forest ( 2 ops., USNM); ibidem, idem, 11-14.XII.1979 (2 ops., USNM). Madre de Dios: Puerto Maldonado, 31.IX.1962, Luis Peña (1 op., DZUP); ibidem, 15 km NE, Reserva Cuzco Amazónica, 12³3'S, 6903'W, 200m, 12.II.1990, Luis Coloma, 41 (26 ops., SEMC; 2 ops., RPSP); ibidem, idem, 42 (2 ops., SEMC), 15.II.1990, 45, ex. Maximilian (2 op., SEMC), Quebrada Juliaca, 190m 22-25.II.1990, 49 (1 op., SEMC), 21.I.1990, 16 (1 op., SEMC); ibidem, 15 km NE, 200m, 10.VI.1989, J. Ashe, R. Leschen, 10, ex: at light (1 op., SEMC); ibidem, idem, 15.VI.1989, 59, ex: light intercept (1 op., SEMC), 22.VI.1989, 205 (1 op., SEMC), 24.VI.1989, 240 (3 ops., SEMC), 26.VI.1989, 291 (1 op., SEMC), 30.VI.1989, 332 (1 op., SEMC), 2.VI.1989, 366 (2 ops., SEMC), 4.VII.1989, 380 (1 op., SEMC), 7.VII.1989, 428, ex. molasses trap. (1 op., SEMC), 24.VI.1989, 242 (1 op., SEMC); Rio Tambopata Res., 30 air km SW, Pto Maldonado, 290m, 16-20.XI.1979, J.B. Heppner, subtropical moist forest (1 op., USNM). Depto.?: San José, Lourdes, $1200 \mathrm{~m}$, Rio Chinchipe, 3.VIII.1948, Weyrauch (1 op., SEMC); Caja, 34-7(data?), P. Weiss (1 op., USNM); Pampaconas R., VIII.1911, Yale Peru Exp. (7 ops., USNM); Rio Namballe, $1.200 \mathrm{~m}$, sem data, Weyrauch (5 ops., SEMC); Divisoria, 1300m, II.1943, Weyrauch (12 ops., SEMC; 2 ops., RPSP); ibidem, idem, 1500m, II.1947 (2 ops., AMNH); Middle Rio Ucayali, 27.X.1923, H. Bassler, F6116 (1 op., Ac. 33591, AMNH). BRASIL. Amazonas: Barcelos, R. Negro, 6.VII.1980, Camargo, Mazucato (2 ops., RPSP); Benjamin Constant, SB-19, 70-4c, 13-14.I.1977, Camargo, M. Mazucato (12 ops., RPSP); Camanaus, R. Negro, SA-19, $66^{\circ} 54^{\prime} \mathrm{W}, 0^{\circ} 8^{\prime} \mathrm{S}, 12-14$.VIII.1980, Camargo, Mazucato (93 ops., RPSP); Carauari, rio Juruá, $66^{\circ} 54^{\prime} \mathrm{W}, 4^{\circ} 53^{\prime} \mathrm{S}$, 22.VII.1993, Camargo, Pedro, Mazucato (75 ops., ninho 520c, RPSP); ibidem, idem (4 ops., 932757, 932761, 932766, 932767, RPSP); Fonte Boa, SA-19, 66-3f.xii, 2425.I.1977, Camargo, M. Mazucato (8 ops., RPSP); Forte da Graça, rio Juruá, $66^{\circ} 6^{\prime} \mathrm{W} 3^{\circ} 39^{\prime} \mathrm{S}, 02-06$.VIII.1993, Camargo, Pedro, Mazucato (60 ops., mais ops. e 10 machos em álcool, ninho 558, 87 ops., ninho 573c, 17 ops., 933750, 933765-766, 933790, 933801-802, 933804 , 960159-165, RPSP); Foz do rio Curicuriari, R. Negro, SA.19, 66 $49^{\circ} \mathrm{W}$, 0'13'30', 15-21.VII.1980, Camargo, Mazucato (50 ops., material em álcool, ninho 213c, RPSP); Igarapé Jaraqui, R. Juruá, $66^{\circ} 23^{\prime} \mathrm{W}, 4^{\circ} 28^{\prime} \mathrm{S}$, 27-29.VII.1993, Camargo, Pedro, Mazucato (2 ops., 933220, 933226, RPSP); Lago Uará, rio Solimões, $65^{\circ} 35^{\prime} \mathrm{W}, 2^{\circ}$ 41' S, 09-13.VIII.1993, Camargo, Pedro, Mazucato (78 ops., mais ops. e 20 machos em álcool, ninho 574c, 60 ops., ninho 597c, RPSP); Paraíso, rio Japurá, $65^{\circ} 5^{\prime} \mathrm{W}$, $2^{\circ}$ 9' S, 20.VIII.1993, Camargo, Pedro, Mazucato (60 ops., ninho 614c, RPSP); São Gabriel da Cachoeira, Morro 6 Lagos, 300m, 28.IX-6.X.1990, J.A. Rafael, J. Vidal, arm. malaise, (2 ops., UFVB); São Paulo de Olivença, SA-19, 69-4b, 19-20.I.1977, Camargo, M. Mazucato (16 ops., RPSP); Tapurucuara, Uaupês, X.1954, A. Aguirre (8 ops., DZUP; 2 ops., RPSP); Tefé, 29.VI.1979, Charles Clements (1 op., RPSP); Uaupês, VII.1956, M. Alvarenga (2 ops., DZUP); Vendaval, SA-19, 69-3,h-vi, 16-18.I.1977, Camargo, M. Mazucato (4 ops., RPSP);Vila Nova do Tonantins, SA-19, 68.3f-ix, 22-23.I.1977, Camargo, Mazucato (22 ops., ninho 97c, RPSP). Acre: Acrelandia, 6.XI.1993, E.F. Morato (1 op., 940121, RPSP); Capixaba, 30.VI.1993, E.F. Morato (2 ops., 940119, 94118, RPSP); Cruzeiro do Sul, II.1963, M. Alvarenga (12 ops., DZUP; 3 ops., RPSP); Feijó, Pe. Guilherme, XII.1956 (2 ops., MZSP); ibidem, XII.1956, Werner (10 ops., MZSP); Parque Nacional Serra do Divisor, Sítio 1, Rio Branco, 
08¹6'51"S - 73¹5’13”W, 10.III.1997, E.F. Morato (4 ops., 97204445, 972047-48, RPSP); ibidem, idem, Sítio 3, T. de caça Piroca, 07²8'38"S - 7341'54”W, 12-13.XI.1996 (6 ops., 970918-970920, 970923-24, 970926, RPSP), Sítio 4, Rio Ouro Preto, 08²4'19”S $72^{\circ} 51$ '28”W, 15.III.1997 (105 ops., 972152-972251, RPSP), Sítio 5, Igarapé Ramon, 07²7’32”S, 7346’28”W, 16.XI.1996 (23 ops., 971293, 971318,971321, 971326, 971339, 971345-48, 971351, 971404, 971406, 971409-11, 971413-16, 971418-20, 971424, RPSP), Sítio 6, Trilha do Anil, 07²6'27"S - 73³9'28”W, 08-09.XI.1996 (2 ops., 971478, 971482, RPSP), Sítio 8, Rio Azul, 07³3’24”S - 73¹6’36”W, 24.XI.1996 (4 ops., 971754, 971756, 971763, 971765, RPSP), Sítio 9, Várzea Gibraltar, 07²7’02”S - 73³6’30”W, 21.XI.1996 (2 ops., 97192122, RPSP), Sítio 10, Rio Juruá, 0852’31”S, 7246’55”W, 24.III.1997 (14 ops., 972916-972929, RPSP), Sítio 11, R. Juruá Várzea, 0851'7’S, 7252’20”W, 25.III.1997 (2 ops., 973206-07, RPSP); Rio Tejo, Alto Juruá, RESEX, 22.VII.1995, M.L. Oliveira (2 ops., AJ0085 e AJ0107, RPSP); Rio Branco, 15-20.XI.1961, F.M. Oliveira (26 ops., DZUP; 5 ops. RPSP); ibidem, idem, 12.VI.1993, 09.V.1994, 27.V.1994, 29.IV.1994 (58 ops., RPSP); ibidem, 20.VI.1993, 3.VII.1993, 20.VIII.1993, E.F. Morato (6 ops., 1 com no. 940116, RPSP); ibidem, IV.1983, W.E. Kerr (7 ops., RPSP); ibidem, 20.V.1990, L.A.O. Campos (4 ops., UFVB); ibidem, idem, 21.V.1990 (1 op., UFVB); ibidem, UFAC/PZ, 29.VI.1995, A.H. Machado, E M Santos, 1.105 (1 op., OLIV); ibidem, idem, 27.IV.1995, 876 (1 op., RPSP), 24.VIII.1995, 1334 (1 op., RPSP), 17.VIII.1995, 1255 (1 op., RPSP); Sena Madureira, Rio Iaco, $68^{\circ} 40^{\prime} 48^{\prime \prime} \mathrm{W}, 09^{\circ} 03^{\prime} 14,4^{\prime \prime} \mathrm{S}, 27 . \mathrm{III} .1994$, E.F. Morato (4 ops., RPSP); ibidem, idem, Rio Caeté, 6840’4,8"W, 0903’14,4"S, 1-2.IV.1994 (3 ops., RPSP). BOLÍVIA. La Paz: Cajuata, 1921-22, W.M. Mann, Mulford BioExpl. (1 op., USNM); Canamina, W.M. Mann, VII.1921-22(?), Mulford BioExpl. (105 ops., USNM; 2 ops., RPSP); Espia, Rio Bopi (sic = Boopi), VII.1921-22(?), Wm. M. Mann, Mulford BioExpl. (3 ops., USNM); Tumupasa, XII.1921-22(?), W.M. Mann, Mulford Bioexpl. (2 ops., USNM). Beni: Blancaflor, W.M. Mann, I.1921-22(?), Mulford BioExpl. (4 ops., USNM); Riberalta, I.1921-22(?),Wm. M. Mann, Mulford BioExpl. (1 op., USNM); Rurrenabaque, Rio Beni, XI.1921-22(?) W.M. Mann, Mulford BioExpl. (19 ops., USNM; 2 ops., RPSP).

Distribuição geográfica e hábitat. Matas tropicais do oeste da Amazônia, Brasil, até os Andes Orientais no Equador, Peru, Colômbia e Bolívia (Fig. 162).

Nidificação. Sob raízes de epífitas, sob a base de folhas de palmeiras (Camargo, et al., obs. pessoal), beirais de telhados e outros lugares protegidos em edificações humanas (Oliveira, com. pessoal).

Etimologia. Do grego, epi + phytón + philos, referindo-se a preferência da espécie para nidificar sob raízes de epífitas.

Discussão. Apresenta como características principais, pelas quais pode ser reconhecida, os dentes da mandíbula muito separados um do outro, em arco profundo (Fig. 33), e cerdas longas na base do escapo (veja também comentários em $P$. nhambiquara sp. nov., . batesi sp. nov., e P. subtilis sp. nov.).

\section{Partamona subtilis sp. nov.}

(Figs. 34, 134, operária; 163, distribuição; Tabs. II-X)

Diagnose. Abelhas de porte pequeno (1.m.c. 2,3-2,4 mm, c.a.a. 5,5-5,8 mm; Tabs. III, IV). Integumento preto, amarelado ou mesclado. Sutura epistomal, basitarso e tíbia III, enegrecidos (em exemplares amarelados, só a metade apical da tíbia III). Mandíbula com a metade basal amarelada e a porção distal ferrugínea, ápice ferrugíneo-escuro, côndilos pretos. Flagelo castanho escuro ou enegrecido, o $1^{\circ}$ artículo mais claro. Estrias paroculares estreitas, ca. $0,8 \mathrm{x}$ o diâmetro do $2^{\circ}$ flagelômero, um pouco alargadas embaixo (ca. 1,0-1,2x o diâmetro do $2^{\circ}$ flagelômero), ou aproximadamente com a mesma largura em toda a extensão, podendo chegar até o topo do olho ou um pouco abaixo. Pilosidade predominantemente preta; cerdas eretas do mesoscuto e escutelo enegrecidas, amareladas ou misturadas; cerdas eretas da metade superior dos lados dos mesepisternos enegrecidas ou esbranquiçadas; cerdas na região ventral dos mesepisternos, coxas, trocanteres, e esternos, esbranquiçadas. Membrana das asas levemente ferrugínea; microtríquias pretas em toda a asa, ou amareladas no pterostigma e partes adjacentes (porção mediana da asa); veias méleas, mas escurecidas pelas microtríquias fuscas. Cerdas do escapo curtas, com uma ou duas cerdas na base um pouco mais longas que as demais $(1,0-1,1 \mathrm{x}$ o diâmetro do escapo; Tab. VII). Cerdas eretas das áreas paroculares, ao lado dos alvéolos, delgadas, mais curtas que o diâmetro do escapo, pouco destacadas em relação às cerdas decumbentes. Cerdas do escutelo $0,9-1,1$ x o comprimento deste. Área basal do propódeo uniformemente pilosa, os pontos pilígeros bem marcados. Dentes da mandíbula muito espaçados (Fig. 34). Área malar, distância interocelar, distância ocelorbital, tíbia III, e comprimento da asa anterior, normais (Tabs. V, VI, VIII, IX). Bifurcação da $\mathrm{M}+\mathrm{Cu}$ anterior à cu-v.

Variação. Uma característica interessante é a variação no padrão de coloração do integumento (inicialmente, os exemplares amarelos e os enegrecidos foram separados como espécies distintas). No material proveniente de Rurrenabaque, Bolívia, de uma mesma série, ocorrem indivíduos com integumento enegrecido e amarelado. Na série tipo, do Acre, os indivíduos são pretos, castanhos ou mesclados.

\section{Operária.}

Dimensões. Comprimento total aproximado, $5,73 \mathrm{~mm}$; da asa anterior, 5,48 $\mathrm{mm}$ (incluindo a tégula, 5,98 $\mathrm{mm}$ ); largura máxima da cabeça, 2,26 mm; do TIII, 2,02 mm (Tab. X).

Cor do integumento. Preto, inclusive o metanoto (em alguns parátipos, castanho ferrugíneo, com sutura epistomal, áreas ao redor dos ocelos, metade apical das tíbias e basitarsos III enegrecidos); os tarsômeros da perna I ferrugíneos. Labro amarelado, mandíbula amarelada na metade basal e ferrugínea em direção ao ápice, côndilos enegrecidos. Escapo enegrecido, exceto por uma pequena mancha mais clara na base. Flagelo castanho escuro, mais enegrecido na face superior. Máculas da face nítidas, as do tórax ausentes, exceto alguns resquícios nas laterais do mesoscuto. Manchas do clípeo aproximadamente triangulares, apagadas medianamente; a distância entre elas, na parte apical do clípeo, menor que o diâmetro do $2^{\circ}$ flagelômero. Mancha supraclipeal irregular; sem mancha frontal, apenas com um triângulo invertido, abaixo do ocelo médio, aproximadamente tão longo quanto o diâmetro do ocelo. Estrias paroculares um pouco alargadas embaixo (ca. 1,29x o diâmetro 
do escapo), afilando suavemente para o ápice, chegando até a altura da linha da menor distância interorbital superior. Genas com uma estria acompanhando os $2 / 3$ inferiores do olho. Membrana das asas levemente ferrugínea, mais escura na metade basal (células radial, $1^{\mathrm{a}}$ e $2^{\mathrm{a}}$ cubitais); microtríquias enegrecidas na base e no ápice, no pterostigma e áreas adjacentes, amarelas; veias méleas, escurecidas pelas microtríquias, $\mathrm{C}$ e $\mathrm{R}$ mais escuras basalmente.

Pilosidade. Predominantemente enegrecida; as cerdas ventrais do tórax, coxas, trocanteres e esternos, branquíssimas. Área basal do propódeo sem faixa glabra mediana. Franja prémarginal do TIII com cerdas muito mais curtas na região mediana que nas laterais. Cerdas da base do escapo 1,08x mais longas que o diâmetro deste. Áreas paroculares inferiores, ao lado dos alvéolos, com cerdas eretas muito curtas, ca. 0,62x o diâmetro do escapo, pouco diferenciadas em relação às cerdas decumbentes. Cerdas do clípeo 1,08x o diâmetro do escapo; na fronte $1,15 x$; no vértice mais longas, ca. 2,15x; no disco do mesoscuto e na porção anterior da linha média 1,23 e 1,85x respectivamente. Cerdas mais longas no ápice do escutelo com ca. de 1,06x o comprimento deste.

Integumento. Liso e polido, apenas com a pontuação pilígera típica do gênero.

Forma e proporções (Tab. X). Cabeça, 1,15x mais larga que longa, 1,30x mais larga que a distância clipeocelar. Olhos 2,53x mais longos que largos, subparalelos. Área malar ca. 0,93x o diâmetro do $2^{\circ}$ flagelômero. Clípeo $0,55 \mathrm{x}$ mais curto que sua largura máxima e $0,36 \mathrm{x}$ a distância clipeocelar. Mandíbulas $0,57 \mathrm{x}$ a distância clipeocelar; os dentes muito espaçados e no nível do bordo distal (Fig. 34). Escapo 0,92x a distância alvéolo-ocelo lateral, seu diâmetro um pouco menor que o do $2^{\circ}$ flagelômero. Distância interocelar 1,13x maior que a ocelorbital e ca. de 1,70x o diâmetro do ocelo médio. Escutelo aproximadamente semicircular, cerca de $0,53 \mathrm{x}$ mais curto que largo. Tíbia III $0,93 \mathrm{x}$ mais curta que a cabeça, e 2,15x mais longa que larga; canto póstero-distal arredondado, pouco projetado, margem apical fracamente sinuada; contorno da margem posterior, suavemente sinuado. Basitarso III 1,67x mais longo que largo; canto pósterodistal anguloso, fortemente projetado, margem apical em ângulo maior que $100^{\circ} \mathrm{em}$ relação à margem anterior. Asa anterior $2,74 \mathrm{x}$ mais longa que larga, e 2,42x mais longa que a largura máxima da cabeça. Bifurcação de $\mathrm{M}+\mathrm{Cu}$ anterior à cu-v. Hâmulos, 5 .

\section{Macho. Desconhecido.}

Material-tipo. Holótipo, operária, de "BRASIL. Acre Parque Nacional Serra do Divisor 0852’31”S - 7246’55”W”, “24/III/1997. E.F. Morato, Rio Juruá - Sítio 10 no. 972933", parátipos, 7 operárias da mesma série, nos. 972913-915, 972930-932, 972934; e 18 operárias de "BRASIL Acre Parque Nacional Serra do Divisor $08^{\circ} 16^{\prime} 51^{\prime \prime S}-73^{\circ} 15^{\prime} 13^{\prime \prime}$ "W", "10/ III/1997, E.F. Morato, Rio Branco - Sítio 1”, nos. 972050 e 972061 , depositados na RPSP.

Material examinado. BRASIL. Acre: Rio Branco, Reserva Catuaba, 12.VIII.1993, M.L. Oliveira (1 op., 940120, RPSP); Sena Madureira,
Rio Caeté, 6840’4,8”W, 0903’14,4”S, 1.IV.1994, E.F. Morato (2 ops., RPSP); ibidem, idem, 2.IV.1994 (2 ops., RPSP). PERU. Cuzco: Cusco, Hacienda Maria, III.1952, F. Woytkowski (1 op., SEMC); Santa Isabel, XI.1951, F. Woytkowski (1 op., SEMC); Madre de Dios: Manu, Pakitza, trails 1 , 1st stream, $12^{\circ} 7^{\prime} \mathrm{S}$ : $70^{\circ} 58^{\prime} \mathrm{W}, 250 \mathrm{~m}, 9-14 . I X .1988$, O. Flint \& N. Adams, malaise trap ( 3 ops., USNM). BOLÍVIA. Beni: Rurrenabaque, 175m, 17.X.1956, L. Peña (1 op., SEMC); ibidem, Rio Beni, XI(ano?), WM Mann, Mulford BioExpl. 1921-22 (23 ops., USNM; 4 ops., RPSP).

Distribuição geográfica e hábitat. Florestas tropicais do extremo oeste da Amazônia (Acre, Brasil, sudeste do Peru e norte da Bolívia, região do Beni; Fig. 163).

\section{Nidificação. Desconhecida}

Etimologia. Do latim, subtilis, fino, delgado, referindo-se a aparência longilínea do corpo.

Discussão. Essa espécie, restrita à porção ocidental da Amazônia parece ser bastante rara. Em coletas intensivas, durante dois anos, na região de Rondônia, nunca foi encontrada e, no estado do Acre, onde também estão sendo feitas coletas periódicas, pouquíssimos indivíduos foram coletados. P. subtilis apresenta algumas características que, combinadas, permitem distinguí-la facilmente das demais espécies: a forma do corpo alongada, o porte pequeno associado a uma mandíbula com dentes muito espaçados (Fig. 34), além da pilosidade ventral branquíssima e bifurcação de $\mathrm{R}+\mathrm{M}$ anterior à cu-v. No Parque Nacional da Serra do Divisor, Acre, Brasil, ocorrem indivíduos com integumento enegrecido e castanho-claro. Material proveniente de ninhos, com machos e dados sobre os hábitos de nidificação, poderão trazer esclarecimentos sobre o relacionamento filogenético com as demais espécies do grupo bilineata / epiphytophyla. Se o grande espaçamento entre os dentes da mandíbula for uma condição derivada dentro do grupo, como sugerido aqui, é possível que $P$. subtilis tenha $P$. epiphytophila como espécie irmã (Figs. 34 e 33).

\section{Partamona nhambiquara sp. nov.}

(Figs. 41, 135, operária; 107, macho; 163, distribuição; Tabs. II-X)

Diagnose. Abelhas de porte médio (1.m.c. 2,5-2,7 mm, c.a.a. 5,9-6,4 mm; Tabs. III, IV). Integumento preto. Mandíbula predominantemente ferrugínea, com ca. 1/4-1/3 da porção basal amarelada, ápice ferrugíneo-escuro, côndilos pretos e a porção apical restante castanho-ferrugínea. Flagelo castanho-escuro. Estrias paroculares estreitas, ca. $0,6-0,8 \mathrm{x}$ o diâmetro do $2^{\circ}$ flagelômero, aproximadamente com a mesma largura em toda a extensão, ou um pouco alargadas embaixo (ca. 1,1-1,2x), chegando até a interorbital superior (Fig. 135). Pilosidade preta. Membrana das asas levemente ferrugínea; microtríquias pretas em toda a asa, ou amarelas apenas na região do pterostigma; veias méleas, mas escurecidas pelas microtríquias fuscas. Cerdas da base do escapo muito mais longas que o diâmetro deste (1,3-1,8x; Tab. VII). Cerdas eretas das áreas paroculares, ao lado dos alvéolos, aproximadamente tão longas quanto o 
diâmetro do escapo. Cerdas do escutelo 0,9-1,0x o comprimeno deste. Área basal do propódeo com uma faixa glabra mediana aproximadamente tão larga quanto o diâmetro do $2^{\circ}$ flagelômero, ou um pouco mais. Dentes da mandíbula muito espaçados, como na figura 41. Área malar, distância interocelar, distância ocelorbital, tíbia III e comprimento da asa anterior, normais (Tabs. V, VI, VIII, IX). Bifurcação da $\mathrm{M}+\mathrm{Cu}$ geralmente coincidente com a cu-v (raramente levemente anterior). Macho, basitarso III alongado, achatado ou convexo-côncavo; tíbia III estreita, como na figura 75 de P. epiphytophila; EVII com a projeção mediana curta e triangular, os chanfros laterais curtos e largos (Fig. 107).

\section{Operária.}

Dimensões. Comprimento total aproximado, $6,23 \mathrm{~mm}$; da asa anterior, $6,35 \mathrm{~mm}$ (incluindo a tégula, 7,14 $\mathrm{mm}$ ); largura máxima da cabeça, 2,70 mm; do TIII, 2,60 mm (Tab. X).

Cor do integumento. Preto, os tarsômeros ferrugíneos. Tégula enegrecida, um pouco mais clara na porção discal. Labro amarelado; mandíbula bem amarelada no terço basal, tornandose castanho-ferrugínea em direção ao ápice; côndilos e ápice enegrecidos. Escapo com a face inferior amarelada e a superior enegrecida. Flagelo com a face inferior castanha e a superior enegrecida. Máculas mais nítidas apenas nas paroculares, nas demais regiões um pouco difusas. Manchas no clípeo aproximadamente triangulares, muito apagadas, só nos cantos laterais inferiores um pouco mais nítidas. Mancha supraclipeal muito difusa, aproximadamente trapezoidal. Sem mancha abaixo do ocelo, apenas com uma pequena estria junto ao sulco frontal, muito apagada. Paroculares aproximadamente com a mesma largura em toda a extensão (ca. $0,63 \mathrm{x}$ o diâmetro do escapo), apenas um pouco mais alargadas embaixo $(0,75 \mathrm{x})$, terminando difusa na altura da linha da menor distância interorbital superior. Genas com uma pequena mancha margeando o terço inferior do olho. Estrias laterais do mesoscuto um pouco difusas; nas axilas apenas uma linha amarela junto a sutura escutelar; o bordo posterior do escutelo com uma estria difusa, interrompida medianamente. Membrana das asas muito levemente ferrugínea, um pouco mais escura na metade basal; microtríquias enegrecidas em toda asa; veias ferrugíneas, $\mathrm{C}$ e $\mathrm{R}$ mais escurecidas na porção basal, pterostigma mais claro.

Pilosidade. Predominantemente enegrecida, apenas o ápice das cerdas ventrais, mais claro. Área basal do propódeo com uma faixa glabra mediana. A franja pré-marginal do TIII com cerdas muito mais curtas na região mediana que nas laterais. Cerdas da base do escapo 1,25x mais longas que o diâmetro deste. Áreas paroculares inferiores, ao lado dos alvéolos, com cerdas eretas tão longas quanto o diâmetro do escapo. Cerdas do clípeo tão longas quanto o diâmetro do escapo; na fronte $1,44 \mathrm{x}$; no vértice mais longas, ca. 2,38x; no disco do mesoscuto e na porção anterior da linha média 1,44 e 2,13x respectivamente. Cerdas mais longas no ápice do escutelo com ca. de $0,93 \mathrm{x}$ do comprimento deste.
Integumento. Liso e polido, apenas com a pontuação pilígera típica do gênero.

Forma e proporções (Tab. X). Cabeça, 1,16x mais larga que longa, 1,31x mais larga que a distância clipeocelar. Olhos 2,34x mais longos que largos, um pouco divergentes embaixo. Área malar ca. de $1,25 x$ o diâmetro do $2^{\circ}$ flagelômero. Clípeo $0,56 x$ mais curto que sua largura máxima e $0,37 \mathrm{x}$ a distância clipeocelar. Mandíbulas 0,57x a distância clipeocelar; os dentes espaçados e no nível do bordo distal (Fig. 41). Escapo 0,95x a distância alvéolo-ocelo lateral, seu diâmetro igual ao do $2^{\circ}$ flagelômero. Distância interocelar 1,39x maior que a ocelorbital e ca. de 1,92x o diâmetro do ocelo médio. Escutelo aproximadamente semicircular, cerca de $0,49 \mathrm{x}$ mais curto que largo. Tíbia III $0,93 \mathrm{x}$ mais curta que a cabeça, e 2,07x mais longa que larga; canto póstero-distal arredondado-subanguloso (em uma das pernas), pouco projetado, margem apical fracamente sinuada; contorno da margem posterior, suavemente sinuado. Basitarso III 1,65x mais longo que largo; canto póstero-distal subanguloso e margem apical em ângulo um pouco mais aberto que $90^{\circ} \mathrm{em}$ relação à margem anterior. Asa anterior $2,67 \mathrm{x}$ mais longa que larga e 2,35x a largura máxima da cabeça. Bifurcação de $\mathrm{M}+\mathrm{Cu}$ coincidente com a cu-v. Hâmulos, 5.

\section{Macho. Figura 107.}

Material-tipo. Holótipo, operária, de "Brasil, Rondônia GuajaráMirim Sa. Pacaás Novos", "20/janeiro/1996 M.L. Oliveira Col.", "PN 0810”, mais 4 operárias, parátipos, depositados na RPSP.

Material examinado. BRASIL. Pará: Jacareacanga, X.1959, M. Alvarenga (1 op., DZUP; 1 op., RPSP). Rondônia: Abunã, XI.1962, W. Bokermann (1 op., SEMC); Ariquemes, $62 \mathrm{~km} \mathrm{~S}$, Faz. Rancho Grande nr. Cacaolândia, $10^{\circ} 32^{\prime} 0^{\prime}$ 'S, 62 48'0”W, 25.XII.1995; D. Kistner, BRA1K 03 No. 5278, ex: flight intercept trap (1 op., SM0135116, SEMC); ibidem, idem, 28.XII.1995, BRA1K 01 No. 5288, ex: flight intercept trap (2 ops., SM0134997, 0135015, SEMC), 29.XII.1995, BRA1K 02 No. 5293, ex: flight intercept trap (3 ops., SM0135030, 0135048, 0135050, SEMC); Alta Floresta, linha 47,5, $11^{\circ} 55,522^{\prime} \mathrm{S}, 62^{\circ} 07,953^{\prime} \mathrm{W}$, 25.IV.1997, Brown, Boina, Vieira (1 op., 8479, RPSP); Buritis, oeste de Buritis, $10^{\circ} 09^{\prime} 07,0^{\prime \prime} \mathrm{S}, 63^{\circ} 55^{\prime} 41,5^{\prime}$ 'W, 10.IX.1997, Brown, Boina, Vieira (1 op., no. 14360, RPSP); Campo Novo, Rio Candeia, Reg. Cpo. Novo, 10-18.VIII.1985, V. Py-Daniel, L. Aquino (11 ops., INPA); ibidem, idem, Ig. Tracoazinho, 1-15.VIII.1985 (2 ops., INPA); Costa Marques, 12²6’05,2”S, 64²0'02,6”W, 19.XI.1996, Brown, Boina, Vieira (1 op., 3363, RPSP); Cujubim, 09²0,765'S, 62³6,792'W, 26.III.1997, Brown, Boina, Vieira (1 op., 7263, RPSP); ibidem, idem, linha 46 a Machadinho, 09²4,606'S, 62³3,479'W, 25.III.1997 (1 op., 7062, RPSP), linha 14, 09²0,154'S, 62³3,110'W, 24.III.1997 (9 ops., 6648, 6649, 6680, $6683,6726,6761,6766,6769,6773$, RPSP), linha C2, $09^{\circ} 23,205^{\prime} \mathrm{S}$, 62 ${ }^{\circ} 34,854$ ”W, 25.III.1997, (8 ops., 7198, 7201-7203, 7219, 7220, 7247, 7248, RPSP); Extrema, linha 4, 09 $44^{\prime} 56,5^{\prime}$ 'S, 66 $26^{\prime} 58,5^{\prime \prime} \mathrm{W}$, 26.VI.1997, Brown, Boina, Vieira (4 ops., 11274, 11294, 11295, 11328, RPSP); Guajará-Mirim, S 10³3,751”, W 6445,463’, 09.IX.1996, Brown, Boina, Vieira (1 op., 701, RPSP); ibidem, idem, S 10³3,751', W 644ㄴ,463'W, 10.IX.1996 (1 op., 544, RPSP), S 10¹9,434', W 64³3,849’W, 11.IX.1996 (4 ops., 429, 430, 432, 436, RPSP); Parque Estadual G.M., 10³4'26,1'S, 6445'23,7'W, 30.VI.1997 (1 op., 11592, RPSP); ibidem, Sa. Pacaás Novos, 22.VIII.1995, F.M. Dantas (2 ops., PN 0431, PN 0438, RPSP); ibidem, idem (8 ops., PN0382, 383, 385, 415, 416, 419, 420, 421, OLIV); ibidem, 16.VI.1995, A.L. Oliveira (1 op., PN0185, OLIV); ibidem, idem, 23.VII.1995 (1 op., PN0302, OLIV), 14.X.1995 (10 ops., PN0647, 659-665, 672, 680, OLIV), 16.XI.1995 
(3 ops., PN0695, 727, 743 OLIV), 27.XII.1995 (1 op., PN0786, OLIV),

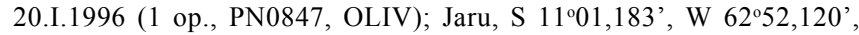
07.I.1997, Brown, Boina Vieira (1 op., 4545, RPSP); Machadinho, linha $32,09^{\circ} 26,939^{\prime} \mathrm{S}, 61^{\circ} 57,042^{\prime} \mathrm{W}, 20 . \mathrm{III} .1997$, Brown, Boina, Vieira (2 ops., 6357, 6359, RPSP); ibidem, idem, Estrada 133 a Tabajara, 09 $03,395^{\prime}$ 'S, 62 $03,749^{\circ}$ W, 22.III.1997, (3 ops., 6536, 6583, 6584, RPSP); Mirante da Serra, S $11^{\circ} 10,181^{\prime}$, W 62 ${ }^{\circ} 51,110^{\prime}$, 25.IX.1996, Brown, Boina, Vieira (5 ops., 2461, 2469, 2448, 2499, 2518, RPSP); ibidem, idem, S $11^{\circ} 03,255^{\prime}$, W 62 ${ }^{\circ} 52,614^{\prime}, 18$.XII.1996 (2 ops., 4336 , 4337, RPSP), S 1056,284', W 62²4,425', 31.I.1997 (1 op., 5135, RPSP), linha $76,11^{\circ} 07,142^{\prime}$ S, $62^{\circ} 48,389^{\prime}$ 'W, $18 . I V .1997$ (5 ops., 7729 ,

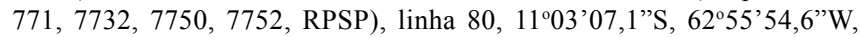

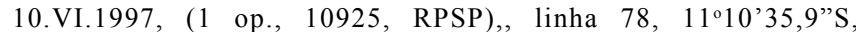
62 46'58,1”W, 17.VII.1997 (1 op., 11617, RPSP), linha 52, 1056'36,9'S, 62040'52,8"W, 14.VIII.1997 (3 ops., 12942, 12944, 12947, RPSP), linha $74,11^{\circ} 08^{\prime} 22,4^{\prime \prime} \mathrm{S}, 62^{\circ} 46^{\prime} 04,9$ 'W, 21.VIII.1997 (1 op., 13568, RPSP), linha 74, $11^{\circ} 08^{\prime} 58,5^{\prime}$ 'S, 62 $47^{\circ} 33,9$ 'W, 21.VIII.1997 (1 op.,

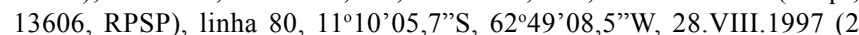
ops., 13704, 13713, RPSP), linha $84,1^{\circ} 08^{\prime} 01,6^{\prime \prime} \mathrm{S}, 62^{\circ} 53^{\prime} 21,3$ ”'W, 29.VIII.1997 (1 op., 13837, RPSP), linha 76, $11^{\circ} 05^{\prime} 18,9$ "S, 62'50'29,6”W, 30.VIII.1997 (4 ops., 13968, 13999, 14002, 14012, RPSP); Nova Califórnia, linha Cascalho, $09^{\circ} 47^{\prime} 10,4^{\prime}$ 'S, 66 $66^{\circ}$ '48,3”W, 25.VI.1997, Brown, Boina, Vieira (8 ops., 11205-11208, 11215, 11232, 11251, 11256, RPSP); ibidem, idem, linha Pioneiros, 0947'57,7”S, 66036'10,7'W, 25.VI.1997 (6 ops., 11080, 11099-11102, 11115, RPSP); Nova Mamoré, S 10¹9,440', W 6446,775', 12.IX.1996, Brown, Boina, Vieira (3 ops., 297, 301, 302, RPSP); Nova União, S 1046,486', W 62²9,550', 26.IX.1996, Brown, Boina, Vieira (1 op., 2591, RPSP); ibidem, idem, S $10^{\circ} 52,532^{\prime}, \mathrm{W} 62^{\circ} 35,181^{\prime}$, 8.XI.1996 (2 ops., 3004, 3005, RPSP), S 1048,715', W 62³3,196', 09.I.1997 (1 op., 4797, RPSP), S 1051,788', W 62²3,348', 08.III.1997 (1 op., 6215, RPSP), linha $48,10^{\circ} 51,026^{\prime} \mathrm{S}, 62^{\circ} 36,654^{\prime} \mathrm{W}, 16 . \mathrm{IV} .1997$ (1 op., 7504, RPSP), linha $28,10^{\circ} 56^{\prime} 17,4$ "S, $62^{\circ} 25^{\prime} 08,3$ "W, 12.VI.1997 (2 ops., 10910, 10912, RPSP), linha 36, 1059'229”'S, 62³4'18,0”W, 18.VII.1997, (1 op., 11787, RPSP), 10'53'16,6”S, 62²6’23,8”'W, 01.VIII.1997 (4 ops., 12417, 12421-12423, RPSP), linha 36, 10 $0^{\circ} 56^{\prime} 09,8^{\prime} \mathrm{S}, 62^{\circ} 34$ ' $16,9^{\prime} \mathrm{W}$, 11.VIII.1997 (1 macho, 12715, RPSP), linha 44, 1055'52,1"S, 62'38'28,8”W, 13.VIII.1997 (1 op., 12854, RPSP); Ouro Preto (= Ouro Preto D'Oeste), S 1041,970', W 62 ${ }^{\circ} 19,332^{\prime}$, 17.XII.1996, Brown, Boina, Vieira (1 op., 4202, RPSP); ibidem, idem, S 10 42,252', W 62²2,075', 10.I.1997 (1 op., 4871, RPSP), S 1042,970', W 62²3,465',

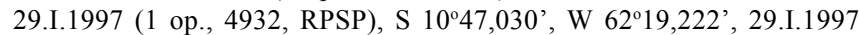
(1 op., 5057, RPSP), S $10^{\circ} 46,84^{\prime}$, W 62 ${ }^{\circ} 46,824^{\prime}$, 30.I.1997, (3 ops., $5062,5063,5076$, RPSP), S $10^{\circ} 48,725^{\prime}$, W 62²3,811', 30.I.1997 (5 ops., 5094-5097, 5108, RPSP), linha $12,10^{\circ} 49,364^{\prime} \mathrm{S}, 6^{\circ} 18,912^{\prime} \mathrm{W}$, 15.IV.1997 ( 2 ops., 7429, 7430, RPSP), linha 16, 1050,959'S,

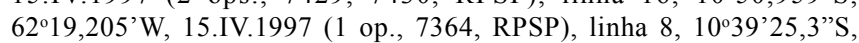
62'23'57,4”W, 21.VII.1997 (2 ops., 11834, 11843, RPSP), linha 16, $10^{\circ} 40^{\prime} 40,6^{\prime}$ 'S, 62 $28^{\prime} 15,5^{\prime} \mathrm{W}, 21 . \mathrm{VII} .1997$ (2 ops., 11876, 11916, RPSP), linha 4, 10² $43^{\prime} 54,4^{\prime \prime}$, 62 $62^{\circ} 17^{\prime} 14,6$ ”'W, 23.VII.1997 (1 op., 11928, RPSP), linha 8, 10 $45^{\prime} 39,3$ "S, $62^{\circ} 18^{\prime} 16,3$ "W, 24.VII.1997 (4 ops., 12013-12016, RPSP), linha $8,10^{\circ} 43^{\prime} 50,5^{\prime \prime} \mathrm{S}, 62^{\circ} 19^{\prime} 57,7^{\prime \prime} \mathrm{W}, 24$.VII.1997 (5 ops., 12033,

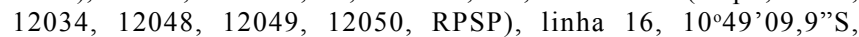
62'23'45,5”W, 27.IX.1997 (5 ops., 2654, 2659, 2666, 2669, 2670, RPSP); Pimenta Bueno, XI.1960, M. Alvarenga (2 ops., DZUP); ibidem, idem, XI.1960 (2 ops., SEMC); Pimenteiras, S 1240,194', W 61²4,825', 19.II.1997, Brown, Boina, Vieira (1 op., 5765, RPSP); ibidem, idem, S $11^{\circ} 00,396^{\prime}$, W $26^{\circ}\left(\operatorname{sic}=62^{\circ}\right) 45,404^{\prime}, 03$. III. 1997 (1 op., 5934, RPSP); Porto Velho, Estação Ecológica Cuniã, 08²4'35,9”S, 63³1'34,2”W, 22.V.1997, Brown, Boina, Vieira (1 op., 9746, RPSP); ibidem, idem, 08'15'30,5”S, 63'28’04,7’W, 27.V.1997 (12 ops., 10499-10510, RPSP); Rolim de Moura, linha 192, $11^{\circ} 42,293^{\prime}$ 'S, $61^{\circ} 42,216^{\prime}$ 'W, 26.IV.1997, Brown, Boina, Vieira (1 op., 8608, RPSP); São Miguel do Guaporé, linha

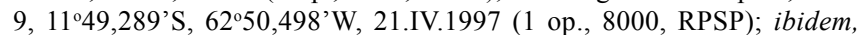
idem, Reserva Indígena Rio Branco, $11^{\circ} 56,132^{\prime} \mathrm{S}, 62^{\circ} 43,033^{\prime} \mathrm{W}$, sem data (2 ops., 8196, 10762, RPSP); Urupá, linha Quarentinha, $11^{\circ} 03$ '58,9'S, 62 32'50,1'W, 11.VI.1997, Brown, Boina, Vieira (2 ops., 10520, 10522, RPSP); Vilhena, XI.1960, M. Alvarenga (1 op., DZUP). Mato Grosso: Chapada, 27.X.1961, F.M. Oliveira (27 ops., DZUP; 5 ops., RPSP); ibidem, I.(ano?), anônimo (7 ops., Ac. 2966, CMNH);
Chapada de Guimarães, 1-4.II.1965, Sebastião Laroca (16 ops., DZUP; 4 ops., RPSP); Cuiabá, 9.XI.1954, A.A. Addor (19 ops., DZUP; 5 ops., RPSP); Diamantino, 15-17.II.1965, S. Laroca (2 ops., DZUP; 1 op., RPSP); ibidem, idem, 16.II.1965 (2 ops., DZUP); ibidem, Faz. P. Branca, 25.V.1954, B. Bruno (2 ops., DZUP); Jacaré, P.N. Xingu, XI.196? (ilegível), Alvarenga, Werner (1 op., DZUP); Rosário Oeste, XI.1963, M. Alvarenga (50 ops., DZUP; 10 ops., RPSP); Serra Dourada, BR158, 04.11.1997, S. Mateus (10 ops., RPSP); Xingu, 31.III.1953, M. Alvarenga (1 op., SEMC). Goiás: Jataí, I.1955, F. Pereira (2 ops., DZUP). BOLÍVIA. Beni: Cavinas, Rio Beni, II.1922, W.M. Mann, Mulford BioExpl. 192122 ( 2 ops., USNM).

Distribuição geográfica e hábitat. Cerrados do planalto do centro-oeste do Brasil, MT, GO até as matas tropicais de RO (Fig. 163).

Nidificação. Em oco de árvore viva, provavelmente associado a térmitas (Oliveira, com. pessoal).

Etimologia. Homenagem aos índios nhambiquaras, habitantes do norte do Mato Grosso.

Discussão. Espécie muito semelhante e contígua geograficamente à $P$. epiphytophila, da qual distingue-se, basicamente, pelos dentes da mandíbula, que apresentam o interespaço um pouco menor (Figs. 41, 33) e por serem, na média, menores (Tab. III). Também diferem pelo substrato de nidificação ( $P$. nhambiquara em ocos de árvores vivas e $P$. epiphytophila sob raízes de epífitas). Das outras espécies de Partamona, pode ser reconhecida pelas cerdas longas do escapo, asas levemente ferrugíneas e dentes da mandíbula espaçados e no nível o bordo distal.

Partamona batesi sp. nov.

(Figs. 42, operária; 76, 106, macho; 163, distribuição; Tabs. II-X)

Partamona pearsoni; ?Roubik, 1989:75; Chittka et al., 1997:107, 108, $109,111,114$.

Diagnose. Abelhas de porte médio (1.m.c. 2,6-2,7 mm, c.a.a. 5,9-6,1 mm; Tabs. III, IV). Integumento preto. Mandíbula com a $1 / 2$ basal amarelada ou predominantemente ferrugínea, ápice ferrugíneo-escuro, côndilos pretos. Flagelo castanho-escuro ou enegrecido. Estrias paroculares estreitas (0,6-0,8x o diâmetro do $2^{\circ}$ flagelômero), aproximadamente com a mesma largura em toda a extensão ou um pouco alargadas embaixo (1,0-1,2x o diâmetro do $2^{\circ}$ flagelômero), chegando até a interorbital superior (como na figura 133 de $P$. epiphytophila). Pilosidade preta. Membrana das asas levemente ferrugínea; microtríquias pretas em toda a asa ou amarelas na região do pterostigma; veias méleas, mas escurecidas pelas microtríquias escuras (exemplares com extensão maior de microtríquias amarelas, na região do pterostigma, apresentam as veias mais claras). Cerdas da base do escapo um pouco mais longas que o diâmetro deste (0,9-1,5x; Tab. VII). Cerdas eretas das áreas paroculares, ao lado dos alvéolos, aproximadamente tão longas quanto o diâmetro do escapo, ou um pouco mais curtas. Cerdas do escutelo 0,9-1,0x o comprimento deste. Área basal do propódeo com uma faixa glabra mediana aproximadamente tão larga quanto 
o diâmetro do $2^{\circ}$ flagelômero. Dentes da mandíbula espaçados (Fig. 42). Área malar, distância interocelar, distância ocelorbital, tíbia III e comprimento da asa anterior normais (Tabs. V, VI, VIII, IX). Bifurcação da $\mathrm{M}+\mathrm{Cu}$ geralmente coincidente com a cu-v (raramente levemente anterior). Macho, basitarso III alongado, achatado ou convexo-côncavo; tíbia III estreita (Fig. 76); EVII com projeção mediana curta e triangular, os chanfros laterais curtos e largos (Fig. 106).

Variação. A extensão ocupada pelas microtríquias amarelas, na região do pterostigma é bastante variável entre os indivíduos.

\section{Operária.}

Dimensões. Comprimento total aproximado, $5,56 \mathrm{~mm}$; da asa anterior, $6,06 \mathrm{~mm}$ (incluindo a tégula, $6,81 \mathrm{~mm}$ ); largura máxima da cabeça, 2,68 mm; do TIII, 2,80 mm (Tab. X).

Cor do integumento. Preto, apenas as tíbias III, pronoto, metanoto e esternos mais claros, e os tarsômeros de todos os pares de pernas, ferrugíneos. Tégulas castanho-ferrugíneas, translúcidas medianamente. Labro amarelo vivo; mandíbula amarela, como o labro no terço basal e ferrugínea em direção ao ápice, côndilos enegrecidos. Escapo com a face inferior amarelada e a superior enegrecida. Flagelo castanho escuro o $1^{\circ} \mathrm{e}$ os dois últimos flagelômeros amarelados. Máculas nítidas, amarelo-marfim. As manchas no clípeo aproximadamente em forma de L, a distância entre elas, na porção mais apical do clípeo, como o diâmetro do $2^{\circ}$ flagelômero, mais nítidas nos cantos inferiores. Mancha supraclipeal aproximadamente triangular. Abaixo do ocelo, um triângulo invertido, alongado, um pouco mais longo que o diâmetro do ocelo médio. Contornando o sulco frontal superiormente, uma estria um pouco apagada. Estrias paroculares um pouco alargadas embaixo (ca. $1,13 \mathrm{x}$ o diâmetro do $2^{\circ}$ flagelômero), estreitando suavemente até a altura da linha da maior distância interorbital, alargando novamente (ca. $0,88 \mathrm{x}$ o diâmetro do $2^{\circ}$ flagelômero) $\mathrm{e}$ chegando até a altura da linha da menor distância interorbital superior. Genas, uma pequena mancha margeando o quarto inferior do olho. Tórax com uma estria pouco conspícua na margem posterior do pronoto; as estrias laterais do mesoscuto mais nítidas posteriormente; as axilas maculadas nos $2 / 3$ anteriores; escutelo com uma estria pouco nítida na margem anterior e outra mais larga no bordo posterior, interrompida medianamente. Basitarso II com uma estria a cada lado, acompanhando as margens anterior e posterior; o basitarso III com estria apenas na margem anterior, mais alargada e nítida distalmente. Membrana da asa anterior levemente ferrugínea; microtríquias predominantemente enegrecidas, apenas o pterostigma e regiões adjacentes com microtríquias amarelas; veias méleas, escurecidas pelas microtríquias, $\mathrm{C}$ e $\mathrm{R}$ mais escuras na base.

Pilosidade. Predominantemente enegrecida, mais clara na porção ventral do tórax (coxas, trocanteres e mesepisternos); esternos com as cerdas enegrecidas na porção basal, despigmentadas na porção apical; cerdas ferrugíneas na face interna dos basitarsos II e III. Área basal do propódeo com uma faixa glabra mediana. A franja pré-marginal do TIII com cerdas muito mais curtas na região mediana que as laterais. Cerdas da base do escapo 1,29x mais longas que o diâmetro deste. Nas áreas paroculares inferiores, ao lado dos alvéolos, as cerdas eretas $1,5 \mathrm{x}$ o diâmetro do escapo. Cerdas do clípeo tão longas quanto as da base do escapo; na fronte $1,14 \mathrm{x}$ o diâmetro do escapo; no vértice mais longas, ca. 2,0x; no disco do mesoscuto e na porção anterior da linha média, 1,50 e 2,71x, respectivamente. As cerdas do ápice do escutelo tão longas quanto o comprimento deste.

Integumento. Liso e polido, apenas com a pontuação pilígera, típica do gênero.

Forma e proporções (Tab. X). Cabeça, 1,20x mais larga que longa, $1,34 \mathrm{x}$ mais larga que a distância clipeocelar. Olhos $2,41 \mathrm{x}$ mais longos que largos, levemente divergentes embaixo. Área malar tão longa quanto o diâmetro do $2^{\circ}$ flagelômero. Comprimento do clípeo igual a $0,55 \mathrm{x}$ a sua largura máxima e $0,35 \mathrm{x}$ a distância clipeocelar. Comprimento das mandíbulas $0,57 \mathrm{x}$ a distância clipeocelar; os dentes um pouco espaçados e no nível do bordo (Fig. 42). Comprimento do escapo 0,96x a distância alvéolo-ocelo lateral, seu diâmetro um pouco menor que o do $2^{\circ}$ flagelômero. Distância interocelar 1,38x maior que a ocelorbital e ca. de 1,83x o diâmetro do ocelo médio. Escutelo aproximadamente semicircular, cerca de $0,50 \mathrm{x}$ mais curto que largo. Tíbia III 0,93x mais curta que a cabeça, e 2,10x mais longa que larga; canto póstero-distal arredondado, pouco projetado, margem apical fracamente sinuada; contorno da margem posterior suavemente sinuado. Basitarso III 1,61x mais longo que largo; canto póstero-distal arredondado e margem apical em ângulo um pouco maior que $90^{\circ} \mathrm{em}$ relação à margem anterior. Asa anterior 2,59x mais longa que larga e 2,26x a largura máxima da cabeça. Bifurcação de $\mathrm{M}+\mathrm{Cu}$ levemente anterior à cu-v. Hâmulos, 5.

\section{Macho. Figuras 76, 106.}

Material-tipo. Holótipo, operária, de "Nogueiras, lago de Tefé AMBrasil, 25-26.08.1993, 64⒋ $\mathrm{W}, 3^{\circ} 19^{\prime} \mathrm{S}^{\circ}$ ", “Camargo, Pedro, Mazucato, leg.", "627c". Parátipos, 59 operárias e 12 machos montados em alfinetes, e centenas de exemplares em álcool, provenientes do mesmo ninho; do ninho " $626 \mathrm{c}$ ", da mesma localidade, data e coletores, 60 operárias e 3 machos em alfinetes, além de centenas de exemplares em álcool, depositados na RPSP.

Material examinado. BRASIL Amazonas: Alvarães, rio Solimões,

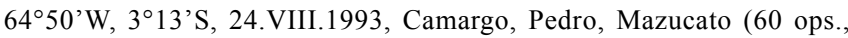
mais ops., e 6 machos em álcool, ninho 623c, 59 ops., 936420-429, 936430-441, 936443-452, 936453-456, 936458-479, RPSP); Arimã,

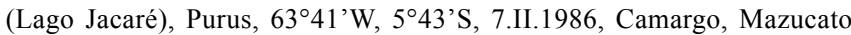
(77 ops., ninho $370 \mathrm{c}$, RPSP); Bacururu, rio Juruá, $66^{\circ} 11^{\prime} \mathrm{W}, 3^{\circ} 45^{\prime} \mathrm{S}$, 30.VII-01.VIII.1993, Camargo, Pedro, Mazucato (2 ops., 933546, 933547, RPSP); Carauari, rio Juruá, $66^{\circ} 54^{\prime}$ w, $4^{\circ} 53^{\prime}$ S, 22.VII. 1993 , Camargo, Pedro, Mazucato (75 ops., ninho 521c, 83 ops., mais 2 machos e muitas ops. em álcool, ninho 522c, 60 ops., mais ops. e 7 machos em álcool, ninho 526c, RPSP); Forte da Graça, rio Juruá, 66 $6^{\circ} \mathrm{W}, 3^{\circ} 39^{\prime} \mathrm{S}$, 02.VIII.1993, Camargo, Pedro, Mazucato (60 ops., mais ops., e 20 machos em álcool, ninho 554c, 60 ops., mais mat. em álcool, ninho 
555c, RPSP); ibidem, 06.VIII.1993 (62 ops., mais material em álcool, ninho 570c, RPSP); ibidem, idem, 02-06.VIII.1993 (19 ops., 933749, 933758-761, 933768-771, 933773, 933775, 933776, 933778, 933779, 933783, 933845, 960152, RPSP); Hyutanahan (sic = Huitanaã) rio Purus, I.1922, S. M. Klages (1 op., Ac. 6963, CMNH); Lago Uará, rio Solimões, $65^{\circ} 35^{\prime} \mathrm{W}, 2^{\circ} 41^{\prime} \mathrm{S}, 13$.VIII.1993, Camargo, Pedro, Mazucato (78 ops., mais ops. e 20 machos em álcool, ninho 574c; 59 ops., 9 machos, mais ops. e 20 machos em álcool, ninho 594c; 53 ops., 934395 , 934409-410, 934413, 934415-419, 934421-423, 934426, 934431, 934444, 934447-454, 934456-457, 934460-463, 934468-479, 934486, RPSP); Nogueiras, Lago de Tefé, $64^{\circ} 48^{\prime} \mathrm{W}, 3^{\circ} 19^{\prime} \mathrm{S}, 25$. VIII.1993, Camargo, Pedro, Mazucato (4 ops., 936278, 936262, 936228, 936269, RPSP); Tefé, 29.I.1977, Camargo, Mazucato (35 ops., mais material em álcool, ninho110 c, RPSP); ibidem, idem, 27-30.I.1977 (30 ops., RPSP); ibidem, 29.VI.1979, Charles Clements (1 op., RPSP); ibidem, 15.XII.1961, F.M. Oliveira (430 ops., 4 machos, DZUP; 63 ops., 1 macho, RPSP); ibidem, idem, 1-4.XII.1961 (2 ops., DZUP), 611.XII.1961 (1 op., DZUP); ibidem, I.1962, E. Carvalho (220 ops., 183 machos, DZUP; 30 ops., 30 machos, RPSP); ibidem, IX.1959, R. Carvalho (1 op., DZUP); ibidem, idem, III.1962 (1 op., DZUP); Rio Ipixuna, $45 \mathrm{~km}$ à montante de Tapauá, $63^{\circ} 20^{\prime} \mathrm{W}, 6^{\circ} 0^{\prime} \mathrm{S}$, 16.I.1986, Camargo, Mazucato (98 ops., ninho 329, 93 ops., 12 machos, mais material em álcool, ninho 330c, 103 ops., 1 macho, mais material em álcool, ninho 333c; 107 ops., 960183-213, 860280, 960454, 860458, $860470,860478,860485-488,860490-492,860494,860496-50$, $860502,860505-506,860508-509,860511-513,860517-520$, RPSP)

Distribuição geográfica e hábitat. Endêmica das florestas tropicais da região de Tefé, AM, Brasil (Fig. 163).

Nidificação. Em termiteiro arborícola externo de Nasutitermes acangussu Bandeira \& Fontes, 1979 (ninhos nos. 522c, 526c e 560c) e de outras espécies de Nasutitermes.

Etimologia. Homenagem ao naturalista inglês Henry Walter Bates (1825-1892).

Discussão. Dentre as espécies do grupo bilineata / epiphytophila, apresenta maior semelhança com $P$. epiphytophila, com a qual entra em simpatria na região de Tefé (Figs. 162, 163). Difere desta pelos dentes da mandíbula, geralmente com espaçamento menor (mas nem sempre, compare as figuras 42 e 33), cerdas da base do escapo mais curtas, e tamanho menor. Uma diferença muito sutil, que pode auxiliar na separação das espécies na região de sobreposição, ocorre na forma do basitarso III das operárias, que em P. epiphytophila tende a ser mais alongado e estreito. Mais nítida é a diferença entre os substratos de nidificação. P. batesi nidifica em termiteiros arborícolas externos, geralmente em áreas mais abertas (queimadas, e roçados, e.g.), freqüentemente formando grandes agregações, enquanto $P$. epiphytophila, nidifica sob raízes de epífitas, não associada à termiteiros.

\section{Partamona yungarum sp. nov.}

(Figs. 40, 136, operária; 163, distribuição; Tabs. II-IX, XI)

Diagnose. Abelhas de porte médio (1.m.c. 2,5-2,7 mm, c.a.a. 6,5-6,8 mm; Tabs. III, IV). Integumento preto. Mandíbula predominantemente ferrugínea, ápice ferrugíneo escuro, côndilos pretos. Flagelo enegrecido. Estrias paroculares pouco conspícuas, apenas um pouco mais claras que o integumento adjacente, mais estreitas que o diâmetro do $2^{\circ}$ flagelômero $(0,6-$ $0,8 \mathrm{x}$ ), aproximadamente com a mesma largura em toda a extensão, ou levemente alargadas embaixo (1,0-1,2x; Fig. 136). Máculas do tórax apagadas. Pilosidade preta; cerdas na região ventral dos mesepisternos, coxas e trocanteres enegrecidas ou esbranquiçadas. Membrana das asas ferrugínea escura; microtríquias pretas; veias alares escurecidas, principalmente na metade basal. Pilosidade longa e abundante, cerdas eretas da fronte e disco do mesoscuto, até $1,5 \mathrm{x}$ mais longas que o diâmetro do $2^{\circ}$ flagelômero. Cerdas da base do escapo nitidamente mais longas que o diâmetro deste (1,5-1,9x; Tab. VII), bem diferenciadas em relação às demais cerdas. Cerdas eretas das áreas paroculares, ao lado dos alvéolos, muito longas e robustas, nitidamente mais longas que o diâmetro do escapo, muito conspícuas em relação às cerdas curtas decumbentes. Cerdas do escutelo 1,0-1,1x o comprimento deste. Área basal do propódeo com uma faixa mediana glabra, aproximadamente tão larga quanto o diâmetro do $2^{\circ}$ flagelômero Dentes da mandíbula espaçados (Fig. 40). Área malar, distância interocelar, distância ocelorbital, tíbia III e comprimento da asa anterior, normais (Tabs. V, VI, VIII, IX). Bifurcação da M+Cu nitidamente anterior à cu-v.

\section{Operária.}

Dimensões. Comprimento total aproximado, $6,56 \mathrm{~mm}$; da asa anterior, $6,64 \mathrm{~mm}$ (incluindo a tégula, 7,47 $\mathrm{mm}$ ); largura máxima da cabeça, 2,56 mm; do TIII, 2,56 mm (Tab. XI).

Cor do integumento. Predominantemente preto; cabeça, tergos II e III, metanoto e tíbias III castanhos (provavelmente exemplar jovem); tarsômeros de todos os pares de pernas, ferrugíneos. Tégula ferrugínea, translúcida. Labro amarelado, irregularmente descolorido; mandíbula amarelada no terço basal e ferrugínea em direção ao ápice, côndilos e ápice escurecidos. Escapo escurecido por inteiro, apenas os extremos basal e apical mais claros. Flagelo por inteiro castanho-escurecido, apenas o $1^{\circ}$ flagelômero mais claro. Máculas apagadas, apenas as estrias paroculares nítidas (marfim-acastanhadas). Manchas do clípeo e fronte inconspícuas. Estrias paroculares um pouco alargadas embaixo (ca. $1,13 \mathrm{x}$ o diâmetro do $2^{\circ}$ flagelômero), com contorno irregular, estreitando medianamente $(0,5 \mathrm{x})$ e alargando novamente na altura da interorbital máxima $(0,63 \mathrm{x})$ e chegando até um pouco acima da linha da menor distância interorbital superior (Fig. 136). Genas com uma estria apagada margeando a metade inferior do olho. Tórax apenas com a porção anterior das axilas manchadas irregularmente de um marfimacastanhado, apagado. Membrana da asa anterior ferrugínea, mais escura na metade basal (células radial, $1^{\mathrm{a}}$ e $2^{\mathrm{a}}$ cubitais); microtríquias enegrecidas em toda asa; veias méleas, escurecidas pelas microtríquias, $\mathrm{C}$ e $\mathrm{R}$ mais escurecidas basalmente.

Pilosidade. Predominantemente enegrecida; porção ventral do tórax (coxas, trocanteres e mesepisternos) e esternos abdominais mais claros, de um palha-sujo (em alguns parátipos as cerdas dos esternos escurecidas na base). Ärea basal do 
propódeo com uma faixa glabra mediana. Franja pré-marginal do TIII com cerdas muito mais curtas na região mediana que nas laterais. Cerdas da base do escapo 1,38x mais longas que $\mathrm{o}$ diâmetro deste. Áreas paroculares inferiores, ao lado dos alvéolos, com cerdas eretas 1,13x o diâmetro do escapo. Cerdas do clípeo 1,44x o diâmetro do escapo; na fronte, $1,31 \mathrm{x}$; no vértice mais longas, ca. 2,0x; no disco do mesoscuto e na porção anterior da linha média, 1,56 e 2,25x, respectivamente. Cerdas do ápice do escutelo tão longas quanto o comprimento deste.

Integumento. Liso e polido, apenas com a pontuação pilígera típica do gênero.

Forma e proporções (Tab. XI). Cabeça, 1,16x mais larga que longa, 1,31x mais larga que a distância clipeocelar. Olhos 2,56x mais longos que largos, paralelos. Área malar ca. de 1,15x o diâmetro do $2^{\circ}$ flagelômero. Comprimento do clípeo $0,58 \mathrm{x}$ sua largura máxima e $0,38 \mathrm{x}$ a distância clipeocelar. Mandíbulas $0,57 \mathrm{x}$ a distância clipeocelar; os dentes um pouco espaçados e no nível do bordo distal (Fig. 40). Escapo 0,98x a distância alvéoloocelo lateral, seu diâmetro como o do $2^{\circ}$ flagelômero. Distância interocelar 1,17x maior que a ocelorbital e ca. de 1,91x o diâmetro do ocelo médio. Escutelo aproximadamente semicircular, cerca de $0,48 x$ mais curto que largo. Tíbia III $0,93 x$ mais curta que a cabeça, e 2,10x mais longa que larga; o canto póstero-distal arredondado, não projetado, a margem apical quase reta; o contorno da margem posterior, suavemente sinuado. Basitarso III 1,89x mais longo que largo; o canto póstero-distal subanguloso e a margem apical em ângulo um pouco maior que $90^{\circ} \mathrm{em}$ relação à margem anterior. Asa anterior $2,72 \mathrm{x}$ mais longa que larga e 2,59x a largura máxima da cabeça. Bifurcação de $\mathrm{M}+\mathrm{Cu}$ anterior à cu-v. Hâmulos, 5 .

\section{Macho. Desconhecido.}

Material-tipo. Holótipo, operária, de "BOLÍVIA La Paz Coroico 1,700 m 5/Dec.1995 (L.E. Peña)”, parátipos, 26 operárias da mesma série, depositados no SEMC, e dois na RPSP; outras 135 operárias, parátipos, de "BOLÍVIA Coroico, La Paz 3-8 Dec 1955 elev. 1800 mtrs. F.H. Walz", depositadas no MSUC, e 10 na RPSP.

Material examinado. BOLÍVIA. La Paz: Chulumani, 19-25.XI.1955, L.E. Peña (26 ops., SEMC; 5 ops., RPSP); Lareeaja, Cerro Paititi, Canthon Maipiri, VIII.1955 (1 op., SEMC); San Jacinto, Yungas, $1.700 \mathrm{~m}$, 6.XII.1955, L. Peña, (8 ops., DZUP; 1 op., RPSP); ibidem, San Tacinto (sic), 1,700 m, 5-8.XII.1955, L.E. Peña (7 ops., SEMC; 1 op., RPSP); Socalama, Yungas, 1600m, 23.XII.1955, anônimo (40 ops., SEMC; 5 ops., RPSP); ibidem, Yungas Mountains, nr. Socalama, $1600 \mathrm{~m}$, 23.XII.1955 (42 ops., MSUC; 5 ops., RPSP); Solacamo, 7,600m (sic = $1,600 \mathrm{~m}$, ou 7,600ft.?), 24-25.XII.1955, L.E. Peña (28 ops., SEMC; 5 ops., RPSP). Cochabamba: Alto Palmar, Chapare, 1100m, X.1948 (1 op., MSUC). PARAGUAI: Dept.? Colony, Carlos Pfanol, III.1951, F.H. Schade (1 op., SEMC).

Distribuição geográfica e hábitat. Yungas bolivianas e um registro no Paraguai (Fig. 163); matas sempre-verdes préandinas orientais, ricas em samambaias arborescentes e epífitas (HUECK, 1972).

Nidificação. Desconhecida.
Etimologia. O nome refere-se às montanhas Yungas, na Bolívia, área de ocorrência da espécie.

Discussão. Espécie com distribuição bastante restrita. Pode ser reconhecida pelas asas escurecidas, máculas quase completamente apagadas e integumento da face marrom muito escuro, cerdas longas na base do escapo, bifurcação de $\mathrm{M}+\mathrm{Cu}$ anterior à cu-v, além dos dentes da mandíbula espaçados e no nível do bordo distal (Fig. 40). É bastante semelhante aos espécimens de $P$. epiphytophila das encostas andinas, que apresentam asas também escurecidas, mas separa-se desta pelas máculas mais apagadas e integumento da cabeça marrom escuro (em P. epiphytophila é geralmente preto), além dos dentes da mandíbula um pouco menos espaçados (Figs. 40,33) e da bifurcação de $\mathrm{M}+\mathrm{Cu}$, geralmente anterior à cu-v.

\section{Partamona vitae sp. nov.}

(Fig. 147, operária; 163, distribuição; Tabs. II-IX, XI)

Diagnose. Abelhas de porte médio (1.m.c. 2,5-2,6 mm; c.a.a. 5,7-6,1 mm; Tabs. III, IV). Integumento amarelado, sutura epistomal, basitarso III e 1/4 apical da tíbia III, escurecidos. Mandíbula com a 1/2 apical ferrugínea e o restante, inclusive côndilos, amarelo-acastanhado. Máculas da face e tórax inconspícuas. Estrias paroculares estreitas $(0,6 \mathrm{x}$ o diâmetro do $2^{\circ}$ flagelômero), um pouco alargadas embaixo (1x o diâmetro do $2^{\circ}$ flagelômero), em cima chegando até o topo do olho (Fig. 147). Pilosidade enegrecida no vértice e tergos; na porção ventral do tórax e esternos, enegrecida (material tipo) ou amarelo-palha; no restante, ferrugínea. Membrana das asas levemente ferrugínea, quase hialina; microtríquias pretas; veias méleas, escurecidas pelas microtríquias, $\mathrm{C}$ e $\mathrm{R}$ mais escuras próximo à base. Cerdas da base do escapo curtas, menores que o diâmetro deste (Tab. VII), apenas um pouco mais longas que as demais cerdas do escapo. Cerdas eretas das áreas paroculares, ao lado dos alvéolos, mais curtas que o diâmetro do escapo, pouco destacadas em relação à pilosidade decumbente. Cerdas do escutelo 1,0-1,1x o comprimento deste. Área basal do propódeo com um faixa glabra mediana estreita, ca. de $1 \mathrm{x}$ o diâmetro do $2^{\circ}$ flagelômero. Dentes da mandíbula espaçados, aproximadamente no nível do bordo apical. Área malar, distância interocelar, distância ocelorbital, tíbia III e comprimento da asa anterior, normais (Tabs. V, VI, VIII, IX). Bifurcação da $\mathrm{M}+\mathrm{Cu}$ anterior à cu-v.

\section{Operária.}

Dimensões. Comprimento total aproximado, $6,47 \mathrm{~mm}$; da asa anterior, $5,73 \mathrm{~mm}$, incluindo a tégula, $6,56 \mathrm{~mm}$ Largura máxima da cabeça, 2,52 mm; do TIII, 2,44 mm (Tab. XI).

Cor do integumento. Amarelo-acastanhado, inclusive labro e tégulas; sutura epistomal, basitarso III e o quarto apical da tíbia III, enegrecidos. Mandíbula com a metade apical ferrugínea, e a metade basal amarelo-acastanhado, inclusive côndilos. Escapo, amarelo-acastanhado. Flagelo castanho. Máculas na face e tórax inconspícuas, apenas as estrias paroculares e nas 
margens laterais do mesoscuto perceptíveis; as paroculares estreitas (ca. 0,6x o diâmetro do $2^{\circ}$ flagelômero), um pouco mais largas embaixo $(0,9 \mathrm{x})$, em cima chegando até a interorbital máxima. Membrana da asa anterior, levemente ferrugínea, quase hialina; microtríquias pretas em toda a asa; veias méleas, escurecidas pelas microtríquias, $\mathrm{C}$ e $\mathrm{R}$ mais escuras próximas à base.

Pilosidade. Enegrecida no vértice, tergos, esternos, porção ventral dos mesepisternos, coxas e trocanteres I-III, basitarsos e tarsômeros II e III e tíbia III; no restante, ferrugínea. Área basal do propódeo com faixa mediana glabra estreita (parcialmente visível, no holótipo). Franja pré-marginal no TIII, com cerdas muito mais curtas na região mediana que nas laterais. Cerdas da base do escapo mais curtas que o diâmetro deste $(0,9 \mathrm{x})$, apenas um pouco mais longas que as demais cerdas do escapo. Áreas paroculares inferiores, ao lado dos alvéolos, com cerdas eretas muito curtas, pouco diferenciadas em relação às cerdas curtas, decumbentes. Cerdas eretas do clípeo e fronte tão longas quanto o diâmetro do escapo; no vértice, $2,14 \mathrm{x}$; no disco do mesoscuto e na porção anterior da linha média, 1,1x e $1,7 \mathrm{x}$ respectivamente. Cerdas mais longas no ápice do escutelo com ca. de 1,07x o comprimento deste.

Integumento. Liso e polido, apenas com a pontuação pilígera típica do gênero.

Forma e proporções (Tab. XI). Cabeça 1,19x mais larga que longa, e 1,35x mais larga que a distância clipeocelar. Olhos, 2,43x mais longos que largos, levemente divergentes embaixo. Área malar tão longa quanto o diâmetro do $2^{\circ}$ flagelômero. Comprimento do clípeo $0,54 \mathrm{x}$ sua largura máxima e $0,37 \mathrm{x}$ a distância clipeocelar. Mandíbula 0,60x a distância clipeocelar; os dentes espaçados, o dente médio praticamente no nível do bordo distal (como na figura 41, de P. nhambiquara). Escapo $0,95 \mathrm{x}$ a distância alvéolo-ocelo lateral, seu diâmetro um pouco menor que o do $2^{\circ}$ flagelômero $(0,14: 0,16)$. Distância interocelar $1,33 \mathrm{x}$ maior que a ocelorbital e ca. de $1,82 \mathrm{x}$ o diâmetro do ocelo médio. Escutelo aproximadamente semicircular, ca. de 0,50x mais curto que largo. Tíbia III 0,95x mais curta que a largura máxima da cabeça, e 2,18x mais longa que larga; canto póstero-distal arredondado, pouco projetado, margem apical fracamente sinuada; contorno da margem posterior, suave. Basitarso III, 1,68x mais longo que largo; canto póstero-distal arredondado, e margem apical em ângulo um pouco maior que $90^{\circ} \mathrm{em}$ relação à margem anterior. Asa anterior 2,65x mais longa que larga, e $2,27 x$ mais longa que a largura máxima da cabeça. Bifurcação de $\mathrm{M}+\mathrm{Cu}$ levemente anterior à cu-v. Hâmulos, 5.

Macho. Desconhecido.

Material-tipo. Holótipo, operária, de "San Juan de Manapiare, Edo Amazonas, Venezuela, 5-XI-1993, P. Vit leg., 18c, 936801”; parátipos, 2 operárias, com as mesmas etiquetas de procedência, números 936799 e 936800; depositados na RPSP.

Material examinado. VENEZUELA. Bolivar: Rancho Las Nieves, $6^{\circ} 20^{`} \mathrm{~N}, 66^{\circ} 50^{`} \mathrm{~W}, 500 \mathrm{~m}, 5-7 . I I .1990$, C.D. Michener (4 ops., SEMC).

Distribuição geográfica e hábitat. Matas do sudoeste da Venezuela (Fig. 163).

Nidificação. Desconhecida.

Etimologia. Homenagem à Dra. Patricia Vit, da Universidad de Los Andes, Mérida, Venezuela.

Discussão. Assemelha-se mais a $P$. mourei e $P$. aequatoriana, pela coloração do integumento, do que às espécies do grupo bilineata / epiphytophila; os dentes da mandíbula, entretanto, colocam-na neste grupo. Pode ser reconhecida, pelo comprimento da área malar (mais longa que em $P$. mourei e mais estreita que em $P$. aequatoriana), dentes da mandíbula, maiores e mais espaçados, e pelas máculas pouco conspícuas na face e tórax.

\section{Grupo musarum}

Partamona musarum (Cockerell, 1917)

(Figs. 66, 148, operária; 167, distribuição; Tabs. II-IX)

Trigona musarum Cockerell, 1917:123, 124.

Trigona testacea subsp.; Michener, 1946:180-182, 189, 190, 193, 195. Trigona testacea musarum; Schwarz, 1934:19; Michener, 1954:170; Wille, 1983:62.

Trigona (Partamona) testacea; Schwarz, 1949:363, 368.

Trigona (Partamona) testacea musarum; Wille, 1961:117, 129; Wille \& Michener, 1973:12, 21, 33, 44, 56, 67, 90,91, 137, 138, 139, 265; Nates-Parra, 1983:156; Cunha, 1991:36.

Trigona (Partamona) musarum; Roubik et al., 1986:97-101.

Partamona musarum; Ramalho et al., 1990:473; Camargo, 1992:81; Pedro \& Camargo, 1996-1997:207.

Partamona peckolti; Roubik et al., 1995:208; Roubik, 1989:108; Griswold et al., 1995:684, 690.

Partamona peckolti musarum; Roubik, 1992:500, 509, 511, 512, 523 (= P. testacea musarum); Roubik, 1993b:549.

Partamona (Partamona) peckolti musarum; Camargo, 1980:9, 63, 64, 74, 75, 164, 165, 166, 173, 174, 175.

Diagnose. Abelhas de porte médio (1.m.c. 2,4-2,5 mm, c.a.a. 5,6-5,9 mm; Tabs. III, IV). Integumento amarelo; sutura epistomal, área ao redor dos ocelos, mesepisternos na porção ventral, basitarso e tíbia III (por inteiro, ou na metade apical), escurecidos ou amarelados. Mandíbula predominantemente amarelada, apenas o ápice ferrugineo, côndilos um pouco escurecidos até amarelados. Flagelo castanho-escuro ou castanho-amarelado. Estrias paroculares largas (ca. 1,0x o diâmetro do $2^{\circ}$ flagelômero) aproximadamente com a mesma largura em toda a extensão ou alargadas embaixo (ca. 1,3x), podendo alcançar o vértice (Fig. 148). Pilosidade predominantemente preta; no vértice e mesoscuto enegrecida, amarelada, ferrugínea, ou misturada; no escutelo, amarelada; nos mesepisternos, coxas, trocanteres e esternos, amarelo-palha ou esbranquiçada. Membrana das asas levemente ferrugínea; microtríquias pretas; veias méleas, mas escurecidas pelas microtríquias fuscas. Cerdas do escapo curtas apenas uma ou duas cerdas na base um pouco mais longas que as demais (1,0-1,1x o diâmetro do escapo, Tab. VII). 
Cerdas eretas das áreas paroculares, ao lado dos alvéolos, mais curtas que o diâmetro do escapo, pouco destacadas em relação às cerdas decumbentes. Cerdas do escutelo $0,9-1,2 \mathrm{x}$ o comprimento deste. Área basal do propódeo com uma faixa glabra mediana, aproximadamente tão larga quanto o diâmetro do $2^{\circ}$ flagelômero Dentes da mandíbula pequenos e muito recuados em relação ao ápice do bordo apical (Fig. 66). Área malar, distância interocelar, distância ocelorbital, tíbia III e comprimento da asa anterior, normais (Tabs. V, VI, VIII, IX). Bifurcação da $\mathrm{M}+\mathrm{Cu}$ freqüentemente posterior, ou em alguns indivíduos, coincidente com a cu-v. Contorno da margem posterior da tíbia III, entre o terço basal, quase vertical, e a porção côncava, com recorte nitidamente sinuado. Macho, basitarso III alongado, achatado ou convexo-côncavo; tíbia III estreita (como na figura 81, de $P$. vicina); EVII com a projeção mediana curta e triangular, os chanfros laterais curtos e largos (como na figura 110, de P. vicina).

Variação. Exemplares dessa espécie podem ser inteiramente amarelos, ou apresentar áreas escurecidas na tíbia e basitarso III, sutura epistomal e parte ventral dos mesepisternos. Os espécimens provenientes da Colômbia (Valledupar Magdalena e Valle Medellin, Antióquia) apresentam o integumento avermelhado, principalmente na face, e é possível que constituam uma população distinta.

Material-tipo. COSTA RICA: "Philadelphia Banana R.” (F. Knab), no USNM; PANAMÁ. Boqueron River May, 1907 (Aug. Busck), no USNM e AMNH. Foram examinados dois síntipos de Boqueron River.

Material examinado. HONDURAS. Atlántida: Tela, Lancetilla Bot.

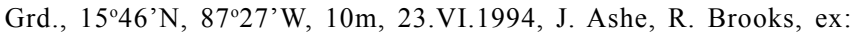
human dung trap (1 op., SEMC). Colón: Rio Sangrelaya, 19.VI.1923, T.H. Hubbell, 319 (1 op., USNM). Yoro: San Juan Pueblo, sem data, anônimo (4 ops., USNM). Olancho: Corocito, 3.IV.1924, anônimo (1 op., AMNH). COSTA RICA. Heredia: La Selva Field Sta. near Puerto Viejo, 21-28.III.1988, W.E. Steiner, J.M. Hill, J.M. Swearingen, J.M. Mitchell (3 ops., USNM); ibidem, 17-19.III.1973, D.C. Rentz, "in cacao grove" (2 ops., USNM); ibidem, idem, at light (1 op., USNM); ibidem, Puerto Viejo, Sarapiqui, 8.III.1987, José Villa, nest 8 (5 ops., SEMC; 1 op., RPSP); ibidem, La Selva W River Trail, 14.II.1992, W. Bell, ex: light intercept (1 op., SEMC); ibidem, 80m, 19.V.1993, J S Ashe, ex: flight intercept trap (1 op., SEMC); Puerto Viejo (Sarapiqui), 28.XI.1959, A. Wille (2 ops., RPSP); ibidem, 40m, 13.VIII.1965, David W. Alsop (2 ops., CUIC); ibidem, idem, 10.VIII.1965 (1 op., CUIC), 16.VIII.1965 (1 op., CUIC); ibidem, 30.VII.1965, D.H. Janzen (1 op., SEMC; 32 ops., USNM; 2 ops., RPSP). San José: Hamburg farm, 25.XI.1936, Nevermann (4 ops., USNM); ibidem, Sta. Clara Pr., 21.I.1938, Nevermann, "Trigona nest no. 33" (7 ops., USNM); Sequirres, 3.XII.1987, Wm. L. Downes Jr. (1 op., MSUC). Cartago: Turrialba, 1.II.1965, R.L. Dressler (2 ops., RPSP; 6 ops., DZUP); ibidem, 11.VII.1964, G.C. Eickwort, "collected in nest" (1 op., AMNH); ibidem, idem, 18.VII.1964 (1 op., RPSP); ibidem, 1950 ft., 5.VII.1963, C.D. Michener, et al. (1 op., SEMC); ibidem, 646m, 12.VII.1964, M.G. Naumann (4 ops., RPSP); ibidem, 15-19.VII.1965, P.J. Spangler (4 ops., USNM); ibidem, 13-17.III.1965, S.S. \& W.D. Duckworth (1 op., USNM); ibidem, 18.IV.1957, R.D. Shenefelt, RDS 57-98, on Crotalaria (1 op., USNM); ibidem, 115.VII.1965, J.P. Miles, J.C. Downey (1 op. MSUC); ibidem, Catie, $600 \mathrm{~m}$, sem data, H \& A Howden (7 ops., SEMC; 2 ops., RPSP); ibidem, idem, 28.II.1980 (3 ops., SEMC). Limón: Beverly, 5 mi. SE de Limón, 9.V.1962, Michener, Wille (5 ops., RPSP); ibidem, near Limon, 26.VIII.1963, C.D. Michener \& Wille (3 ops., RPSP); Bord de la Riviera, Reventazón, Plaines de Sta. Clara, 150m, XII.1904, P. Biolley (4 ops.,
CNMH); Bribri, 10m, III.1993, J. Lobo (1 op., RPSP); ibidem, 4 km NE, 50m, IX-XI.1989, Paul Hanson (1 op., RPSP); Guapiles, 8 km SW, 200m, 19.VIII.1964, M. G. Naumann (1 op., RPSP); Pandora, 23.VIII.1963, Michener, A. Wille (8 ops., DZUP; 7 ops., RPSP); ibidem, Puerto Limon, 23.VIII.1963, Michener, Wille (1 op., RPSP); Quebrada Gonzales Viquez, 300m, III.1993, J. Lobo (1 op., RPSP); Rio Toro Amarillo, nr. Guapiles, 20.VIII.1964, G.C. Eickwort (1 op., RPSP). PANAMÁ. Chiriqui: Chiriqui, 1904, anônimo (1 op., AMNH). Colón: Cerro Santa Rita, 30 km E Colón, 14.I.1981, C.D. Michener, on white Eupatorium (3 ops., SEMC); Colón, $30 \mathrm{~km} \mathrm{SW,} \mathrm{Santa} \mathrm{Rita} \mathrm{Ridge,}$ 20.I.1983, D. Yanega (1 op., SEMC); ibidem, $30 \mathrm{~km}$ E Sta. Rita, 4.I.1981, D. Roubik, 14 (1 op., RPSP); Parque Nacional Soberania, Pipeline Road, km 10 N Gamboa, 8.X.1982, D. Roubik, 118 (1 op., RPSP); ibidem, Pipeline Rd. km 6.1, $09^{\circ} 07^{\prime} \mathrm{N}, 79^{\circ} 45^{\prime} \mathrm{W}, 40 \mathrm{~m}, 7-21 . \mathrm{VI} .1995$, J. Ashe, R. Brooks, 265, ex: flight intercept trap (1 op., SM0057336 KUNHMENT, SEMC); Portobelo, $15 \mathrm{~km}$ SW Santa Rita Ridge, 18.VIII.1985, Camargo (100 ops., 851671-851732, RPSP); Puerto Pilón, 24 km NE SR (?), 22.XII.1982, D. Roubik, 71 (1 op., STRI; 3 ops., RPSP). Coclé: El Copé, 21.I.1979, D. Roubik, 2 (1 op., RPSP); ibidem, $7.2 \mathrm{~km} \mathrm{NE}$, $08^{\circ} 37^{\prime} \mathrm{N}, 80^{\circ} 35^{\prime} \mathrm{W}, 730 \mathrm{~m}, 20 . \mathrm{V}-7 . \mathrm{VI} .1995$, J. Ashe, R. Brooks, flt. intercept trap, 140 (3 ops., SM0057333, 0057334, 0057335 KUNHMENT, SEMC; 1 op., SM0057332 KUNHM-ENT, RPSP); ibidem, 20.VI.1995, 251, Clibadium (1 op., SM0057288 KUNHM-ENT, SEMC). Panamá: Capira, Cerro Campana, 14.I.1983, D. Roubik, 38 (1 op., STRI); ibidem, idem, 11.VII.1982, 39 (1 op., RPSP), 18.VI.1981, 26 (1 op., RPSP), 11.X.1982, 40 (1 op., RPSP); Cerro Campana, 23.VIII.1975, G.W. Otis (3 ops., SEMC); ibidem, 900m, 17.V.1987, D. Roubik, at chem. (2 ops., STRI); ibidem, 8 km NW Capira. $1000 \mathrm{~m}$, 4.V.1981, R.W. Brooks (1 op., SEMC); Cerro Jefe, 2000 ft., 12.III.1969, R.L. Fischer (1 op. MSUC); Chepo, Carti, 1.X.1980, D. Roubik, 34 (2 ops., STRI; 2 ops., RPSP); ibidem, idem, 18.I.1980, 9 (1 op., RPSP), 23 km NE Carti R. 26.V.1982, 46 (1 op., RPSP), 8 km NE Carti R., 7.I.1981, 16 (1 op., RPSP), 32 km NE, C. Rd., 9.VI.1982, 60 (1 op., STRI), 7.VII.1979, 2 (1 op., STRI); ibidem, 10 km NE, Carti Rd., 10.V.1981, Robt. W. Brooks (1 op., SEMC); El Llano - Carti Rd. km 15, 20.IV.1984, D. Roubik (2 ops., STRI); Gamboa, Pipeline Rd., 5.I.1980, D. Roubik, 38 (1 op., RPSP); ibidem, 9 Mi. N, 23.VIII.1979, D. Roubik, 12 (3 ops., STRI); ibidem, $9 \mathrm{~km} \mathrm{~N}$ El Llano, 600m, 7.I.1981, C.D. Michener, on Mikania amblyolepis (4 ops., SEMC); ibidem, idem, $600 \mathrm{~m}$, on white Eupatorium (3 ops., SEMC), 600m, on Solanum hayesi (1 op., SEMC); ibidem, 12,8 km N, 18-29.II.1980, Brian H. Smith (1 op., SEMC). San Blás: Kuna Yala, Carti - 8 km S, 15.VIII.1985, D. Roubik, honey $\mathrm{H}_{2} \mathrm{O}(3$ ops., STRI); ibidem, Res. Indígena Kuna, $78^{\circ} 30^{\prime} \mathrm{W}, 9^{\circ} 20^{\prime} \mathrm{N}$, 14,16.VIII.1985, Camargo (202 ops., 85085-85959); Prov. ?: Boqueron Riv., V.1907, August Busck (1 op., USNM, exemplar da série tipo); ibidem, idem, "Trigona musarum Ck11., cotype" (1 op., Ac. 38008, AMNH). COLÔMBIA. Magdalena: Valledupar, 4-7.VI.1968, Borys Malkin (2 ops., AMNH); ibidem, idem, 21-24.V.1968 (2 ops., AMNH). Antióquia: Valle Medellin, VII.1946, F.L. Gallego M., 21-72 (2 ops., 1 macho, 176630, USNM). Cundinamarca: Paime, 3.IV.1977, G.N. Parra (4 ops., RPSP).

Distribuição geográfica e hábitat: Matas tropicais do norte da Colômbia até Honduras (Fig. 167).

Nidificação. Em ninhos abandonados de aves (WILLE \& MiCHENER, 1973).

Discussão. Foram examinados dois exemplares da série tipo, de "Boqueron Riv. May 07, August Busck", um deles com a etiqueta de Cockerell, ac. 38008, "Trigona musarum Ckll., cotype", depositado no AMNH. Não foi designado lectótipo, visto que não se conhece o material de Philadelphia Banana, Costa Rica. Esta é a única espécie com integumento amarelado na América Central, o que a diferencia das demais espécies que aí ocorrem. Além da cor do integumento, as cerdas curtas no 
escapo e nas áreas paroculares, ao lado dos alvéolos, também são caracteres úteis para o reconhecimento da espécie. De $P$. aequatoriana, com a qual se sobrepõe no leste do Panamá, distingue-se, principalmente, pelo contornno mais fortemente sinuado da tíbia III (entre o terço basal e a porção apical convexa), pela área malar, geralmente um pouco mais curta, e pelas manchas paroculares, geralmente um pouco mais estreitas embaixo. Esta é a única espécie do grupo musarum, que alcança a América Central. Sua provável espécie irmã é $P$. aequatoriana, com a qual compartilha a bifurcação de $\mathrm{R}+\mathrm{M}$ posterior à $\mathrm{cu}-\mathrm{V}$ (mas podem aparecer exemplares com a bifurcação coincidente ou levemente anterior em ambas as espécies), além da coloração do integumento, área malar relativamente longa, cerdas da base do escapo e áreas paroculares curtas, e outros caracteres, como cor da asa, substrato de nidificação (não associado a térmitas), que embora presentes também em outras espécies, ocorre de forma combinada nessas duas.

Partamona aequatoriana Camargo, 1980

(Figs. 1, 64, 65, 149, operária; 167, distribuição; Tabs. II-IX)

Partamona (Partamona) aequatoriana Camargo, 1980:56-57, 22, 72, 76, 161-162.

Partamona aequatoriana; Camargo, 1992:81; Coloma, 1986:26, 32, $35,69,107,125,132,136,137,140$.

Diagnose. Abelhas de porte médio (1.m.c. 2,5-2,7 mm, c.a.a. 6,0-6,4 mm; Tabs. III, IV). Integumento amarelo ou, raramente, mesclado com castanho. Sutura epistomal, área ao redor dos ocelos, mesepisternos na porção ventral, mesoscuto, basitarso e tíbia III (metade apical ou por inteiro), amarelados ou escurecidos. Mandíbula predominantemente amarela, ápice ferrugíneo, côndilos escurecidos até amarelados. Flagelo castanho escuro ou castanho amarelado. Estrias paroculares largas (ca. 1,0-1,2x o diâmetro do $2^{\circ}$ flagelômero), muito alargadas embaixo, preenchendo todo o espaço entre o olho e a sutura epistomal ou quase, estreitadas na altura dos alvéolos e chegando até o topo do olho ou alcançando o vértice em alguns indivíduos (Fig. 149). Cerdas eretas do vértice, mesoscuto e escutelo, amareladas, ferrugíneas ou misturadas; na metade superior dos lados dos mesepisternos amareladas ou esbranquiçadas; na região ventral dos mesepisternos, coxas, trocanteres e esternos, esbranquiçadas; no resto, enegrecidas. Membrana das asas levemente ferrugínea; microtríquias pretas; veias méleas, mas escurecidas pelas microtríquias fuscas, $\mathrm{C}$ e $\mathrm{R}$ mais escuras e pterostigma mais claro. Cerdas do escapo curtas, apenas uma ou duas cerdas na base um pouco mais longas (1,0-1,1x o diâmetro do escapo; Tab. VII). Cerdas eretas das áreas paroculares, ao lado dos alvéolos, mais curtas que o diâmetro do escapo, pouco destacadas em relação às cerdas decumbentes. Cerdas do escutelo 0,9-1,2x o comprimento deste. Área basal do propódeo com faixa mediana glabra aproximadamente tão larga quanto o diâmetro do $2^{\circ}$ flagelômero. Dentes da mandíbula pequenos e recuados em relação ao ápice do bordo apical (Figs. 64, 65). Área malar longa (ca. 1,3-1,7x o diâmetro do $2^{\circ}$ flagelômero; Tab. V). Distância interocelar maior que a ocelorbital (Tab. VI). Tíbia III e comprimento da asa anterior, normais (Tabs. V, VI, VIII, IX). Bifurcação da $\mathrm{M}+\mathrm{Cu}$ freqüentemente posterior ou, em alguns indivíduos, coincidente com cu-v.

Variação. Alguns exemplares apresentam áreas escurecidas na fronte, área ao redor dos ocelos, mesoscuto, tíbia e basitarso III. Outros dados em CAmargo (1980).

\section{Macho. Desconhecido.}

Material-tipo. Holótipo, "Esmeraldas, ECUADOR, IX.1959, F. H. Walz" (DZUP); parátipos, 11 operárias da mesma procedência, data e coletor (DZUP e RPSP) e uma operária de "Colômbia, Dep. del Valle del Cauca, Buenaventura, 17 Mar. 1967, Plant. Palmeras d. Pacífico, lowld. rainfor., R. B. Root, W. L. Brown" (CUIC). Todos os exemplares tipo foram examindos.

Material examinado. PANAMÁ. Colón: Parque Nac. Soberania, Pipeline Rd. Nr. Gamboa, $09^{\circ} 07^{\prime}$ N, $79^{\circ} 45^{\prime}$ W, 20.V.1995, J. Jolly, G. Kidd, C. Chaboo, B. Hayford (1 op., SM0057337 KUNHM-ENT, SEMC).

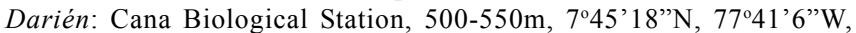
03.VI.1996; J. Ashe, R. Brooks, PAN1AB96 015, ex: Ludwigia (1 op., SM0034628 KUNHM-ENT, SEMC); ibidem, idem, 04.VI.1996, PAN1AB96 016, ex: misc collecting (1 op., SM0034645 KUNHMENT, SEMC), 750m, 05.VI.1996, PANAB96 023, ex: coming to sweat (4 ops., SM0034844, SM0034845, SM0034847, SM0034848 KUNHMENT, SEMC; 1 op., SM0034846 KUNHM-ENT, RPSP), 600m, 0307.VI.1996, PAN1AB96 067, ex: flight intercept trap (1 op., SM0011450 KUNHM-ENT, SEMC), 530m, 07-09.VI.1996, PAN1AB96 113, ex: flight intercept trap (1 op., SM0011443 KUNHM-ENT, SEMC), 600m, 07-09.VI.1996, PAN1AB96 115, ex: flight intercept trap (1 op., SM0011435 KUNHM-ENT, SEMC), 530m, 10.VI.1996, PAN1AB96 141 (1 op., SEMC). COLÔMBIA. Chocó: Solano, 25.VI.1950, Richter, CM 153 (1 op., SEMC). Risaralda: Mistrató, Pto. de Oro, 900m, IX.1991, Fernando Fernández, CM 166, ojo 25 (1 op., SEMC). Valle: Rio Anchicaya, 400m, 10.II.1977, M.D. Breed \& C.D. Michener (3 ops., SEMC); ibidem, idem, 480m, $11 . I I .1977$ (6 ops., SEMC; 1 op., RPSP); ibidem, 400m, 28.IX.1976, Bell, Breed \& Michener (14 ops., SEMC; 2 ops., RPSP). EQUADOR. Esmeraldas: Alto Tambo, 2.VIII.1991, D. Roubik, "rainy" (2 ops., STRI); Bilsa, 0²0'0"S, 7943'0”W, 10.V.1996 - 5.VI.1997; P. Hibbs ECU1H96 010, ex: flight intercept trap (1 op., SM0092258 KUNHM-ENT, SEMC); ibidem, idem, 5.VI-7.VII1996, ECU1H96 014 (2 ops., SM0092286, SM0092303 KUNHM-ENT, SEMC); Cupa, I.1985, F. Bravo (1 op., RPSP); Quinindé, VI.1968, G. Onore, "sacando resina de Cocos nucifera" (2 ops., RPSP); San Mateo, sem data, anônimo (6 ops., SEMC); ibidem, 19.IX.1956, anônimo (2 ops., SEMC); ibidem, 22.VII.1956, anônimo (1 op., SEMC). Imbabura: Lita, XI.1986, W. Uricatta (1 op., RPSP); ibidem, XI.1986, M.H. Lopez (1 op., RPSP). Pichincha: La Florida, III.1986, L. Coloma (2 ops., RPSP); ibidem, X.1985, L. Coloma (1 op., RPSP); Quito, 45 km NNW, Macquipucuna Station, 1600-1650m, 16.IV-5.V.1996, P. Hibbs, ECU1H96 013, ex: flight intercept trap (3 ops., SM0092238, SM0092240, SM0092318, SEMC; 1 op., SM0092239 KUNHM-ENT, RPSP); ibidem, idem, 3-18.IV.1996, ECU1H96 012 (3 ops., SM00872270087229, KUNHM-ENT, SEMC); ibidem, 50 km NW, Maquipucuna For. Res., 1300m, 23.XII.1991, C. Carlton, R. Leschen, 71, ex: at light (1 op., SEMC); Rio Palanque (sic) Res. Sta., 200m, II.1983, M. Sharkey, L. Masner (2 ops., SEMC); Rio Palenque, 200m, 25.IV-6.VI.1996, P. Hibbs, ECU1H96 002, ex: flight intercept trap (1 op., SM0092222 KUNHM-ENT, SEMC); Santo Domingo de los Colorados, 2000', 8.II.1958, R.W. Hodges, (1 op., MSUC). Cotopaxi: Las Pampas, 23.IX.1997, Mateus, banana (3 ops., 973512-973514, RPSP); Palo Quemado, VI.1986, Onore (7 ops., RPSP). Prov.? Pilaton, 5.II.1958, R.W. Hodges (1 op., MSUC).

Distribuição geográfica e hábitat. Matas tropicais da costa do Pacífico no norte do Equador e Colômbia, chegando até o 


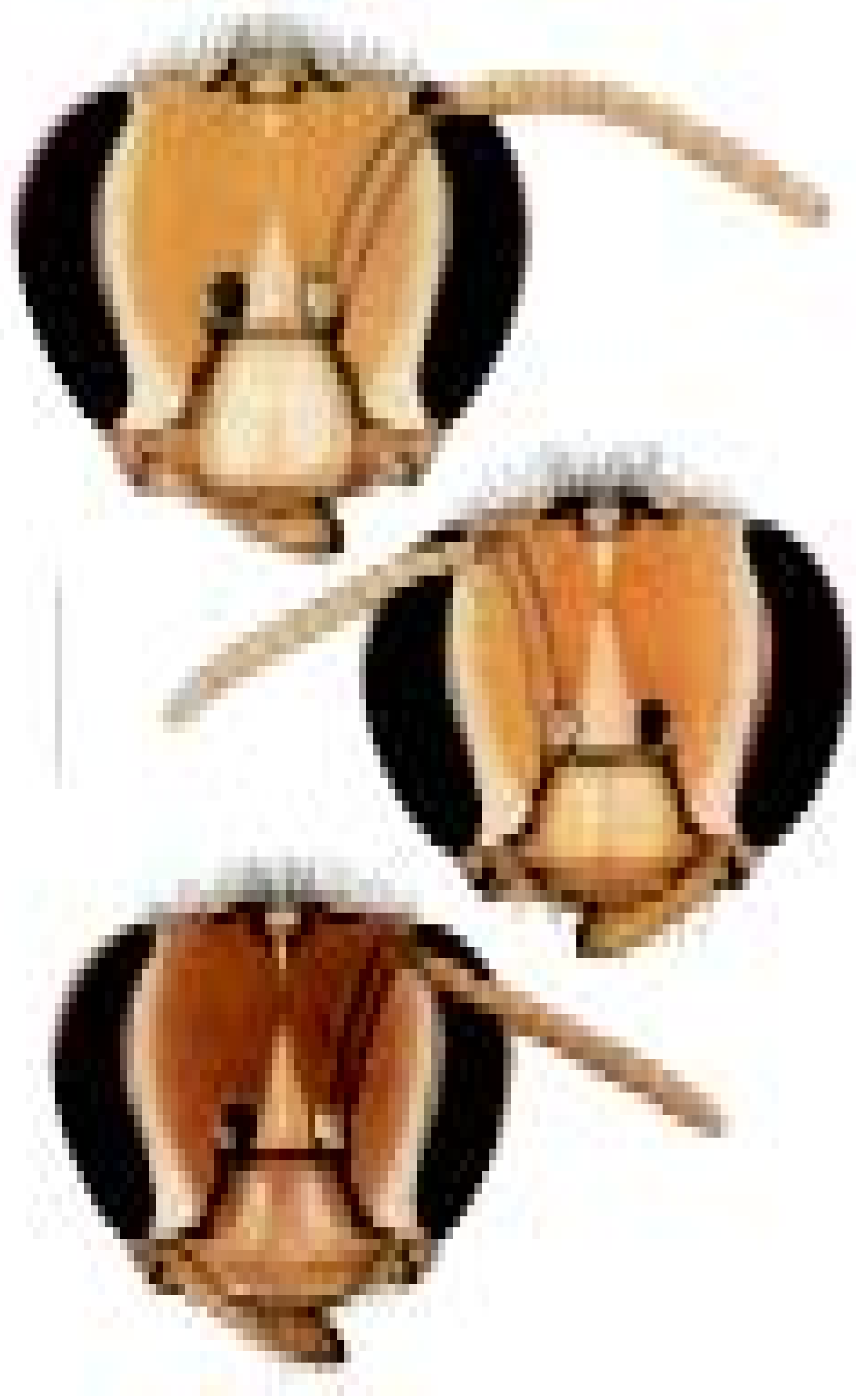

Fig. 1. Operárias: Em cima, Partamona aequatoriana, holótipo, Esmeraldas, Equador; no centro, P. mourei, holótipo, Barcelos-AM, Brasil; embaixo, P. mulata, holótipo, Cuiabá-MT, Brasil. Escala = 1,0 mm (reproduzido de CAMARGO, 1980). 
Panamá central (Fig. 167).

Nidificação. Ninho sob raízes de epífitas (ColomA, 1986).

Discussão. Distingue-se das demais espécies que ocorrem a oeste dos Andes, pelo integumento amarelado ou mesclado, pelas cerdas curtas no escapo e áreas paroculares ao lado dos alvéolos e dentes da mandíbula um pouco recuados em relação ao bordo apical (Figs. 64, 65). P. aequatoriana é a única espécie do grupo musarum que ocorre a oeste dos Andes. Sua provável espécie irmã é $P$. musarum (veja discussão em $P$. musarum). No leste do Panamá, onde chegam a se sobrepor, a separação entre as duas é bastante difícil. $P$. aequatoriana tende a ser maior (Tabs. III, IV), apresenta área malar mais longa, e o contorno da margem posterior da tíbia III é mais suavemente sinuado (outros comentários na discussão sobre $P$. musarum). $\mathrm{O}$ estudo dos machos, ainda desconhecidos, e detalhes sobre os hábitos de nidificação de $P$. aequatoriana poderão auxiliar no esclarecimento das relações com $P$. musarum, da qual pode constituir apenas uma população geográfica.

Partamona vicina Camargo, 1980

(Figs. 62, 146, operária; 81, 110, macho; 165, distribuição; Tabs. II-IX)

Partamona (Partamona) vicina Camargo, 1980:11, 18, 21, 23, 45 49,71, 72, 73, 133-142, 144-148; Absy et al., 1984:228, 231.

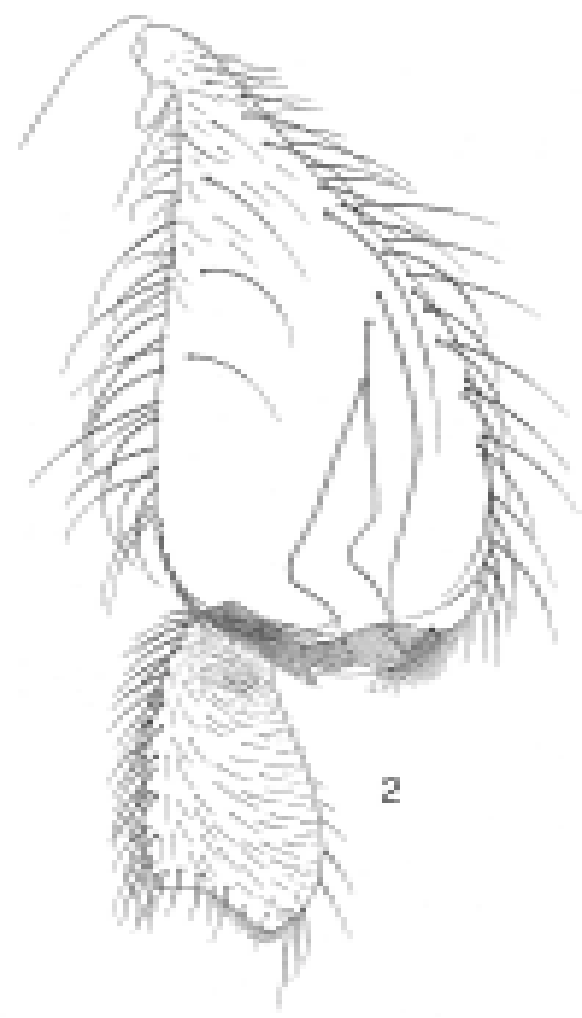

Partamona (Partamona) pseudomusarum Camargo, 1980:16, 21, 23, 49-52,58, 64, 74, 75, 143, 149-158; Absy et al., 1984:228, 229, 231, 236. Syn. nov.

Partamona vicina; Camargo, 1988a:294, 306; Roubik, 1989:219, 221; Ramalho et al., 1990:471; Camargo, 1992:81; Camargo, 1994:50.

Partamona pseudomusarum; Camargo, 1988b:358; Baumgartner \& Roubik, 1989:14, 16; Roubik, 1989:221; Cruz-Landim \& Mota, 1990:587, 588; Ramalho et al., 1990:471; Camargo, 1992:81; Mota, 1992:320, 321; Bravo, 1992:864; Camargo, 1994:50, 52; Oliveira, \& Morato, 1994:291; Oliveira et al., 1995:16, 18,19; NogueiraNeto, 1970:45.

Partamona musarum; Engel \& Dingemans-Bakels, 1980:350.

?Partamona cupira; Engel \& Dingeman-Bakels, 1980:346, 350 (não há dados seguros para identificação da espécie).

Melipona pallida pallida; Ducke, 1916:15, 24, 34, 114, 118 (partim), 119, 41a; 1925:409, 420, 340, 411, 42a. (partim).

Melipona pallida pallida aberr. rhumbleri; Ducke, 1916:119, 120, (partim) (NW de MT, Coxipó).

Trigona rhumbleri; Silvestri, 1902:153, 155, Figs. 15, 18, 36, (partim); Nogueira-Neto, 1970:41.

Trigona pallida; Friese, 1900:389.

Trigona (Patera) testacea var. musarum; Schwarz, 1938:476, 477.

Trigona (Partamona) testacea musarum; Schwarz, 1940:9; 1948:485; Kerr, et al., 1967:286 (partim); Roubik, 1979:446; ?Cunha, 1973:3, Figs. 2, 3, 4, 5, 6, 7.

Ptilotrigona musarum; Nogueira-Neto, 1970:42.

Diagnose. Abelhas de porte médio a pequenas (l.m.c. 2,32,5 mm, c.a.a. 5,2-5,6 mm; Tabs. III, IV). Integumento amarelo, inclusive mesepisternos, sutura epistomal e área ao redor dos ocelos; basitarso e tíbia III por inteiro amarelados ou parcialmente escurecidos. Mandíbula amarela, inclusive

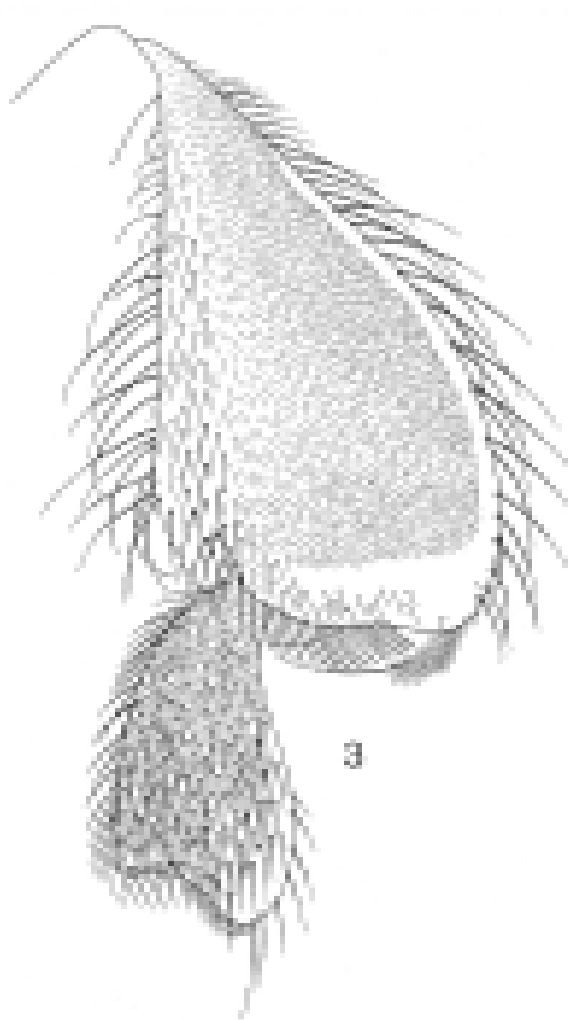

Figs. 2-3. Partamona vicina, operária (Barra do Garças - MT, Brasil, 20-21c), tíbia e basitarso III: 2. Vista externa; 3. Vista interna. Escala = 1,0 mm. 
côndilos. Flagelo castanho escuro ou castanho amarelado. Estrias paroculares aproximadamente com a mesma largura em toda a extensão ( $0,8-1,0 \mathrm{x}$ diâmetro $2^{\circ}$ flagelômero) ou apenas um pouco alargadas embaixo (1,0-1,2x; Fig. 146). Cerdas eretas do vértice, mesoscuto e escutelo amareladas ou ferrugíneas; na metade superior dos mesepisternos amareladas ou esbranquiçadas; na região ventral dos mesepisternos, coxas, trocanteres e esternos, esbranquiçadas; nos tergos, enegrecidas, ferrugíneas ou misturadas. Membrana das asas hialina, raramente levemente ferrugínea; microtríquias pretas; veias méleas mas escurecidas pelas microtríquias. Cerdas do escapo curtas, apenas uma ou duas cerdas na base um pouco mais longas (1,0-1,1x o diâmetro do escapo; Tab. VII). Cerdas eretas das áreas paroculares, ao lado dos alvéolos, mais curtas que o diâmetro do escapo. Cerdas do escutelo 0,9-1,0x o comprimento deste. Área basal do propódeo com faixa mediana glabra aproximadamente tão larga quanto o diâmetro do $2^{\circ}$ flagelômero. Dentes da mandíbula pequenos e recuados em relação ao ápice do bordo apical (Fig. 62). Área malar, distância interocelar, distância ocelorbital, tíbia III e comprimento da asa anterior normais (Tabs. V, VI, VIII, IX). Bifurcação da $\mathrm{M}+\mathrm{Cu}$ geralmente coincidente com a cu-v (raramente levemente anterior). Macho, basitarso III alongado, achatado ou convexocôncavo; tíbia III estreita (Fig. 81); EVII com a projeção mediana curta e triangular, os chanfros laterais curtos e largos (Fig. $110)$.

\section{Variação. Veja discussão.}

\section{Macho. Descrição em CAMARGo (1980). Figuras 81, 110.}

Material-tipo. Holótipo e alótipo, de "Brasil, Mato Grosso, Barra do Garças, 10-24.I.1971, Camargo leg.”, ninho 20c; parátipos, de mesma procedência, data e coletor, 12 ops., mais exemplares em álcool, inclusive machos, ninhos 20c, 21c (RPSP). Outros parátipos de, Mato Grosso: Alto Paraguai, 26 Outubro, 1954, A.A. Addor (46 ops., DZUP; 10 ops., RPSP); Chavantina (sic=Xavantina), VII,1962, Alvarenga-Oliveira (12 ops., DZUP); Diamantino, 10-14.II.65, S. Laroca leg. (1 op., DZUP); ibidem, idem 16-II-65 (2 ops., DZUP); Mato Grosso, 2-XI-61, F. M. Oliveira (90 ops., DZUP; 10 ops., RPSP); P. Branca, A. Paraguai, 26 Out. 1954, A.A. Addor (58 ops., DZUP; 6 ops. RPSP); Amapá: Serra do Navio, I.1957, Machado e F. Pereira (23 ops., DZUP; 4 ops., RPSP); Goiás: Aragarças, 13-I-1971, col. Camargo (11 ops., RPSP); ibidem, 13I-1971, Y. Terada (10 ops., RPSP). Todos os exemplares foram examinados.

Material examinado. COLÔMBIA: Cundinamarca: Paime, 3.IV.1977, G.N. Parra (3 ops., RPSP). Meta: San Juan de Arama, Reserva La Macarena, 6.XII.1986, A. Bolinna, ex: Caño La Curia, CM 157 (1 op., SEMC). Amazonas: Araracuara, Bosque Maduro, 28.VII.1988, M. Torres, "sobre Schelea ataleoides" (1 op., 910019, RPSP); Letícia, 65 km W Amacayacu Nat. Park, 17-30.IX.1986, D. Roubik (3 ops., 870323325, RPSP). VENEZUELA. Amazonas: Mt. Duida region, 4.XI.1928, G.H.H. Tate, 99 (2 ops., Ac. 29500, AMNH); Raudal Guaharibus, 8.VIII.1951, Fco. Ven. Alto Orinoco (4 ops., USNM); Rio Jureba, Orinoco, 6.II.1992, D. Wittmann (2 ops., WITT). GUIANA: Baracara to First falls of Mazaruni R., 13.VIII.1920, R.E. Wheeler, 624, W.3 (2 ops., AMNH); Bartica District, 30.III.1924, Peccary, "entrails I" (2 ops., AMNH); Camaria, Bartica District, 30.VI.1924, J. F. Pearson (1 op, 2468, AMNH); Essequibo R., Moraballi Creek, 13.VIII.1929, Oxf. Univ. Expedn. (1 op., BMNH); ibidem, idem, B.M. 1929-485, (1 op., RPSP; 2 ops., Ac. 33005, AMNH); Georgetown, sem data, anônimo (1 op.,
CMNH); Kaieteur, 26.V.1929, A. Mackis (1 op., AMNH); ibidem, 26.VII.1911, anônimo (1 op., 24513, AMNH); Kamakusa, sem data, H. Lang (1 op., AMNH); Kangarume, 23.V.1929, J. Ogilvie (1 op., USNM); Kartabo, 24.VII.1926, anônimo (1 op., RPSP); ibidem, 26.VIII.1920, W.M. Wheeler (6 ops., Ac. 35657, AMNH); ibidem, Bartica District, 9.VIII.1920, anônimo (1 op., AMNH); Issororo (?, ilegível), N.W.D. B. Guiana, VI.1915, C.E. Bodkin (1 op., BMNH); Shudihar R., 29.XII.1937, W.G. Hassler (1 op., RPSP; 2 ops., Ac. 36159, AMNH); Tukeit, 16.VII.1911, anônimo, 17 (1 op., 24513, AMNH); Wismar, 20.VII.1934, A.S. Pinkus ( 1 ops., RPSP; 2 ops., Ac. 33362, AMNH). SURINAME: Surinam (localidade?), sem data, anônimo, 1.002, "Trigona pallida Latr. 1.002 Surinam Ducke rev. 13" (2 ops., parátipos, 95489, 95490, MZSP); Surinam (localidade?), 1900, anônimo (2 ops., AMNH); Tapanahony river, $17 \mathrm{~km}$ downstream from Paloemeu, 27.II.1993, B. De Dijn (2 ops., I 928, NZCS); Paramaribo, Oost-West verbindings road km 78 East of Paramaribo, 09.XII.1993, B. De Dijn, I 1117 (3 ops., NZCS; 1 op., RPSP). GUIANA FRANCESA: Kourou, $11 \mathrm{~km} \mathrm{SW,} \mathrm{26.II.1977,} \mathrm{C.D.}$ Michener (1 op., RPSP; 1 op., SEMC); ibidem, 18.I.1977, D. Roubik, 85 (2 ops., SEMC); ibidem, idem, 19.I.1977, 85 (1 op., SEMC), 18 km SW, Degrad Saramaca, 27.IV.1982, 84 (1 op., STRI), km 19 SW, 22.II.1977, 93 (3 ops., SEMC), 5.III.1977, 100 (1 op., STRI), 21 km SW, 23.V.1981,

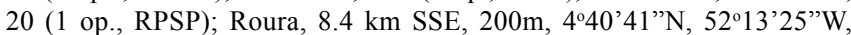
22-24.V.1997; J. Ashe, R. Brooks FG1AB97 028, ex: malaise trap (1 op., SM0092096 KUNHM-ENT, SEMC); Saül, 7 km N, 3 km NW Les Eaux Claires, Mt. La Fumée, 3³9'46”'N, 53¹3’19”W, 490m, 1.VI.1997; J. Ashe, R. Brooks FG1AB97 102 (11 ops., SM0102862-0102866, 0102868-0102870, 0102872-0102874, KUNHM-ENT, SEMC; 2 ops., SM1012867, 0102871, RPSP); Synnamary, $15 \mathrm{~km} \mathrm{SE,} \mathrm{palm} \mathrm{plantation}$ rd., 5.V.1982, D. Roubik, 64 (3 op., RPSP). EQUADOR. Napo: Jatun Sacha Biol. Sta., $21 \mathrm{~km}$ E Puerto Napo, 400m, 9.VII.1994, Francois Génier, ex: feces trap (2 ops., SEMC); Parque Nacional Yasuni, km 9 Via Tibacuno, 08.II.1997, E. Baus, nido A1 (4 ops., 973478-973481, RPSP); ibidem, SC Yasuni, 230m, II.1997, E. Baus, ex: nest on Cedrelinga catenaeformis trunk (3 ops., RPSP); ibidem, Yasuni Nat. Pk. - Católica, 13-27.IV.1998, D. Roubik, 42 (2 ops., RPSP); ibidem, idem, 44 (3 ops., RPSP). PERU: Loreto: Iquitos, $25 \mathrm{~km}$ SW, Callicebus Res. Station Mishana, Rio Nanay, 120m, 10-17.I.1980, J.B. Heppner, "tropical wet forest" (2 ops., USNM); Pucallpa, Rio Calleria, 19.VII.1962, W.T. Van Velzen (2 ops., MSUC); San Alejandro, 300m, VI.1947, W. Weyrauch (1 op., AMNH); Teniente Lopez, $1.5 \mathrm{~km} \mathrm{~N}, 2^{\circ} 35.66^{\prime} \mathrm{S}, 76^{\circ} 06.92^{\prime} \mathrm{W}, 210-240 \mathrm{~m}$, 26.VII.1993, Richard Leschen, 212, ex: flight intercept trap (2 ops., RPSP); ibidem, idem, 213 (1 op., RPSP). Pasco: Puerto Bermudez, 10 km W, 200m, 16.XII.1981, B. Greenberg, asynanthropic, liver bait, 1130 (1 op., STRI). Madre de Dios: Puerto Maldonado, $15 \mathrm{~km} \mathrm{NE}$, Tambopata Prov., Rio Heath, Reserva de Pampas del Heath, Quebrada Juliaca, 190m, 22-25.II.1990, Luis Coloma, 49 (1 op., SEMC). Depto.?: Yurac, 300m, VI.1947, Weyrauch (8 ops., SEMC; 1 op., RPSP). BRASIL:

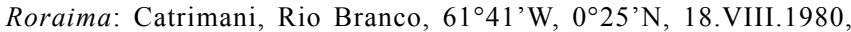
Camargo, Mazucato (93 ops., RPSP); Igarapé Castanho, rio Branco, 6150'W, $0^{\circ} 49^{\prime}$ 'S, 21.VIII.1980, Camargo, Mazucato (55 ops., ninho 287c, RPSP); Maloca Aldeia da Tábua Lascada, 16.IV.1996, Silva (30 ops., 960072-960101, mais exemplares em álcool, RPSP); Santa Maria do Boiaçu, 61²7'W, 0³0'20''S, 19-20.VIII.1980, Camargo, Mazucato (49 ops., 27 machos, mais ops. e 27 machos em álcool, ninho 284c, RPSP); ibidem, idem (6 ops., RPSP). Amapá: Alto Amaparú, 8.IX.1957, K. Lenko (1 op., parátipo de P. pseudomusarum, DZUP); Oyapock, Est. do Pará (sic) 29.V.1904, Ducke (1 op., parátipo de $P$. pseudomusarum, 95493, MZSP); Serra do Navio, X.1957, K. Lenko (parátipos de P. pseudomusarum: 1 op., RPSP; 2 ops., DZUP). Amazonas: Acanga-Barcelos, rio Negro, 62 ${ }^{\circ} 43^{\prime} \mathrm{W}, 1^{\circ} 7^{\prime} \mathrm{S}, 6-8$.VIII. 1980 , Camargo, Mazucato (52 ops., mais exemplares em álcool, ninho 264c; 99 ops., RPSP); Alvarães, 6450'W, $3^{\circ} 13^{\prime}$ 'S, 24.VIII.1993, Camargo, Pedro, Mazucato (117 ops., 936342-354, 936361-418, 936397B, RPSP); Arimã, rio Purus, $63^{\circ} 41^{\prime} \mathrm{W}, 5^{\circ} 43^{\prime}$ 'S, 3-8.II.1986, Camargo, Mazucato (87 ops., 861733-43, 861745, 861748-62, 861764, 861766, RPSP); B.A.B.A. ( sic = Bê-á-bá), Purus, $62^{\circ} 53^{\prime} \mathrm{W}, 4^{\circ} 52^{\prime}$ 'S, 12-13.II.1986, Camargo, Mazucato (102 ops., 862005-862038, RPSP); Bacururu, rio Juruá, $66^{\circ} 11^{\prime} \mathrm{W}, 3^{\circ} 45^{\prime}$ S, 01.VIII.1993, Camargo, Pedro, Mazucato (60 ops., mais ops. e 20 machos em álcool, ninho $548 \mathrm{c}$, e mais 26 ops., 933490, 933492-93, 933497, 933499, 933500-507, 933509-520, 
933524, RPSP); Beruri, r. Purus, 16.X.1991, G.A.R. Melo (1 op., MELO); BR 174, ZF8 km 23, 02.IV.1986, M.V.B. Garcia, Proj. DBFF.WFF, Acamp. Forestal (6 ops., RPSP); Camanaus, rio Negro, $66^{\circ} 54^{\prime} \mathrm{W}, 0^{\circ} 8^{\prime} \mathrm{S}, 12-$ 14.VII.1980, Camargo, Mazucato (53 ops., RPSP); Camaruã, $64^{\circ} 25^{\prime} \mathrm{W}$, $5^{\circ} 46$ 'S, 29.I.1986, Camargo-Mazucato (1 op., 862563, RPSP); ibidem, $15 \mathrm{~km}$ à jusante, $64^{\circ} 25^{\prime} \mathrm{W}, 5^{\circ} 40^{\prime} \mathrm{S}, 31 . \mathrm{I}-1 . \mathrm{II} .1986$, Camargo, Mazucato (97 ops., 861354-385, 861169, RPSP); ibidem, 31.I.1986, M.V.B. Garcia (88 ops., UFVB); Fonte Boa, SA-19, 66-3f.xii, 24-25.I.1977, Camargo, M. Mazucato ( 2 ops., RPSP); Foz do Rio Curicuriari, rio Negro, $66^{\circ} 49^{\prime} \mathrm{W}$, 0 13 '30'S, 15-21.VII.1980, Camargo, Mazucato (50 ops., mais exemplares em álcool, ninho $221 \mathrm{c}$; e mais 48 ops., RPSP); F. do Rio Daraã, R. Negro, 644ㄱ'W, $0^{\circ} 25^{\prime}$ WS2, 4.VIII.1980, Camargo, Mazucato (1 op., RPSP); Itacoatiara, $30 \mathrm{~km} \mathrm{W,} \mathrm{rio} \mathrm{Urubu,} \mathrm{15.I.1981,} \mathrm{Ekis} \mathrm{\&}$ Davidson, primary forest, malaise trap (1 op., CMNH); Lago Uaicurapá, Paraná do Ramos, 56 ${ }^{\circ} 45^{\prime} \mathrm{W}, 2^{\circ} 46^{\prime} \mathrm{S}, 20-21 . \mathrm{II} .1979$, Camargo et al. (60 ops., mais exemplares em álcool, ninho 196c, 56 ops., 2 machos, mais material em álcool, ninho 198c, 69 ops., 1 macho, ninho 199c, 69 ops., ninho 200c, e outras 64 ops., RPSP); Lago Uará, rio Solimões, $65^{\circ} 35^{\prime} \mathrm{W}$, $2^{\circ} 41$ 'S, 13.VIII.1993, Camargo, Pedro, Mazucato (60 ops., mais exemplares em álcool, ninho 593c, e outras 61 ops., 934500-545, RPSP); Manacapuru, V.1926, S.M. Klages (1 op., Ac. 10593, CMNH); Manaus, 1981, Falcão (2 ops., RPSP); ibidem, I-II.1963, Exp. FFCLRC (8 ops., parátipos de P. pseudomusarum, RPSP); ibidem, VIII.1959, C. Elias (6 ops., parátipos de P. pseudomusarum, RPSP); ibidem, $65 \mathrm{Km} \mathrm{N}$, km 45 BR174, 11-13.VIII.1994, S.R.M Pedro (1 op., RPSP); ibidem, VI.1955, A.P. Duarte (parátipos de P. pseudomusarum, 37 ops., DZUP; 5 ops., RPSP); ibidem, Reserva Ducke, 27.II.1976, B. Mascarenhas (1 op., INPA); ibidem, R. Ducke, 12.V.1981, F. Peralta (2 ops., INPA); Maraã, rio Japurá, $65^{\circ} 35^{\prime} \mathrm{W}, 1^{\circ} 53^{\prime} \mathrm{S}$, 17.VIII.1993, Camargo, Pedro, Mazucato (69 ops., 12 machos, mais ops. e 20 machos em álcool, ninho 602c, e outras 38 ops., 935382-935405, RPSP); Nogueiras, Lago de Tefé, 644ㅇ' W, $3^{\circ} 19^{\prime}$ S, 25-28.VIII.1993, Camargo, Pedro, Mazucato (1 op., 936221); Paricatuba, rio Purus, $61^{\circ} 53^{\prime} \mathrm{W}, 4^{\circ} 25^{\prime}$ 'S, 17-19.II.1986, Camargo, Mazucato (93 ops., 862422-450, RPSP); Rio Ipixuna, $42 \mathrm{~km}$ à montante do Tapauá, $63^{\circ} 20^{\circ} \mathrm{W}, 6^{\circ} 0^{\circ} \mathrm{S}$, 20.I.1986, Camargo, Mazucato (79 ops., 19 machos, mais exemplares em álcool, ninho $337 \mathrm{c}$, e outras 149 ops., 860263, 860276, 860300-307, 860482, 860521-527, 860529566, RPSP); São Paulo de Olivença, margem direita do Solimões, SA.19, 69-4b, 19.I.1977, Camargo, Mazucato (holótipo e parátipos de $P$. pseudomusarum, 34 ops., mais material em álcool, ninho $84 \mathrm{c}$, e mais 17 ops., RPSP); Tapurucuara, VII.1962, F.M. Oliveira (parátipos de $P$. pseudomusarum, 19 ops., RPSP; 104 ops., DZUP); Tefé, I.1962, E. Carvalho (1 op., parátipo de P. pseudomusarum, DZUP); ibidem, 2730.I.1977, Camargo, M. Mazucato (14 ops., parátipos de $P$. pseudomusarum, RPSP); ibidem, praia Camaleão, 28.I.1988, M.L. de Oliveira, vanilina a $10 \%$ (1 op., 2954, UFVB); ibidem, $30 \mathrm{~km} \mathrm{SE}$, Poço Pion, Petrobrás, 1988, W.E. Kerr (1 op., 881708, RPSP); Vendaval, margem esquerda do rio Solimões, SA-19, 69-3 h-vi, 18.I.1977, Camargo, Mazucato (parátipos de $P$. pseudomusarum, 36 ops., mais material em álcool, ninho 82c, e outras 7 ops., RPSP); Vila Nova do Tonantins, SA.19, 68-3f.ix, 22.I.1977, Camargo, Mazucato (parátipos de $P$. pseudomusarum, 30 ops., ninho 92c, e mais 14 ops., RPSP). Pará: Alter do Chão, 19.IX.1969, Exp. Perm. Amaz. (parátipos de $P$. pseudomusarum, 8 ops., MZSP; 2 ops., RPSP); ibidem, Rio Tapajós, $54^{\circ} 57^{\prime} \mathrm{W}, 2^{\circ} 30^{\prime} \mathrm{S}, 3-4 . \mathrm{II} .1979$, Camargo et al. (44 ops., 67 machos, mais ops. e 66 machos em álcool, ninho 169c, 38 ops., mais material em álcool, ninho 173c, outras 7 ops., RPSP); Cachimbo, VI.1952, Alvarenga, Oliveira (1 op., DZUP); ibidem, IX.1954, M. Alvarenga (1 op., parátipo de P. pseudomusarum, DZUP); Cachoeira da Porteira, $57^{\circ} 3^{\prime} \mathrm{W}, 1^{\circ} 5^{\prime} \mathrm{S}$, 9-12.II.1979, Camargo et al. (24 ops., mais exemplares em álcool, ninho 177c, RPSP); Gradaus, $7^{\circ} 48^{\prime} \mathrm{S}, 51^{\circ} 7^{\prime} \mathrm{W}, 30$.VII.1978, Posey (7 ops., 512, RPSP); Jacareacanga, Humaitá, Transamazônica, km 53,0 SB-21, f-III, sem data, anônimo, "coletada em tronco de árvore oca ocupando antigo cupinzeiro" (11 ops., parátipos de P. pseudomusarum, RPSP); Lago do Uaicurapá, 29.II.1979, Othonyel R.L. Filho (30 ops., T-84, INPA); Mangabeira, Mocajuba, IV.1963, Orlando Rego (22 ops., DZUP; 2 ops., RPSP); ibidem, idem, III.1953 (1 op., parátipo de $P$. pseudomusarum, DZUP); Mussum $($ sic $=$ Muçum) $15 \mathrm{~km}$ sul de Aveiro, margem esq.do Tapajós, $55^{\circ} 25^{\prime} \mathrm{W}, 3^{\circ} 40^{\prime}$ S, 24-28.I.1979, Camargo et al. (61 ops., mais exemplares em álcool, ninho 145c, 143 ops., mais exemplares em álcool, ninho 153c, e mais 61 ops., RPSP); Paragominas (30 km S), SA-23, 47.II-3g, 11.II.1984, Camargo, Mazucato (3 ops., 840032-840034, RPSP); Rio Acre, 1902, Ducke(?), “Trigona pallida Latr. 18.305 Rio Acre (Est. Amaz.) Ducke rev. 13" (1 op., parátipo de $P$. pseudomusarum, 18.305, 95491, MZSP); ibidem, idem, 369, (2 ops., AMNH); Rio Mapuera, Cach. da Bateria, 06.VI.1986, Ulysses Carvalho (2 ops., INPA); ibidem, idem, Cach. Assunção, 16.VI.1986 (2 ops., INPA), Cach. Égua, 20.VI.1986 (14 ops., INPA; 5 ops., RPSP), Rio Trombetas, Lago Moura, 8.III.1986, anônimo (1 op. INPA); ibidem, idem, Lago Juquiri, 8.III.1986, F.J.A. Peralta (2 ops., INPA), Lago Caetano, 09.III.1986, anônimo (1 op., INPA); Santa Maria - Itaituba, 55 $58^{\prime} \mathrm{W}, 4^{\circ} 13^{\prime}$ 'S, 18-20.I.1979, Camargo et al. (21 ops., 11 machos, mais exemplares em álcool, ninho 134c, RPSP); Santana, rio Tapajós, 55³4'W, 359'S, 21-23.I.1979, Camargo (22 ops., RPSP); São Luís do Tapajós, 56 ${ }^{\circ} 14^{\prime} \mathrm{W}, 4^{\circ} 26^{\prime}$ 'S, 14-17.I.1979, Camargo et al. ( 52 ops., mais espécimens em álcool, ninho $122 \mathrm{c}, 38$ ops., mais material em álcool, ninho 128c, RPSP); ibidem, 15.I.1979, Othonyel R.L. Filho (2 ops., INPA); Tauari, $80 \mathrm{~km} \mathrm{~N}$ Aveiro, margem direita do Tapajós, $55^{\circ} 7^{\prime} \mathrm{W}$, $3^{\circ} 5^{\prime}$ S, 29.I-1.II.1979, Camargo et al. (51 ops., 1 macho, mais exemplares em álcool, ninho 156c, 44 ops., 2 machos, mais ops. e 30 machos em álcool, ninho 167c, outras 36 ops., RPSP); Tauari: Santarém, 30.I.1974, Othonyel R. L. Filho (3 ops., T-46-47, INPA); Tiriós, Alto Parú D’Oeste, I-II.1968, Machado \& Pereira (parátipos de P. pseudomusarum, 20 ops., MZSP; 4 ops., RPSP). Acre: Brasiléia, S. Porongaba, 30.X.1993, M.L. Oliveira (1 op., 940124, RPSP); Parque Nacional Serra do Divisor, Sítio 3, T. de caça Piroca, 07'28'38”S, 7341'54”W, 12-13.X.1997, E.F. Morato (1 op., 970925, RPSP); ibidem, idem, Sítio 4, Rio Ouro Preto, 08²4'19”S, 7251'28”W, 15.III.1997 (3 ops., 972252-54, RPSP), Sítio 6, Rio das Minas, 08³3'30”S, 7253’30”W, 19.III.1997 (2 ops., 972443-44, RPSP), Sítio 6, Trilha do Anil, 07²6’27”S, 73³9'28”W, 08-09.XI.1996 (1 op., 971540, RPSP), Sítio 8, Rio Azul, 07³3'24"S, 73¹6’36”W, 24.XI.1996 (2 ops., 971833, 971837, RPSP), Sítio 11, R. Juruá Várzea, 0851'37”S, 7252’20”W, 25.III.1997 (7 ops., 973199-973205, RPSP); Rio Branco, 15-20.XI.1961, F.M. Oliveira (parátipos de P. pseudomusarum: 3 ops., RPSP; 3 ops., DZUP); ibidem, 21.V.1990, L.A.O. Campos, "BR 317, FUNTAC" (4 ops., UFVB). Rondônia: Campo Novo, Ig. Tracoazinho, 1-15.VIII.1985, V. Py-Daniel, L. Aquino (11 ops., INPA); ibidem, Rio Candeias, 10-18.VIII.1985, V. Py- Daniel, L. Aquino (15 ops., INPA); ibidem, idem, 3.VIII.1985 (2 ops., INPA), 14.VIII.1985 (2 ops., INPA); Cerejeiras, S 13²14,366', W 60 50,462', 24.II.1997, Brown, Boina, Vieira (2 ops., 5393, 5408, RPSP);

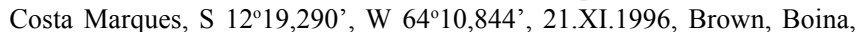
Vieira (1 op., 3619, RPSP); ibidem, idem, estrada 478, 12²6'05,2”S, 64'20'02,6”W, 19.XI.1996 (2 ops., 3320, 3372, RPSP); Costa Marques/ Guajará-Mirim, S 1200,812', W 64¹9,767', 24.XI.1996, Brown, Boina, Vieira (10 ops., 3811, 3817, 3818, 3821, 3829, 3839, 3841, 3846,

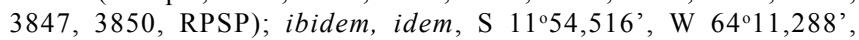
26.XI.1996 (8 ops., 4145-4148, 4174-4177, RPSP); Cujubim, Reserva Rio Cujubim, $09^{\circ} 20,308^{\prime} \mathrm{S}, 62^{\circ} 34,440^{\prime} \mathrm{W}, 24 . I I I .1997$, Brown, Boina, Vieira (1 op., 6913, RPSP); ibidem, idem, linha 14, 09²0,154'S, 62³3,110’W, 24.III.1997 (25 ops. 6608-6610, 6651, 6652, 6656, 6659, $6661,6764,6767,6770,6810-6823$, RPSP), linha C2, 09²3,205'S, $62^{\circ} 34,854^{\prime}$ W, 25.III.1997 (1 op., 7223, RPSP); Extrema, linha 5, 0946’04,0”S, 66²9'36,1'W, 26.VI.1997, Brown, Boina, Vieira (1 op., 11388, RPSP); Guajará-Mirim, S 10³3,751', W 6445,463', 10.IX.1996, Brown, Boina, Vieira (14 ops., 550-554, 587, 643-650, RPSP); ibidem, idem, S 10019,434', W 64³3,849', 11.IX.1996 (5 ops., 439, 441, 442, 515,1469 , RPSP), S $10^{\circ} 53,534^{\prime}, \mathrm{W} 65^{\circ} 01,703$ ', 6.X.1996 (1 op.,

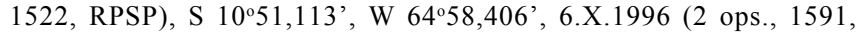
1598, RPSP), S 1049,871', W 64'55,984', 7.X.1996 (1 op., 1661, RPSP), S 1049,464', W 6454,282', 9.X.1996 (1 op., 1767, RPSP), S $10^{\circ} 45,516^{\prime}$, W $64^{\circ} 42,761^{\prime}, 9 . X .1996$ (2 ops., 1829, 1830, RPSP), S

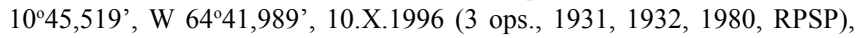
S $10^{\circ} 45,767^{\prime}, \mathrm{W}$ 64\%41,402', 10.X.1997 (5 ops., 2008-2012, RPSP), S $10^{\circ} 45,683^{\prime}$, W $64^{\circ} 42,519^{\prime}, 11 . X .1996$ (5 ops., 2093-2097, RPSP), S $10^{\circ} 48,114^{\prime}$, W $64^{\circ} 48,025^{\prime}, 11 . X .1996$ (11 ops., 2142, 2163, 21892196, 2202, RPSP), Parque Estadual G.M., 10³4'26,1'S, 64²5'23,7’W, 30.VI.1997 (3 ops., 11543, 11565, 11575, RPSP), Parque Estadual G.M., 10³3'44,8'S, 6400,6'W, 30.VI.1997 (3 ops., 11516, 11536, 11537, FFC:); Machadinho, linha 32, 09²6,939'S, 61 ${ }^{\circ} 57,042^{\prime} \mathrm{W}$, 
20.III.1997, Brown, Boina, Vieira (2 ops., 6303, 6308, RPSP); ibidem,

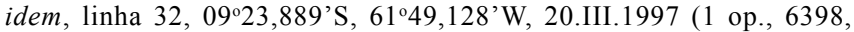
RPSP); Mirante da Serra, S $11^{\circ} 10,076^{\prime}$, W 62 ${ }^{\circ} 53,104^{\prime}$, 25.IX.1996, Brown, Boina, Vieira (5 ops., 2311, 2312, 2346, 2377, 2429, RPSP); ibidem, idem, S $11^{\circ} 10,181^{\prime}$, W 62 $51,110^{\prime}, 25 . I X .1996$ (4 ops., 2453, 2457, 2458, 2508, RPSP), S 1056,497', W 6244,630', 31.I.1997 (1 op., 5270, RPSP), linha $68,11^{\circ} 04,481^{\prime} \mathrm{S}, 62^{\circ} 43,437^{\prime} \mathrm{W}, 17 . \mathrm{IV} .1997$ (1

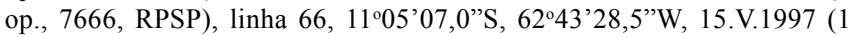

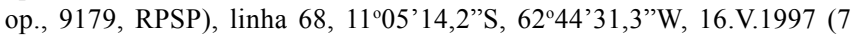
ops., 9190, 9191, 9196, 9197, 9208, 9209, 9212, RPSP), linha 50,

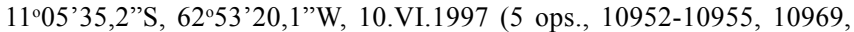
RPSP), linha 76, $11^{\circ} 05^{\prime} 18,9^{\prime \prime} \mathrm{S}, 62^{\circ} 50^{\prime} 29,6^{\prime} \mathrm{W}, 30$.VIII.1997 (3 ops., 13961, 13974, 13975, RPSP); Nova Califórnia, linha Pioneiros, 0946'47,7'S, 66 37'41,2”W, 24.VI.1997, Brown, Boina, Vieira (2 ops., 11044, 11045, RPSP); ibidem, idem, linha Pioneiros, 0947'56,7'S, 66036'10,7'W, 25.VI.1997 (1 op., 11081, RPSP), linha Cascalho, 0947'10,4”S, 66³9'48,3”W, 25.VI.1997 (1 op., 11217, RPSP); Nova Mamoré, S 10¹9,434', W 64 33,849', 7.IX.1996, Brown, Boina, Vieira (1 op., 1296, RPSP); ibidem, idem, S 10¹9,434', W 64³3,849', 8.IX.1996 (22 ops., 986-991, 993-1004, 1019, 1020, 1022, 1023, 1203, RPSP), S 10 $19,440^{\prime}$, W 64²46,775', $12 . I X .1996$ (37 ops., 157, $158,160,162,164,167-170,172-174,176-180,182,184,185,192$, 244, 277-279, 286-290, 303, 306-309, 312, 318, RPSP), S 10²2,632', W 6510,943', 13.IX.1996 (5 ops., 151-155, RPSP); Nova União, S 1044,906', W 62³0,157', 26.IX.1996, Brown, Boina, Vieira (1 op., 2599, RPSP); ibidem, idem, S 1051,788', W 62²3,348', 8.III.1997 (6 ops., 6186, 6218-6221, 6248, RPSP), linha 48, 10 $51,026^{\prime} \mathrm{S}$; 62³6,654'W, 16.IV.1997 (1 op., 7511, RPSP), linha 28, 1055'18,9'S, 62 ${ }^{\circ} 6^{\prime} 25,8^{\prime \prime} \mathrm{W}, 12$.VI.1997 (4 ops., 10613-10616, RPSP), linha 36, 1059'22,9”'S, 62³4'18,0”W, 18.VII.1997 (1 op., 11789, RPSP); Porto Velho, 12-22.X.1966, Camargo (1 op. RPSP); ibidem, Estação Ecológica

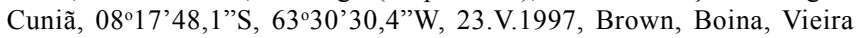
(6 ops., 9772, 9773, 9840-9842, 9852, RPSP); ibidem, idem, Estação Ecológica Cuniã, 08¹7’48,2”S, 6329'41,4”W, 23.V.1997 (9 ops., 9916, 9920-9922, 9950, 9951, 9975, 9976, 9977, RPSP), 08¹9’04,8”S, 6329'58,1'W, 21.V.1997 (8 ops., 9533-9537, 9545, 9546, 9551, RPSP), 0810'56,1"S, 6322'22,2”W, 25.V.1997 (1 op., 10126, RPSP); Rolim

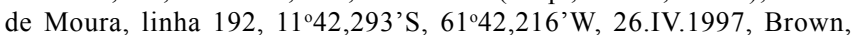
Boina, Vieira (3 ops., 8550-8552, RPSP); São Miguel do Guaporé, linha $82,11^{\circ} 46,568^{\prime} \mathrm{S}, 62^{\circ} 43,531^{\prime} \mathrm{W}, 20 . I V .1997$, Brown, Boina, Vieira (2

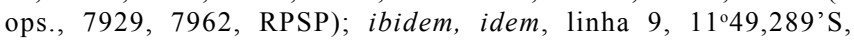
62 ${ }^{\circ} 50,498$ 'W, 21.IV.1997 (5 ops., 7995, 7996, 7998, 8001, 8023, RPSP), linha $82,1^{\circ} 39,079^{\prime} \mathrm{S}, 62^{\circ} 43,079^{\prime} \mathrm{W}, 22 . \mathrm{IV} .1997$ (6 ops., 8110 , $8112-8115,8118$, RPSP), linha $82,11^{\circ} 40,836^{\prime} \mathrm{S}, 6^{\circ} 43,256^{\prime} \mathrm{W}$, 22.IV.1997 (3 ops., 8157, 8159, 8160, RPSP); Vilhena, 22.VII5.VIII.1983, F.J.A. Peralta (2 ops., 27, 60-C, INPA); ibidem, idem (3 machos., 54-CA e 57, INPA). Mato Grosso: Aripuanã, Base INPA, 1977, O.N. Cano (6 ops., RPSP); Chavantina (sic=Xavantina), VII.1962, Alvarenga, Oliveira (1 op., RPSP); Cuiabá, 03.II.1986, G. Melo (1 op., 252/1/20, MELO); Nova Xavantina, 25.VII.1995, W.E. Kerr, "ninho em parede de resid." (2 ops., 952022, 952023, RPSP); ibidem, sem data, anônimo, colônias 171, 172, 173 (18 ops., RPSP); Serra das Araras, 57 $7^{\circ} 14^{\prime} \mathrm{W}, 15^{\circ} 27^{\prime}$ 'S, 19-27.IX.1987, Gimenes (1 op., RPSP); Serra de São

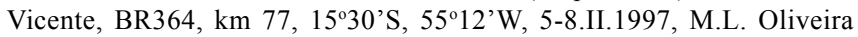
(7 ops., RPSP); Serra do Roncador, Base Camp, 19.VII.1968, Laroca \& Azevedo (1 op., DZUP); West Border Matto Grosso, V.1931, R.C. Shannon (1 op, USNM). BOLÍVIA: La Paz: Rio Heath, $\sim 13^{\circ} \mathrm{S}, 69^{\circ} \mathrm{W}$, 600m, 20.II.1990, Luis Coloma, 47 (3 ops., SEMC); ibidem, idem, 21.II.1990, 48 (2 ops., SEMC). Santa Cruz: Roboré, X.1959, anônimo (1 op., SEMC); Santiago, XI.1959 (2 ops., SEMC).

Distribuição geográfica e hábitat. Floresta amazônica e cerrados do Brasil central (Fig. 165).

Nidificação. Em termiteiros vivos fixados em troncos de árvores (CAMARGO, 1980). SiLVESTRI (1902) refere-se a P. vicina (= T. rhumbleri) em cavidade subterrânea (prov. equívoco).
Hospedeiros identificados: Nasutitermes cf. kenneri Snyder \& Emerson, 1949 (ninho no. 20c), Constrictotermes cyphergaster (Silvestri, 1901) (ninho no. 21c), Constrictotermes cavifrons (Holmgren, 1910) (ninho no. 82c), Amitermes excellens Silvestri, 1923 (ninhos nos. 153c, 196c) e Nasutitermes cf. similis Emerson, 1935 (ninho no. 169c).

Discussão. Inicialmente, CAMARGo (1980) considerou $P$. vicina (constituída de 3 populações habitando áreas disjuntas de cerrado) e P. pseudomusarum como espécies distintas, a julgar pela distribuição geográfica dos exemplares com as tíbias III escurecidas ( $P$. vicina) disponíveis para estudo na época. Entretanto, com o acúmulo de material e ampliação da representatividade geográfica, este mesmo autor teve oportunidade de verificar a ocorrência de exemplares com tíbias inteiramente amarelas e com diferentes graus de escurecimento, dentro de ninhos (ninhos 153c, 167c, 169c, 173c, coletados na região do baixo Tapajós, PA). Além disso, alguns exemplares da região de Alvarães, rio Solimões, Amazonas, e algumas outras localidades ( $c f$. material examinado), também apresentam uma pequena mancha, levemente escurecida na porção apical da tíbia III, inclusive os machos. Também, naquela ocasião (CAMARGO, 1980), uma série de exemplares procedentes de Boa Vista - RR, foi equivocadamente interpretada como sendo uma população disjunta de $P$. vicina, com as tíbias III parcialmente enegrecidas, sendo, na realidade, exemplares pessimamente conservados de $P$. mourei (retirados de alguma substância fixadora, bastante deformados). Dessa forma, parece que a decisão mais acertada é a de se considerar $P$. vicina e $P$. pseudomusarum como uma única espécie (a primeira com precedência pelo número da página em que foi descrita). Ao norte e oeste de sua distribuição, $P$. vicina pode ser reconhecida por ser a única espécie com integumento totalmente amarelado (inclusive sutura epistomal, áreas ao redor dos ocelos, porção ventral dos mesepisternos, e geralmente, pernas), o que a diferencia inclusive de $P$. mourei e $P$. testacea com as quais se sobrepõe (Figs. 164, 165, 167). Além disso, P. vicina apresenta os dentes da mandíbula mais espaçados, quando comparado à P. mourei (Figs. 62, 63), e bem menos recuados em relação a $P$. testacea (compare as figuras 62 com 60 e 61); em relação à $P$. testacea, distingue-se, ainda, pela membrana das asas mais clara e a bifurcação de $\mathrm{R}+\mathrm{M}$ geralmente coincidente com a cu$\mathrm{v}$ (em P. testacea é nitidamente anterior). As demais espécies que ocorrem em simpatria com $P$. vicina possuem integumento enegrecido ou acastanhado (formas mais claras de P. mulata). As relações filogenéticas de $P$. vicina, dentro do grupo musarum, não foram esclarecidas; os caracteres estudados são pouco informativos. Se a coloração amarela do integumento, ao menos dentro do grupo, constituir uma derivação única, o candidato mais provável a espécie irmã de $P$. vicina seria $P$. mourei. Essa hipótese é plausível quando se consideram os hábitos de nidificação; $P$. vicina e $P$. mourei habitam termiteiros arborícolas externos (considerando-se a associação com térmitas como estado apomórfico) e apresentam grande similaridade na estrutura de entrada. 
Partamona mourei Camargo, 1980

(Figs. 1, 63, operária; 80, 111, macho; 167, distribuição; Tabs. II-IX)

Partamona (Partamona) mourei Camargo, 1980:18, 21-23, 53-55, 70, 159-160; Absy et al., 1984:228-231; Andre, 1985:244.

Partamona mourei; Ramalho et al., 1990:471, 473; Camargo, 1994:50, 52, 58; Oliveira et al., 1995:16-18.

Partamona moure (sic); Camargo, 1992:81.

Partamona vicina Camargo, 1980:48 (partim, exemplares de "Boa Vista, RR, 8.XI.1953, C.R. Gonçalves").

Melipona pallida aberr. rhumbleri; Ducke, 1916:119-120 (partim); 1925:411 (partim).

Diagnose. Abelhas de porte médio (1.m.c. 2,5-2,6 mm, c.a.a. 5,4-6,0 mm, Tabs. III, IV). Integumento amarelado até castanhoferrugíneo. Mesepisterno, na porção ventral, enegrecido. Basitarso e 1/2-1/3 apical da tíbia III enegrecidos. Sutura epistomal e área ao redor dos ocelos enegrecidas ou, raramente, amareladas. Mandíbula predominantemente amarela, ápice ferrugíneo, côndilos amarelados ou um pouco escurecidos. Flagelo alaranjado ou castanho-amarelado. Estrias paroculares aproximadamente tão largas quanto o diâmetro do $2^{\circ}$ flagelômero, com a mesma largura em toda a extensão ou um pouco mais largas embaixo ( $1,2 \mathrm{x}$ o diâmetro do $2^{\circ}$ flagelômero) e chegando até o topo do olho (como na figura 146, de P. vicina). Cerdas eretas do vértice, mesoscuto e escutelo amareladas, ferrugíneas, enegrecidas ou misturadas; nos mesepisternos, coxas, trocanteres e esternos, amarelo-palha ou esbranquiçadas; nos tergos III-VI enegrecidas. Membrana das asas hialina; microtríquias pretas; veias méleas, mas escurecidas pelas microtríquias fuscas. Cerdas do escapo curtas $(0,7-0,9 \mathrm{x}$ o diâmetro do escapo), apenas uma ou duas cerdas na base um pouco mais longas que as demais (1,0-1,1x o diâmetro do escapo; Tab. VII). Cerdas eretas das áreas paroculares mais curtas que o diâmetro do escapo. Cerdas do escutelo 1,0-1,3x o comprimento deste. Área basal do propódeo com uma faixa mediana glabra tão larga quanto o diâmetro do $2^{\circ}$ flagelômero. Dentes da mandíbula pequenos e muito recuados em relação ao bordo apical (Fig. 63). Área malar curta (ca. 0,8x o diâmetro do $2^{\circ}$ flagelômero; Tab. V). Distância interocelar, distância ocelorbital, tíbia III e comprimento da asa anterior normais (Tabs. V, VI, VIII, IX). Bifurcação da $\mathrm{M}+\mathrm{Cu}$ geralmente coincidente com a cu-v (raramente levemente anterior). Basitarso III do macho alongado, achatado ou convexo-côncavo; tíbia III estreita, como na figura 80. EVII do macho com a projeção mediana curta e triangular, os chanfros laterais curtos e largos (Fig. 111).

Variação. Machos de populações da região do rio Trombetas com integumento preto.

\section{Macho. Figuras 80, 111.}

Material-tipo. Holótipo, operária, e 1 parátipo, operária, de Barcellos (sic), Amazonas, Brasil, rio Negro, 21.VII.1927, J.F. Zikán (DZUP). Outros parátipos do Brasil, Amazonas: Manaus, SA-20, 60-3c, 1-2-1976, J.M.Camargo (1 op., RPSP); Pará: Óbidos, 20-7-1902, Ducke, etiqs. adicionais de Friese "TYPUS", "Trigona rhumbleri 1913 Friese det. Fr."
( 2 ops., USNM); ibidem, idem, etiq. adicional de Ducke "Trigona pallida Latr. v. rhumbleri det. Ducke, 1911" (1 op., no. 18.241 e 95497, MZSP); sem etiqueta de procedência, apenas os seguintes nos.: 2502 (4 ops., DZUP, 3 ops., RPSP), 2911 (1 op., DZUP; 3 ops., RPSP); 2875 (1 op., RPSP). Todos os exemplares foram examinados.

Material examinado. GUIANA: Camaria, Bartica District, sem data, J.F. Pearson (1 op., AMNH); Essequibo R., Moraballi Creek, 24.VIII.1929, Oxf. Univ. Expedn. (1 op., BMNH); Kalacoon, Bartica District, 20.X.1920, anônimo (1 op., AMNH); Kamakusa, sem data, H. Lang (1 op., AMNH); Kartabo, 24.VII.1926, anônimo (2 ops., AMNH); ibidem, 9.VIII.1920, W.M. Wheeler, 449 (2 ops., AMNH); ibidem, Bartica District, 12.IV.1924, anônimo (1 op., AMNH); Kuyuwini R., 22.XI.1923, W.G. Hassler (1 op., Ac. 36159, RPSP). SURINAME: Coppename R., 28.V.1929, J.G. Myers, B.M. 1929-406, s. 6 (3 ops., AMNH); Tapanahony-river, $17 \mathrm{~km}$ downstream from Paloemeu, 27.II.1993, B. De Dijn (3 ops., I 921, NZCS); Paloemeu-river, km 66 from Tapanahony, near Temomairem-rapids, 25.II.1993, B.De Dijn, (5 ops., I 969, NZCS; 2 ops., RPSP). BRASIL: Roraima: Boa Vista, 8.XI.1953, C.R. Gonçalves (10 ops., parátipos de "P. vicina", DZUP; 1 op., RPSP); Caracaraí, $61^{\circ} 8^{\prime} \mathrm{W}, 1^{\circ} 48^{\prime} \mathrm{N}, 13,15$.VIII.1980, Camargo, Mazucato (62 ops. e 36 machos, mais exemplares em álcool, incluindo 3 machos, ninho $271 \mathrm{c}$, 50 ops., ninho $273 \mathrm{c}, 58$ ops. e 20 machos, mais exemplares em álcool, ninho 274c, RPSP); Carmo (Rio Branco), 31.VIII.1924 (1 op., AMNH); Ireng R. to Roraima, 10.VIII.1911, anônimo, C.3 (1 op., 24511, AMNH); Maloca Aldeia da Tábua Lascada, 16.IV.1994, Silva (17 ops., 960055960071, RPSP); Mucajaí, $60^{\circ} 5^{\prime} \mathrm{W}, 2^{\circ} 30^{\prime} \mathrm{N}, \mathrm{BR} 174,15 . \mathrm{VIII} .1980$, Camargo, Mazucato (56 ops., ninho 275c, 54 ops. ninho 276c, RPSP); Ilha de Maracá, 20-23.V.1988, L.S. Aquino, arm. de copa (5 ops., INPA); ibidem, Furo Maraca, rio Uraricoera, 24.IV.1987, F.J.A. Peralta (77 ops., INPA); ibidem, 21-30.XI.1987, J.A. Rafael e equipe, armadilha de Shannon (2 ops., INPA); ibidem, idem, armadilha de malaise (1 op., 1 macho, INPA), armadilha suspensa (1 op., 2 machos, INPA); ibidem, 14.III.1988, Eq. J.A. Rafael, arm. de Shannon (2 ops., INPA); ibidem, idem, 02-13.V.1987, arm. de malaise (4 ops., INPA); ibidem, 0213.V.1987, J..A. Rafael, J.E.R. Brasil, L.S. Aquino, armadilha de malaise ( 2 ops., INPA); ibidem, idem, armadilha suspensa (1 macho., INPA); ibidem, 18-23.VIII.1987, J. A. Rafael, L.S. Aquino, J.F. Vidal, Elias Binde (1 op., INPA); ibidem, 06-15.X.1987, L.S. Aquino, arm. malaise (1 op., INPA); ibidem, 29.III.1987, F.J. A. Peralta, 31, "cachoeira do tipo regina" (? ilegível) (1 op., INPA); ibidem, furo Sta. Rosa, Ig. Trairão, 31.III.1987, V.C. Barbosa (1 op., INPA). Amazonas: Acanga, $30 \mathrm{~km}$ abaixo de Barcelos, rio Negro, $62^{\circ} 43^{\prime} \mathrm{W}, 1^{\circ} 7^{\prime} \mathrm{S}, 6,8$.VIII.1980, Camargo, Mazucato (50 ops. mais exemplares em álcool, ninho 268c, mais 4 ops., RPSP); BR-174, km 41, Agric. Ecol., 18-19.V.1980, A. Weber, flor $R$. mисоsa (3 ops., RPSP); Carvoeiro, rio Negro-rio Branco, 26.VIII.1924, anônimo, "PARATYPE", "Trigona (Partamona) testacea var. carvoeiroensis H.F. Schwarz" (1 op., RPSP); Foz do Rio Daraã, rio Negro, $64^{\circ} 47^{\prime} \mathrm{W}, 0^{\circ} 25^{\prime}$ 'S, 2-4.VIII.1980, Camargo, Mazucato (42 ops., RPSP); Lago Curiuaú, rio Negro-AM, 61 ${ }^{\circ} 13^{\prime} \mathrm{W}, 0^{\circ} 55^{\prime} \mathrm{S}, 24-25$.VIII.1980, Camargo, Mazucato (50 ops., mais exemplares em álcool, ninho 291c, RPSP); Livramento, rio Negro, 66¹1'20'” W, 0¹9'S, 24-26.VII.1980, Camargo, Mazucato (50 ops., mais exemplares em álcool, ninho $235 \mathrm{c}$, 52 ops. ninho 241c, 51 ops., ninho 242c, RPSP); Manaus, 1981, Falcão (1 op., RPSP); ibidem, INPA, 16.VII.1980, Francisco Peralta (11 ops., INPA); ibidem, estr. Mauá, km 3, CRIS, 29.IX.1977, C. Gondin (1 op., INPA); ibidem, R. Ducke, 12.V.1981, F. Peralta (1 op., INPA); ibidem, Res. Ducke, $2^{\circ} 56^{\prime}$ 'S, $59^{\circ} 58^{\prime} \mathrm{W}, 23 . \mathrm{VIII} .1994$, S. Pedro (9 ops., 941276 , 941278, 941284, 941292, 941293, 941299B, RPSP); ibidem, $70 \mathrm{~km}$ N, 2²7'S, 59'46'2' W, 05-09.VIII.1994, S. Pedro (1 op., 941214, RPSP); ibidem, 26 km Itacoatiara Hwy., Amazon Reserve Ducke, 12-23.V.1972, Munroe (1 op., SEMC); São Gabriel da Cachoeira, Morro 6 Lagos, 800m, 28.IX-6.X.1990, J.A. Rafael, J. Vidal, arm. malaise (1 macho, UFVB). Pará: Juquiri, rio Trombetas 08.III.1986, anônimo (1 op., INPA); Lago Caetano, rio Trombetas, 09.III.1986, anônimo (2 ops., INPA); Lago Carimum, rio Trombetas, $56^{\circ} 6^{\prime} \mathrm{W}, 1^{\circ} 32^{\prime} \mathrm{S}, 16,17 . \mathrm{II} .1979$, Camargo et al. (31 ops. e 45 machos, mais material em álcool, operárias e 26 machos, ninho 188c; 28 ops. e 22 machos, mais exemplares em álcool incluindo 18 machos, ninho 189c, 28 ops. ninho 190 c, mais 1 op., RPSP); Rio Mapuera, Cach. da Bateria, 06.VI.1986, Ulysses Carvalho (6 ops., INPA); 
ibidem, idem, 11.VI.1986 (4 ops., INPA).

Distribuição geográfica e hábitat. Florestas e áreas antrópicas ao norte do rio Amazonas, até as Guianas (Fig. 167).

Nidificação. Em termiteiros arborícolas externos. Hospedeiro identificado: Amitermes excellens Silvestri, 1923 (ninho 271c).

Discussão. Esta espécie, restrita ao norte da bacia amazônica, caracteriza-se pelo integumento geralmente castanho-ferrugíneo (raramente por inteiro amarelado, ou preto), com áreas enegrecidas junto à sutura epistomal, áreas ao redor dos ocelos, porção ventral dos mesepisternos e parte da tíbia e basitarso III; dentes da mandíbula como na figura 63 e pela área malar mais curta que o diâmetro do $2^{\circ}$ flagelômero. $\mathrm{Na}$ região do rio Trombetas aparece uma população um pouco divergente, com machos pretos e algumas peculiaridades na estrutura de entrada dos ninhos. Outros comentários em $P$. vicina.

Partamona pearsoni (Schwarz, 1938)

(Figs. 54, 143, operária; 78, 79, 112, machos; 166, distribuição; Tabs. II-IX)

Trigona (Patera) testacea pearsoni Schwarz, 1938:478.

Trigona (Partamona) pearsoni; Cunha, 1973: 3, Figs. 2, 3, 4, 5, 6, 7. Partamona pearsoni; Roubik, 1989:75; Camargo, 1994:50.

Partamona cf. pearsoni; Oliveira et al., 1995:16, 18;

Partamona (P.) pearsoni; Rosa \& Flechtman, 1983:273.

Diagnose. Abelhas pequenas (1.m.c. 2,2-2,4 mm, c.a.a. 4,9$5,3 \mathrm{~mm}$, Tabs. III, IV). Integumento preto. Mandíbula predominantemente amarela, ápice ferrugíneo, côndilos pretos. Flagelo castanho-escuro. Estrias paroculares ca. de 0,8x mais estreitas que o diâmetro do $2^{\circ}$ flagelômero, alargadas embaixo $(1,2-1,3 \mathrm{x})$ até a altura das fóveas tentoriais, em cima chegando até o topo do olho (Fig. 143). Pilosidade predominantemente preta; na região ventral dos mesepisternos, coxas, trocanteres e esternos, branca. Membrana das asas hialina; microtríquias pretas em toda a asa, ou, na região do pterostigma, amarelas; veias méleas, mas escurecidas pelas microtríquias fuscas. Cerdas da base do escapo muito mais longas que o diâmetro deste (1,7-2,5x, Tab. VII). Cerdas eretas das áreas paroculares, ao lado dos alvéolos, tão longas quanto o diâmetro do escapo. Cerdas do escutelo 0,9-1,0x o comprimento deste. Área basal do propódeo com uma faixa glabra mediana tão larga quanto o diâmetro do $2^{\circ}$ flagelômero. Franja pré-marginal contínua na porção mediana do TIII; cerdas, nessa região, com comprimento aproximadamente igual $(0,7-1,2 \mathrm{x})$ ao diâmetro do escapo. Área malar, distância interocelar, distância ocelorbital, tíbia III e comprimento da asa anterior normais (Tabs. V, VI, VIII, IX). Bifurcação da $\mathrm{M}+\mathrm{Cu}$ geralmente coincidente com a cu-v (raramente levemente anterior). Macho, basitarso III alongado, achatado ou convexo-côncavo; tíbia III estreita (Figs. 78, 79); EVII com a projeção mediana curta e triangular, os chanfros laterais curtos e largos (Fig. 112).
Macho. Figuras 78, 79, 112.

Material-tipo. Holótipo, operária, da Guiana, Kartabo e 17 parátipos de Kartabo e Camaria, Guiana (holótipo e parátipos, no AMNH, coleção Pearson, e dois parátipos na RPSP). Foram examinados parátipos com as seguintes etiquetas: GUIANA: Camaria, 31-VII-1924, collected by Jay F. W. Pearson, no verso "659", etiqs. adicionais "PARATYPE", "Trigona testacea pearsoni H.F. Schwarz" (1 op., AMNH); Kartabo, 20-VII-1924, collected by Jay F.W. Pearson, no verso "24212" e "24.215", etiqs. adicionais "PARATYPE", "Trigona testacea pearsoni H.F. Schwarz" (2 ops., AMNH); outros parátipos, com mesma procedência e coletor, com as seguintes datas: 22 -VII-1924, no verso " 228 " (1 op., AMNH); 27 VII-1924, no verso "474" ( 2 ops., no. 56064, USNM; 1 op., AMNH); 27-VII-1924, no verso "473" (1 op., RPSP); 29-VII-1924, no verso "561" e "558" (2 ops., AMNH); e de Kartabo, 8-VI-1924, anônimo (1 op., AMNH).

Material examinado. VENEZUELA. Amazonas: Cerro de la Neblina Basecamp, 0 $0^{\circ} 50^{\prime} \mathrm{N}, 6^{\circ} 9^{\prime} 44^{\prime}$ 'W, 140m, 13-20.II.1984, D. Davis \& T. MacCabe (3 ops., USNM); ibidem, idem, 21-29.II.1984 (1 op., USNM); Cerro Unturan Camp, 65⒈'W, 01 ${ }^{\circ} 33^{\prime}$ N , 1100m, 11-15.III.1989, D.A. Grimaldi, Phipps-FUDECI Exped. by Amer. Mus. Nat. Hist., (1 op., AMNH); Orinoco, 1992, D. Wittmann (1 op., WITT). GUIANA: Kartabo, 29.VII.1924, Jay F.W. Pearson, "578"(1 op., RPSP). SURINAME: Brownsberg Nature Reserve, road from top to Brownsweg, 29.XII.1993, B. De Dijn (1 op., I 1077, NZCS); Paloemeu, 2.III.1993, B. De Dijn (1 op., I 960, NZCS). GUIANA FRANCESA: Cayenne, 33.5 $\mathrm{km} \mathrm{S}$ and $8.4 \mathrm{~km} \mathrm{NW}$ of Hwy N2 on Hwy D5, 30m, 4 $48^{\prime} 18^{\prime \prime} \mathrm{N}$, 52²8'41"W, 29.V-9.VI.1997, J. Ashe, R. Brooks FG1AB97 171 ex: flight intercept trap (1 op., SM0092049 KUNHM-ENT, SEMC); Kourou, 15 km W, 26.IV.1982, D. Roubik, 78 (2 ops., STRI); Synnamary, 27 km SW, ORSTOM Station Road, 8.V.1982, D. Roubik, 66 (3 ops., RPSP). BRASIL. Amapá: Serra do Navio, 7.II.1962, F.M. Oliveira (28 ops., DZUP; 5 ops., RPSP). Amazonas: Anavilhanas, rio Negro, 2125.III.1988, F.J.A. Peralta (1 op., INPA); BR174, $59^{\circ} 51^{\prime}$ W, $2^{\circ} 23^{\prime}$ S, 03.VI.1986, M.V.B. Garcia (6 ops., RPSP); Foz do Rio Curicuriari, rio Negro, 6649'W, 0¹3'30'’S, 15-21.VII.1980, Camargo, Mazucato (48 ops., mais exemplares em álcool, ninho 222c, RPSP); Foz do Rio Daraã, rio Negro, 644ㄱ'30' 'W, $0^{\circ} 25^{\prime}$ 'S, 2-4.VIII.1980, Camargo, Mazucato (54 ops., 1 macho, mais exemplares em álcool, ninhos $249 \mathrm{c}, 50$ ops., 34 machos, mais exemplares em álcool, ninho $257 \mathrm{c}$, e mais 9 ops., RPSP); Foz do Rio Marié, rio Negro, 66²6’30' W, 0²6’30'’S, 26-27.VII.1980, Camargo, Mazucato (52 ops., mais exemplares em álcool, ninho $245 \mathrm{c}$, RPSP); Lago Curiuau, rio Negro, $61^{\circ} 13^{\prime} \mathrm{W}, 1^{\circ} 55^{\prime} \mathrm{S}, 24-25$.VIII.1980, Camargo, Mazucato (50 ops., 21 machos, mais exemplares em álcool, ninho 292c, RPSP); Manaus, 1981, Falcão (2 ops., RPSP); ibidem, 2831.I.1963, FF Rio Claro (1 op., DZUP); ibidem, BR 174, ZF3, 8.VI.1989, M.L. Oliveira (1 op., UFVB); ibidem, ZF3, km 23, 28.I.1986, A.C. Oliveira (1 op., UFVB); ibidem, 26 km Itacoatiara Hwy., Amazon Reserve Ducke, 12-23.IV.1972, Munroe (1 op., SEMC); Santa Izadel (sic = Izabel), R. Negro, 11-13.X.1990, Maturaca (1 macho, UFVB); São Gabriel da Cachoeira, Morro Seis Lagos, 300m, 28.IX-6.X.1990, arm. malaise, J. A. Rafael, J. Vidal (2 ops., UFVB). Pará: Capanema, SA-23, 47ii-1c, 15.II.1984, Camargo, Mazucato (11 ops., 840165-840173, 840175, 840176, RPSP); Gorotire (= Gradaus), 20.VII-5.IX.1983, Camargo (3 ops., 830869, 830871, 830870, RPSP); Il. Combú, Mun. Acará, 30.V.1990, John Humboldt (1 op., RPSP); Inst. Agrico., 19.VIII.1954, N. Cerqueira (2 ops., DZUP); Lago Água Fria, rio Trombetas, $56^{\circ} 51^{\prime} \mathrm{W}$, $1^{\circ} 25^{\prime}$ S, 13-15.II.1979, Camargo (1 op., RPSP); Mangaberia, Mocajuba, VI.1953, Orlando Rego (1 op., DZUP); Óbidos, X.1954, F.M. Oliveira (5 ops., DZUP; 1 op., RPSP); ibidem, idem, XI.1954 (2 ops., DZUP), I.1955 (5 ops., DZUP; 1 op., RPSP); Rio Acará, 24.VIII.1954, N. Cerqueira (1 op., DZUP); Rio Trairão (50 km NE Gradaus), SB-22, $51^{\circ} 49$ W, $7^{\circ} 21^{\prime}$ S, 21-24.VII.1979, Mazucato (8 ops., RPSP). Maranhão: Buriticupu, $20 \mathrm{~km} \mathrm{NE}, 4^{\circ} 22^{\prime} \mathrm{W}, 4^{\circ} 7^{\prime}$ 'S, 09-10.XI.1994, Camargo, Pedro (7 ops., 941699-941705, RPSP); Nova Olinda, 15.II.1984, SA-23, 46 vi-3f, Camargo, Mazucato (1 op., 840085, RPSP); Rosário, 28.XI.1982, Mazucato, Aily (1 op., 822786, RPSP). 
Distribuição geográfica e hábitat. Florestas tropicais do norte-nordeste da Amazônia; a leste chegando até o Maranhão e sudeste do Pará, já em região de matas decíduas e cerrados (Fig. 166).

Nidificação. Em termiteiros arborícolas externos. Hospedeiros identificados: Nasutitermes cf. peruanos (Holmgren, 1910) (ninhos 222c, 245c, 249c) e Amitermes excellens Silvestri, 1923 (ninho 292c).

Discussão. É uma espécie facilmente reconhecível por uma combinação exclusiva de caracteres da operária: abelhas pequenas, cerdas muito longas na base do escapo, pilosidade ventral branquíssima, contrastando com o integumento preto, dentes da mandíbula pequenos e muito recuados (Fig. 54), e o TIII apresentando uma franja pré-marginal contínua na porção mediana (autapomórfico).

\section{Partamona ferreirai sp. nov.}

(Figs. 53, 144, operária; 83, 84, 108, 109, macho; 168, distribuição; Tabs. II-IX, XI)

?Partamona nigrior; Camargo, 1994:50.

Diagnose. Abelhas de porte médio (1.m.c. 2,5-2,6 mm, c.a.a. 5,5-5,9 mm; Tabs. III, IV). Integumento preto. Mandíbula predominantemente ferrugínea, apenas o $1 / 4-1 / 5$ basal amarelados ou descoloridos, ápice ferrugíneo-escuro, côndilos pretos. Flagelo castanho-escuro ou enegrecido. Máculas da face e tórax apagadas ou pouco conspícuas; estrias paroculares estreitas $\left(0,6-0,8 \mathrm{x}\right.$ o diâmetro do $2^{\circ}$ flagelômero), levemente alargadas embaixo (1,0-1,2x o diâmetro do $2^{\circ}$ flagelômero), chegando até a interorbital superior (Fig. 144). Pilosidade preta. Membrana das asas hialina; microtríquias predominantemente amarelas, pretas apenas no ápice da asa; veias uniformemente méleo-claras. Cerdas da base do escapo um pouco mais longas que o diâmetro deste $(0,8-1,6 x$; Tab. VII). Cerdas eretas das áreas paroculares, ao lado dos alvéolos, um pouco mais longas que o diâmetro do escapo $(0,9-1,0 x)$. Cerdas do escutelo tão longas quanto o comprimento deste. Área basal do propódeo com uma faixa glabra mediana, tão larga quanto o diâmetro do $2^{\circ}$ flagelômero. Dentes da mandíbula pequenos e muito recuados em relação ao ápice do bordo apical (Fig. 53). Área malar, distância interocelar, distância ocelorbital, tíbia III e comprimento da asa anterior, normais (Tabs. V, VI, VIII, IX). Bifurcação da $\mathrm{M}+\mathrm{Cu}$ geralmente coincidente com a cu-v (raramente levemente anterior). Macho, basitarso III curto e largo, achatado ou convexo-côncavo; tíbia III alargada em direção ao ápice (Figs. 83, 84); EVII com a projeção mediana curta e triangular, os chanfros laterais curtos e largos (Figs. 108, 109).

Variação. Asas com microtríquias pretas e veias escurecidas nas populações da região do rio Negro, AM, ou com microtríquias amareladas em toda a asa e veias uniformemente méleo-claras, nas populações da região do rio Trombetas, PA.
Máculas mais nítidas na cabeça em exemplares de Maraã, AM.

\section{Operária.}

Dimensões. Comprimento total aproximado, 5,64 mm; da asa anterior, 5,81 $\mathrm{mm}$ (incluindo a tégula, $6,56 \mathrm{~mm}$ ); largura máxima da cabeça, 2,56 mm; do TIII, 2,40 mm (Tab. XI).

Cor do integumento. Predominantemente preto, apenas o metanoto e as tíbias III mais claros, e os tarsômeros de todos os pares de pernas, ferrugíneos. Tégula ferrugínea, translúcida. Labro amarelado, mandíbula um pouco descolorida no terço basal e ferrugínea em direção ao ápice, côndilos enegrecidos. Escapo ferrugíneo-enegrecido, apenas a parte basal, na face inferior, amarelada. Flagelo com a face inferior ferrugíneoamarelada, a superior mais escurecida. Máculas da face acastanhadas e difusas, apenas as paroculares um pouco mais nítidas, no tórax muito apagadas. Manchas do clípeo aproximadamente triangulares, mas muito apagadas. Mancha supraclipeal irregular, apagada, com limites difusos. Sem manchas na fronte. Estria parocular de cor amarelo-palha, estreita ( $0,75 \mathrm{x}$ o diâmetro do escapo), afilando gradualmente para o ápice, terminando muito estreita e difusa na altura da linha da distância interorbital máxima. Sem manchas nas genas. Tórax com as estrias laterais do mesoscuto muito apagadas; as axilas escurecidas, levemente acastanhadas no bordo anterior; contornando todo o escutelo, uma estria muito difusa. Membrana da asa anterior hialina, muito levemente amarelada no ápice da célula radial; microtríquias amarelas em toda a asa; veias méleo-claras, apenas $\mathrm{C}$ e $\mathrm{R}$ um pouco mais escuras.

Pilosidade. Enegrecida, apenas o ápice das cerdas dos esternos descolorido. Área basal do propódeo com uma faixa glabra mediana. Franja pré-marginal do TIII com cerdas muito mais curtas na região mediana que as laterais. Cerdas da base do escapo 1,29x mais longas que o diâmetro deste. Áreas paroculares inferiores, ao lado dos alvéolos, com as cerdas eretas 1,07x o diâmetro do escapo, como as do clípeo; na fronte, $1,29 x$; no vértice mais longas, ca. $2,43 x$; no disco do mesoscuto e na porção anterior da linha média, 1,57 e 2,71x, respectivamente. Cerdas mais longas no ápice do escutelo com ca. de $0,93 \mathrm{x}$ o comprimento deste.

Integumento. Liso e polido, apenas com a pontuação pilígera típica do gênero.

Forma e proporções (Tab. XI). Cabeça, 1,21x mais larga que longa, e 1,33x mais larga que a distância clipeocelar. Olhos 2,37x mais longos que largos, um pouco convergentes embaixo. Área malar tão longa quanto o diâmetro do $2^{\circ}$ flagelômero. Comprimento do clípeo 0,58x sua largura máxima e 0,36x a distância clipeocelar. Comprimento das mandíbulas $0,59 \mathrm{x}$ a distância clipeocelar; os dentes pequenos, bem recuados (Fig. 53). Comprimento do escapo $0,94 \mathrm{x}$ a distância alvéolo-ocelo lateral, seu diâmetro um pouco menor que o do $2^{\circ}$ flagelômero. Distância interocelar 1,44x maior que a ocelorbital e ca. de 1,77x o diâmetro do ocelo médio. Escutelo aproximadamente 
semicircular, cerca de $0,49 \mathrm{x}$ mais curto que largo. Tíbia III $0,92 \mathrm{x}$ mais curta que a cabeça, e 2,11x mais longa que larga; canto póstero-distal arredondado, pouco projetado, a margem apical fracamente sinuada; contorno da margem posterior suavemente sinuado. Basitarso III 1,53x mais longo que largo; canto pósterodistal arredondado e a margem apical em ângulo um pouco maior que $90^{\circ} \mathrm{em}$ relação à margem anterior. Asa anterior $2,67 \mathrm{x}$ mais longa que larga e 2,27x a largura máxima da cabeça. Bifurcação de $\mathrm{M}+\mathrm{Cu}$ coincidente com a cu-v. Hâmulos, 5.

\section{Macho. Figuras 83, 84, 108, 109.}

Material-tipo. Holótipo operária, de "Lago Água Fria, PA. rio Trombetas - Brasil SA.21-X-C, 56 $6^{\circ} 1^{\prime} \mathrm{W}, 1^{\circ} 25^{\prime} \mathrm{S}, 13-15$,II-1979. Camargo", ninho "183c (:T 69)", parátipos 27 operárias e 2 machos em alfinetes, além de vários machos e operárias em álcool; com a mesma etiqueta de procedência, também os seguintes ninhos: "181c", 35 operárias e 4 machos em alfinetes, vários exemplares em álcool, "182c", 35 operárias e 1 macho em alfinetes, e vários exemplares em álcool, "184c", 32 operárias, "186c", 31 operárias em alfinetes e 1 rainha em álcool, depositados na RPSP.

Material examinado. VENEZUELA. Bolivar: C. Bolivar, sem data, M.A. Carriker, on Convolvulus (13 ops., USNM). GUIANA. U. Essequibo R., 23.XII.1937, W.G. Hassler (1 op., Ac. 36159, AMNH).

SURINAME. Paloemeu, 02.III.1993, B. De Dijn (1 op., I 960, NZCS); Paramaribo, Oost-West verbindings road km 79 east of Paramaribo, 08.IX.1993, B. De Dijn (1 op., I 1089, NZCS); Tapanahony river, 17 km downstream from Paloemeu, 27.II.1993, B. De Dijn (10 ops., I 953, NZCS); Anapaike, rio Lawa, XI.1963, B. Malkin (1 op., MZSP). GUIANA FRANCESA. Kourou, km 11 SW., 10.III.1977, D. Roubik, 108 (1 op., STRI); St. Laurent, 4.VIII.1975, G.W. Otis, purple legume vine, 33 (1 op., SEMC; 1 op., STRI). BRASIL. Roraima: Ilha de Maracá, 5-10.X.1987, Lucio A. O. Campos, Marcos V.B. Garcia (1 op., UFVB). Amapá: Serra do Navio, 7.II.1962, F.M. Oliveira (2 ops., DZUP). Amazonas: Anavilhanas, rio Negro, 21-25.III.1988, F.J.A. Peralta (31 ops., INPA; 5 ops., RPSP); ibidem, 18.12.1975, H. Schubart (2 ops., 0183, INPA); Barcelos, r. Negro, 6.VII.1980, Camargo, Mazucato (6 ops., RPSP); Camanaus, r. Negro, SA-19, 6654'W, 08'S, 12-14.VII.1980, Camargo, Mazucato (2 ops., RPSP); Carvoeiro, r. Negro, 5.VII.1980, Camargo, Mazucato (102 ops., RPSP); F. do r. Daraã, rio Negro, $64^{\circ} 47^{\prime} \mathrm{W}, 0^{\circ} 25^{\prime}$ S, 24.VIII.1980, Camargo, Mazucato (51 ops., ninho 250; 54 ops., mais exemplares em álcool, ninho 251; 50 ops., mais exemplares em álcool, ninho $252 \mathrm{c}$, mais 53 ops., RPSP); Lago Curiuaú, rio Negro, $61^{\circ} 13^{\prime} \mathrm{W}, 1^{\circ}$ 55' S, 25.VIII.1980, Camargo, Mazucato (50 ops., mais exemplares em álcool, ninho 293c, RPSP); Manaus, III.1945, W. Praetorius (2 ops., AMNH); ibidem, SA-20, 60-3c, 1.II.1976, J.M. Camargo (5 ops., RPSP); ibidem, VI.1955, A.P. Duarte (1 op., DZUP); ibidem, IX.1959, C. Elias (1 op., DZUP); ibidem, idem, VIII.1959 (6 ops., DZUP; 1 op., RPSP); ibidem, IV.1960, F.M. Oliveira (7 ops., DZUP; 1 op., RPSP); ibidem, 2.XI.1953, C.R. Gonçalves (2 ops., DZUP); ibidem, Hotel Trop., 11.V.1982, D. Roubik, 5 (1 op., STRI); Maraã, 15-19.VIII.1993, 65³5’W, 153'S, Camargo, Pedro, Mazucato (34 ops., 935406, 935407, 935410, 935411, 935413, 935415-425, RPSP); Pta. do Gavião, r. Negro, SA-20, $61^{\circ} 45^{\prime} \mathrm{W}, 1^{\circ} 25^{\prime}$ 'S, 22-23.VIII.1980, Camargo, Mazucato (39 ops., RPSP); Reserva Praia Grande, rio Negro, 32'S, 60³2’W, 18.VIII.1994, Pedro (54 ops, ninho 651c, RPSP). Pará: Cachoeira da Porteira, 11.III.1986, anônimo (1 op., INPA); ibidem, rio Trombetas, SA-21, $57^{\circ} 2^{\prime} \mathrm{W}, 1^{\circ} 4^{\prime} \mathrm{S}$, 9-12.II.1979, Camargo (48 ops., RPSP); Juquiri, rio Trombetas, 8.III.1986, anônimo (1 op., INPA); Lago Água Fria, rio Trombetas, SA21-X-c, 56 $51^{\prime}$ 'W, 125'S, 13-15.II.1979, Camargo (5 ops., RPSP); ibidem, 14.II.1979 Othonyel R.L. Filho (2 ops., INPA); Lago Caetano, rio Trombetas, 09.III.1986, anônimo (1 op., INPA); ibidem, 13.III.1986, anônimo (1 op., INPA); Lago Carimun, Rio Trombetas, SA.21-x-c, 56ㅇ' $6^{\prime} \mathrm{W}, 1^{\circ} 32$ 'S, 16-17.II.1979, Camargo (1 op., RPSP); Óbidos, XI.1954, F.M. Oliveira (1 op., DZUP); ibidem, idem, I.1962 (1 op., DZUP); Lago $\mathrm{RPQ}$, rio Trombetas, sem data, anônimo (1 op., INPA).
Distribuição geográfica e hábitat. Endêmica das florestas ao norte do rio Amazonas, até Guianas e Venezuela (Fig. 168).

Nidificação. Em termiteiros no interior de ocos de árvores mortas e de galhos secos. Hospedeiro identificado: Termes cf. hispaniolae (Banks, 1918) (ninho 252c).

Etimologia. Homenagem ao naturalista brasileiro Alexandre Rodrigues Ferreira (1756-1815), autor de "Viagem Filosófica ao Rio Negro".

Discussão. Apresenta duas populações distintas, uma com asas amareladas (membrana hialina, microtríquias amarelas, com veias méleo-claras), da região do rio Trombetas (Óbidos, Lago Água Fria, Cachoeira da Porteira, Lago Carimum, PA, até Guianas), e outra com microtríquias enegrecidas em toda a asa (região do rio Negro, Brasil, até Venezuela). A primeira é praticamente indistinguível de $P$. gregaria, exceto pela distribuição geográfica ( $P$. gregaria ocorre ao sul do rio Amazonas, na região do rio Tapajós, Fig. 166), e pelo substrato de nidificação ( $P$. ferreirai em termiteiros no interior de ocos de árvores mortas ou galhos secos e $P$. gregaria em termiteiros arborícolas externos). Material adicional das Guianas e Venezuela, juntamente com informações sobre os ninhos, poderão esclarecer melhor os padrões de politipia de P. ferreirai.

\section{Partamona gregaria sp. nov.}

(Figs. 59, 145, operária; 77, 105, macho; 166, distribuição; Tabs. II-IX, XI)

Diagnose. Abelhas de porte médio (1.m.c. 2,4-2,6 mm, c.a.a. 5,4-6,1 mm; Tabs. III, IV). Integumento preto. Mandíbula predominantemente ferrugínea, apenas o $1 / 5$ basal amarelado ou descolorido, ápice ferrugíneo-escuro, côndilos pretos. Flagelo castanho-escuro. Estrias paroculares estreitas $(0,6-0,8 \mathrm{x}$ o diâmetro do $2^{\circ}$ flagelômero), levemente alargadas embaixo (1,0-1,2x o diâmetro do $2^{\circ}$ flagelômero), chegando até a interorbital superior (Fig. 145). Pilosidade predominantemente preta; cerdas na região ventral dos mesepisternos, coxas e trocanteres, enegrecidas ou esbranquiçadas. Membrana das asas hialinas; microtríquias predominantemente amarelas, somente no ápice e/ou base da asa, escurecidas; veias uniformemente méleo-claras. Cerdas da base do escapo um pouco mais longas que o diâmetro deste $(0,9-1,7 \mathrm{x}$; Tab. VII). Cerdas eretas das áreas paroculares, ao lado dos alvéolos um pouco mais longas que o diâmetro do escapo. Cerdas escutelo 0,9-1,0x o comprimento deste. Área basal do propódeo com uma faixa glabra mediana, aproximadamente tão larga quanto o diâmetro do $2^{\circ}$ flagelômero. Dentes da mandíbula pequenos e muito recuados em relação ao ápice do bordo apical (Figs. 59). Área malar, distância interocelar, distância ocelorbital, tíbia III e comprimento da asa anterior, normais (Tabs. V, VI, VIII, IX). Bifurcação da $\mathrm{M}+\mathrm{Cu}$ geralmente coincidente com a cu-v (raramente levemente anterior). Macho, basitarso III alongado, achatado ou convexo-côncavo; tíbia III estreita (Fig. 77); EVII com a projeção mediana curta e triangular, os chanfros laterais 
curtos e largos (Fig. 105).

\section{Operária.}

Dimensões. Comprimento total aproximado, $6,31 \mathrm{~mm}$; da asa anterior, 5,54 $\mathrm{mm}$ (incluindo a tégula, $6,47 \mathrm{~mm}$ ); largura máxima da cabeça, 2,54 mm; do TIII, 2,30 mm (Tab. XI).

Cor do integumento. Predominantemente preto; face, abdômen, metanoto e tíbias III mais claros (exemplar jovem); os tarsômeros de todos os pares de pernas, ferrugíneos. Tégula ferrugínea escura, mais clara e translúcida na porção discal mediana. Labro amarelado, mandíbula castanho-amarelada no quarto basal e ferrugínea em direção ao ápice, côndilos enegrecidos. Escapo com a face inferior amarelada e a superior enegrecida, mais escuro apicalmente. Flagelo com a face inferior castanha, a superior mais escurecida, a metade apical do $1^{\circ}$ flagelômero e os dois últimos um pouco mais claros. Máculas da face nítidas, principalmente as paroculares; as do tórax um pouco mais apagadas. Manchas no clípeo aproximadamente em forma de L contrapostos, a distância entre elas, na porção mais apical do clípeo, menor que o diâmetro do $2^{\circ}$ flagelômero, apagadas, apenas nos cantos inferiores mais nítidas. Mancha supraclipeal aproximadamente triangular, irregular. Abaixo do ocelo, um triângulo invertido, alongado, um pouco mais longo que o diâmetro do ocelo médio. Uma mancha apagada nos lados do sulco frontal. Estrias paroculares muito estreitas (ca. 0,4x o diâmetro do $2^{\circ}$ flagelômero), embaixo um pouco mais largas, $(0,5 \mathrm{x})$, desaparecendo na altura da linha da distância interorbital máxima. Genas com uma pequena mancha abaixo do meio do olho. Tórax com as estrias laterais do mesoscuto nítidas apenas posteriormente; as axilas com a mácula mais nítida na margem interna, posteriormente escurecidas; escutelo com uma estria acastanhada acompanhando o bordo posterior, um pouco apagada medianamente. Basitarso II com uma estria a cada lado, acompanhando as margens anterior e posterior; o basitarso III com estria apenas na margem anterior, mais alargada e nítida distalmente. Membrana da asa anterior hialina; microtríquias amarelas em toda a asa, exceto no extremo apical, onde são fuscas; veias méleo-claras.

Pilosidade. Predominantemente enegrecida; mais clara, palha-sujo, na porção ventral do tórax (coxas, trocanteres e mesepisternos) e esternos. Área basal do propódeo com uma faixa glabra mediana. Franja pré-marginal do TIII com cerdas muito mais curtas na região mediana que as laterais. Cerdas da base do escapo tão longas quanto o diâmetro deste. Áreas paroculares inferiores, ao lado dos alvéolos, com as cerdas eretas 1,07x o diâmetro do escapo. Cerdas do clípeo mais curtas $0,87 \mathrm{x}$ o diâmetro do escapo; na fronte, $1,13 \mathrm{x}$; no vértice mais longas, ca. 2,27x; no disco do mesoscuto e na porção anterior da linha média, 1,33 e 2,60x, respectivamente. As cerdas mais longas no ápice do escutelo com ca. de $0,96 \mathrm{x}$ o comprimento deste.

Integumento. Liso e polido, apenas com a pontuação pilígera típica do gênero.
Forma e proporções (Tab. XI). Cabeça, 1,18x mais larga que longa, e 1,34x mais larga que a distância clipeocelar. Olhos $2,47 \mathrm{x}$ mais longos que largos, levemente divergentes embaixo. Área malar ca. de 1,06x o diâmetro do $2^{\circ}$ flagelômero. Comprimento do clípeo $0,53 x$ sua largura máxima e $0,36 x$ a distância clipeocelar. Comprimento das mandíbulas $0,55 \mathrm{x}$ a distância clipeocelar; os dentes pequenos e recuados em relação ao bordo distal (Fig. 59). Comprimento do escapo 0,90x a distância alvéolo-ocelo lateral, seu diâmetro um pouco menor que o do $2^{\circ}$ flagelômero. Distância interocelar 1,64x maior que a ocelorbital e ca. de 1,92x o diâmetro do ocelo médio. Escutelo aproximadamente semicircular, cerca de $0,49 \mathrm{x}$ mais curto que largo. Tíbia III $0,93 \mathrm{x}$ mais curta que a cabeça, e 2,11x mais longa que larga; canto póstero-distal arredondado, pouco projetado, a margem apical fracamente sinuada; contorno da margem posterior, suavemente sinuado. Basitarso III 1,67x mais longo que largo; canto pósterodistal subanguloso e margem apical em ângulo um pouco maior que $90^{\circ} \mathrm{em}$ relação à margem anterior. Asa anterior 2,50x mais longa que larga e 2,22x a largura máxima da cabeça. Bifurcação de $\mathrm{M}+\mathrm{Cu}$ levemente anterior à cu-v. Hâmulos, 5 .

\section{Macho Figuras 77, 105.}

Material-tipo. Holótipo, operária, de "São Luis do Tapajós PA Brasil, SB-21,56 ${ }^{\circ} 4^{\prime} \mathrm{W}$; 426'S, 14,17-I-1979 Camargo", ninho "118c (:T 4)", parátipos do mesmo ninho, 31 operárias e 10 machos montados em alfinetes e várias operárias e rainha em álcool; outros ninhos do mesmo agregado, $115 \mathrm{c}, 58$ operárias em alfinetes (muitas outras em álcool), $116 \mathrm{c}, 16$ operárias em alfinetes, além de material em álcool, $117 \mathrm{c}$, muitos exemplares em álcool, depositados na RPSP.

Material examinado. BRASIL. Amazonas: Maués, 6.IV.1995, M.V.B. Garcia (4 ops., RPSP). Pará: Lago Uaicurapá, Paraná do Ramos, 56 $45^{\circ} \mathrm{W}$, 246’S, 20-21.II.1979, Camargo et al. (40 ops., mais material em álcool, ninho 194c; 40 ops., mais material em álcool, ninho 195c; 50 ops., mais material em álcool, ninho 197c, mais 39 ops., RPSP); ibidem, 20.II.1979, Othonyel R.L Filho (19 op., T-83, INPA); Jacareacanga, X.1959, M. Alvarenga (2 ops., DZUP); Mangabeira, Mocajuba, VI.1953, Orlando Rego (8 ops. DZUP; 2 ops., RPSP); Mussum $($ sic $=$ Muçum) $15 \mathrm{~km} \mathrm{~S}$ Aveiro, margem esquerda do Tapajós, $55^{\circ} 25^{\prime} \mathrm{W}, 3^{\circ} 40^{\prime}$ S, 24-28.I.1979, Camargo et al. (86 ops., mais material em álcool, ninhos 146-147c; 131 ops., 970185-970224, RPSP); Santa Maria, Itaituba, SB-21, 5558'W, 4¹3'S, 18-20.I.1979, Camargo (1 op., RPSP); São Luís do Tapajós, SB21, 56 ${ }^{\circ} 14^{\prime} \mathrm{W}, 4^{\circ} 26^{\prime}$ 'S, 14-17.I.1979, Camargo (4 ops., RPSP); Serra de Parintins, rio Amazonas, 19.II.1979, Camargo, Mazucato (74 ops., mais material em álcool, ninho 193c, RPSP); Tauari, rio Tapajós, SA-21$55^{\circ} 7^{\prime} \mathrm{W}, 3^{\circ} 5^{\prime}$ 'S, 29.I-1.II.1979, Camargo (12 ops., RPSP); ibidem, 80 $\mathrm{km} \mathrm{S}$ Aveiro, margem direita do Tapajós, 55 $5^{\circ}$ 'W, $3^{\circ} 5^{\prime}$ 'S, 29.I-01.II.1979, Camargo et al. (21 ops., ninho 166c, RPSP).

Distribuição geográfica e hábitat. Endêmica das matas e manchas de cerrado na região do baixo Tapajós; a leste, até a região do baixo Tocantins. Prefere lugares abertos e secos de áreas antrópicas (Fig. 166).

Nidificação. Termiteiros arborícolas externos - tipo estróbilo, principalmente. Hospedeiros identificados: Nasutitermes $c f$. tatarendae (Holmgren, 1910) (ninhos nos. 115c-120c); Nasutitermes acangussu Bandeira \& Fontes, 1979 (ninhos nos. 194c, 195c); Amitermes excellens Silvestri, 1923 (ninhos nos. $146 \mathrm{c}, 147 \mathrm{c})$. 
Etimologia. Do latim gregarius, referindo-se ao fato de formar grandes agregações de ninhos, muitas vezes em um único termiteiro.

Discussão. Restrita à região do baixo rio Tapajós e Tocantins, PA. Distingue-se das demais espécies do grupo principalmente pela cor das asas (microtríquias amarelas), mas é praticamente idêntica às populações da região do rio Trombetas de P. ferreirai. Estas, entretanto, excluem-se geograficamente (Figs. 166 e 168). Os hábitos de nidificação e estrutura da entrada do ninho também são bastante divergentes, o que dá certa garantia para a decisão de considerá-las como espécies distintas.

Partamona testacea (Klug, 1807)

(Figs. 60, 61, 150, operária; 82, 113, 114, macho; 164, distribuição; Tabs. II-IX, XIV)

Melipona testacea Klug, 1807:265; Smith, 1854:406.20; DallaTorre, 1896:584.

Melipona pallida pallida aberr. rhumbleri; Ducke, 1916:118-121 (partim); 1925:411, (partim).

Trigona pallida; ? Lutz, 1924:205, 209, 216.

Trigona testacea; Klug, 1807: est. 7, Fig. 4; Smith, 1854:413.41; Cockerell, 1923:240; Schwarz, 1932a:238, 253, 259, 298, 391, 392; 1939b:90 (partim); Darchen \& Louis, 1961:29.30.

Trigona rhumbleri Friese, 1900:389.38 (partim, exemplares do Pará); Marianno, 1911:124.59; Nogueira-Neto, 1970:41.

Trigona cupira var. rhumbleri; Schwarz, 1929:145-150, pl. 6; Kerr \& Laidlaw, 1956:128.

Trigona testacea var. rhumbleri; Schwarz, 1932a:298; 1934:18.

Trigona musarum; Cockerell, 1920:464.

Trigona (Patera) testacea var. testacea; Schwarz, 1938:475, 476, 477.

Trigona (Partamona) sakagamii Moure, in Kerr et al., 1967: 286; Wille \& Michener, 1973:12, 21; Camargo, 1980:37. Nom. nud.

Trigona (Partamona) testacea; Schwarz, 1939a:23; 1948:80, 485; Reyne, 1962:35; Kerr, 1969:160, 162, 163; Michener, 1974: 218, 339; Roubik, 1980:840-842.

Trigona (Partamona) testacea testacea; Schwarz, 1940:9; 1948:14, 44, 69, 94, 298, 299, 301, 314, 353; Kerr, et al., 1967:286-290, Fig. 11; Camargo, 1970:211-214, 227(Fig.1), 229 (Fig. 2); Cunha, 1973:3, Figs. 3, 4, 5, 6, 7; Wille \& Michener, 1973:12, 56, 67, 87, 137; Gonçalves, 1973:3, 4, 6 (boca-de sapo); Wille, 1983:50; Cunha, 1991:36.

Partamona testacea; Moure, 1950:257; 1951:58; Coloma, 1986:27, 104, 132, 133, 136; Camargo, 1988b:358; Wittmann, 1989:22; Camargo \& Wittmann, 1989:223, 224; Cruz-Landin \& Mota, 1990:587, 588; Michener, 1990:115; Bego et al., 1991:126; Camargo, 1992:81; Roubik, 1992:503; Mota, 1992:320, 321; Bravo, 1992:864; Camargo, 1994:50, 52, 54, 57; Oliveira \& Morato, 1994:291; Oliveira, et al., 1995:16, 18; Rocha et al., 1991:251, 253, 255; Nogueira-Neto, 1970:32, 34, 45, 258; Camargo, 1996b:74; Camargo \& Moure, 1996:119; Lenko \& Papavero, 1996:263, 264 (Fig. 56), 265 (Fig. 57), 266.

Partamona (Partamona) testacea; Moure, 1953:248; Camargo, 1980:9, 12, 13, 21-45, 48, 49, 56-58, 70-72, 79-142.

Partamona (Partamona) testacea testacea; Sakagami et al., 1964:50, 57; Wille \& Michener, 1973:12; Camargo, 1974:460, 462, 463.

"Cupira"; Castello Branco, 1845:67 (abelha amarela, "casa naquellas moradas de certas formigas ... na superficie da terra").

Diagnose. Abelhas de porte médio (1.m.c. 2,3-2,6 mm, c.a.a. 5,7-6,4 mm; Tabs. III, IV). Integumento geralmente amarelado. Sutura epistomal, área ao redor dos ocelos, porção ventral dos mesepisternos enegrecidos ou amarelados. Basitarso III e 1/3$1 / 2$ apical da tíbia III pretos ou escurecidos. Mandíbula toda amarela ou predominantemente amarela, ápice ferrugíneo, côndilos escurecidos. Flagelo castanho-escuro. Máculas da face geralmente pouco conspícuas; estrias paroculares aproximadamente com a mesma largura em toda a extensão $(0,8$ $1,0 \mathrm{x}$ o diâmetro do $2^{\circ}$ flagelômero), ou um pouco mais larga embaixo (1,2x o diâmetro do $2^{\circ}$ flagelômero), alcançando o topo do olho (Fig. 150). Máculas do tórax apagadas. Cerdas eretas do vértice enegrecidas; cerdas eretas do mesoscuto e escutelo, enegrecidas, amareladas, ferrugíneas, ou misturadas; na metade superior dos lados dos mesepisternos amareladas; nos esternos esbranquiçadas; nos tergos III-VII enegrecidas. Membrana das asas levemente ferrugíneo-amarelada na metade basal; microtríquias pretas; veias méleas, escurecidas pelas microtríquias fuscas, ou escurecidas principalmente na metade basal. Cerdas do escapo curtas, apenas com uma ou duas cerdas na base um pouco mais longas que as demais $(1,0-1,1 \mathrm{x}$ o diâmetro do escapo, Tab. VII). Cerdas eretas das áreas paroculares, ao lado dos alvéolos, mais curtas que o diâmetro do escapo. Cerdas do escutelo 1,0-1,2x o comprimento deste. Área basal do propódeo uniformemente pilosa, os pontos bem marcados. Dentes da mandíbula pequenos e muito recuados em relação ao ápice do bordo apical (Figs. 60, 61). Área malar, distância interocelar, distância ocelorbital, tíbia III e comprimento da asa anterior, normais (Tabs. V, VI, VIII, IX). Bifurcação da $\mathrm{M}+\mathrm{Cu}$, nitidamente anterior à cu-v. Macho, basitarso III alongado, achatado ou convexo-côncavo; tíbia III alargada (Fig. 82); EVII com a projeção mediana longa e triangular, os chanfros laterais profundos e estreitos (Figs. 113, 114).

Variação. Integumento preto ou mesclado em populações das encostas orientais andinas acima de $750 \mathrm{~m}$. Outras variações em CAMARGO, 1980.

Operária.

Dimensões. Comprimento total aproximado, $5,81 \mathrm{~mm}$; da asa anterior, 5,56 $\mathrm{mm}$ (incluindo a tégula $6,23 \mathrm{~mm}$ ); largura máxima a cabeça, 2,40 mm; do TIII 2,22 mm (Tab. XIV).

Cor do integumento. Amarelado-ferrugíneo, inclusive a sutura epistomal, em grande parte tanslúcido; apenas a metade distal da tíbia III, o basitarso e o $1^{\circ}$ tarsômero da mesma perna, enegrecidos. Máculas da face e tórax imperceptíveis devido à transparência do integumento. Membrana das asas levemente tingidas de amarelo-ferrugíneo, as microtríquias bem evidentes, ferrugíneo escuras; veias amarelo-ferrugíneas, da cor do corpo, $\mathrm{C}$ e R mais escuras na base.

Pilosidade. Cerdas ferrugíneo-fuscas e enegrecidas na fronte e vértice; no tórax ferrugíneo-amareladas, nos tergos escurecidas. Fêmur e tíbia da perna posterior com pilosidade bem enegrecida. Na parte ventral do tórax e abdômen, a pilosidade amarelo-palha. 
Integumento. Liso e polido, apenas com a pontuação pilígera típica do gênero.

Forma e proporções (Tab. XIV). Cabeça 1,28x mais larga que a distância clipeocelar. Olhos 2,39x mais longos que largos, um pouco divergentes abaixo. Área malar tão longa quanto o diâmetro do $2^{\circ}$ flagelômero. Comprimento do clípeo $0,54 \mathrm{x}$ sua largura máxima e $0,36 \mathrm{x}$ a distância clipeocelar. Comprimento das mandíbulas $0,58 \mathrm{x}$ a distância clipeocelar; os dentes bastante recuados, ca. de $0,08 \mathrm{~mm}$, em relação ao bordo distal (Figs. 60, 61). Comprimento do escapo $0,87 \mathrm{x}$ a distância alvéolo-ocelo lateral; seu diâmetro praticamente igualando ao do $2^{\circ}$ flagelômero. Distância interocelar 1,41x maior que a ocelorbital e 1,73x o diâmetro do ocelo. Escutelo x $0,55 x$ mais curto que largo. Tíbia III $0,93 x$ mais curta que a largura máxima da cabeça e 2,04x mais longa que larga; o canto póstero-distal arredondado, pouco projetado. Basitarso III 1,72x mais longo que largo. Asa anterior 2,75x mais longa que larga e 2,32x mais longa que a largura máxima da cabeça. Bifurcação de $\mathrm{M}+\mathrm{Cu}$ anterior à cu-v.

\section{Macho. Descrição em CAMARGo (1980). Figuras 82, 113, 114.}

Material-tipo. O exemplar tipo, aqui reconhecido como holótipo (KLUG, 1807, não menciona a existência de mais que um exemplar), não contém localidade especificada, apenas as seguintes etiquetas: "430"; "Type", Mus. Berol."; T. pallida Latr. testacea m Brazil"; "wohl Typen für Melipona testacea K1." (etiqueta pouco legível, os dizeres, como interpretados por nós), "Zool. Mus. Berlin"; depositado no ZMHB. Na descrição original KLUG (1807) menciona apenas "In Brasilia".

Material examinado. COLÔMBIA. Cundinamarca: Guayabetal, 18.IX.1965, J.A. Ramos (2 machos, forma melânica, USNM). Meta: Restrepo, 500m, 1936, J. Bequaert (1 op., Ac. 25658, RPSP); Villavicencio, 1.XI.1965, J.A. Ramos (1 macho, USNM). Amazonas: Letícia, 65 km W Amacayacu Nat. Park, 17-30.IX.1986, D. Roubik (3 ops., 870326-870328, RPSP). SURINAME. Tapanahony river, $17 \mathrm{~km}$ downstream from Paloemeu, 27.II.1993, B. De Dijn (1 op., I 1938, NZCS); Paloemeu, 26.II.1993, B. De Dijn (3 ops., I 1951, NZCS); Brownsberg Nature Park, 27.XII.1993, B. De Dijn (6 ops., I 1072, NZCS; 2 ops., RPSP). GUIANA FRANCESA: Roura, $8.4 \mathrm{~km} \mathrm{SSE,} 200 \mathrm{~m}$ 440'41'N, 52¹3'25'W, 25-29.V.1997; J. Ashe, R. Brooks FG1AB97 089, ex: malaise trap (1 macho, SM0092094, SEMC); ibidem, idem, 29.V-10.VI.1997, FG1AB97 183, ex: malaise trap (1 macho, SM0092055, SEMC); Saül, 7 km N, Les Eaux Claires 339'46”N, 53¹3'19”W, 220m, 1.VI.1997; J. Ashe, R. Brooks FG1 AB97 100 (4 ops., SM0102857-0102860, SEMC; 1 op., SM0102861, RPSP); ibidem, idem, $7 \mathrm{~km} \mathrm{~N}, 3 \mathrm{~km} \mathrm{NW}$ Les Eaux Claires, Mt. La Fumée, 3 3939'46”N, 53¹3'19"W, 490m, 1-8.VI.1997, FG1AB97 162, ex: flight intercept trap (1 op., SM0092004, SEMC); Sinnamary, $10 \mathrm{~km} \mathrm{SE,} \mathrm{palm} \mathrm{plantation}$ rd., 28.IV.1982, D. Roubik, 61 (1 op., STRI); ibidem, idem, $15 \mathrm{~km} \mathrm{SE,}$ 5.V.1982, 64 (1 op., RPSP). EQUADOR. Napo: Archidona, XII.1986, A.J. Salazar (2 ops., RPSP); ibidem, XII.1986, M.H. Lopez (2 ops., forma melânica, RPSP); ibidem, Cuevas de San Bernardo, Andes Orientais, $77^{\circ} 49^{\prime} \mathrm{W}, 0^{\circ} 55^{\prime} \mathrm{S}, 750 \mathrm{~m}, 06 . \mathrm{VI} .1987$, Camargo, Bravo, Onore (124 ops., 6 machos, ninho $411 \mathrm{c}, 46$ ops., ninho $412 \mathrm{c}, 112$ ops. e 4 machos, ninho $413 \mathrm{c}, 49$ ops. e 3 machos, ninho $414 \mathrm{c}$ - agregação com 16 ninhos, alguns com a forma amarela, outros com as formas melânicas e outros com ambas - RPSP); Limoncocha, 9.VI.1977, Malaise, P.J. Spangler \& D.R. Givens, 109 (1 op., forma melânica, USNM); ibidem, 14.VI.1977, Dave L. Vincent (1 macho, USNM); ibidem, $20 \mathrm{~km}$ from Limoncocha, on Jivena River, 24.VI.1965, C.R. Patrick (102 ops., formas melânica e normal, MSUC; 10 ops., RPSP); S. Carlos, VI.1984, G. Onore, "Abeja del suelo" (1 op., RPSP); Sacha Lodge, $0.5^{\circ} \mathrm{S}, 76.5^{\circ} \mathrm{W}, 270 \mathrm{~m}, 22 . \mathrm{II}-$
4.III.1994, Hibbs, ex: malaise (1 macho, SEMC); ibidem, idem, 414.III.1994 (3 machos, SEMC), 14-24.III.1994 (3 machos, SEMC), 24.III-3.VI.1994 (2 machos, SEMC), 3.IV-4.V.1994 (1 macho, SEMC), 3-13.IV.1994 (1 macho, SEMC), 13-23.VI.1994 (1 macho, SEMC), 23.VI-3.VII.1994 (3 machos, SEMC), 3-13.VII.1994 (2 machos, SEMC), 25.VII-3.VIII.1994 (2 machos, SEMC), 30.IX-10.X.1994 (2 ops., SEMC), 10-21.X.1994 (1 macho, SEMC), 21-31.X.1994 (1 macho, SEMC), 31.X-10.XI.1994 (1 machos, SEMC), 10-21.XI.1994 (1 machos, SEMC), 1-31.XII.1994 (3 ops., 8 machos, SEMC; 1 macho, RPSP); Tena, 28.V.1977, Dave L. Vincent (1 macho, forma melânica, USNM); Yasuni Nat. Park, Est. La Catolica, 13-27.IV.1998, D. Roubik, 34 (1 op., RPSP); ibidem, idem, 14-26.IV.1998, 27 (1 op., RPSP), 14-26.IV.1998, 51 (1 op., RPSP). Tungurahua: Baños, $32 \mathrm{~km} \mathrm{E,} \mathrm{28.I.1976,} \mathrm{Spangler} \mathrm{et}$ al. (2 ops., forma melânica, USNM). Pastaza: Puyo, Andes Orientais, $78^{\circ} 0^{\prime} \mathrm{W}, 1^{\circ} 29^{\prime} \mathrm{S}, 750 \mathrm{~m}, 07 . \mathrm{VI} .1987$, Camargo, Bravo, Onore (2 ops., RPSP); ibidem, 30.I.1976, Spangler et al. (1 op., forma melânica, USNM); ibidem, idem, 1-7.II.1976, in malaise trap (1 macho, forma melânica, USNM); ibidem, $1.5 \mathrm{~km}$ NE, 14.V.1977, P.J. Spangler \& D.R. Givens, 42 (2 ops., forma melânica, USNM); ibidem, $22 \mathrm{~km} \mathrm{E,} \mathrm{2.II.1976,} \mathrm{Spangler}$ et al. (7 ops., forma melânica, USNM); ibidem, Rosal, VIII.1986, G. Onore (2 ops., RPSP); ibidem, VIII.1986, G. Onore, "ex: nido en el suelo junto al de otra especie" (3 ops., forma melânica, RPSP); Llandia, 17 km N Puyo, 1000m, 19.VII.1994, F. Génier, "remnant rain for., feces tr." (3 ops., SEMC); ibidem, idem, 20.VII.1994 (4 ops., SEMC); Shell, Mera, 3.VIII.1984, L Coloma, "nido en el suelo de bosque secundario" (1 op., SEMC; 1 op., RPSP). PERU: Perú (localidade?), sem data, anônimo, "Trigona rhumbleri Fr. 18.242 Peru Ducke Rev. 13" (1 op., 18242, 95498, MZSP). Loreto: San Alejandro, 300m, VI.1947, W. Weyrauch (1 op., AMNH); Teniente Lopez, $1.5 \mathrm{~km} \mathrm{~N}, 2^{\circ} 35,66^{\prime} \mathrm{S}$, 7606,92'W, 210-240m, 18.VII.1993, Richard Leschen, 119, 117, ex. flight intercept trap (3 ops., RPSP); ibidem, idem, 18.VII.1993, 120, ex: flight intercept trap (1 op., SEMC), 24.VII.1993, 192 (1 macho, RPSP), 26.VII.1993, 212, 213 (3 ops., SEMC). Huánuco: Acamayo to Tingo Maria en route, 19.VII.1946, R. M. Straw (3 ops., forma melânica, USNM); Chanchamayo, 10.IX.1935, Wille (2 ops., 242-35, forma melânica, USNM); Col. Perené, 26.VI.1920, Cornell U., Lot 569 sub 375, "PARATYPE", "Trigona (Partamona) testacea var. atahualpa, H.F. Schwarz" (3 ops., RPSP; 2 ops., STRI; 2 ops., AMNH); San Ramon, Valle Chanchamayo, 800m, 12.II.1940, W. Weyrauch, 17 (2 ops., forma melânica, Ac. 37363, AMNH); ibidem, idem, 18.II.1940, (2 ops., forma melânica, Ac. 37363 AMNH), 25.II.1940, 27 (1 op., 4 machos, forma melânica, Ac. 37363, AMNH), 25.II.1940, 26 (4 ops., forma melânica, Ac. 37363 AMNH), 25.II.1940, 25 (3 ops., forma melânica, Ac. 37363, AMNH), 8.II.1940, 12 (3 ops., forma melânica, Ac. 37363, AMNH), II.1940, 9 (1 op., AMNH); Satipo, 600m, 1940, Weyrauch, 136 (1 op., RPSP). Cuzco. Avispas, 20.IX.1962, Luis E. Peña (4 ops., DZUP); ibidem, idem, SE Cusco, IX.1962 (2 ops., MZSP); Quincemil, 9.XI.1961, Luis E. Peña (3 ops., 26 machos, DZUP; 4 machos, RPSP). BRASIL. Amapá: Oyapock, 29.V.1904, Ducke, "Trigona rhumbleri (=pallida v. rhumbleri) Oyapock (Est. Amaz.) Ducke rev. 13” (1 op., 18.243 e 95495, MZSP); Serra do Navio, IX.1957, K. Lenko (8 ops., 1 macho, DZUP); ibidem, idem, X.1957 (9 ops., DZUP; 4 ops., RPSP); ibidem, I.1957, Machado, Fevereiro (1 op., DZUP). Amazonas: Arimã, rio Purus, SB20, 634ㄴ' 'W, 543'S, 3-8.II.1986, Camargo, Mazucato (1 op., 861729, RPSP); Bacururu, rio Juruá, $66^{\circ} 11^{\prime} \mathrm{W}, 3^{\circ} 45^{\prime}$ 'S, 30.VII-01.VIII.1993, Camargo, Pedro, Mazucato (62 ops., e exemplares em álcool, ninho $544 \mathrm{c}, 84$ ops. e 8 machos, mais operárias em álcool, ninhos 550c, 551c, mais 9 ops., 933487-489, 933491, 933494-496, 933498, 933508, RPSP); Benjamin Constant, SB-19, 70-4c, 13-14.I.1977, Camargo, Mazucato (34 ops., ninho 55c, 35 ops., ninho, 58c, e exemplares em álcool de ambos os ninhos, RPSP); Camaruã, rio Purus, SB-20, $64^{\circ} 25^{\prime} \mathrm{W}, 5^{\circ} 46^{\prime} \mathrm{S}$, Camargo, Mazucato (1 op., 862562, RPSP); Estirão del Equador, 28.X.1976, Bob Hill (1 op., INPA); Forte da Graça, rio Juruá, $66^{\circ} 6^{\prime} \mathrm{W}$, $3^{\circ} 39^{\prime}$ S, 06.VIII.1993, Camargo, Pedro, Mazucato (59 ops., ninho 571c, mais 35 ops., 933686-96, 933699, 933701-704, 933706, 933708-711, 933713-715, 933717, 933722, 933724-733, RPSP); Manaus, I-II.1963, Exp. FFCLRC (6 ops., RPSP); ibidem, 1981, Falcão (1 op., RPSP); ibidem, VI.1955, A.P. Duarte (5 ops., DZUP; 1 op., RPSP); ibidem, 2831.I.1963, F.F. Rio Claro (1 op., DZUP); ibidem, Res. Ducke, $2^{\circ} 56$ 'S, 5958'W, 23.VIII.1994, S. Pedro (7 ops., 941277, 941285, 941289, 
941290, 941293-B, 941288-B, 941299, RPSP); ibidem, R.B. Campinas, 27.VIII.1975, L.P.A. (1 op., INPA); ibidem, Reserva Campinas, $60 \mathrm{~km}$ N Manaus, 14.I.1977, B.C. Ratcliffe (9 ops., INPA); Maraã, $65^{\circ} 35^{\prime} \mathrm{W}$, $1^{\circ} 53$ 'S, Camargo, Pedro, Mazucato (73 ops., 935333-935379, RPSP); Maués, 06.IV.1995, M.V. Garcia (1 op., RPSP); Paricatuba, rio Purus, SB-20, 61 ${ }^{\circ} 53^{\prime} \mathrm{W}, 4^{\circ} 25^{\prime}$ 'S, 17-19.II.1986, Camargo, Mazucato (2 ops., 862419,862420 , RPSP); Rio Ipixuna, $42 \mathrm{~km}$ à montante do Tapauá, $63^{\circ} 20^{\prime} \mathrm{W}, 6^{\circ} 0^{\prime} \mathrm{S}, 22 . \mathrm{I} .1986$, Camargo, Mazucato (67 ops., ninho 341c, 107 ops., 1 macho, mais exemplares em álcool, ninho $342 \mathrm{c}$, mais 101 ops., 860714-860746, 860678-860687, RPSP); Tabatinga, X.1956, F.M. Oliveira (1 op., DZUP); Vendaval, margem esquerda do rio Solimões, SA-19, 69-3 h-vi, 16-18.I.1977, Camargo, Mazucato (35 ops., ninho $63 \mathrm{c} ; 37$ ops., ninho 64c; 17 ops., ninho 67c; 26 ops., ninho 68c; 67 ops., ninhos $71 \mathrm{c}-81 \mathrm{c}$ e exemplares em álcool de todos os ninhos; mais 4 ops., RPSP). Pará: Pará (localidade?), 22.IV.1902, Ducke, "Trigona pallida Latr. v. rhumbleri Fr. det. Ducke, 1911", "Trigona rhumbleri Fr. (=pallida v. rhumbleri) Est. Pará Ducke" (1 op., 18240 e 95496, MZSP); ibidem, 26.VI.1902, Ducke (1 op., 18240 e 95492, MZSP); Belém, I.1938, L.F. Martorell (3 ops., Ac. 131-38, USNM); Belterra, 20.VII.1993, G. C. Venturieri, em Stachytarpheta cayennensis, 10:36 hs., 011 (1 op., 940129, RPSP); Canindé, Rio Gurupí, IV.1963, Malkin \& Pinheiros (1 op., RPSP); Capanema, 18.XI.1953, C.R.Gonçalves (2 ops., DZUP); Corací - 15 km. NW Canindé, rio Gurupí, IV.1963, B. Malkin (18 ops., MZSP); Igarapé-Açu, 12.V.1993, F. Frota, em Dichromena ciliata, 08:40 hs., 011 (1 op., 940125, RPSP); ibidem, 12.V.1993, P. Neves, em Dichromena ciliata, 09:53 hs. (1 op., 011, 940126, RPSP); ibidem, 17.II.1993, G. Venturieri, em Myrcia bracteata, 8:40 hs. (2 ops., 011, 940127, 940128, RPSP); I. Marajó, r. Anajás, 2.VI.1900, Ducke (1 op., BMNH); Rio Mapuera, Cach. Assunção, 16.VI.1986, Ulysses Carvalho (3 ops., INPA); Rio Trairão, $50 \mathrm{~km} \mathrm{NE}$ de Gradaus, SB-22, 51 ${ }^{\circ} 49^{\prime} \mathrm{W}, 7^{\circ} 21^{\prime} \mathrm{S}, 21$ 24.VII.1979, Mazucato (20 ops., RPSP); Santana, margem direita do

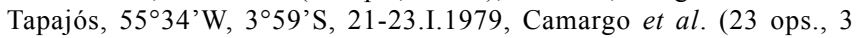
machos, ninho 137c, RPSP); ibidem, Brasília Legal, 22.II.1979, Othonyel, R.L. Filho (1 op., INPA); Santarém, sem data, anônimo (4 ops., Ac.2966, CMNH); São Luís do Tapajós, 56²14’W, 4²6'S, 14-17.I.1979, Camargo et al. (40 ops. e exemplares em álcool, ninho $121 \mathrm{c}$, RPSP); ibidem, 15.I.1979, Othonyel R.L. Filho (23 ops., INPA); Vila do Carmo, 1.XII.53, anônimo (1 op., DZUP). Acre: Brasiléia, Seringal Porongaba, 30.X.1993, M.L. Oliveira (1 op., 940123, RPSP); Cruzeiro do Sul, II.1963, M. Alvarenga (1 op., DZUP); Feijó, XII.1956, Werner (3 ops., MZSP); Parque Nacional Serra do Divisor, Sítio 5, Igarapé Ramon, 07²7'32”S, 7346'28"W, 16.XI.1996, E. F. Morato (65 ops., 1 macho, 971115-17, 971260, 971263-68, 971327-35, 971340, 971344, 971353-54, 971357, 971359,-67, 971369-401, RPSP); ibidem, idem, Sítio 6, Trilha do Anil, 8-9.XI.1996 (1 op., 971541, RPSP), Sítio 8, Rio Azul, 24.XI.1996 (33 ops., 971785-971815, 971819, 971842, RPSP); Rio Branco, 27.V.1994, M.L. Oliveira (18 ops., 1 macho, RPSP); ibidem, 3.VII.1993, E.F. Morato (1 op., RPSP); ibidem, 15-20.XI.1961, F.M. Oliveira (5 ops., DZUP); ibidem, 29.X.1954, M. Alvarenga (1 op., DZUP); ibidem, 20.05.1990, L.A.O. Campos (1 op., UFVB); ibidem, idem, 21.05.1990, BR317, FUNTAC (14 ops., UFVB); ibidem, UFAC/PZ, 04.XI.1995, A.H. Machado, E.M. Santos (8 ops., OLIV); ibidem, idem, 18.XI.1995, 1500 (1 op., OLIV); Sena Madureira, 2.IV.1994, Rio Caeté, 6840'4,8”W, 0903'14,4”S, E.F. Morato (3 ops., RPSP); Xapuri, 26.IX.1989, Dain, 19 (4 ops., 900069-900072, RPSP). Rondônia: Alta Floresta, 24.IV.1997, linha P50, $11^{\circ} 58,192^{\prime}$ 'S, $61^{\circ} 59,803^{\prime} \mathrm{W}$, Brown, Boina, Vieira

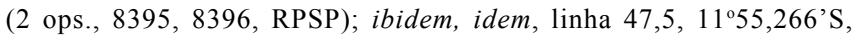
6203,068”W, 25.IV.1997 (1 op., 8474, RPSP); Ariquemes, $62 \mathrm{~km} \mathrm{~S}$, Faz. Rancho Grande, nr. Cacaolândia, $10^{\circ} 32^{\prime} 0^{\prime \prime} \mathrm{S}, 62^{\circ} 48^{\prime} 0^{\prime} \mathrm{W}$, 25.XII.1995, D. Kistner, BRA1K 03 No. 5278, ex: flight intercept trap (27 ops., SM0135110-114, 0135117-122, 0135124-135, 0135140-142, 0135144, SEMC; 01 op., SM0135136, RPSP); ibidem, idem, 28.XII.1995, BRA1K01, No. 5288, ex: flight intercept trap (25 ops., SM0107110, 0107113, 0107116, 0133489, 0134984, 0134986, 0134989-991, 0134993-994, 0134996, 0134999, 0135005, 0135008009, 0135011, 0135014, 0135016-017, 0135019, 0135020, 0135022, 0135022, 0135025, SEMC; 01 op., SM0135000, RPSP), 29.XII.1995, BRA1K02, No. 5293, ex: flight intercept trap (21 ops., SM0135028029, 0135033-035, 0135038, 0135043-047, 0135057-059, 0135061, 0135063, 0135076, 0135079, 0135081-082, 0135145, SEMC); Campo
Novo, BR-421 oeste de C.N., 10²7'06,1”S, 6351'52,8”W, 11.IX.1997, Brown, Boina, Vieira (7 ops., 14286, 14293-14295, 14325, 14326, 14345, RPSP); ibidem, idem, BR-421, Rio Jaci-Paraná, 10²6'13,0”'S, 6407'36,1”W, 11.IX.1997 (7 ops., 14198, 14202-14204, 14257-14259, RPSP), estrada C.N. - Buritis, 10²3’32,2”S, 63³9’25,6”W, 10.IX.1997 (2 ops., 14512, 14513, RPSP); ibidem, Ig. Tracoazinho, Reg. Cpo. Novo, 1-15.VIII.1985, V. Py-Daniel, L. Aquino (75 ops., INPA); ibidem, idem, 5.VIII.1985 (2 ops., INPA), Rio Candeias, 3.VIII.1985 (26 ops., INPA), 6.VIII.1985 (2 ops., INPA), 14.VIII.1985 (13 ops., INPA), 1018.VIII.1985 (48 ops., INPA); Cerejeiras, S 13ำ14,366', W 600 50,462', 24.II.1997, Brown, Boina, Vieira (6 ops., 5397, 5413, 5419, 5426, 5446, 5447, RPSP); ibidem, idem, S 1316,113', W 6050,945', 25.II.1997 (1 op., 5362, RPSP); Chupinguaia, S 12 $33,840^{\prime}$, W $61^{\circ} 12,919^{\prime}$, 21.II.1997, Brown, Boina, Vieira (1 op., 6285, RPSP); ibidem, idem, S 12³2,867', W 6110,798', 22.II.1997 (8 ops., 5477, $5478,5486-5488,5514,5517,5527$, RPSP); Costa Marques, estrada 478, 12²6’05,2"S, 64²0'02,6”W, 19.XI.1996, Brown, Boina, Vieira (3 ops., 3330, 3373, 3392, RPSP); Cujubim, linha 14, 09²0,154'S, 62 $33,110^{\circ} \mathrm{W}, 24 . I I I .1997$, Brown, Boina, Vieira (16 ops., 6653, 6655, $6658,6660,6663,6684-6686,6727-6729,6762,6765,6779,6780$, 6796, RPSP); ibidem, idem, $09^{\circ} 20,765^{\prime} \mathrm{S}, 6^{\circ} 36,792^{\prime} \mathrm{W}, 26 . \mathrm{III} .1997$ (12 ops., 7268-7270, 7274, 7275, 7279, 7280, 7281, 7289, 7290, 7291, 7301, RPSP), Reserva Rio Cujubim, $09^{\circ} 20,308^{\prime} \mathrm{S}, 62^{\circ} 34,440^{\prime} \mathrm{W}$, 24.III.1997 (10 ops., 6846, 6847, 6892-6895, 6910, 6954, 6955, 6956, RPSP), linha C2, $09^{\circ} 23,205^{\prime} \mathrm{S}, 62^{\circ} 34,854^{\prime} \mathrm{W}$, 25.III.1997 (18 ops., 7204$7218,7222,7236,7250$, RPSP), linha 46 a Machadinho, $09^{\circ} 24,606^{\prime} \mathrm{S}$, 62³3,479'W, 25.III.1997 (19 ops., 7016, 7017, 7058-7060, 70717075, 7094, 7097, 7098, 7100-7103, 7127, 7128, RPSP); Extrema, linha 4, 0944'56,5”S, 66 $26^{\circ} 58,5^{\prime}$ ”, 26.VI.1997, Brown, Boina, Vieira (12 ops., 11275, 11281, 11282, 11284, 11296, 11306, 11315, 11316 , $11326,11327,11377,11378$, RPSP); ibidem, idem, linha 5, 0946'04,0”S, 66²9'36,1”W, 26.VI.1997 (2 ops., 11395, 11411, RPSP); Guajará-Mirim, S 10³3,751', W 64'45,463', 10.IX.1996, Brown, Boina, Vieira (28 ops., 581-586, 588-595, 596, 597, 599-605, 619, 620, 624, 653, RPSP); ibidem, idem, S 10¹9,434', W 64³3,849', 11.IX.1996 (1

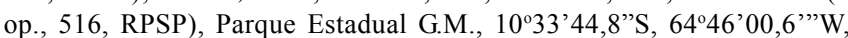
30.VI.1997 (1 op., 11517, RPSP), 10³4'26,1”S, 6445'23,7”W 30.VI.1997 (4 ops., 11540, 11548, 11549, 11550, RPSP); Jaciparaná, BR-364, 0908'38,9”S, 64¹0’03,1”W, 28.VI.1997, Brown, Boina, Vieira ( 2 ops., 11465, 11466, RPSP); Jarú, S $11^{\circ} 02,465^{\prime}$, W 62 ${ }^{\circ} 54,239^{\prime}$, 18.XII.1996, Brown, Boina, Vieira (6 ops., 4266, 4267, 4281, 4282,

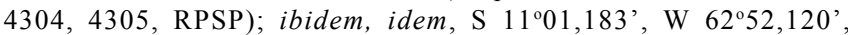
07.I.1997 (9 ops., 4548-4550, 4554, 4558-4561, 4591, RPSP);

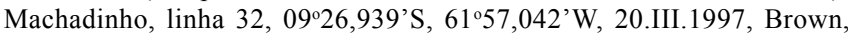
Boina, Vieira (9 ops., 6286, 6291-6293, 6352-6356, RPSP); ibidem, idem, linha 32, 09 $23,889^{\prime} \mathrm{S}, 61^{\circ} 49,128^{\prime} \mathrm{W}$ (1 op., 6427, RPSP), estrada 133 a Tabajara, $09^{\circ}, 26,945^{\prime} \mathrm{S}, 61^{\circ} 51,445^{\prime} \mathrm{W}, 21 . \mathrm{III} .1997$ (1 op., 6521, RPSP), estrada 133 a Tabajara, $09^{\circ} 03,395^{\prime}$ 'S, $62^{\circ} 03,749^{\prime} \mathrm{W}, 22 . \mathrm{III} .1997$ (9 ops., 6538, 6554, 6559, 6594-6596, 6603, 6604, RPSP); Mirante da Serra, S 1059,881', W 6250,764', 24.IX.1996, Brown, Boina, Vieira (6 ops., 2242-2246, 2248, 3 machos, 2240, 2241, 2247, RPSP); ibidem, idem, S 11'10,076', W 6253,104', 25.IX.1996 (1 op., 2430, RPSP), S $11^{\circ} 10,181^{\prime}$, W $62^{\circ} 51,110$ ', 25.IX.1996 (8 ops., 2439, 2441, 2442,

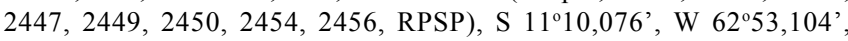
26.IX.1996 ( 1 op., 2431, RPSP), S1101,516', W6248,750', 07.XI.1996

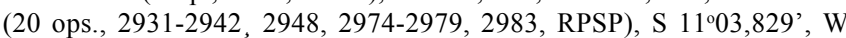
6240,728', 07.XI.1996 (3 ops., 2999-3001, RPSP), S $11^{\circ} 03,255^{\prime}$, W 62 ${ }^{\circ} 52,614$ ', 18.XII.1996 (13 ops., 4311, 4321, 4323, 4325, 4327, $4328,4331-433,4338,4345,4346,4360$, RPSP), S $11^{\circ} 02,690^{\prime}, \mathrm{W}$ 62 50,400 ', 07.I.1997 (9 ops., 4596, 4634-4638, 4640, 4643, 4648, RPSP), S 10 $56,284^{\prime}, \mathrm{W} 62^{\circ} 42,425^{\prime}, 31 . I .1997$ (3 ops., 5145-5147, RPSP), S $11^{\circ} 00,396^{\prime}$, W $26^{\circ}\left(\right.$ sic $\left.=62^{\circ}\right) 45,404^{\prime}$, 03. III. 1997 (8 ops., 5896, $5898,5928,5935-5937,6279,6281$, RPSP), S 11 ${ }^{\circ} 87,900^{\prime}, \mathrm{W}$ 62 $50,228^{\prime}$, 04.III.1997, (2 ops., 5980, 5995, RPSP), linha 76, $11^{\circ} 07,142^{\prime} \mathrm{S}, 62^{\circ} 48,389^{\prime} \mathrm{W}, 18 . \mathrm{IV} .1997$ ( 2 ops., 7766, 7767, RPSP), linha $64,10^{\circ} 58^{\prime} 35,3$ "S, 62047'08,0"W, 16.V.1997 (9 ops., 9242-9246, $9249,9250,9256,9257$, RPSP), linha $80,11^{\circ} 03^{\prime} 07,1^{\prime} \mathrm{S}, 62^{\circ} 55^{\prime} 54,6^{\prime \prime} \mathrm{W}$, 10.VI.1997 (6 ops., 10917-10920, 10927, 10946, RPSP), linha 80 $11^{\circ} 05^{\prime} 35,2$ "S, 62 53'20,1"W, 10.VI.1997 (2 ops., 10956, 10959, RPSP), Fazenda Urupá, $11^{\circ} 02^{\prime} 44,7^{\prime}$ S, 62³4'41,8”W, 11.VI.1997 (11 ops., 
10972-10974, 10979, 10988, 10993-10995, 11002, 11025, 11026,

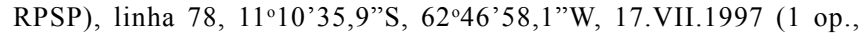
11634, RPSP), linha 60, $11^{\circ} 00^{\prime} 03,5^{\prime} \mathrm{S}, 62^{\circ} 43^{\prime} 55,4^{\prime \prime} \mathrm{W}, 15$.VIII.1997 (1 op., 13052, RPSP), linha $72,11^{\circ} 04^{\prime} 19,8^{\prime \prime}$ S, 62 $48^{\circ} 42,4^{\prime \prime} \mathrm{W}, 20 . \mathrm{VIII} .1997$ ( 3 ops., $13476,13479,13480$, RPSP), linha $74,11^{\circ} 09^{\prime} 36,7^{\prime} \mathrm{S}$, 62044'26,5”W, 21.VIII.1997 (4 ops., 13528-13531, RPSP), linha 74, $11^{\circ} 08^{\prime} 22,4^{\prime}$ 'S, 62 ${ }^{\circ} 46^{\prime} 04,9$ 'W, 21.VIII.1997 (4 ops., 13562, 13564, 13565,13596 , RPSP), linha $74,11^{\circ} 06^{\prime} 45,8^{\prime \prime} \mathrm{S}, 62^{\circ} 49^{\prime} 28,4^{\prime \prime} \mathrm{W}$,

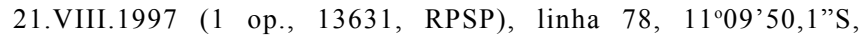
$62^{\circ} 47^{\prime} 42,3$ 'W, 28.VIII.1997 (2 ops., 13668, 13669, RPSP), linha 80, $11^{\circ} 10^{\prime} 05,7$ "S, $62^{\circ} 49^{\prime} 08,5$ ”W, 28.VIII.1997 (2 ops., 13715, 13726, RPSP), linha $80,1^{\circ} 06^{\prime} 46,3^{\prime \prime}$ S, 62 ${ }^{\circ} 51^{\prime} 03,6$ "W, 29.VIII.1997 (8 ops., 13889-13891, 13911-13913, 13918, 13919, RPSP), linha 84, $11^{\circ} 08^{\prime} 01,6$ ”'S, 62 $53^{\circ}$ '21,3”W, 29.VIII.1997 (1 op., 13880, RPSP), linha

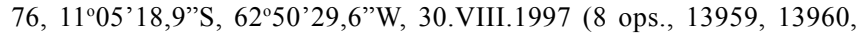
13972, 13973, 14009, 14010, 14037, 14046, RPSP); Nova Califórnia, linha Pioneiros, 9046'47,7”S, 66³7'41,2”W, 24.VI.1997, Brown, Boina, Vieira (1 op., 11043, RPSP); ibidem, idem, linha Pioneiros, 0947'56,7”S, 66³6'10,7'W 25.VI.1997 (10 ops., 11079, 11104, $11119,11120,11123,11124,11168,11177,11178,11187$, RPSP), linha Cascalho, 0947'10,4”S, 66³9'48,3”W, 25.VI.1997 (4 ops., 11254, 11255, 11263, 11264, RPSP); Nova Mamoré, S 10²19,434', W 64³3,849', 7.IX.1996, Brown, Boina, Vieira (1 op., 1433, RPSP); ibidem, idem, S 10¹9,434', W 64³3,849', 8.IX.1996 (13 ops., 813, $822,975,981,982,1005,1014,1021,1055-1059$, RPSP), S 10³3,751', W 644ㄴ,463', 9.IX.1996 (19 ops., 702-720, RPSP), S 10²19,440', W 64²46,775', 12.IX.1996, (15 ops., 156, 159, 161, 163, 165, 166, 171, $175,181,183,282,304,305,379,399$, RPSP), S 10²4,410', W 6500,406', 13.IX.1996 (6 ops., 14, 50-52, 54, 55, RPSP), S 10²3,832', W 6500,467', 13.IX.1996 (2 ops., 109, 110, RPSP); Nova União, S $10^{\circ} 46,486^{\prime}$, W 62²9,550', 26.IX.1996, Brown, Boina, Vieira (3 ops., 2586, 2588, 2589, RPSP), ibidem, idem, S 10 ${ }^{\circ} 52,532^{\prime}$, W 62 $35,181^{\circ}$, 8.XI.1996, (22 ops., 3015-3017, 3032, 3034, 3067-3070, 3078-3081, 3090, 3093, 3095, 3105, 3107, 3108, 3110-3112, RPSP), S 1049,958', W 62²9,930', 19.XII.1996 (17 ops., 4371-4375, 4389-4393, 4398,

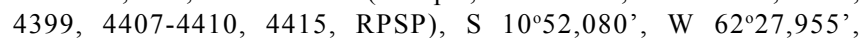
20.XII.1996 (1 op., 4474, RPSP), S 1048,715', W 62³3,196', 9.I.1997 (17 ops., 4756-4759, 4767-4770, 4772, 4773, 4793, 4794, 4799, 4802, $4807,4813,4820$, RPSP), linha 48, $10^{\circ} 53,862^{\prime} \mathrm{S}, 62^{\circ} 39,944^{\prime} \mathrm{W}$, 16.IV.1997 (1 op., 7453, RPSP), linha 40, 1054'08,0”S, 62'32'58,6”'W, 14.V.1997 (3 ops., 8970-8972, RPSP), linha 40, 105 '49,7"S, 62 ${ }^{\circ} 28^{\prime} 55,2^{\prime \prime} \mathrm{W}, 14 . \mathrm{V} .1997$ (6 ops., 9044, 9050, 9051, 9053-9055, RPSP), linha $28,10^{\circ} 55^{\prime} 18,9^{\prime \prime}$, $62^{\circ} 26^{\prime} 25,8^{\prime \prime} \mathrm{W}, 12$.VI.1997 (11 ops., 10530-10532, 10535, 10546, 10556, 10609-10612, 10817, RPSP), linha 36, 1059'22,9”S, 62³4'18,0”W, 18.VII.1997 (3 ops., 11785, 11788,11790 , RPSP), linha $24,10^{\circ} 44^{\prime} 35,7^{\prime \prime} \mathrm{S}, 62^{\circ} 31^{\prime} 35,8^{\prime \prime} \mathrm{W}$, 31.VII.1997 (4 ops., 12337, 12338, 12349, 12350, RPSP), linha 28, 1050'36,8”S, 62'27'52,7'W, 1.VIII.1997 (2 ops., 12461, 12462, RPSP), linha $32,10^{\circ} 49^{\prime} 54,1^{\prime}$ 'S, 62'32'22,6”W, 4.VIII.1997 (1 op., 12555, RPSP), linha $36,10^{\circ} 52^{\prime} 40,9^{\prime}$ 'S, 62³2'20,2”W, 11.VIII.1997 (2 ops., 12674, 12675, RPSP), linha 40, 1051'42,4”S, 62³6’31,7’W, 12.VIII.1997 (3 ops., 12733-12735, RPSP); Ouro Preto (= Ouro Preto D'Oeste), S $10^{\circ} 41,970^{\prime}$, W 62 ${ }^{\circ} 19,332^{\prime}$, 17.XII.1996, Brown, Boina, Vieira (1 op., 4226, RPSP); ibidem, idem, S 1042,252', W 62²2,075', 10.I.1997 (10 ops., 4855, 4869, 4876, 4877, 4879-4882, 4900, 4901, RPSP), S $10^{\circ} 42,970^{\prime}, \mathrm{W} 62^{\circ} 23,465^{\prime}, 29 . \mathrm{I} .1997$ (1 op., 4935, RPSP), S 1047,030', W 62 ${ }^{\circ} 19,222^{\prime}$, 29.I.1997 (2 ops., 5054, 5055, RPSP), S 1048,725', W $62^{\circ} 23,811^{\prime}, 30 . I .1997$ (8 ops., 5098-5102, 5113, 5114, 5116, RPSP), linha $4,10^{\circ} 43,565^{\prime} \mathrm{S}, 62^{\circ} 18,562^{\prime} \mathrm{W}, 14 . \mathrm{IV} .1997$ (4 ops., 7338, 73407342 , RPSP), linha $16,10^{\circ} 50,959^{\prime} \mathrm{S}, 62^{\circ} 19,205^{\prime} \mathrm{W}, 15 . \mathrm{IV} .1997$ (3 ops., 7365-7367, RPSP), linha $12,10^{\circ} 49,364^{\prime} \mathrm{S}, 62^{\circ} 18,912^{\prime} \mathrm{W}, 15 . \mathrm{IV} .1997$ (1 op., 7431, RPSP), linha 16, 10'44'40,0”S, 62 26 '20,1”W, 13.V.1997 (4 ops., 8932, 8933, 8956, 10483, RPSP), linha 8, 10³9'25,3"S, 62 $23^{\prime} 57,4$ ”W, 21.VII.1997 (3 ops., 11812, 11821, 11823, RPSP), linha 4, 10'43'54,4S, 62 ${ }^{\circ} 17^{\prime} 14,6^{\prime}$ 'W, 23.VII.1997 (2 ops., 11929, 11930, RPSP), linha 8, 1045'39,3”S, 62¹8'16,3”W, 24.VII.1997 (1 op., 12017, RPSP), linha $12,10^{\circ} 43^{\prime} 35,4^{\prime \prime} \mathrm{S}, 62^{\circ} 23^{\prime} 00,6^{\prime} \mathrm{W}, 28$.VII.1997 (1 op., 12118, RPSP); Pimenteiras, S $10^{\circ} 48,715^{\prime}$, W 62³3,196', 9.I.1997, Brown, Boina, Vieira (1 op., 4806, RPSP); ibidem, idem, S 12040,194', W 61 ${ }^{\circ} 24,825^{\prime}$, 19.II.1997 (10 ops., 5731-5736, 5741, 5743, 5767,
5768, RPSP), S $12^{\circ} 35,642^{\prime}$, W 6127,764', $20 . I I .1997$ (12 ops., 56675673, 5685-5687, 5696, 5697, RPSP); Porto Velho, 22.XII.1966, Camargo (17 ops., RPSP); ibidem, Guaporé, XI.1954, M. Alvarenga, Dente, F. Pereira, Werner (43 ops., DZUP; 1 op., RPSP); ibidem, XII.1954, M. Alvarenga (17 ops., DZUP; 4 ops., RPSP); São Miguel do

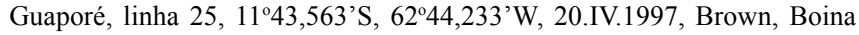
Vieira (10 ops., 7817, 7818, 7855-7858, 7886, 7892, 7893, RPSP); ibidem, idem, linha $82,11^{\circ} 46,568^{\prime}$ 'S, 62 $2^{\circ} 43,531^{\prime}$ 'W, $20 . I V .1997$ (7 ops., 7930, 7963, 7967-7971, RPSP), Reserva Indígena Rio Branco,

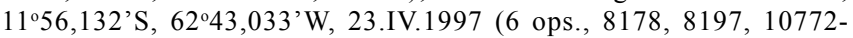
10774, RPSP); Vilhena, 22.VII-5.VIII.1983, F.J.A. Peralta (2 ops., INPA); V. Rondônia, 378 km S de P. Velho (atual Ji-Paraná), 25.I-9.II.1961, Pereira, A. Machado (1 op., MZSP). Maranhão: Igarapé Gurupí - Uma $($ sic $=$ Una?) Aldeia Araçu, $50 \mathrm{~km}$ E de Canindé, V.1963, Malkin (1 op., RPSP); Imperatriz, 20.II.1962, F.M. Oliveira (1 op., RPSP); ibidem, 1.VII.1964, Sebastião Laroca (1 op., RPSP); ibidem, idem, SB-23, 476a, 18.XII.1972 (2 ops., RPSP); Nova Olinda, SA-23, 46 vi-3f, 15.II.1984, Camargo, Mazucato (2 ops., 840055, 840056, RPSP). Ceará: Viçosa do Ceará, SA-24, 41-4a, X.1969, F. Gomes (1 op., RPSP). BOLÍVIA. La Paz: Tumupasa, XII(ano?), W.M. Mann, Mulford BioExpl. 1921-22 (6 ops., USNM). Beni: C. Esperanza, III(ano?), Wm. M. Mann, Mulford BioExpl. 1921-22 (7 ops., USNM); Guayaramerim, 6.XII.1956, Fritz (1 macho, SEMC); Ivon, II(ano?), W.M. Mann, Mulford BioExpl. 1921-22 (2 ops., USNM); Riberalta, XII.1956, Fritz (7 ops., SEMC; 1 op., RPSP); ibidem, I(ano?), Wm. M. Mann, Mulford BioExpl. 1921-22 (15 ops., USNM; 2 ops., RPSP).

Distribuição geográfica e hábitat. Floresta amazônica; ocupa toda a bacia, desde a região pré-andina até o oeste do Maranhão, Brasil; há vários registros para o Estados do Ceará e Piauí, Brasil (Castello Branco, 1845; Gonçalves, 1973; Camargo, 1980; Fig. 164).

Nidificação. Ninhos subterrâneos, em termiteiros (KERR et al., 1967; CAmargo, 1970, 1980), em ninhos de Atta spp., e vários outros tipos de cavidades subterrâneas não associadas a ninhos de insetos sociais (CAMARGO, 1980 e Camargo, et al., obs. pessoal). Hospedeiros identificados (ninho no. 55c): Syntermes spinosus (Latreille, 1804), Atta spp.

Discussão. Esta espécie apresenta ampla distribuição, com padrões de politipia que foram estudados por CAMARGO (1980). Apenas um fato novo merece ser mencionado. Posteriormente àquela revisão, esse mesmo autor coletou ninhos de P. testacea nos Andes Orientais (750 m altitude), onde encontrou populações mistas de indivíduos amarelos, mesclados e até completamente enegrecidos. Ao que tudo indica, indivíduos enegrecidos de $P$. testacea só aparecem na encostas andinas e, possivelmente, o maior grau de melanismo deve estar associado à variação altitudinal. São incluídos aqui, os exemplares determinados por Schwarz como "Trigona (Partamona) testacea var. atahualpa", espécie não publicada, de Colonia Perené, Chanchamayo, Peru, da qual foram examinados alguns parátipos, todos correspondendo à forma melânica de $P$. testacea. A presente espécie pode ser reconhecida pela cor do integumento, geralmente amarelado, com áreas enegrecidas na sutura epistomal, áreas ao redor dos ocelos, porção ventral dos mesepisternos e 1/2-1/3 das tíbias e basitarsos III, pelos dentes da mandíbula fortemente recuados (Figs. 60, 61), e bifurcação de $\mathrm{R}+\mathrm{M}$ anterior à cu-v; os machos apresentam a tíbia III fortemente alargada, como na figura 82, e o EVII possui 
a projeção mediana bastante alongada e estreita com chanfros laterais profundos e estreitos (Figs. 113, 114). É uma espécie bastante característica dentre as Partamona, por ser a única que nidifica exclusivamente em cavidades subterrâneas, em ninhos abandonados de Atta, termiteiros vivos ou abandonados, e possivelmente elabora toda a cavidade (CAMARGo, 1980). Ocorre em toda a bacia amazônica, sendo entretanto, mais abundante na parte sul (Camargo, obs. pessoal); ao norte está mais restrita à região leste, no Suriname e Guiana Francesa. Nas encostas dos Andes, apresenta formas melânicas, castanhas até enegrecidas.

\section{Grupo nigrior}

\section{Partamona nigrior (Cockerell, 1925)}

(Figs. 51, 52, 154, operária; 85, 86, 87, 115, 116, macho; 169, distribuição; Tabs. II-IX)

Trigona cupira nigrior Cockerell, 1925:627.

Trigona (Patera) testacea nigrior; Schwarz, 1938:477, 478.

Trigona (Partamona) testacea nigrior; Schwarz, 1940:9; 1948:103.

?Trigona (Partamona) nigrior; Cunha, 1973:3, Figs. 3, 4, 5, 6, 7; 1991:36 (prov. erro de identificação).

?Trigona (Partamona) cupira; Vit, 1992:7.

?Partamona aff. nigrior; Bravo, 1992:864 (prov. erro de identificação).

Diagnose. Abelhas pequenas (1.m.c. 2,3-2,5 mm, c.a.a. 5,1$5,6 \mathrm{~mm}$; Tabs. III, IV). Integumento preto. Labro enegrecido ou descolorido. Mandíbula enegrecida ou castanho-escura quase por inteiro, ou ao menos na $1 / 2$ apical, no restante amarelada ou descolorida, côndilos e ápice enegrecidos. Flagelo alaranjado ou castanho amarelado. Máculas da face e tórax apagadas ou pouco conspícuas; estrias paroculares alargadas embaixo (ca. $1,5 \mathrm{x}$ o diâmetro do $2^{\circ}$ flagelômero) e afilando suavemente, até desaparecer na altura da interorbital máxima (Fig. 154). Pilosidade preta. Membrana das asas hialina; microtríquias pretas; veias méleas mas escurecidas pelas microtríquias fuscas. Cerdas do escapo curtas, apenas uma ou duas na base um pouco mais longas que as demais (1,0-1,1x o diâmetro do escapo, Tab. VII). Cerdas eretas das áreas paroculares, ao lado dos alvéolos mais curtas que o diâmetro do escapo. Cerdas do escutelo 0,9-1,0x o comprimento deste. Dentes da mandíbula pequenos e muito recuados em relação ao ápice do bordo apical (Figs. 51, 52). Área basal do propódeo com uma faixa glabra mediana, aproximadamente tão larga quanto o diâmetro do $2^{\circ}$ flagelômero. Área malar, distância interocelar, distância ocelorbital, tíbia III e comprimento da asa anterior, normais (Tabs. V. VI, VIII, IX). Bifurcação da $\mathrm{M}+\mathrm{Cu}$ geralmente coincidente com a cu-v (raramente anterior). Macho, basitarso III curto e largo, achatado ou convexo-côncavo; tíbia III alargada em direção ao ápice (Figs. 85, 86, 87); EVII com a projeção mediana longa, de lados aproximadamente subparalelos, os chanfros laterais profundos e largos (Figs. 115, 116).

Variação. Exemplares da ilha de Trinidad são, em geral, menores que aqueles do continente e parte dos exemplares examinados apresentava o labro descolorido.
Macho. Figuras 85, 86, 87, 115, 116.

Material-tipo. De "Trinidad, B.W.I, April 16, 1925", 3 operárias (Hester M. Rohwer)", provavelmente depositados no AMNH. Os tipos não foram examinados.

Material examinado. TRINIDAD: Arima, Springhill Estate, 5.I.1983, W.L. Murphy (5 ops., USNM); ibidem, 18.VIII.1924, Jay F.W. Pearson, ( 2 ops., 787, 798, AMNH); ibidem, St. George Co., Asa Wright Nature Centre, 6.VII.1994, C. Chaboo, ex: beating vegetation (1 op., SEMC); ibidem, idem, 7.VII.1994 (1 op., SEMC); Aripo Savanna, 26.X.1918, Harold Morrison, A-841 (1 op., USNM); ibidem, 10.VII.1964, F.D. Bennett (1 op., RPSP); ibidem, idem, 7.VII.1964, cucumber flowers (4 ops., RPSP); ibidem, Rapsey's Est. Aripo, height 17-71, Sommeyer (1 op., RPSP); ibidem, Aripa (sic) Valley, 1500', 30.XII.1971, C.D. Michener (10 ops., SEMC); Balandra, II.1953, F.D. Bennett (4 ops., 483, 484, 486, 487, USNM); ibidem, idem, I.1966 (6 ops., RPSP), VIII.1966 (2 ops., RPSP); Curepe, 5.I.1972, C.D. Michener (1 op., SEMC); ibidem, V.1966, F.D. Bennett, at light trap (3 ops., RPSP); ibidem, idem, 14.V.1966, at fls. of Adenocalymna allialela (4 ops., RPSP); ibidem, 21.II.1979, anônimo, ex: malaise trap (1 macho, SEMC); ibidem, III.1979, M. Sommeijer (4 ops., SEMC); Mamon, 5.VIII.1945, R.G. Donald, A187 (1 macho, AMNH); Maracas Fall, 19.VIII.1924, Jay F. W. Pearson (1 op., 773, AMNH); ibidem, St. Joseph rd. to Maracas Falls, 15.VII.1994, C. Chaboo, ex: beating vegetation (4 ops., SEMC); Moruga Village, 7 miles NW, 13.VI.1925, P. Andrews (3 ops., USNM); Port of Spain, 31.X.1931, M. Kisliuk Jr., C.E. Cooley (1 op., "K. \& C. Trinidad No. 319", USNM); ibidem, Dept. Agr. grounds, 23.XI.1918, Harold Morrison, A-1065 (33 ops., USNM; 3 ops., RPSP); Salibea, 31.XII.1971, C.D. Michener (114 ops., SEMC; 5 ops., RPSP); San Fernando, 16.VIII.1924, Jay F.W. Pearson (2 ops., 726, 724, AMNH); ibidem, idem, 16.VIII.1924 (1 op., RPSP); Sangre Grande, 18.VIII.1924, Jay F.W. Pearson (1 op., 760, AMNH); St. Augustine, 12.IX.1945, R.G. Donald A222 (1 rainha, 1 op., AMNH); Verdant Vale, 28-30.X.1918, Urich \& Morrison, A845 (3 ops., USNM); sem localidade especificada: Trinidad Is., 19.VIII.1933, A.S. Pinkus (1 op., RPSP; 2 ops., AMNH); ibidem, I-II.1931. Capt. A.K. Totton, B.M. 1931-183 (2 ops., AMNH, 1 op., RPSP); ibidem, V.1924, L.E. Cheesman, St. George Exp. B.M., 1925-573 (2 ops., AMNH); ibidem, 24.VIII.1934, H.F. Schwarz (2 ops., AMNH); ibidem, F.W. Urich (1 macho, Ac. 33267, AMNH). VENEZUELA. Aragua: Rancho Grande, $1100 \mathrm{~m}, 25-26 . I .1978$, J.B. Heppner blacklight, cloud forest (1 macho, USNM). Sucre: San Rafael, Cumanacoa, 21.XI.1929, G. Netting (1 op., Ac. 8696, CMNH). Bolivar: Santa Elena, 28.VIII.1976, D. Roubik (2 ops., STRI, 6 ops., RPSP; 38 ops., SEMC); Santa Elena de Uairén, 910 m, 21.II.1988, P. Vit Olivier, 01 (9 ops., 880972-880980, RPSP); Tumaremo, 23.VIII.1976, D. Roubik (36 ops., 6 machos, SEMC; 5 ops., 1 macho, RPSP). GUIANA. Camaria, Bartica District, 30.VI.1924, anônimo (1 op., AMNH); Kalacoon, 7.VIII.1920, Wheeler, 419 (3 ops., 2 machos, Ac. 35657, AMNH); Kartabo, Bartica Dist., 10.VII.1922, gift of New York Zoo. Soc. Dept. Tropical Research William Beebe, Dir. (1 op., AMNH); Penal Settlement, Bartic District, 22.IV.1924, anônimo (2 ops., AMNH); Wismar, 19.V.1934, A.S. Pinkus (1 op., Ac. 33362, AMNH). BRASIL. Roraima: Maloca Aldeia da Tábua Lascada, 16.IV.1994, Silva (50 ops., 960102960151, RPSP); Rio Uraricoera, Ilha de Maracá, 1-4.III.1988, Eq. J.A. Rafael, arm. suspensa (1 macho, INPA); ibidem, 24.III.1987, F.J.A. Peralta, 30 (6 ops., INPA); ibidem, idem, 24.III.1987, 26 (10 ops., 2 machos, INPA; 2 ops., 1 macho, RPSP), Furo Maracá, 24.IV.1987 (2 ops., INPA); ibidem, 02-13.V.1987, Eq. J.A. Rafael, armadilha de malaise (1 op., INPA); ibidem, idem, 21-30.XI.1987, "inseticida, fogging" (1 op., INPA).

Distribuição geográfica e hábitat. Matas tropicais e subtropicais em Trinidad, norte da Venezuela e Guiana até Roraima, Brasil (Fig. 169).

Nidificação. Schwarz (1938: 478) menciona uma nota, junto com um material coletado em Kalacoon (Guiana), onde consta 
"Clay nest on lab. wall with pieces in the nest like red sealing wax".

Discussão. Caracteriza-se por apresentar labro e mandíbulas enegrecidos, asas com microtríquias predominantemente enegrecidas, e distribuição restrita à ilha de Trinidad, Venezuela, Guiana, até Roraima, Brasil (Fig. 169). Compartilha a cor do labro e mandíbula com mais 3 espécies, P. auripennis sp. nov., $P$. combinata sp. nov. e $P$. nigrilabris sp. nov., que provavelmente constituem um grupo monofilético. O padrão de máculas da face, principalmente das estrias paroculares (alargadas embaixo, um pouco difusas e terminando na altura da interorbital máxima) sugerem maior afinidade com $P$. auripennis sp. nov. (contígua geograficamente, Fig. 169) e $P$. nigrilabris sp. nov. (só conhecida de Salvador, BA). De $P$. auripennis sp. nov., distingue-se pelas microtríquias das asas predominantemente enegrecidas (amarelas em P. auripennis sp. nov.), e pelo tamanho geralmente menor. É possível que $P$. nigrior sp. nov. e P. auripennis sp. nov. possam constituir populações de uma mesma espécie; entretanto, seria necessário examinar material adicional da Guiana (região de contato), inclusive material de ninhos e dados sobre os hábitos de nidificação de ambas as formas. Os exemplares da ilha de Trinidad são, em geral, menores que aqueles do continente e uma proporção grande dos indivíduos da ilha apresenta o labro descolorido. É possível que exemplares da ilha façam parte de uma população reprodutivamente isolada daquelas do continente, entretanto, não foram encontradas descontinuidades relevantes nos caracteres estudados, inclusive genitália e esternos pré-genitais dos machos. Detalhes sobre os hábitos de nidificação das populações insular e continental poderiam auxiliar a esclarecer a questão.

\section{Partamona auripennis sp. nov.}

(Figs. 55, 56, 155, operária; 88, 117, macho; 169, distribuição; Tabs. II-IX, XI)

Partamona cf. nigrior; Camargo, 1988b:357; Oliveira et al., 1995:16,18. Partamona nigrior; Roubik, 1996:178 (at Mimosa pudica).

?Partamona cupira; Engel \& Dingemans-Bakels, 1980:350 (não há dados seguros para o reconhecimento da espécie).

Partamona aff. cupira; Camargo, 1988b:357.

Diagnose. Abelhas de porte médio (1.m.c. 2,3-2,5 mm, c.a.a. 5,3-5,8 mm; Tabs. III, IV). Labro enegrecido. Mandíbula enegrecida ou castanho-escura quase por inteiro. Flagelo castanho-escuro. Estrias paroculares alargadas embaixo (ca. $1,5 \mathrm{x}$ o diâmetro do $2^{\circ}$ flagelômero) e afilando suavemente, até desaparecer na altura da interorbital máxima (Fig. 155). Máculas do tórax apagadas ou pouco conspícuas. Pilosidade preta. Membrana das asas hialina; microtríquias amarelas em toda asa (raramente enegrecidas na base e no ápice); veias uniformemente méleo-claras (inclusive $\mathrm{C}$ e $\mathrm{R}$, ou estas apenas um pouco mais ferrugíneas). Cerdas da base do escapo um pouco mais longas que o diâmetro deste (entre 0,9-1,2x; Tab. VII). Cerdas eretas das áreas paroculares, ao lado dos alvéolos, tão longas quanto o diâmetro do escapo. Cerdas do escutelo 0,9-1,0x o comprimento deste. Área basal do propódeo com uma faixa mediana glabra, da largura do diâmetro do $2^{\circ}$ flagelômero. Dentes da mandíbula pequenos e muito recuados em relação ao ápice do bordo apical (Figs. 55, 56). Área malar, distância interocelar, distância ocelorbital, tíbia III e comprimento da asa anterior, normais (Tabs. V, VI, VIII, IX). Bifurcação da $\mathrm{M}+\mathrm{Cu}$ geralmente coincidente com a cu-V (raramente levemente anterior). Macho, basitarso III curto e largo, achatado ou convexo-côncavo; tíbia III estreita (Fig. 88); EVII com projeção mediana longa, de lados aproximadamente subparalelos, os chanfros laterais profundos e largos (Fig. 117).

\section{Operária.}

Dimensões. Comprimento total aproximado, $5,64 \mathrm{~mm}$; da asa anterior, 5,64 $\mathrm{mm}$ (incluindo a tégula, 6,39 $\mathrm{mm}$ ); largura máxima da cabeça, $2,50 \mathrm{~mm}$; do TIII, 2,52 mm (Tab. XI).

Cor do integumento. Predominantemente preto, o metanoto e as tíbias III mais claros, os tarsômeros de todos os pares de pernas, ferrugíneos; tégula castanho-escura, translúcida medianamente. Labro enegrecido; mandíbula predominantemente ferrugíneo-enegrecida. Escapo por inteiro enegrecido, apenas o terço basal um pouco mais claro. Flagelo castanho-escuro, apenas o $1^{\circ} \mathrm{e}$ os dois últimos flagelômeros amarelados. Máculas da cabeça e tórax pouco conspícuas. As manchas no clípeo apagadas, um pouco mais nítidas apenas nos cantos inferiores. Mancha supraclipeal aproximadamente trapezoidal, pouco conspícua. Sem manchas na fronte e abaixo do ocelo médio. Estrias paroculares pouco conspícuas, mais nítidas apenas na altura da área malar, alargadas embaixo (ca. $1,2 \mathrm{x}$ mais largas que o diâmetro do $2^{\circ}$ flagelômero), estreitandose gradualmente para cima, chegando, já bem apagadas, até a altura da linha da menor distância interorbital superior. Nas genas uma pequena mancha margeando a extremidade inferior do olho. Estrias laterais do mesoscuto muito apagadas, um pouco menos na altura das tégulas; nas axilas e no bordo posterior do escutelo um pouco mais nítidas. Membrana da asa anterior hialina (dando a impressão de amarelada, devido a presença de resina); microtríquias predominantemente amarelas, fuscas no ápice e ferrugíneas na base; veias méleas, C e R um pouco mais ferrugíneas basalmente.

Pilosidade. Enegrecida, mais clara apenas a porção apical das cerdas ventrais do tórax e abdômen, onde são mais delgadas. Área basal do propódeo com uma faixa glabra mediana. Franja pré-marginal do TIII com cerdas muito mais curtas na região mediana que as laterais. Cerdas da base do escapo $1,4 \mathrm{x}$ mais longas que o diâmetro deste. Nas áreas paroculares inferiores, ao lado dos alvéolos, as cerdas eretas 1,6x mais longas que o diâmetro do escapo; no clípeo 1,5x e as da fronte 1,4x; no vértice, mais longas, ca. 1,9x; no disco do mesoscuto e na porção anterior da linha média 1,07 e 2,4x, respectivamente. As cerdas mais longas no ápice do escutelo com ca. de 1,07 x o comprimento deste.

Integumento. Liso e polido, apenas com a pontuação pilígera 
típica do gênero.

Forma e proporções (Tab. XI). Cabeça, 1,20x mais larga que longa, e 1,12x mais larga que a distância clipeocelar. Olhos $2,44 \mathrm{x}$ mais longos que largos, um pouco convergentes embaixo. Área malar ca. de 1,06x o diâmetro do $2^{\circ}$ flagelômero. Clípeo $1,94 \mathrm{x}$ mais longo que sua largura máxima e $0,34 \mathrm{x}$ a distância clipeocelar. Comprimento das mandíbulas $0,57 \mathrm{x}$ a distância clipeocelar (mandíbulas fechadas no holótipo; nos parátipos, os dentes pequenos, curtos, recuados; Fig. 56). Escapo 0,90x a distância alvéolo-ocelo lateral, seu diâmetro um pouco menor que o do $2^{\circ}$ flagelômero. Distância interocelar 1,4x maior que a ocelorbital e ca. $1,75 \mathrm{x}$ o diâmetro do ocelo médio. Escutelo aproximadamente semicircular, ca. $0,47 \mathrm{x}$ mais curto que largo. Tíbia III $0,93 \mathrm{x}$ mais curta que a cabeça e $2,11 \mathrm{x}$ mais longa que larga; canto pósterodistal arredondado, pouco projetado, a margem apical fracamente sinuada; contorno da margem posterior suavemente sinuado. Basitarso III 1,62x mais longo que largo; canto pósterodistal anguloso e margem apical em ângulo um pouco maior que $90^{\circ} \mathrm{em}$ relação à margem anterior. Asa anterior 2,69x mais longa que larga e 2,26x a largura máxima da cabeça. Bifurcação de $\mathrm{M}+\mathrm{Cu}$ levemente anterior à cu-v. Hâmulos, 5.

\section{Macho. Figuras 88, 117.}

Tipos. Holótipo, operária, de "Tauri, PA, Rio Tapajós Brasil SA-21 557'W; 305'S, 29-I, 1-II-79, Camargo", ninho "168c (: T 54)", mais parátipos, 41 operárias e 2 machos montados em alfinetes, além de 4 machos e muitas operárias em álcool, da mesma série e ninho, depositados na RPSP.

Material examinado. COLÔMBIA. Meta: Puerto López, $4 \mathrm{~km} \mathrm{E,}$ 26.VI.1985, D. Roubik, "nest in termite nest" (3 ops., STRI). VENEZUELA. Amazonas: Cerro de la Neblina, Base Camp, $0^{\circ} 50^{\prime} \mathrm{N}$, 66 9'44', 140m, 13-20.II.1984, D. Davis, T. Mac Cabe (2 ops., USNM); ibidem, idem, 21-29.II.1984 (1 op., USNM). GUIANA. Kartabo, 17.VII.1924, Jay F.W. Pearson, (2 ops., 24153, 24147, AMNH); ibidem, idem, 22.VII.1924, 227 (1 op., AMNH); Kuyuwini R., 22.XI.1932, W.G. Hassler (1 op., Ac. 36159, AMNH); Matope, 23.VI.1924, Jay F.W. Pearson (2 ops., AMNH); ibidem, idem, 23.VII.1924, 296 (1 op., SEMC); Waranama, 15.XI.1936, J. Ogilvie (Ac. 34970, 1 op., USNM, 2 ops., AMNH). SURINAME: Surinam (localidade?), 1900, anônimo (1 macho, AMNH); Paloemeu, 2.III.1993, B. De Dijn, I 960 (3 ops., NZCS); Princie dorp, 6.VII.1991, B. De Dijn, I 1121 (4 ops., NZCS; 3 ops., RPSP); Paramaribo, VI.1920, G. Reyne, 10, “... hairs ....” (ilegível) (1 op., USNM). GUIANA FRANCESA. Cayenne, II.1917, anônimo (1 op., Ac. $5873, \mathrm{CMNH}$ ); ibidem, $33.5 \mathrm{~km} \mathrm{~S}$ and $8.4 \mathrm{~km} \mathrm{NW}$ of Hwy N2 on Hwy D5, 448'18”N, 52²8'41”W, 30m, 25.V.1997, J. Ashe, R. Brooks FG1AB97 036, ex: misc. collecting (1 op., SM0086671 KUNHM-ENT, SEMC); Kourou, $11.5 \mathrm{~km} \mathrm{SW,} \mathrm{11.VII.1977,} \mathrm{C.D.} \mathrm{Michener} \mathrm{(1} \mathrm{op.,}$ SEMC); ibidem, idem, $10 \mathrm{~km} \mathrm{NW,} \mathrm{22.VII.1977} \mathrm{(1} \mathrm{op.,} \mathrm{SEMC),} 11 \mathrm{~km}$ SW, 18.VII.1977 (1 op., RPSP), $11 \mathrm{~km} \mathrm{W,} \mathrm{23.VII.1977} \mathrm{(1} \mathrm{op.,} \mathrm{RPSP);}$ ibidem, km 4.5 SW, 13.X.1976, D. Roubik, 26 (2 ops., SEMC); ibidem, idem, 20.XII.1976, 74 (2 ops., SEMC), km 15 E., 18.VII.1976, 1 (1 op., STRI, 2 ops., RPSP), $15 \mathrm{~km} \mathrm{E,} \mathrm{new} \mathrm{road} \mathrm{to} \mathrm{Cayenne,} \mathrm{4.V.1982,} \mathrm{D.}$ Roubik, 69 (2 ops., RPSP); ibidem, idem, 15 km SW, degrad. Saramaca, 1.V.1982, 75 (1 op., RPSP); St. Laurent, 4.VIII.1975, G.W. Otis (1 op., STRI). BRASIL. Amapá: Oiapoque, V.1959, M. Alvarenga (1 op., DZUP); Serra do Navio, 7.II.1962, F.M. Oliveira (2 ops., DZUP). Amazonas: BR174, ZF3, km 23, 25.IV.1986, M.V.B. Garcia (1 op., UFVB); ibidem, idem, ZF6, km 9, 14.VII.1986 (2 ops., UFVB); ibidem, km 41, Agric. Ecol., 18.V.1980, A. Webber, flor R. Mucosa (4 ops., RPSP); Manaus, IV.1960, F.M. Oliveira (1 op., DZUP); ibidem, VII.1958, C. Elias (1 op., DZUP); ibidem, 1981, Falcão (1 op., RPSP); ibidem, Centro, 27.V.1990,
L.A.O. Campos (4 ops., UFVB; 1 op., RPSP); ibidem, 20.VI.1988, E.F. Morato, acetato, 1 (1 op., UFVB); ibidem, idem, 4.III.1988, INPA/ WWF PDBFF78 (1 op., UFVB); ibidem, Hotel Trop., 11.V.1981, D. Roubik, 5 (1 op., STRI); ibidem, IX.1962, K. Lenko (1 op., MZSP); ibidem, Boulevard, 1239, 31.III.1986, M.V.B. Garcia (4 ops., RPSP); ibidem, idem, 14.IV.1986, ninho 3 (6 ops., RPSP); ibidem, 27.V.1980, L.A.O. Campos, ninho em parede (5 ops., UFVB; 1 op., RPSP); ibidem, 4.III.1988, E.F. Morato, 78 (1 op., UFVB); ibidem, Reserva Ducke, V.1968, Faustino (1 op., 2847, INPA); ibidem, Res. Ducke, 2056'S, 59 58'W, 23.VIII.1994, S. Pedro (6 ops., 941279, 941280,941291, 941294, 941300, 941301, RPSP); ibidem, Fazenda Esteio, $60 \mathrm{~km} \mathrm{~N} \mathrm{de}$ Manaus, ZF-3, km 23, 8.VII.1990, M.L. Oliveira (1 op., 2362, UFVB); ibidem, km 30, Manaus-Itacoatiara - CEPLAC, 7.V/1976, Joselita Maria Santon ( 1 op., INPA); Lago Uará, rio Solimões, $65^{\circ} 35^{\prime} \mathrm{W}, 2^{\circ} 41^{\prime} \mathrm{S}, 09$ 13.VIII.1993, Camargo, Pedro, Mazucato (2 ops., 934412, 934420 , RPSP); Tefé, SA-20, 65-3g.iii, 27-30.I.1977, Camargo, M. Mazucato (9 ops., RPSP); ibidem, XII.1961, F.M. Oliveira (2 ops., RPSP); ibidem, idem, 1-4.XII.1961 (1 op., DZUP); ibidem, I.1962, E. Carvalho (8 ops., DZUP; 2 ops., RPSP); ibidem, idem, III.1962 (1 op., DZUP); Uaupês, VII.1956, M. Alvarenga (1 op., DZUP). Pará: Jacareacanga, X.1959, M. Alvarenga (8 ops., DZUP; 1 op., RPSP); Lago Água Fria, rio Trombetas, SA-21, X-C, 56 $51^{\circ}$ 'W, $1^{\circ} 25^{\prime}$ 'S, 13-15.II.1979, Camargo (1 op., RPSP); Mangabeira, Mocajuba, VI.1953, Orlando Rego (4 ops., DZUP); Tauari, rio Tapajós, SA-21, 557'W, 35'S, 29.I-1.II.1979, Camargo (20 ops., RPSP); ibidem, Tauari-Santarém, 31.I.1979, Othonyel R.L. Filho (7 ops., T-54, INPA; 1 op., RPSP).

Distribuição geográfica e hábitat: Florestas tropicais, do norte da Amazônia até as Guianas (Fig. 169).

Nidificação. Em termiteiro arborícola externo (Camargo, obs. pessoal). Dados de etiquetas: "Colombia, Meta Depto. Puerto López, 4 km E, 26 June 85 - nest in termite nest, D. Roubik", e de Manaus, L.A.O. Campos "ninho em parede".

Etimologia. Do latim, aureus $=$ dourado + penna $=$ asa, referindo-se a cor dourada das asas.

Discussão. Pelos dentes da mandíbula pequenos e muito recuados, e pelo EVII do macho com projeção mediana de lados subparalelos, faz parte do grupo nigrior ( $P$. nigrior, $P$. combinata $\mathbf{s p . ~ n o v . , ~} P$. nigrilabris sp. nov., $P$. chapadicola $\mathbf{s p .}$ nov., P. seridoensis $\mathbf{s p . ~ n o v . , ~}$. littoralis $\mathbf{s p .}$ nov.). Com as três primeiras espécies do grupo compartilha o labro enegrecido. Pode ser reconhecida dentre as espécies de Partamona pelos caracteres do grupo já mencionados, pelas asas amarelas (membrana hialina, veias e microtríquias amarelas), e labro e mandíbulas enegrecidos. Difere de P. nigrior, com a qual se sobrepõe na Guiana (Fig. 169), pelas microtríquias da asa, amarelas e pelo tamanho, em geral, maior, além da distribuição mais à leste da bacia amazônica. Outros comentários em $P$. nigrior.

\section{Partamona nigrilabris sp. nov.}

(Figs. 157, operária; 169, distribuição; Tabs. II-IX, XII)

?Partamona cupira; Martins, 1994:231.

Diagnose. Abelhas de porte pequeno (1.m.c. 2,2-2,4 mm, c.a.a. 4,9-5,4 mm; Tabs. III, IV). Integumento preto. Labro amarelado, descolorido ou enegrecido. Mandíbula predominantemente castanho-escura, ou predominantemente 
amarelada em alguns indivíduos. Flagelo castanho escuro ou castanho amarelado. Máculas da cabeça e tórax apagadas ou pouco conspícuas; estrias paroculares alargadas embaixo (ca. $1,5 \mathrm{x}$ o diâmetro do $2^{\circ}$ flagelômero) e afilando suavemente, até desaparecer na altura da interorbital máxima. Pilosidade preta. Membrana das asas hialina; microtríquias fuscas em toda a asa ou amarelas apenas na região do pterostigma; veias alares méleas, escurecidas pelas microtríquias escuras. Cerdas do escapo curtas, apenas uma ou duas na base um pouco mais longas que as demais (1,0-1,1x o diâmetro do escapo; Tab. VII). Cerdas eretas das áreas paroculares, ao lado dos alvéolos, tão longas quanto o diâmetro do escapo. Cerdas do escutelo curtas, ca. 0,8x o comprimento deste. Área basal do propódeo com uma faixa mediana glabra, aproximadamente tão larga quanto o diâmetro do $2^{\circ}$ flagelômero. Dentes da mandíbula pequenos e recuados em relação ao ápice do bordo apical (como na figura 56 de P. auripennis). Área malar, distância interocelar, distância ocelorbital, tíbia III e comprimento da asa anterior, normais (Tabs. V, VI, VIII, IX). Bifurcação da $\mathrm{M}+\mathrm{Cu}$ coincidente com a cu-v.

\section{Operária.}

Dimensões. Comprimento total aproximado, 6,23 mm; da asa anterior, 5,15 $\mathrm{mm}$ (incluindo a tégula, 5,69 $\mathrm{mm}$ ); largura máxima da cabeça, 2,38 mm; do TIII, 2,10 mm (Tab. XII).

Cor do integumento. Predominantemente preto, um pouco acastanhado ventralmente, metanoto e tíbias III mais claros; os tarsômeros ferrugíneos. Tégula ferrugínea, na porção discal translúcida. Labro enegrecido, com algumas manchas amareladas nos lados; mandíbula amarelada na metade basal e ferrugínea em direção ao ápice, côndilos enegrecidos. Escapo com a face inferior amarelada e a superior enegrecida. Flagelo com a face inferior castanho-ferrugínea e a superior mais escurecida. Máculas da face mais nítidas apenas nas paroculares, as demais um pouco apagadas. Manchas do clípeo aproximadamente triangulares, um pouco apagadas medianamente, a distância entre elas, na porção mais apical do clípeo, menor que o diâmetro do $2^{\circ}$ flagelômero. Mancha supraclipeal difusa, irregular. Sem manchas na fronte. Estrias paroculares curtas, bem alargadas embaixo (ca. 1,13x o diâmetro do $2^{\circ}$ flagelômero), estreitando-se gradualmente e terminando na altura do meio da fronte, na linha da distância interorbital máxima. Genas com uma pequena mancha margeando o terço inferior do olho. Tórax com as estrias laterais do mesoscuto nítidas; as axilas praticamente por inteiro amareladas; o bordo posterior do escutelo com uma estria muito difusa, apagada medianamente. Membrana da asa anterior muito levemente ferrugínea; microtríquias acastanhadas para a base e amareladas em direção ao ápice da asa; veias méleo-castanhas, C e R mais escurecidas, pterostigma méleo.

Pilosidade. Predominantemente enegrecida, apenas o ápice das cerdas na parte ventral do tórax mais claras. Área basal do propódeo com uma faixa glabra mediana. A franja pré-marginal do TIII com cerdas muito mais curtas na região mediana que nas laterais. Cerdas da base do escapo curtas, $0,8 \mathrm{x}$ o diâmetro deste. Áreas paroculares inferiores, ao lado dos alvéolos, com as cerdas eretas 1,2x o diâmetro do escapo. As cerdas do clípeo tão longas quanto o diâmetro do escapo; na fronte, 1,33x; no vértice mais longas, ca. $2,07 \mathrm{x}$; no disco do mesoscuto e na porção anterior da linha média 1,33 e 1,80x, respectivamente. As cerdas mais longas no ápice do escutelo com ca. de 0,8 x o comprimento deste.

Integumento. Liso e polido, apenas com a pontuação pilígera típica do gênero.

Forma e proporções (Tab. XII). Cabeça, 1,19x mais larga que longa, e 1,32x mais larga que a distância clipeocelar. Olhos $2,33 x$ mais longos que largos, levemente convergentes embaixo. Área malar ca. de 1,06x o diâmetro do $2^{\circ}$ flagelômero. Clípeo $0,55 \mathrm{x}$ mais curto que sua largura máxima e $0,36 \mathrm{x}$ a distância clipeocelar. Mandíbulas 0,55x a distância clipeocelar; os dentes pequenos e recuados em relação ao bordo (Fig. 56). Escapo $0,92 \mathrm{x}$ a distância alvéolo-ocelo lateral, seu diâmetro um pouco menor que o do $2^{\circ}$ flagelômero. Distância interocelar $1,43 \mathrm{x}$ maior que a ocelorbital e ca. de 1,90x o diâmetro do ocelo médio. Escutelo aproximadamente semicircular, cerca de $0,49 x$ mais curto que largo. Tíbia III 0,89x mais curta que a cabeça, e 2,12x mais longa que larga; o canto póstero-distal subanguloso, pouco projetado, a margem apical fracamente sinuada; o contorno da margem posterior, suavemente sinuado. Basitarso III 1,52x mais longo que largo; o canto póstero-distal subanguloso e a margem apical em ângulo um pouco maior que $90^{\circ} \mathrm{em}$ relação à margem anterior. Asa anterior 2,58x mais longa que larga e 2,16x a largura máxima da cabeça. Bifurcação de $\mathrm{M}+\mathrm{Cu}$ levemente posterior à cu-v. Hâmulos, 4-5.

Macho. Desconhecido.

Material-tipo. Holótipo, operária, de "Salvador - BA, Brail (sic = Brasil) 19-III $61 \mathrm{H}$ e A. Cordeiro", parátipos, 20 operárias da mesma série, depositadas no DZUP (16) e RPSP (4).

Material examinado. Apenas o material-tipo.

Distribuição geográfica e hábitat. Só conhecida de Salvador, BA, Brasil (Fig. 169).

Nidificação. Desconhecida.

Etimologia. Do latim, niger = preto, negro + labrum = lábio, indicando a cor enegrecida do labro.

Discussão. Praticamente idêntica a $P$. nigrior, apenas a descontinuidade geográfica (Fig. 169), indica que, possivelmente, constituam unidades históricas independentes. Pode ser reconhecida entre as espécies que ocorrem na região nordeste, principalmente pela forma das estrias paroculares e pelo labro enegrecido. Outros comentários na discussão sobre P. nigrior. 
Partamona combinata sp. nov.

(Figs. 156, operária; 89, 118, 119, macho; 169, distribuição; Tabs. II-IX, XII)

Partamona cf. cupira; Posey \& Camargo, 1985:252 (Fig. 2E); Camargo \& Posey, 1990:23 (Fig.2E); Kerr et al., 1996:33.

Diagnose. Abelhas de porte médio (1.m.c. 2,3-2,6 mm, c.a.a. 5,4-6,0 mm; Tabs. III, IV). Integumento preto. Mandíbula predominantemente enegrecida ou castanho-escura com o 1/ 3-1/2 basal amarelado, ápice ferrugíneo-escuro, côndilos pretos. Flagelo castanho escuro. Estrias paroculares um pouco mais estreitas que o diâmetro do $2^{\circ}$ flagelômero, levemente alargadas embaixo (ca. $1,3 \mathrm{x}$ o diâmetro do $2^{\circ}$ flagelômero) ou aproximadamente com a mesma largura em toda a sua extensão, chegando até a interorbital superior (Fig. 156). Pilosidade preta. Membrana das asas hialina; microtríquias pretas em toda a asa ou amarelas apenas na região do pterostigma; veias méleas, mas escurecidas quando revestidas por microtríquias fuscas. Cerdas da base do escapo mais curtas até um pouco mais longas que o diâmetro deste $(0,8-1,3 \mathrm{x}$; Tab. VII). Cerdas eretas das áreas paroculares, ao lado dos alvéolos, aproximadamente tão longas quanto o diâmetro do escapo. Cerdas do escutelo 0,9-1,0x o comprimento deste. Área basal do propódeo com uma faixa mediana glabra, aproximadamente tão larga quanto o diâmetro do $2^{\circ}$ flagelômero Dentes da mandíbula pequenos e muito recuados em relação ao ápice do bordo apical (como na figura 56, de P. auripennis). Área malar, distância interocelar, distância ocelorbital, tíbia III e comprimento da asa anterior, normais (Tabs. V, VI, VIII, IX). Bifurcação da M+Cu geralmente coincidente com a cu-v (raramente levemente anterior). Macho, basitarso III curto e largo, achatado ou convexo-côncavo; tíbia III estreita (Fig. 89); EVII com projeção mediana longa, de lados aproximadamente subparalelos, os chanfros laterais profundos e largos (Figs. 118, 119).

Variação. Ao longo de toda a distribuição ocorrem indivíduos com labro escurecido e amarelado; em exemplares do mesmo ninho ocorrem ambas as formas.

\section{Operária.}

Dimensões. Comprimento total aproximado, $5,98 \mathrm{~mm}$; da asa anterior, $5,81 \mathrm{~mm}$ (incluindo a tégula, $6,72 \mathrm{~mm}$ ); largura máxima da cabeça, 2,54 mm; do TIII, 2,52 mm (Tab. XII).

Cor do integumento. Predominantemente enegrecido, apenas o metanoto, propódeo e tíbias III mais claros; os tarsômeros das pernas I e II ferrugíneos. Tégula ferrugínea, translúcida. Labro enegrecido na porção mediana, com manchas amareladas na base e lados; mandíbula amarelada no terço basal e ferrugíneo-escura em direção ao ápice, côndilos enegrecidos. Escapo com a face inferior amarelada, descolorida, e a superior enegrecida. Flagelo com a face inferior castanha, mais escurecido na face superior. Máculas da face nítidas, principalmente as paroculares; as do tórax um pouco mais apagadas. Manchas no clípeo aproximadamente em forma de L contrapostos, apagadas, a distância entre elas, na porção mais apical do clípeo, menor que o diâmetro do $2^{\circ}$ flagelômero. Mancha supraclipeal aproximadamente trapezoidal. Sem manchas na fronte. Estrias paroculares um pouco alargadas embaixo (ca. 1,13x o diâmetro do $2^{\circ}$ flagelômero), afilando suavemente para o ápice e tornando-se menos conspícuas, chegando, já bem apagadas, até um pouco antes da altura da linha entre menor distância interorbital superior. Genas com uma pequena mancha bem apagada, no quarto inferior da margem orbital. Tórax com as estrias laterais do mesoscuto apagadas; axilas praticamente por inteiro de um amarelo apagado; bordo posterior do escutelo com uma faixa apagada. Membrana da asa anterior hialina ou apenas levemente ferrugínea na metade basal (células radial, $1^{\text {a }}$ e $2^{\text {a }}$ cubitais); microtríquias predominantemente amarelas, ocupando a metade apical da asa, escurecidas na base; veias méleas, escurecidas pelas microtríquias; C e R mais escuras na porção basal; pterostigma méleo-claro.

Pilosidade. Predominantemente enegrecida; nos lados dos mesepisternos, região ventral do tórax, coxas e trocanteres, amarelo-palha; esternos com cerdas enegrecidas, apenas o ápice das cerdas mais claros. Área basal do propódeo com uma faixa glabra mediana. Franja pré-marginal do TIII com cerdas muito mais curtas na região mediana que as laterais. Cerdas da base do escapo 1,2x mais longas que o diâmetro deste. Áreas paroculares inferiores, ao lado dos alvéolos, com as cerdas eretas $1,07 \mathrm{x}$ mais longas que o diâmetro do escapo. Cerdas do clípeo tão longas quanto o diâmetro do escapo; na fronte, $1,13 \mathrm{x}$; no vértice mais longas, ca. $2,13 \mathrm{x}$; no disco do mesoscuto e na porção anterior da linha média 1,27 e 2,33x, respectivamente. As cerdas mais longas no ápice do escutelo com ca. de $0,87 \mathrm{x}$ o comprimento deste.

Integumento. Liso e polido, apenas com a pontuação pilígera típica do gênero.

Forma e proporções (Tab. XII). Cabeça, 1,20x mais larga que longa e 1,34x mais larga que a distância clipeocelar. Olhos 2,50x mais longos que largos, levemente divergentes embaixo. Área malar ca. de $1,13 \mathrm{x}$ o diâmetro do $2^{\circ}$ flagelômero. Clípeo $0,57 \mathrm{x}$ mais curto que sua largura máxima e $0,36 \mathrm{x}$ a distância clipeocelar. Mandíbulas 0,57x a distância clipeocelar; os dentes pequenos e recuados (como na figura 56). Escapo 0,90x a distância alvéolo-ocelo lateral, seu diâmetro um pouco menor que o do $2^{\circ}$ flagelômero. Distância interocelar 1,40x maior que a ocelorbital e ca. de 1,75x o diâmetro do ocelo médio. Escutelo aproximadamente semicircular, cerca de $0,50 \mathrm{x}$ mais curto que largo. Tíbia III $0,95 x$ mais curta que a cabeça, e 2,02x mais longa que larga; canto póstero-distal arredondado, pouco projetado, margem apical fracamente sinuada; contorno da margem posterior, suavemente sinuado. Basitarso III 1,36x mais longo que largo; canto póstero-distal levemente anguloso e margem apical em ângulo um pouco maior que $90^{\circ} \mathrm{em}$ relação à margem anterior. Asa anterior 2,57x mais longa que larga e 2,29x a largura máxima da cabeça. Bifurcação de $\mathrm{M}+\mathrm{Cu}$ coincidente com a cu- 
v. Hâmulos, 5.

\section{Macho. Figuras 89, 118, 119}

Material-tipo. Holótipo, operária de "Barra do Garças MT-Brasil 10-24-I-1971 Col. W.E. Kerr", ninho "4c"; parátipos da mesma série, 10 operárias e 2 machos montados em alfinete, além de algumas operárias em álcool, depositados na RPSP.

Material examinado. PERU. Loreto: Pucallpa, 17.VII.1962, W.T. Van Velzen ( 2 ops., MSUC); ibidem, idem, 31.VII.1962 (3 ops., MSUC), 3.VIII.1962 (3 ops., MSUC), 4.VIII.1962 (7 ops., MSUC; 1 op., RPSP), 5.VIII.1962 (1 op., MSUC). BRASIL. Pará: Belém, VI.1966, R. Zucchi (16 ops., RPSP); ibidem, X.1948, W.E. Kerr (1 op., AMNH); ibidem, Aurá, 22.XI.1955, Michener, Moure (3 ops., SEMC); ibidem, Aurá, 29.IV.1956, E. Lobato (1 op., DZUP); ibidem, Ariboca, 21.XI.1955, Michener, Moure (1 op., SEMC); Cachimbo, VI.1962, Alvarenga, Oliveira (87 ops., 2 machos, DZUP; 20 ops., SEMC; 17 ops., RPSP); ibidem, IX.1954, M. Alvarenga (4 ops., DZUP); ibidem, X.1955, Pe. Pereira (1 op., MZSP); Gorotire (= Gradaus), SB-22, 51-8a, 20.VIII5.IX.1983, Camargo (40 ops., ninho 304c, RPSP); Gradaus, 19.VI.1978, Posey (1 op., 334, RPSP); ibidem, idem, 6.VII.1978 (1 op., 356, RPSP); Inst. Agrico. (Belém?), 19.VIII.1954, N. Cerqueira (1 op., DZUP); Marabá, V.1959, M. Alvarenga (3 ops., DZUP); ibidem, 4-6.V.1959 (M. Alvarenga) (2 ops., SEMC); ibidem, idem, 5. V.1959 (1 op., SEMC); Rio Acará, 21.VIII.1954, N. Cerqueira (2 ops., DZUP); ibidem, idem, 23.VIII.1954 (1 op., DZUP); Rio Trairão (50 km NE Gradaús), SB-22, 51 ${ }^{\circ} 49^{\prime} \mathrm{W}, 7^{\circ} 21^{\prime}$ 'S, 21-24.VII.1979, Mazucato (24 ops., RPSP); São Caetano de Odivelas, SA-22, 48-1 a, 15.XII.1973, Ayres (5 ops., RPSP); Pará (localidade?, prov. Belém), 5.VII.1902, Ducke (1 op., Ac. 35178, AMNH); ibidem, idem, XII.1901 (2 ops., Ac. 22899, 35178, AMNH); ibidem, 1898, Golti (2 ops., AMNH). Acre: Parque Nacional Serra do Divisor, Sítio 5, Igarapé Ramon, 07²7’32”S, 7346’28”W, 16.XI.1996, E.F. Morato (1 op., 971356, RPSP); Rio Branco, 15-20.XI.1961, F.M. Oliveira (2 ops., DZUP). Rondônia: Ariquemes, $62 \mathrm{~km} \mathrm{S,} \mathrm{Faz.} \mathrm{Rancho}$ Grande, nr. Cacaolândia, 10³2'0”S, 6248'0”W, 28.XII.1995, D. Kistner BRA1K01, No. 5288, ex: flight intercept trap (1 op., SM0135021, SEMC); Campo Novo, estrada C.N., Buritis, $10^{\circ} 23^{\prime} 32,2^{\prime \prime} \mathrm{S}, 63^{\circ} 39^{\prime} 25,6^{\prime \prime} \mathrm{W}$, 10.IX.1997, Brown, Boina, Vieira (6 ops., 14499, 14500, 14507, 14509, 14510, 14511, RPSP); ibidem, Ig. Tracoazinho, reg. Cpo. Novo, 115.VIII.1985, V. Py-Daniel, L. Aquino (6 ops., INPA); Costa Marques, S $12^{\circ} 19,466^{\prime}$, W 64ำ $14,397^{\prime}, 18 . X I .1996$, Brown, Boina, Vieira (1 op., 3215, RPSP); Cujubim, 09²0,765'S, 62³6,792'W, 26.III.1997, Brown, Boina, Vieira (2 ops., 7264, 7302, RPSP); ibidem, idem, linha 14, 09 $20,154^{\prime} \mathrm{S}, 62^{\circ} 33,110^{\prime} \mathrm{W}, 24 . \mathrm{III} .1997$ (10 ops., 6646, 6647, 6650, 6681, 6682, 6723, 6725, 6768, 6771, 6772, RPSP); Extrema, linha 4, 0944'56,5”S, 66'26'58,5”W, 26.VI.1997, Brown, Boina, Vieira (1 op., 11292, RPSP); Guajará-Mirim, S 1045,516', W 64²42,761', 9.X.1996, Brown, Boina, Vieira (4 ops., 1860, 1862, 1863, 1865, RPSP); Machadinho, linha 32, 09²6,939'S, 61 ${ }^{\circ} 57,042^{\prime} \mathrm{W}, 20 . \mathrm{III} .1997$, Brown, Boina, Vieira (1 op., 6358, RPSP); ibidem, idem, estrada 133 a Tabajara, $09^{\circ} 03,395^{\prime} \mathrm{S}, 62^{\circ} 03,749^{\prime} \mathrm{W}, 22 . \mathrm{III} .1997$, (1 op., 6564, RPSP); Mirante

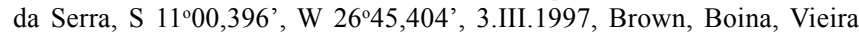
(1 op., 6280, RPSP); ibidem, idem, linha $68,11^{\circ} 05^{\prime} 14,2$ "S, 6244'31,3”W, 16.V.1997 (7 ops., 9187-9189, 9193, 9194, 9210, 9211, RPSP), Fazenda Urupá, $11^{\circ} 02^{\prime} 44,7$ ”S, 62³4'41,8”W, 11.VI.1997, (5 ops., 10991, 10992, 10999, 11000, 11001, RPSP), linha 74, $11^{\circ} 09^{\prime} 09,8^{\prime}$ 'S, 62 ${ }^{\circ} 44^{\prime} 56,2^{\prime}$ 'W, 17.VII.1997 (1 op., 11662, RPSP), linha 52, 1056’36,9”S, 6240'52,6”W, 14.VIII.1997 (1 op., 12945, RPSP), linha $72,11^{\circ} 10^{\prime} 17,4^{\prime \prime} \mathrm{S}, 62^{\circ} 40^{\prime} 00,1^{\prime \prime} \mathrm{W}$ 20.VIII.1997 (1 op., 13388, RPSP), linha $72,11^{\circ} 05^{\prime} 11,3^{\prime}$ 'S, $62^{\circ} 41^{\prime} 45,5^{\prime}$ 'W 20.VIII.1997 (1 op.,

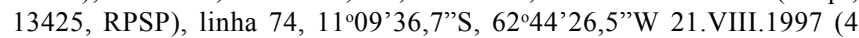

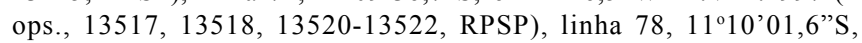
$62^{\circ} 45^{\prime} 56,6^{\prime \prime} \mathrm{W}, 28$. VIII.1997 (1 op., 13672, RPSP), linha 76, $11^{\circ} 05^{\prime} 18,9$ "S, 62 50 '29,6”W, 30.VIII.1997 (4 ops., 13970, 14008, 14011, 14013, RPSP); Ouro Preto (= Ouro Preto D'Oeste), S 1200,812', W 6419,767', 24.XI.1996, Brown, Boina, Vieira (1 op., 3826, RPSP); Pimenta Bueno, XI.1960, M. Alvarenga (1 op., DZUP); ibidem, XI.1960, M. Alvarenga (2 ops., SEMC); Pimenteiras, S 1327,073', W 6059,850',
26.II.1997, Brown, Boina, Vieira (2 ops., 5315, 5318, RPSP); Porto Velho, Estação Ecológica Cuniã, 08²1'44,8”S, 63³7’45,8”W, 24.V.1997, Brown, Boina, Vieira (2 ops., 10020, 10021, RPSP); Rolim de Moura,

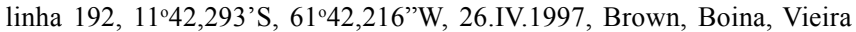
(7 ops., 8543, 8547, 8564, 8567, 8607, 8609, 8610, RPSP); ibidem, idem, linha 168, 11³3,966'S, 61 ${ }^{\circ} 54,845^{\prime}$ 'W, 27.IV.1997 (1 op., 8808, RPSP); São Miguel do Guaporé, linha $82,11^{\circ} 46,568^{\prime} \mathrm{S}, 62^{\circ} 43,531^{\prime} \mathrm{W}$, 20.IV.1997, Brown, Boina, Vieira (2 ops., 7964, 7965, RPSP); ibidem, idem, linha 82, $11^{\circ} 39,079^{\prime}$ 'S, 62²43,193'W, 22.IV.1997 (1 op., 8071,

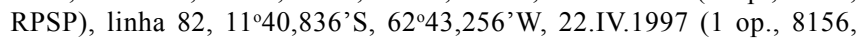
RPSP); Urupá, linha Quarentinha, $11^{\circ} 03^{\prime} 58,9^{\prime} \mathrm{S}, 62^{\circ} 32^{\prime} 50,1$ ”W, 11.VI.1997, Brown, Boina, Vieira (1 op., 10521, RPSP); Vilhena, XI.1960, M. Alvarenga (8 ops., DZUP; 2 ops., RPSP); ibidem, 22.VII5.VIII.1983, F.J.A. Peralta, 27, 59c (11 ops., INPA), ibidem, idem, 26, 52-c (1 op., INPA). Tocantins: Dianópolis, 2.III.1962, FM Oliveira (1op., DZUP); Natividade, 17.VI.1964, S. Laroca (2 ops., DZUP); Res. Krahó Galheiros, 45 Km SE Itacajá, SC-23, 47²2'W, 8²9'S, 1721.I.1993, Camargo, Tavares, Pedro (105 ops., ninho 500c, RPSP). Maranhão: Imperatriz, 1.VII.1964, Sebastião Laroca (1 op., DZUP). Mato Grosso: Aldeia Juruna, Rio Xingu, 8-9.VIII.1957, D. Dias (6 ops., SEMC); Barracão Queimado, XI.1960, M. Alvarenga (2 ops., DZUP); Chapada, XI.1963, M. Alvarenga (11 ops., DZUP; 2 ops., RPSP); C. Guimarães, 1.II.1986, G. Melo, 254/1/21 (3 ops., MELO; 4 ops., UFVB); Jacaré, P.N. Xingu, XI.1961, Alvarenga, Werner (1 op., DZUP); ibidem, 25-30.XI.1965, M. Alvarenga (1 op., DZUP); Nhanbiquaras (sic), XI.1960, M. Alvarenga (1 op., SEMC); Parecis, XI.1960, M. Alvarenga (1 op., DZUP); Rio Verde (Mato Grosso do Sul?), BR-29, XI.1960, M. Alvarenga (1 op., DZUP); Rodovia Cuiabá - Santarém, km 206, 1975, Juliani (1 rainha, RPSP); Serra do Roncador, MT-R.S. Base Camp, 20.VII.1968, Laroca, Azevedo (1 op., DZUP); Serra de São Vicente,

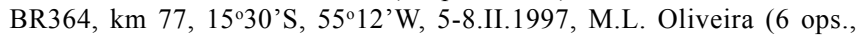
OLIV); Utiariti, rio Papagaio, X.1966, Lenko, Pereira (4 ops., MZSP); ibidem, idem, 1-12.XI.1966 (1 op., MZSP). Goiás: Aragarças, 1024.I.1971, Camargo et al. (2 ops., RPSP); Córrego do Paina, btwn. Brasília \& Formosa, 25.X.1974, anônimo (1 op., USNM); Couto Magalhães, VII.1959, M. Alvarenga (13 ops., SEMC; 2 ops., RPSP); Cristalina, 1964, R. Zucchi (10 ops., RPSP); Jataí, Faz. Aceiro, X.1962, Exp. Dep. Zool. (1 op., MZSP); ibidem, Faz. Cachoeirinha, X.1962, Exp. Dep. Zool. (1 ops., MZSP); ibidem, Faz. Nova Orlandia, I.1964, Martins, Morgante, Silva (1 op., MZSP); Silvania, 18.IV.1994, Carvalho (5 ops., 940442-446, RPSP). Distrito Federal: Brasília, XI.1964, A. Cordeiro (87 ops., DZUP; 15 ops., RPSP). Mato Grosso do Sul: Porto Atlântida, VII.1954, W.E. Kerr (1 op., DZUP); Três Lagoas, 24.V.1964, Exp. Dept. Zool., capoeira (2 ops., MZSP). Minas Gerais: Campina Verde, X.1960, M. Alvarenga (1 op., DZUP); Conceição das Alagoas, SE-22, 48-20a, 29.III.1973, Camargo, Terada, Schiavoni, Penha (198 ops., mais ops. em álcool, ninho 37c, RPSP); ibidem, 23.III.1973, G. Penha (4 ops., 2 machos, RPSP); ibidem, 20.IX.1973, Penha (25 ops., mais ops. e 4 machos em álcool, ninho 52c; 36 ops., mais ops. em álcool, ninho 53c; mais 5 ops., RPSP); Uberlândia, 20.V.1993, G.A.R. Melo, "clube caça e pesca" (2 ops., MELO). São Paulo: Igarapava, SF-23, 4820 a-I, 5.V.1977, Toscano (1 op., RPSP); Jundiahy, 1898, França (? ilegível) (1 op., AMNH); Pedregulho, sem data, anônimo (3 ops., 1 macho, RPSP). BOLÍVIA. La Paz: Lower Rio Madidi, I(ano?), W.M. Mann, Mulford BioExpl. 1921-22 (1 op., USNM); Rio Heath, $\sim 13^{\circ} \mathrm{S}$, $69^{\circ} \mathrm{W}, 600 \mathrm{~m}, 20 . I I .1990$, Luis Coloma, 47 (2 ops., SEMC); ibidem, idem, 21.II.1990, 48 (3 ops., SEMC; 1 op. RPSP). Beni: El Trapiche, 26.VII.1988, R. Altamirano (2 ops., STRI); El Beni, Beni Stn., Palm. Camp, savannah, NE of San Borja, 25.VII.1988, Robert W. Brooks, BIOLAT - SI/MAB (1 op., SEMC); ibidem, idem, 28.VII.1988 (3 ops., SEMC), 29.VII.1988 (3 ops., SEMC); ibidem, El Povenir Stn., NE of San Borja, 22.VII.1988, Robert W. Brooks, BIOLAT-SI/MAB (3 ops., SEMC); ibidem, idem, 5.VIII.1988 (1 op., SEMC); Cavinas, II(ano?), Wm. M. Mann, Lopez, Mulford BioExpl. 1921-22 (1 op., USNM); Rurrenabaque, rio Beni, 23.VII.1950, R. Snelling (2 ops., AMNH). Cochabamba: Chapare, Alto Palmar, 1100m, X.1948, anônimo (4 ops., MSUC). Santa Cruz: Buena Vista, Depto. Ichilo, 26.IV.1950, L.E. Peña (3 ops., 1 rainha, SEMC), ibidem, idem, 2.VII.1950 (3 ops., SEMC). 
Distribuição geográfica e hábitat: Cerrados do Brasil Central, até Belém - PA; a oeste até às matas tropicais de Rondônia , Bolívia e Peru (Fig. 169).

Nidificação. Em termiteiros arborícolas externos. Hospedeiros identificados: Nasutitermes cf. kenneri Snyder \& Emerson, 1949 (ninho 37c), Microcerotermes cf. strunki (Sorensen, 1884) (ninho 52c) e Microcerotermes spp. (ninhos 53c e 500c).

Etimologia. Do latim, combinatus, particípio de combinus, juntar duas coisas, reunir, referindo-se a presença de dois estados de um mesmo carácter (labro enegrecido e amarelado) na mesma espécie.

Discussão. Difere de P. nigrior por apresentar máculas mais nítidas, com as estrias paroculares mais estreitas embaixo, chegando até a interorbital superior, e pelo tamanho geralmente maior. Amplamente distribuída no Brasil Central (Fig. 169), esta espécie possui indivíduos com labro e mandíbulas tanto enegrecidos quanto amarelados, inclusive em um mesmo ninho. Quando se têm em mão exemplares com labro enegrecido, a distribuição é suficiente para se chegar a uma diagnose; entretanto, quando apresentam labro amarelo, o reconhecimento se torna difícil. Os dentes da mandíbula mais recuados (Fig. 89) auxiliam a separá-la das espécies do grupo cupira, mas nem sempre as mandíbulas encontram-se em condições de serem analisadas (apresentando desgaste, ou estando recolhidas). As asas podem variar bastante com relação a coloração das microtríquias, desde completamente enegrecidas, até com uma grande área na porção mediana (pterostigma e adjacências) com microtríquias amarelas. (por exemplo, ninho 4c de Barra do Garças, MT). P. combinata $\mathbf{s p .}$ nov. compartilha com $P$. auripennis sp. nov. a forma da estrutura de entrada (ambas nidificam em termiteiros arborícolas externos), escavada no substrato, em forma de concha lisa; isto pode constituir uma sinapomorfia para essas duas espécies; entretanto, a entrada dos ninhos de $P$. nigrior e $P$. nigrilabris sp. nov. não são conhecidas. Outros comentários na discussão sobre P. nigrior e $P$. auripennis sp. nov.

Partamona chapadicola sp. nov.

(Figs. 57, 151, operária; 90, 120, macho; 170, distribuição; Tabs. II-IX, XII)

"Boca de barro"; Castello Branco, 1845:68.

Partamona sp.; Rego \& Brito, 1996:244, 246.

Partamona cupira; Chittka et al., 1997:114.

Diagnose. Abelhas de porte médio (1.m.c. 2,3-2,6 mm, c.a.a. 5,5-5,9 mm; Tabs. III, IV). Integumento preto. Mandíbula predominantemente ferrugínea, com o $1 / 4-1 / 5$ basal amarelado ou descolorido; ápice ferrugíneo-escuro, côndilos pretos. Flagelo castanho escuro. Estrias paroculares estreitas $(0,6-0,8 \mathrm{x}$ o diâmetro do $2^{\circ}$ flagelômero), levemente alargadas embaixo (ca. 1,1-1,2x o diâmetro do $2^{\circ}$ flagelômero), chegando até a altura da interorbital superior (Fig. 151). Pilosidade preta. Membrana das asas hialina; microtríquias pretas em toda a asa ou amarelas apenas na região do pterostigma; veias alares méleas, mas escurecidas pelas microtríquias fuscas. Cerdas da base do escapo um pouco mais longas que o diâmetro deste (1,2-1,3x; Tab. VII). Cerdas eretas das áreas paroculares, aproximadamente tão longas quanto o diâmetro do escapo. Cerdas do escutelo 0,9-1,0x o comprimento deste. Área basal do propódeo com uma faixa glabra mediana um pouco mais larga que o diâmetro do $2^{\circ}$ flagelômero. Dentes da mandíbula pequenos e muito recuados em relação ao ápice do bordo distal (Fig. 57). Área malar, distância interocelar, distância ocelorbital, tíbia III e comprimento da asa anterior normais (Tabs. V, VI, VIII, IX). Bifurcação da $\mathrm{M}+\mathrm{Cu}$ geralmente coincidente com a cu-v (raramente levemente anterior). Macho, basitarso III curto e largo, achatado ou convexo-côncavo; tíbia III alargada em direção ao ápice (Fig. 90); EVII com a projeção mediana longa, de lados aproximadamente subparalelos, os chanfros laterais profundos e largos (Fig. 120).

\section{Operária.}

Dimensões. Comprimento total aproximado, $6,64 \mathrm{~mm}$; da asa anterior, 5,89 $\mathrm{mm}$ (incluindo a tégula, 6,72 $\mathrm{mm}$ ); largura máxima da cabeça, 2,64 mm; do TIII, 2,72 mm (Tab. XII).

Cor do integumento. Predominantemente preto, apenas o metanoto mais claro, e os tarsômeros de todos os pares de pernas, ferrugíneos. Tégula ferrugínea, translúcida, apenas uma mancha enegrecida para o ápice. Labro amarelado; mandíbula amarelada no terço basal e ferrugínea em direção ao ápice; côndilos e ápice enegrecidos. Escapo com a face inferior amarelada e a superior enegrecida. Flagelo castanho escuro, o $1^{\circ} \mathrm{e}$ os dois últimos flagelômeros mais claros. Máculas da face nítidas, principalmente as paroculares, as do tórax um pouco menos. Manchas no clípeo aproximadamente em forma de dois L contrapostos, a distância entre elas, na porção mais apical do clípeo, menor que o diâmetro do $2^{\circ}$ flagelômero, nítidas. Mancha supraclipeal aproximadamente em forma de acento circunflexo. Abaixo do ocelo, um triângulo invertido, alongado, aproximadamente tão longo quanto o diâmetro do ocelo médio. Margeando o sulco frontal, a cada lado, uma estria fina. Estrias paroculares um pouco alargadas embaixo (como o diâmetro do $2^{\circ}$ flagelômero), afilando na altura das fóveas tentoriais ( $2 / 3 \mathrm{do}$ diâmetro do $2^{\circ}$ flagelômero), e com largura mais ou menos uniforme, chegando até a altura da linha da menor distância interorbital superior. Genas com uma pequena mancha margeando o quarto inferior do olho. Estrias laterais do mesoscuto mais nítidas posteriormente; nas axilas uma mancha na parte anterior, um pouco apagada; o bordo posterior do escutelo com uma faixa estreita interrompida medianamente. Basitarso II com uma estria a cada lado, acompanhando as margens anterior e posterior, muito apagadas. Membrana da asa anterior hialina; microtríquias enegrecidas em toda a asa; veias méleas, escurecidas pelas microtríquias, $\mathrm{C}$ e $\mathrm{R}$ escurecidas basalmente. 
Pilosidade. Predominantemente enegrecida, mais clara nas coxas e trocanteres; esternos com as cerdas enegrecidas na porção basal, despigmentadas na porção apical onde são mais delgadas. Área basal do propódeo com uma larga faixa glabra mediana. Franja pré-marginal do TIII com cerdas muito mais curtas na região mediana que as laterais. Cerdas da base do escapo $0,94 \mathrm{x}$ mais curtas que o diâmetro deste. Áreas paroculares inferiores, ao lado dos alvéolos, com cerdas eretas tão longas quanto o diâmetro do escapo. Cerdas do clípeo um pouco mais longas, $1,06 \mathrm{x}$ o diâmetro do escapo; na fronte $0,88 \mathrm{x}$; no vértice ca. 2,13x; no disco do mesoscuto e porção anterior da linha média 1,13 e 2,06x, respectivamente. As cerdas mais longas no ápice do escutelo com ca. de 0,86 x o comprimento deste.

Integumento. Liso e polido, apenas com a pontuação pilígera típica do gênero.

Forma e proporções (Tab. XII). Cabeça, 1,22x mais larga que longa, e 1,36x mais larga que a distância clipeocelar. Olhos 2,39x mais longos que largos, levemente convergentes embaixo. Área malar ca. de $0,89 x$ o diâmetro do $2^{\circ}$ flagelômero. Clípeo $0,54 \mathrm{x}$ mais curto que sua largura máxima e $0,37 \mathrm{x}$ a distância clipeocelar. Mandíbulas 0,57x a distância clipeocelar; os dentes pequenos, bem recuados (Fig. 57). Escapo 0,91x a distância alvéolo-ocelo lateral, seu diâmetro um pouco menor que o do $2^{\circ}$ flagelômero. Distância interocelar 1,41x maior que a ocelorbital e ca. de $1,88 \mathrm{x}$ o diâmetro do ocelo médio. Escutelo aproximadamente semicircular, cerca de $0,46 x$ mais curto que largo. Tíbia III 0,94x mais curta que a cabeça e $2,07 \mathrm{x}$ mais longa que larga; canto póstero-distal arredondado, pouco projetado, margem apical fracamente sinuada; contorno da margem posterior suavemente sinuado. Basitarso III 1,62x mais longo que largo; canto póstero-distal anguloso, projetado e margem apical em ângulo maior que $100^{\circ} \mathrm{em}$ relação à margem anterior. Asa anterior 2,68x mais longa que larga e 2,23x a largura máxima da cabeça. Bifurcação de $\mathrm{M}+\mathrm{Cu}$ coincidente com a cu-v. Hâmulos, 5 .

\section{Macho. Figuras 90, 120.}

Material-tipo. Holótipo, operária de "39 km S Chapadinha, Brasil, MA, 4330'W, 505'S, 12-13/IX/1994 Camargo, Pedro leg.", ninho "665c", parátipos, 59 operárias do mesmo ninho, e mais 39 operárias de outro ninho, " $663 \mathrm{c}$ ", com a mesma etiqueta de procedência, depositados na RPSP.

Material examinado. BRASIL. Pará: (localidade ?), III.1901, Ducke (1 op., USNM); (localidade?), sem data, Baker (2 ops., 8217, USNM); Belém, I.1938, L. F. Martorell (1 op., Ac. 131-38, USNM); Capanema, SA.23, 47 II-1c, 15.II.1984, Camargo, Mazucato (1 op., 840174, RPSP); Conceição Araguaia, VII.1959, M. Alvarenga, "boca de barro" (2 ops., DZUP; 2 ops., RPSP); Coraci, 15 km NW Canindé, rio Gurupi, IV.1963, B. Malkin (2 ops., MZSP); Gorotire (=Gradaús), SB-22, 51-8 a, 20.VIII5.IX.1983, Camargo (4 ops., 830663, 830668, 830837, 830859, RPSP); Paragominas, $30 \mathrm{~km} \mathrm{~S}$, SA-23, 47ii-3g, 11.II.1984, Camargo, Mazucato (4 ops., 840044-047, RPSP). Tocantins: Lizarda, 4440'W, 9³6's, 18.XI.1994, Camargo, Pedro (53 ops., 3 machos, 675c, RPSP); Reserva Krahó, Galheiros, 45 km SE Itacajá, SC.23, 47²2’W, 8²9’S, 18.I.1993, Camargo, Tavares, Pedro (105 ops., mais mat. em álcool, ninho 487c, mais 11 ops., 930420, 930422, 930593, 930595, 930597-599, 930601-
603, 930606, RPSP). Maranhão: Balsas, 40 km L, 29.VII.1982, J.M.F. Camargo (1 op., 821217, RPSP); Buriticupu, 20 km NE, 46 $22^{\prime}$ 'W, 47'S, 09-10.XI.1994, Camargo, Pedro (4 ops., 941724-941727, RPSP); Carolina, 6.I.1961, anônimo (1 op., USNM); Chapadinha, $39 \mathrm{~km} \mathrm{~S}$,

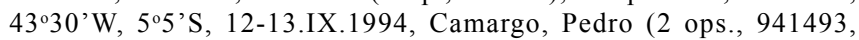
941531, RPSP); Igarapé Gurupi-Una, Aldeia Yararuhu (Aracu), about 50 km E Canindé, rio Gurupi, PA, 11-25.II.1966, Borys Malkin (1 op., AMNH); Pastos Bons, 30.VII.1982, Camargo (2 ops., 821272, 821273, RPSP); Rosário, 28.XII.1982, Mazucato, Aily (2 ops., 822781, 822782, RPSP); São Luís, 11.XII.1982, Mazucato, Aily (1 op., 821912, RPSP); ibidem, idem, 30.XII.1982 (1 op., 822912, RPSP) Timon, 4.III.1984, Camargo, Mazucato (40 ops., ninho 315c, RPSP). Piauí: Canto do Buriti, 16.III.1983, Mazucato, Camargo (1 op., 830159, RPSP). Pernambuco: Petrolina, 18.11.1988, F.N.P. Haji, 3140, algaroba (1 op., 960659, RPSP).

Distribuição geográfica e hábitat. Cerrados, caatingas e matas decíduas; leste do PA, MA, norte do TO, até PE, Brasil (Fig. 170).

Nidificação. Em termiteiros no interior de ocos de troncos e galhos de árvores vivas.

Etimologia. Pela sufixação latina, indicando que esta espécie habita as regiões das chapadas.

Discussão. Praticamente não apresenta caracteres distintivos das demais espécies do grupo nigrior, principalmente de $P$. seridoensis sp. nov. e exemplares com labro amarelo de $P$. combinata sp. nov.. Partamona. chapadicola $\mathbf{s p .}$ nov. é contígua geograficamente à $P$. seridoensis sp. nov. e distingue-se desta, por apresentar o integumento um pouco menos enegrecido e asas com veias mais claras e, em alguns exemplares, com microtríquias amarelas na região do pterostigma. Quanto ao substrato de nidificação e estrutura de entrada do ninhos são bastante distintas: $P$. chapadicola $\mathbf{s p}$. nov. ocorre em termiteiros no interior de troncos de árvores vivas e $P$. seridoensis $\mathbf{s p . ~ n o v . ~ e m ~ t e r m i t e i r o s ~ a r b o r i ́ c o l a s ~ e x t e r n o s ~}$ de terra. Com relação aos exemplares com labro amarelo de $P$. combinata sp. nov., não apresenta caracteres distintivos.

Partamona seridoensis sp. nov.

(Figs. 58, 152, operária; 91, 121, macho; 170, distribuição; Tabs. II-IX, XII)

Partamona cupira; Melo et al., 1997:14, 15, 16.

Partamona sp.1; Aguiar et al., 1995:107.

"Cupira"; Castello Branco, 1845:67 (partim, abelhas com cera "amarella côr de açafrão"); Gonçalves, 1973:7, 8.

Diagnose. Abelhas de porte médio (1.m.c. 2,4-2,5 mm, c.a.a. 5,6-5,9 mm; Tabs. III, IV). Integumento preto. Mandíbula predominantemente ferrugínea, com ca. 1/4 basal amarelado, ápice ferrugíneo-escuro, côndilos pretos. Flagelo castanhoescuro. Estrias paroculares estreitas (ca. 0,6-0,8x o diâmetro do $2^{\circ}$ flagelômero), levemente alargadas embaixo (ca. 1,0-1,2x o diâmetro do $2^{\circ}$ flagelômero), chegando até a interorbital superior (Fig. 152). Máculas do tórax apagadas. Pilosidade predominantemente preta; cerdas na região ventral dos mesepisternos, coxas e trocanteres, enegrecidas ou 
esbranquiçadas. Membrana das asas hialina; microtríquias pretas; veias escurecidas, principalmente na metade basal da asa. Cerdas da base do escapo um pouco mais longas que o diâmetro deste (1,2-1,3x; Tab. VII). Cerdas eretas das áreas paroculares, ao lado dos alvéolos, tão longas quanto o diâmetro do escapo. Cerdas do escutelo curtas, ca. 0,7-0,9x o comprimento deste. Área basal do propódeo com uma faixa glabra mediana, aproximadamente tão larga quanto o diâmetro do $2^{\circ}$ flagelômero Dentes da mandíbula pequenos e muito recuados em relação ao ápice do bordo apical (Fig. 58). Área malar, distância interocelar, distância ocelorbital, tíbia III e comprimento da asa anterior, normais (Tabs. V, VI, VIII, IX). Bifurcação da $\mathrm{M}+\mathrm{Cu}$ geralmente coincidente com a cu-v (raramente levemente anterior). Macho, basitarso III curto e largo, achatado ou convexo-côncavo; tíbia III alargada em direção ao ápice (Fig. 91); EVII com a projeção mediana longa, de lados aproximadamente subparalelos, os chanfros laterais profundos e largos (Fig. 121).

\section{Operária.}

Dimensões. Comprimento total aproximado, $5,81 \mathrm{~mm}$; da asa anterior, 5,56 $\mathrm{mm}$ (incluindo a tégula, $6,31 \mathrm{~mm}$ ); largura máxima da cabeça, 2,46 mm; do TIII, 2,44 mm (Tab. XII).

Cor do integumento. Predominantemente preto, apenas o metanoto um pouco mais claro e os tarsômeros ferrugíneos. Tégulas castanho-escuras com algumas manchas um pouco mais claras. Labro amarelado, mandíbula amarelada no quarto basal e ferrugínea em direção ao ápice, côndilos enegrecidos. Escapo com a face inferior amarelada e a superior enegrecida. Flagelo castanho-amarelado, na face superior mais escurecido. Máculas nítidas, no tórax mais apagadas. Manchas no clípeo aproximadamente triangulares, a distância entre elas, na porção mais apical do clípeo, menor que o diâmetro do $2^{\circ}$ flagelômero, um pouco apagadas medianamente. Mancha supraclipeal aproximadamente trapezoidal. Abaixo do ocelo, um triângulo invertido, alongado, um pouco mais longo que o diâmetro do ocelo médio. Uma mancha acompanhando o sulco frontal. Estrias paroculares um pouco alargadas embaixo (ca. 0,88x o diâmetro do escapo), estreitando um pouco medianamente $(0,63 x)$ e tornando-se mais largas em cima $(0,75 x)$, chegando difusas até um pouco abaixo da linha da menor distância interorbital superior. Genas com pequena mancha difusa margeando o terço inferior do olho. Estrias laterais do mesoscuto bem apagadas; as axilas praticamente por inteiro amareladas; o bordo posterior do escutelo com uma faixa estreita e difusa, interrompida medianamente. Membrana da asa anterior hialina; microtríquias enegrecidas em toda asa; veias méleas, escurecidas pelas microtríquias, $\mathrm{C}$ e $\mathrm{R}$ mais escuras para a base.

Pilosidade. Enegrecida, apenas o ápice das cerdas ventrais mais claro. Área basal do propódeo com uma faixa glabra mediana. Franja pré-marginal do TIII com cerdas muito mais curtas na região mediana que nas laterais. Cerdas da base do escapo tão longas quanto o diâmetro deste. Área parocular inferior, ao lado dos alvéolos, com as cerdas eretas $0,8 \mathrm{x}$ o diâmetro do escapo; cerdas do clípeo $0,87 x$; na fronte, $1,07 x$; no vértice mais longas, ca. 2,27x; no disco do mesoscuto e porção anterior da linha média 1,07 e 1,73x, respectivamente. Cerdas mais longas no ápice do escutelo com ca. de $0,82 \times$ o comprimento deste.

Integumento. Liso e polido, apenas com a pontuação pilígera típica do gênero.

Forma e proporções (Tab. XII). Cabeça, 1,21x mais larga que longa e 1,35x mais larga que a distância clipeocelar. Olhos $2,42 \mathrm{x}$ mais longos que largos, paralelos. Área malar ca. de 1,13x o diâmetro do $2^{\circ}$ flagelômero. Clípeo $0,51 \mathrm{x}$ mais curto que sua largura máxima e $0,35 \mathrm{x}$ a distância clipeocelar. Comprimento das mandíbulas $0,58 \mathrm{x}$ a distância clipeocelar; os dentes pequenos e curtos (o bordo distal gasto); nos parátipos, os dentes recuados (Fig. 58). Escapo 0,89x a distância alvéoloocelo lateral, seu diâmetro um pouco menor que o do $2^{\circ}$ flagelômero. Distância interocelar 1,63x maior que a ocelorbital e ca. de $1,83 \mathrm{x}$ o diâmetro do ocelo médio. Escutelo aproximadamente semicircular, cerca de $0,51 \mathrm{x}$ mais curto que largo. Tíbia III $0,95 x$ mais curta que a cabeça e $2,05 x$ mais longa que larga; canto póstero-distal subanguloso, um pouco projetado, margem apical fracamente sinuada; contorno da margem posterior suavemente sinuado. Basitarso III 1,60x mais longo que largo; canto póstero-distal subanguloso e margem apical em ângulo um pouco maior que $90^{\circ} \mathrm{em}$ relação à margem anterior. Asa anterior 2,50x mais longa que larga e 2,26x a largura máxima da cabeça. Bifurcação de $\mathrm{M}+\mathrm{Cu}$ levemente anterior à cu-v. Hâmulos, 5.

\section{Macho. Figuras 91, 121.}

Material-tipo. Holótipo, operária, de " $80 \mathrm{~km} \mathrm{SW} \mathrm{-} \mathrm{Alto} \mathrm{Parnaíba,}$ MA-Brasil 23-I-1993 SC-23, 46²8'W-9'36'S", "Camargo, Tavares, Pedro leg.", ninho "502c" (RPSP); mais 101 parátipos, operárias, do mesmo ninho e, do ninho "501c", com os mesmos dados de procedência, data e coletor, 48 parátipos, operárias, depositados na RPSP.

Material examinado. BRASIL. Maranhão: Mirador, 12.III.1997, M. Bezerra, N-2 (3 ops., 971948-50, RPSP); ibidem, idem, N-3 (3 ops., 971951-53, RPSP), 14.II.1997, N-9 (3 ops., RPSP), 15.III.1997, N-17 (3 ops., 971993-95, RPSP), 16.III.1997, N-22 (3 ops., 972008-10, RPSP), 16.III.1997, N-23 (3 ops., 972011-13, RPSP), 17.III.1997, N27 (3 ops., 972023-25, RPSP); ibidem, 8.I.1998, Gisele G. Azevedo (37 ops., RPSP); Urbano Santos, 10 km N, 8.XI.1982, Camargo (108 ops., ninho 300c, RPSP). Ceará: Abaira (sic = Abaiara), SB-24, 39-7c, IX.1969, J. Cláudio, 384 (1 op., RPSP); Beberibe, SB-24, 38-4c, 1970, I. O. de Sá, 40 (12 ops., RPSP); Brejo Santo, SB-24, 39-8a, V.1970, C.L. Quental, 302 (1 op., RPSP); Groairas, SA-24, 40-2 a, III.1970, D. O. Parente, 414 (1 op., RPSP); Juazeiro do Norte, SB-24, 39-7c, X.1969, M. Brito, 377 (2 ops., RPSP); Missão Velha, SB-24, 39-7c, X.1969, L. P. Nogueira, 401 (1 op., RPSP); Morrinhos, SA-24, 40-3c, 1970, C. Penes, 28 (2 ops., RPSP); Pacajás (sic = Pacajus), SB-24, 39-4d, 1970, Marcondes, 181 (8 ops., RPSP); Pacatuba, SA-24, 39-4b, 1970, Glória, 146 (3 ops., RPSP); Quixoá, SA-24, 39-6c, 1970, A.E. Rolim, 156 (16 ops., RPSP); S. Gonçalo do Amarante, SA-24, 39-4b, V.1969, J.T. Costa, 112 (10 ops., RPSP); Sta. Quitéria, SB-24, 40-4c, V.1970, A.P. Duarte, 460 (4 ops., RPSP); Tauá, SB-24, 40-6c, 1970, Joel, 96 (6 ops., RPSP); Triari, SA-24, 39-3c, X.1969, R. Teófilo, 232 (2 ops., RPSP). Rio Grande do Norte: Jardim de Seridó, 4.II.1995, E.M. Macedo (9 ops., 950115-950123, 
RPSP); Santana do Seridó, 27.X.1996, Macedo, E.R.M., “ninho em cupinzeiro de árvore rente ao chão, vegetação: caatinga" (30 ops., 12 machos, 960683-960725, RPSP); ibidem, idem, 26.IV.1997, 154 (19 ops., 7 machos, RPSP); ibidem, 23.I.1998, Azevedo, G.G., 153 (7 ops., 11 machos, RPSP). Paraíba: Cabaceiras, Sítio Bravo, $11 \mathrm{~km} \mathrm{~S}$ Boa Vista, 31.III.1992, C. F. Martins (4 ops., RPSP); Paraíba (localidade?), sem data, anônimo (7 ops., SEMC; 1 op., RPSP); Santa Luzia, 12.V.1955, L. Portela, C.R. Gonçalves, “abelha 'cupira', ninho em cupinzeiro" (40 ops., DZUP; 8 ops., RPSP); São João do Cariri, 01.VI.1994, C.M.L. Aguiar, SJC689 (1 op., RPSP). Pernambuco: Petrolina, Faz. Catalunha, 23.VII.1995, L.H. Piedade, "Jacquemontia" (1 op., 960658, RPSP); Serra Talhada, 50 km sudoeste, 27.IX.1992, H.G. dos Santos, "cupira" (3 ops., 920796-798, RPSP).

Distribuição geográfica e hábitat. Regiões xéricas do nordeste do Brasil - seridó, caatingas e agreste (Fig. 170).

Nidificação. Em termiteiros arborícolas externos de terra.

Etimologia. Pela sufixação latina, indicando que essa espécie habita a região do seridó.

Discussão. Espécie muito semelhante a $P$. chapadicola $\mathbf{s p .}$ nov., da qual difere pelo integumento mais enegrecido e asas com veias mais escuras, apenas com microtríquias enegrecidas e, também, pelos hábitos de nidificação. Outros comentários em P. chapadicola $\mathbf{s p . ~ n o v . ~}$

Partamona littoralis sp. nov.

(Fig. 153, operária; 169, distribuição; Tabs. II-IX, XIII)

Diagnose. Abelhas de porte médio (1.m.c. 2,5 mm, c.a.a. 5,5$5,9 \mathrm{~mm}$; Tabs. III, IV). Integumento preto. Mandíbula com ca. 1/ 3 a 2/3 da porção basal amarelada ou descolorida e a porção apical restante ferrugínea, côndilos pretos. Flagelo castanho escuro. Estrias paroculares muito estreitas (ca. 0,5x o diâmetro do $2^{\circ}$ flagelômero), aproximadamente com a mesma largura em toda a sua extensão, ou apenas um pouco mais largas embaixo (0,7-0,8x o diâmetro do $2^{\circ}$ flagelômero; Fig. 153). Máculas do tórax apagadas. Pilosidade preta. Membrana das asas ferrugínea escura; microtríquias pretas; veias méleas, escurecidas pelas microtríquias fuscas. Cerdas da base do escapo um pouco mais longas que o diâmetro deste (1,2-1,3x; Tab. VII). Cerdas eretas das áreas paroculares, ao lado dos alvéolos, mais longas que o diâmetro do escapo. Cerdas do escutelo curtas, ca. de 0,8-0,9x o comprimento deste. Área basal do propódeo com faixa glabra mediana, aproximadamente tão larga quanto o diâmetro do $2^{\circ}$ flagelômero. Dentes da mandíbula pequenos, um pouco recuados em relação ao ápice do bordo distal. Área malar curta (ca. 0,8x o diâmetro do $2^{\circ}$ flagelômero; Tab. V). Distância interocelar, distância ocelorbital, tíbia III e comprimento da asa anterior, normais (Tabs. V, VI, VIII, IX). Bifurcação da $\mathrm{M}+\mathrm{Cu}$ coincidente com a cu-v.

Operária.

Dimensões. Comprimento total aproximado, 7,14 mm (abdômen distendido); da asa anterior, 5,77 $\mathrm{mm}$ (incluindo a tégula, 6,52 mm); largura máxima da cabeça, 2,52 mm; abdômen amassado (Tab. XIII).

Cor do integumento. Predominantemente preto, apenas as tíbias III e abdômen mais claros; os tarsômeros de todos os pares de pernas ferrugíneos. Labro amarelado, um pouco descolorido medianamente; mandíbula predominantemente amarelada, só o quarto distal ferrugíneo; côndilos enegrecidos. Escapo com a face inferior amarelada e a superior escurecida. Flagelo com a face inferior castanha a superior mais escurecida. Máculas nítidas, no tórax um pouco mais difusas. Manchas do clípeo aproximadamente triangulares, bem amarelas, a distância entre elas, na porção apical do clípeo, menor que o diâmetro do $2^{\circ}$ flagelômero. Mancha supraclipeal como um acento circunflexo. Abaixo do ocelo, um triângulo invertido muito alongado, chegando até o meio da fronte $(1,82 x$ mais longo que o diâmetro do ocelo médio), praticamente unido com a mancha em forma de $\mathrm{V}$ invertido no sulco frontal. Estrias paroculares um pouco alargadas embaixo (ca. $0,75 \mathrm{x}$ o diâmetro do escapo), estreitadas medianamente (ca. $0,38 \mathrm{x}$ ) e novamente alargadas em cima $(0,63 \mathrm{x})$, terminando acima da altura da linha da menor distância interorbital superior. Genas com pequena mancha muito estreita e nítida, abaixo do meio do olho. Tórax com as estrias laterais do mesoscuto muito nítidas; axilas praticamente por inteiro amareladas; bordo posterior do escutelo com faixa muito difusa, interrompida medianamente. Basitarso II com estria muito difusa acompanhando a margem anterior; basitarso III com estria apenas na margem anterior, mais alargada e nítida distalmente. Membrana da asa anterior ferrugínea-escura; microtríquias enegrecidas em toda asa; veias muito escurecidas, principalmente na metade basal, apenas o pterostigma um pouco mais claro.

Pilosidade. Enegrecida, apenas o ápice das cerdas ventrais mais claro. Cerdas da base do escapo tão longas quanto o diâmetro deste. Área basal do propódeo com uma faixa glabra mediana. Franja pré-marginal do TIII com cerdas muito mais curtas na região mediana que nas laterais. Área parocular inferior, ao lado dos alvéolos com cerdas eretas $0,88 x$ o diâmetro do escapo; no clípeo 0,94x; na fronte, como o diâmetro do escapo; no vértice ca. $2,13 x$; no disco do mesoscuto e na porção anterior da linha média 1,19 e 1,88x, respectivamente. Cerdas mais longas no ápice do escutelo com ca. de $0,93 \times$ o comprimento deste.

Integumento. Liso e polido, apenas com a pontuação pilígera típica do gênero.

Forma e proporções (Tab. XII). Cabeça, 1,21x mais larga que longa, e 1,37x mais larga que a distância clipeocelar. Olhos $2,40 \mathrm{x}$ mais longos que largos, paralelos. Área malar ca. de $0,82 \mathrm{x}$ o diâmetro do $2^{\circ}$ flagelômero. Clípeo $0,53 \mathrm{x}$ mais curto que sua largura máxima e $0,35 \mathrm{x}$ a distância clipeocelar. Mandíbulas $0,57 \mathrm{x}$ a distância clipeocelar; dentes pequenos, mas não muito recuados. Escapo 0,90x a distância alvéolo-ocelo lateral, seu diâmetro um pouco menor que o do $2^{\circ}$ flagelômero. Distância interocelar 1,31x maior que a ocelorbital e ca. de 1,73x o diâmetro 
do ocelo médio. Escutelo aproximadamente semicircular, cerca de $0,50 \mathrm{x}$ mais curto que largo. Tíbia III $0,93 \mathrm{x}$ mais curta que a cabeça, e 2,05x mais longa que larga; canto póstero-distal arredondado, pouco projetado, margem apical fracamente sinuada; contorno da margem posterior, suavemente sinuado. Basitarso III 1,46x mais longo que largo; canto póstero-distal levemente anguloso e margem apical em ângulo um pouco maior que $90^{\circ} \mathrm{em}$ relação à margem anterior. Asa anterior 2,67x mais longa que larga e 2,29x a largura máxima da cabeça. Bifurcação de $\mathrm{M}+\mathrm{Cu}$ levemente posterior à cu-v. Hâmulos, 5.

\section{Macho. Desconhecido.}

Material-tipo. Holótipo, operária de "BRASIL Rio Grande do Norte, Natal December 1951 M. Alvarenga"; parátipos, 55 operárias, da mesma série, e 18 operárias de "BRAZIL Rio Grande do Norte, Natal, October 1951 (M. Alvarenga)”, depositados no SEMC, alguns parátipos na RPSP.

Material examinado. Apenas o material-tipo.

Distribuição geográfica e hábitat. Zona do agreste do extremo nordeste do Brasil, Rio Grande do Norte (Fig. 169);

\section{Nidificação. Desconhecida.}

Etimologia. Pela sufixação latina de litoral, região de onde é conhecida.

Discussão. A inclusão dessa espécie no grupo nigrior é um tanto duvidosa, já que os exemplares disponíveis para análise não se encontram em condições apropriadas para o exame das mandíbulas e não há machos nem dados sobre a biologia. Chamam a atenção as asas escurecidas, as estrias paroculares muito estreitas e a mancha abaixo do ocelo muito alongada, que distinguem $P$. littoralis sp. nov.das demais espécies.

\section{Grupo cupira}

Partamona cupira (Smith, 1863)

(Figs. 43, 137, operária; 94, 123, macho; 172, distribuição; Tabs. II-IX, XIV)

Trigona cupira Smith, 1863:507; 1868:134; ?Schulz, 1905:138; Marianno, 1911:89.13 (partim); Wheeler, 1913:3, 4; ?Lutz, 1924:205, 209, 212, 215, 216, 218; ?Michener \& Fraser, 1978:465; Moure \& Camargo, 1991:57; Ayala, 1999:5.

?Trigona (Patera) testacea cupira; Schwarz, 1938: 477, 478.

?Trigona (Partamona) cupira; Kerr, 1969:166; Cunha, 1973:3, Figs. 2, 3, 4, 5, 6, 7; 1991:36; Pisani et al., 1977:233-245 (não há dados que permitam reconhecer a espécie).

Trigona (Partamona) testacea cupira; Schwarz, 1948:15, 30, 33?, 44, 51?, 53, 68?, 83?, 95, 312.

Melipona cupira; DallaTorre, 1896:577.

Melipona pallida subsp. cupira; Ducke, 1916:16, 120.41.b (partim); 1925:412. 42c (partim).

Partamona cupira; Moure, 1951:58; ?Francke et al., 1985:145-147 (não há dados que permitam reconhecer a espécie); Michener, 1990:115; Nassar \& Carvalho, 1990:704, 705; Ayala, 1992:29, 31, apêndice 2 (tabela); 1999:5, 55; ?Roig-Alsina \& Michener, 1993:127 (não há dados que permitam a identificação da espécie); Lenko \&
Papavero, 1996: 262, 263, 266; Camargo \& Moure, 1996:110. Partamona cupira cupira; Nogueira-Neto, 1970:31, 33, 34, 291, 301. Partamona aff. cupira; ?Camargo \& Moure, 1988: 294, 305; ?Bravo, 1992:864 (não há dados que permitam a identificação da espécie). Partamona cf. cupira; Carvalho \& Bego, 1996:149.

Diagnose. Abelhas de porte médio (1.m.c. 2,3-2,5 mm, c.a.a. 5,3-6,1 mm; Tabs. III, IV). Integumento preto. Mandíbula predominantemente ferrugínea, $1 / 4-1 / 5$ basal amarelado, ápice ferrugíneo-escuro, côndilos pretos. Flagelo alaranjado ou castanho-alaranjado por inteiro. Estrias paroculares estreitas (0,6-0,8x o diâmetro do $2^{\circ}$ flagelômero), um pouco alargadas em baixo (ca. 1,0-1,2x o diâmetro do $2^{\circ}$ flagelômero), chegando até a interorbital superior (Fig. 137). Máculas do tórax inconspícuas. Pilosidade predominantemente preta; cerdas na região ventral dos mesepisternos, coxas e trocanteres enegrecidas ou esbranquiçadas. Membrana das asas levemente tingida de ferrugíneo; microtríquias pretas; veias méleas, mas escurecidas pelas microtríquias escuras. Cerdas do escapo curtas, apenas uma ou duas na base um pouco mais longas que as demais (1,0-1,1x o diâmetro do escapo; Tab. VII). Cerdas eretas das áreas paroculares, ao lado dos alvéolos, tão longas quanto o diâmetro do escapo. Cerdas do escutelo curtas, 0,7$0,9 \mathrm{x}$ o comprimento deste. Área basal do propódeo com faixa glabra mediana, aproximadamente tão larga quanto o diâmetro do $2^{\circ}$ flagelômero. Dentes da mandíbula aproximadamente eqüidistantes e um pouco recuados em relação ao ápice do bordo apical (Fig. 43). Área malar, distância interocelar, distância ocelorbital, tíbia III e comprimento da asa anterior, normais (Tabs. V, VI, VIII, IX). Bifurcação da $\mathrm{M}+\mathrm{Cu}$ geralmente coincidente com a cu-v (raramente levemente anterior). Macho, basitarso III curto e largo, achatado ou convexo-côncavo; tíbia III alargada em direção ao ápice (Fig. 94); EVII com a projeção mediana longa, de lados aproximadamente subparalelos, os chanfros laterais profundos e largos (Fig. 123).

\section{Operária.}

Dimensões. Comprimento total aproximado, 6,60 mm; da asa anterior, 5,48 $\mathrm{mm}$ (incluindo a tégula, 6,27 $\mathrm{mm}$ ); largura máxima da cabeça, 2,40 mm; abdômen muito danificado (Tab. XIV).

Cor do integumento. Predominantemente preto. Tíbia e basitarso III um pouco mais claros que o restante do corpo; distitarsos de todos os pares de pernas castanho-claro. Labro por inteiro castanho-amarelado; terço basal da mandíbula castanho-amarelado, a porção apical castanho-ferrugínea, os côndilos enegrecidos. Superfície anterior do escapo amarelada, flagelo, por inteiro, castanho-claro. Tergos III e IV com a metade basal castanho-amarelada; margem apical dos esternos translúcidas, mais claras que o restante do corpo. Máculas na face, nítidas, amareladas. No disco do clípeo, duas manchas opostas em forma de triângulo-retângulo, espaço entre elas maior que metade do diâmetro do $2^{\circ}$ flagelômero. Área supraclipeal com mancha aproximadamente trapezoidal e uma mancha gutiforme abaixo do ocelo médio, aproximadamente tão larga quanto metade do diâmetro deste. Estria parocular 
acompanhando a órbita interna até um pouco acima do meio da fronte, alargada embaixo, ca. de $0,12 \mathrm{~mm}$, estreitando para cima (ca. de 0,06 mm) e terminando suavemente. Genas, uma estria com ca. de $0,12 \mathrm{~mm}$ de largura máxima, margeando o terço inferior do olho. Tórax sem desenhos aparentes. Basitarso II com uma estria apagada acompanhando a margem posterior. Membrana das asas anteriores quase hialinas, levemente tingidas de amarelo, principalmente para a base; veias amarelo-pardas, incluindo o pterostigma; Cu mais amarelada, C e R ferrugíneoenegrecidas; microtríquias fuscas, abundantes, fortes e longas (ca. de 0,04 mm na parte média e nas células submarginais).

Pilosidade. Predominantemente enegrecida; na região ventral, incluindo coxas, trocanteres e mesepisternos, de um amarelo sujo; nos esternos as cerdas fuscas na base e amareladas para o ápice; nas pernas, predominantemente amarelada, apenas no ápice da tíbia e todo o basitarso, um pouco mais escura. Não foi possível observar a pilosidade do propódeo. Cerdas da base do escapo curtas, $0,80 \mathrm{x}$ do diâmetro deste. Cerdas do clípeo aproximadamente tão longas quanto o diâmetro do escapo; na fronte, um pouco mais longas e abundantes. Cerdas eretas no disco do mesoscuto 1,33x mais longas que o diâmetro do escapo. Cerdas na metade posterior da superfície do escutelo, mais curtas que o comprimento deste.

Integumento. Liso e polido, apenas com a pontuação pilígera típica do gênero.

Forma e proporções (Tab. XIV). Cabeça 1,33x mais larga que a distância clipeocelar. Olhos 2,35x mais longos que largos, ligeiramente convergentes embaixo. Área malar um pouco mais curta que o diâmetro do $2^{\circ}$ flagelômero. Comprimento do clípeo $0,48 \mathrm{x}$ a sua largura máxima e $0,34 \mathrm{x}$ a distância clipeocelar. Comprimento da mandíbula $0,56 \mathrm{x}$ a distância clipeocelar; os dois dentes um pouco recuados; o espaço entre eles aproximadamente igual à distância entre o dente médio e o ápice interno do bordo distal (Fig. 43). Comprimento do escapo $0,90 x$ seu diâmetro. Distância interocelar $1,45 x$ maior que a ocelorbital e 1,91x o diâmetro do ocelo médio. Mesoscuto 1,11x mais largo que longo. Escutelo 0,45x mais curto que largo. Tíbia III $0,92 x$ mais curta que a largura máxima da cabeça e $1,90 x$ mais longa que larga; ângulo posterior projetado e a margem apical sinuada. Basitarso III 1,55x mais longo que largo. Asa anterior 2,28x mais longa que a largura máxima da cabeça. Bifurcação de $\mathrm{M}+\mathrm{Cu}$ coincidente com a cu-v. Hâmulos, 5.

Material-tipo. O lectótipo e 2 paralectótipos, operárias, designados da série de síntipos, com as seguintes etiquetas: Lectótipo: "Type", "2." , "B.M. TYPE HYM. 17B .1088”, "Trigona cupira Sm.”, "Smith coll. pres. by Mrs. Farren White 99-303", "LECTOTYPE Partamona cupira (Smith) Des. Camargo \& Pedro, 1995"; Paralectótipo 1: “2.", "Brazil”, "Smith coll. pres. by Mrs. Farren White 99-303", "Partamona cupira (op. simb.) (Smith) det. J.S. Moure", "PARALECTOTYPE Partamona cupira (Smith) Des. Camargo \& Pedro, 1995"; Paralectótipo 2: “2.", "cupira 2", "Smith coll. pres. by Mrs. Farren White 99-303", “Trigona testacea var. cupira (Smith) Det. H.F. Schwarz", "PARALECTOTYPE Partamona cupira (Smith) Des. Camargo \& Pedro, 1995". Depositados no BMNH. Duas operárias, etiquetas "2", "Brazil", "Smith coll. pres. by
Mrs. Farren White. 99-303”, paralectótipos, depositados no AMNH.

Material examinado. BRASIL. Goiás: R. Preto, $20 \mathrm{~km}$ NE Brasília, S. Formosa, 21.X-7.XI.1974, L. Knutson (1 op., USNM); Jataí, Faz. Nova Orlândia, I.1964, Martins, Morgante, Silva, "cerrado" (5 ops., MZSP). Distrito Federal: Brasília, XI.1964, A. Cordeiro (54 ops., DZUP; 10 ops., RPSP). Mato Grosso do Sul: Três Lagoas, Faz. Floresta, 1320.IX.1964, Exp. Depto. Zool. (1 op., MZSP). Minas Gerais: Alpinópolis, II.1961, Claudionor Elias (12 ops., DZUP; 2 ops., RPSP); idem, ibidem, 15-24.V.1963 (2 ops., DZUP); Araxá, 17-23.II.1965 C. Elias (1 op., DZUP); ibidem, ibidem, 5.V.1965 (1op., DZUP), 8.VII.1965 (9 ops., DZUP; 1 op. RPSP); ibidem, 5-10.V.1965, C. \& T. Elias (1 op., DZUP); ibidem, idem, 3.VII.1965 (3 ops., DZUP), 22.VII.1965 (3 ops., DZUP), 5.VIII.1965 (1 op., DZUP); Barbacena, 14-16.II.1962, M. Alvarenga (3 ops., DZUP); Belo Horizonte, 18.I.1996, Y. Antonini, Est. Ecológica 0095-0352 (1 op., BHMH); Brasilândia, 30.IX.1996, A.G. Damasceno, P. emarginatus (1 op., BHMH); ibidem, idem, 22.X.1996, P. emarginatus (1 op., BHMH), 27.XI.1996, D. alata (1 op., BHMH), 28.XI.1996, D. alata (1 op., BHMH), 3.XII.1993, D. alata (1 op., BHMH; 1 op., RPSP), 15.XII.1996, D. alata (1 op., BHMH); Brazópolis, XII.1961, Claudionor Elias (8 ops., DZUP; 1 op., RPSP); Conceição das Alagoas, 29.III.1973, Camargo (11 ops., ninho 35c, RPSP); ibidem, SE-22, 48-20 a, 23.III.1973, G. Penha (1 op., 2 machos, RPSP); Estrela da Barra, 7.VI.1985, Mazucato (1 rainha, 218 ops., 850505, 850587-850698, RPSP); Florestal, 23.VII.1985, G. Melo, C21 (1 op., 1 macho, RPSP); Ibiá, 10.XII.1965, C. Elias (41 ops., DZUP; 10 ops., RPSP); ibidem, 11.X.1965, C. Elias (1 op., DZUP); ibidem, 18.VI.1965, C. Elias (2 ops., DZUP); Ibiraci, X.1961, C. Elias (40 ops., DZUP; 11 ops., RPSP); ibidem, 15.X.1962, C. Elias (6 ops., DZUP); Igarapé, 21.II.1986, G. Melo (4 ops., UFVB; 1 op., RPSP; 3 ops., 280/1/17, MELO); idem, ibidem, 23.II.1986 (2 ops., UFVB), 27.VII.1986 (1 macho, 1 op., 329/1/19, MELO; 2 machos, 1 op., UFVB); Itabirito, 1.I.1987, F. A. Silveira (1 op., 163/438, UFVB); Lagoa Santa, 30.IV.1960, Hurd (1 op., DZUP); Lontra, 44 ${ }^{\circ} 23^{\prime} \mathrm{W}, 15^{\circ} 36^{\prime} \mathrm{S}$, 23.VII.1988, M. Mazucato (24 ops., ninho 463c, RPSP); Luislandia D'Oeste, $45^{\circ} 35^{\prime} \mathrm{W}, 17^{\circ} 1^{\prime} \mathrm{S}, 25$.VII.1988, M. Mazucato (13 ops., mais exemplares em álcool, ninho 464c, RPSP); Nova Resende, 22 27.VII.1963, Claudionor Elias (4 ops., DZUP); Passos, III.1961, Claudionor Elias (9 ops., DZUP); ibidem, idem, V.1961 (9 ops., DZUP),VI.1961 (3 ops., DZUP), VIII.1961 (17 ops., DZUP; 4 ops., RPSP), IX.1961 (3 ops., DZUP), 5-10.XI.1961 (1 op., DZUP), 1318.XI.1961 (1 op., DZUP), 20-25.XI.1961 (2 ops., DZUP),1-8.III.1962 (4 ops., DZUP), 24.II.1962 (2 ops., DZUP), 22-26.V.1962 (5 ops., DZUP), 28.V.1962 (3 ops., DZUP), 29-30.V.1962 (6 ops., DZUP), 1 7.VI.1962 (1 op., DZUP), 13-16.VI.1962 (12 ops., DZUP), 2.VII.1962 (1 op., DZUP), 3.VII.1962 (1 op., DZUP), 18-24.VII.1962 ( 2 ops., DZUP), 22-31.VIII.1962 (1 op., DZUP), 1-7.IX.1962 (2 op., DZUP), 28.XI-7.XII.1962 (1 op., DZUP), 17-22.XII.1962 (1 op., DZUP), 23 31.I.1963 (1 op., DZUP), 7.V.1963 (7 ops., DZUP), 25-31.V.1963 (2 ops., RPSP), 1-8.VI.1963 (1 op., DZUP), 10-15.VI.1963 (1 op., DZUP), 17-22.VI.1963 (8 ops., DZUP), 8-13.VII.1963 (3 ops., DZUP), 1520.VII.1963 (8 ops., DZUP), 29.VII- 3.VIII.1963 (3 ops., DZUP), 27.XI.1963 (1 op., DZUP), 16-21.IX.1963 (66 ops., DZUP; 10 ops., RPSP), 1-5.X.1963 (1 op., DZUP), 24.X.1963 (10 ops., DZUP), 2831.X.1963 (9 ops., DZUP), 4-9.XI.1963 (32 ops., DZUP; 7 ops., RPSP), 18-23.XI.1963 (33 ops., DZUP; 8 ops., RPSP); Patos de Minas, 23.XI.1965, Claudionor Elias (1 op., DZUP); Poços de Caldas, 23.XI.1962, Claudionor Elias (2 ops., DZUP); ibidem, idem, XI.1961 (1 op. DZUP); Ritápolis, SF-23, 44-21d, 19.I.1974, M. Mazucato, Velthuis, J.M.F. Camargo (6 ops., RPSP); Sabará, 24.XI.1996, F.A. Silveira, 0683-1625 (1 op., BHMH); Santa Juliana, 29.VII.1965, C. Elias (1 op., DZUP); ibidem, idem, 4.VI.1965 (1 op., DZUP); Santa Rita de Cássia (= Cássia ?), V.1961, C. Elias (1 op., DZUP); São João Batista da Glória, V.1961, Cladionor (sic) Elias (9 ops., DZUP; 2 ops., RPSP); São João del Rei, SF-23, 44-21c, 5-9.I.1975, Welthuis, J.M.F. Camargo (19 ops., homótipos, RPSP); São José do Barreiro, Serra da Canastra, 03-04.VII.1988, Camargo, Aily, (11 ops., RPSP); São Sebastião do Paraíso, VI.1961, Claudionor Elias (7 ops., DZUP; 1 op., RPSP); Tapira, 27.V.1965, C. Elias (9 ops., DZUP); Vargem Bonita, 23.I.1984, 
M. Mazucato (25 ops., 840473-840482, RPSP); Uberlândia, 08.VI.1993, G.A.R. Melo (1 op., MELO). São Paulo: Patrocínio Paulista, X.1961, Cladionor (sic) Elias (1 op., DZUP).

Distribuição geográfica e hábitat. Cerrados de Minas Gerais e oeste do Mato Grosso do Sul até a mata atlântica do sudeste de Minas Gerais (Fig. 172).

Nidificação. Em termiteiro epígeo (MaRianno, 1911, Camargo, obs. pessoal).

Discussão. Distingue-se das demais espécies do grupo cupira, pela cor da asa, levemente tingida de amarelo na metade basal, flagelo amarelo-alaranjado por inteiro, e pelas cerdas muito curtas no escapo. O exame do material tipo de P. cupira esclareceu uma importante questão dentro do gênero Partamona, já que esse nome vinha sendo usado como um repositório para várias espécies de diversas regiões ( $c f$. CAMARGO, 1988b:357).

Partamona mulata Moure, in Camargo, 1980

(Figs. 1, 44, 138, operárias; 96, 124, macho; 172, distribuição; Tab. II-IX)

Partamona (Partamona) mulata Moure, in Camargo, 1980:9, 18, 23, 52, 53, 55, 76, 143, 159; Camargo, 1992:81.

Partamona mulata; Michener \& Roubik, 1993:256.

Partamona aff. cupira; Camargo \& Moure, 1988:294, 305.

Melipona pallida peckolti; Ducke, 1916:121.41c (partim); 1925:412.42c (partim).

Trigona peckolti; Silvestri, 1902:152, 153.

Trigona cupira; ?Silvestri, 1902:151, 152, 154; Cortopassi-Laurino, 1977:183.

Trigona cupira peckolti; Marianno, 1911:90.13A (partim).

Trigona rhumbleri; Silvestri, 1902:153-155, Figs. 1-4, 33-37, 44(partim).

Trigona (Partamona) testacea cupira; Schwarz, 1948:105, 312.

Diagnose. Abelhas de porte médio (1.m.c. 2,4-2,6 mm, c.a.a. 5,6-6,1; Tabs. III, IV). Integumento preto, mesclado ou castanhoferrugíneo. Sutura epistomal, área ao redor dos ocelos, mesepisternos na porção ventral, basitarso e tíbia III (por inteiro, ou a metade apical), enegrecidos (exemplares pretos e castanhos). Mandíbula com ca. de 1/3-2/3 da porção basal amarelados e a porção apical restante castanho-ferrugínea, ápice ferrugíneo-escuro, côndilos pretos. Flagelo castanho-escuro até amarelado. Estrias paroculares alargadas embaixo (ca. 1,3x o diâmetro do $2^{\circ}$ flagelômero), estreitadas na altura dos alvéolos $\left(0,8 \mathrm{x}\right.$ o diâmetro do $2^{\circ}$ flagelômero), chegando até a altura da interorbital superior (exemplares pretos) ou ao topo do olho (exemplares castanhos) (Fig. 138). Máculas do tórax pouco conspícuas ou apagadas. Pilosidade preta. Membrana das asas levemente ferrugínea; microtríquias pretas; veias méleas, mas escurecidas pelas microtríquias fuscas. Cerdas do escapo curtas, apenas uma ou duas na base um pouco mais longas que as demais (1,0-1,1x o diâmetro do escapo; Tab. VII). Cerdas eretas das áreas paroculares, ao lado dos alvéolos, mais curtas que o diâmetro do escapo. Pilosidade do corpo curta, cerdas do disco do mesoscuto subiguais ao diâmetro do escapo.
Cerdas do escutelo curtas, ca. 0,8-0,9x o comprimento deste. Área basal do propódeo com faixa mediana glabra, aproximadamente tão larga quanto o diâmetro do $2^{\circ}$ flagelômero. Dentes da mandíbula aproximadamente eqüidistantes e um pouco recuados em relação ao ápice do bordo apical (Fig. 44). Área malar, distância interocelar, distância ocelorbital, tíbia III e comprimento da asa anterior, normais (Tabs. V, VI, VIII, IX). Bifurcação da $\mathrm{M}+\mathrm{Cu}$ geralmente coincidente com a cu-v (raramente levemente anterior). Macho, basitarso III curto e largo, achatado ou convexo-côncavo; tíbia III alargada em direção ao ápice (Fig. 96); EVII com a projeção mediana longa, de lados aproximadamente subparalelos, os chanfros laterais profundos e largos (Fig. 124).

Variação. Exemplares dentro do mesmo ninho podem apresentar integumento preto até castanho-ferrugíneo. Os exemplares da Bolívia, todos com integumento preto, apresentam o basitarso um pouco mais alargado e a pilosidade mais curta.

\section{Macho. Figuras 96, 124.}

Material-tipo. Holótipo, operária, de "BRASIL. MT: Cuiabá, 22-II65, S. Laroca", parátipos, 17 operárias, com a mesma etiqueta de procedência, depositados no DZUP; outros parátipos, de Cuiabá, I-1963, M. Alvarenga (14 ops., DZUP, 6 ops., RPSP). Todos os exemplares foram examinados.

Material examinado. BRASIL. Mato Grosso: Cáceres, 19.X.1961, FM Oliveira (20 ops., DZUP; 4 ops., RPSP); Cuiabá, 19.I.1965, S. Laroca (1 macho, DZUP); ibidem, idem, 31.I.1986, G. Melo (2 ops., UFVB); ibidem, idem, 1.II.1986 (1 op., UFVB), 2.II.86 (1 op., 335/1/20, UFVB), 4.II.86 (4 ops., 332/1/19, UFVB), 5.II.1986 (1 op., 290/1/17, UFVB; 8 ops., 267/1/16, UFVB, 12 ops., RPSP), 7.II.1986 (2 ops., 263/1/16, UFVB); ibidem, Campus da UFMT, 19.VII.1997, Rogerio Ribon, "ninho em termiteiro no chão, murundum" (7 ops., 973419-973425, RPSP); ibidem, sem data, anônimo (12 ops., RPSP); Sto. Antonio do Leverger, $15^{\circ} 45^{\prime}$ S, 56 $02^{\circ}$ 'W, 25.I.1997, Mazucato (1 op., 970065, RPSP); West border Matto Grosso, V.1931, RC Shannon (1 op., USNM). Mato Grosso do Sul: Campo Grande, 9.X.1961, FM Oliveira (1 op., DZUP); Selvíria, 28.I.1986, Diniz, J.L.M., 26 (4 ops., RPSP); Três Lagoas, VIII.1965, R. Zucchi (61 ops., DZUP; 15 ops., RPSP); ibidem, Faz. Retiro de Telhas, 21.V.1964, Exp. Depto. Zool., "várzea”, KL.10 (1 op., MZSP); ibidem, Faz Dr. José Mendes, 16.VI.1964, Exp. Depto. Zool., KL.14 (4 ops., MZSP). BOLÍVIA. Beni: Ibiato Loc., Prov. Cercado, 5.VIII.1992, M. E. Montaño, Ac. 14 (3 ops., SEMC). Santa Cruz: Santa Cruz, Bolívia Oriental (localidade?), 500m, 12.VI.1955, Zischka (7 ops., SEMC; 1 op., RPSP). Santa Cruz de la Sierra, X.1961, N. Kempf (6 ops., 1 macho, DZUP; 1 op., RPSP).

Distribuição geográfica e hábitat. Cerrados do sudoeste do Brasil até as savanas da Bolívia (Fig. 172)

Nidificação. Segundo SiLVESTRI (1902), no solo e em troncos de árvores. De acordo com informações pessoais e fotos fornecidas por G. Melo e R. Ribon, nidifica em termiteiros epígeos.

Discussão. Distingue-se das demais espécies do grupo cupira, principalmente pela pilosidade curta e cerdas da base do escapo também curtas. 
Partamona ailyae Camargo, 1980

(Figs. 47, 142, operária; 97, 126, macho; 171, distribuição; Tabs. II-IX)

Partamona (Partamona) ailyae Camargo, 1980:9, 21, 42, 51, 55-56, 74-75, 143, 161; Camargo, 1992:81.

Partamona ailyae; Camargo, 1994:50.

?Partamona nigrior; Camargo \& Roubik, 1991:20 (prov. erro de ident.).

"Cupira"; Castello Branco, 1845:67 (partim, abelhas com cera "vermelha côr de sangue").

Diagnose. Abelhas grandes (1.m.c. 2,6-2,7 mm, c.a.a. 6,1-6,6 $\mathrm{mm}$, Tabs. III, IV). Integumento preto. Mandíbula por inteiro ou predominantemente ferrugínea, apenas o 1/4 basal amarelado ou descolorido; ápice ferrugíneo-escuro, côndilos pretos. Flagelo castanho-escuro, principalmente na face inferior. Brilho violeta no clípeo e áreas paroculares. Estrias paroculares um pouco alargadas embaixo (ca. 1,3x o diâmetro do $2^{\circ}$ flagelômero), com os limites difusos e irregulares, estreitadas um pouco acima das fóveas tentoriais (ca. 0,8x o diâmetro do $2^{\circ}$ flagelômero), chegando até a interorbital superior (Fig. 142); manchas clipeais afastadas por uma distância maior que o diâmetro do escapo. Pilosidade preta. Membrana das asas levemente ferrugínea; microtríquias pretas; veias méleas, escurecidas pelas microtríquias fuscas; $\mathrm{C}$ e R mais escuras, pterostigma mais claro. Cerdas da base do escapo um pouco mais longas que o diâmetro deste (0,9-1,3 x, Tab. VII). Cerdas eretas das áreas paroculares, ao lado dos alvéolos, mais curtas que o diâmetro do escapo. Escutelo com duas ou mais cerdas muito longas no ápice (ca. $1,2-1,5 \mathrm{x}$ o comprimento deste), que se cruzam nas pontas. Área basal do propódeo com faixa glabra mediana, aproximadamente tão larga quanto o diâmetro do $2^{\circ}$ flagelômero. Dentes da mandíbula aproximadamente eqüidistantes e um pouco recuados em relação ao ápice do bordo apical (Fig. 47). Área malar, distância interocelar, distância ocelorbital, tíbia III e comprimento da asa anterior, normais (Tabs. V, VI, VIII, IX). Bifurcação da $\mathrm{M}+\mathrm{Cu}$ nitidamente anterior à cu-v. Macho, basitarso III curto e largo, achatado ou convexo-côncavo; tíbia III alargada em direção ao ápice (Fig. 97); EVII com a projeção mediana longa, de lados aproximadamente subparalelos, os chanfros laterais profundos e largos (Fig. 126).

Variação. Exemplares do Brasil Central apresentam as cerdas do escutelo um pouco mais curtas que aqueles da região amazônica. Alguns poucos exemplares de Tauari, PA, apresentam microtríquias mais claras na região do pterostigma.

\section{Macho. Figuras 97, 126.}

Material-tipo. Holótipo, operária de "Tefé-AM, Brasil, SA-20, 653d, R Carvalho leg., XI.1959” (DZUP) (exemplar descolorido, examinado).

Material examinado. VENEZUELA. Amazonas: Cerro de la Neblina, Basecamp, 050'N, 66 9'44' 'W, 140m, 21-29.II.1984, D. Davis, T. McCabe (2 ops., USNM); ibidem, idem, 13-20.II.1984 (1 op., USNM); Orinoco, 24.1.1992, D. Wittmann (1 op., WITT); ibidem, idem, 14.II.1992 (1 op., WITT), rio Jureba, 6.II.1992 (1 op., WITT). GUIANA. Kuyuwini R., 22.XI.1937, W.G. Hassler (1 op., Ac. 36159, AMNH).
PERU. Loreto: Iquitos, III-IV.1931, R.C. Shannon (1 op., USNM); Satipo, sem data, P. Paprzycki, Collection of Grace H. and John L. Sperry, Al Melander Collection, 1961 (3 ops., USNM); ibidem, idem, I.1943 (1 op., USNM). Madre de Dios: Pto. Maldonado, Tambopata, 31.IX.1962, Luis Peña (8 ops., DZUP; 2 ops., RPSP); ibidem, Puerto Maldonado 15 km NE, Reserva Cuzco Amazônica, 12³3'S, 6903’W, 200m, 5.II.1990, Luis Coloma, 39 (22 ops., SEMC; 4 ops., RPSP); ibidem, $15 \mathrm{~km} \mathrm{NE}$ Pto. Maldonaldo (sic), 22.VI.1989, J.S. Ashe, R. A. Leschen, 195, ex: light intercept (1 op., SEMC); ibidem, $15 \mathrm{~km} \mathrm{NE} \mathrm{Pro.} \mathrm{Maldonado,}$ Tambopata Prov., Reserva Cuzco Amazónica, 12³3'S, 6903'W, 200m, 5.II.1990, Luis Coloma, 39 (8 ops., SEMC, 1 op., RPSP); ibidem, 2.VII.1989, J. Ashe, R. Leschen, 366, ex: ligth intercept (1 op., SEMC); ibidem, idem, 19.VII.1989, 522, light intercerpt (1 op., SEMC). BRASIL: Amazonas: Alvarães, rio Solimões, $64^{\circ} 50^{\prime} \mathrm{W}, 3^{\circ} 13^{\prime}$ 'S, 24.VIII.1993, Camargo, Pedro, Mazucato (60 ops., ninho 624c, mais 2 ops., 936419, 936442, RPSP); Arimã, Rio Purus, SB.20, 634''W, 5²43'S, 3.II.1986, Camargo, Mazucato (74 ops., mais material em álcool, ninho 362c, RPSP); B.A.B.A. (sic = Bê-á-bá), Purus, SB-20, 62 $53^{\prime} \mathrm{W}, 4^{\circ} 52^{\prime} \mathrm{S}, 12-$ 13.II.1986, Camargo, Mazucato (87 ops., 861957-964, 861966-981, 861983-992, RPSP); Camanaus, r. Negro, SA-19, 66 ${ }^{\circ} 54^{\prime} \mathrm{W}, 0^{\circ} 8^{\prime} \mathrm{S}, 12-$ 14.VII.1980, Camargo, Mazucato (1 op., RPSP); Forte da Graça, rio Juruá, 66²'W, 3³9'S, 02-06.VIII.1993, Camargo, Pedro, Mazucato (33 ops., 933747-748, 933751-757, 933762-764, 933767, 933772, 933774, 933777, 933780-782, 933784, 933798, 933803, 933805, 960153-960158, RPSP); Foz do Rio Daraã, r. Negro, SA-19, 64²4’'W, $0^{\circ} 25^{\prime}$ S, 2-4.VIII.1980, Camargo, Mazucato (1 op., RPSP); Foz do rio

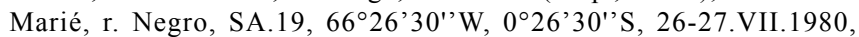
Camargo, Mazucato (57 ops., mais exemplares em álcool, ninho $247 \mathrm{c}$, RPSP); Lago Uará, rio Solimões, $65^{\circ} 35^{\prime} \mathrm{W}, 2^{\circ} 41^{\prime} \mathrm{S}$, 9-13.VIII.1993, Camargo, Pedro, Mazucato (60 ops., 22 machos, mais ops. e 20 machos em álcool, ninho $575 \mathrm{c}$; 60 ops., ninho $576 \mathrm{c} ; 60$ ops., ninho $595 \mathrm{c}$; mais 63ops., 930166-167, 934396-408, 934411, 934424-425, 934427-430, 934432-443, 934445-446, 934455, 934458-459, 934464-467, RPSP); Lago Uaicurapá, SA-21, $56^{\circ} 45^{\prime} \mathrm{W}, 2^{\circ} 46$ 'S, 20.II.1979, Camargo (1 op., RPSP); Maraã, rio Japurá, $65^{\circ} 35^{\prime} \mathrm{W}, 1^{\circ} 53^{\prime}$ 'S, 17.VIII.1993, Camargo, Pedro, Mazucato (78 ops., mais ops. e 20 machos em álcool, ninho 601c, mais 9 ops., 935408-409, 935412, 935426, 935428, 935432, 935434, 935436, RPSP); Moura, rio Negro, 27-30.IV.1949, Th. Dobzhansky (1 op., DZUP); Nogueiras, Lago de Tefé, 644ㅇ' $\mathrm{W}, 3^{\circ} 19^{\prime} \mathrm{S}$, 25-26.VIII.1993, Camargo, Pedro, Mazucato (60 ops., mais ops. e 14 machos em álcool, ninho 630c; 60 ops., ninho 633c; mais 2 ops., 936271,

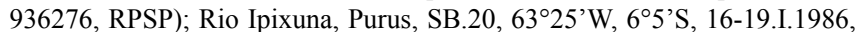
Camargo, Mazucato (15 ops., 860264, 860271, 860483-484, 860489, $860493,860495,860501,860503-504,860507,860510$, 860514516, RPSP); Rio Maturacá, 8-12.XII.1930, Holt, Blake, Agostini (5 ops., USNM); Tefé, SA.20, 65.3g.iii, 29.I.1977, Camargo, Mazucato (35 ops., ninho 114c, RPSP); ibidem, idem, 27-30.I.1977 (128 ops., RPSP); ibidem, 1-4.XII.1961, F.M. Oliveira (1 op., DZUP); ibidem, I.1962, E. Carvalho (2 ops., DZUP); ibidem, IX.1959, R. Carvalho (1 op., DZUP); Vila Nova do Tonantins, SA-19, 68-3f,ix, 22-23.I.1977, Camargo, M. Mazucato (35 ops., RPSP). Pará: Belém, VI.1966, R. Zucchi (4 op., RPSP); Cachimbo, VI.1962, Alvarenga, Oliveira (1 op., DZUP); ibidem, X.1955, M Alvarenga (1 op., SEMC); Capanema, SA23, 47II-1c, 15.II.1984, Camargo, Mazucato (99 op., 840177-840209, RPSP); Conceição Araguaia, VII.1959, M. Alvarenga (2 ops., DZUP); Corací, 15 km NW Canindé, rio Gurupí, IV.1963, B. Malkin (4 ops., MZSP); Gradaus, $7^{\circ} 48^{\prime} \mathrm{S}, 5^{\circ} 7^{\prime} \mathrm{W}, \mathrm{X} .1977$, Posey, 96 (1 op., RPSP); ibidem, idem, 03.VIII.1978, 581 (1 op., RPSP); Jacareacanga, X.1959, M. Alvarenga leg. (3 ops., DZUP); Mangabeira, Mocajuba, VI.1953, Orlando Rego (5 ops., DZUP); Mussum (sic = Muçum) $15 \mathrm{~km} \mathrm{~S}$ Aveiro,

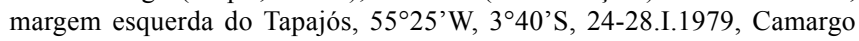
et al. (8 ops, ninho 148c, RPSP); ibidem, 25.I.1979, Othonyel R.L. Filho (3 ops., T-32/33, INPA); Rio Gurupí, IX.1955, A. Aguirre (1 op.,

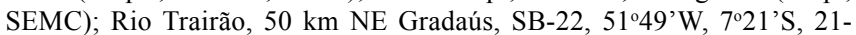
24.VII.1979, Mazucato (3 ops., RPSP); São Luís do Tapajós, SB-21, 56 ${ }^{\circ} 14^{\prime} \mathrm{W}, 4^{\circ} 26^{\prime}$ 'S, 14-17.I.1979, Camargo (1 op., RPSP); Tauari, $80 \mathrm{~km}$ $\mathrm{N}$ Aveiro, $55^{\circ} 7^{\prime} \mathrm{W}, 3^{\circ} 5^{\prime} \mathrm{S}, 29 . \mathrm{I}-1 . \mathrm{II} .1979$, Camargo et al. (38 ops., 1 macho, mais exemplares em álcool, ninho 163c; 37 ops., ninho 164c, RPSP); ibidem, 31.I.1979, Othonyel R.L. Filho (13 ops., T-50, INPA). Acre: Nova Califórnia, 28.X.1994, E. F. Morato, 0127 (5 ops., RPSP); 
Parque Nacional Serra do Divisor, Sítio 1, Morro Queimado, 07²6’36”S, 7340'28”W, 10.XI.1996, E. F. Morato (3 ops., 971037-39, RPSP); ibidem, idem, Sítio 1, Rio Branco, 08 ${ }^{\circ} 16^{\prime} 51^{\prime \prime S}, 7^{\circ} 15^{\prime} 13^{\prime \prime W}, 10 . I I I .1997$ (2 ops., 972046, 972049, RPSP), Sítio 4, Rio Ouro Preto, 08²4'19”S, 7251'28”W, 15.III.1997 (1 op., 972151, RPSP), Sítio 6, Trilha do Anil, 07²6'27"S, 73039'28"W, 08-09.XI.1996 (27 ops., 1 macho, 971455-76, 971479-80, 971483-84, 971486-87, RPSP), Sítio 8, Rio Azul, 07³3'24”'S, 73¹6’36”'W, 24.XI.1996 (6 ops., 971555, 971758, 971759, 971760, 971762, 971890, RPSP); Rio Branco, 15-20.XI.1961, F. M. Oliveira (5 ops., DZUP); Sena Madureira, Rio Caeté, $68^{\circ} 40^{\prime} 4,8^{\prime \prime} \mathrm{W}$, 0903'14,4'S, 1.IV.1994, E. F. Morato (12 ops., RPSP); ibidem, idem, Rio Iaco, 68 $40^{\prime} 4,8^{\prime \prime} \mathrm{W}, 09^{\circ} 03^{\prime} 14,4^{\prime}$ 'S, 1.IV.1994 (1 op., RPSP). Rondônia: Alta Floresta, linha P50, $12^{\circ} 06,987^{\prime} \mathrm{S}, 62^{\circ} 00,049^{\prime} \mathrm{W}$, 24.IV.1997, Brown, Boina, Vieira (6 ops., 8422, 8423, 8439, 8440, 8441, 8442, RPSP); Ariquemes, $62 \mathrm{~km} \mathrm{S,} \mathrm{Faz.} \mathrm{Rancho} \mathrm{Grande,} \mathrm{nr.}$ Cacaolândia, $10^{\circ} 32^{\prime} 0^{\prime}$ S, 62 $48^{\circ} 0$ ”'W, 28.XII.1995, D. Kistner BRA1K 01 No. 5288, ex: flight intercept trap (2 ops., SM0135006, 0135023, SEMC); ibidem, idem, 29.XII.1995, BRA1K 02, No. 5293, ex: flight intercept trap (3 ops., SM0135036, 0135039, 0135062, SEMC); Campo Novo, BR-421/Rio Jaci-Paraná, $10^{\circ} 26^{\prime} 13,0^{\prime \prime} \mathrm{S}, \quad 64^{\circ} 07^{\prime} 36,1$ ”W, 11.IX.1997, Brown, Boina, Vieira (1 op., 14255, RPSP); ibidem, idem, estrada CN, Buritis, 10²3'32,2”S, 63³9'25,6”W, 10.IX.1997 (2 ops., 14501, 14508, RPSP), BR-421 oeste de C.N., 11.IX.1997, 10²7'06,1”S, $63^{\circ} 51^{\prime} 52,8^{\prime \prime} \mathrm{W}$ (2 ops., 14291, 14320, RPSP); ibidem, Ig. Tracoazinho, Reg. Cpo. Novo, 1-15.VIII.1985, V. Py-Daniel, L. Aquino (5 ops., INPA); ibidem, Rio Candeias, Reg. Cpo. Novo, 6.VIII.1985, V. Py-Daniel, L. Aquino (19 ops., INPA); ibidem, idem, 14.VIII.1985 (1 op., INPA), 1018.VIII.1985 (1 op., INPA); Cerejeiras, S 1314,366', W 6050,462', 24.II.1997, Brown, Boina, Vieira (6 ops., 5395, 5414-5418, RPSP); ibidem, idem, S 13¹6,113', W 60'50,945', 25.II.1997, (1 op., 5350, RPSP); Chupinguaia, S $12^{\circ} 32,867^{\prime}$, W $61^{\circ} 10,798^{\prime}, 22$. II.1997, Brown, Boina, Vieira (14 ops., 5471-5476, 5479, 5484, 5485, 5512, 5513,

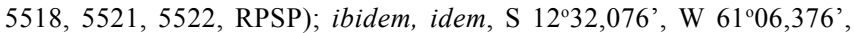
22.II.1997 (1 op., 5580, RPSP), S 12³2,867', W 61010,798', 22.II.1997

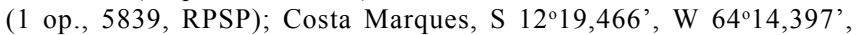
18.XI.1996, Brown, Boina, Vieira (4 ops., 3264-3267, RPSP); ibidem, idem, S 1052,188', W 62³0,632', 8.I.1997 (1 op., 4710, RPSP); Costa Marques / Guajará Mirim, S $11^{\circ} 54,922^{\prime}$, W 64º $12,769^{\prime}$, 26.XI.1996, Brown, Boina, Vieira (1 op., 4136, RPSP); ibidem, idem, S 11 ${ }^{\circ} 54,516^{\prime}$, W 641ำ $288^{\prime}$, 26.XI.1996, (1 op., 4185, RPSP); Cujubim, 09²0,765'S, 62³6,792'W, 26.III.1997, Brown, Boina, Vieira (1 op., 7288, RPSP);

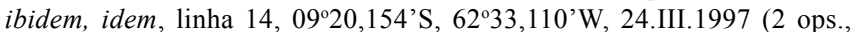
6679, 6724, RPSP), Reserva Rio Cujubim, 09²0,308'S, 62³4,440’W, 24.III.1997 (4 ops., 6911, 6912, 6915, 6957, RPSP); Extrema, linha 4, 094' 56,5”S, 66 26'58,5”W, 26.VI.1997, Brown, Boina, Vieira (3 ops., 11280, 11305, 11329, RPSP); Guajará Mirim, Sa. Pacaás Novos, 22.VIII.1995, F.M. Dantas (2 ops., PN0438, PN0431, RPSP); ibidem, S $10^{\circ} 33,751^{\prime}$, W 6445,463', 10.IX.1996, Brown, Boina, Vieira (1 op., 575, RPSP); ibidem, idem, S $10^{\circ} 19,434^{\prime}$, W 64³3,849', 11.IX.1996 (3 ops., 523, 528, 529, RPSP), S 1051,113', W 64²58,406', 6.X.1996, (2 ops., 1568, 1573, RPSP), S 1050,391', W 64ํ5, $509^{\circ}$ ', 7.X.1996 (1 op., 1698, RPSP), S 1048,908', W 6453,691', 8.X.1996, (2 ops., 1713, 1717, RPSP), S $10^{\circ} 45,516^{\prime}$, W $64^{\circ} 42,761^{\prime}$, 9.X.1996, (9 ops., 1812-1814, 1818, 1871, 1878, 1898, 1900, 1903, RPSP), S 1049,464', W 64'54,282', 9.X.1996 (4 ops., 1771, 1787, 1810, 1811, RPSP), S

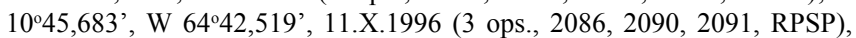
Parque Estadual GM, 10'33'44,8”S, 6446'00,6”W, 30.VI.1997 (12 ops., $11514,11515,11519,11532-11535,11544,11551,11560,11561$, 11570 , RPSP); Jaciparaná, BR-364, $09^{\circ} 08^{\prime} 38,9^{\prime} \mathrm{S}, 64^{\circ} 10^{\prime} 03,1$ ”W, 28.VI.1997, Brown, Boina, Vieira (1 op., 11437, RPSP); Machadinho, 09²6,958'S, 6151,445'W, 21.III.1997, Brown, Boina, Vieira (1 op., 6490, RPSP); ibidem, idem, estrada 133 a Tabajara, $09^{\circ} 03,395^{\prime} \mathrm{S}$, $62^{\circ} 03,749^{\prime}$ W, $22 . I I I .1997$ (1 op., 6590, RPSP); Mirante da Serra, S $11^{\circ} 10,181^{\prime}$, W $62^{\circ} 51,110^{\prime}, 25$. IX.1996, Brown, Boina, Vieira (4 ops., $2343,2459,2503,2522$, RPSP); ibidem, idem, S $11^{\circ} 03,255^{\prime}$, W

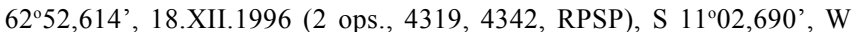
62 ${ }^{\circ} 50,400^{\prime}, 7 . I .1997$ (4 ops., 4632, 4633, 4641, 4642, RPSP), S $10^{\circ} 56,284^{\prime}$, W $62^{\circ} 42,425^{\prime}, 31 . I .1997$ (7 ops., 5134, 5136, 5137, 5180, 5192-5194, RPSP), S $11^{\circ} 03,694^{\prime}$, W 62²42,789', 3.III.1997 (2 ops., 5850, 5851, RPSP), S $11^{\circ} 04,356^{\prime}$, W 62054,673', 4.III.1997 (4 ops.,

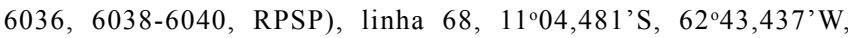
17.IV.1997 ( 1 op., 7549, RPSP), linha 76, $11^{\circ} 07,142^{\prime} \mathrm{S}, 62^{\circ} 48,389^{\prime} \mathrm{W}$,

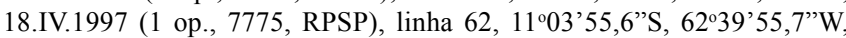
15.V.1997 (1 op., 9163, RPSP), linha 66, $11^{\circ} 05^{\prime} 07,0^{\prime \prime}$ S, 62 $62^{\circ} 3^{\prime} 28,5^{\prime \prime} \mathrm{W}$, 15.V.1997 (2 ops., 9177, 9178, RPSP), linha 64, 1058'35,3”S, $62^{\circ} 47^{\prime} 08,0$ ”'W, 16.V.1997 (2 ops., 9254, 9255, RPSP), linha 68, $11^{\circ} 05^{\prime} 14,2$ ”S, 62 $44^{\prime} 31,3$ ”W, 16.V.1997 (3 ops., 9192, 9195, 9216 , RPSP), linha $80,11^{\circ} 05^{\prime} 35,2^{\prime}$ 'S, 62 $53^{\circ} 20,1^{\prime \prime W}, 10 . V I .1997$ (8 ops., 10949-10951, 10960, 10966-10968, 10970, RPSP), linha 74 , $11^{\circ} 08^{\prime} 22,4$ "S, 62 $46^{\prime} 04,9$ 'W, 21.VIII.1997 (3 ops., 13566, 13567 , 13572, RPSP), linha 78, $11^{\circ} 10^{\prime} 01,6^{\prime}$ 'S, $61^{\circ} 45^{\prime} 56,6^{\prime} \mathrm{W}, 28$.VIII.1997 (1 op., 13673, RPSP), linha $80,1^{\circ} 06^{\prime} 46,3^{\prime \prime}$, 62 62 $51^{\prime} 03,6^{\prime \prime} \mathrm{W}, 29 . \mathrm{VIII} .1997$ ( 2 ops., 13916, 13917, RPSP), linha $84,11^{\circ} 08^{\prime} 01,6^{\prime \prime} \mathrm{S}, 62^{\circ} 53^{\prime} 21,3^{\prime \prime} \mathrm{W}$, 29.VIII.1997 (1 op., 13816, RPSP); Montenegro, estrada a Buritis, $10^{\circ} 20^{\prime} 43,9$ "S, 6326'10,4”W, 9.IX.1997, Brown, Boina, Vieira (3 ops. 14167, 14168, 14169, RPSP); Nova Califórnia, linha Pioneiros, 09'46'47,7”S, 66 37'41,2”W, 24.VI.1997, Brown, Boina, Vieira (3 ops., $11041,11042,11075$, RPSP); Nova Mamoré, S 10¹9,434', W 64³3,849', 7.IX.1996, Brown, Boina, Vieira (1 op., 1301, RPSP); ibidem, idem, S $10^{\circ} 19,440^{\prime}$, W 6446,775', $12 . I X .1996$ (9 ops., 189, 252, 275, 276, 280, 281, 298-300, RPSP); Nova União, S 1047,659', W 62 28,431 ', 26.IX.1996, Brown, Boina, Vieira (1 op., 2537, RPSP); ibidem, idem, S $10^{\circ} 52,532^{\prime}$, W 62³5,181', 8.XI.1996, (1 op., 3058, RPSP), S 1052,198', W 62³3,421', 8.XI.1996 (1 op., 3156, RPSP), S $10^{\circ} 51,788^{\prime}, \mathrm{W} 62^{\circ} 23,348^{\prime}, 8 . \mathrm{III} .1997$ (13 ops., 6122-6124, 6130, 6138, $6139,6173,6175-6177,6183-6185$, RPSP), linha $48,10^{\circ} 53,863$ 'S, 6239,944'W, 16.IV.1997 (5 ops., 7450-7452, 7465, 7467, RPSP), linha 40, 1054'08,0"S, 62'32'58,6”W, 14.V.1997 (1 op., 8986, RPSP), linha $36,10^{\circ} 59^{\prime} 22,9^{\prime} \mathrm{S}, 62^{\circ} 34^{\prime} 18,0$ "W, 18.VII.1997 (1 op., 11767 , RPSP), linha $28,10^{\circ} 53^{\prime} 16,6^{\prime} \mathrm{S}, 62^{\circ} 26^{\prime} 23,8^{\prime \prime} \mathrm{W}, 1$.VIII.1997 (2 ops., 12411,12424 , RPSP), linha $36,10^{\circ} 50^{\prime} 56,1^{\prime \prime S}, 62^{\circ} 34^{\prime} 18,8^{\prime \prime} \mathrm{W}$ 11.VIII.1997 (1 op., 12647, RPSP), linha 40, 1051'42,4”S, 62'36'31,7'W, 12.VIII.1997 (2 ops., 12727, 12728, RPSP), linha 36, $10^{\circ} 48^{\prime} 30,9$ "S, 62³6'27,1”W, 1.IX.1997 (6 ops., 14144-14147, 14154 ,

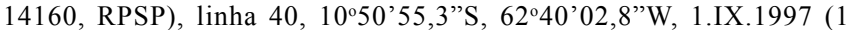
op., 14133, RPSP); Ouro Preto (= Ouro Preto D'Oeste), S 1044,920', W 6218,205', 9.I.1997, Brown, Boina, Vieira (1 op., 4853, RPSP); ibidem, idem, S $10^{\circ} 48,725^{\prime}, \mathrm{W} 62^{\circ} 23,811^{\prime}, 30 . \mathrm{I} .1997$ (1 op., 5088), linha 16, 1044'40,0"S, 62'26'20,1"W, 13.V.1997 (3 ops., 8952-8954, RPSP), linha 8, 10³9'25,3"S, 62'23'57,4”W, 21.VII.1997 ( 4 ops., $11810,11813,11824,11835$, RPSP), linha $20,10^{\circ} 50$ '35,7”S, $62^{\circ} 22^{\prime} 45,1$ 'W, 30.VII.1995 (1 op., 12277, RPSP); Pimenta Bueno, XI.1960, M. Alvarenga (4 ops., DZUP); ibidem, (Guaporé) XI.1960, M.

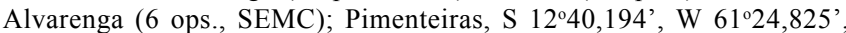
19.II.1997, Brown, Boina, Vieira (1 op., 5742, RPSP); ibidem, idem, S $12^{\circ} 38,100^{\prime}, \mathrm{W} 61^{\circ} 26,147^{\prime}, 20$. II.1997 (1 op., 5628, RPSP); Porto Velho, 12-22.X.1966, Camargo (1 op., RPSP); ibidem, XI.1954, M. Alvarenga, Dente, F. Pereira, Werner (1 op., DZUP); ibidem, Estação Ecológica Cuniã, 08¹7'48,1'S, 63³0’30,4”W, 23.V.1997, Brown, Boina, Vieira (7 ops., 9849, 9904, 9918, 9919, 9952, 9953, 9972, RPSP);

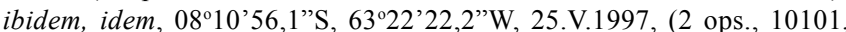
10127, RPSP), 08²0'00,6”S, 63³1'29,6”W, 26.V.1997 (1 op., 10333, RPSP); Rolim de Moura, linha 192, $11^{\circ} 42,293^{\prime} \mathrm{S}, 6^{\circ} 42,216^{\prime} \mathrm{W}$, 26.IV.1997, Brown, Boina, Vieira (5 ops., 8541, 8544, 8545, 8565, 8566 , RPSP); ibidem, idem, linha $168,11^{\circ} 33,966^{\prime} \mathrm{S}, 61^{\circ} 54,845^{\prime} \mathrm{W}$, 27.IV.1997 (1 op., 8807, RPSP); São Miguel do Guaporé, linha 25, $11^{\circ} 43,563^{\prime}$ 'S, 62 $44,233^{\prime} \mathrm{W}, 20 . I V .1997$, Brown, Boina, Vieira (7 ops., $7859-7862,7877,7878,7887$, RPSP); ibidem, idem, linha 9, $11^{\circ} 49,289^{\prime}$ 'S, 62 $2^{\circ} 50,498^{\prime} \mathrm{W}, 21 . I V .1997$ (1 op., 8042, RPSP), linha 82, $11^{\circ} 39,079^{\prime} \mathrm{S}, 62^{\circ} 43,193^{\prime} \mathrm{W}, 22 . I V .1997$ (3 ops., 8119-8121, RPSP),

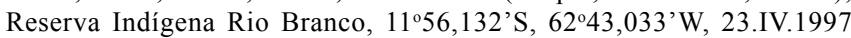
(1 op., 8195, RPSP); Vilhena, XI.1960, M. Alvarenga (1 op., DZUP).

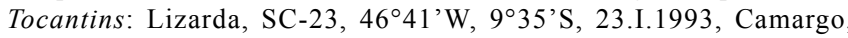

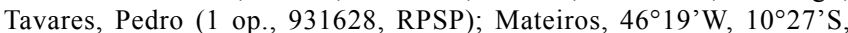
650m, 10-12.VII.1995, Camargo, Pedro (1 op., 950965, RPSP); Paraíso do Tocantins, $20 \mathrm{~km} \mathrm{~N}, 48^{\circ} 4^{\prime} \mathrm{W}, 8^{\circ} 4^{\prime} \mathrm{S}$, 9.XI.1994, Camargo, Pedro (5 ops., 941959-963, RPSP); Reserva Krahó-Galheiros, 45 km SE de Itacajá, 20-21.I.1993, Camargo, Tavares, Pedro (43 ops., ninho 497c; 123 ops., ninho 499c, mais 17 ops., 930408, 930410-413, 930419, 930423 , 930428, 930430-432, 930591-592, 930594, 930596, 930600, 931303, 
RPSP). Maranhão: Carolina, 7.I.1961, anônimo (1 op., USNM); Chapadinha, sem data, Brito, Rego (4 ops., RPSP); Imperatriz, SB-23, 47-6a, 22.VII.1972, Laroca (2 ops., RPSP); Igarapé Gurupí - Uma (sic = Una?) Aldeia Araçú, $50 \mathrm{~km} \mathrm{E.} \mathrm{de} \mathrm{Canindé,} \mathrm{V.1963,} \mathrm{Malkin} \mathrm{(6} \mathrm{ops.,}$ MZSP); Mirador, 12.III.1997, M. Bezerra, N-4 (3 ops., 971954-956, RPSP); ibidem, idem, 15.III.1997, N-12 (3 ops., 971978-980, RPSP), 16.III.1997, N-25 (3 ops., 972017-019, RPSP), 17.III.1997, N-28 (3 ops., 972027-028, RPSP); Nova Olinda, SA-23, 46 vi-3f, 15.II.1984, Camargo, Mazucato (2 ops., 040086, 040087, RPSP); São Luis, 24.XII.1982, Mazucato, Aily, Camargo (1 op., 822574); São Raimundo das Mangueiras, 29.VII.1982, Camargo (3 ops., 820987, 820991, 820994, RPSP). Piauí: Bom Jesus $30 \mathrm{~km} \mathrm{NW,} \mathrm{Brejo} \mathrm{da} \mathrm{Conceição,} \mathrm{mun.}$

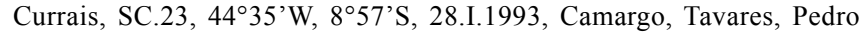
(72 ops., ninho 510c, RPSP); ibidem, idem, 25-29.I.1993 (2 ops., 931498, 931486, RPSP); ibidem, 39 km NW Bom Jesus, 16.XI.1994, Camargo, Pedro (60 ops., 1 macho, mais ops. e 6 machos em álcool, ninho 666c; 33 ops., ninho 670c; mais 7 ops., 941821, 941824-829,

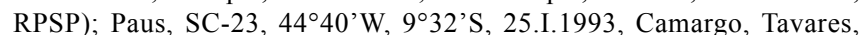
Pedro (2 ops., 931784, 931785, RPSP); Sta. Filomena 48 km SE, SC.23, $45^{\circ} 38^{\prime} \mathrm{W}, 9^{\circ} 18^{\prime} \mathrm{S}, 24 . \mathrm{I} .1993$, Camargo, Tavares, Pedro (105 ops., mais ops. e 50 machos em álcool, ninho 505c, RPSP); Uruçuí-Una, Bom

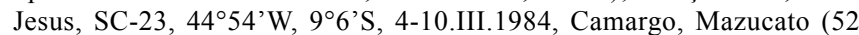
ops., mais mat. em álcool, ninho 316c, mais 24 ops., 840306, 840331, 840336, 840337, 840409, 840405-406, 840407-408, 840410-414, RPSP). Ceará: Ubajara, 16.XII.1982, Mazucato, Aily (1 op., 822298, RPSP); Viçosa do Ceará, SA-24, 39-18a., III.1970, E. Mopurunga (1 op., RPSP). Mato Grosso: Nova Xavantina, sem data, anônimo (12 ops., RPSP); Rio das Mortes, Chavantina (sic), VII.1962 M. Alvarenga, F. M. Oliveira, DR 12 (1 op., SEMC); Utiariti, rio Papagaio, X.1966, Lenko, Pereira (2 ops., MZSP); Xavantina, 3.VIII.1964, M. Alvarenga (1 op., DZUP). Goiás: Aragarças, 10-24.I.1971, Camargo et al. (13 ops., ninho 2c, 6 ops., mais material em álcool, ninho 6c, mais 29 ops., RPSP); ibidem, 13.I.1971, Y. Terada (2 ops., RPSP); ibidem, I.1955, F.M. Oliveira (3 ops., DZUP); Dianópolis, 12.III.1962, F.M. Oliveira (5 ops., DZUP; 1 op., RPSP); Goiânia, 20.III.1962, F.M. Oliveira (1 op. DZUP);

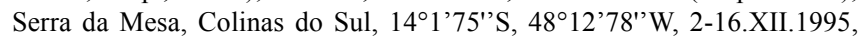
Silvestre (1 op., 960027, RPSP). Mato Grosso do Sul: Três Lagoas, VIII.1965, R. Zucchi (76 ops., DZUP). Minas Gerais: Uberaba, X.1961, C. Elias (3 ops., DZUP). BOLÍVIA. La Paz: Rio Heath, $\sim 13^{\circ} \mathrm{S}, 69^{\circ} \mathrm{W}$, 600m, 20.II.1990 Luis Coloma, 47 (12 ops., SEMC; 3 ops., RPSP). Beni: Rurrenabaque, 175m, 17.X.1956, L. Peña (1 op., SEMC); Chapare, El Palmar, 900m, 15.IX.1956, L. Peña (12 ops., SEMC; 3 ops., RPSP).

Distribuição geográfica e hábitat. Amplamente distribuída, ocorrendo na floresta amazônica, cerrados do Brasil central e chegando até as regiões xéricas do nordeste, no Piauí e Ceará (Fig. 171).

Nidificação. Na Amazônia habita, usualmente, termiteiros em tocos de árvores secas ou podres e termiteiros no interior da base de troncos de árvores vivas; no Brasil Central e nordeste, habita termiteiros epígeos e subterrâneos. Hospedeiros identificados: Syntermes molestus (Burmeister, 1839) (ninhos nos. 6c e 505c) e Termes cf. medioculatus Emerson, 1925 (ninho 148c).

Discussão. O holótipo é um tanto descolorido, de cor castanha, e foi incluída no "grupo" das espécies "amarelas" por CAMARGo (1980); só agora, com material abundante, foi possível reconhece-la como uma das espécies mais comuns na Amazônia e Brasil Central. No grupo cupira, destaca-se pela ampla distribuição geográfica. É importante destacar que esta espécie pode se constituir de duas populações distintas, como sugerem os hábitos de nidificação: uma ocupando as florestas amazônicas (ninhos em termiteiros de troncos podres ou de árvores vivas) e outra de regiões mais secas, ocorrendo nos cerrados do Brasil central, que nidifica em termiteiros subterrâneos, geralmente no "pé" de árvores vivas ou em termiteiros epígeos do tipo "murundu". Pode ser facilmente reconhecida pelas longas cerdas na margem posterior do escutelo, presença de brilho violeta no clípeo, fronte e áreas paroculares, manchas clipeais afastadas, ausência de cerdas longas nas áreas paroculares ao lado dos alvéolos, bifurcação de $\mathrm{R}+\mathrm{M}$ anterior à cu-v e asas levemente ferrugíneas. Exceto pela cor das asas, é muito semelhante a $P$. sooretamae sp. nov. (esta com asas ferrugíneo-escuras), das matas atlânticas do Espírito Santo, sua provável espécie-irmã.

\section{Partamona sooretamae sp. nov.}

(Fig. 171, distribuição; Tabs. II-IX, XIII)

Diagnose. Abelhas grandes (1.m.c. 2,6-2,8 mm, c.a.a. 6,6-6,8 $\mathrm{mm}$, Tabs. III, IV). Integumento preto. Mandíbula predominantemente ferrugínea, apenas o 1/4 basal amarelo, ápice ferrugíneo-escuro, côndilos pretos. Flagelo castanhoescuro. Brilho violeta no clípeo e áreas paroculares inferiores. Estrias paroculares um pouco alargadas embaixo (ca. 1,3x o diâmetro do $2^{\circ}$ flagelômero), com os limites difusos e irregulares, estreitadas um pouco acima das fóveas tentoriais (ca. $0,8 \mathrm{x}$ o diâmetro do $2^{\circ}$ flagelômero), chegando até a interorbital superior (como na figura 142 de P. ailyae); manchas clipeais afastadas, por uma distância maior que o diâmetro do escapo. Pilosidade preta. Membrana das asas ferrugínea escura; microtríquias pretas; veias escurecidas, principalmente na metade basal da asa. Cerdas da base do escapo um pouco mais longas que o diâmetro deste (1,2-1,3x; Tab. VII). Cerdas eretas das áreas paroculares, ao lado dos alvéolos, mais curtas que o diâmetro do escapo. Ápice do escutelo com duas ou mais cerdas longas, ca. 1,1-1,2x o comprimento do escutelo, que se cruzam nas pontas. Área basal do propódeo com faixa glabra mediana, aproximadamente tão larga quanto o diâmetro do $2^{\circ}$ flagelômero Dentes da mandíbula aproximadamente eqüidistantes e um pouco recuados em relação ao ápice do bordo apical (como na figura 47 de P. ailyae). Área malar, distância interocelar, distância ocelorbital, tíbia III e comprimento da asa anterior, normais (Tabs. V, VI, VIII, IX). Bifurcação da M+Cu nitidamente anterior à cu-v.

\section{Operária.}

Dimensões. Comprimento total aproximado, $6,14 \mathrm{~mm}$; da asa anterior, 6,64 $\mathrm{mm}$ (incluindo a tégula, 7,47 $\mathrm{mm}$ ); largura máxima da cabeça, 2,68 mm; do TIII, 2,74 mm (Tab. XIII).

Cor do integumento. Predominantemente preto, apenas metanoto e tíbias III mais claros, tarsômeros ferrugíneos. Tégulas castanho-ferrugíneas. Com brilho violeta no clípeo e áreas paroculares inferiores. Labro amarelado, mandíbula amarelada na metade basal e ferrugínea em direção ao ápice, côndilos enegrecidos. Escapo enegrecido, exceto por uma mancha amarelada no terço basal e no extremo apical. Flagelo 
castanho, mais escurecido na face superior. Máculas da face nítidas, as do tórax apagadas. Manchas no clípeo aproximadamente em forma de $\mathrm{L}$, acastanhadas, a distância entre elas, na porção apical do clípeo, maior que o diâmetro do $2^{\circ}$ flagelômero. Mancha supraclipeal como um acento circunflexo. Abaixo do ocelo, um triângulo invertido, alongado, aproximadamente tão longo quanto o diâmetro do ocelo médio. Uma mancha irregular junto ao sulco frontal. Estrias paroculares alargadas embaixo (ca. 1,38x o diâmetro do escapo), com os limites difusos e irregulares, estreitando-se na alturas da fóveas tentoriais, mantendo a largura mais ou menos uniforme $(0,63 \mathrm{x})$ até um pouco antes da linha da menor distância interorbital superior, aí já bem apagadas. Genas com pequena mancha margeando o terço inferior do olho. Estrias laterais do mesoscuto um pouco apagadas; axilas irregularmente manchadas; bordo posterior do escutelo apenas um pouco mais claro que o restante do integumento. Membrana da asa anterior ferrugíneo-escura, um pouco mais tingida na metade basal (células radial, $1^{\mathrm{a}} \mathrm{e} 2^{\mathrm{a}}$ cubitais); microtríquias enegrecidas em toda asa; veias méleas, escurecidas pelas microtríquias, $\mathrm{Ce}$ $\mathrm{R}$ mais escuras para a base.

Pilosidade. Predominantemente enegrecida; mais clara, amarelo-palha, na porção ventral do tórax (coxas, trocanteres e mesepisternos) e esternos. Área basal do propódeo aparentemente sem faixa glabra mediana. Franja pré-marginal do TIII com cerdas muito mais curtas na região mediana que nas laterais. Cerdas da base do escapo tão longas quanto o diâmetro deste. Área parocular inferior, ao lado dos alvéolos, com cerdas eretas $0,8 \mathrm{x}$ o diâmetro do escapo; no clípeo, 1,07x; na fronte, $1,27 \mathrm{x}$; no vértice mais longas, ca. $2,47 \mathrm{x}$; no disco do mesoscuto e na porção anterior da linha média, 1,53 e 2,27x respectivamente. Cerdas mais longas no ápice do escutelo com ca. de 1,05x o comprimento deste (nos parátipos, mais longas).

Integumento. Liso e polido, apenas com a pontuação pilígera típica do gênero.

Forma e proporções (Tab. XIII). Cabeça, 1,18x mais larga que longa, 1,33x mais larga que a distância clipeocelar. Olhos 2,46x mais longos que largos, divergentes embaixo. Área malar ca. de $1,13 \mathrm{x}$ o diâmetro do $2^{\circ}$ flagelômero. Clípeo $0,56 \mathrm{x}$ mais curto que sua largura máxima e $0,38 \mathrm{x}$ a distância clipeocelar. Mandíbulas $0,58 \mathrm{x}$ a distância clipeocelar; dentes recuados, espaçados (Fig. 47). Escapo 0,95x a distância alvéolo-ocelo lateral, seu diâmetro um pouco menor que o do $2^{\circ}$ flagelômero. Distância interocelar 1,26x maior que a ocelorbital e ca. de 1,72x o diâmetro do ocelo médio. Escutelo aproximadamente semicircular, cerca de $0,46 \mathrm{x}$ mais curto que largo. Tíbia III 0,97x mais curta que a cabeça, e 2,10x mais longa que larga; o canto póstero-distal arredondado, não projetado, a margem apical quase reta; contorno da margem posterior suavemente sinuado. Basitarso III 1,72x mais longo que largo; canto póstero-distal subanguloso e margem apical em ângulo um pouco maior que $90^{\circ} \mathrm{em}$ relação à margem anterior. Asa anterior 2,63x mais longa que larga e 2,48x a largura máxima da cabeça. Bifurcação de
$\mathrm{M}+\mathrm{Cu}$ anterior à cu-v. Hâmulos, 5 .

Macho. Desconhecido.

Material-tipo. Holótipo, operária, de "Itarana - Brasil, ES - 12/2/ 1966 C. Elias leg." (DZUP); parátipos, 18 operárias da mesma série, depositados no DZUP (10) e RPSP (08).

Material examinado. BRASIL. Bahia: Porto Seguro, Praia de Taperapuã, 39¹'7'W, 16'22'42”S, 15-21.XII.1998, S.R.M Pedro (3 ops., 981287, 981290, 981420, RPSP). Espirito Santo: Colatina, 25.IV.1964, C. Elias (13 ops., DZUP; 3 ops., RPSP); Conceição da Barra, 1.VIII.1968, C. Tadeu Elias (1 op., DZUP); ibidem, 5.V.1969, C.T. \& C. Elias (3 ops., DZUP); ibidem, idem, 11.VIII.1969 ( 2 ops., DZUP), 26.VIII.1969 (1 op., DZUP), 27.XII.1969 (1 op., DZUP); Domingos Martins, 16-28.II.1966, C. Elias (1 op., DZUP); Linhares, I.1962, Claudionor Elias (1 op., DZUP); ibidem, Parque Sooretama, X.1962, M. Alvarenga (4 ops. DZUP; 1 op., RPSP); Santa Tereza, 23.I.1964, C. Elias (1 op., DZUP); ibidem, idem, 5.II.1964 (1 op., DZUP), 5.IV.1964 (1 op. DZUP), 4.V.1964 (2 ops., DZUP), 22.V.1964 (1 op., DZUP), 6.VI.1964 (1 op., DZUP); ibidem, 5.I.1967, C.T. \& C. Elias (1 op., DZUP); São João de Petrópolis, 12.II.1964, C. Elias (1 op., DZUP); Viana, 5.VII.1966, C.T. \& C. Elias (1 op., DZUP).

Distribuição geográfica e hábitat. Endêmica da mata atlântica, no Espírito Santo, Brasil (Fig. 171).

\section{Nidificação. Desconhecida.}

Etimologia. Pela sufixação de Sooretama, denominação Tupi para Mata Atlântica, indicando a região onde habita.

Discussão. Muito semelhante à $P$. ailyae, da qual difere apenas pelas asas mais ferugíneo-escuras e pela distribuição geográfica restrita ao Espírito Santo. Outros comentários em $P$. ailyae.

\section{Partamona criptica sp. nov.}

(Figs. 45, 140, operária; 95, 125, macho; 172, distribuição; Tabs. II-IX; XIII)

Diagnose. Abelhas de porte médio (1.m.c. 2,3-2,6 mm, c.a.a. 6,0-6,6 mm, Tabs. III, IV). Integumento preto. Mandíbula predominantemente amarela, ápice ferrugíneo escuro, côndilos pretos. Flagelo castanho-escuro. Estrias paroculares alargadas embaixo (ca. 1,5x o diâmetro do $2^{\circ}$ flagelômero), afilando abruptamente um pouco acima das fóveas tentoriais e chegando até a interorbital máxima (Fig. 140). Máculas do tórax pouco conspícuas. Pilosidade preta. Membrana das asas ferrugínea escura; microtríquias das asas anteriores enegrecidas; veias alares escurecidas. Cerdas da base do escapo um pouco mais longas que o diâmetro deste (0,9-1,3x; Tab. VII). Cerdas eretas das áreas paroculares, ao lado dos alvéolos, aproximadamente tão longas quanto o diâmetro do escapo. Cerdas do escutelo 0,9-1,0x o comprimento deste. Área basal do propódeo com faixa glabra mediana larga, ca. 1,5x o diâmetro do $2^{\circ}$ flagelômero. Dentes da mandíbula aproximadamente eqüidistantes e um pouco recuados em relação ao ápice do bordo apical (Fig. 45). Área malar, distância interocelar, distância ocelorbital, tíbia III e comprimento da asa anterior, normais (Tabs. V, VI, VIII, IX). 
Bifurcação da $\mathrm{M}+\mathrm{Cu}$ geralmente coincidente com a cu-v (raramente levemente anterior). Macho, basitarso III curto e largo, achatado ou convexo-côncavo; tíbia III alargada em direção ao ápice (Fig. 95); EVII com projeção mediana longa, de lados aproximadamente subparalelos, chanfros laterais profundos e largos (Fig. 125).

\section{Operária.}

Dimensões. Comprimento total aproximado, 6,39 $\mathrm{mm}$; da asa anterior, 6,47 $\mathrm{mm}$ (incluindo a tégula, 7,14 mm); largura máxima da cabeça, 2,56 mm; do TIII, 2,48 mm (Tab. XIII).

Cor do integumento. Predominantemente preto, apenas o metanoto e as tíbias III mais claros; os tarsômeros de todos os pares de pernas, ferrugíneo-claros. Tégula enegrecida, apenas a porção discal mediana acastanhada. Labro amarelado, mandíbula predominantemente amarelada, ferrugínea em direção ao ápice, côndilos e ápice enegrecidos. Escapo com a face inferior amarelada e a superior enegrecida. Flagelo com a face inferior castanha e a superior mais escurecida, $1^{\circ}$ flagelômero um pouco mais claro. Máculas da face nítidas, no tórax apenas as manchas axilares. Manchas no clípeo em forma de dois L irregulares, nítidas; distância entre elas, na porção mais apical do clípeo, bem menor que o diâmetro do $2^{\circ}$ flagelômero. Mancha supraclipeal aproximadamente triangular, nítida. Abaixo do ocelo, um triângulo invertido, alongado, mais longo que o diâmetro do ocelo médio, apagado, quase imperceptível. Parte superior do sulco frontal, com mancha apagada. Estrias paroculares bem alargadas embaixo (ca. 1,25x o diâmetro do $2^{\circ}$ flagelômero), estreitando-se gradualmente até desaparecer na altura da linha da menor distância interorbital superior. Genas com pequena mancha margeando o terço inferior do olho. Tórax apenas com fina estria amarelada na parte anterior da margem interna das axilas. Membrana da asa anterior ferrugínea escura; microtríquias enegrecidas em toda asa; veias ferrugíneas, mais escurecidas na metade basal, principalmente $\mathrm{C}$ e R.

Pilosidade. Predominantemente preta, mais clara apenas nas coxas e trocanteres; esternos com as cerdas enegrecidas na porção basal, e de cor palha para o ápice, onde são mais delgadas. Área basal do propódeo com uma larga faixa glabra mediana. Franja pré-marginal do TIII com cerdas muito mais curtas na região mediana que nas laterais. Cerdas da base do escapo $1,13 \mathrm{x}$ mais longas que o diâmetro deste. Áreas paroculares inferiores, ao lado dos alvéolos, com cerdas eretas mais curtas, $0,88 \mathrm{x}$ o diâmetro do escapo; no clípeo $1,19 \mathrm{x}$; na fronte ca. 1,38x; no vértice mais longas, ca. 2,13x; no disco do mesoscuto e na porção anterior da linha média 1,75 e 2,38x, respectivamente. Cerdas mais longas no ápice do escutelo com ca. de $0,86 x$ o comprimento deste.

Integumento. Liso e polido, apenas com a pontuação pilígera típica do gênero.

Forma e proporções (Tab. XIII). Cabeça, 1,19x mais larga que longa e 1,31x mais larga que a distância clipeocelar. Olhos 2,40x mais longos que largos, paralelos. Área malar tão longa quanto o diâmetro do $2^{\circ}$ flagelômero. Clípeo $0,52 \mathrm{x}$ mais curto que sua largura máxima e $0,35 x$ a distância clipeocelar. Mandíbulas $0,56 \mathrm{x}$ a distância clipeocelar; os dentes aproximadamente eqüidistantes e um pouco recuados (Fig. 45). Escapo 0,94x a distância alvéolo-ocelo lateral, seu diâmetro igual ao do $2^{\circ}$ flagelômero. Distância interocelar 1,28x maior que a ocelorbital e ca. de 1,58x o diâmetro do ocelo médio. Escutelo aproximadamente semicircular, cerca de $0,48 \mathrm{x}$ mais curto que largo. Tíbia III 0,97x mais curta que a cabeça, e 2,07x mais longa que larga; canto póstero-distal arredondado, pouco projetado, margem apical fracamente sinuada; contorno da margem posterior, suavemente sinuado. Basitarso III 1,65x mais longo que largo; canto póstero-distal levemente anguloso e margem apical em ângulo um pouco maior que $90^{\circ} \mathrm{em}$ relação à margem anterior. Asa anterior 2,61x mais longa que larga e 2,53x a largura máxima da cabeça. Bifurcação de $\mathrm{M}+\mathrm{Cu}$ coincidente ou levemente anterior à cu-v. Hâmulos, 5.

\section{Macho. Figuras 95, 125.}

Material-tipo. Holótipo, operária, de "Caeté - MG Brasil 21/03/ 1985 I. Stanciola", "colonia 386 M (livro de Registro do Apiário - UFV); parátipos, do mesmo ninho, 6 operárias, 1 macho e 1 rainha, na RPSP, e mais 3 operárias e 1 macho do mesmo ninho, na coleção particular de G. Melo.

Material examinado. BRASIL. Minas Gerais: Barbacena, V.1955, F. M. Oliveira (4 ops., DZUP); Juiz de Fora, Poço D’Anta, 23.XI.1986, M.L. de Oliveira, sal. de metila (2 ops., UFVB); ibidem, idem, 9.XII.1986 (1 op., UFVB); Lima Duarte, SF-23, 43-22d, IX(ano?), A. de Souza (3 ops., RPSP); Passos, III.1964, C. T. Elias (1 op., MZSP); Parque Estadual Serra do Brigadeiro, 16.IV.1989, E.F. Morato (2 ops., 2953, UFVB); Serra do Caraça, 1380m, XI.1961, Kloss, Lenko, Martins, Silva (2 ops., MZSP). Espirito Santo: Espírito Santo (localidade?), sem data, anônimo (1 op., AMNH); Baixo Guandu, 17.IX.1966, Claudionor Elias (2 ops., DZUP); Colatina, 25.IV.1964, C. Elias (3 ops., DZUP); Domingos Martins, 16-28.II.1966, C. Elias (1 op., DZUP); Fundão, 20.V.1964, C. Elias (6 ops., DZUP); Santa Tereza, 5.II.1964, C. Elias (1 op., DZUP); ibidem, idem, 8.IV.1964 (8 ops., DZUP; 1 op., RPSP), 27.V.1964 (14 ops., DZUP; 3 ops., RPSP), 6.VI.1964 (5 ops., DZUP; 1 op., RPSP), 10.VI.1964 (4 ops., DZUP), 18.VI.1964 (6 ops., DZUP), 6.VII.1964 (1 op., DZUP), 16.VII.1964 (1 op., DZUP), 7.XII.1964 (1 op., DZUP), 19.V.1966 (4 ops., DZUP); ibidem, 5.V.1966, C. Tadeu Elias (1 op., DZUP); ibidem, 21.VII.1966, C.T. \& C. Elias (2 ops., DZUP); ibidem, idem, 11.VIII.1966 (5 ops., DZUP), 5.II.1967 (3 ops., DZUP); São Domingos, 27.III.1966, Claudionor Elias (1 op., DZUP); São João de Petrópolis, 1-8.VI.1966, C. Elias (1 op., DZUP). Rio de Janeiro: Parque Nacional do Itatiaia, 800m, III.1955, H. Gouveia (8 ops., DZUP; 1 op., RPSP); ibidem, idem, 830m, III.1955 (4 ops., DZUP; 1 op., RPSP); ibidem, IV.1961, F. M. Oliveira (1 op., DZUP); ibidem, 700m, V.1951, M. Zikan (1 op., DZUP); ibidem, Itatiaia, 16.XII.1991, W. Wilms, "wald" (1 op., MZSP); Santa Maria Madalena, 750m, VII.1960, M. Alvarenga (2 ops., DZUP). São Paulo: Boracéia, 19.VII.1969, J. Campbell (1 op., SEMC); Salesópolis, Estação Biológica Boracéia, 22.IX.1991, W. Wilms (1 op., MZSP); ibidem, idem, 15.XI.1991(1 op., MZSP), 29.XII.1991 (1 macho, MZSP), 2.III.1992 (1 op., MZSP), 13.III.1992 (1 op., MZSP), 25.IV.1992 (1 op., MZSP), 8.V.1992 (1 op., MZSP), 13.VI.1992 (1 op., MZSP), 2.VII.1992 (1 op., MZSP), 30.VII.1992 (4 ops., MZSP), 31.VII.1992 (1 op., MZSP), 14.IX.1992 (2 ops., MZSP), 6.X.1992 (1 op., MZSP), 14.XI.1992 (1 op., MZSP), 2.I.1993 (1 op., MZSP), 3.I.1993 (1 op., MZSP), 6.I.1993 (1 op., MZSP), 30.I.1993 (1 op., MZSP), 17.VI.1993 (2 ops., MZSP), 23.VII.1993 (2 ops., MZSP), 5.XI.1993 (1 op., MZSP), 16.XI.1993 (2 
ops., MZSP); ibidem, XI.1960, K. Lenko (1 op., MZSP).

Distribuição geográfica e hábitat. Mata atlântica, Serra da Mantiqueira e Serra do Mar, sudeste do Brasil, SP, MG, RJ, ES (Fig. 172).

Nidificação. Em termiteiro em oco de tronco de árvore (I. Stanciola, inf. pessoal).

Etimologia. Do grego, kryptós, escondido, oculto, referindose à sua semelhança com $P$. helleri.

Discussão. Dentre as espécies do grupo cupira, pode ser confundida com $P$. helleri pelas asas escurecidas, com a qual ocorre em simpatria nos estado de MG, RJ e ES. Distingue-se desta pelas cerdas da base do escapo mais curtas, ca. de 1,0 a 1,3 vezes o diâmetro deste, e pela estria parocular alargada abaixo das fóveas tentoriais, com limites difusos na maioria dos exemplares.

\section{Partamona rustica sp. nov.}

(Figs. 46, 139, operária; 93, 122, macho; 172, distribuição; Tabs. II-IX, XIII)

Diagnose. Abelhas de porte médio (1.m.c. 2,4-2,5 mm, c.a.a. 5,6-6,0 mm, Tabs. III, IV). Integumento preto. Mandíbula por inteiro ou predominantemente ferrugínea, apenas o $1 / 5$ basal amarelado ou descolorido. Flagelo alaranjado ou castanhoamarelado. Estrias paroculares alargadas embaixo (ca. 1,3x o diâmetro do $2^{\circ}$ flagelômero) e, em cima, afilando gradualmente, até a interorbital superior. Máculas do tórax apagadas ou pouco conspícuas. Pilosidade preta. Membrana das asas ferrugínea escura; microtríquias pretas; veia escurecidas principalmente na metade basal da asa. Cerdas da base do escapo nitidamente mais longas que o diâmetro deste (1,3-1,6x; Tab. VII), bem diferenciadas em relação às demais cerdas. Cerdas eretas das áreas paroculares, ao lado dos alvéolos, robustas, mais longas que o diâmetro do escapo. Cerdas do escutelo ca. 0,8-0,9x o comprimento deste. Área basal do propódeo com uma faixa glabra mediana, larga, ca. 1,5x o diâmetro do $2^{\circ}$ flagelômero. Dentes da mandíbula aproximadamente eqüidistantes e um pouco recuados em relação ao ápice do bordo apical (Fig. 46). Área malar, distância interocelar, distância ocelorbital, tíbia III e comprimento da asa anterior, normais (Tabs. V, VI, VIII, IX). Bifurcação da $\mathrm{M}+\mathrm{Cu}$ geralmente coincidente com a cu-v (raramente levemente anterior). Macho, basitarso III curto e largo, achatado ou convexo-côncavo; tíbia III alargada em direção ao ápice (Fig. 93); EVII com a projeção mediana longa, de lados aproximadamente subparalelos, os chanfros laterais profundos e largos (Fig. 122).

Operária.

Dimensões. Comprimento total aproximado, $5,81 \mathrm{~mm}$; da asa anterior, $5,73 \mathrm{~mm}$ (incluindo a tégula, $6,39 \mathrm{~mm}$ ); largura máxima da cabeça, 2,42 mm; do TIII, 2,48 mm (Tab. XIII).
Cor do integumento. Preto, sem áreas mais claras, inclusive no metanoto. Tégula enegrecida, apenas medianamente um pouco translúcida. Labro amarelo. Mandíbula amarela no terço basal e ferrugíneo-clara em direção ao ápice, côndilos enegrecidos. Escapo enegrecido, com a face inferior um pouco amarelada. Flagelo castanho-amarelado, na face superior um pouco mais escurecido. Máculas da face nítidas, principalmente as paroculares; no tórax apenas as axilas maculadas. Manchas no clípeo aproximadamente em forma de L, a distância entre elas, na porção apical do clípeo, menor que o diâmetro do $2^{\circ}$ flagelômero, mais nítidas nos cantos inferiores. Mancha supraclipeal aproximadamente trapezoidal. Sem estrias na fronte. Estrias paroculares curtas, alargadas embaixo, aproximadamente tão largas quanto o diâmetro do escapo, afilando suavemente e terminando na altura da linha da distância interorbital máxima. Genas uma faixa muito apagada terminando no meio do olho. Tórax apenas com o bordo interno das axilas amarelado. Membrana da asa anterior ferrugíneo-escura, mais escurecida na metade basal (radial, $1^{\text {a }}$ e $2^{\text {a }}$ cubitais); microtríquias enegrecidas em toda asa; veias escurecidas, principalmente na metade basal; $\mathrm{C}$ e $\mathrm{R}$ enegrecidas para a base.

Pilosidade. Enegrecida, apenas o ápice das cerdas ventrais mais claro. Área basal do propódeo com uma faixa glabra mediana. Franja pré-marginal do TIII com cerdas muito mais curtas na região mediana que as laterais. Cerdas da base do escapo $1,63 \mathrm{x}$ mais longas que o diâmetro deste. Áreas paroculares inferiores, ao lado dos alvéolos, com as cerdas eretas $1,13 \mathrm{x}$ o diâmetro do escapo; no clípeo $0,88 \mathrm{x}$; na fronte, $1,06 \mathrm{x}$; no vértice $2,0 \mathrm{x}$; no disco do mesoscuto e na porção anterior da linha média, 0,88 e 1,5x, respectivamente. Cerdas mais longas no ápice do escutelo com ca. de $0,87 \mathrm{x}$ o comprimento deste.

Integumento. Liso e polido, apenas com a pontuação pilígera típica do gênero.

Forma e proporções (Tab. XIII). Cabeça, 1,16x mais larga que longa, e 1,32x mais larga que a distância clipeocelar. Olhos $2,47 \mathrm{x}$ mais longos que largos, levemente convergentes embaixo. Área malar tão longa quanto o diâmetro do $2^{\circ}$ flagelômero. Clípeo $0,54 \mathrm{x}$ mais curto que sua largura máxima e $0,35 \mathrm{x}$ a distância clipeocelar. Mandíbulas 0,58x a distância clipeocelar; os dentes eqüidistantes, um pouco recuados (Fig. 46). Escapo 0,96x a distância alvéolo-ocelo lateral, seu diâmetro como o do $2^{\circ}$ flagelômero. Distância interocelar 1,50x maior que a ocelorbital e ca. de $1,83 \times$ o diâmetro do ocelo médio. Escutelo aproximadamente semicircular, cerca de $0,74 \mathrm{x}$ mais curto que largo. Tíbia III $0,94 x$ mais curta que a cabeça e $2,11 x$ mais longa que larga; o canto póstero-distal anguloso, projetado, a margem apical sinuada; o contorno da margem posterior, suavemente sinuado. Basitarso III, 1,45x mais longo que largo; canto póstero-distal anguloso, projetado; margem apical em ângulo maior que $100^{\circ} \mathrm{em}$ relação à margem anterior. Asa anterior 2,65x mais longa que larga e 2,37x a largura máxima da cabeça. Bifurcação de $\mathrm{M}+\mathrm{Cu}$ coincidente com a cu-v. Hâmulos, 5. 
Macho. Figuras 93, 122.

Material-tipo. Holótipo, operária, de "Santo Antonio Cocos - BA, Brasil 4440'W, 148'S", "24,27-VII-1995 Mazucato leg.", ninho "699c", parátipos, do mesmo ninho, 59 operárias e, com a mesma etiqueta de procedência, data e coletor, ninho " $698 \mathrm{c}$ ", 59 operárias; outras 6 operárias, de mesma procedência, data e coletor, nos. 951522, 951523, 951720, 951721, 951764, 951829, todos na RPSP.

Material examinado. BRASIL: Bahia: Maracás, IX.1965, F.M. Oliveira (30 ops., DZUP; 7 ops., RPSP); ibidem, 14.IX.1965, F. Oliveira (4 ops., DZUP); St. Moça Branca - Ssa-BA, 4.XII.1998, Milson Batista, ninho 4 (2 ops., RPSP). Minas Gerais: Cônego Marinho, $44^{\circ} 25^{\prime} \mathrm{W}, 15^{\circ}$ 18'S, 29.III.1988, Nereu (28 ops., 880452, 880632-880648, RPSP); ibidem, 13-15.III.1988, M. Mazucato (1 rainha, 76 ops., ninho 424c; 1 op., 880452, RPSP); Itamarandiba, Faz. Penedo Serrinha, 27.VII.1997, F. A. Silveira (1 op., 1441-3782, BHMH; 1 op., 1436-3761, RPSP); Jaíba, 13.I.1986, G. Melo (1 macho, 1 op. 302/1/18, MELO); Janaúba, 13.IX.1985, G. Melo (4 ops., 211/1/12, UFVB); ibidem, idem, 11.I.1986 (1 op., 305/1/18, MELO), 14.I.1986 (4 ops., 265/1/16, UFVB; 1 op., RPSP); Lontra, $44^{\circ} 18^{\prime} \mathrm{W}, 15^{\circ}$ 6’S, 17-19.III.1988, M. Mazucato (1 rainha, 67 ops., ninho 439c, RPSP); ibidem, idem, 23.VII.1988 (96 ops., ninho 460c, RPSP).

Distribuição geográfica e hábitat. Endêmica do norte de Minas Gerais até a região de Maracás na Bahia, acompanhando a Serra do Espinhaço (Fig. 172).

Nidificação. Termiteiro arborícola externo e em cumeeira de habitação humana (M. Mazucato e G. Melo, inf. pessoal).

Etimologia. Do latim, rusticus, rústico, campestre, referindose a região de ocorrência da espécie.

Discussão. Distingue-se de $P$. helleri pela forma do basitarso, fortemente projetado-anguloso, pela estria parocular um pouco alargada abaixo das fóveas tentoriais, porém bastante apagada, com limites difusos e pela cor do flagelo, alaranjado (como em $P$. cupira). De $P$. criptica sp. nov. distingue-se pelas cerdas longas da base do escapo, ca. de 1,5 a 1,8 vezes o diâmetro deste. De $P$. cupira difere, também, pelas cerdas mais longas do escapo e pelas asas escuras. Apresenta porte pequeno a médio, largura máxima da cabeça ca. de $2,48 \mathrm{~mm}$ (2,44-2,54 mm). Além da cor do flagelo e forma do basitarso, também possui hábitos de nidificação distintos de $P$. helleri, nidificando em termiteiros arborícolas. Com P. cupira, compartilha a cor do flagelo e o basitarso projetado-anguloso, porém cor da asa e padrão de manchas da face são distintos, além disso, P. cupira nidifica em termiteiros epígeos. No município de Lontra-MG, foram coletados ninhos tanto de $P$. rustica sp. nov. como de $P$. cupira.

Partamona helleri (Friese, 1900)

(Figs. 20-28, 48, 49, 50, 141, operárias; 92, 127, macho; 173, distribuição; Tabs. II-IX, XIV)

Trigona helleri Friese, 1900:385.23; Ihering, H. von, 1903:209, 210, $219,237,239,240,242,275,278,286$, prs. 15, 16 (nome vernacular, "Iraxim"); 1930:471, 472, 484, 485 (Fig. 13), 486 (Fig. 14), 487, 651, 652, 654, 655, 691, 699, 712 (nome vernacular, "Iraxim"); Marianno, 1911:104.35; Cockerell, 1925:627; Darchen \& Louis,
1961:21; Ihering, R. von, 1968:270, 360.

Trigona cupira; Ihering, H. von, 1903:187, 207, 220, 237, 239, 240, $242,247,251,252,258,278,285$, pr. 13 (nome vernacular, "Iraxim"); 1930:445, 468, 469 (Fig. 5), 470, 471, 472, 487, 651, $652,653,654,655,656,661,665,673,699,712$ (nome vernacular, "Iraxim"); Marianno, 1911:89.13 (partim); Schwarz, 1932a:242, 253, 259, 391 (citação de F. Müller).

Trigona pallida; Ihering, H. von, 1930:712.

Trigona kohli; Ihering, H. von, 1930:712.

Trigona (Partamona) cupira; Esch et al., 1965:320; Kerr \& Esch, 1965:532, 533, 535

Trigona (Partamona) cupira helleri; Kerr, 1969:141.

Trigona (Patera) testacea helleri; Schwarz, 1938:478.

Trigona (Partamona) testacea helleri; Schwarz, 1948:69,109,437; Wille \& Michener, 1973:12, 21, 44, 56, 67; Wille, A., 1983:50; Kerr et al., 1996:45.

Melipona pallida subsp. cupira aberr. helleri; Ducke, 1916:120, 121.41.b (partim); 1925:412(partim).

Partamona helleri; Camargo, 1988b:357; Michener, 1990:115; Machado \& Contel, 1991:594, 596, 598; Taura \& Laroca, 1991:95, 96; Bego et al., 1991:122; Brandeburgo, 1992: 1993:68, 147; Bravo, 1992:864, 865; ?Martins, 1994:235, 237, 245, 253; 1995:126, 135, 136; Wilms, 1996:200; Pedro, 1996:250; Azevedo et al., 1996:262; Mateus et al., 1996:338; Sofia \& Bego, 1996:339; Wilms et al., 1996:140, 141-145, 146, 147, 148, 149; Chittka et al., 1997:109; Viana et al., 1997:213, 214; Wilms et al., 1997:224; Ayala, 1999:58. Partamona cupira; ?Hartfeld \& Engels, 1989:3, 5-9; Cruz-Landin \& Mota, 1990:587, 588; Bego et al., 1991:125; Campos, 1992:90; Costa, 1992:124,125; Costa et al., 1992:802, 803, 804, 805; Pompolo, 1992:63, 64; Stort \& Moraes, 1992:209; Knoll et al., 1993:33; Sakagami et al., 1993:243; Silveira \& Campos, 1995:377; ?Nieh \& Roubik, 1995:64, 65; Diniz-Filho et al., 1995:63,64,65; Brito et al., 1997:185, 186, 187.

Partamona cupira helleri; Nogueira-Neto, 1970:32, 33, 34, 37; Knoll et al., 1992:188; Lenko \& Papavero, 1996: 263, 266.

Partamona cfr. cupira; ?Silveira et al., 1993:599.

Partamona (Partamona) helleri; Falcão \& Contel, 1990:735, 733, 741, 742, 745, 747; 1991a: 47, 48, 50, 54; 1991b: 61, 62, 65, 66, 67, 69; Falcão, 1992:150-153.

Diagnose. Abelhas de porte médio a grande (1.m.c. 2,4-2,50 $\mathrm{mm}$; c.a.a. 5,6-6,1 mm; Tabs. III, IV). Integumento preto. Mandíbula predominantemente ferrugínea, ápice ferrugíneo escuro, côndilos pretos. Flagelo castanho-escuro. Estrias paroculares estreitas $\left(0,6-0,8 \mathrm{x}\right.$ o diâmetro do $2^{\circ}$ flagelômero), levemente alargadas embaixo (ca. 1,0-1,2x o diâmetro do $2^{\circ}$ flagelômero), chegando até a altura da interorbital superior (Fig. 141). Máculas do tórax pouco conspícuas ou apagadas. Pilosidade preta. Membrana das asas ferrugínea escura microtríquias pretas; veias escurecidas, principalmente na metade basal. Cerdas da base do escapo nitidamente mais longas que o diâmetro deste (1,7-2,1x; Tab. VII), bem diferenciadas em relação as demais cerdas. Cerdas eretas das áreas paroculares, ao lado dos alvéolos, robustas, mais longas que o diâmetro do escapo. Cerdas do escutelo 0,9-1,0x o comprimento deste. Área basal do propódeo com um faixa glabra mediana, larga, ca. 1,5x o diâmetro do $2^{\circ}$ flagelômero. Dentes da mandíbula aproximadamente eqüidistantes e um pouco recuados (Figs. 48, 49, 50). Área malar, distância interocelar, distância ocelorbital, tíbia III e comprimento da asa anterior, normais (Tabs. V, VI, VIII, IX). Bifurcação da $\mathrm{M}+\mathrm{Cu}$ geralmente coincidente com a cu-v (raramente levemente anterior). Macho, basitarso III curto e largo, achatado ou 
convexo-côncavo; tíbia III alargada em direção ao ápice (Fig. 92); EVII com projeção mediana longa, de lados aproximadamente subparalelos, os chanfros laterais profundos e largos (Fig. 22, 127).

Variação. Nos estados do Rio de Janeiro e Espírito Santo foram examinados exemplares maiores (1.m.c.: 2,6-2,8 mm; c.a.a.: 6,2-6,7 mm) e com as cerdas da base do escapo proporcionalmente mais curtas (1,0-1,5x o diâmetro do escapo; Tab. VII) em simpatria com exemplares normais. Exemplares provenientes de Paraopeba-MG, apresentam as asas mais claras, apenas levemente ferrugíneas.

\section{Operária.}

Dimensões. Comprimento total aproximado, 6,3-6,23 mm; da asa anterior, 5,89-6,10 mm (incluindo a tégula, 6,64-7,06 mm); largura máxima da cabeça, 2,44-2,54 mm; do TIII, 2,36 mm (medidas obtidas, respectivamente, nos exemplares de "Brasil Blumenau 1897 Virgil", um deles com etiquetas adicionais “Trigona helleri Fr. 1909 Friese det." e "TYPUS", “Zool. Mus. Berlin", depositado no ZMHB (Tab. XIV); o outro com etiqueta adicional "Trigona cupira Sm Friese det. 25", depositado no AMNH.

Sobre o exemplar do ZMHB, com etiqueta de "TYPUS", são apresentadas as notas abaixo:

Cor do integumento. Preto, apenas um pouco descolorido nas pernas. Labro e mandíbulas amarelo-ferrugíneos; ápice e base das mandíbulas enegrecidos. Flagelo, do lado inferior, mais claro, amarelo-sujo. Estria parocular estreita, embaixo com cerca de $3 / 4$ do diâmetro do flagelo, estreitando-se gradativamente para cima e terminando no meio da fronte. Sem manchas no tórax. Membrana das asas por inteiro de um ferrugíneo-enfumaçado; veias fuscas; microtríquias fuscas.

Pilosidade. Predominantemente enegrecida, inclusive na região ventral (esternos, coxas, trocanteres); nos lados dos mesepisternos e propódeo, mais clara.

Integumento. Liso e polido, apenas a pontuação pilígera típica do gênero.

Forma e proporções (Tab. XIV). Cabeça, 1,33x mais larga que a distância clipeocelar. Olhos, 2,51x mais longos que largos, levemente convergentes embaixo. Comprimento da área malar aproximadamente igual ao diâmetro do $2^{\circ}$ flagelômero. Clípeo um pouco mais longo que a metade de sua largura máxima, ca. $0,36 \mathrm{x}$ mais curto que a distância clipeocelar, e um pouco mais curto que sua largura na altura das fóveas. Mandíbulas $0,58 \mathrm{x}$ mais curtas que a distância clipeocelar; os dentes levemente recuados. Escapo 0,88x a distância alvéolo-ocelo lateral, seu diâmetro igual ao do $2^{\circ}$ flagelômero. Distância interocelar $1,11 \mathrm{x}$ maior que a ocelorbital e 1,82x maior que o diâmetro do ocelo médio. Mesoscuto 1,06x mais largo que longo. Escutelo aproximadamente semicircular, 0,49x mais curto que largo. Tíbia
III $0,92 x$ mais curta que a largura máxima da cabeça e 2,07x mais longa que larga. Basitarso III 1,74x mais longo que largo. Asa anterior 2,41x mais longa que a largura máxima da cabeça (não foi possível medir a largura da asa). Hâmulos, 5 .

Macho. Figuras 20-28, 92, 127.

A descrição é baseada em um macho procedente de: "Massaranduba-Blumenau, Brazil Sept-Oct, 1935 Ac. 34235", "Trigona (Partamona) testacea var. helleri (Friese) Det. H.F. Schwarz", RPSP. Exemplar em bom estado, porém muito sujo, com os pêlos grudados, as asas um pouco dobradas e com a genitália, aparentemente, faltando.

Dimensões. Comprimento total aproximado, $6,64 \mathrm{~mm}$; da asa anterior, 5,54 $\mathrm{mm}$ (incluindo a tégula, $6,47 \mathrm{~mm}$ ). Largura máxima da cabeça, 2,46 mm; abdômen um pouco amassado (Tab. XIV).

Cor do integumento. Predominantemente preto, os esternos um pouco mais claros; distitarsos de todos os pares de pernas, tíbia e basitarso III mais claros, acastanhados. Escapo com a superfície interna amarelada, flagelo castanho-escuro superiormente e um pouco mais claro na superfície inferior, o $1^{\circ}$ flagelômero mais amarelado; labro e mandíbulas castanhoamarelados. Máculas amarelas, nítidas: duas manchas em L, opostas, no clípeo; estria parocular um pouco mais estreita que o diâmetro do $2^{\circ}$ flagelômero, chegando até um pouco antes da tangente interorbital superior; mancha supraclipeal aproximadamente trapezoidal, e uma mancha triangular abaixo do ocelo médio; genas com uma estria forte acompanhando grande parte da órbita externa e, embaixo, chegando até os côndilos. Tórax com uma estria fina, a cada lado, acompanhando os lados do mesoscuto; axilas, praticamente por inteiro, amarelas; escutelo com faixa muito apagada acompanhando o bordo distal. Asas hialinas, microtríquias fuscas; veias fusco-ferrugíneas, C e R mais escuras.

Pilosidade. Ferrugíneo-fusca no mesoscuto, escutelo, escapo, fronte, vértice e pernas; enegrecida nos tergos; na região ventral do tórax e abdômen amarelo-palha (machos de Ribeirão Preto - SP, ninho 635c, RPSP, com cerdas eretas longas e finas; ferrugíneo-fuscas no vértice, mesoscuto, escutelo e pernas; nos tergos, enegrecidas; amarelo-palha na fronte, clípeo, região hipostomal, lados dos mesepisternos, lado ventral do tórax, lados do propódeo e esternos). Propódeo com larga faixa mediana glabra, ca. $2 \mathrm{x}$ mais larga que o diâmetro do $2^{\circ}$ flagelômero. Cerdas eretas da base do escapo tão longas quanto o diâmetro deste. No clípeo, $0,90 \mathrm{x}$ o diâmetro do escapo; na fronte e vértice mais longas, $1,90 \mathrm{x}$ e 2,55x respectivamente; no disco do mesoscuto, 1,82x; nos lados dos mespisternos, 2,36x. As cerdas do escutelo 0,70x mais curtas que o comprimento deste.

Integumento. Como na operária. 
Forma e proporções (Tab. XIV). Cabeça 1,18x mais larga que longa e $1,37 \mathrm{x}$ mais larga que a distância clipeocelar. Olhos 2,18x mais longos que largos, fortemente convergentes embaixo. Área malar curta, $0,35 \mathrm{x}$ o diâmetro do $2^{\circ}$ flagelômero. Comprimento do clípeo $0,69 \mathrm{x}$ a sua largura máxima e $0,39 \mathrm{x}$ a distância clipeocelar. Comprimento da mandíbula $0,39 \mathrm{x}$ a distância clipeocelar. Comprimento do escapo $0,81 \mathrm{x}$ a distância alvéolo-ocelo lateral, seu diâmetro igual ao do $2^{\circ}$ flaglômero. Distância interocelar 1,5x maior que a ocelorbital, e 1,68x maior que o diâmetro do ocelo médio. Comprimento do mesoscuto $1,05 \mathrm{x}$ maior que sua largura. Escutelo aproximadamente semicircular, seu comprimento igual a $0,60 \mathrm{~mm}$ (não foi possível medir a largura). Tíbia III $0,78 x$ mais curta que a largura máxima da cabeça e 2,37x mais longa que larga, com uma pequena área levemente côncava no quinto distal. Basitarso III, 1,8x mais longo que largo, achatado, de lados subparalelos; canto póstero-distal arredondado. Asa anterior 2,29x mais longa que a largura máxima da cabeça (não foi possível medir sua largura). Bifurcação de $\mathrm{M}+\mathrm{Cu}$ coincidente com a cu-v. Hâmulos, 5 . Genitália e esternos pré-genitais como nas figuras 20-28 (exemplar de Ribeirão Preto).

Material-tipo. FrIESE (1900: 385) menciona 12 operárias de "Brasilia: Espirito Santo, Rio de Janeiro und Blumenau". Entretanto, obtivemos apenas 1 operária do Museu de Berlim (ZMHB), com as seguintes etiquetas: "Brasil Blumenau 1897 Virgil"; "Trigona helleri 1909 Friese det. Fr."; "TYPUS"; Zool. Mus. Berlin", que provavelmente faz parte da série tipo, a qual está sendo considerada para efeito de interpretação da espécie; o lectótipo, entretanto, só deve ser designado quando toda a série for conhecida. Posteriormente, recebemos, do AMNH, um segundo exemplar com a mesma etiqueta de procedência, porém com a seguinte etiqueta de identificação "Trigona cupira Sm. (símbolo de operária) Friese det. 25", que, possivelmente, também faz parte da série tipo e foi equivocadamente identificado como P. cupira, por Friese. De São Paulo e Jundiaí também recebemos, do USNM, exemplares marcados como tipo, com as seguintes etiquetas: "Brasil 43 S. Paulo 14-10 1899 Ihering", "Brasil S. Paulo 43101899 Ihering", "Brasil Jundiahy 1898", os três com etiqueta de cor salmon, impressa "Typus" e etiqueta adicional "Trigona helleri 1913 Friese (símbolo de operária) det. Fr.”, também, nestes casos, a designação como tipo deve ter sido posterior à descrição da espécie.

Material examinado. BRASIL. Estado?: Monat (?), IV.1935, P. Sandig (3 ops., USNM). Bahia: Alagoinhas, 11.I.1985, Giovanini, K A (2 ops., RPSP); Jequié, 10.VIII.1964, C. Elias (2 ops., DZUP); Maracás, II.1963, F.M. Oliveira (4 ops., DZUP; 1 op., RPSP); ibidem, idem, IX.1965, (1 op., DZUP); ibidem, 18.VIII.1964, C. Elias (2 ops., DZUP); Porto Seguro, Praia de Taperapuã, 39 $1{ }^{\circ} 7^{\prime}$ W, 16²2'42"S, 15-21.XII.1998, S.R.M. Pedro (30 ops., 981256, 981273-274, 981277-278, 981280, 981284-286, 981289, 091291, 981298, 981363-364, 981366, 981368370, 981374-377, 981380-381, 981384, 981386, 981415, 981427, 981430, RPSP); Salvador, 19.III.1961, H. e A. Cordeiro (164 ops., DZUP; 20 ops., RPSP); ibidem, St. Moça Branca, 04.XII.1998, Milson Batista, ninho 4 (2 ops., RPSP); Santo Antonio de Jesus, 1986, anônimo

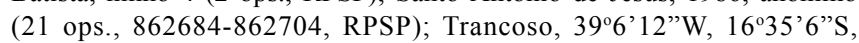
16.XII.1998, S.R.M. Pedro (4 ops., 981226, 981229, 981231, 981234, RPSP); Vitória da Conquista, 10-20.V.1961, F.M. Oliveira (2 ops., DZUP). Minas Gerais: Araxá, 22.VII.1965, C. \& T. Elias (1 op., DZUP); Belo Horizonte, 28.IV.1949, A. Costa Jr., "irapuá, ninho em parede" (3 ops., DZUP); Boa Sorte, SE-23, 46³6’W, 1658'S, 22.VII.1994, Mazucato (60 ops., ninho 644c, RPSP); Brasilândia, 21.X.1996, A.G. Damasceno, P. emarginatus (1 op., BHMH); ibidem, idem, 27.XI.1996 (13 ops., BHMH; 1 op., RPSP), 28.XI.1996 (8 ops., BHMH), 3.XII.1996 (9 ops., BHMH; 2 ops., RPSP), 5.XII.1996 (2 ops., BHMH); ibidem, $17^{\circ} 00^{\prime}$ 's, 4600'W, 30.XII.1998, M. Mazucato (3 ops., 990045, 990049, 990051, RPSP); Brazópolis, XII.1961, Claudionor Elias (2 ops., DZUP); Florestal,
23.VII.1985, G. Melo, C26 (1 op., RPSP; 1 op., UFVB); Governador Valadares, 29.VI.1985, G. Melo, C16 (1 op., UFVB); Ibirité, 3.IX.1985, G. Melo, C32 (1 op., RPSP; 1 op., UFVB); Itamarandiba, Faz. Penedo Serrinha, 27.VII.1997, F. A. Silveira (5 ops., 1442, 3788-3790, 3792, 3793, BHMH; 1 op., 1442-3787, RPSP); Juiz de Fora, SF-23, 43-22d-X, 1977, A. Amaral (1 op., RPSP); Lagoa Formosa, 10.VIII.1991, S. Mateus (1 op., 910768, RPSP); Lagoa Santa, S. do Cipó, 2.IV.1983, Silveira, Sida spp. (1 op., UFVB); Lima Duarte, SF-23, 43-22-d-IX, A. de Souza (4 ops., RPSP); Mandaçaia, 42 ${ }^{\circ} 43^{\prime} \mathrm{W}, 16^{\circ} 57^{\prime} \mathrm{S}, 22-23$.VII.1989, Mazucato (11 ops., 890242-890254, RPSP); Minas Novas, 14.II.1988, G. Melo, A. Soares, Acaua Fz., 40 (2 ops., UFVB); Paraopeba, 30.IX.1986, F. A. Silveira, (3 ops., 30/100, 30/101, 30/102, UFVB); ibidem, idem, 7.I.1987 (1 op., 188/470, UFVB), 5.II.1987, (1 op., 210/509, UFVB), 3.III.1987 (1 op., 222/529, UFVB), 30.VIII.1987, (3 ops., 491/1278, 491/1279, 491/1281, UFVB), 12.X.1987 (3 ops., 536/1427, 536/1430, 536/14/31, UFVB), 4.VIII.1986, ninho 10 (3 ops., UFVB), 5.VIII.1986 ( 2 ops., UFVB), 2.IX.1986, ninho 10 (4 machos,UFVB; 1 macho, RPSP), data ?, ninho 07 (9 ops., UFVB; 2 ops., RPSP), 3.IX.1986, ninho 04 (8 ops., UFVB; 1 op., RPSP); P.E. Rio Doce, 20.IV.1990, J.C.L. Oliveira, 2952 (1 op., UFVB); Posses, SE-23, 4244’W, 170'S, 17.VIII.1994, Mazucato (46 ops., 940882-940924, RPSP); Porto Firme, V.1996, anônimo (1 op., 1 macho, 960571-572, RPSP); Rio Piracicaba, V.1955, A.G.A. Silva (1 op., DZUP); Sabará, 14.VIII.1961, N.L.H. Krauss (3 ops., SEMC); São José do Barreiro, Serra da Canastra, 03-04.VII.1988, Camargo, Aily (34 ops., 881292-881306, 881310, RPSP); Três Marias, 5.VII.1985, G. Melo, C36 (1 op., RPSP); Varginha, I.1960, Alvarenga, Seabra, (4 ops., SEMC); ibidem, II.1954, L.C. Alvarenga (1 op., DZUP); Viçosa, 27.XI.1990, L.A.O Campos (1 op., 1 macho, MELO); ibidem, VII.1995, Azevedo G.G. (8 ops., 4 machos, 960419-430, RPSP). Espírito Santo: Colatina, 25.IV.1964, Claudionor Elias (1 op., DZUP); idem, ibidem, 15.IV.1966 (4 ops., DZUP); Conceição da Barra, 12.III.1966, C.T. \& C. Elias (1 op., RPSP); ibidem, idem, 26.IV.1968 (2 ops., DZUP), 26.V.1968 (2 ops., DZUP), 26.IX.1968 (1 op., DZUP), 5.V.1969 (2 ops., DZUP), 18.VIII.1969, (1 op., DZUP), 22.XI.1969 (1 op., DZUP); Córrego Itá, X.1954, W. Zikan (12 ops., DZUP; 3 ops., RPSP); Fundão, 20.V.1964, C. Elias (1 op., DZUP); Itarana, 12.II.1966, C. Elias (2 ops., DZUP); Linhares, I.1962, Claudionor Elias (5 ops., DZUP; 1 op., RPSP); ibidem, Parque Sooretama, X.1962, M. Alvarenga (1 op., DZUP); ibidem, III.1954, P. A. Teles ( 1 op., DZUP); idem, ibidem, V.1953 (1 op., DZUP); Santa Leopoldina, 1897, anônimo (1 op., AMNH); ibidem, 9.IX.1966, C.T. \& C. Elias (3 ops., DZUP; 1 op., RPSP); ibidem, Claudionor Elias, 3.IX.1964, (1 op., DZUP); idem, ibidem, 4.III.1964 (2 ops., DZUP); Santo Antonio, 28.IV.1966, Claudionor Elias (1 op., DZUP); São Domingos, 27.III.1966, Claudionor Elias (1 op., DZUP); São João de Petrópolis, 1-8.VI.1966, C. Elias (3 ops., DZUP); idem, ibidem, 12.II.1964 (1 op., DZUP); ibidem, IV.1954, P.A. Teles (1 op., DZUP); Santa Tereza, 23.I.1964, C. Elias (4 ops., DZUP); ibidem, idem, 5.II.1964 (1 op., DZUP), 23.III.1964 (1 op., DZUP), 28.III.1964 (4 ops., DZUP), 8.IV.1964 (1 op., DZUP), 4.V.1964 (3 ops., DZUP), 27.V.1964 (1 macho, 3 ops., DZUP), 6.VI.1964 (12 ops., DZUP; 3 ops., RPSP), 10.VI.1964 (4 ops., DZUP), 18.VI.1964 (4 ops., DZUP), 6.VII.1964 (9 ops., DZUP; 1 op., RPSP), 16.VII.1964 (2 ops., DZUP), 4.X.1964 (1 op., DZUP), 19.X.1964 (3 ops., DZUP); ibidem, 21.II.1966, C. Tadeu Elias (4 ops., DZUP); ibidem, idem, 5.V.1966 (2 ops., DZUP); ibidem, 4.IV.1966, C.T. \& C. Elias (1 op., DZUP); ibidem, idem, 5.VI.1966 (1 op., DZUP), 25.VI.1966 (1 op., DZUP), 21.VII.1966 (1 op., DZUP), 11.VIII.1966 (1 op., DZUP), 21.I.1967 (1 op., DZUP), 13.I.1970 (1 op., DZUP); Viana, 5.VII.1966, C.T. \& C. Elias (2 ops., DZUP). Rio de Janeiro: Angra dos Reis, Faz. Japuhyba, 15.IX.1951, L.T.F. (1 op., MZSP); Est. Sumaré, 8.IV.1955, C.A.C. Seabra (1 op., DZUP); ibidem, idem, 29.VII.1953 (1 op., DZUP),18.VIII.1954, (1

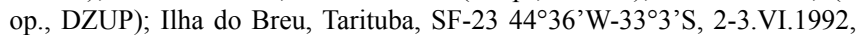
Camargo et al. (1 op., 920328, RPSP); Itatiaia, 2.200m, 6.I.1954, W. Zikan (1 op., DZUP); ibidem, 750m, 14.X.1961, Barth (2 ops., DZUP), ibidem, 800m, III.1955, H. Gouveia (1 op., DZUP); ibidem, idem, 830m, III.1955 (1 op., DZUP); ibidem, 16.XII.1991, W. Wilms, "wald" (1 op., MZSP); Mangaratiba, IV.1959, M. Alvarenga (1 op., SEMC); ibidem, VIII.1938-II.1939, R.C. Shannon (2 ops., 1 macho, USNM); Maricá, V.1954, Figueiredo (1 op., DZUP); Paineiras, Guanabara, 6.V.1961, M. Alvarenga (1 op., SEMC); Petrópolis, IV.1961, M. 
Alvarenga (1 op., DZUP); Rep. R. Grande, 30.X.1964, F.M. Oliveira (41 ops., DZUP; 5 ops., RPSP); idem, ibidem, $10 . I V .1962$ (2 ops., DZUP), III.1965, (4 ops., DZUP; 1 op., RPSP); Retiro Pedro do Rio, III.1954, C.A.C. Seabra (1 macho, DZUP); Rio de Janeiro, X.1937-I.1938, R.C. Shannon (1 op., USNM); ibidem, idem, IX.1938 (3 ops., USNM), X.1938 (6 ops., USNM), I.1939 (2 ops., USNM); ibidem, Floresta da Tijuca, I.1954, C.A.C. Seabra (4 ops., DZUP; 2 ops., SEMC; 1 op., RPSP); idem, ibidem, II.1954, (3 ops., DZUP; 3 ops., SEMC), 23.III.1953 (1 op., DZUP); ibidem, VII.1957, M. Alvarenga (4 ops., DZUP; 1 op., RPSP); ibidem, idem, IX.1959 (1 op., DZUP), IV.1966 (1 op., MZSP); ibidem, Jardin Boatanko (= Jardim Botânico?), 6.III.1978, D.K. MCE Kevan (4 ops., SEMC); ibidem, Praia da Gávea, 6.III.1978, D.K. MCE. Kevan (2 ops., SEMC); Alto da Boa Vista, I.1951, C.A.C. Seabra (2 ops., DZUP); S. A. Imbé, S.M. Madalena, VII.1960, M. Alvarenga (7 ops., DZUP; 2 ops., RPSP); Santa Maria Madalena, VII.1960, M. Alvarenga (14 ops., SEMC; 3 ops., RPSP); Theresopolis, 2.II.1987, anônimo, 88137 (1 op., BMNH). São Paulo: Altinópolis, 24.V.1987, P.F. da Silva (29 ops., 870387-870415, RPSP); Batatais, 23.VIII.1973, Camargo, Zucchi (32 ops., ninho 46c, RPSP); ibidem, I.1946, Pe. J. Moure (14 ops., DZUP); Cajuru, 8.II.1987, Camargo, Tavares (10 ops., 870166870175, RPSP), ibidem, 6.IV.1985, Mazucato, Camargo (1 op., 850387, RPSP); ibidem, Faz. Sta. Carlota, 6.IV.1989, S. Mateus (3 ops., RPSP); ibidem, idem, 7.IV.1989 (6 ops., RPSP); Campinas, sem data, anônimo (2 machos, 2803, AMNH); ibidem, 23.XII.1998, S.R.M Pedro (9 ops., 981164, 981167, 981170-171, 981174, 981178-81, RPSP); Caraguatatuba, 27.VIII.1992, A. C. Faria (1 op., 920924, RPSP); ibidem, Res. Flor., 40m, VII.1965, Exp. Dep. Zool., (2 ops., MZSP); ibidem, idem, 22.V-1.VI.1962 (5 ops., MZSP; 2 ops., RPSP), 7-14.VII.1962 (1 op., MZSP); Cosmópolis, 20.XII.1971, C.D. Michener (28 ops., SEMC); Itapecerica da Serra, XI.1983, M.A.C. Oliveira (6 ops., 910698-910703, RPSP); Jacupiranga, Vale do Ribeira, 1986, Silvia Regina (1 op., 863172, RPSP); Jundiaí, sem data, anônimo, "Trigona alfkeni Fr. 1925 Friese Det.", "Trigona testacea var. helleri (Friese) Det. H.F. Schwarz" (2 ops., Ac. 35178, AMNH); ibidem, "Brasil Jundiahy 1898 Franca", "Trigona cupira Sm. Friese det. 25" (1 op., AMNH); Nova Europa, Faz. Itaquerê, 26.XI.1963, K. Lenko (2 ops., MZSP); ibidem, idem, 29.XI.1963 (1 op., MZSP), I.1964 (2 ops., MZSP); Osasco, III.1956, M.A. Vulcano (3 ops., MZSP); Ribeirão Preto, X.1967, J. Camargo (11 ops., DZUP); ibidem, idem, SF-23, 48-21d, 7.VII.1971 (68 ops., ninho 26c, RPSP), 23.X.1992 (15 machos, 1 op., 920995-921005, RPSP); ibidem, 23.IX.1975, M. Mazucato (20 ops., RPSP); ibidem, idem, 27.V.1977 (51 ops., RPSP), 23.IV.1982 (10 ops., RPSP); ibidem, 25.IX.1975, M. Mazucato, Laércio (69 ops., RPSP); ibidem, 12.IX.1993, S.R.M. Pedro (4 machos, 86 ops., ninho 635c, RPSP); ibidem, idem, 12.IV.1999, "ninho em oco de árvore viva" (1 op., RPSP); ibidem, 11.V.1996, Tavares (4 ops., 960417-418, RPSP); Salesópolis, Est. Biol. Boraceia, 17.IV.1962, K. Lenko (6 ops., MZSP); ibidem, 2.II.1992, Wilms (1 op., MZSP); ibidem, idem, 3.II.1992 (1 op., MZSP), 28.V.1992 (1 macho, MZSP), 15.VI.1992 (1 op., MZSP), 12.VIII.1992 (1 ор., MZSP), 12.X.1992 (1 op., MZSP), 25.X.1992 (1 op., MZSP), 15.XII.1992 (1 op., MZSP), 17.XII.1992 (5 ops., MZSP), $22 . I I I .1993$ (1 op., MZSP), 9.IV.1993 (1 op., MZSP), $21 . I V .1993$ (1 op., MZSP), 3.VI.1993 (1 op., MZSP), 23.VII.1993 (1 op., MZSP), 13.X.1993 (1 op., MZSP), 27.XI.1993 (1 op., MZSP), 7.XII.1993 (2 ops., MZSP), 4.I.1994 (1 op., MZSP), 7.I.1994, (1 op., MZSP), 18.I.1994 (2 ops., MZSP), 20.I.1994 (1 op., MZSP); São Paulo, 14.X.1899, Ihering (2 ops., com etiqueta de "TYPUS", USNM); ibidem, idem, 16.IX.1899, "Trigona helleri Fr. Friese Det. 25 jung", "Trigona (Partamona) testacea var. helleri (Friese) callow Det. H. F. Schwarz" (2 ops., AMNH); ibidem, Ibirapuera, III.1984, M.A.C. Oliveira, "ninho em raízes de Monstera" (12 ops., 910686-910697, RPSP); ibidem, S. Amaro, X.1962, J. Lane (1 op., MZSP); São Sebastião, 12-13.XI.1965, Camargo (1 op., RPSP); São Vicente, IV.1954, N.L.H. Krauss, 15 (1 op., SEMC); Ubatuba, Piúva, 13.VII.1963, B. Vieira, A. Tacla (?), A. Rocha (11 ops., MZSP). Paraná: Alexandra, 2.IX.1969, S. Laroca (1 op., SEMC); Antonina, 21.I.1966, Marinoni, Azevedo (1 op., DZUP); Caiubá, I.1961, Moure (3 ops., DZUP); Curitiba, 25.III.1963, S. Laroca (1 macho, SEMC). Santa Catarina: Blumenau, 1897, Virgil (1 op., com etiqueta de TYPUS, ZMHB; 1 op., sem etiqueta de tipo, AMNH); Corupá, III.1954, A. Maller (10 ops., DUZP; 1 op., RPSP); ibidem, idem, I.1956 (1 op., DZUP);
Massaranduba - Blumenau, IX-X.1935, anônimo (2 ops., Ac. 34235, AMNH); ibidem, idem, "Trigona (Partamona) testacea var. helleri (Friese) Det. H.F. Schwarz" (2 ops., 1 macho, RPSP).

Distribuição geográfica e hábitat: Do nordeste de Santa Catarina até a região de Salvador na Bahia, acompanhando a mata atlântica; a oeste chega até o vale do São Francisco em Minas Gerais, na região dos cerrados (Fig. 173).

Nidificação. Ninhos livres ou semi-expostos, em beirais de casa, dentro de condicionadores de ar, ocos de árvores, ninhos abandonados de aves e entre raízes de epífitas (IHERING, 1903, 1930; Mariano, 1911; DuCKe, 1916 e observações pessoais).

Discussão. Os dentes da mandíbula, eqüidistantes, pouco recuados, e EVII do macho com projeção mediana aproximadamente de lados subparalelos colocam essa espécie no grupo cupira. Pode ser reconhecida pelas longas cerdas no escapo, pelas asas escurecidas e máculas do tórax pouco conspícuas. Assemelha-se a P. rustica sp. nov. da qual difere pela cor mais escura do flagelo e hábitos de nidificação e,

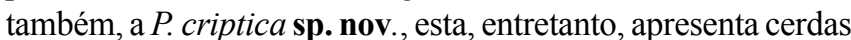
mais curtas no escapo e manchas paroculares mais alargadas embaixo. P. helleri apresenta, possivelmente, uma população (espécie ?) distinta na faixa atlântica que vai do RJ ao ES, mas o pequeno número de exemplares dessa região e falta de machos e dados sobre a biologia, não permite uma decisão mais segura. Exemplares de Paraopeba-MG, também podem constituir uma população distinta; segundo F. Silveira, esses exemplares foram coletados em termiteiros arborícolas.

Agradecimentos. Pelo emprésimo de material, a Robert W. Brooks e Charles D. Michener, Jerome G. Rozen Jr., Ronald McGinley, David G. Notton, Jesus Santiago Moure, Frederick Stehr, David W. Roubik, John E. Rawlins, Jorge Arturo Lobo Segura, F. Koch e Anette Kleine Möllhoff, Roberto F. Brandão, Francisco Peralta, B. De Djin, Lúcio A.O. Campos, Fernando Silveira, Gabriel A. R. Melo e George Eickwort (in memorian), Elder F. Morato, Márcio L. Oliveira e Christopher Brown. A Reginaldo Constantino e a Eliana M. Cancello, pela identificação dos Isoptera. A Gisele Garcia Azevedo, pela doação de exemplares e fotografias de ninhos de Partamona seridoensis sp. nov. e Rute Magalhães Brito-Ribon, pelas fotografias do ninho de Partamona mulata. Aos Srs. Menderson Mazucato, exímio coletor e preparador, principal responsável pela montagem da coleção de abelhas da FFCLRP (RPSP) e José Amílcar Tavares Filho, pelo auxílio na preparação, triagem do material e atualização dos fichários sobre Meliponini. Aos Diretores e pesquisadores do Instituto Nacional de Pesquisas da Amazônia - INPA, Warwick E. Kerr, Enéas Salati, Roberto Vieira, José Alberto S. Nunes de Mello, Ozório J.M. Fonseca e à tripulação dos barcos Marupiara, Pyatã e Pium, cuja colaboração foi fundamental para a realização de diversas expedições ao Amazonas. A Carlos Roberto Ferreira Brandão, Sérgio Antonio Vanin, Dalton de Souza Amorim, pelas sugestões. Ao Pe. Jesus Santiago Moure, pelos valiosos comentários, sugestões e apoio, além do empréstimo de grande parte do material para este estudo. Aos assessores anônimos, pelas correções e sugestões. À FAPESP, pela bolsa de doutorado (SRMP). Pelos auxílios financeiros, ao INPA - Projetos Especiais (1977, 1979), CNPq (procs. 152.3.0010/81, 40.6235/84), e FAPESP (procs. 84/2482$8,85 / 2842-7,92 / 2732-0,98 / 11605-9)$. 
Tabela III. Dimensões, espécies de Partamona - Largura máxima da cabeça (mm), operárias.

\begin{tabular}{|c|c|c|c|c|}
\hline & $\mathrm{n}$ & média (mm) & limites $(\mathrm{mm})$ & desvio padrão \\
\hline P. xanthogastra & 10 & 2,86 & $2,76-2,94$ & 0,061 \\
\hline P. grandipennis & 10 & 2,82 & $2,78-2,86$ & 0,028 \\
\hline P. helleri (pops. RJ e ES) & 10 & 2,72 & $2,66-2,76$ & 0,039 \\
\hline P. sooretamae & 10 & 2,70 & $2,66-2,76$ & 0,031 \\
\hline P. epiphytophila & 10 & 2,67 & $2,58-2,72$ & 0,050 \\
\hline P. ailyae & 10 & 2,66 & $2,60-2,72$ & 0,035 \\
\hline P. batesi & 10 & 2,63 & $2,56-2,68$ & 0,039 \\
\hline P. aequatoriana & 10 & 2,60 & $2,50-2,65$ & 0,049 \\
\hline P. nhambiquara & 10 & 2,59 & $2,50-2,66$ & 0,044 \\
\hline P. gregaria & 10 & 2,56 & $2,36-2,64$ & 0,075 \\
\hline P. yungarum & 10 & 2,56 & $2,48-2,66$ & 0,052 \\
\hline P. ferreirai & 10 & 2,55 & $2,48-2,64$ & 0,050 \\
\hline P. vitae & 7 & 2,53 & $2,48-2,60$ & 0,041 \\
\hline P. mourei & 10 & 2,52 & $2,48-2,58$ & 0,032 \\
\hline P. littoralis & 02 & 2,52 & 2,52 & - \\
\hline P. criptica & 10 & 2,51 & $2,34-2,60$ & 0,071 \\
\hline P. mulata & 10 & 2,49 & $2,36-2,58$ & 0,064 \\
\hline P. chapadicola & 10 & 2,49 & $2,34-2,60$ & 0,069 \\
\hline P. combinata & 10 & 2,48 & $2,30-2,60$ & 0,087 \\
\hline P. auripennis & 10 & 2,48 & $2,32-2,56$ & 0,070 \\
\hline P. orizabaensis & 10 & 2,46 & $2,28-2,60$ & 0,101 \\
\hline P. musarum & 10 & 2,46 & $2,38-2,54$ & 0,048 \\
\hline P. cupira & 10 & 2,45 & $2,30-2,52$ & 0,068 \\
\hline P. helleri & 10 & 2,44 & $2,38-2,50$ & 0,040 \\
\hline P. testacea & 10 & 2,44 & $2,32-2,60$ & 0,092 \\
\hline P. seridoensis & 10 & 2,44 & $2,40-2,52$ & 0,037 \\
\hline P. rustica & 10 & 2,43 & $2,40-2,48$ & 0,027 \\
\hline P. bilineata & 10 & 2,41 & $2,28-2,48$ & 0,061 \\
\hline P. peckolti & 10 & 2,40 & $2,32-2,52$ & 0,071 \\
\hline P. vicina & 10 & 2,39 & $2,32-2,48$ & 0,050 \\
\hline P. nigrior & 10 & 2,38 & $2,28-2,50$ & 0,071 \\
\hline P. subtilis & 10 & 2,34 & $2,28-2,42$ & 0,045 \\
\hline P. nigrilabris & 10 & 2,31 & $2,24-2,38$ & 0,039 \\
\hline P. pearsoni & 10 & 2,30 & $2,24-2,40$ & 0,045 \\
\hline
\end{tabular}


Tabela IV. Dimensões, espécies de Partamona - comprimento da asa anterior, operárias.

\begin{tabular}{|c|c|c|c|c|}
\hline & $\mathrm{n}$ & média (mm) & limites (mm) & desvio padrão \\
\hline P. grandipennis & 10 & 8,04 & $7,88-8,30$ & 0,114 \\
\hline P. xanthogastra & 10 & 7,03 & $6,85-7,14$ & 0,100 \\
\hline P. sooretamae & 10 & 6,68 & $6,56-6,81$ & 0,075 \\
\hline P. yungarum & 10 & 6,63 & $6,47-6,81$ & 0,111 \\
\hline P. helleri (pops. RJ, ES) & 10 & 6,49 & $6,23-6,72$ & 0,148 \\
\hline P. epiphytophila & 10 & 6,44 & $6,23-6,81$ & 0,190 \\
\hline P. criptica & 10 & 6,35 & $5,98-6,56$ & 0,149 \\
\hline P. ailyae & 10 & 6,28 & $6,14-6,56$ & 0,114 \\
\hline P. aequatoriana & 10 & 6,22 & $5,98-6,43$ & 0,147 \\
\hline P. nhambiquara & 10 & 6,13 & $5,89-6,39$ & 0,133 \\
\hline P.testacea & 10 & 6,04 & $5,69-6,39$ & 0,265 \\
\hline P. batesi & 10 & 6,00 & $5,89-6,14$ & 0,091 \\
\hline P. orizabaensis & 10 & 5,96 & $5,48-6,31$ & 0,229 \\
\hline P. peckolti & 10 & 5,96 & $5,48-6,31$ & 0,228 \\
\hline P. vitae & 5 & 5,93 & $5,73-6,06$ & 0,126 \\
\hline P. mulata & 10 & 5,88 & $5,64-6,06$ & 0,136 \\
\hline P. helleri & 10 & 5,83 & $5,56-6,06$ & 0,150 \\
\hline P. gregaria & 10 & 5,81 & $5,44-6,06$ & 0,162 \\
\hline P. rustica & 10 & 5,80 & $5,56-5,98$ & 0,132 \\
\hline P. littoralis & 10 & 5,79 & $5,56-5,89$ & 0,093 \\
\hline P. combinata & 10 & 5,74 & $5,40-5,98$ & 0,149 \\
\hline P. musarum & 10 & 5,73 & $5,56-5,89$ & 0,113 \\
\hline P. seridoensis & 10 & 5,73 & $5,56-5,89$ & 0,098 \\
\hline P. cupira & 10 & 5,71 & $5,31-6,06$ & 0,243 \\
\hline P. chapadicola & 10 & 5,71 & $5,48-5,89$ & 0,128 \\
\hline P. bilineata & 10 & 5,69 & $5,31-6,06$ & 0,217 \\
\hline$P$. ferreirai & 10 & 5,69 & $5,48-5,89$ & 0,114 \\
\hline P. subtilis & 10 & 5,66 & $5,52-5,81$ & 0,102 \\
\hline P. mourei & 10 & 5,59 & $5,44-5,98$ & 0,146 \\
\hline P. auripennis & 10 & 5,45 & $5,27-5,81$ & 0,154 \\
\hline P. vicina & 10 & 5,40 & $5,23-5,64$ & 0.098 \\
\hline P. nigrior & 10 & 5,30 & $5,10-5,60$ & 0,183 \\
\hline P.pearsoni & 10 & 5,09 & $4,90-5,31$ & 0,117 \\
\hline P. nigrilabris & 10 & 5,07 & $4,90-5,40$ & 0,136 \\
\hline
\end{tabular}


Tabela V. Proporções, espécies de Partamona, operárias - comprimento da área malar em relação ao diâmetro do $2^{\circ}$ flagelômero.

\begin{tabular}{|c|c|c|c|c|}
\hline & $\mathrm{n}$ & média (mm) & limites (mm) & desvio padrão \\
\hline P. grandipennis & 10 & 1,56 & $1,40-1,81$ & 0,129 \\
\hline P. aequatoriana & 10 & 1,45 & $1,31-1,67$ & 0,090 \\
\hline P.pearsoni & 10 & 1,20 & $1,14-1,33$ & 0,065 \\
\hline P. xanthogastra & 10 & 1,15 & $1,00-1,25$ & 0,071 \\
\hline P. musarum & 10 & 1,15 & $1,00-1,33$ & 0,107 \\
\hline P. yungarum & 10 & 1,14 & $1,00-1,34$ & 0,116 \\
\hline P. epiphytophila & 10 & 1,14 & $0,88-1,25$ & 0,110 \\
\hline P. peckolti & 10 & 1,14 & $0,75-1,50$ & 0,183 \\
\hline P. orizabaensis & 10 & 1,13 & $0,89-1,21$ & 0,108 \\
\hline P. testacea & 10 & 1,13 & $0,94-1,38$ & 0,146 \\
\hline P. criptica & 10 & 1,13 & $0,93-1,25$ & 0,092 \\
\hline P. vitae & 7 & 1,12 & $0,94-1,25$ & 0,132 \\
\hline P. nhambiquara & 10 & 1,10 & $1,00-1,19$ & 0,070 \\
\hline P. helleri & 10 & 1,08 & $1,00-1,22$ & 0,067 \\
\hline P. sooretamae & 10 & 1,07 & $0,94-1,19$ & 0,082 \\
\hline P. nigrior & 10 & 1,07 & $0,88-1,19$ & 0,087 \\
\hline P. auripennis & 10 & 1,07 & $1,00-1,13$ & 0,054 \\
\hline P. helleri (pops. RJ, ES) & 10 & 1,06 & $0,95-1,18$ & 0,061 \\
\hline P. gregaria & 10 & 1,06 & $1,00-1,13$ & 0,049 \\
\hline P. cupira & 10 & 1,06 & $0,82-1,25$ & 0,014 \\
\hline P. combinata & 10 & 1,06 & $1,00-1,20$ & 0,069 \\
\hline P. ailyae & 10 & 1,05 & $1,00-1,13$ & 0,055 \\
\hline P. bilineata & 10 & 1,04 & $1,00-1,07$ & 0,034 \\
\hline P. batesi & 10 & 1,03 & $0,94-1,18$ & 0,084 \\
\hline P. nigrilabris & 10 & 1,03 & $0,94-1,13$ & 0,059 \\
\hline P. rustica & 10 & 1,01 & $0,93-1,13$ & 0,055 \\
\hline P. subtilis & 10 & 0,99 & $0,93-1,07$ & 0,052 \\
\hline P. chapadicola & 10 & 0,98 & $0,88-1,06$ & 0,055 \\
\hline P. mulata & 10 & 0,97 & $0,88-1,13$ & 0,087 \\
\hline P. vicina & 10 & 0,97 & $0,82-1,14$ & 0,107 \\
\hline P. seridoensis & 10 & 0,95 & $0,86-1,13$ & 0,090 \\
\hline P. ferreirai & 10 & 0,94 & $0,88-1,00$ & 0,048 \\
\hline P. mourei & 10 & 0,81 & $0,75-0,93$ & 0,061 \\
\hline P. littoralis & 10 & 0,81 & $0,72-0,89$ & 0,048 \\
\hline
\end{tabular}


Tabela VI. Proporções, espécies de Partamona, operárias - distância interocelar em relação à ocelorbital.

\begin{tabular}{|c|c|c|c|c|}
\hline & $\mathrm{n}$ & média (mm) & limites (mm) & desvio padrão \\
\hline P. nigrilabris & 10 & 1,50 & $1,43-1,58$ & 0,058 \\
\hline P. mourei & 10 & 1,48 & $1,40-1,56$ & 0,055 \\
\hline P. auripennis & 10 & 1,46 & $1,31-1,56$ & 0,067 \\
\hline P. rustica & 10 & 1,46 & $1,33-1,57$ & 0,067 \\
\hline P. chapadicola & 10 & 1,46 & $1,34-1,65$ & 0,086 \\
\hline P. ferreirai & 10 & 1,46 & $1,35-1,52$ & 0,044 \\
\hline P. seridoensis & 10 & 1,45 & $1,33-1,58$ & 0,077 \\
\hline P. nigrior & 10 & 1,44 & $1,36-1,56$ & 0,064 \\
\hline P. littoralis & 10 & 1,44 & $1,36-1,50$ & 0,052 \\
\hline P. mulata & 10 & 1,43 & $1,21-1,54$ & 0,085 \\
\hline P. ailyae & 10 & 1,41 & $1,33-1,52$ & 0,052 \\
\hline P. cupira & 10 & 1,41 & $1,33-1,50$ & 0,057 \\
\hline P. epiphytophila & 10 & 1,40 & $1,11-1,59$ & 0,129 \\
\hline P. gregaria & 10 & 1,40 & $1,29-1,47$ & 0,045 \\
\hline P. batesi & 10 & 1,40 & $1,24-1,47$ & 0,072 \\
\hline P. nhambiquara & 10 & 1,39 & $1,33-1,48$ & 0,048 \\
\hline P. vicina & 10 & 1,38 & $1,16-1,58$ & 0,091 \\
\hline P. helleri (pops. RJ, ES) & 10 & 1,38 & $1,20-1,60$ & 0,108 \\
\hline P. helleri & 10 & 1,37 & $1,21-1,47$ & 0,069 \\
\hline P. pearsoni & 10 & 1,37 & $1,26-1,48$ & 0,068 \\
\hline P. combinata & 10 & 1,37 & $1,26-1,50$ & 0,072 \\
\hline P. orizabaensis & 10 & 1,32 & $1,18-1,54$ & 0,098 \\
\hline$P$. criptica & 10 & 1,30 & $1,13-1,40$ & 0,073 \\
\hline P. peckolti & 10 & 1,30 & $1,18-135$ & 0,051 \\
\hline P. aequatoriana & 10 & 1,27 & $1,21-1,40$ & 0,064 \\
\hline P. sooretamae & 10 & 1,27 & $1,24-1,31$ & 0,029 \\
\hline P. musarum & 10 & 1,27 & $1,19-1,34$ & 0,057 \\
\hline P. testacea & 10 & 1,25 & $1,06-1,44$ & 0,104 \\
\hline P. bilineata & 10 & 1,25 & $1,18-1,32$ & 0,053 \\
\hline P. yungarum & 10 & 1,18 & $1,11-1,27$ & 0,054 \\
\hline P. subtilis & 10 & 1,18 & $1,10-1,29$ & 0,049 \\
\hline P. xanthogastra & 10 & 1,00 & $0,92-1,06$ & 0,038 \\
\hline P. grandipennis & 10 & 0,85 & $0,83-0,90$ & 0,027 \\
\hline P. vitae & 7 & 1,36 & $1,25-1,48$ & 0,094 \\
\hline
\end{tabular}


Tabela VII. Proporções, espécies de Partamona, operárias - comprimento das cerdas da base do escapo em relação ao diâmetro do escapo.

\begin{tabular}{|c|c|c|c|c|}
\hline & $\mathrm{n}$ & média (mm) & limites (mm) & desvio padrão \\
\hline P. helleri & 10 & 1,97 & $1,67-2,14$ & 0,161 \\
\hline P. pearsoni & 10 & 1,92 & $1,69-2,46$ & 0,249 \\
\hline P. peckolti & 10 & 1,89 & $1,71-2,20$ & 0,160 \\
\hline P. yungarum & 10 & 1,74 & $1,50-1,88$ & 0,116 \\
\hline P. grandipennis & 10 & 1,55 & $1,29-1,75$ & 0,164 \\
\hline P. orizabaensis & 10 & 1,55 & $1,27-1,75$ & 0,166 \\
\hline P. nhambiquara & 10 & 1,52 & $1,33-1,80$ & 0,135 \\
\hline P. epiphytophila & 10 & 1,51 & $1,25-1,73$ & 0,229 \\
\hline P. rustica & 10 & 1,40 & $1,27-1,64$ & 0,119 \\
\hline P. xanthogastra & 10 & 1,36 & $1,29-1,44$ & 0,053 \\
\hline P. batesi & 10 & 1,34 & $0,93-1,47$ & 0,163 \\
\hline P. helleri (pops. ES, RJ) & 10 & 1,30 & $1,00-1,50$ & 0,137 \\
\hline P. gregaria & 10 & 1,23 & $0,93-1,73$ & 0,224 \\
\hline$P$. ferreirai & 10 & 1,15 & $0,86-1,57$ & 0,184 \\
\hline P. criptica & 10 & 1,14 & $0,86-1,47$ & 0,175 \\
\hline P. littoralis & 10 & 1,11 & $0,94-1,31$ & 0,118 \\
\hline P. combinata & 10 & 1,09 & $0,86-1,27$ & 0,124 \\
\hline P. ailyae & 10 & 1,05 & $0,80-1,33$ & 0,160 \\
\hline P. chapadicola & 10 & 1,05 & $0,81-1,20$ & 0,113 \\
\hline P. testacea & 10 & 0,99 & $0,77-1,15$ & 0,133 \\
\hline P. auripennis & 10 & 0,98 & $0,86-1,00$ & 0,093 \\
\hline P. seridoensis & 10 & 0,95 & $0,80-1,14$ & 0,101 \\
\hline P. vitae & 7 & 0,94 & $0,86-1,14$ & 0,122 \\
\hline P. sooretamae & 10 & 0,93 & $0,75-1,20$ & 0,119 \\
\hline P. vicina & 10 & 0,93 & $0,77-1,15$ & 0,122 \\
\hline P. bilineata & 10 & 0,92 & $0,80-1,13$ & 0,102 \\
\hline P. mulata & 10 & 0,90 & $0,67-1,00$ & 0,106 \\
\hline P. nigrior & 10 & 0,90 & $0,71-1,00$ & 0,091 \\
\hline P. subtilis & 10 & 0,88 & $0,69-1,17$ & 0,132 \\
\hline P. cupira & 10 & 0,88 & $0,79-1,00$ & 0,056 \\
\hline P. nigrilabris & 10 & 0,88 & $0,71-1,00$ & 0,080 \\
\hline P. aequatoriana & 10 & 0,80 & $0,63-1,00$ & 0,110 \\
\hline P. mourei & 10 & 0,80 & $0,60-1,00$ & 0,136 \\
\hline P. musarum & 10 & 0,79 & $0,53-0,87$ & 0,097 \\
\hline
\end{tabular}


Tabela VIII. Proporções, espécies de Partamona, operárias - Tíbia III: comprimento em relação à largura.

\begin{tabular}{|c|c|c|c|c|}
\hline & $\mathrm{n}$ & média (mm) & limites (mm) & desvio padrão \\
\hline P. grandipennis & 10 & 2,30 & $2,22-2,36$ & 0,044 \\
\hline P. yungarum & 10 & 2,17 & $2,12-2,23$ & 0,032 \\
\hline P. criptica & 10 & 2,16 & $2,11-2,29$ & 0,047 \\
\hline P. subtilis & 10 & 2,15 & $2,11-2,24$ & 0,037 \\
\hline P. xanthogastra & 10 & 2,15 & $2,10-2,19$ & 0,027 \\
\hline P. nigrilabris & 10 & 2,14 & $2,06-2,24$ & 0,048 \\
\hline P. testacea & 10 & 2,12 & $2,07-2,21$ & 0,044 \\
\hline P. vitae & 6 & 2,12 & $2,09-2,18$ & 0,034 \\
\hline P. pearsoni & 10 & 2,11 & $2,06-2,17$ & 0,039 \\
\hline P. sooretamae & 10 & 2,11 & $2,05-2,15$ & 0,028 \\
\hline P. helleri & 10 & 2,11 & $2,02-2,17$ & 0,048 \\
\hline P. musarum & 10 & 2,10 & $2,05-2,17$ & 0,035 \\
\hline P. auripennis & 10 & 2,10 & $2,04-2,15$ & 0,042 \\
\hline P. nhambiquara & 10 & 2,10 & $2,03-2,18$ & 0,040 \\
\hline P. combinata & 10 & 2,10 & $2,03-2,16$ & 0,032 \\
\hline P. ferreirai & 10 & 2,10 & $2,03-2,18$ & 0,047 \\
\hline P. epiphytophila & 10 & 2,10 & $2,03-2,21$ & 0,050 \\
\hline P. chapadicola & 10 & 2,10 & $2,04-2,15$ & 0,041 \\
\hline P. peckolti & 10 & 2,09 & $2,02-2,19$ & 0,052 \\
\hline P. orizabaensis & 10 & 2,09 & $1,97-2,16$ & 0,050 \\
\hline P. cupira & 10 & 2,09 & $2,05-2,13$ & 0,025 \\
\hline P. gregaria & 10 & 2,08 & $2,04-2,16$ & 0,040 \\
\hline P. mourei & 10 & 2,07 & $1,95-2,13$ & 0,052 \\
\hline P. nigrior & 10 & 2,07 & $1,96-2,16$ & 0,062 \\
\hline P. bilineata & 10 & 2,07 & $2,02-2,13$ & 0,038 \\
\hline P. seridoensis & 10 & 2,06 & $2,02-2,11$ & 0,029 \\
\hline P. aequatoriana & 10 & 2,06 & $2,00-2,14$ & 0,039 \\
\hline P. helleri (pops. ES, RJ) & 10 & 2,06 & $2,00-2,13$ & 0,034 \\
\hline P. vicina & 10 & 2,05 & $1,98-2,16$ & 0,048 \\
\hline P. batesi & 10 & 2,05 & $1,95-2,16$ & 0,061 \\
\hline P. rustica & 10 & 2,05 & $1,95-2,13$ & 0,052 \\
\hline P. ailyae & 10 & 2,04 & $1,97-2,13$ & 0,043 \\
\hline P. mulata & 10 & 2,04 & $1,98-2,10$ & 0,041 \\
\hline P. littoralis & 10 & 1,99 & $1,95-2,04$ & 0,033 \\
\hline
\end{tabular}


Tabela IX. Proporções, espécies de Partamona - comprimento da asa anterior em relação à largura máxima da cabeça.

\begin{tabular}{|c|c|c|c|c|}
\hline & $\mathrm{n}$ & média (mm) & limites (mm) & desvio padrão \\
\hline P. grandipennis & 10 & 2,85 & $2,80-3,01$ & 0,058 \\
\hline P. yungarum & 10 & 2,59 & $2,54-2,63$ & 0,023 \\
\hline P. criptica & 10 & 2,53 & $2,46-2,59$ & 0,044 \\
\hline P. sooretamae & 10 & 2,48 & $2,43-2,51$ & 0,023 \\
\hline P. xanthogastra & 10 & 2,45 & $2,39-2,49$ & 0,032 \\
\hline P. testacea & 10 & 2,44 & $2,38-2,50$ & 0,039 \\
\hline P. peckolti & 10 & 2,42 & $2,31-2,52$ & 0,077 \\
\hline P. epiphytophila. & 10 & 2,42 & $2,33-2,63$ & 0,090 \\
\hline P. orizabaensis & 10 & 2,41 & $2,38-2,47$ & 0,049 \\
\hline P. subtilis & 10 & 2,41 & $2,31-2,55$ & 0,057 \\
\hline P. aequatoriana & 10 & 2,39 & $2,32-2,50$ & 0,059 \\
\hline P. helleri (pops. ES, RJ) & 10 & 2,39 & $2,31-2,44$ & 0,037 \\
\hline P. rustica & 10 & 2,38 & $2,32-2,42$ & 0,034 \\
\hline P. helleri & 10 & 2,38 & $2,32-2,44$ & 0,040 \\
\hline P nhambiquara & 10 & 2,37 & $2,33-2,40$ & 0,024 \\
\hline P. ailyae & 10 & 2,37 & $2,32-2,43$ & 0,039 \\
\hline P. mulata & 10 & 2,37 & $2,31-2,42$ & 0,034 \\
\hline P. seridoensis & 10 & 2,35 & $2,31-2,38$ & 0,023 \\
\hline P. bilineata & 10 & 2,34 & $2,24-2,45$ & 0,064 \\
\hline$P$. vitae & 5 & 2,34 & $2,27-2,41$ & 0,061 \\
\hline P. cupira & 10 & 2,33 & $2,25-2,40$ & 0,044 \\
\hline P. musarum & 10 & 2,31 & $2,26-2,36$ & 0,034 \\
\hline P. littoralis & 02 & 2,31 & 2,31 & - \\
\hline P. chapadicola & 10 & 2,29 & $2,22-2,36$ & 0,038 \\
\hline P. batesi & 10 & 2,28 & $2,23-2,36$ & 0,043 \\
\hline P. combinata & 10 & 2,27 & $2,16-2,34$ & 0,057 \\
\hline P. gregaria & 10 & 2,27 & $2,22-2,32$ & 0,028 \\
\hline P. vicina & 10 & 2,26 & $2,18-2,33$ & 0,037 \\
\hline$P$. ferreirai & 10 & 2,23 & $2,19-2,27$ & 0,026 \\
\hline P. pearsoni & 10 & 2,23 & $2,18-2,28$ & 0,033 \\
\hline P. mourei & 10 & 2,21 & $2,12-2,24$ & 0,070 \\
\hline P. nigrior & 10 & 2,20 & $2,14-2,30$ & 0,043 \\
\hline P. auripennis & 10 & 2,19 & $2,09-2,27$ & 0,056 \\
\hline P. nigrilabris & 10 & 2,18 & $2,16-2,25$ & 0,027 \\
\hline
\end{tabular}


Tabela X. Medidas (mm) dos holótipos, operárias, de Partamona epiphytophila sp. nov., Partamona subtilis, sp. nov., Partamona nhambiquara sp. nov. e Partamona batesi sp. nov.

\begin{tabular}{|c|c|c|c|c|}
\hline Medidas (mm) & P. epiphytophila & P. subtilis & P. nhambiquara & P. batesi \\
\hline Comprimento total aproximado & 5,98 & 5,73 & 6,23 & 5,56 \\
\hline Largura máxima da cabeça & 2,64 & 2,26 & 2,70 & 2,68 \\
\hline Comprimento da cabeça & 2,24 & 1,96 & 2,32 & 2,24 \\
\hline Comprimento do olho & 1,76 & 1,52 & 1,78 & 1,78 \\
\hline Largura do olho & 0,73 & 0,60 & 0,76 & 0,74 \\
\hline Distância interorbital superior & 1,50 & 1,29 & 1,56 & 1,50 \\
\hline Distância interorbital máxima & 1,80 & 1,52 & 1,82 & 1,76 \\
\hline Distância interorbital inferior & 1,52 & 1,28 & 1,58 & 1,52 \\
\hline Diâmetro do ocelo médio & 0,24 & 0,20 & 0,24 & 0,24 \\
\hline Distância interocelar & 0,44 & 0,34 & 0,46 & 0,44 \\
\hline Distância ocelorbital & 0,31 & 0,30 & 0,33 & 0,32 \\
\hline Distância interalveolar & 0,32 & 0,28 & 0,32 & 0,24 \\
\hline Distância alveolorbital & 0,40 & 0,34 & 0,42 & 0,40 \\
\hline Distância alvéolo-ocelo lateral & 1,08 & 0,96 & 1,11 & 1,06 \\
\hline Diâmetro do alvéolo & 0,24 & 0,21 & 0,24 & 0,24 \\
\hline Comprimento do clípeo & 0,75 & 0,62 & 0,76 & 0,69 \\
\hline Largura máxima do clípeo & 1,34 & 1,12 & 1,36 & 1,26 \\
\hline Larg. do clípeo nas fóveas tentoriais & 0,80 & 0,66 & 0,82 & 0,80 \\
\hline Distância clipeocelar & 2,00 & 1,74 & 2,06 & 2,00 \\
\hline Comprimento da área malar & 0,18 & 0,13 & 0,20 & 0,16 \\
\hline Comprimento do escapo & 1,03 & 0,88 & 1,06 & 1,02 \\
\hline Diâmetro do escapo & 0,16 & 0,13 & 0,16 & 0,14 \\
\hline Diâmetro do $2^{\circ}$ flagelômero & 0,16 & 0,14 & 0,16 & 0,16 \\
\hline Comprimento da mandíbula & 1,14 & 0,99 & 1,17 & 1,14 \\
\hline $\begin{array}{l}\text { Comprimento da asa anterior (do ápice do } \\
\text { esclerito C) }\end{array}$ & 6,31 & 5,48 & 6,35 & 6,06 \\
\hline $\begin{array}{l}\text { Comprimento da asa anterior (incluindo } \\
\text { tégulas) }\end{array}$ & 7,22 & 5,98 & 7,14 & 6,81 \\
\hline Largura da asa anterior & 2,34 & 2,00 & 2,38 & 2,34 \\
\hline Número de hâmulos & 5 & 5 & 5 & 5 \\
\hline Largura do mesoscuto & 1,76 & 1,40 & 1,74 & 1,74 \\
\hline Comprimento do mesoscuto & 1,58 & 1,14 & 1,66 & 1,64 \\
\hline Largura do escutelo & 1,18 & 0,90 & 1,22 & 1,20 \\
\hline Comprimento do escutelo & 0,58 & 0,48 & 0,60 & 0,60 \\
\hline Comprimento da tíbia III & 2,52 & 2,11 & 2,52 & 2,50 \\
\hline Largura máxima da tíbia III & 1,22 & 0,98 & 1,22 & 1,19 \\
\hline Comprimento do basitarso III & 0,92 & 0,90 & 1,02 & 1,00 \\
\hline Largura do basitarso III & 0,62 & 0,54 & 0,62 & 0,62 \\
\hline Largura do TIII & 2,60 & 2,02 & 2,60 & 2,80 \\
\hline Compr. cerdas da base do escapo & 0,24 & 0,14 & 0,20 & 0,18 \\
\hline Compr. cerdas do clípeo & 0,16 & 0,14 & 0,16 & 0,18 \\
\hline Compr. cerdas da fronte & 0,17 & 0,15 & 0,23 & 0,16 \\
\hline Compr. cerdas do vértice & 0,34 & 0,28 & 0,38 & 0,28 \\
\hline Compr. cerdas do disco do mesoscuto & 0,21 & 0,16 & 0,23 & 0,21 \\
\hline $\begin{array}{l}\text { Compr. cerdas da margem anterior do } \\
\text { mesoscuto }\end{array}$ & 0,40 & 0,24 & 0,34 & 0,38 \\
\hline Comprimento das cerdas do escutelo & 0,60 & 0,51 & 0,56 & 0,60 \\
\hline Compr. cerdas das paroculares & 0,14 & 0,08 & 0,16 & 0,21 \\
\hline
\end{tabular}


Tabela XI. Medidas (mm) dos holótipos, operárias, de Partamona yungarum sp. nov., Partamona vitae sp. nov., Partamona ferreirai sp. nov., Partamona gregaria sp. nov., e Partamona auripennis sp. nov.

\begin{tabular}{|c|c|c|c|c|c|}
\hline Medidas (mm) & P. yungarum & P. vitae & P. ferreirai & P. gregaria & P. auripennis \\
\hline Comprimento total aproximado & 6,56 & 6,47 & 5,64 & 6,31 & 5,64 \\
\hline Largura máxima da cabeça & 2,56 & 2,52 & 2,56 & 2,54 & 2,50 \\
\hline Comprimento da cabeça & 2,20 & 2,12 & 2,12 & 2,16 & 2,08 \\
\hline Comprimento do olho & 1,64 & 1,70 & 1,68 & 1,68 & 1,66 \\
\hline Largura do olho & 0,64 & 0,70 & 0,71 & 0,68 & 0,68 \\
\hline Distância interorbital superior & 1,50 & 1,39 & 1,50 & 1,44 & 1,44 \\
\hline Distância interorbital máxima & 1,78 & 1,70 & 1,74 & 1,68 & 1,68 \\
\hline Distância interorbital inferior & 1,50 & 1,42 & 1,45 & 1,45 & 1,42 \\
\hline Diâmetro do ocelo médio & 0,22 & 0,22 & 0,26 & 0,24 & 0,24 \\
\hline Distância interocelar & 0,42 & 0,40 & 0,46 & 0,46 & 0,42 \\
\hline Distância ocelorbital & 0,36 & 0,30 & 0,32 & 0,28 & 0,30 \\
\hline Distância interalveolar & 0,32 & 0,30 & 0,34 & 0,34 & 0,34 \\
\hline Distância alveolorbital & 0,40 & 0,38 & 0,38 & 0,40 & 0,38 \\
\hline Distância alvéolo-ocelo lateral & 1,04 & 1,02 & 1,06 & 1,06 & 1,04 \\
\hline Diâmetro do alvéolo & 0,22 & 0,22 & 0,23 & 0,22 & 0,24 \\
\hline Comprimento do clípeo & 0,75 & 0,68 & 0,70 & 0,68 & 0,64 \\
\hline Largura máxima do clípeo & 1,30 & 1,26 & 1,20 & 1,28 & 1,24 \\
\hline Larg. do clípeo nas fóveas tentoriais & 0,78 & 0,78 & 0,78 & 0,80 & 0,74 \\
\hline Distância clipeocelar & 1,96 & 1,86 & 1,92 & 1,90 & 1,86 \\
\hline Comprimento da área malar & 0,20 & 0,16 & 0,16 & 0,17 & 0,17 \\
\hline Comprimento do escapo & 1,02 & 0,97 & 1,00 & 0,95 & 0,94 \\
\hline Diâmetro do escapo & 0,16 & 0,14 & 0,14 & 0,15 & 0,14 \\
\hline Diâmetro do $2^{\underline{0}}$ flagelômero & 0,16 & 0,16 & 0,16 & 0,16 & 0,16 \\
\hline Comprimento da mandíbula & 1,12 & 1,12 & 1,14 & 1,05 & 1,06 \\
\hline $\begin{array}{l}\text { Comprimento da asa anterior } \\
\text { (do ápice do esclerito C) }\end{array}$ & 6,64 & 5,73 & 5,81 & 5,64 & 5,64 \\
\hline $\begin{array}{l}\text { Comprimento da asa anterior } \\
\text { (incluindo tégulas) }\end{array}$ & 7,47 & 6,56 & 6,56 & 6,47 & 6,39 \\
\hline Largura da asa anterior & 2,44 & 2,16 & 2,18 & 2,26 & 2,10 \\
\hline Número de hâmulos & 5 & 5 & 5 & 5 & 5 \\
\hline Largura do mesoscuto & 1,82 & 1,68 & 1,74 & 1,68 & 1,72 \\
\hline Comprimento do mesoscuto & 1,60 & 1,48 & $?$ & 1,52 & 1,56 \\
\hline Largura do escutelo & 1,21 & 1,12 & 1,18 & 1,14 & 1,14 \\
\hline Comprimento do escutelo & 0,58 & 0,56 & 0,58 & 0,56 & 0,54 \\
\hline Comprimento da tíbia III & 2,38 & 2,40 & 2,36 & 2,36 & 2,32 \\
\hline Largura máxima da tíbia III & 1,06 & 1,10 & 1,12 & 1,12 & 1,10 \\
\hline Comprimento do basitarso III & 1,02 & 1,06 & 0,92 & 1,00 & 0,94 \\
\hline Largura do basitarso III & 0,54 & 0,63 & 0,60 & 0,60 & 0,58 \\
\hline Largura do TIII & 2,56 & 2,44 & 2,40 & 2,30 & 2,52 \\
\hline Compr. cerdas da base do escapo & 0,22 & 0,12 & 0,18 & 0,15 & 0,19 \\
\hline Compr. cerdas do clípeo & 0,23 & 0,16 & 0,18 & 0,13 & 0,21 \\
\hline Compr. cerdas da fronte & 0,21 & 0,15 & 0,18 & 0,17 & 0,20 \\
\hline Compr. cerdas do vértice & 0,32 & 0,30 & 0,34 & 0,34 & 0,26 \\
\hline $\begin{array}{l}\text { Compr. cerdas do disco do } \\
\text { mesoscuto }\end{array}$ & 0,25 & 0,15 & 0,22 & 0,20 & 0,15 \\
\hline $\begin{array}{l}\text { Compr. cerdas da margem anterior } \\
\text { do mesoscuto }\end{array}$ & 0,36 & 0,24 & 0,38 & 0,39 & 0,58 \\
\hline Comprimento das cerdas do escutelo & 0,58 & 0,60 & 0,54 & 0,54 & 0,23 \\
\hline Compr. cerdas das paroculares & 0,18 & 0,12 & 0,16 & 0,16 & 0,33 \\
\hline
\end{tabular}


Tabela XII. Medidas (mm) dos holótipos, operárias, de Partamona nigrilabris sp. nov., Partamona combinata sp. nov., Partamona chapadicola sp. nov. e Partamona seridoensis sp. nov.

\begin{tabular}{|c|c|c|c|c|}
\hline Medidas (mm) & P. nigrilabris & P. combinata & P. chapadicola & P. seridoensis \\
\hline Comprimento total aproximado & 6,23 & 5,98 & 6,64 & 5,81 \\
\hline Largura máxima da cabeça & 2,38 & 2,54 & 2,64 & 2,46 \\
\hline Comprimento da cabeça & 2,00 & 2,12 & 2,16 & 2,04 \\
\hline Comprimento do olho & 1,54 & 1,70 & 1,72 & 1,60 \\
\hline Largura do olho & 0,66 & 0,68 & 0,72 & 0,66 \\
\hline Distância interorbital superior & 1,37 & 1,43 & 1,54 & 1,40 \\
\hline Distância interorbital máxima & 1,60 & 1,72 & 1,80 & 1,64 \\
\hline Distância interorbital inferior & 1,35 & 1,44 & 1,50 & 1,40 \\
\hline Diâmetro do ocelo médio & 0,21 & 0,24 & 0,24 & 0,24 \\
\hline Distância interocelar & 0,40 & 0,42 & 0,45 & 0,44 \\
\hline Distância ocelorbital & 0,28 & 0,30 & 0,32 & 0,27 \\
\hline Distância interalveolar & 0,30 & 0,32 & 0,36 & 0,32 \\
\hline Distância alveolorbital & 0,34 & 0,38 & 0,42 & 0,36 \\
\hline Distância alvéolo-ocelo lateral & 0,98 & 1,06 & 1,08 & 1,02 \\
\hline Diâmetro do alvéolo & 0,23 & 0,24 & 0,24 & 0,22 \\
\hline Comprimento do clípeo & 0,64 & 0,68 & 0,72 & 0,64 \\
\hline Largura máxima do clípeo & 1,16 & 1,20 & 1,34 & 1,26 \\
\hline Larg. do clípeo nas fóveas tentoriais & 0,70 & 0,76 & 0,78 & 0,74 \\
\hline Distância clipeocelar & 1,80 & 1,90 & 1,94 & 1,82 \\
\hline Comprimento da área malar & 0,17 & 0,18 & 0,16 & 0,18 \\
\hline Comprimento do escapo & 0,90 & 0,95 & 0,98 & 0,91 \\
\hline Diâmetro do escapo & 0,15 & 0,16 & 0,16 & 0,15 \\
\hline Diâmetro do $2^{\circ}$ flagelômero & 0,16 & 0,16 & 0,18 & 0,16 \\
\hline Comprimento da mandíbula & 0,99 & 1,08 & 1,11 & 1,05 \\
\hline $\begin{array}{l}\text { Comprimento da asa anterior } \\
\text { (do ápice do esclerito C) }\end{array}$ & 5,15 & 5,81 & 5,89 & 5,56 \\
\hline $\begin{array}{l}\text { Comprimento da asa anterior } \\
\text { (incluindo tégulas) }\end{array}$ & 5,69 & 6,72 & 6,72 & 6,31 \\
\hline Largura da asa anterior & 2,00 & 2,26 & 2,20 & 2,22 \\
\hline Número de hâmulos & $4-5$ & 5 & 5 & 5 \\
\hline Largura do mesoscuto & 1,60 & 1,76 & 1,76 & 1,72 \\
\hline Comprimento do mesoscuto & 1,38 & 1,60 & 1,60 & 1,52 \\
\hline Largura do escutelo & 1,02 & 1,20 & 1,26 & 1,10 \\
\hline Comprimento do escutelo & 0,50 & 0,60 & 0,58 & 0,56 \\
\hline Comprimento da tíbia III & 2,12 & 2,42 & 2,48 & 0,94 \\
\hline Largura máxima da tíbia III & 1,00 & 1,20 & 1,20 & 1,14 \\
\hline Comprimento do basitarso III & 0,82 & 0,90 & 1,02 & 0,96 \\
\hline Largura do basitarso III & 0,54 & 0,66 & 0,63 & 0,60 \\
\hline Largura do TIII & 2,10 & 2,52 & 2,72 & 2,44 \\
\hline Compr. cerdas da base do escapo & 0,12 & 0,17 & 0,15 & 0,15 \\
\hline Compr. cerdas do clípeo & 0,15 & 0,17 & 0,17 & 0,13 \\
\hline Compr. cerdas da fronte & 0,20 & 0,18 & 0,14 & 0,16 \\
\hline Compr. cerdas do vértice & 0,31 & 0,28 & 0,34 & 0,34 \\
\hline $\begin{array}{l}\text { Compr. cerdas do disco do } \\
\text { mesoscuto }\end{array}$ & 0,20 & 0,23 & 0,18 & 0,16 \\
\hline $\begin{array}{l}\text { Compr. cerdas da margem anterior } \\
\text { do mesoscuto }\end{array}$ & 0,07 & 0,30 & 0,33 & 0,26 \\
\hline Comprimento das cerdas do escutelo & 0,40 & 0,48 & 0,50 & 0,46 \\
\hline Compr. cerdas das paroculares & 0,18 & 0,15 & 0,16 & 0,12 \\
\hline
\end{tabular}


Tabela XIII. Medidas (mm) dos holótipos, operárias, de Partamona littoralis sp. nov., Partamona sooretamae sp. nov., Partamona criptica sp. nov., Partamona rustica sp. nov.

\begin{tabular}{|c|c|c|c|c|}
\hline Medidas (mm) & P. littoralis & P. sooretamae & P. criptica & P. rustica \\
\hline Comprimento total aproximado & 7,14 & 6,14 & 6,39 & 5,81 \\
\hline Largura máxima da cabeça & 2,52 & 2,68 & 2,56 & 2,42 \\
\hline Comprimento da cabeça & 2,08 & 2,28 & 2,16 & 2,08 \\
\hline Comprimento do olho & 1,68 & 1,82 & 1,68 & 1,63 \\
\hline Largura do olho & 0,70 & 0,74 & 0,70 & 0,66 \\
\hline Distância interorbital superior & 1,40 & 1,51 & 1,48 & 1,38 \\
\hline Distância interorbital máxima & 1,63 & 1,78 & 1,76 & 1,60 \\
\hline Distância interorbital inferior & 1,40 & 1,54 & 1,48 & 1,36 \\
\hline Diâmetro do ocelo médio & 0,22 & 0,25 & 0,26 & 0,23 \\
\hline Distância interocelar & 0,38 & 0,43 & 0,41 & 0,42 \\
\hline Distância ocelorbital & 0,29 & 0,34 & 0,32 & 0,28 \\
\hline Distância interalveolar & 0,30 & 0,34 & 0,32 & 0,32 \\
\hline Distância alveolorbital & 0,36 & 0,40 & 0,42 & 0,37 \\
\hline Distância alvéolo-ocelo lateral & 1,04 & 1,10 & 1,04 & 0,98 \\
\hline Diâmetro do alvéolo & 0,27 & 0,25 & 0,23 & 0,22 \\
\hline Comprimento do clípeo & 0,64 & 0,76 & 0,68 & 0,65 \\
\hline Largura máxima do clípeo & 1,20 & 1,35 & 1,30 & 1,20 \\
\hline Larg. do clípeo nas fóveas tentoriais & 0,76 & 0,79 & 0,76 & 0,72 \\
\hline Distância clipeocelar & 1,84 & 2,02 & 1,96 & 1,84 \\
\hline Comprimento da área malar & 0,14 & 0,18 & 0,18 & 0,16 \\
\hline Comprimento do escapo & 0,94 & 1,04 & 0,98 & 0,94 \\
\hline Diâmetro do escapo & 0,16 & 0,15 & 0,16 & 0,16 \\
\hline Diâmetro do $2^{\underline{0}}$ flagelômero & 0,17 & 0,16 & 0,16 & 0,16 \\
\hline Comprimento da mandíbula & 1,04 & 1,18 & 1,10 & 1,06 \\
\hline $\begin{array}{l}\text { Comprimento da asa anterior } \\
\text { (do ápice do esclerito C) }\end{array}$ & 5,77 & 6,64 & 6,47 & 5,73 \\
\hline $\begin{array}{l}\text { Comprimento da asa anterior } \\
\text { (incluindo tégulas) }\end{array}$ & 6,52 & 7,47 & 7,14 & 6,39 \\
\hline Largura da asa anterior & 2,16 & 2,52 & 2,48 & 2,16 \\
\hline Número de hâmulos & $4-5$ & 5 & 5 & 5 \\
\hline Largura do mesoscuto & 1,80 & 1,82 & 1,76 & 1,70 \\
\hline Comprimento do mesoscuto & 1,58 & 1,66 & 1,58 & 1,48 \\
\hline Largura do escutelo & 1,12 & 1,34 & 1,20 & 1,10 \\
\hline Comprimento do escutelo & 0,56 & 0,62 & 0,58 & 0,53 \\
\hline Comprimento da tíbia III & 2,34 & 2,60 & 2,48 & 2,28 \\
\hline Largura máxima da tíbia III & 1,14 & 1,24 & 1,20 & 1,08 \\
\hline Comprimento do basitarso III & 0,92 & 1,10 & 1,02 & 0,84 \\
\hline Largura do basitarso III & 0,63 & 0,64 & 0,62 & 0,58 \\
\hline Largura do III tergo & $?$ & 2,74 & 2,48 & 2,48 \\
\hline Compr. cerdas da base do escapo & 0,16 & 0,15 & 0,18 & 0,26 \\
\hline Compr. cerdas do clípeo & 0,15 & 0,16 & 0,19 & 0,14 \\
\hline Compr. cerdas da fronte & 0,16 & 0,19 & 0,22 & 0,17 \\
\hline Compr. cerdas do vértice & 0,34 & 0,37 & 0,34 & 0,32 \\
\hline Compr. cerdas do disco do mesoscuto & 0,19 & 0,23 & 0,28 & 0,14 \\
\hline $\begin{array}{l}\text { Compr. cerdas da margem anterior do } \\
\text { mesoscuto }\end{array}$ & 0,30 & 0,34 & 0,38 & 0,24 \\
\hline Comprimento das cerdas do escutelo & 0,52 & 0,65 & 0,50 & 0,26 \\
\hline Compr. cerdas das paroculares & 0,14 & 0,12 & 0,14 & 0,18 \\
\hline
\end{tabular}


Tabela XIV. Medidas (mm) dos tipos, operárias, de Partamona orizabaensis (Strand), Partamona testacea (Klug) e Partamona cupira (Smith), e operária e macho de Partamona helleri (Friese).

\begin{tabular}{|c|c|c|c|c|c|}
\hline Medidas (mm) & P. orizabaensis & P. testacea & P. cupira & $\begin{array}{l}\text { P. helleri } \\
\text { operária }\end{array}$ & $\begin{array}{l}\text { P. helleri } \\
\text { macho }\end{array}$ \\
\hline Comprimento total aproximado & 7,30 & 5,81 & 6,60 & 6,31 & 6,64 \\
\hline Largura máxima da cabeça & 2,52 & 2,40 & 2,40 & 2,44 & 2,46 \\
\hline Comprimento da cabeça & 2,06 & - & - & - & 2,08 \\
\hline Comprimento do olho & 1,64 & 1,65 & 1,60 & 1,58 & 1,66 \\
\hline Largura do olho & 0,67 & 0,69 & 0,68 & 0,63 & 0,76 \\
\hline Distância interorbital superior & 1,47 & 1,30 & 1,38 & 1,45 & 1,34 \\
\hline Distância interorbital máxima & 1,71 & 1,54 & 1,58 & 1,67 & 1,47 \\
\hline Distância interorbital inferior & 1,48 & 1,34 & 1,34 & 1,41 & 1,08 \\
\hline Diâmetro do ocelo médio & 0,24 & 0,22 & 0,22 & 0,22 & 0,25 \\
\hline Distância interocelar & 0,42 & 0,38 & 0,42 & 0,40 & 0,42 \\
\hline Distância ocelorbital & 0,32 & 0,27 & 0,29 & 0,36 & 0,28 \\
\hline Distância interalveolar & 0,30 & 0,30 & 0,30 & 0,30 & 0,26 \\
\hline Distância alveolorbital & 0,42 & 0,35 & 0,34 & 0,39 & 0,24 \\
\hline Distância alvéolo-ocelo lateral & 1,02 & 1,03 & 0,98 & 1,04 & 0,94 \\
\hline Diâmetro do alvéolo & 0,24 & 0,22 & 0,24 & 0,24 & 0,24 \\
\hline Comprimento do clípeo & 0,67 & 0,68 & 0,62 & 0,67 & 0,70 \\
\hline Largura máxima do clípeo & 1,28 & 1,26 & 1,28 & 1,28 & 1,02 \\
\hline Larg. do clípeo nas fóveas tentoriais & 0,72 & 0,73 & 0,76 & 0,72 & 0,66 \\
\hline Distância clipeocelar & 1,87 & 1,87 & 1,80 & 1,84 & 1,80 \\
\hline Comprimento da área malar & 0,20 & 0,15 & 0,14 & 0,17 & 0,07 \\
\hline Comprimento do escapo & 0,96 & 0,90 & 0,88 & 0,92 & 0,76 \\
\hline Diâmetro do escapo & 0,16 & 0,14 & 0,15 & 0,16 & 0,22 \\
\hline Diâmetro do $2^{\mathrm{o}}$ flagelômero & 0,18 & 0,15 & 0,17 & 0,16 & 0,20 \\
\hline Comprimento da mandíbula & 1,05 & 1,08 & 1,00 & 1,06 & 0,70 \\
\hline $\begin{array}{l}\text { Comprimento da asa anterior } \\
\text { (do ápice do esclerito C) }\end{array}$ & 6,14 & 5,56 & 5,48 & 5,89 & 5,54 \\
\hline $\begin{array}{l}\text { Comprimento da asa anterior } \\
\text { (incluindo tégulas) }\end{array}$ & 6,97 & 6,23 & 6,27 & 6,64 & 6,47 \\
\hline Largura da asa anterior & 2,22 & 2,02 & - & - & - \\
\hline Número de hâmulos & 5 & - & 5 & 5 & 5 \\
\hline Largura do mesoscuto & 1,70 & 1,55 & 1,62 & 1,64 & 1,68 \\
\hline Comprimento do mesoscuto & 1,56 & 1,38 & 1,46 & 1,54 & 1,76 \\
\hline Largura do escutelo & 1,18 & 0,98 & 1,12 & 1,10 & - \\
\hline Comprimento do escutelo & 0,58 & 0,54 & 0,50 & 0,54 & 0,60 \\
\hline Comprimento da tíbia III & $2,36^{*}$ & 2,24 & 2,20 & 2,24 & 1,91 \\
\hline Largura máxima da tíbia III & $1,12 *$ & 1,10 & 1,16 & 1,08 & 0,70 \\
\hline Comprimento do basitarso III & $1,04 *$ & 1,00 & 0,96 & 0,94 & 0,90 \\
\hline Largura do basitarso III & $0,62 *$ & 0,58 & 0,62 & 0,54 & 0,50 \\
\hline Largura do TIII & 2,24 & 2,22 & 2,22 & 2,36 & - \\
\hline Compr. cerdas da base do escapo & 0,28 & - & 0,12 & - & 0,11 \\
\hline Compr. cerdas do clípeo & 0,16 & - & 0,16 & - & 0,10 \\
\hline Compr. cerdas da fronte & 0,18 & - & 0,18 & - & 0,21 \\
\hline Compr. cerdas do vértice & 0,36 & - & - & - & 0,28 \\
\hline $\begin{array}{l}\text { Compr. cerdas do disco do } \\
\text { mesoscuto }\end{array}$ & 0,30 & - & 0,20 & - & 0,20 \\
\hline Comprimento das cerdas do escutelo & 0,55 & - & 0,40 & - & 0,42 \\
\hline Compr. cerdas das paroculares & 0,16 & - & - & - & - \\
\hline
\end{tabular}

* Medidas tomadas de um dos paralectótipos de P. orizabaensis. 

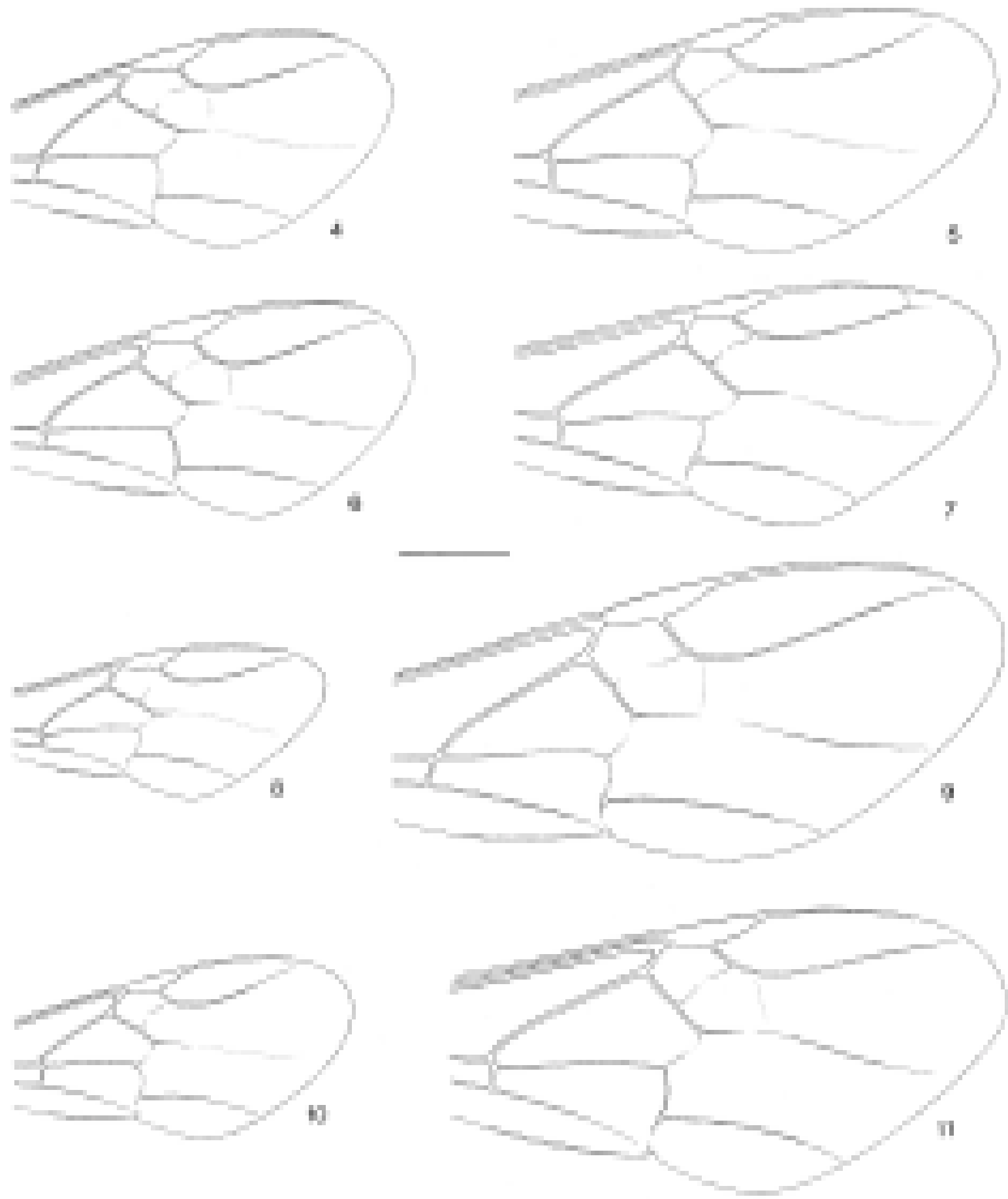

Figs. 4-11. Asa anterior, operária: 4. Plebeia remota (Holmberg, 1903) (Curitiba, PR, Brasil); 5. Meliwillea bivea Roubik, Lobo, Camargo, 1997 (Zurqui de Moravia, San Jose, Costa Rica); 6. Nogueirapis butteli (Friese, 1900) (Maraã, AM, Brasil); 7. Scaptotrigona polysticta (Moure, 1950) (Martinópolis, SP, Brasil); 8. Paratrigona lineata (Lepeletier, 1863) (Cajuru, SP, Brasil); 9. Parapartamona vittigera Moure, 1992 (1996) (Sta. Rosa, Equador, Andes Ocidentais, 2.450m, 407c); 10. Nannotrigona testaceicornis (Lepeletier, 1836) (Passos, MG, Brasil); 11. Partamona epiphytophila sp. nov. (Carauari, Rio Juruá, AM, Brasil, 520c). Escala =1,0 mm. 


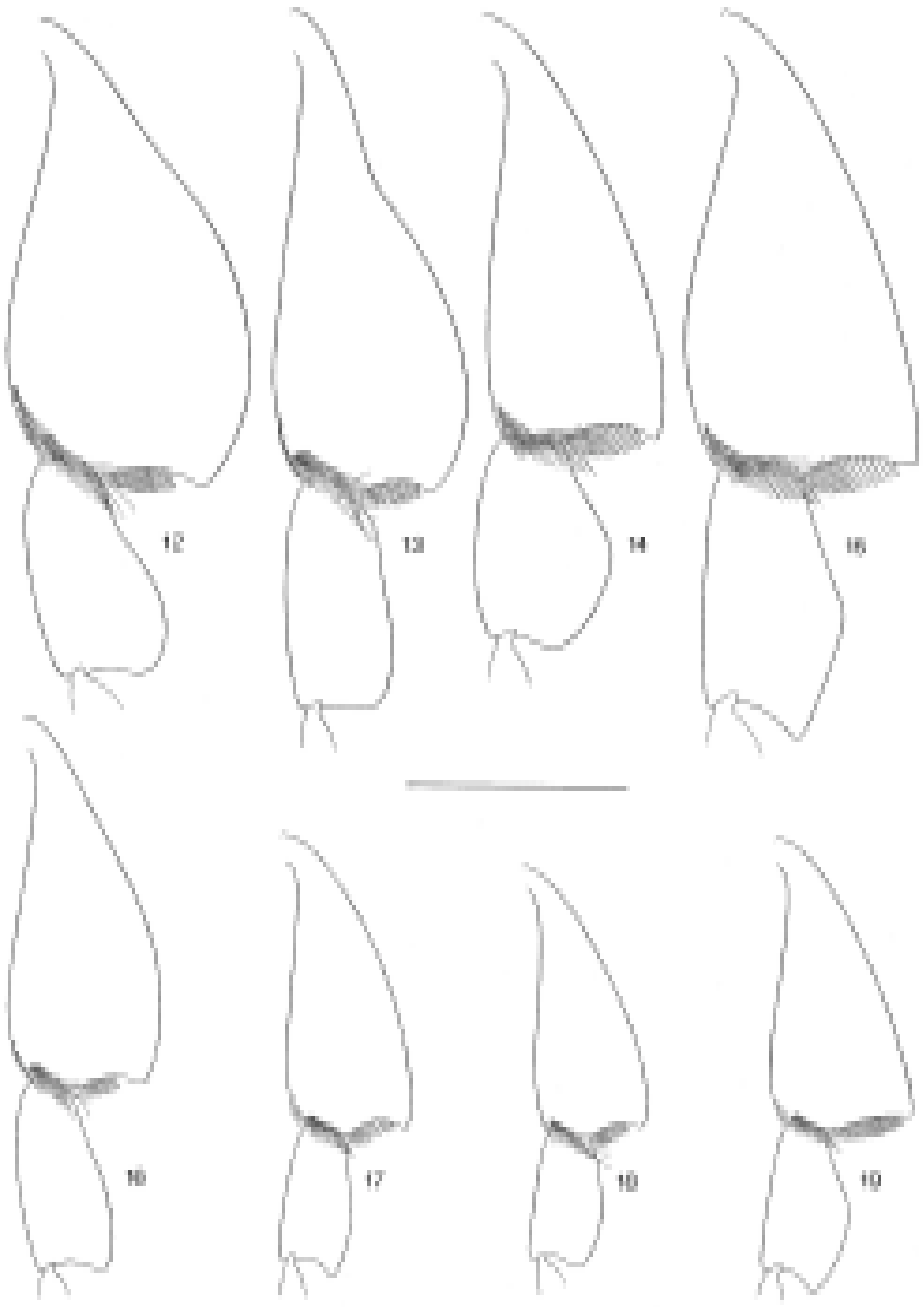

Figs. 12-19. Tíbia e basitarso III, operária: 12. Partamona helleri (Ribeirão Preto, SP, Brasil); 13. Parapartamona brevipilosa (Schwarz, 1948) (Palmeiras, Equador, Andes Ocidentais, $1750 \mathrm{~m}, 408 \mathrm{c}$ ); 14. Meliwillea bivea (Zurqui de Moravia, San Jose, Costa Rica); 15. Scaptotrigona polysticta (Local do Massacre - MT, Brasil); 16. Nogueirapis butteli (Foz do Rio Curicuriari, Rio Negro, AM, Brasil); 17. Paratrigona lineata (Passos, MG, Brasil); 18. Plebeia droryana (Friese, 1900) (Prudentópolis, PR, Brasil); 19. Nannotrigona melanocera (Schwarz, 1938) (Porto Velho, RO, Brasil). Escala $=1,0 \mathrm{~mm}$. 

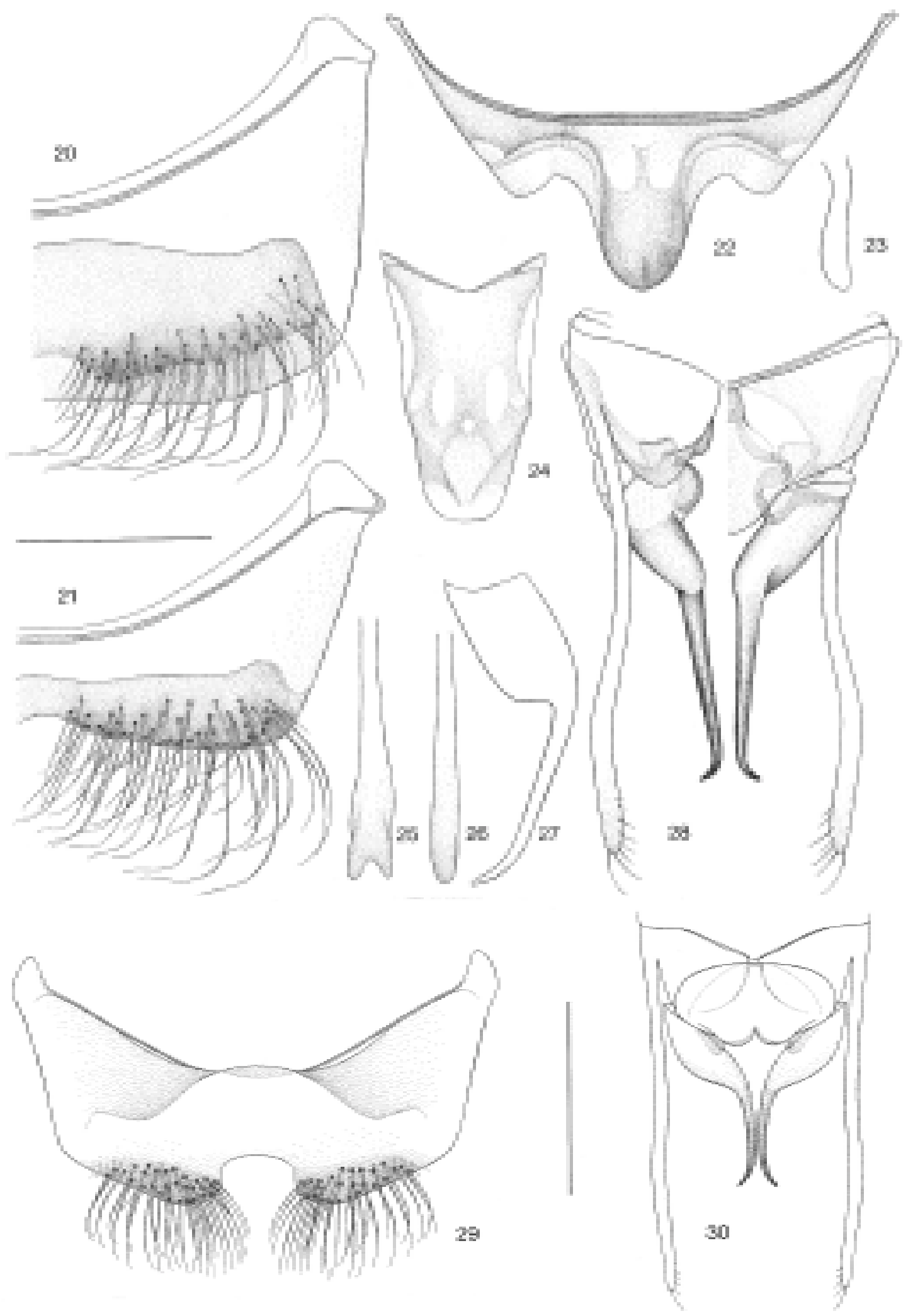

Figs. 20-30. Partamona helleri (Ribeirão Preto, SP, Brasil, 635c), macho: 20. Esterno V; 21. Esterno VI; 22. Esterno VII; 23. Esterno VII, vista de perfil do espículo mediano; 24. Esterno VIII; 25, 26. Esterno IX ( 2 exemplares do mesmo ninho); 27. Gancho (=valva), vista de perfil; 28. Cápsula genital, vista ventral e dorsal, respectivamente. 29-30. Nogueirapis butteli (Maraã, Rio Japurá, AM, Brasil, 604c), macho: 29. Esterno VI; 30. Cápsula genital, vista dorsal. Escala $=0,5 \mathrm{~mm}$. 


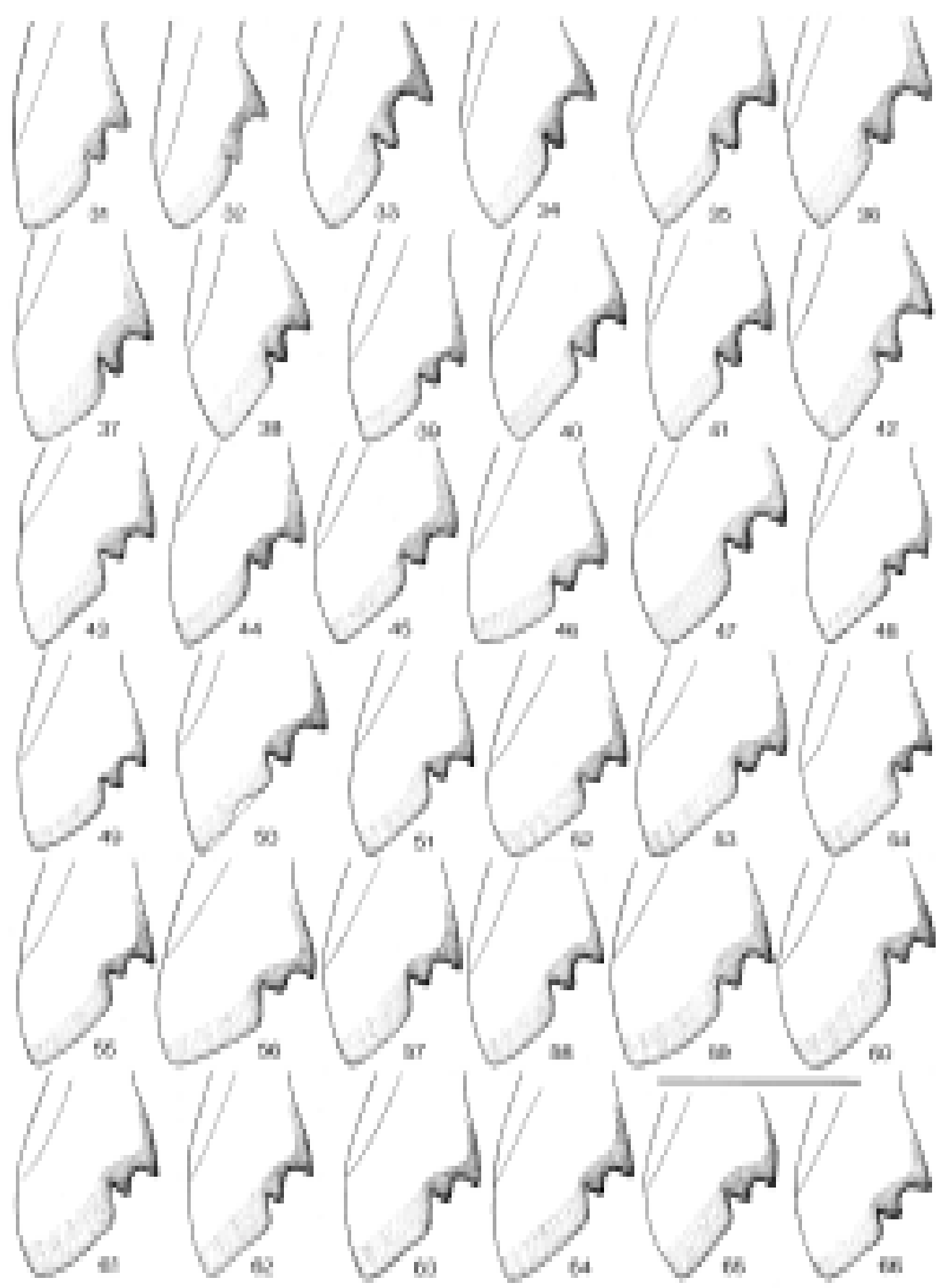

Figs. 31-66. Mandíbula, operária: 31. Parapartamona vittigera (Sta. Rosa, Equador, Andes Ocidentais, 2450 m, 407c); 32. Nogueirapis butteli (Vendaval, AM, Brasil); 33. Partamona epiphytophila sp. nov. (Vendaval, AM, Brasil); 34. P. subtilis sp. nov. (P.N. Serra do Divisor, 0852’31’'S $72^{\circ} 46$ '55”W, Rio Juruá, Sítio 10, AC, Brasil); 35. P. grandipennis (6 Km N Bouquete, Cerro Pate Macho, Chiriqui, Panamá, $\left.1000 \mathrm{~m}\right)$; 36. P. xanthogastra (Parátipo, Portobelo, 15 Km SW Sta. Rita Ridge, Colon Prov., Panamá); 37. P. orizabaensis (Tegucigalpa, Honduras); 38. P. bilineata (Merida, Yucatan); 39. P. peckolti (Esmeraldas, Quinindé, Equador); 40. P. yungarum sp. nov. (Coroico, La Paz, Bolívia, 1.700 m); 41. P. nhambiquara sp. nov. (Chapada dos Guimarães, MT, Brasil); 42. P. batesi sp. nov. (Carauari, Rio Juruá, AM, Brasil, 522c); 43. P. cupira (Vargem Bonita, MG, Brasil); 44. P. mulata (Cuiabá, MT, Brasil); 45. P. criptica sp. nov. (Itatiaia, RJ, Brasil); 46. P. rustica sp. nov. (Janaúba, MG, Brasil); 47. P. ailyae (Nova Mamoré, S 10¹9.440', W 6446.775', RO, Brasil); 48. P. helleri (Ribeirão Preto, SP, Brasil); 49. P. helleri (Salvador, BA, Brasil); 50. P. helleri (Conceição da Barra, ES, Brasil); 51. P. nigrior (Balandra, Trinidad); 52. P. nigrior (Sta. Elena, Bolivar, Venezuela); 53. P. ferreirai sp. nov. (Lago Água Fria, Trombetas, PA, Brasil., 184c); 54. P. pearsoni (Lago Curiuaú, Rio Negro, AM, Brasil, 292c); 55. P. auripennis sp. nov. (Manaus, AM, Brasil); 56. P. auripennis sp. nov. (Tauari, PA, Brasil, 168c); 57. P. chapadicola sp. nov. (Reserva Kraho, Galheiros, $45 \mathrm{Km}$ SE de Itacajá, TO, Brasil, 487c); 58. P. seridoensis sp. nov. (Santana do Seridó, RN, Brasil); 59. P. gregaria sp. nov. (São Luís do Tapajós, PA, Brasil, 116c); 60. P. testacea (Serra do Navio, AP, Brasil); 61. P. testacea (Tumupasa, Bolívia); 62 . P. vicina (Acanga - Barcelos, R. Negro, AM, Brasil); 63. P. mourei (Foz do Rio Daraã,, R. Negro, Brasil); 64. P. aequatoriana (Esmeraldas, Equador); 65. P. aequatoriana (Lita, Imbabura, Equador); 66. P. musarum (Hamburg Farm, Sta. Clara, Costa Rica). Escala $=0,5 \mathrm{~mm}$. 

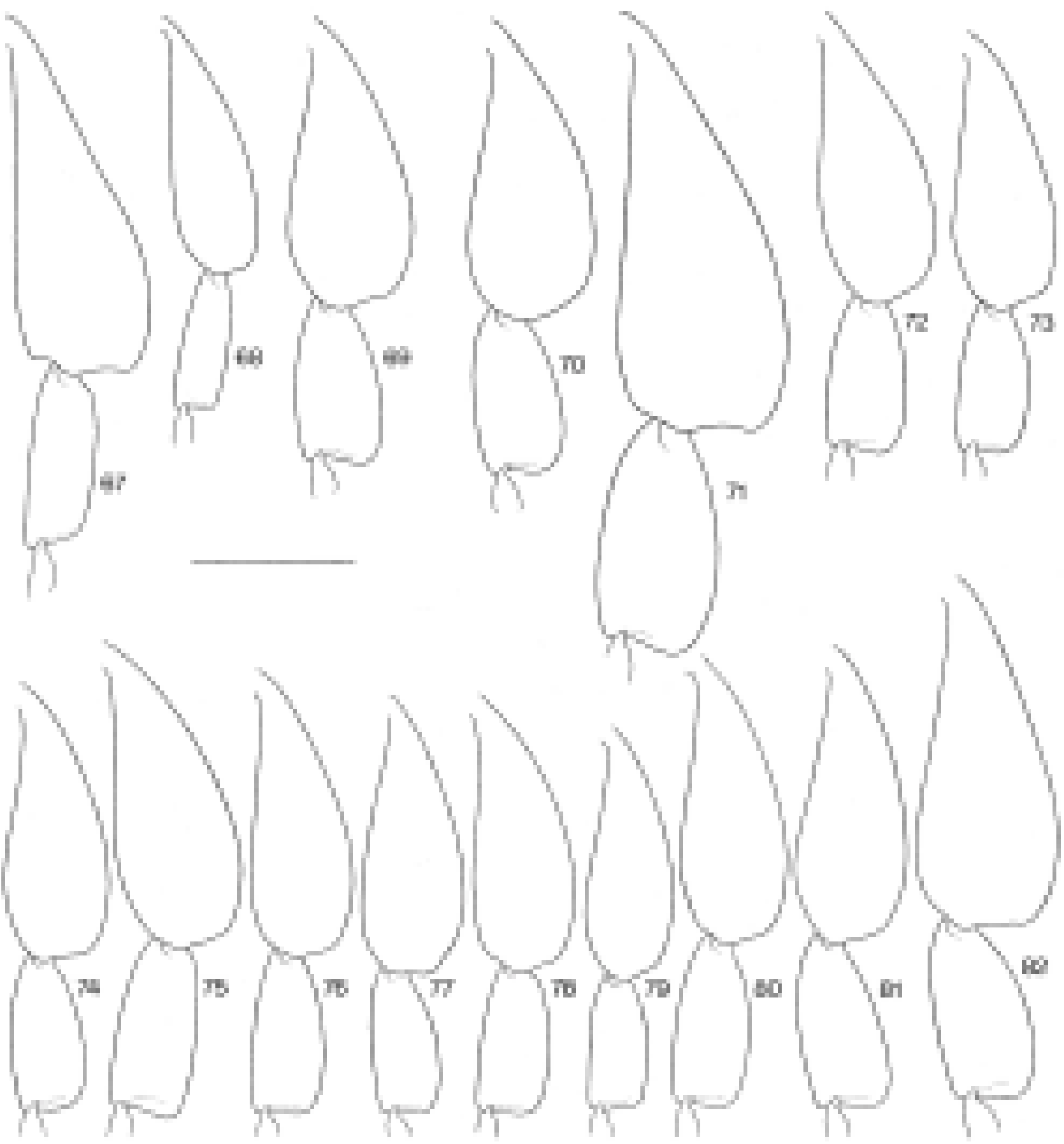

Figs. 67-82. Tíbia e basitarso III, macho: 67. Parapartamona brevipilosa (Palmeiras, Equador, Andes Ocidentais, 1.750 m, $408 \mathrm{c}$ ); 68. Nogueirapis butteli (Maraã, Rio Japurá, AM, Brasil, 604c); 69. Partamona bilineata (Mérida, Yucatan, México); 70. P. bilineata (Corozal, British Honduras); 71. P. grandipennis (Monteverde, Costa Rica); 72. P. orizabaensis (Tegucigalpa, Honduras); 73. P. peckolti (Coco Solo, Colón Prov., Panamá); 74. P. peckolti (Villeta, Cundinamarca, Colômbia); 75. P. epiphytophila sp. nov. (São Paulo de Olivença, AM, Brasil, 85c); 76. P. batesi sp. nov. (Tefé, AM, Brasil); 77. P. gregaria sp. nov. (São Luís do Tapajós, PA, Brasil, 118c); 78. P. pearsoni (Foz do Rio Daraã, R. Negro, AM, Brasil, 257c); 79. P. pearsoni (Lago Curiruaú, R. Negro, AM, Brasil, 292c); 80. P. mourei (Lago Carimum, rio Trombetas, PA, Brasil, 188c); 81. P. vicina (Santa Maria - Itaituba, PA, Brasil, 134c); 82. P. testacea (1.5 Km N Teniente Lopez, Dep. Loreto, Peru). Escala = 1,0 mm. 

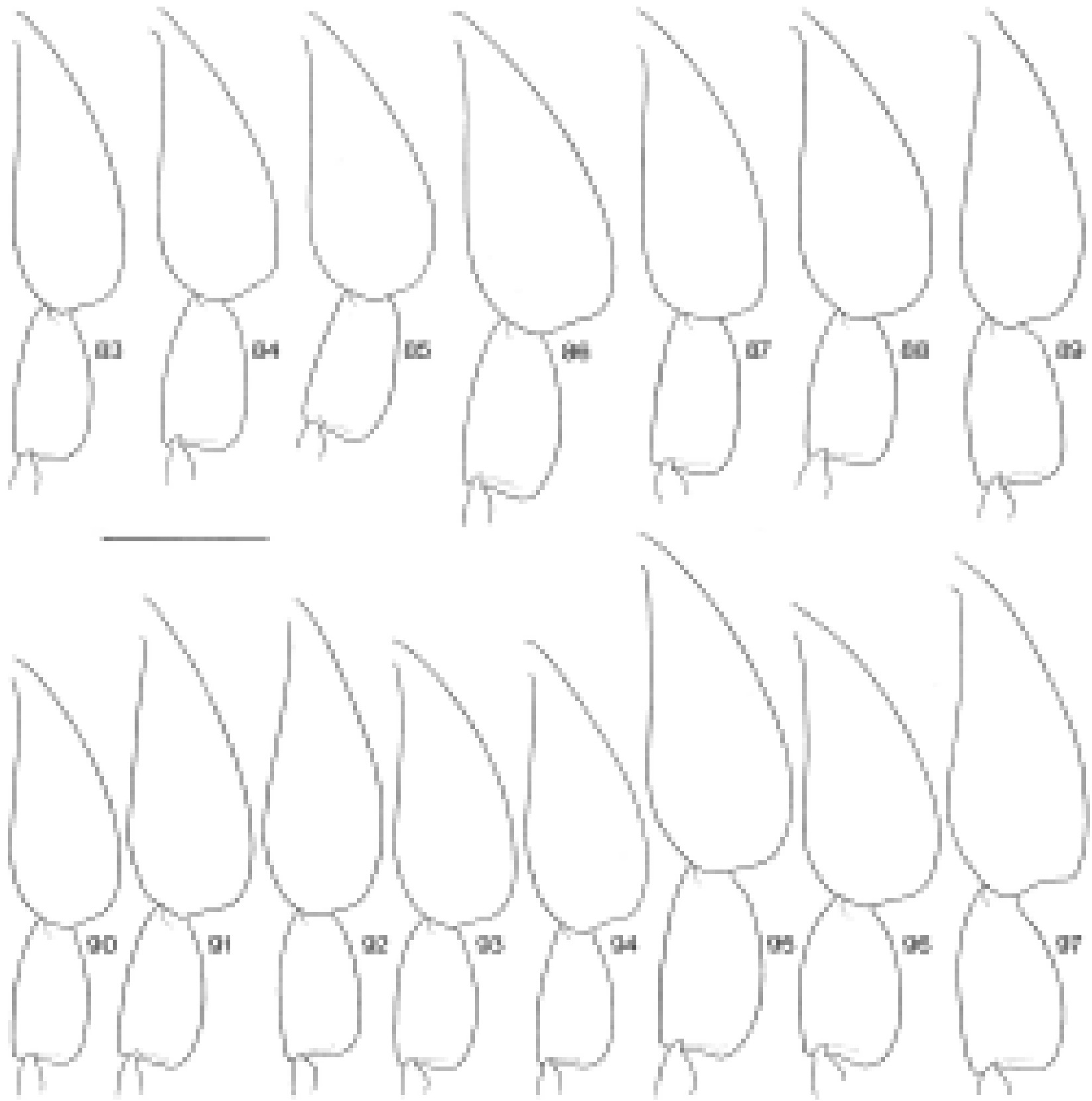

Figs. 83-97. Tíbia e basitarso III, macho: 83. Partamona ferreirai sp. nov. (Lago Água Fria, Trombetas, PA, Brasil, 181c); 84. P. ferreirai sp. nov. (Foz do Rio Daraã, R. Negro, AM, Brasil, 252c); 85. P. nigrior (Mamon, Trinidad); 86. P. nigrior (Bolivar, Tumaremo, Venezuela); 87. P. nigrior (Uraricoera, RR, Brasil); 88. P. auripennis sp. nov. (Tauari, PA, Brasil, 168c); 89. P. combinata sp. nov. (Aragarças, GO, Brasil, 4c); 90. P. chapadicola sp. nov. (Lizarda, TO, Brasil, 675c); 91. P. seridoensis sp. nov. (Santana do Seridó, RN, Brasil); 92. P. helleri (Sta. Teresa, ES, Brasil); 93. P. rustica sp. nov. (Jaíba, MG, Brasil); 94. P. cupira (Conceição das Alagoas, MG, Brasil); 95. P. criptica sp. nov. (Caeté, MG, Brasil); 96. P. mulata (Cuiabá, MT, Brasil); 97. P. ailyae (Lago Uará, rio Solimões, AM, Brasil, 575c). Escala =1,0 mm. 


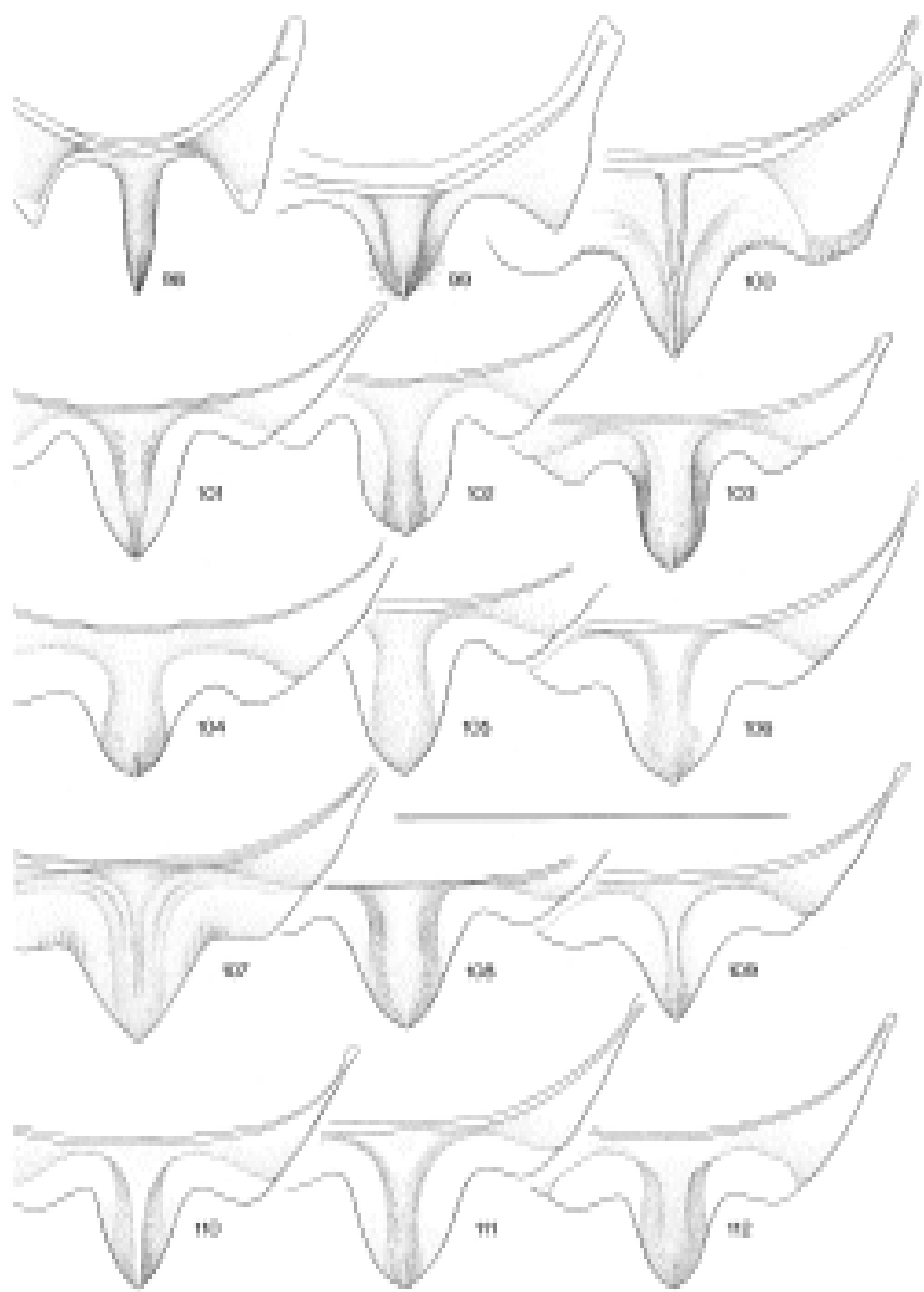

Figs. 98-112. Esterno VII, macho: 98. Nogueirapis butteli (Maraã, Rio Japurá, AM, Brasil, 604c); 99. Parapartamona vittigera (Cosanga, Equador, Andes Orientais, 1800m, 410c); 100. Partamona grandipennis (Guanacaste, Monteverde Nat. Park, Costa Rica); 101. P. bilineata (Mérida, Yucatan, México); 102. P. orizabaensis (Tegucigalpa, Honduras); 103. P. peckolti (Cali, Valle, Colômbia); 104. P. epiphytophila sp. nov. (São Paulo de Olivença, AM, Brasil, 85c); 105. P. gregaria sp. nov. (Lago Uaicurapá, Paraná do Ramos, AM, Brasil, 197c.); 106. P. batesi sp. nov. (Nogueiras,

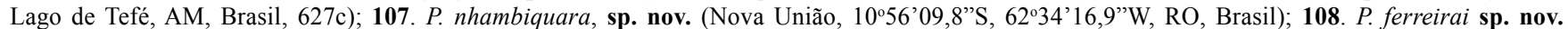
(Lago Água Fria, rio Trombetas, PA, Brasil, 181c); 109. P. ferreirai sp. nov. (Foz do Rio Daraã, R. Negro, AM, Brasil, 252c); 110. P. vicina (Sta. Maria - Itaituba, PA, Brasil, 134c); 111. P. mourei (Lago Carimum, rio Trombetas, PA, Brasil, 188c); 112. P. pearsoni (Foz do Rio Daraã, R. Negro, $\mathrm{AM}$, Brasil, 257c). Escala $=1,0 \mathrm{~mm}$. 


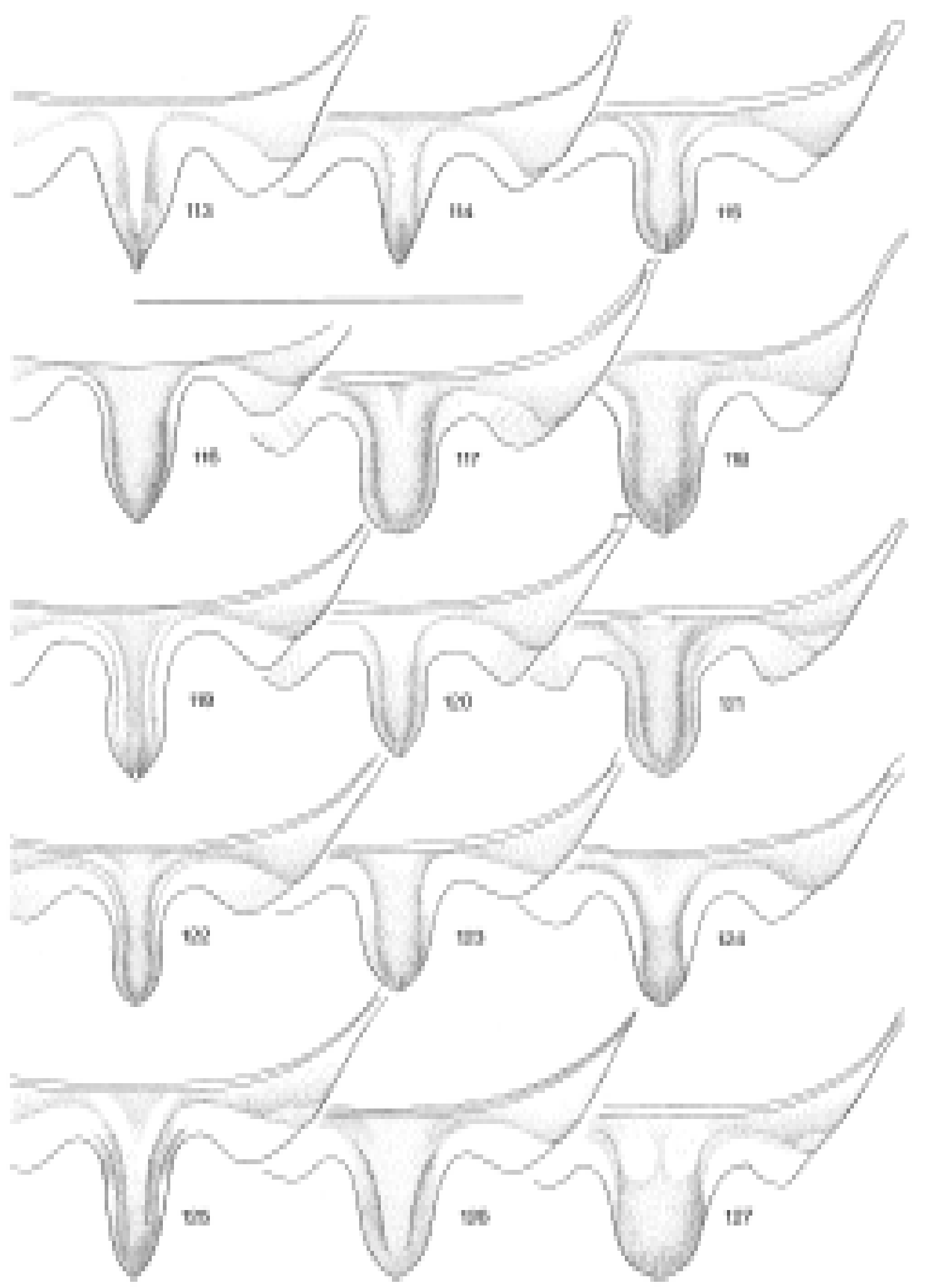

Figs. 113-127. Esterno VII, macho: 113. Partamona testacea $(1.5 \mathrm{~km} \mathrm{~N}$ Teniente Lopez, Loreto, Peru); 114. P. testacea (Archidona, Equador, Andes Orientais, 750m, 413c); 115. P. nigrior (Mamon, Trinidad); 116. P. nigrior (Tumaremo, Bolívar, Venezuela); 117. P. auripennis sp. nov. (Tauari, PA, Brasil, 168c); 118. P. combinata sp. nov. (Aragarças, GO, Brasil, 4c); 119. P. combinata sp. nov. (Conceição das Alagoas, MG, Brasil, 52c); 120. P. chapadicola sp. nov. (Lizarda, TO, Brasil, 675c); 121. P. seridoensis sp. nov. (Santana do Seridó, RN); 122. P. rustica sp. nov. (Jaíba, MG, Brasil); 123. P. cupira (Conceição das Alagoas, MG, Brasil); 124. P. mulata (Cuiabá, MT); 125. P. criptica sp. nov. (Caeté, MG, Brasil); 126. P. ailyae (Nogueiras, Lago de Tefé, AM, Brasil, 630c); 127. P. helleri (Ribeirão Preto, SP, Brasil, 635c). Escala $=1,0 \mathrm{~mm}$. 

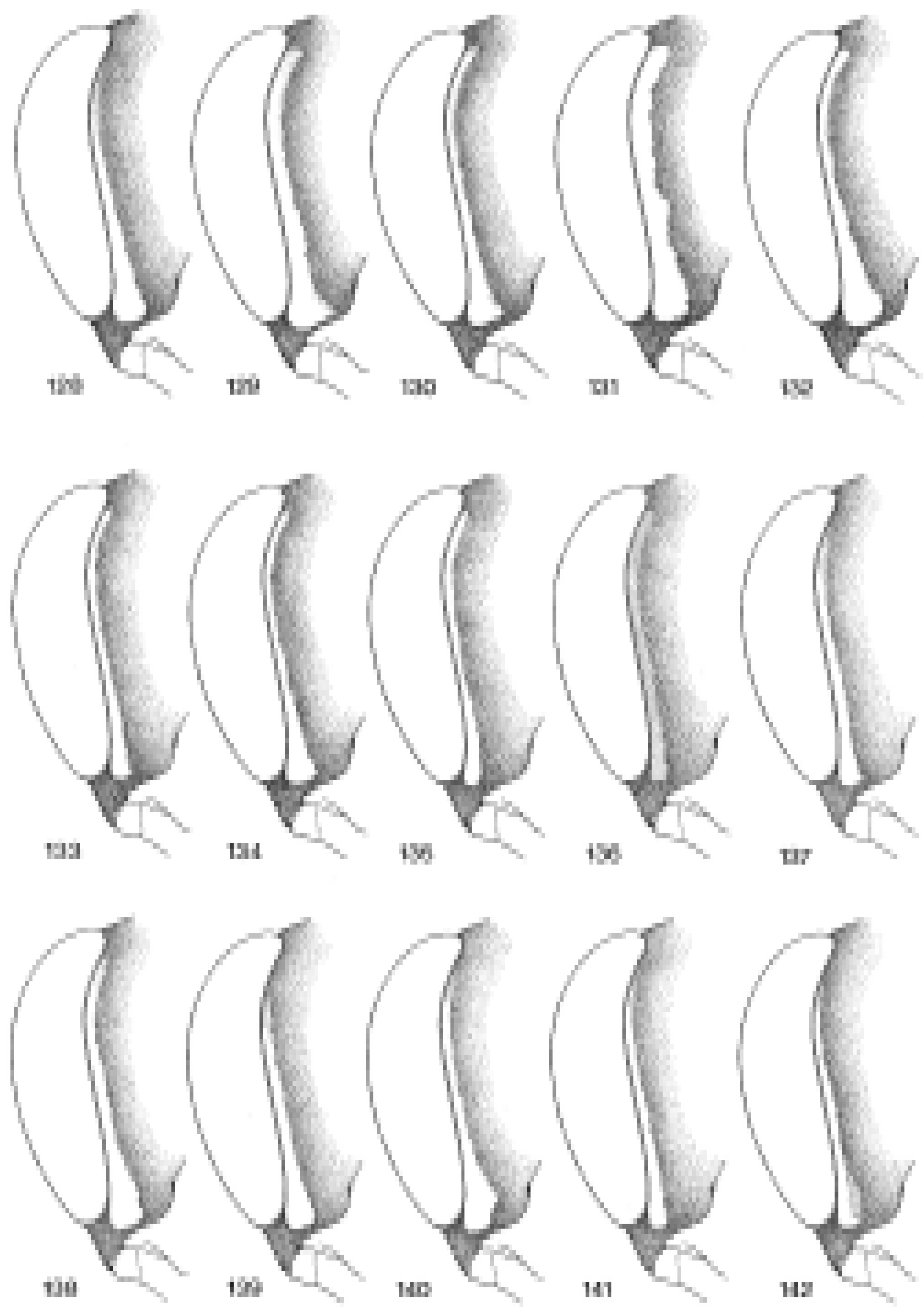

Figs. 128-142. Padrões de estrias paroculares, operárias: 128. Partamona bilineata; 129. P. orizabaensis; 130. P. peckolti; 131. P. xanthogastra; 132. P. grandipennis; 133. P. epiphytophila sp. nov.; 134. P. subtilis sp. nov.; 135. P. nhambiquara sp. nov.; 136. P. yungarum sp. nov.; 137. P. cupira; 138. P. mulata; 139. P. rustica sp. nov.; 140. P. criptica sp. nov.; 141. P. helleri; 142. P. ailyae. Os tamanhos das cabeças não estão representados na mesma escala. 

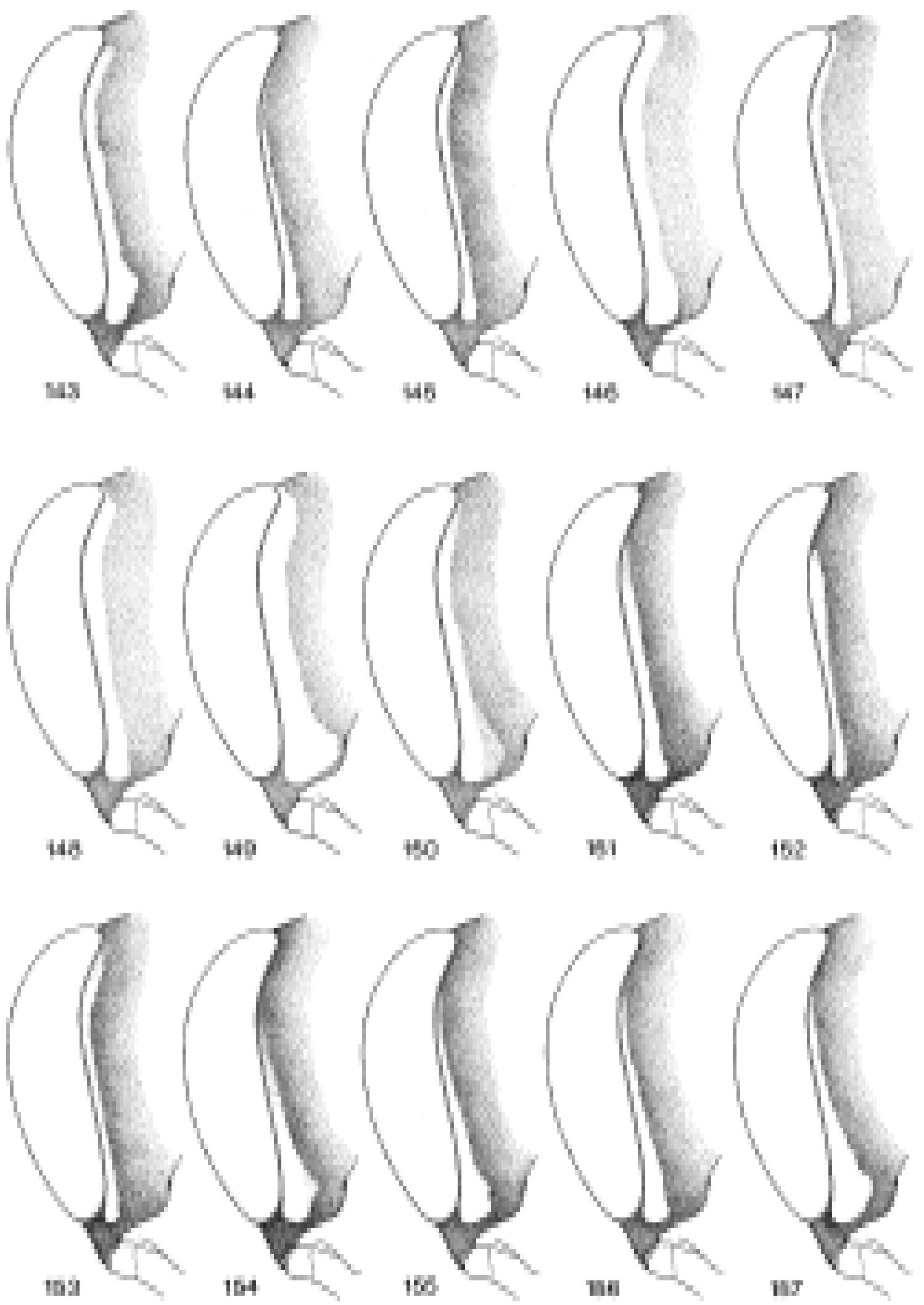

Figs. 143-157. Padrões de estrias paroculares, operárias: 143. Partamona pearsoni; 144. P. ferreirai sp. nov.; 145. P. gregaria sp. nov.; 146. P. vicina; 147. . vitae sp. nov.; 148. P. musarum; 149. P. aequatoriana; 150. P. testacea; 151. P. chapadicola $\mathbf{s p . ~ n o v . ; ~ 1 5 2 . ~ P . ~ s e r i d o e n s i s ~ s p . ~ n o v . ; ~}$ 153. P. littoralis sp. nov.; 154. P. nigrior; 155. P. auripennis sp. nov.; 156. P. combinata sp. nov.; 157. P. nigrilabris sp. nov. Os tamanhos das cabeças não estão representados na mesma escala. 

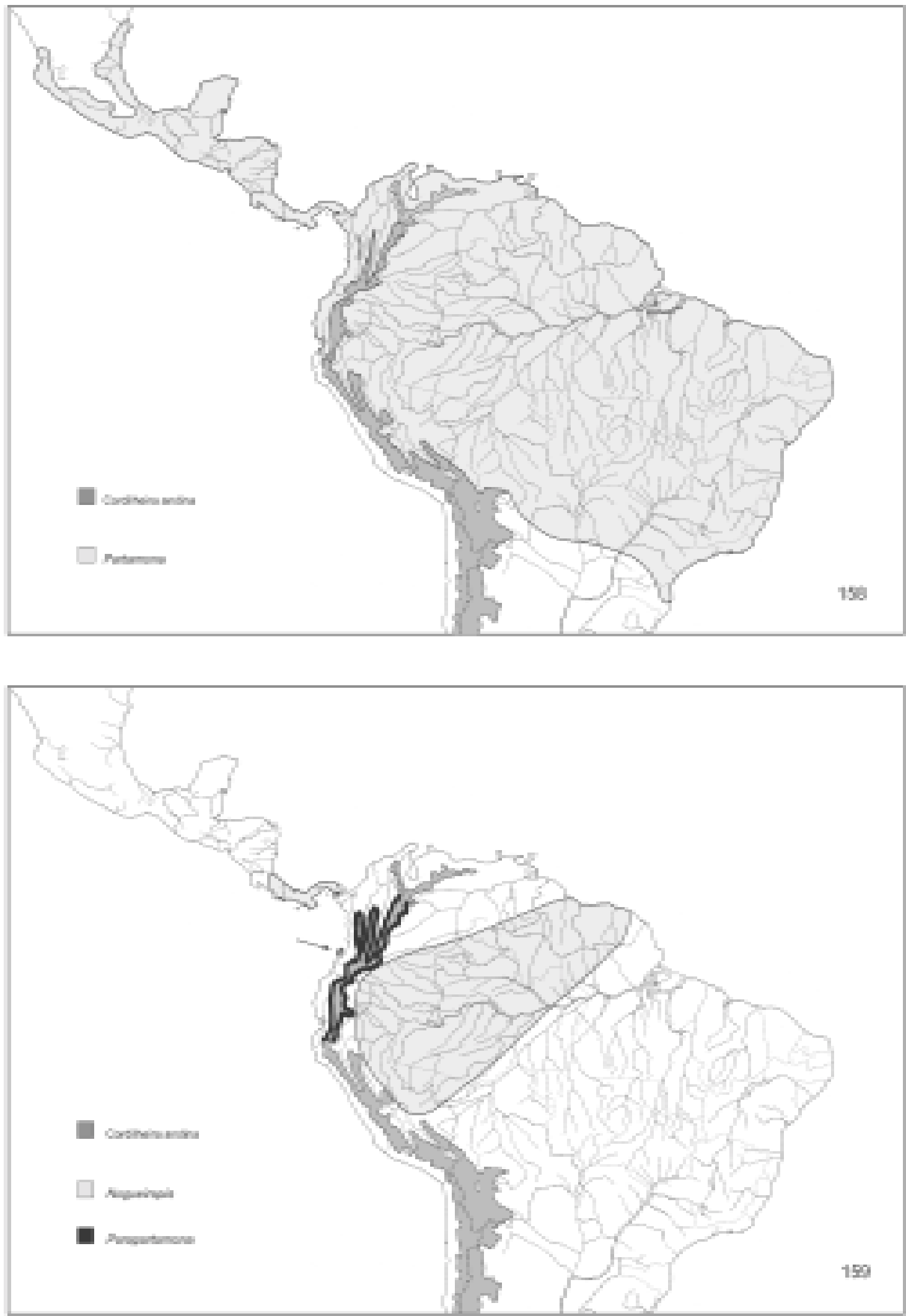

Figs 158-159. Distribuição geográfica: 158. Gênero Partamona; 159. Gêneros Parapartamona e Nogueirapis. A seta indica a ilha de Gorgona, onde há registro de ocorrência de Nogueirapis mirandula (Cockerell, 1927) (material de Cheesman, estudado por WILLE, 1964). 

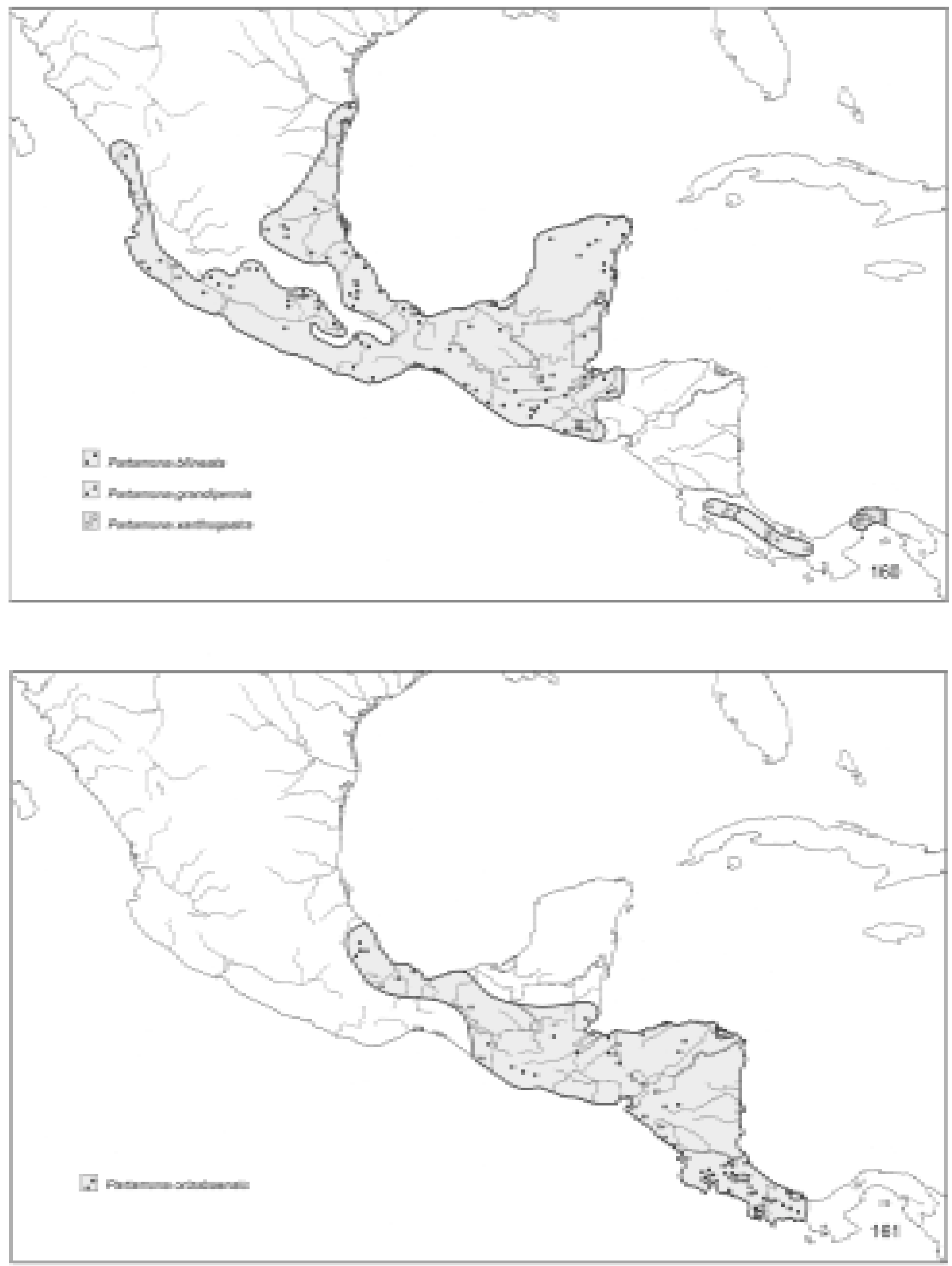

Figs. 160-161. Distribuição geográfica: 160. Partamona bilineata, P. grandipennis e P. xanthogastra; 161. P. orizabaensis. 

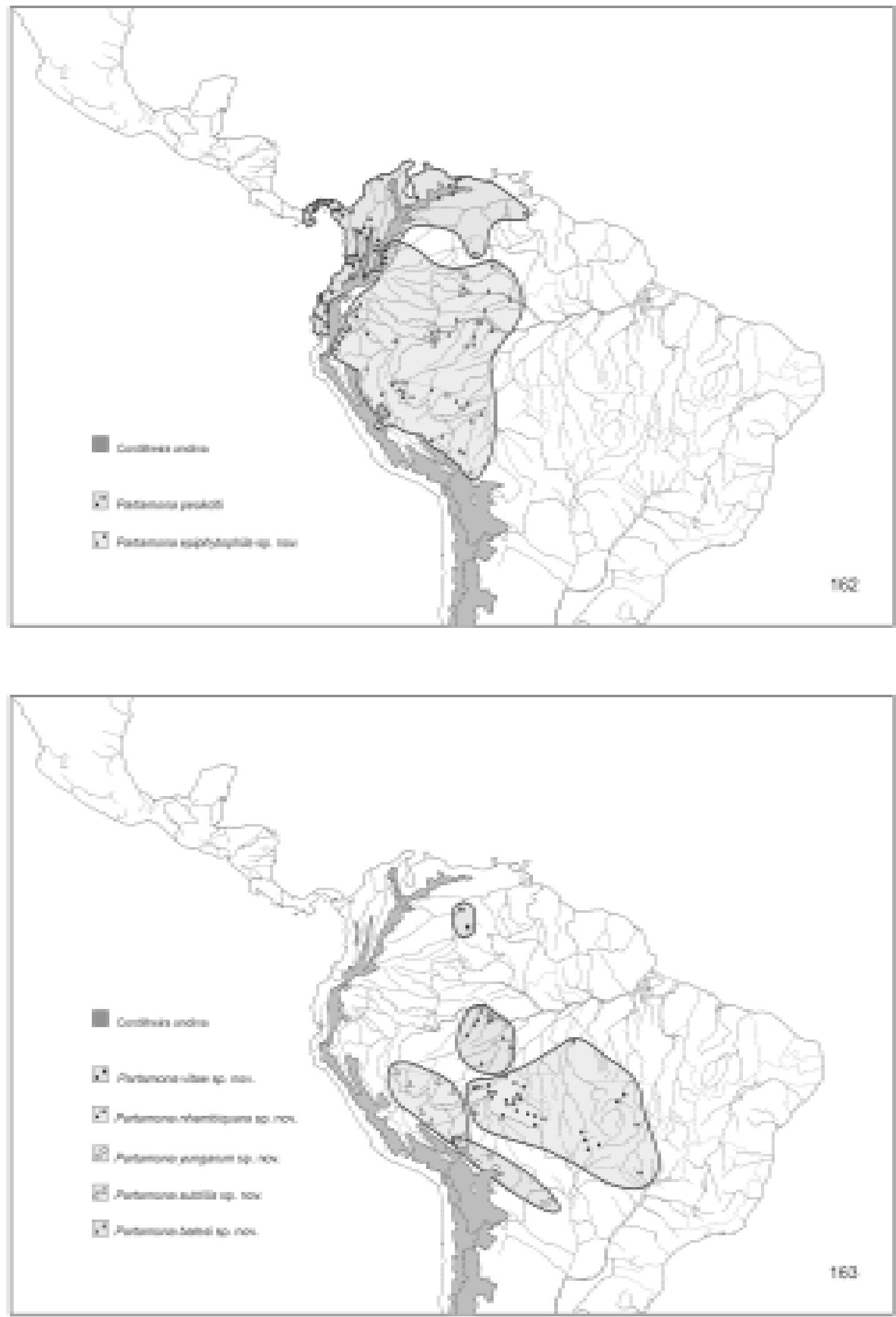

Figs. 162-163. Distribuição geográfica: 162. Partamona peckolti e $P$. epiphytophila sp. nov.; 163. $P$. vitae sp. nov., $P$. nhambiquara sp. nov., $P$. yungarum sp. nov., $P$. subtilis sp. nov. e $P$. batesi sp. nov. O ponto de interrogação refere-se a "Colony Carlos Pfanol, Paraguai" (P. yungarum), que não foi localizada. 

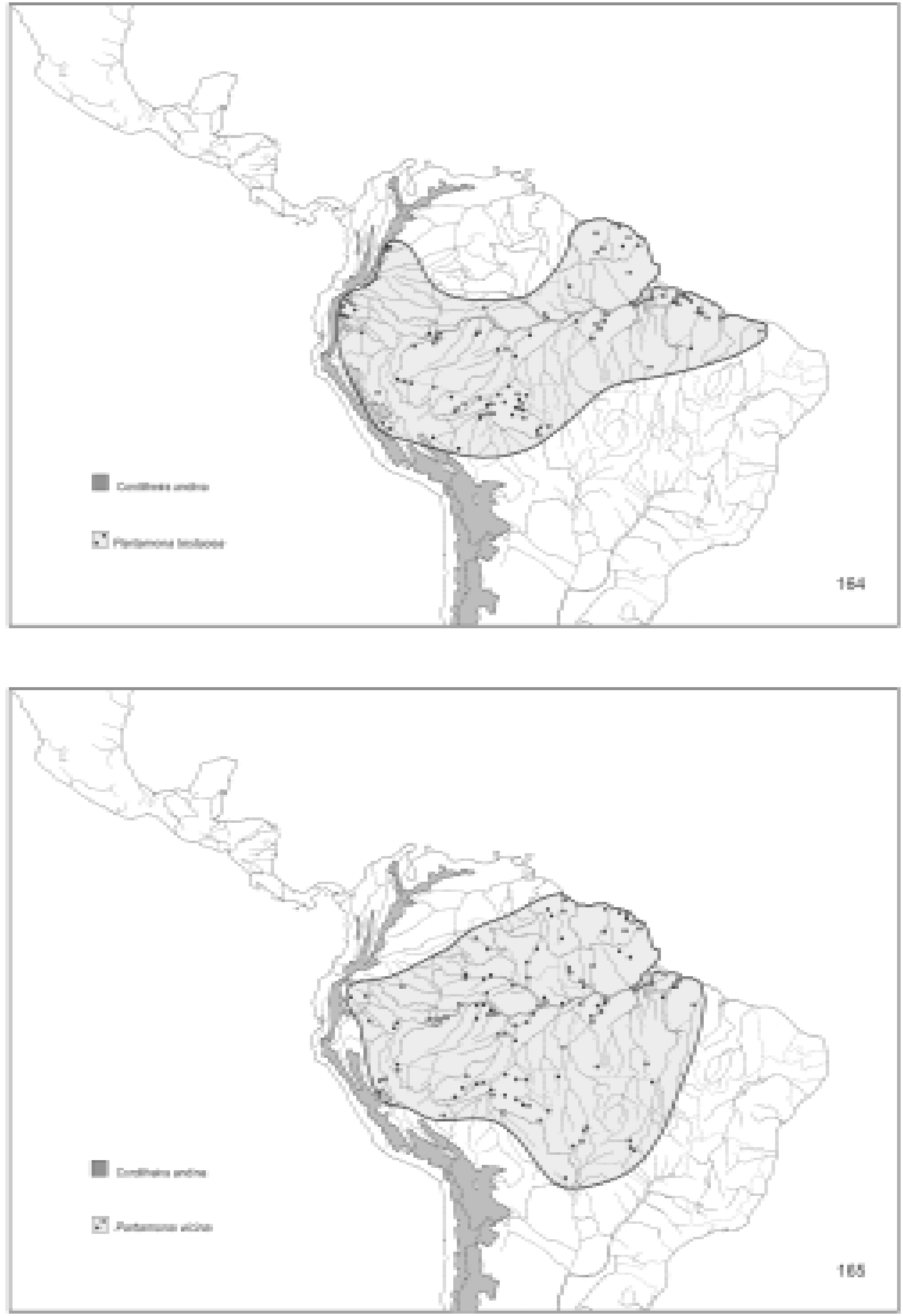

Figs. 164-165. Distribuição geográfica: 164. Partamona testacea; 165. P. vicina. 

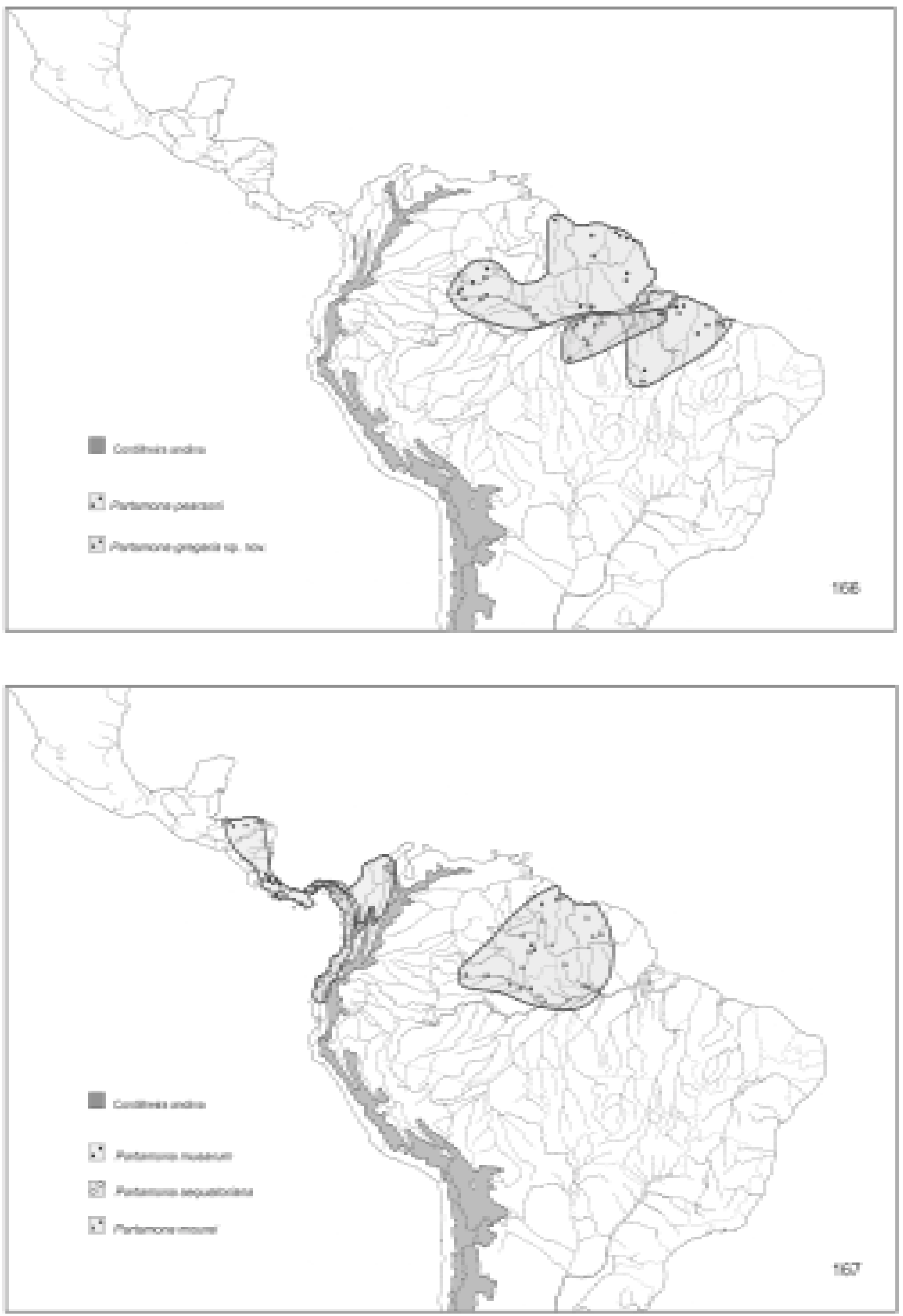

Figs. 166-167: Distribuição geográfica: 166. Partamona pearsoni e P. gregaria sp. nov.; 167. P. musarum, P. aequatoriana e P. mourei. 

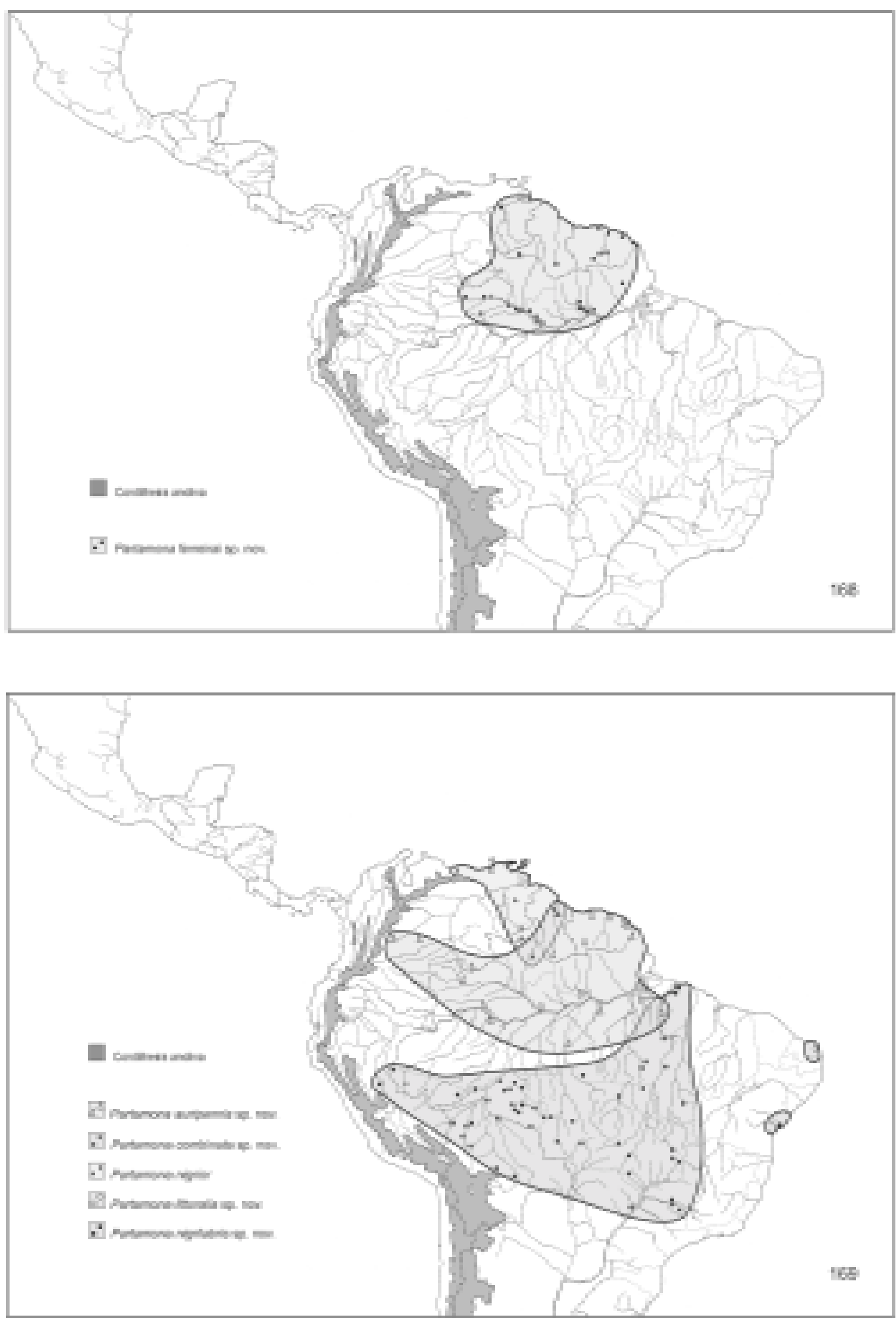

Figs.168-169. Distribuição geográfica: 168. Partamona ferreirai sp. nov.; 169. P. auripennis sp. nov., P. combinata sp. nov., P. nigrior, P. littoralis, sp. nov. e $P$. nigrilabris sp. nov. 

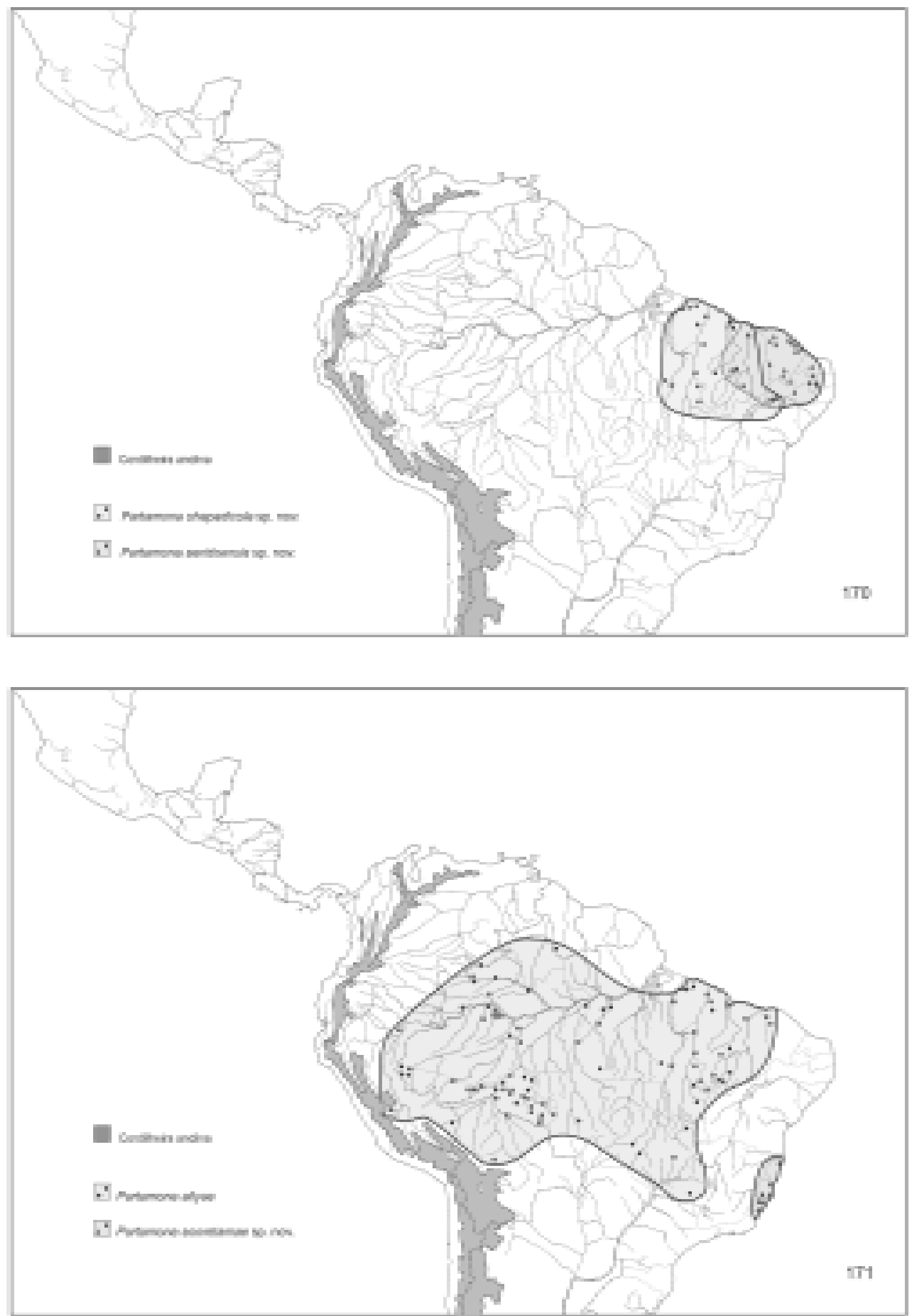

Figs. 170-171. Distribuição geográfica: 170. Partamona chapadicola $\mathbf{s p . ~ n o v . ~ e ~ P . ~ s e r i d o e n s i s ~}$ sp. nov.; 171. P. ailyae e $P$. sooretamae sp. nov. 

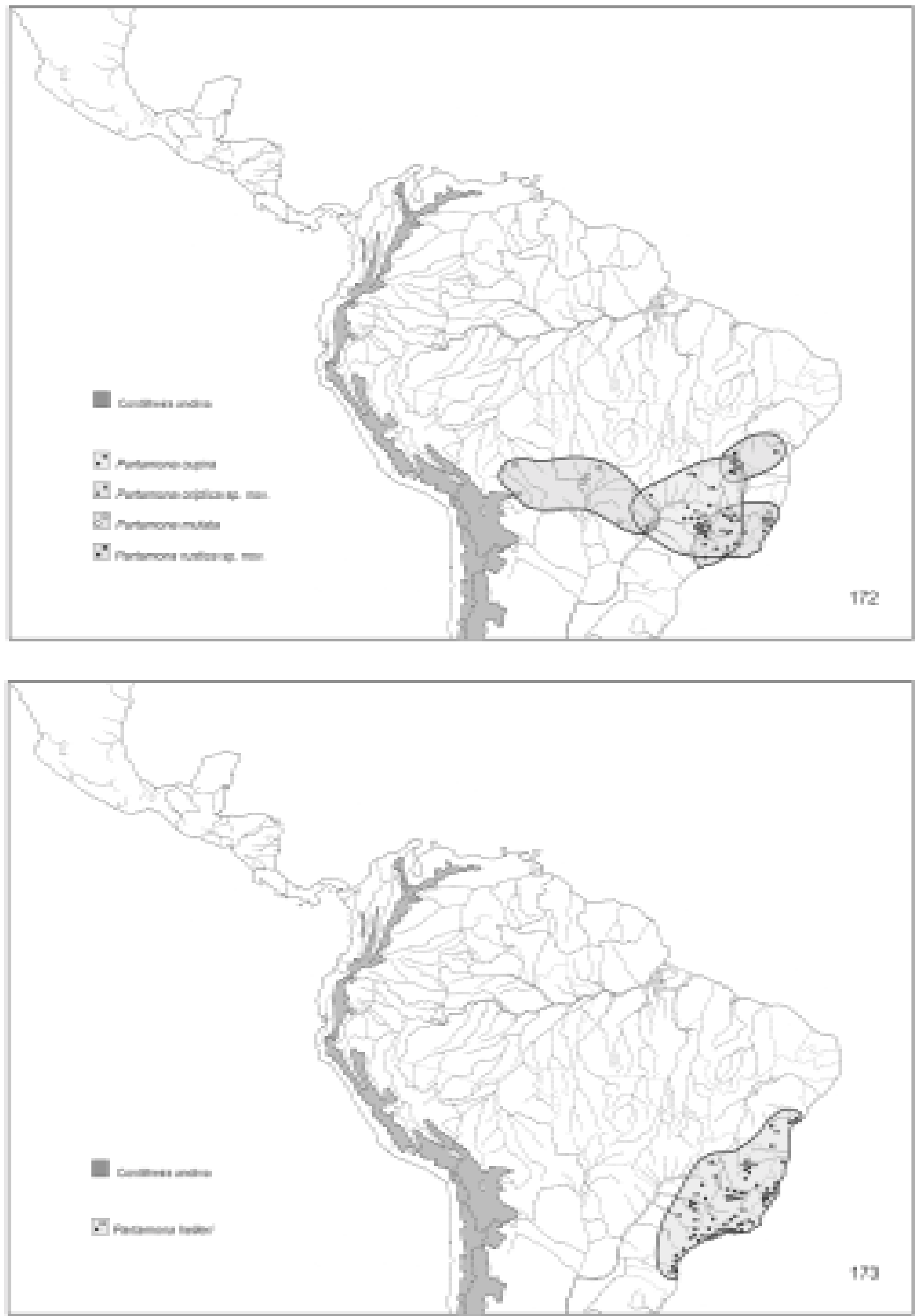

Figs. 172-173. Distribuição geográfica: 172. Partamona cupira, P. criptica sp. nov., P. mulata e P. rustica sp. nov.; 173. P. helleri. 

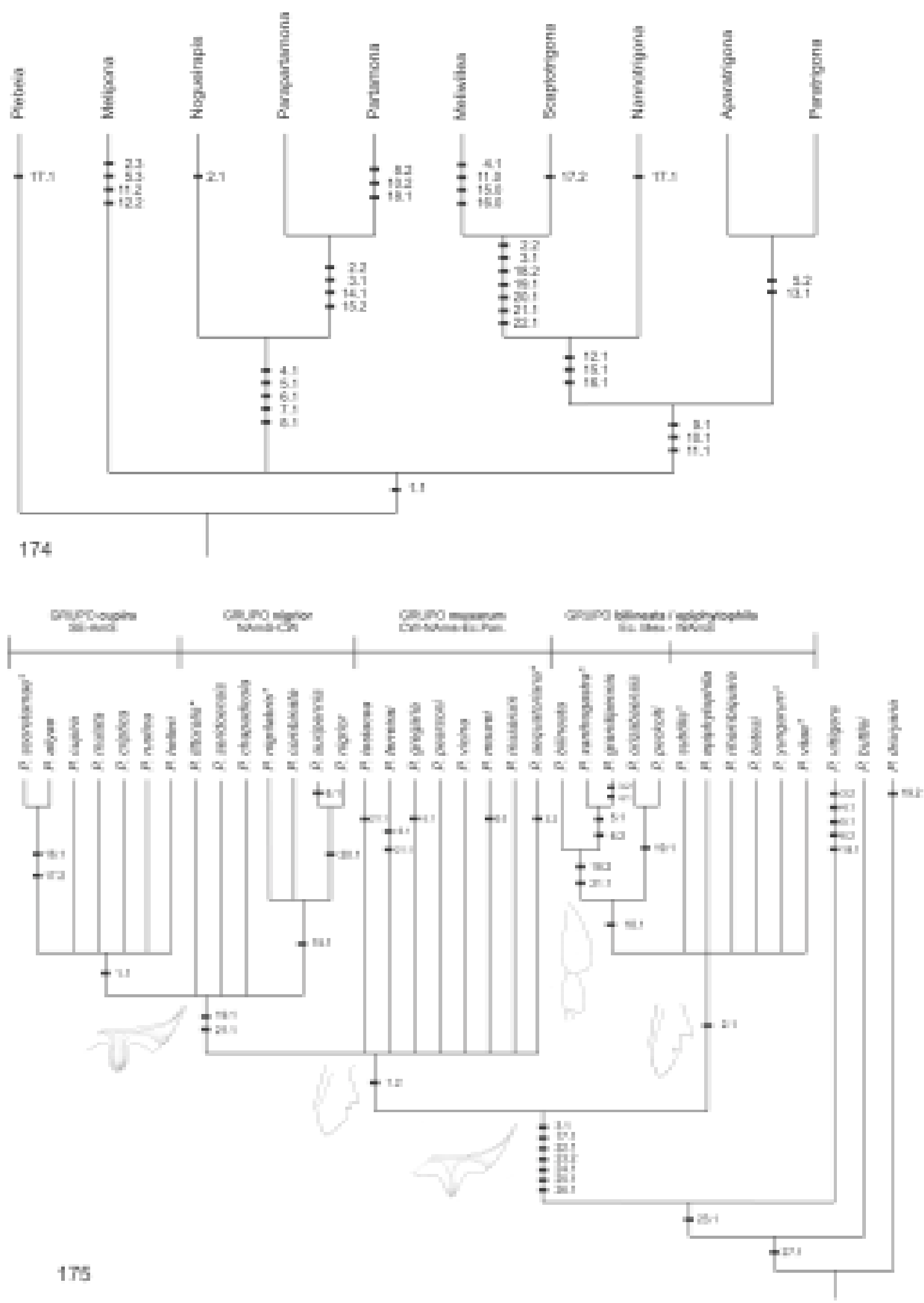

Figs. 174-175. Hipóteses de filogenia: 174. Partamona e gêneros relacionados; 175. Espécies de Partamona. As abreviações indicam: SE-AmS = sudeste da América do Sul, ao sul do alinhamento dos rios Solimões e Amazonas (exceto P. ailyae que chega um pouco mais ao norte, mapa 14); NAmS = norte da América do Sul, ao norte do alinhamento dos rios Solimões e Amazonas; $\mathrm{CW}=$ centro-oeste da América do Sul; Ec.Pan. = do oeste do Equador ao Panamá; Ec.Mex.= do oeste do Equador às terras baixas do México; WAmS = oeste da América do Sul até as encostas andinas orientais. As figuras das mandíbulas das operárias e esterno VII, tíbia e basitarso III do macho, indicam os estados dos caracteres para os principais clados. Os asteriscos $(*)$ indicam as espécies cujos machos não são conhecidos. 


\section{REFERÊNCIAS}

Absy, M. L.; J. M. F. Camargo; W. E. Kerr \& I. P. A. Miranda. 1984. Espécies de plantas visitadas por Meliponinae (Hymenoptera: Apoidea), para coleta de pólen na região do Médio Amazonas. Revista Brasileira de Biologia 44(2): 227-237.

Ägren, J. \& D. W. Schemske. 1991. Pollination by deceit in a Neotropical monoecious herb, Begonia involucrata. Biotropica 23(3): 235241

Aguiar, C. M. L.; C. F. Martins \& A. C. A. Moura. 1995. Recursos florais utilizados por abelhas (Hymenoptera, Apoidea) em área de caatinga (São João do Cariri, Paraíba). Revista Nordestina de Biologia 10(2): 101-117.

ANDRE, H. M. 1985. Acari domum meliponinarum brasiliensium habitants 10. Melissotydeus macrosolenus gen.n., sp. n. (Acari: Tydeidae). Bulletin et Annales de la Société Royale Belge d'Entomologie 121: 243-246.

Arnett, R. H., JR.; G. A. Samuelson \& G. M. Nishida. 1993. The Insect and Spider Collections of the World. Gainsville, Sandhill Crane Press, vi+309 p.

Ayala, R. B. 1988. Abejas silvestres (Hymenoptera: Apoidea) de Chamela, Jalisco, México. Folia Entomologica Mexicana 77: 395-493.

Ayala, R. B. 1992. Revision de las Abejas sin Aguijon de Mexico (Hymenoptera: Apidae: Meliponinae). Universidad Nacional Autonoma de Mexico, Mexico, D.F., 74 p. (Tese de Mestrado; texto impresso e distribuído pelo autor).

Ayala, R. B. 1999. Revisión de las abejas sin aguijon de Mexico (Hymenoptera: Apidae: Meliponini). Folia Entomologica Mexicana 106: 1-123.

Azevedo, G. G.; L. A. O. Campos \& P. De Marco JR. 1996. Influência de fatores climáticos na atividade de vôo de Partamona helleri (Friese) (Hymenoptera, Apidae, Meliponinae). Anais do Encontro Sobre Abelhas, Ribeirão Preto, SP, 2: 262.

BAUMgartner, D. L. \& D. W. RoubiK. 1989. Ecology of necrophilous and filth-gathering stingless bees (Apidae: Meliponinae) of Peru. Journal of the Kansas Entomological Society 62(1): 11-22.

Bego, L. R.; R. ZuCCHI \& S. MATEuS. 1991. Notas sobre a estratégia alimentar (cleptobiose) de Lestrimelitta limao Smith (Hymenoptera, Apidae, Meliponinae). Naturalia 16: 119-127.

Brandeburgo, M. A. M. 1992. A competição entre operárias de abelhas africanizadas (Apis mellifera) em alimentadores artificiais, p. 147. In: Anais do Encontro Brasileiro de Biologia e Abelhas e Outros Insetos Sociais. Naturalia, número especial, São Paulo, Editora UNESP, $283 \mathrm{p}$.

Brandeburgo, M. A. M. 1993. Competition among bees at artificial feeders. Evolución Biológica 7: 63-69.

Bravo, F. 1992. Sistemática e distribuição de Parapartamona Schwarz (Hymenoptera, Apidae, Meliponinae). Revista Brasileira de Entomologia 36(4): 863-878.

Brito, R. M.; M. A. Costa \& S. G. Pompolo. 1997. Characterization and distribution of supernumerary chromosomes in 23 colonies of Partamona helleri (Hymenoptera, Apidae, Meliponinae). Revista Brasileira de Genética 20(2): 185-188.

Bullock, S. H.; C. Martínez Del Rio \& R. Ayala.1989. Bee visitaion rates to trees of Prockia crucis differing in flower number. Oecologia 78: 389-393.

Camargo, J. M. F. 1970. Ninhos e biologia de algumas espécies de Meliponídeos (Hymenoptera: Apidae) da região de Pôrto Velho, Território de Rondônia, Brasil. Revista de Biologia Tropical 16(2): 207-239.

Camargo, J. M. F. 1974. Notas sobre a morfologia e biologia de Plebeia (Schwarziana) quadripunctata quadripunctata (Hym., Apidae). Studia Entomologica 17(1-4): 433-470.

Camargo, J. M. F. 1980. O grupo Partamona (Partamona) testacea (Klug): suas espécies, distribuição e diferenciação geográfica (Meliponinae, Apidae, Hymenoptera). Acta Amazônica 10(4), supl., $175 \mathrm{p}$.

Camargo, J. M. F. 1988a. Notas sobre os Meliponinae (Hymenoptera, Apidae) colecionados por Filippo Silvestri na Bacia do Rio da Prata.
Revista Brasileira de Entomologia 32(2): 293-314.

CAmargo, J. M. F. 1988b. Meliponinae (Hymenoptera, Apidae) da coleção do "Istituto di Entomologia Agraria", Portici, Itália. Revista Brasileira de Entomologia 32(3/4): 351-374.

Camargo, J. M. F. 1989. Comentários sobre a sistemática de Meliponinae (Hymen. Apidae). In: Anais do XIV Simpósio Anual da ACIESP, suplemento, $\mathrm{n}^{\circ}$ 68: 41-61.

Camargo, J. M. F. 1992. O grupo Partamona (Partamona) testacea (Klug): suas espécies, distribuição e diferenciação geográfica (Meliponinae, Apidae, Hymenoptera) (cit. dissertação de mestrado), p. 81-82. In: A. E. E. SOARES \& D. DE JONG (eds.). Pesquisas com abelhas no Brasil. Ribeirão Preto, Revista Brasileira de Genética, $680 \mathrm{p}$.

Camargo, J. M. F. 1994. Biogeografia de Meliponini (Hymenoptera, Apidae, Apinae): A Fauna Amazônica. Anais do Encontro sobre Abelhas, Ribeirão Preto, SP, 1: 46-59.

Camargo, J. M. F. 1996a. Meliponini Neotropicais (Apinae, Apidae, Hymenoptera): Biogeografia Histórica. Anais do Encontro sobre Abelhas, Ribeirão Preto, SP, 2: 107-121.

CAmargo, J. M. F. 1996b. Meliponini Neotropicais: O Gênero Camargoia Moure, 1989 (Apinae, Apidae, Hymenoptera). Arquivos de Zoologia 33(2): 71-92.

Camargo, J. M. F. \& J. S. Moure. 1988. Notas sobre os Meliponinae (Hymenoptera, Apidae) colecionados por Felippo Silvestri na Bacia do Rio da Prata. Revista Brasileira de Entomologia 32(2): 293 314.

Camargo, J. M. F. \& J. S. Moure. 1994. Meliponinae Neotropicais: os Gêneros Paratrigona Schwarz, 1938 e Aparatrigona Moure, 1951 (Hymenoptera, Apidae). Arquivos de Zoologia 32(2): 33-109.

Camargo, J. M. F. \& J. S. Moure. 1996. Meliponini Neotropicais: O Gênero Geotrigona Moure, 1943 (Apinae, Apidae, Hymenoptera), com especial referência à filogenia e biogeografia. Arquivos de Zoologia 33(3): 95-161.

Camargo, J. M. F. \& S. R. M. Pedro. 1992a. Sistemática de Meliponinae (Hymenoptera, Apidae): sobre a polaridade e significado de alguns caracteres morfológicos. In: Anais do Encontro Brasileiro sobre Biologia de Abelhas e outros Insetos Sociais. Naturalia, número especial, p. 45-49.

Camargo, J. M. F. \& S. R. M. Pedro. 1992b. Systematics, phylogeny and biogeography of the Meliponinae (Hymenoptera, Apidae): a minireview. Apidologie 23: 509-522.

Camargo, J. M. F. \& D. A. Posey. 1990. O conhecimento dos Kayapó sobre as abelhas sociais sem ferrão (Meliponidae, Apidae, Hymenoptera): notas adicionais. Boletim do Museu Paraense Emílio Goeldi, sér. Zoologia, 6(1): 17-42.

Camargo, J. M. F. \& D. W. Roubik 1991. Systematics and bionomics of the apoid obligate necrophages: the Trigona hypogea group (Hymenoptera: Apidae; Meliponinae). Biological Journal of the Linnean Society 44: 13-39.

Camargo, J. M. F. \& D. WitTmann. 1989. Nest architecture and distribution of the primitive stingless bee, Mourella caerulea (Hymenoptera, Apidae, Meliponinae): evidence for the origin of Plebeia (s. lat.) on the Gondwana continent. Studies on Neotropical Fauna and Environment 24(4): 213-229.

CAmpos, L. A. O. 1992. O hormônio juvenil nas abelhas: seu papel na diferenciação das castas e nos aspectos do controle social (cit. tese de doutorado), 90-91. In: A. E. E. SOARES \& D. DE JONG (eds.) Pesquisas com abelhas no Brasil. Ribeirão Preto, Revista Brasileira de Genética, $680 \mathrm{p}$.

Carvalho, A. M. C. \& L. R. Bego. 1996. Studies on Apoidea fauna of cerrado vegetation at the Panga Ecological Reserve, Uberlândia, MG, Brazil. Revista Brasileira de Entomologia 40(2): 147-156.

Castello Branco, L. S. D. 1845. Memoria (sic) á cerca das abelhas da Provincia (sic) do Piauhy no Imperio (sic) do Brasil. O Auxiliador da Indústria Nacional 13(2): 49-64, continuação 13(3): 65-72.

Cepeda, O. I. A. 1996. Hongos y bacterios asociados con colonias de meliponinos (Apidae: Meliponinae). Tacaya no. 5:7-9.

Chittka, L.; J. Schorn; J. M. DE Souza; D. F. Ventura \& J. M. F. Camargo. 1997(1999). The nest entrance signal of the Amazonian bees Partamona pearsoni - a case where insects design their own flight 
targets, 107-116. In: V. E. Kipyatkov (ed.). Proceedings of the International Colloquia on Social Insects, vol. 3-4. St. Petersburg, Socium, $311 \mathrm{p}$.

Cockerell, T. D. A. 1905. Notes on some bees in the British Museum. Transactions of the American Entomological Society 31: 309 364.

Cockerell, T. D. A. 1912. Descriptions and Records of Bees - XLVI. Annals and Magazine of Natural History, sér. 8, 10: 311-320.

COCKERELL, T. D. A. 1913. Meliponine bees from Central America. Psyche 20: 10-14

Cockerell, T. D. A. 1917. New social bees. Psyche 24: 120-128.

Cockerell, T. D. A. 1920. Some Neotropical meliponid bees. Bulletin of the American Museum of Natural History 42: 459-468.

Cockerell, T. D. A. 1923. Descriptions and records of bees. - XCVIII. Annals and Magazine of Natural History, sér. 9, 12: 238-247.

Cockerell, T. D. A. 1925. Descriptions and Records of Bees - CVII. Annals and Magazine of Natural History, sér. 9, 16: 626-627.

Cockerell, T. D. A. 1928. Bees collected by Dr. W. M. Wheeler at flowers of Triplaris. Psyche 35: 170-172.

Cockerell, T. D. A. 1949. Bees from Central America, principally Honduras. Proceedings of the United States National Museum 98: $429-490$.

Coloma, L. A. R. 1986. Contribución para el conocimiento de las abejas sin aguijón (Meliponinae, Apidae, Hymenoptera) de Ecuador. Pontificia Universidad Catolica de Ecuador, 146 p. (Monografia de Licenciatura).

Cortopassi-Laurino, M. 1977. Notas sobre associações de Trigona (Oxytrigona) tataira (Apidae, Meliponinae). Boletim de Zoologia da Universidade de São Paulo 2: 183-187.

Costa, M. A. 1992. Estudos citogenéticos em colônias de abelhas Partamona cupira (Hymenoptera, Apidae) na região de Viçosa, MG, p. 124-125 (cit. de monografia). In: A. E. E. SoAres \& D. De Jong (eds.). Pesquisas com abelhas no Brasil. Ribeirão Preto, Revista Brasileira de Genética, 680 p.

Costa, M. A.; S. G. Pompolo \& L. A. O. Campos. 1992. Supernumerary chromosomes in Partamona cupira (Hymenoptera, Apidae, Meliponinae). Revista Brasileira de Genética 15(4): 801-806.

CRuz-Landim, C. \& M. H. V. B. Mota. 1990. Occurrence of tegumentary glands in stingless bees (Hymenoptera, Apidae, Meliponinae), p. 587-588. In: G. K. Veeresh; B. Mallik \& C. A. Viraktamath (eds.). Social Insects and the Environment, Proceedings of the 11th International Congress of IUSSI, Bangalore, India. New Delhi, Mohan Primlani for Oxford \& IBH Publishing Co., xxxi+765 p.

Cunha, R. A. 1973. Taxonomia numérica de alguns Meliponinae (Hymenoptera - Apidae). Ciência Biológica (Portugal) 1: 25-42 (separata p. 1-18)

CunHA,ÁR.ÁA1.991. Revisão da taxonomia de alguns Meliponinae por métodos fenéticos (Hym., Apidae). Naturalia 16: 33-53.

Dalla Torre, K. W. (C. G.). 1896. Catalogous Hymenopterorum; Hucusque Descriptorum Systematicus et Synonymicus. Vol. 10 Apidae (Anthophila). Leipzig, Engelmann, viii+643 p.

DArchen, R. \& J. Louis. 1961. Les mélipones et leur élevage. Melipona Trigona - Lestremelitta (sic). Annales de l'Abeille 4(I): 5-39.

Diniz-Filho, J. A. F.; E. D. Araújo \& M. I. B. Pignata. 1995. Evolution of size and shape in stingless bee workers (Apidae, Meliponinae): patterns of phylogenetic autocorrelation. Comunicações do Museu de Ciência e Tecnologia da PUCRS, sér. zoologia 8: 61-71.

Ducke, A.1902. Die stachellosen Bienen (Melipona Ill.) von Pará, nach dem Meteriale der Sammlung des Museu Goeldi beschrieben. Zoologische Jahrbücher Abteilung für Systematik, Geographie und Biologie der Tiere 17: 285-328.

Ducke, A. 1916. Enumeração dos Hymenopteros colligidos pela Commissão e Revisão das espécies de abelhas do Brasil. Commissão de Linhas Telegraphicas e Estrategicas de Matto Grosso ao Amazonas, publicação no. 35, annexo 5, Hist. Nat. Zool., Rio de Janeiro, Ministério da Agricultura, 177 p.+Figs. 13-25 + errata.

Ducke, A. 1925. Die stachellosen Bienen (Melipona) Brasiliens. Nach morphologischen und ethologischen Merkmalen geordnet. Zoologische Jahrbücher Abteilung für Systematik, Geographie und Biologie der Tiere 49:335-448+Figs.1-24, pls.
3,4 .

Engel, M. S. \& F. Dingemans-Bakels. 1980. Nectar and pollen resources for stingless bees (Meliponinae, Hymenoptera) in Surinam (South America). Apidologie 11(4): 341-350.

Esch, H.; I. Esch \& W. E. Kerr. 1965. Sound: an element common to communication of stingless bees and to dances of the honey bee. Science 149: 320-321.

FalCão, T. M. M. A. 1992. Polimorfismos protéicos em populações naturais de abelhas brasileiras, p. 150-155 (cit. tese de doutorado). In: A. E. E. Soares \& D. De Jong (eds.). Pesquisas com abelhas no Brasil. Ribeirão Preto, Revista Brasileira de Genética, 680 p.

Falcão, T. M. M. A. \& E. P. B. Contel. 1990. Genetic variability in natural populations of Brazilian social bees. I. Isozyme patterns and polymorphism for esterases and total protein. Revista Brasileira de Genética 13(4): 731-754.

FALCÃo, T. M. M. A. \& E. P. B. Contel. 1991a. Genetic variability in natural populations of Brazilian social bees: II. Electrophoretic data for PGM and $\mathrm{MDH}$ give evidence for multiple fertilizations in stingless bees. Revista Brasileira de Genética 14(1): 47-59.

Falcão, T. M. M. A. \& E. P. B. Contel. 1991b. Genetic variability in natural populations of Brazilian social bees: III. Electrophoretic data for ME, GPD, SOD and IDH. Revista Brasileira de Genética 14(1): 61-72.

Francke, W.; W. Mackenroth; W. Schröder \& S. Schulz. 1985. Identification of cyclic enolethers from insects: alkyldihydropyranes from bees and alkyldihydro-4H-pyran-4-ones from a male moth. Zeitschrift für Naturforschung 40c: $145-147$.

FrIESE, H. 1900. Neue Arten der Bienengattungen Melipona Ill. und Trigona Jur. Természetrajzi Füzetek 23: 381-391.

Friese, H. 1901. Neue Arten der Bienengattung Trigona Jur. (Hym.). Zeitschrift für systematische Hymenopterologie und Dipterologie 1: 265-271.

Godinez, L. M. 1997. Melitofauna de Algunos Bosques Mesofilos de Montaña de la Sierra Madre Oriental. Universidad Nacional Autonoma de Mexico, México, D.F., 54 p. (Tese de Mestrado).

GonçAlves, J. A. 1973. Ocorrência e abundância de abelhas indígenas no estado do Ceará (Brasil). Boletim Cearense de Agronomia 14: $1-13$

GonZales, J. 1983-1984. Acerca de la regionalización de la nemenclatura maya de las abejas sin aguijón (Melipona sp) en Yucatán. Revista de Geografía Agrícola, nos. 5-6: 190-193

Griswold, T.; F. D. Parker \& P. E. Hanson. 1995. The Bees (Apidae), p.650-691. In P. E. Hanson \& I. D. Gauld (eds.). The Hymenoptera of Costa Rica. Oxford, UK, Oxford University Press, 893 p.

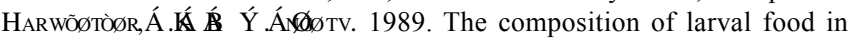
stingless bees: evaluating nutritional balance by chemosystematic methods. Insectes Sociaux 36(1): 1-14.

Hueck, K. 1972. As Florestas da América do Sul. Brasília, Editora da Universidade de Brasília, 466 p.

IHERING, H. von. 1903. Biologie der stachellosen Honigbienen Brasiliens. Zoologische Jahrbücher. Abteilung für Systematik, Geographie und Biologie der Tiere 19(1904): 179-287, Figs. A-H, pls. 1022 .

IHERING, H. vON. 1930. Biologia das abelhas melliferas do Brasil. Boletim de Agricultura, Secretaria do Estado de São Paulo, 31: 435-506, 649-714, Figs. 1-22, pl1 (tradução de H. von Ihering, 1903, por R. von Ihering e B. Sampaio de Corrêa).

Ihering, R. von. 1968. Dicionário de Animais do Brasil. Brasília, Editora da Universidade de Brasília, 790 p.

KERR, W. E. 1969. Some aspects of the evolution of social bees (Apidae). Evolutionary Biology 3: 119-175.

Kerr, W. E. \& H. Esch. 1965. Comunicação entre as abelhas sociais brasileiras e sua contribuição para o entendimento da sua evolução. Ciência e Cultura 17(4): 529-538.

Kerr, W. E. \& H. H. Laidlaw. 1956. General genetics of bees. Advances in Genetics 8: 109-153.

Kerr, W. E.; G. A. Carvalho \& V. A. Nascimento. 1996. Abelha Uruçu: Biologia, Manejo e Conservação. Belo Horizonte, Fundação Acangaú, $144 \mathrm{p}$.

Kerr, W. E.; S. F. Sakagami; R. Zucchi; V. Portugal-Araújo \& J. M. F. 
CAmargo. 1967. Observações sobre a arquitetura dos ninhos e comportamento de algumas espécies de abelhas sem ferrão das vizinhanças de Manaus, Amazonas (Hymenoptera, Apoidea). Atas do Simpósio sobre a Biota Amazônica, 5(zool.): 255-309.

KLUG, D. F. 1807. Species Apiariarum familiae novas, descripsit, generumque characteres adjecit. Magazin für die neuesten entdeckungen in der gesammten Naturkunde 1: 263265+estampa VII, Figs. 2-5.

Knoll, F. R. N.; L. R. Bego \& V. L. Imperatriz-Fonseca. 1992. Estudo preliminar sobre a fauna de abelhas na estação ecológica da Juréia, SP, (24o 30'S; 47o 15', em três habitats: mata atlântica, restinga e campo, p. 188. In: Anais do Encontro Brasileiro de Biologia e Abelhas e Outros Insetos Sociais. Naturalia, número especial, São Paulo, Editora UNESP, 283 p.

Knoll, F. R. N.; L. R. Bego \& V. L. Imperatriz-Fonseca. 1993. As abelhas em áreas urbanas, um estudo no campus da Universidade de São Paulo, p. 31-42. In: J. R. Pirani \& M. Cortopassi-Laurino (coord.). Flores e abelhas em São Paulo. São Paulo, EDUSP/FAPESP, 192 $\mathrm{p}$.

Le Conte, J. L. (ed.) 1859. The Complete Writings of Thomas Say on the Entomology of North America, 2 vols. New York, Baillière Brothers, $814 \mathrm{p}$.

Lenko, K. \& N. Papavero. 1996. Insetos no Folclore. 2a. ed. rev. ampl., São Paulo, Plêiade, FAPESP, 468 p.

LuTZ, F. E. 1924. Apparently non-selective characters and combinations of characters, including a study of ultraviolet in relation to the flower visiting habits of insects. Annals of the New York Academy of Sciences 29: 181-283.

Machado, M. F. P. S. \& E. P. B. Contel. 1991. Glycerol-3-phosphate dehydrogenase isozyme variation in adult meliponids (Hymenoptera: Apidae). Biochemical Genetics 29(11/12): 593-600.

Maddison, W. P. \& D. R. Maddison. 1995. Analysis of Phylogenetic and Character Evolution. Version 3.0.5. (programa de computador).

Marianno, J. 1911. Ensaio sobre as Meliponidas do Brasil. Rio de Janeiro, edição do Autor, $140 \mathrm{p}$.

Martins, C. F. 1994. Comunidade de abelhas (Hym., Apoidea) da caatinga e do cerrado com elementos de campo rupestre do estado da Bahia, Brasil. Revista Nordestina de Biologia 9(2): 225-257.

Martins, C. F. 1995. Flora apícola e nichos tróficos de abelhas (Hym., Apoidea) na Chapada Diamantina (Lençóis-BA, Brasil). Revista Nordestina de Biologia 10(2): 119-140.

Matheus, S.; M. R. Mechi \& L. R. Bego. 1996. Abundância relativa, sazonalidade e preferência floral das abelhas da família Apidae em área natural de cerrado na estação ecológica de Jataí - Luiz Antônio, SP. Anais do Encontro Sobre Abelhas, Ribeirão Preto, SP, 2: 338

Melo, C. G.; E. U. Alves; M. C. A. Lorenzon \& J. L. Baptista. Polinizadores de Malpighia glabra L. Mensagem Doce, APACAME, no. 42: 1417

Michener, C. D. 1946. Notes on the habits of some Panamanian stingless bees (Hymenoptera, Apidae). Journal of the NewYork Entomological Society 54: 179-197.

Michener, C. D. 1954. Bees of Panamá. Bulletin of the American Museum of Natural History 104: 1-175.

Michener, C. D. 1974.The Social Behavior of the Bees. Cambridge, Harvard University Press, xii+404 p.

Michener, C. D. 1990. Classification of the Apidae (Hymenoptera). The University of Kansas Science Bulletin 54(4): 75-164.

Michener, C. D. \& A. Fraser. 1978. A comparative anatomical study of mandibular structure in bees. The University of Kansas Science Bulletin 51(14): 463-482.

Michener, C. D. \& D. W. RoubiK. 1993. Observations on the labium of meliponine bees (Hymenoptera: Apidae), p. 251-265. In: T. INOUE \& S. Yamane (eds.). Evolution of Insect Societies: Comparative Sociology of Bees, Wasps and Ants. Tokyo, Hakuhin-sha Publishing Co., 532 p.

MотA, M. H. V. B. 1992. Estudo comparativo das glândulas epidérmicas do abdômen dos Meliponíneos (Hymenoptera, Apidae, Meliponinae), p. 320-322 (cit. tese de doutorado). In: A. E. E. Soares \& D. De Jong (eds.). Pesquisas com abelhas no Brasil. Ribeirão Preto, Revista Brasileira de Genética, $680 \mathrm{p}$.

Moure, J. S. 1950. Contribuição para o conhecimento das espécies brasileiras de Hypotrigona Cockerell (Hymen. - Apoidea). Dusenia 1(4): 241-260.

Moure, J. S. 1951. Notas sôbre Meliponinae (Hymenopt. - Apoidea). Dusenia 2(1): 25-70.

Moure, J. S. 1953. Nogueirapis, no $($ sic $=$ novo $)$ grupo de Trigonini da região neotropical (Hymenoptera-Apoidea). Ciência e Cultura 5(4): 247-249.

Moure, J. S. 1961. A preliminary supra-specific classification of the OldWorld Meliponinae bees (Hymenoptera, Apoidea). Studia Entomologica 4(1-4): 181-242.

Moure, J. S. 1992. Notas sobre o gênero Parapartamona Schwarz (Hymenoptera, Apidae). Acta Biológica Paranaense 21 $(1,2,3,4): 121-134$

Moure, J. S. \& J. M. F. CAmargo. 1991. Geotrigona inusitata, uma nova espécie de Meliponinae do sudeste do Brasil (Hymenoptera, Apidae). Acta Biológica Paranaense 20(1,2,3,4): 53-59.

Moure, J. S. \& J. M. F. CAmargo. 1994. Melipona (Michmelia) capixaba, uma nova espécie de Meliponinae (Hymenoptera, Apidae) do sudeste do Brasil. Revista Brasileira de Zoologia 11(2): 289-296.

Nassar, N. M. A. \& C. G. P. CARVAlHo. 1990. Insetos polinizadores e seus comportamentos nas espécies silvestres de mandioca, Manihot spp. Ciência e Cultura 42(9): 703-706.

NAtes-PARRA, G. 1983. Abejas de Colombia: I. Lista preliminar de algunas especies de abejas sin aguijón (Hymenoptera, Apidae, Meliponinae) Revista de Biologia Tropical 31(1): 155-158.

Nates-Parra, G. \& O. I. Cepeda. 1983. Comportamiento defensivo en algunas especies de meliponinos colombianos (Hymenoptera: Meliponinae). Boletim do Departamento de Biologia da Universidad Nacional de Colombia 1(5): 65-82.

NieH, J. C. \& D. W. RoubiK. 1995. A stingless bee (Melipona panamica) indicates food location without using a scent trail. Behavior, Ecology and Sociobiology 37: 63-70.

Nogueira-Neto, P. 1970. A Criação de Abelhas Indígenas sem Ferrão São Paulo, Tecnapis, 365 p.

Oliveira, M. L. \& E. F. Morato. 1994. Abelhas sem ferrão (Apidae, Meliponinae) do estado do Acre. Anais do Encontro sobre Abelhas, Ribeirão Preto, SP, 1: 291.

Oliveira, M. L.; E. F. Morato \& M. V. B. Garcia. 1995. Diversidade de espécies e densidade de ninhos de abelhas sociais sem ferrão (Hymenoptera, Apidae, Meliponinae) em floresta de terra firme na Amazônia Central. Revista Brasileira de Zoologia 12(1): 13-24.

PARRA, G. P. 1988-1990. Bionomia de las abejas sin aguijon (Apidae Meliponinae) del occidente colombiano. Cespedesia 57-58: 77 116.

Pedro, S. R. M. 1996. Lista preliminar dasespécies de abelhas (Hymenoptera, Apoidea) que ocorrem na região de Ribeirão Preto e Cajuru, SP. Anais do Encontro Sobre Abelhas, Ribeirão Preto, SP, 2: $248-258$

Pedro, S. R. M. \& J. M. F. Camargo. 1996-1997. A new species of Partamona (Hymenoptera: Apidae) endemic to eastern Panama and notes on P. grandipennis. Revista de Biologia Tropical 44(3)/ 45(1): 199-208

Pisani, J. F.; W. E. KerR \& R. A. Cunha. 1977. Estrutura multidimensional dos meliponídeos. Acta Amazônica 7: 233-245.

Pompolo, S. G. 1992. Estudos citogenéticos em Meliponinae, p. 62-66. In: Anais do Encontro Brasileiro de Biologia e Abelhas e Outros Insetos Sociais. Naturalia, número especial, São Paulo, Editora UNESP, $283 \mathrm{p}$.

Posey, D. A. \& 1985. Additional notes on the classification and knowledge of stingless bees (Meliponinae, Apidae, Hymenoptera) by the Kayapó indians of Gorotire, Pará, Brazil. Annals of Carnegie Museum 54(8): $247-274$.

Ramalho, M.; A. Kleinert-Giovannini \& \& V. L. Imperatiz-Fonseca. 1990. Important bee plants for stingless bees (Melipona and Trigonini) and Africanized honeybees (Apis mellifera) in Neotropical habitats: a review. Apidologie 21: 469-488.

RAU, P. 1933. The Jungle Bees and Wasps of Barro Colorado 
Island (with notes on other insects). Kirkwood, privately printed, $324 \mathrm{p}$.

RAU, P. 1943. Notes on the nesting habits of certain social and solitary bees of Mexico. Annals of the Entomological Society of America 36:641-646.

RêGo, M. \& C. Brito. 1996. Abelhas sociais (Apidae: Meliponini) em um ecossistema de cerrado s.l. (Chapadinha - MA, BR): distribuição dos ninhos. Anais do Encontro Sobre Abelhas, Ribeirão Preto, SP, 2: 238-247.

Reyne, A. 1962. Angelloze bijen (Meliponidae) voorkomende in Suriname. Entomologische Berichten 22(2): 30-37.

Rocha, I. R. D.; H. C. Morais \& K. Kitayama. 1991. Visitantes diurnos de flores quiropterófilas. Revista Brasileira de Biologia 51(1): 249256.

Roig-Aslsina, A. \& C. D. Michener. 1993. Studies of the phylogeny and classification of long-tongued bees (Hymenoptera: Apoidea). The University of Kansas Science Bulletin 55(4): 123-162.

Rosa, A. E. \& C. H. W. Flechtmann. 1983. Acari domum meliponinarum brasiliensium habitants. III. Proctotydaeus partamonae, sp. n. (Acari: Acariformes, Tydeidae). Revista Brasileira de Biologia 43(3): $273-276$

Roubik, D. W. 1979. Nest and colony characteristics of stingless bees from French Guiana (Hymenoptera: Apidae). Journal of the Kansas Entomological Society 52(3): 443-470.

RouBIK, D. W. 1980. Foraging behavior of competing africanized honeybees and stingless bees. Ecology 61(4): 836-845.

RouBiK, D. W. 1981. Comparative foraging behavior of Apis mellifera and Trigona corvina (Hymenoptera: Apidae) on Baltimora recta (Compositae). Revista de Biologia Tropical 29(2): 177-183.

RoubiK, D. W. 1982. The ecological impact of nectar-robbing bees and pollinating hummingbirds on a tropical shrub. Ecology 63(2): 354 360 .

RoubiK, D. W. 1983. Nest and colony characteristics of stingless bees from Panama (Hymenoptera: Apidae). Journal of the Kansas Entomological Society 56(3): 327-355.

RoubiK, D. W. 1989. Ecology and Natural History of Tropical Bees. New York, Cambridge University Press, $\mathrm{x}+514 \mathrm{p}$.

RoubiK, D. W. 1990. Nesting and defence in tropical honeybees and stingless bees: you are what eats you?, p. 662-663. In: G. K. VeERESH; B. Mallik \& C. A. Viraktamath (eds.). Social Insects and the Environment, Proceedings of the 11th International Congress of IUSSI, Bangalore, India. New Delhi, Mohan Primlani for Oxford \& IBH Publishing Co., xxxi+765 p.

Roubik, D. W. 1992. Stingless bees: a guide to Panamanian and Mesoamerican species and their nests (Hymenoptera: Apidae: Meliponinae), p. 495-524. In: D. QUINTERO \& A. AIELLO (eds.) Insects of Panama and Mesoamerica. Selected Studies, Oxford, UK, Oxford University Press, 692 p.

RouBIK, D. W. 1993a. Tropical pollinators in the canopy and understory: field data and theory for stratum "preferences". Journal of Insect Behavior 6(6): 659-673.

RoubiK, D. W. 1993b. Direct costs of forest reproduction, bee-cycling and the efficiency of pollination modes. Journal of Bioscience 18(4): $537-552$.

RoubiK, D. W. 1996. African honey bees as exotic pollinators in French Guiana, p. 173-182. In A. Matheson; S. L. Buchmann; C. O’Toole; P. Westrich \& I. H. Williams (eds.). The Conservation of Bees. San Diego, Academic Press, xiii +254 p.

RoubiK, D. W. \& Q. D. Wheeler. 1982. Flightless beetles and stingless bees: phoresy of Scotocryptine beetles (Leiodidae) on their Meliponine hosts (Apidae). Journal of the Kansas Entomological Society 55(1): 125-135.

RoubiK, D. W.; J. A. S. Lobo \& J. M. F. Camargo. 1997. New stingless bee genus endemic to Central American cloudforests: phylogenetic and biogeographic implications (Hymenoptera: Apidae: Meliponini). Systematic Entomology 22: 67-80.

Roubik, D. W.; J. Enrique Moreno; C. Vergara \& D. Wittmann. 1986. Sporadic food competition with the African honey bee: projected impact on Neotropical social bees. Journal of Tropical Ecology 2: 97-111.
Roubik, D. W.; D. Yanega; M. Aluja S.; S. L. Buchmann \& D. W. Inouye. 1995. On optimal nectar foraging by some tropical bees (Hymenoptera: Apidae). Apidologie 26: 197-211.

Sakagami, S. F.; D. Beig \& Y. Akahira. 1964. Behavior studies of the stingless bees, with special reference to the oviposition process. III. Appearance of laying workers in an orphan colony of Partamona (Partamona) testacea testacea (Klug). Japanese Journal of Ecology 14(2): 50-57.

SAKagami S. F.; D. W. RoubiK \& R. Zucchl. 1993. Ethology of the robber stingless bee, Lestrimelitta limao (Hymenoptera: Apidae). Sociobiology 21(2): 237-277.

SAY, T. 1837. Descriptions of new species of North American Hymenoptera, and observations on some already described. Boston Journal of Natural History 1(4): 361-416.

Schulz, W. A. 1905. Hymenopteren-Studien. Leipzig, Engelmann, $147 \mathrm{p}$.

Schwarz, H. F. 1929. A gynandromorphic specimen of Trigona cupira var. rhumbleri (Friese). Journal of the New York Entomological Society 37: $145-150+$ pl.VI.

Schwarz, H. F. 1932a. The genus Melipona: the type genus of the Meliponidae or stingless bees. Bulletin of the American Museum of Natural History 63: 231-460+pls. 1-10.

Schwarz, H. F. 1932b Stingless bees in combat. Observations on Trigona pallida Latreille on Barro Colorado Island. Natural History (The Journal of the American Museum of Natural History) 32(5): 552553.

Schwarz, H. F. 1934. The social bees (Meliponidae) of Barro Colorado Island, Canal Zone. American Museum Novitates no. 731, 23 p.

Schwarz, H. F. 1938. The stingless bees (Meliponidae) of British Guiana and some related forms. Bulletin of the American Museum of Natural History 74: 437-508 + 10 pls.

Schwarz, H. F. 1939a. A substitute name for Patera Schwarz (Hymenoptera: Meliponidae). Entomological News 50:23.

Schwarz, H. F. 1939b. The Indo-Malayan species of Trigona. Bulletin of the American Museum of Natural History 76(3): 83-141.

SchwarZ, H. F. 1940. Additional species and records of stingless bees (Meliponidae) from British Guiana. American Museum Novitates no. $1078,12 \mathrm{p}$.

Schwraz, H. F. 1948. Stingless bees (Meliponidae) of the Western Hemisphere. Bulletin of the American Museum of Natural History 90: 1-546+xvii.

Schwraz, H. F. 1949. The stingless bees (Meliponidae) of Mexico. Anales del Instituto de Biología, Mexico, 20(1,2): 357-370.

SchwarZ, H. F. 1951. New Stingless Bees (Meliponidae) from Panama and Canal Zone. American Museum Novitates, 1505: 1-16.

Silveira, F. A. \& M. J. O. Campos. 1995. A melissofauna de Corumbataí (SP) e Paraopeba (MG) e uma análise da biogeografia das abelhas do cerrado brasileiro (Hymenoptera, Apoidea). Revista Brasileira de Entomologia 39(2): 371-401.

Silveira, F. A.; L. B. Rocha; J. R. Cure \& M. J. F. Oliveira. 1993. Abelhas silvestres (Hymenoptera, Apoidea) da zona da mata de Minas Gerais. II. Diversidade, abundância e fontes de alimento em uma pastagem abandonada em Ponte Nova. Revista Brasileira de Entomologia 37(3): 595-610.

SiLVestri, F. 1902. Contribuzione alla conoscenza dei Meliponidi del Bacino del Rio de la Plata. Rivista di Patologia Vegetale, Portici, 10(1904): 121-174+Figs. 1-19, pls. 103.

Silvestri, F. 1910. Della Trigona cupira Smith e di due ospiti del suo nido nel Messico. Bolletino del Laboratorio di Zoologia Generale e Agraria della R. Scuolla Superiore D'Agricoltura in Portici 5(1911): 65-71+Figs. 1-6.

SмIтн, F. 1854. Catalogue of Hymenopterous Insects in the Collection of the British Museum. Part 2. London, British Museum, p. 199-465+pls.vii-xii.

VмгшңÁ Õ.1863. Descriptions of Brazilian honey bees belonging to the genera Melipona and Trigona, which were exhibited, together with samples of their honey and wax, in the Brazilian court of the International Exhibition of 1962. Transactions of the Royal Entomological Society of London 11(sér. 3, vol. I): 497-512, pl. 20 . 
SмIтн, F. 1868. Observations on the economy of Brazilian insects, chiefly Hymenoptera, from the notes of Mr. Peckolt. Transactions of the Royal Entomological Society of London 16: 133-136.

Sofia, S. H. \& L. R. Bego. 1996. As abelhas da família Apidae em suas visitas às flores do campus da USP, Ribeirão Preto, SP. Anais do Encontro Sobre Abelhas, Ribeirão Preto, SP, 2: 339

Stort, A. C. \& M. M. B. Moraes. 1992. Morfologia a nível de microscopia eletrônica de varredura de mandíbulas de abelhas de diferentes graus de sociabilidade, p. 209. In: Anais do Encontro Brasileiro de Biologia e Abelhas e Outros Insetos Sociais. Naturalia, número especial, São Paulo, Editora UNESP, 283 p.

Strand, E. 1919(1917). Über einige Apidae des Deutschen Entomologischen Museums. Archiv für Naturgeschichte, Abt. A 83(11): 57-71.

Swofford, D. L. 1993. PAUP: Phylogenetic Analysis Using Parsimony. Version 3.1.1. Programa de computador distribuído pelo Illinois Natural History Survey, Champaign, Illinois, USA.

Taura, H. M. \& S. Laroca. 1991. Abelhas altamente sociais (Apidae) de uma área restrita em Curitiba (Brasil): distribuição dos ninhos e abundância relativa. Acta Biológica Parananense 20(1,2,3,4): $85-101$

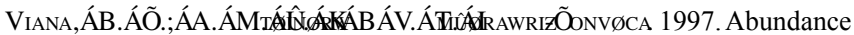
and flower visits of bees in a cerrado of Bahia, tropical Brazil. Studies on Neotropical Fauna and Environment 32: 212-219.

Villa, A. L. \& C. B. Vergara. 1982. Contribución al estudio de los hábitos de nidificación de algunas especies de abejas nativas sin aguijón (Hymenóptera, Apidae). Scientiae 1(2): 147-163.

Vit, P. O. 1992. Caracterización de Mieles de Abejas sin Aguijón Producidas en Venezuela. Universidad de Los Andes, Mérida, Venezuela, 125 p. (Tese Professor Asociado).

Waddington, K. D.; L. H. Herbst, \& D. W. Roubik. 1986. Relationship between recruitment systems of stingless bees and within-nest worker size variation. Journal of the Kansas Entomological Society 59(1): 95-102.

Wheeler, W. M. 1913. Notes on the habits of some Central American stingless bees. Psyche 20: 1-9.
WiLle, A. 1961. Evolutionary trends in the ventral nerve cord of the stingless bees (Meliponini). Revista de Biologia Tropical 9(1): 117-129.

Wille, A. 1964. Notes on a primitive stingless bee, Trigona (Nogueirapis) mirandula. Revista de Biologia Tropical 12(1): 117-151.

Wille, A. 1979. Phylogeny and relationships among the genera and subgenera of the stingless bees (Meliponinae) of the world. Revista de Biologia Tropical 27(2): 241-277.

Wille, A. 1983. Biology of the stingless bees. Annual Review of Entomology 28: 41-64.

WiLle, A. \& C. D. Michener. 1973. The nest architecture of stingless bees with special reference to those of Costa Rica (Hymenoptera, Apidae). Revista de Biologia Tropical 21(supl.1):1-128.

Wille, A. \& E. Orozco. 1975. Observations on the founding of a new colony by Trigona cupira (Hymenoptera: Apidae) in Costa Rica. Revista de Biologia Tropical 22(2): 253-287.

Ý ITMV,ÁÝ. 1996. The highly eusocial bees of Boracéia: community structure, resource partitioning, and their role as pollinators. Anais do Encontro Sobre Abelhas, Ribeirão Preto, SP, 2: 196-204.

Wilms, W.; V. L. Imperatriz-Fonseca \& W. Engels. 1996. Resource partitioning between highly eusocial bees and possible impact of the introduced africanized honey bee on native stingless bees in the Brazilian atlantic rainforest. Studies on Neotropical Fauna and Environment 31: 137-151.

Wilms W.; L. Wendel; A. Zillikens; B. Blochtein \& W. Engels. 1997. Bees and other insects recorded on flowering trees in a subtropical Araucaria forest in southern Brazil. Studies on Neotropical Fauna and Environment 32: 220-226.

WitTMANN, D. 1989. Nest architecture, nest site preferences and distribution of Plebeia wittmanni in Rio Grande do Sul, Brazil (Apidae: Meliponinae). Studies on Neotropical Fauna and Environment 24(1): 17-23.

Zanella, F. C. V.; M. L. Oliveira \& M. C. Gaglianone. 2000. Standardizing lists of locality data for examined specimens in systematics and biogeography studies of New World taxa. Biogeographica 76(4): 145-160. 


\section{ÍNDICE}

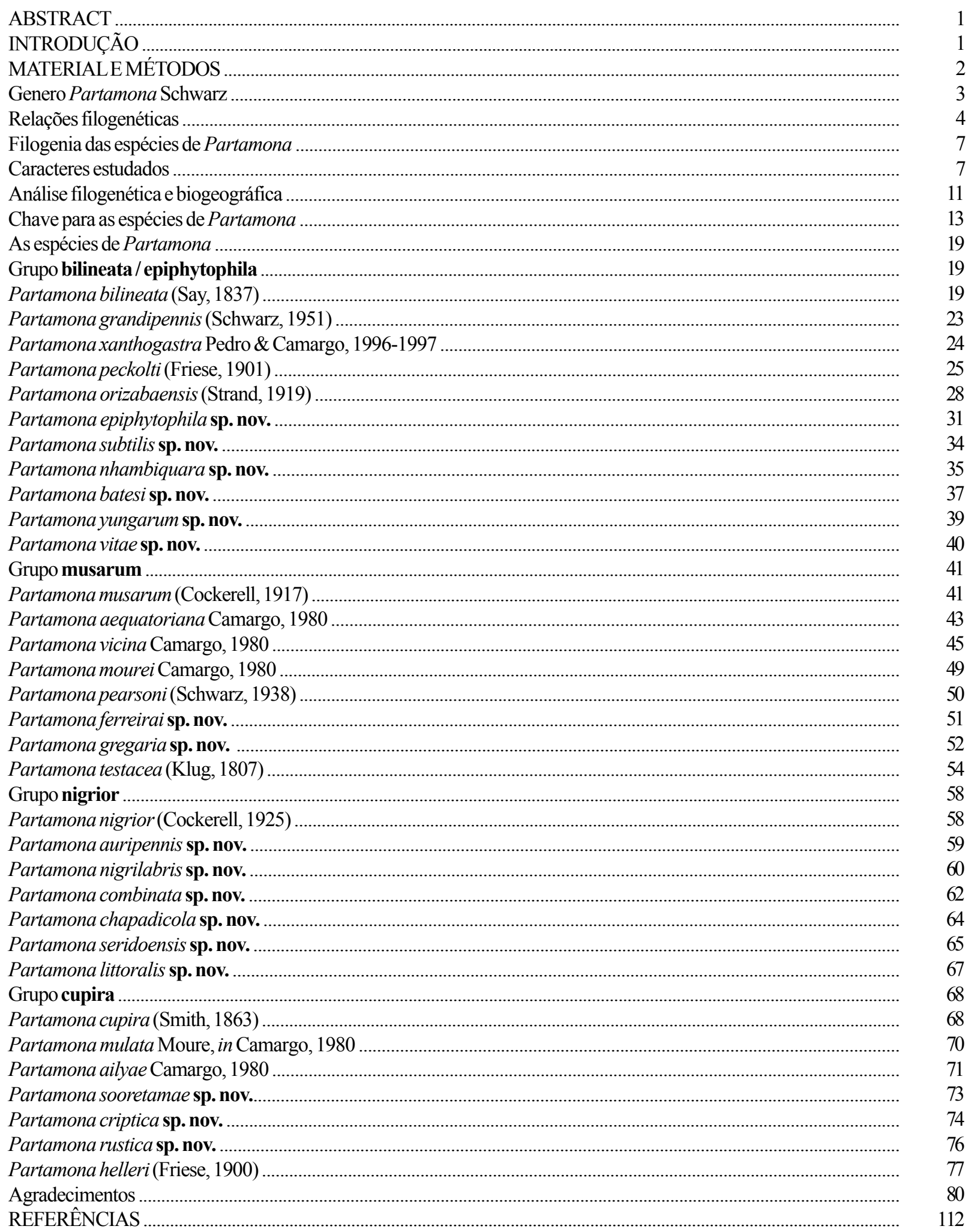

